Arnd Reitemeier (Hg.)

Kommunikation \& Kulturtransfer im Zeitalter der Personalunion zwischen Großbritannien und Hannover »to prove that Hanover and England are not entirely synonymous"

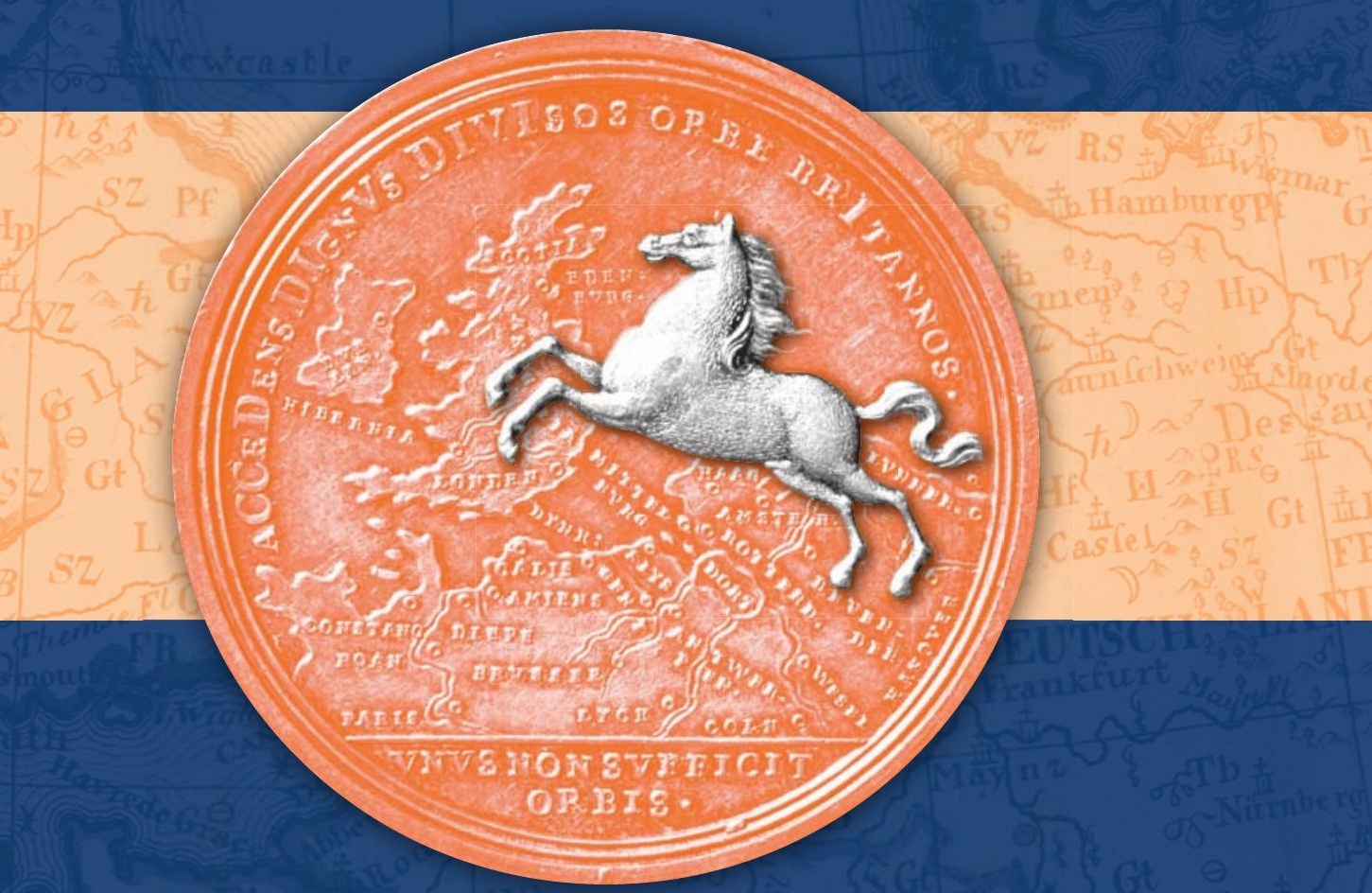

Universitätsverlag Göttingen 

Arnd Reitemeier (Hg.)

Kommunikation und Kulturtransfer im Zeitalter der Personalunion zwischen Großbritannien und Hannover

Dieses Werk ist lizenziert unter einer Creative Commons Namensnennung - Weitergabe unter gleichen Bedingungen 4.0 International Lizenz. 
erschienen im Universitätsverlag Göttingen 2014 
Arnd Reitemeier (Hg.)

Kommunikation und

Kulturtransfer im Zeitalter

der Personalunion zwischen

Großbritannien und

Hannover

sto prove that Hanover and England

are not entirely synonymous

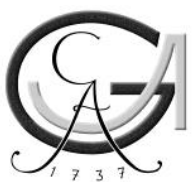

Universitätsverlag Göttingen 2014 


\section{Bibliographische Information der Deutschen Nationalbibliothek}

Die Deutsche Nationalbibliothek verzeichnet diese Publikation in der Deutschen Nationalbibliographie; detaillierte bibliographische Daten sind im Internet über $<$ http://dnb.ddb.de $>$ abrufbar.

Die Durchführung der Ringvorlesung und die Drucklegung des Sammelbands wurden vom Universitätsbund Göttingen e.V. und vom Promotionskolleg „Die Personalunion zwischen Großbritannien und Hannover 1714 bis 1837 als internationaler Kommunikations- und Handlungsraum“ unterstützt.

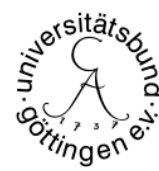

Anschrift des Herausgebers

Prof. Dr. Arnd Reitemeier

Georg-August-Universität Göttingen

Institut für Historische Landesforschung

Kulturwissenschaftliches Zentrum

Heinrich-Düker-Weg 14

D - 37073 Göttingen

E-Mail: arnd.reitemeier@phil.uni-goettingen.de

Dieses Buch ist auch als freie Onlineversion über die Homepage des Verlags sowie über den Göttinger Universitätskatalog (GUK) (http://www.sub.uni-goettingen.de) erreichbar. Es gelten die Lizenzbestimmungen der Onlineversion.

Satz und Layout: Katja Töpfer Umschlaggestaltung: Jutta Pabst

Titelabbildung: Rothe Grafik in Zusammenarbeit mit Presse, Kommunikation und Marketing der Universität Göttingen

(C) 2014 Universitätsverlag Göttingen

http://univerlag.uni-goettingen.de

ISBN: 978-3-86395-173-3 


\section{Inhalt}

Vorwort

Prof. Dr. Arnd Reitemeier ................................................... 7

Kurfürst oder König: Zur Legitimation des Januskopfes

Arnd Reitemeier

I I

Die Hannoveraner Könige im Zerrspiegel der britischen Karikatur

Barbara SchafF

Von Georg II. zu George Washington: Überlegungen zur Visualisierung von

Legitimität im Übergang von Monarchie zu Demokratie

VOLKER DEPKAT

Zwischen Empire und Reich.

Zur Kommunikation des globalen Siebenjährigen Krieges

im Raum der Personalunion

Marian FüsSEL

Die Formierung der anglo-schottisch-irischen Union im 18. Jahrhundert

JÜRGEN ELVERT

IOI

Continental European Involvement in the Eighteenth-Century British Empire

STEPHEN Conway 
Zwischen Union und Devianz.

Der Transfer religiöser Ideen im Raum der Personalunion

Manfred Jakubowski-Tiessen

William Hogarth in Göttingen:

Wendungen eines Kultur- und Medientransfers

Christian Scholl I6I

Musik als Wissenschaft im Raum der Personalunion

ANDreas WaczKat I79

Kooperation oder Konkurrenz?

Die Göttinger Königliche Gesellschaft der Wissenschaften und die Royal Society im 18. Jahrhundert

Peter Aufgebauer 195

Ein König - viele Wege zum Bücherwissen.

Die Göttinger Universitätsbibliothek im Kontext der deutschen und britischen Bibliothekslandschaften 1734-1820

Wilfried EnderLe 207

Im Netz der Dinge.

Kulturen des gelehrten Sammelns in der Personalunion Dominik Collet 235

Anschriften der Autoren 


\section{Vorwort}

(...) to prove that Hanover and England are not entirely synonymous.

\section{Kommunikation und Kulturtransfer im Jahrhundert der Personalunion}

Die Universität Göttingen wurde 1734 von Georg August, Kurfürst von Hannover und zugleich König von Großbritannien, gegründet; sie etablierte sich rasch als Bildungsstätte des europäischen Adels, und sie profitierte im 18. wie im 19. Jahrhundert von den Kontakten zu Gelehrten in Großbritannien wie in den britischen Kolonien. Tatsächlich wurde die Politik im Europa des 18. Jahrhunderts nicht nur von der Personalunion zwischen dem Königreich Großbritannien und dem Kurfürstentum Hannover geprägt, sondern von einer ganzen Reihe von Personalunionen bestimmt: Seit 1697 waren Sachsen und Polen, seit 1699 Dänemark und die Grafschaft Oldenburg und seit 1713 auch Dänemark und die Herzogtümer Schleswig und Holstein jeweils in Personalunion miteinander verbunden. Rechtlich wie politisch aber unterschied sich die Verbindung zwischen Großbritannien und Kurhannover von den übrigen dynastischen Verbindungen, denn sie entstand aus einer spezifischen politisch-dynastischen Situation in Folge der englischen Revolution von 1688, und sie führte zu einem verfassungsrechtlichen Nebeneinander von Kurhannover und Großbritannien. Dieses war von englischer Seite her gewollt und wurde von der Hannoverschen Seite akzeptiert, weil es dem Kurfürsten außenpolitische Spielräume eröffnete, die zu nutzen sich lange Zeit auch ökonomisch lohnte. Juristisch fungierten einzig die Herrscher als verbindendes Element, denen die Schwierigkeiten und Unzulänglichkeiten einer Verwaltung auf die Distanz deutlich vor Augen standen und die sich wiederholt 
mit dem Gedanken der Auflösung der Verbindung trugen, auch wenn sie selbst an ihrer Legitimität keinen Zweifel hatten.

Ein Jahr vor dem Tod Georgs II. bezeichnete sein Neffe und Thronfolger das Kurfürstentum als that horrid electorate ${ }^{1}$. Doch einmal im Amt stand Georg III. fest zur Dynastie und zu seinem Erbe, das er schon wenige Jahre später als „sein deutsches Vaterland" bezeichnete. Außenpolitisch versuchte er die Politik seines Großvaters nahtlos fortzuführen. Der Unabhängigkeitskrieg der amerikanischen Kolonien, die dem König unmittelbar unterstanden, bedeutete einen wesentlichen Rückschlag für Regierung und Monarch. Nach Josiah Tucker war Großbritannien insgesamt zu integrativen Anstrengungen nicht befähigt:

[...] the genius of the English is often unfit to be joined with any other people on earth, of which their behavior towards the Scotch and Irish as well as towards the Hanoverians is too striking an example. ${ }^{2}$ Sicherlich gingen von Großbritannien keinerlei Initiativen aus, die kulturelle, soziale und eben auch politische Distanz zu überwinden. Allerdings trug auch der König selbst hierzu bei: Im Jahr 1785 schlossen sich Hannover, Sachsen und Preußen zu einer Allianz zusammen, dem sog. Fürstenbund, und traten für die Bewahrung der Reichsverfassung ein, wobei sie zugleich den Expansionsbestrebungen Österreichs entgegentraten. Bei diesen Verhandlungen agierte Georg III. ausschließlich in seiner Eigenschaft als Kurfürst von Hannover und informierte seine britischen Minister weniger umfassend als von diesen gewünscht. Nach außen also mussten die britischen Diplomaten zur Personalunion stehen, doch weil sie fürchteten, in einen Krieg im Reich hineingezogen zu werden, ging die britische Regierung intern zu Hannover auf Distanz. Frustriert schrieb Francis Osborne, Duke of Leeds, seit 1783 Secretary of State und damit gleichsam britischer Außenminister, an Thomas Townsend, Lord Sydney, Home Secretary und quasi britischer Innenminister: I have been labouring to prove that Hanover and England are not entirely synonymous. ${ }^{3}$ Politisch agierten Großbritannien und Kurhannover damit erkennbar asynchron, was sich ganz wesentlich mit Defiziten in der wechselseitigen Kommunikation erklären lässt.

Diese Kommunikation über die Grenzen und Kulturräume hinweg war ein bedeutendes Hindernis der inneren Entwicklung der Personalunion, denn auch wenn die lingua franca der Höfe des 18. Jahrhunderts Französisch war, so sprach man am

1 Timothy Blanning, „That Horrid Electorate“ or „Ma Patrie Germanique“? George III, Hanover and the Fürstenbund of 1785, in: The Historical Journal 20/2 (1977), S. 311-344 (ich danke Frau Solveig Grebe für den Hinweis).

2 Josiah Tucker, A Series of Answers to Certain Popular Objections Against Separating from the Rebellious Colonies and Discarding Them Entirely, Gloucester 1776, S. 57 (ich danke Frau Solveig Grebe für den Hinweis).

3 Blanning, 1977 (wie Anm. 1), S. 311-344. 
englischen Hof wie in der politischen Führungsschicht Großbritanniens nahezu ausschließlich Englisch, am Hof in Hannover hingegen Deutsch - und die Anzahl derjenigen, die beide oder besser noch alle drei Sprachen beherrschten, war gering. Die Möglichkeiten eines bilateralen Kulturtransfers waren also beschränkt, doch was auf englischer Seite ignoriert oder akzeptiert wurde, das versuchten viele in Deutschland durch intensive Briefkontakte und Reisen, durch Übersetzungen aus dem Englischen ins Deutsche und schließlich durch die Übernahme britischer Moden zu überwinden. Eine besondere Funktion kam hierbei der 1734 von Georg II. gegründeten Universität Göttingen zu, die sich rasch zu einer der führenden Forschungs- und Bildungsstätten der Aufklärung mit europa- und bald weltweitem Renommee entwickelte.

Spätestens mit dem Ausbruch der Revolutionskriege musste Georg III. alles daran setzen, die Integrität Kurhannovers zu wahren, so dass dann sein Eintreten für Hannover den außenpolitischen Interessen Großbritanniens entsprach. Nach 1789 wandelte sich Georg III. in der öffentlichen Wahrnehmung „zum Repräsentanten und Sympathieträger der Mehrheit der britischen Bevölkerung ". ${ }^{4}$ Die Folge war, dass sich Großbritannien auch Ende des 18. und Anfang des 19. Jahrhunderts zu keiner rein atlantischen Macht entwickeln konnte, denn Hannover fesselte es an Europa und an das europäische Staatensystem. Zeitgleich wuchs in Deutschland die Begeisterung für alles Britische, denn in Folge insbesondere militärischer Interventionen Frankreichs im Verlauf des 18. Jahrhunderts im Reich, der französischen Revolution und des Todes von Ludwig XVI. sowie schließlich des Kampfes gegen Napoleon orientierte sich besonders das nun auch im Reich erwachsende Bürgertum an Großbritannien.

Angesichts der beschriebenen Voraussetzungen und Entwicklungen wird im Folgenden die Personalunion zwischen Großbritannien und Hannover als verfassungspolitisches Konstrukt wie als Träger kultureller Austauschprozesse im 18. Jahrhundert gesehen. Folglich werden einerseits umfassend die Facetten der kulturellen, sozialen, wissenschaftlichen, ökonomischen und politischen Entwicklungen besonders Großbritanniens und Hannovers im 18. Jahrhundert aufgezeigt, wobei andererseits besonderes Augenmerk auf die wechselseitigen Verbindungen gelegt wird. Dies greift die aktuellen Ansätze der transkulturellen Geschichte wie der entangled history auf und wendet sie auch auf die Geschichte der Universität Göttingen an, die selbst Produkt wie Träger der Personalunion und der damit verbundenen Transferprozesse war und ist. ${ }^{5}$

4 Torsten Riotte, Großbritannien, Hannover und das Ende des Alten Reiches 1806, Niedersächsisches Jahrbuch für Landesgeschichte, 79 (2007), S. 29-50, hier insb. S. 49; umfassend siehe Linda Colley, Britons. Forging the Nation 1707-1837, New Haven / London 1992.

5 Michael Rohrschneider, Zusammengesetzte Staatlichkeit in der Frühen Neuzeit. Aspekte und Perspektiven der neueren Forschung am Beispiel Brandenburg-Preußens, in: Archiv für Kulturgeschichte 90 (2008), S. 321-350; Helmut Georg Koenigsberger, Monarchies and Parliaments in Early Modern Europe. Do- 
Indem Großbritannien selbst eine Union diverser Einheiten - England, Wales, Schottland, Irland, Kolonien - war, gilt die Untersuchung zunächst den politischen, sozialen, militärischen und ökonomischen Prozessen, ihrer Verortung in Europa sowie ihrer wechselseitigen Rezeption. Sodann wird der Blick auf religiöse, kunst- und musikhistorische Austauschprozesse gelenkt, um schließlich in einem letzten Abschnitt wissenschaftliche Rezeptions- und Transfervorhaben zu analysieren. Damit wendet sich die Perspektive von den verbindenden Elementen auf die Universität Göttingen, so dass abschließend nach dem Impetus der Universität Göttingen für die Personalunion und für die Kommunikation im Europa des 18. Jahrhunderts gefragt wird.

Die Vorträge wurden im Rahmen der Ringvorlesung des Wintersemesters 2013-2014 gehalten und für den Druck überarbeitet. Sie markierten den Auftakt zum Jahr der 300jährigen Wiederkehr der Krönung von Kurfürst Georg I. August zum König von Großbritannien und damit des Beginns der bis 1837 dauernden Personalunion zwischen Großbritannien und Hannover, die das Land Niedersachsen im Jahr 2014 mit einer großen Landesausstellung beging. Sie ordnete sich auch in das im Jahr 2012 begangene Jubiläum der Universität Göttingen ein, indem sie zentrale historische und kulturwissenschaftliche Aspekte aufgriff, die zur Gründung der Universität führten und mit dieser verbunden waren.

Großer Dank gilt dem Präsidium der Universität Göttingen wie der Akademie der Wissenschaften zu Göttingen. Die Ringvorlesung wurde von den Trägern des Promotionskollegs „Die Personalunion zwischen Großbritannien und Hannover 1714 bis 1837 als internationaler Kommunikations- und Handlungsraum“ organisiert. Aus ihrem Kreis kam die Mehrheit der Referentinnen und Referenten, wobei die Freude groß war, dass eine Reihe namhafter Kollegen aus dem In- und Ausland gerne bereit war zu partizipieren. Besonderer Dank gilt dem Universitätsbund Göttingen, der maßgeblich zur Finanzierung der Reisekosten wie der Drucklegung beitrug.

Prof. Dr. Arnd Reitemeier

Institut für Historische Landesforschung Göttingen, Trinitatis 2014

minium Regale or Dominium Politicum et Regale, in: Theory and Society 5 (1978), S. 191-217; Helmut Georg Koenigsberger, Monarchies, States Generals and Parliaments. The Netherlands in the Fifteenth and Sixteenth Centuries, Cambridge 2001; Helmut Georg Koenigsberger, Prince and States General. Charles $\mathrm{V}$ and the Netherlands (1506-1555), in: Transactions of the Royal Society 4 (1994), S. 127-151; John H. Elliott, A Europe of Composite Monarchies, in: Past \& Present 137 (1992), S. 48-71. 


\title{
Kurfürst oder König: Zur Legitimation des Januskopfes
}

\author{
Arnd Reitemeier
}

Aus England kömmt jetzt unsre Wonne;

Ein Held aus jenes Helden Blut

Dir, König! Englands Thron zu geben /

Und uns / Herr! Was wir heut erleben

Die Klugheit / die den Staat im Krieg und Frieden stützet I

zeigt hier ein Janus-Kopf: auf beydes giebt er acht.

Durch hohe Wachsamkeit sind Land und Reich beschützet;

wie dorthin für sein Volk des Kranichs Vorsicht wacht. ${ }^{1}$

Michael Christoph Brandenburg, der dieses Bild in seinem Lobgedicht auf den Besuch Georgs II. 1748 verwendete, wirkte seit 1744 als Assessor des Konsistoriums des Herzogtums Lauenburg und betätigte sich zugleich in zahlreichen Publikationen als Dichter. ${ }^{2}$ Er gehörte also durchaus zur erweiterten intellektuellen Elite Norddeutschlands. Das verwendete Bild eines Januskopfes, der mit zwei Gesichtern nach vorne wie nach hinten zugleich schaut, impliziert eine Zwiespältigkeit, eine innere Zerrissenheit eines Herrschers, der wie Georg II. über zwei voneinander getrennte Herrschaftsräume regierte. Damit liegt die Vermutung nahe, dass die Personalunion zwischen Großbritannien und dem Kurfürstentum Hannover als ein Konstrukt voller

Ich danke Frau Jenny van den Heuvel sowie Frau Sara Müller und Herrn Lauritz Kawe für ihre ergänzenden Recherchen.

1 Michael Christoph Brandenburg, Das über die Ankunft seines grossen Königes frolockende Herzogthum Lauenburg dem Herrn Georg dem Andern vorgestellet Michael Christoph Brandenburg, o. O. 1748, S. 6.

2 Zur Biographie Brandenburgs siehe: Hans-Christian Brandenburg, Sic transit gloria mundi. In memoriam Michael Christoph Brandenburg, des lange vergessenen lauenburgischen Dichterpfarrers und Consistorial-Assessors (1694-1766), in: Lauenburgische Heimat 146 (1997), S. 63-97. 
Widersprüche angesehen wurde, erst recht, als beide Herrschaftsräume politisch wie ökonomisch heterogen strukturiert und ausgerichtet waren. ${ }^{3}$

Vor diesem Hintergrund wird im Folgenden zunächst die verfassungsrechtliche Verbindung der beiden Herrschaftsräume dahingehend untersucht, ob den Herrschern der Personalunion zwischen Großbritannien und Hannover tatsächlich eine Doppelgesichtigkeit und damit eine widersprüchliche Politik zugeschrieben werden kann. In einem zweiten Schritt wird dann analysiert, ob die Könige in der Öffentlichkeit als janusgesichtig wahrgenommen wurden. Hierfür werden die zahlreichen zwischen 1714 und 1837 publizierten und stets ähnlich aufgebauten Lob- und Preisgedichte untersucht.

Die verfassungsrechtliche Ausgangslage wurde erstmals von Johann Stephan Pütter dargelegt und seither wiederholt betrachtet. ${ }^{4}$ Besonders die Ausgangssituation bis zur Krönung Georgs I. am 31. Oktober 1714 in London wurde ausführlich von Schnath in seiner Geschichte Hannovers untersucht, was jüngst um die Edition der Prunkurkunden der Personalunion erweitert wurde. ${ }^{5}$ Die Kasuallyrik in Hannover wie in Großbritannien harrt, anders als beispielsweise vergleichbare Gelegenheitsdichtung am Dresdner Hof, einer umfassenden Untersuchung. ${ }^{6}$ Sie war Ausdruck „des sozialen und politischen Gratifikations- und Disziplinierungssystems ${ }^{\text {"7 }}$ und diente folglich zugleich der Legitimation der Herrschaft. ${ }^{8}$ Den fünf Herrschern der

3 Zu den wirtschaftlichen Unterschieden vgl.: Uriel Dann, Hannover und England 1740-1760. Diplomatie und Selbsterhaltung, Hildesheim 1986, Kapitel 6, S. 146-150. Das Modell des Januskopfes ist ein prominentes in der britischen Geschichtsschreibung, die traditionell die britische Außenpolitik als hin- und hergerissen zwischen dem überseeischen Empire und der Diplomatie auf dem europäischen Kontinent sieht: Nick Harding, Hanover and the British Empire, 1700-1837, Woodbridge 2007, S. 1; sowie zum Janus-Modell: Timothy Garton Ash, Free World. America, Europe, and the Surprising Future of the West, New York 2004, S. 13-45.

4 Johann Stephan Pütter, Beyträge zum Teutschen Staats- und Fürstenrechte, Göttingen 1777, S. 22-23.

5 Georg Schnath, Geschichte Hannovers im Zeitalter der neunten Kur und der englischen Sukzession 1674-1714, Bd. 4: Georg Ludwigs Weg auf den englischen Thron. Die Vorgeschichte der Thronfolge 1698-1714, Hildesheim 1982; Malte-Ludolf Babin / Gerd van den Heuvel / Ulrike Weiß, Brief und Siegel für ein Königreich. Die Prunkurkunden zur hannoverschen Thronfolge in Großbritannien, Göttingen 2014.

6 Kerstin Heldt, Der vollkommene Regent. Studien zur panegyrischen Casuallyrik am Beispiel des Dresdner Hofes Augusts des Starken, Frühe Neuzeit 34, Tübingen 1997.

7 Heldt, 1997 (wie Anm. 6), S. 20.

8 Jan Anders, Auf Poesie ist die Sicherheit der Throne gegründet. Huldigungsrituale und Gelegenheitslyrik im 19. Jahrhundert, Frankfurt am Main 2005; Pierre Béhar / Herbert Schneider (Hg.), Der Fürst und sein Volk. Herrscherlob und Herrscherkritik in den habsburgischen Ländern der frühen Neuzeit, St. Ingbert 2004; Angela Borchert, Poetische Praxis. Gelegenheitsdichtung und Geselligkeitsdichtung an Herzogin Anna Amalias Hof in Weimar, Ettersburg und Tiefurt (1759-1807), Würzburg 2010; Rudolf Drux, Causalpoesie, in: Harald Steinhagen (Hg.), Deutsche Literatur. Eine Sozialgeschichte, Bd. 3: Zwischen Gegenreformation und Frühaufklärung. Späthumanismus, Barock, 1572-1740, Hamburg 1986, S. 408-417; zahlreiche Beiträge im Sammelband Dorette Frost / Gerhard Knoll (Hg.), Gelegenheitsdichtung. Referate der Arbeitsgruppe 6 auf dem Kongress des Internationalen Arbeitskreises für Deutsche Barockliteratur 
Personalunion zwischen Großbritannien und dem Kurfürstentum resp. Königreich Hannover wurden zahlreiche gedruckte Lob- und Preisgedichte gewidmet. ${ }^{9}$ Anlässe hierfür boten in erster Linie die Krönungen, Geburtstage, Reisen in ihre Stammlande, militärischen Erfolge oder der Tod von Familienmitgliedern. Es ist unklar, ob die Gedichte dem jeweiligen Herrscher übergeben und dann nachträglich gedruckt wurden, oder ob sie öffentlich deklamiert wurden. ${ }^{10}$ Im Kurfürstentum wurden wesentlich mehr Gedichte gedruckt als in Großbritannien, wobei insgesamt gesehen die Anzahl der Gedichte zwischen 1714 bis 1837 zurückging. ${ }^{11}$ Die überwiegende Mehrzahl der Gedichte wurde in der jeweiligen Landessprache publiziert, während nur wenige Gedichte auf Latein erschienen. Übereinstimmend bedachten die Autoren in beiden Ländern die Herrscher mit den zentralen Attributen ihrer Herrschaft, was besonders allgemeine Symbole wie den englischen Löwen oder das springende Pferd der Welfen umfasste. ${ }^{12}$

\section{I.}

Die Personalunion zwischen Großbritannien und Hannover nahm ihren Beginn mit dem Beschluss des englischen Parlaments von 1701, An Act for the further limitation

Wolfenbüttel, 28.8.-31.8.1976, Bremen 1977; Elisabeth Klecker, Tradition und Moderne im Dienst des Herrscherlobes. Beispiele lateinischer Panegyrik für Maria Theresia, in: Franz M. Eybl (Hg.), Strukturwandel kultureller Praxis. Beiträge zu einer kulturwissenschaftlichen Sicht des theresianischen Zeitalters, Wien 2002, S. 233-247; Claudia Kleinbub / Johannes Mangei (Hg.), Vivat! Huldigungsschriften am Weimarer Hof, Göttingen 2010; Wulf Segebrecht, Das Gelegenheitsgedicht. Ein Beitrag zur Geschichte und Poetik der deutschen Lyrik, Stuttgart 1977; siehe auch Theodor Verweyen, Barockes Herrscherlob. Rhetorische Tradition, Sozialgeschichtliche Aspekte, Gattungsprobleme, in: Der Deutschunterricht 28,2 (1976), S. 25-45; Alexandra Zimmermann, Von der Kunst des Lobens. Eine Analyse der Textsorte Laudatio, München 1993.

9 Umfangreiche Sammlungen an Lobgedichten befinden sich in der Gottfried-Wilhelm-Leibniz-Bibliothek in Hannover und in der Universitätsbibliothek Göttingen.

10 Vgl. Heldt, 1997 (wie Anm. 6), S. 17.

11 Raymont Anselment, The Oxford University Poets and Caroline Panegyrik, in: John Donne Journal 3 (1984), S. 181-201; John A. Burrow, The poetry of praise, Cambridge 2008; Oswald Doughty, English Lyric in the Age of Reason, London 1922; Robert Folkenflik (Hg.), The English Hero 1660-1800, Newark 1982; David Foxon, English Verse, 1701-1750, London 1975; Dustin Griffin, Patriotism and poetry in eighteenth-century Britain Cambridge 2002; Suvir Kaul, Poems of Nation, Anthems of Empire. English Verse in the Long Eighteenth Century, Charlottesville 2000; John Lucas, England and Englishness. Ideas of Nationhood in English Poetry 1688-1900, London 1991; Norman Maclean, From Action to Image. Theories of the Lyric in the Eighteenth Century, in: Ronald S. Crane (Hg.), Critics and Critism, Chigago 1952, S. 409f.; Murray G. H. Pittock, Poetry and Jacobite Politics in Eighteenth-Century Britain and Ireland, Cambridge 1994.

12 John Harvey Pinches, The Royal Heraldry of England, London 1974; Christian Weyers, Das Sachsenross. Biographie eines Hoheitszeichens, in: Archiv für Diplomatik, Schriftgeschichte, Siegel- und Wappenkunde 54 (2008), S. 99-146. 
of the Crown and better securing the rights and liberties of the subject, der gemeinhin als Act of Settlement bezeichnet wird. ${ }^{13}$ Ursache dieses Beschlusses war die Kinderlosigkeit von William III. von Oranien, der 1688 in England gelandet und 1689 zum englischen König gekrönt worden war, und seiner bereits 1694 gestorbenen Ehefrau Queen Mary II., Tochter von James II. ${ }^{14}$ William III. folgte 1702 seine Schwägerin Queen Anne, die mit dem Bruder des dänischen Königs verheiratet war und deren Kinder vorzeitig gestorben waren. ${ }^{15}$ Mit dem Tod von Queen Anne wäre die Thronfolge wieder auf diejenige Linie der Stuarts übergegangen, die 1688 des Landes vertrieben worden war. Dies versuchte das Parlament zu verhindern, denn es bekannte sich seit 1689 konsequent zum Protestantismus, während James II. römisch-katholisch war. ${ }^{16}$ Gemäß dem Act of Settlement sollte nun die Mutter von Georg Ludwig, Sophie von der Pfalz, auf den britischen Thron folgen, die als Tochter von Elisabeth Stuart und Friedrich V. von der Pfalz die erste erbberechtigte Protestantin war. ${ }^{17}$ Das Parlament sprach nun Sophia die Thronfolge und die Herrschaft über the Kingdoms of England, France, and Ireland, and of the dominions thereunto belonging, [...] and all honours, styles, titles, regalities, prerogatives, powers, jurisdictions and authorities zu. ${ }^{18}$ Gemäß der Glorious Revolution musste die zukünftige Monarchin der anglikanischen Kirche angehören sowie einen Eid auf die protestantische Kirche ablegen. Auch formulierte das Parlament eine Vielzahl an Vorbehalten für das bilaterale Verhältnis zu Hannover. Grundsätzlich musste die zukünftige Herrscherin alle politischen Entscheidungen innerhalb Großbritanniens treffen. Zugleich durfte Kurhannover nur mit Zustimmung des Parlaments militärisch verteidigt werden. Nach ihrer Krönung durfte sie ihre Stammlande nicht ohne Zustimmung des Parlaments besuchen. Nicht-Engländer waren von der Übertagung von Ländereien ausgenommen und kein Nicht-Engländer durfte ein politisches Mandat wahrnehmen. Auch durfte die Königin keinem Nicht-Engländer eine Pension übertragen. Diese Vorbehalte hatten eine doppelte Ursache: Zum einen versuchte das Parlament Konsequenzen aus der Politik Williams III. zu ziehen, der nicht nur zahlreiche Vertraute an den englischen Hof gebracht hatte, sondern der sich immer wieder für längere Zeit in den Niederlanden aufgehalten hatte. ${ }^{19}$ Damit zielte der Act of Settlement zum einen auf die Sicherung der protestantischen Thronfolge in England und zugleich auf die Vermeidung ei-

13 John Raithby (Hg.), Statutes of the Realm, Bd. 7: 1695-1701, o. O. 1820, S. 636-638, hier S. 636.

$14 \mathrm{Zu}$ William III. ist eine Reihe von Biographien erschienen. Vgl. z. B.: Tony Claydon, William and Mary, Oxford 2007; Wout Troost, William III, the stadholder-king. A political Biography, Aldershot 2005.

15 Edward Gregg, Queen Anne, New Haven 2001, S. 100.

16 An Act Declaring the Rights and Liberties of the Subject and Settling the Succession of the Crown, 1689.

17 J. N. Duggan, Sophia of Hanover. From Winter Princess to Heiress of Great Britain, London 2010, S. 161.

18 Raithby, 1820 (wie Anm. 13), S. 637.

19 Brendan Simms, Three Victories and a Defeat. The Rise and Fall of the First British Empire, 1714-1783, London 2007, S. 83. 
nes Zusammengehens beider Herrschaftsräume - Großbritannien und Hannover -, so dass der Begriff einer Union gar nicht erst verwendet wurde. Sophie und Georg Ludwig erwarteten für ihre Dynastie einen wesentlichen Prestigegewinn und akzeptierten daher die Thronfolge. ${ }^{20}$ Zugleich bestand für die Welfen die Möglichkeit, mit ihrer Verbindung zu Großbritannien das Lager der protestantischen Fürsten im Reich zu stärken. ${ }^{21}$ Ganz selbstverständlich betonten die Welfen die Erbberechtigung und bekannten sich zur dynastischen Legitimität, denn auf diese Weise wiesen sie die Ansprüche von James II. Stuart zurück und rückten die Relevanz des Parlamentsbeschlusses in den Hintergrund. ${ }^{22}$

Nach dem Tod seiner Mutter Sophie am 8. Juni 1714 übernahm Georg Ludwig die Herrschaft in Kurhannover. Er wurde sodann zum König von Großbritannien und Irland proklamiert, nachdem am 12. August 1714 Queen Anne gestorben war. ${ }^{23}$ Zu diesem Zeitpunkt war Georg Ludwig 54 Jahre alt und ein militärisch wie politisch in Europa erfahrener Fürst. Vor seiner Abreise aus Hannover am 11. September 1714 erließ er am 29. August 1714 das sogenannte Regierungsreglement, in dem er festgelegte:

\section{Unser [...] des Königs von Grossbritannien und Churfürsten zu Braunschweig und Lüneburg Reglement, nach welchem in Unserm Abwesen nach Unsern Kö- nigreichen jetzt und künftig bis zu anderweiter Verordnung Unsere allhier hin- terlassende Geheimte Räte wegen der Regierung Unserer Braunschweig-Lüneburg und dazu gehörigen Lande sich zu achten. ${ }^{24}$}

Georg Ludwig traf Regelungen für seine Abwesenheit, in denen er nicht darauf einging, dass er zukünftig nur mit Genehmigung des britischen Parlaments wieder zurückkehren durfte, und in denen ebenfalls nicht von einer Union die Rede war. Tatsächlich blieb die uneingeschränkte Staatsgewalt in den Händen des Kurfürsten, auch wenn er gewisse Teile der Ausübung auf den geheimen Rat übertrug. Dieser durfte bei militärischen Gefahren selbständig handeln, musste aber bei allen weiteren Angelegenheiten die Weisung des Landesherrn einholen. Auch behielt der Kurfürst die alleinige Kontrolle über die Kammer, die Kriegskanzlei und die Ernennung der Staatsdiener. Schließlich war er auch weiterhin persönlich für alle dynastischen und auswärtigen Angelegenheiten zuständig.

20 Ragnhild Hatton, George I. Elector and King, New Haven 2001, S. $76 \mathrm{ff}$.

21 Hannah Smith, Georgian Monarchy. Politics and Culture, 1714-1760, Cambridge 2006, S. 50.

22 Smith, 2006 (wie Anm. 21), S. 37.

23 Hatton, 2001 (wie Anm. 20), S. 109.

24 Richard Drögereit (Hg.), Quellen zur Geschichte Kurhannovers im Zeitalter der Personalunion mit England 1714-1803, Hildesheim 1949, S. 5. 
In Konsequenz etablierte sich in London ein Teil des Hannoveraner Ratskollegiums und bildete dort die sog. Deutsche Kanzlei. ${ }^{25}$ Parallel dazu berichteten die in Hannover zurückbleibenden geheimen Räte über alle Ereignisse und Entwicklungen von Relevanz und schickten dem Kurfürsten zugleich sämtliche Dokumente zu Vorgängen, die seiner Zustimmung bedurften. ${ }^{26}$ Mit Ausnahme derjenigen Zeiten, in denen Hannover von fremden Truppen besetzt war, transportierte die Post von nun an bis 1837 mehrfach die Woche umfangreiche Brief- und Aktenbündel zwischen den Regierungsstellen in Hannover und dem Hof in London. ${ }^{27}$ Innerhalb kurzer Zeit etablierte sich damit ein Kommunikationssystem der Verwaltung auf die Distanz, das nur gelegentlich von den Besuchen der Könige in ihren Stammlanden unterbrochen wurde.

Georg Ludwig ließ sich von seinem Sohn Georg August als zukünftigem Prince of Wales nach England begleiten und vertrat damit unmissverständlich einen in die Zukunft gerichteten dynastischen Anspruch. Zugleich aber blieb der sieben Jahre alte Friedrich Ludwig, Enkel Georgs I. und Sohn Georgs II., in Hannover zurück und fungierte auf diese Weise als Stammhalter und Stellvertreter der Dynastie. ${ }^{28}$

Georg I. passte sich ohne große Mühe an die anderen politischen Bedingungen in England an, übertrug diese aber nicht auf das Kurfürstentum..$^{29}$ Er ließ sich auf die für ihn neuen kulturellen Rahmenbedingungen ebenso ein wie er seinen Platz in der Öffentlichkeit einnahm sowie Modifikationen des höfischen Zeremoniells durchzusetzen versuchte. Georg blieb Kurhannover verbunden, aber er vernachlässigte in keiner Weise die englische Politik. Beispielhaft hierfür steht der Erwerb des 1648 Schweden zugesprochenen Fürstbistums Bremen-Verden, so dass das Kurfürstentum entscheidend von der Intervention Großbritanniens im nordischen Krieg profitierte. ${ }^{30}$ Auch konnte sich Georg I. ohne Mühe gegen die Aufstände der Stuarts behaupten, die zugleich zeigten, dass Großbritannien ein sozial ungefestigtes und konfessionell zerrissenes Machtkonglomerat war. ${ }^{31}$

25 Grundlegend zur Deutschen Kanzlei siehe: Benjamin Bühring, Verwaltung und Personalunion. Die Deutsche Kanzlei in London und die English Chancery in Hannover als Träger der Personalunion zwischen Großbritannien und Kurhannover 1714-1760, Diss. phil. masch. Göttingen 2012.

26 Rudolf Grieser, Die Deutsche Kanzlei in London, ihre Entstehung und Anfänge. Eine behördengeschichtliche Studie, in: Blätter für deutsche Landesgeschichte 89 (1952), S. 153-168, hier S. $154 f$.

27 Bühring, 2012 (wie Anm. 25), S. 118ff.

28 Andrew C. Thompson, George II. King and Elector, New Haven 2011, S. 39.

29 Hatton, 2001 (wie Anm. 20), S. 119f.

$30 \mathrm{Zu}$ Georgs Rolle im Nordischen Krieg immer noch grundlegend: James Fredrick Chance, George I and the Northern War. A Study of British-Hannoverian Policy in the North of Europe in the Years 1709 to 1721, London 1909.

31 Hatton, 2001 (wie Anm. 20), S. 175. 
Trotz seiner Erfolge glaubte Georg I. nicht an die Fortdauer der Personalunion zwischen Großbritannien und Hannover, wie er ausführlich in seinem Testament von Anfang Januar 1716 festhielt: In diesem nahm er zunächst auf das Testament seines Vaters Bezug und unterstrich die Notwendigkeit von Primogenitur und Unteilbarkeit des Fürstentums, um gemäß den Bestimmungen der Goldenen Bulle von 1356 die Kurwürde zu erhalten. Sodann legte er fest:

Weil aber seithero durch sonderbare Schickung Gottes [...] sich zugetragen, dass uns die Gross-Britannische Crohn und Königreiche zugefallen, welchem nach, wann der Primogenitus Unseres Mannsstammes allezeit Successor und Regent zugleich gedachter Crohn und Unserer Teutschen Chur-und übrigen Lande sein sollte, draus folgen würde, dass, solange Unser Mannsstamm in Gross-Britannien regierete, gedachte unsere Chur- und übrige Teutsche Lande ein perpetuierliches annexum und gleichsamb ein Dependenz von der Crohn Gross-Britannien werden würden; welches aber nicht allein der Wohlfahrt selbiger Lande in viele Wege sehr nachteilig sein, sondern auch in publicis und in Respicierung der Unseren Descendenten als Churfürsten obliegenden Teutschen Reichsgeschäften zu allerhand Inconvenientien Anlass geben würde, dem vorzubeugen kein anderes Mittel anzusinnen ist als das die königliche und churfürstliche Regierungen in Unserem Hause geteilet werden dergestalt, dass, wann Gott den von uns postestierenden Mannsstamm mit mehreren männlichen Nachkommen gesegnen wird, alsdann der Primogenitus von der einen Linie in Gross-Britannien, der Primogenitus von der anderen Linie in unseren Chur- und übrigen Teutschen Landen - independenter einer von dem anderen, jedoch allezeit secundum ordinem Iuris Primogeniturae in jeder Linie - regiere [...]. ${ }^{32}$

Damit sollte die Herrschaft auf Georg II. übergehen, dann aber nachfolgend unter Friedrich Ludwig, geboren 1707, sowie Wilhelm Augustus, geboren 1721, aufgeteilt werden. Die Aufspaltung der Dynastie war ein Kunstgriff, um die Primogenitur im Kurfürstentum zu erhalten. Georg I. sah gut ein Jahr nach Antritt seiner Herrschaft in London keine Chance, dem Kurfürstentum sowie Großbritannien unter den ihm auferlegten Bedingungen gerecht zu werden:

Dieweil aber, wie schon obberühret, leicht vorherzusehen, es sich auch zum Teil schon zeiget, in was für Abnahme und schlechtem Zustand Unsere gute Teutsche Lande und dortige liebe und getreue Untertanen geraten und wie sie sich mit der Zeit als eine unterworfene Provinz von Gross-Britannien geachtet und traktieret

32 Drögereit, 1949 (wie Anm. 24), S. 25 f. 
werden dörften, wann sie blosserdings von Engelland aus allezeit regieret und ohn ein eigenes Haupt ganz und gar gelassen werden sollten [...].33

Aus der Sicht des Königs war also keine Regierung auf die Distanz möglich. Zugleich verfügte Georg I. letztlich dasselbe wie es das englische Parlament im Act of Settlement vorsah:

Sollen auch zur Gouvernier- oder Administrierung Unserer Teutschen Lande wie auch in denen Collegiis oder sonst zu Civil-Bedienung selbiger Lande keine Ausländer von Gross-Britannischer oder anderer frembder Nation, sondern allein Teutsche und allein vol solcher Religion wie es in denen Pactis Unseres Hauses verordnet und in Unseres Herrn Vaters christmildesten Andenkens letzten Willens-Disposition bestätigt ist, gebraucht werden. ${ }^{34}$

Somit wurde nun auch jeder britischen Einflussnahme in Kurhannover ein Riegel vorgeschoben. Im Endeffekt also hatte die Personalunion unter Georg I. gewisse Züge eines Januskopfes, denn Georg I. war innerlich zwischen den Interessen beider Herrschaftsräume zerrissen, auch wenn er diese zu synchronisieren versuchte. Letztlich aber gestand er sich ein, dass Großbritannien und Kurhannover unterschiedlich regiert werden mussten.

Dennoch kam es erst 1837 zur Auflösung der Personalunion, da Georg II. das Testament kassierte. Sein Vater hatte zwar Kopien bei diversen Höfen hinterlegt, doch Georg gelang es in mühsamer diplomatischer Arbeit, diese Verfügungen ungeöffnet zurückzuerhalten. ${ }^{35}$ Tatsächlich nutzte Georg II. sehr geschickt die Möglichkeit, als Kurfürst und als englischer König zugleich Politik machen zu können. Nicht immer wussten seine Minister und Räte, wie Georg jeweils als der andere Herrscher agierte. ${ }^{36} \mathrm{Im}$ Schatten des österreichischen Erbfolgekrieges wie des Siebenjährigen Krieges entwickelte sich Großbritannien zu einer globalen Macht - und zugleich blieb es in Folge der Verbindung zu Kurhannover eine europäische Macht. ${ }^{37}$ Georg II. versuchte während seiner dreiunddreißig Jahre währenden Herrschaft, sich einen doppelten maximalen Handlungsraum zu erhalten, denn die Hemmnisse der einen Herrschaft versuchte er durch Spielräume der anderen auszugleichen. Einer der Höhepunkte war sicherlich die Schlacht am 27. Juni 1743 bei Dettingen, bei der Georg II. persönlich die englischen wie die hannoverschen Truppen erfolgreich gegen das französische

33 Drögereit, 1949 (wie Anm. 24), S. 26.

34 Drögereit, 1949 (wie Anm. 24), S. 28.

35 Hatton, 2001 (wie Anm. 20), S. 169.

36 Thompson, 2011 (wie Anm. 28), S. $294 f f$.

37 Vgl. hierzu: Torsten Riotte, Hannover in der britischen Politik 1892-1815. Dynastische Verbindung als Element außenpolitischer Entscheidungsprozesse, Münster 2005, S. 31-41 zu den konkurrierenden Elementen in der britischen Außenpolitik im letzten Drittel des 18. Jahrhunderts. 
Heer ins Feld führte. Intensiver noch als während der Herrschaft seines Vaters wurde Georg II. von der immer wieder öffentlich geführten Debatte verfolgt, dass Hannover britische Steuern zur Finanzierung kontinentaler Auseinandersetzungen verwenden und damit die außereuropäischen Expansionsbemühungen behindern würde. William Pitt argumentierte im Anschluss an den Sieg bei Dettingen, dass offensichtlich ein Königreich wie England aus der Sicht des Kontinents nur Provinz eines Kurfürstentums wäre. ${ }^{38}$ Der britische innenpolitische Druck ging nicht spurlos an Georg II. vorüber, der nun 1744 - wie sein Vater 1716 - an der Fortführung der Verbindung beider Territorien zu zweifeln begann. Seine um Rat gefragten Hannoveraner Räte plädierten aber für die Beibehaltung der Union, denn sie sahen mehr politische Vorteile für Kurhannover als Nachteile für England. In der finalen Fassung seines Testaments knüpfte Georg II. zum einen an die Verfügungen seines Großvaters an, denn wie auch bereits sein Vater betonte er die Primogenitur und die Unteilbarkeit Kurhannovers. Zum anderen aber betonte er explizit die verfassungsrechtliche Verbindung zwischen Kurhannover und Großbritannien. ${ }^{39}$ Damit hatte Georg I. zwar die Grundlagen der praktischen politischen Ausgestaltung der Personalunion gelegt, aber letztlich verlieh Georg II. dieser das rechtliche Gesicht. Georg II. machte sich die Parallelwelt zu Eigen, was zugleich hieß, dass er allein an der politischen Spitze beider Länder stand. Unter ihm festigten sich die Strukturen und Mechanismen der Regierung Kurhannovers über die Distanz. Zugleich nutzte er die Möglichkeiten beider Länder zum jeweils wechselseitigen Vorteil und hielt an der dynastischen Verbindung fest. Unter Georg II. also ähnelte die Personalunion in keiner Weise einem Januskopf, denn der König verfolgte die Interessen Kurhannovers wie Großbritanniens zugleich.

Letztlich setzte dies sein Enkel unter anderen Vorzeichen fort. Allerdings war Georg III. bei seiner Krönung lediglich 22 Jahre alt und hatte niemals zuvor Kurhannover besucht. In seiner Thronrede distanzierte er sich von seinem Vorgänger: Born and educated in this country, I glory in the name of Britain. Letztlich sah Georg III. in seiner Eigenschaft als König von Großbritannien nunmehr Kurhannover als sein Privateigentum an, was rechtlich korrekt war. Hatte Georg noch 1759 Kurhannover als this horrid electorate bezeichnet, so stand er doch nach seiner Krönung fest zur Dynastie und seinem Erbe, das er schon wenige Jahre später als sein deutsches Vaterland bezeichnete. ${ }^{40}$ Anders als seine Vorgänger versuchte Georg III. aktiv Einfluss auf

38 It is now too apparent that this great, this powerful, this formidable kingdom, is considered only as a province to a despicable Electorate. Zitat nach: Simms, 2007 (wie Anm. 19), S. 317. Für eine genauere Analyse der Sichtweise William Pitts auf das Kurfürstentum Hannover vgl.: Brendan Simms, Pitt and Hanover, in: Ders. /Torsten Riotte (Hg.), The Hanoverian dimension in British History, 1714-1837, Cambridge 2007, S. 28-57.

39 Thompson, 2011 (wie Anm. 28), S. $210 f f$.

40 Torsten Riotte, Großbritannien, Hannover und das Ende des Alten Reiches 1806, in: Niedersächsisches Jahrbuch für Landesgeschichte 79 (2007), S. 29-50, hier S. 38-39; T. C. W. Blanning, „That horrid Electorate“ or „Ma Patrie Germanique“? George III and the Fürstenbund of 1785, in: Historical Journal 20 (1977), S. 311-344, hier S. 338. 
die britische Innenpolitik zu nehmen und suchte immer wieder eine Prärogative in der Außenpolitik zu wahren. Wenn auch anders fundiert, standen ihm vergleichbare Rechte als Kurfürst unumstritten zu. Georg III. änderte also nichts an der verfassungspolitischen Qualität der Personalunion. Diese wurde 1777 erstmals von Johann Stephan Pütter beschrieben, der, 1746 an die Universität Göttingen berufen, einer der bedeutendsten und einflussreichsten Staatsrechtler Deutschlands im 18. Jahrhundert wurde. ${ }^{41}$ Er definierte die Personalunion in seinen „Beyträgen zum teutschen Staatsund Fürstenrechte" wie folgt:

Wenn zwey der mehrere Staaten zwar einerley Regenten haben, aber doch in ihren Grundgesetzen unterschieden bleiben, wie z. B. Ungarn und Böhmen, Großbritannien und Hannover usw., so ist das nur eine persönliche Vereinigung, die nicht hindert, dass ein jeder Staat für sich vom andern unabhängig bleibt, ohne daß man davon noch Beyspiele eigentlich zusammengesetzter Staaten hernehmen kann. Denn da wird aus den verschiedenen Staaten noch nicht ein Staat gemacht; sondern jene behalten nach wie vor ihre völlige Absonderung, vermöge derer ein jeder mit einem andern nur persönlich verbundener Staat doch immer ein eigener Staat bleibet. ${ }^{42}$

War der Begriff einer Union als Verbindung zwischen zwei Staaten bereits seit langem etabliert, da beispielsweise die 1707 durch das englische und schottische Parlament beschlossene Verbindung als Act of Union bezeichnet wurde, so etablierte sich nun ausgehend von Pütter der Begriff der Personalunion zwischen Großbritannien und Hannover.

Gut eine Generation nach seiner Krönung aber musste Georg III. erkennen, dass sich die Trennung zwischen den beiden politischen Herrschaftsbereichen nicht unbegrenzt durchhalten ließ. Spätestens seit dem Ausbruch der Revolutionskriege ging es entscheidend um die Bewahrung der Integrität Kurhannovers. Zugleich hatte sich Großbritannien seit dem Doppelfrieden von Hubertusburg und Paris 1763 zu einer globalen Macht mit Kolonien auf nahezu allen Kontinenten entwickelt. Das Eintreten Georgs III. für Kurhannover entsprach also im Wesentlichen den außenpolitischen Interessen Großbritanniens und wurde auch so von der britischen Bevölkerung anerkannt. So wandelte sich der Monarch nach 1789 in der öffentlichen Wahrnehmung zum Repräsentanten und Sympathieträger letztlich sowohl einer

41 Zu Pütter vgl.: Christoph Link, Johann Stephan Pütter (1725-1807). Staatsrecht am Ende des alten Reiches, in: Fritz Loos (Hg.), Rechtswissenschaft in Göttingen. Göttinger Juristen aus 250 Jahren, Göttingen 1987, S. 75-99.

42 Pütter, 1777 (wie Anm. 4), S. 22. 
Mehrheit in der britischen Bevölkerung als auch und noch mehr in der Bevölkerung Kurhannovers. ${ }^{43}$

Georg IV. setzte diese Politik sowohl als Regent als auch als König nahtlos fort. Im Jahr 1820 besuchte er als erster Monarch seit mehr als zwei Generationen wieder seine Stammlande. ${ }^{44}$ Anders als sein Vater überließ er jedoch die Regierungsgeschäfte zunehmend den britischen wie den hannoverschen Ministern. Anders noch als unter Georg I. und Georg II. stand weder für Georg IV. noch für seinen Bruder Wilhelm IV. ein politisches Auseinandergehen beider Herrschaftsräume zur Debatte. Vielmehr hatte die Diskontinuität der Personalunion nach dem Tod Wilhelms IV. rein dynastische Gründe, denn während in England die weibliche Linie erbberechtigt war und somit Viktoria zur Königin gekrönt wurde, folgte auf der Grundlage des salischen Rechts Ernst August auf den Thron im Königreich Hannover. ${ }^{45}$

\section{II.}

Die Krönung von Kurfürst Georg Ludwig zum König von Großbritannien als Beginn einer verfassungsrechtlichen Verbindung war in Deutschland Gegenstand einiger weniger publizierter Gedichte. ${ }^{46}$ In Kurhannover wurde die Krönung als Erfolg gefeiert:

Wo ist solcher Fürst? Ein solches Licht der Erden? I Das seiner Sternen Glanz auff fremde Länder leg't I Dem Weißheit und Verstand zu Kron und Scepter werden I

43 Torsten Riotte, 2007 (wie Anm. 40), S. 49; siehe älter aber sehr ausführlich zu Großbritannien Linda Colley, The Apotheosis of George III. Loyalty, Royalty and the British Nation 1760-1820, in: Past and Present 102 (1984), S. 94-129, hier insb. S. 102, ausführlich dies., Britons. Forging the Nation 1707-1837, New Haven / London 1992.

44 Zum Besuch Georgs IV. in Hannover vgl.: Christine van den Heuvel, At Table we heard of nothing but Hanover. Der Besuch Georgs IV. im Königreich Hannover im Jahr 1821, in: Arnd Reitemeier / Uwe Ohainski (Hg.), Aus dem Süden des Nordens. Studien zur niedersächsischen Landesgeschichte für Peter Aufgebauer zum 65. Geburtstag, Bielefeld 2013, S. 211-234.

45 Mijndert Bertram, The End of the dynastic Union, 1815-1837, in: Brendan Simms / Torsten Riotte (Hg.), The Hanoverian Dimension in British History, 1714-1837, Cambridge 2007, S. 111-127, hier S. 126.

46 Siehe beispielsweise: Christian Ulrich Grupen, An dem Hohen Geburts-Tage Des Durchlauchtigsten und Großmächtigsten Fürsten und Herrn, Herrn Georg Ludewigs Hertzogen zu Braunschweig und Lüneburg / Des Heiligen Römischen Reichs Ertz-Schatzmeisters und Churfürsten [et]c. [et]c. Wurde zu Jena Bey der in der Collegen-Kirche Im Nahmen der gesamten Chur-Hannöverischen Landsmannschafft öffentlich gehaltenen Rede, Nachstehende Cantata abgesungen, Jena [1714]; Johannes Henrich Kindervater, Cvm Serenissimvs atque Potentissimvs Princeps ac Dominvs Dominvs Georgivs Lvdovicvs, Dvx Brvnsvic. \& Lvnebvrg. S. Rom. Imp. Archithesavrarivs \& Elector \&c. \&c. post obitum ... Reginae Annae Iure Haereditario vnanimi Statuum Consensu Magnæ Britanniæ Franciæ atque Hiberniae Rex [...] Mense vere Augusto publice declararetur, magnoque Applausu proclamaretur, Hoc qualicunque Carmine Hexametro-Anacreontico Anagrammati superstructo Svmman Maiestatem, Nordhausen 1714. 
Der in der hohen Brust auch Vater=Liebe heg't. / Das bist Du König ja / Gott hat Dich selbst erkohren / Dich betet Engelland von selbt als König an. ${ }^{47}$

Jacob Carl Spener, der Anfang des 18. Jahrhunderts u. a. in Oxford studiert hatte und 1710 auf ein Ordinariat für Philosophie an der Universität Halle berufen worden war, begrüßte die Krönung in einem Pamphlet:

Ich seh Hannovers Haupt / auf Englands Königsthron / Zu derer Freunde Trost I zur Feinde Schrecken sitzen [...] Geprießnes Engelland! Wie glücklich bist du nicht / dergleichen Helden nun zum König zu erlangen / in Ihm ist dir anitzt ein neuer Glanz und Licht I nach kurtzer Finsterniß von neuem aufgegangen. ${ }^{48}$

Spener hob damit besonders die militärischen Erfolge Georg Ludwigs hervor, auf die auch zahlreiche andere Autoren eingingen:

Da das Geschütze kracht, / und wer die Zeitung hört, von Hertzens-Wonne lacht: [...] Es wallt die tapffre Brust von lauter Helden=Blut; / Drum eilt Georg und nimmt den schaff=gewetzten Degen, / Und rennt dem Vatter zu, und seinem Feind entgegen. / Er trifft das teutsche Heer im Blut=vergiessen an, [...] Doch bringt Georgens Geist dem Volcke neue Kräffe. ${ }^{49}$

Englische Autoren gingen sowohl auf den Tod von Königin Anne als auch auf die Thronfolge von Georg Ludwig ein. ${ }^{50}$ In Schottland hingegen publizierte Ralph Erskine, prominenter Prediger der presbyterianischen Kirche, in Dunfermline ein congratulatory poem aus Anlass der Krönung. Er lobte den aus Hannover nach Großbritannien kommenden Georg I. und verglich seine Krönung mit dem Aufgang der Sonne

47 Henrich Friedrich Engelhart, Als Dem Durchläuchtigsten Fürsten und Herrn / Hn. Georg Ludewig / Herzogen zu Braunschw. und Lüneburg / des Heil. Röm. Reichs Erz-SchatzMeistern und Churfürsten / Die Krone von Groß Britannien höchstwürdigst conferiret wurde / Wolte Ihro Königl. Mayest. [...] In diesen geringen Versen unterthänigst gratuliren, Hannover 1714, S. 2.

48 Jacob Carl Spener, An Seine Königliche Majestät Von Groß-Britannien, Franckreich und Irrland ... Hertzogen zu Braunschweig und Lüneburg, des Heiligen Römischen Reichs Ertz-Schatzmeistern und Churfürsten, über dero erwünschte Antretung Königlicher Regierung, Halle 1714, S. $4 \mathrm{f}$.

49 Georg Ludwig Oeder (Hg.), Esaia Pufendorff. Leben und Thaten George des Ersten, Königs von Groß-Britannien. In einem Helden-Gedichte beschrieben, Und Ihro Majestät glorwürdigstem Gedächtnisse geheiliget, Anspach [1727], o. S.

50 George Smalridge, A poem on the death of our most gracious sovereign Queen Anne: and the accession of his most excellent majesty, King George. By the Right Revd Father in God, George Lord Bishop of Bristol, London 1715. Siehe auch: Henry Player, A poem on the arrival of His Majesty King George, London 1714; Anon., A poem upon the happy arrival of His most serene Majesty King George [Dublin] [1714]; P. Turner, Augustus. A poem on the accession of His Majesty King George. Humbly dedicated to the Right Honourable Charles, Lord Hallifax, one of the Lords Justices appointed by His Majesty, London 1714; Dennis, A poem upon the death of her late sacred majesty Queen Anne. And the Most Happy and most Auspicious Accession Of his Sacred Majesty King George, To the Imperial Crowns of Great Britain, France and Ireland. With an Exhortation to all True Britons to Unity, London 1714. 
im Osten, verdammte aber gleich darauf die Union Schottlands mit England und führte zahlreiche Missstände auf. ${ }^{51}$ Die konfessionelle Zerrissenheit Großbritanniens zeigen Pamphlete wie The jacobite curse, or, excommunication of King George and his subjects. ${ }^{52}$ Die englischen und schottischen Autoren konzentrierten sich somit völlig auf die Aufgaben des neuen Herrschers in Großbritannien, wohingegen sie die Fortführung der Herrschaft über Kurhannover nicht thematisierten.

Anders als britische Zeitungen, die umfassend über Verabschiedung und Rückkehr des Herrschers nach London berichteten, kommentierten Lobgedichte nur höchst selten die ab 1716 aufgenommenen Reisen Georgs I. in seine Stammlande. ${ }^{53}$ Umgekehrt wurden 1716 gleich mehrere Gedichte auf die Ankunft Georg Ludwigs in Hannover veröffentlicht. ${ }^{54}$ In England war dagegen der Geburtstag Georgs I. 1717 Thema der Lyrik. ${ }^{55}$ Zahlreiche Gedichte wurden zudem aus Anlass des Todes von Georg I. im Jahr 1727 verfasst, in denen die Verdienste des Monarchen hervorgehoben, das Kurfürstentum jedoch allenfalls am Rande erwähnt wurde: ${ }^{56}$ Long ére Albion

51 Ralph Erskine, A congratulatory poem upon the coronation of His Majesty King George: with Dunfermline's Address to His Majesty for redressing Scotland's grievances, Edinburgh 1714, S. 4.

52 William Wright, The jacobite curse, or, excommunication of King George and his subjects; with some reflections on the same, to which is added, a poem on the Protestant succession, by a lover of the Protestant religion, his countrey, and the Protestant succession, Glasgow 1714.

$53 \mathrm{Mr}$. Daniel, A poem on the return of His Majesty King George from Hanover: inscribed to Her Royal Highness the Princess of Wales, London [1717]. Siehe auch: Anon., A poem on the happy return of His most Sacred Majesty King George. Humbly inscrib'd to His Royal Highness the Prince, London 1719.

54 Henrich Friedrich Engelhart, Wie der Aller-Durchlauchtigste und Großmächtigste Fürst und Herr / Herr Georg, König von Groß-Britannien / Franckreich und Irrland / ... Hertzog zu Braunschweig und Lüneburg ... Seine Erb-Länder / Nach zwey-jähriger Abwesenheit / Durch seine hohe Gegenwart / Als Eine wolthätige Sonne / ... wiederum bestrahlete / Solte Seine Freude darüber ... zu erkennen geben ..., Stade 1716; Jacob Vogel, Gottes Schutz wider Seba Trutz Uber Den Durchlauchtigsten ... Herrn Georg, König von Groß-Britannien / Franckreich und Irrland ... Hertzog zu Braunschweig und Lüneburg / ... in tieffster Unterthänigkeit vorgestellet und bey Ihr. Königl. Majest. und Chur-Fürstl. Durchl. ersten glücklichen Zurückkunfft aus Ihren Groß-Britannischen Reichen in Dero Hertzogthüme Zu Dero Königlichen Füssen geleget, Lauenburg [1716].

55 Anon., A poem on the anniversary of the birth-day of his Majesty King George. Humbly inscrib'd to His Majesty, London [1717]; Henry Nevil, A poem on the birth-day of His Most Sacred Majesty King George. Humbly presented to Sir Hans Sloane, London [1717]; Anon., Poem On The Birth-Day Of his most Sacred Majesty King George. Humbly Presented to Seignior Mahomet, Servant to His most Sacred Majesty King George, London 1717.

56 Oeder, 1727 (wie Anm. 49); Anon., Betrachtungen Einiger Umstände bey dem Tod Des grossen Frieden-Stifters der Europäischen Welt, Des Herrn Georg des Ersten, [...] [S.1.], 1727; A. L. Schumacher, Fata Singularia Georgii Primi Magnæ Brittanniæ Regis Gloriosissimi Ex Fatis Factisque Præcipuis Henrici Secundi Tristissimo, Rinteln [1727]; Johann Heinrich Borkenstein, Die thränende Jrene Als Der Allerdurchlauchtigste und Großmächtigste Fürst und Herr, Herr Georg Ludowig, [...] Durch einen plötzl. doch höchstseeligsten Todt [...] von dieser Welt schieden, Hannover 1727; Alexander de Mackphaill, Europa Lugens In Funere Serenissimi Et Potentissimi Principis Ac Domini, Georgii Primi, D. G. Magnæ Britanniæ, Franciæ Et Hiberniæ Regis ... Brvnsvicensivm Et Lvnebvrgensivm Dvcis ... Qui, Ex Itinere Britannico Redvx, Osnabrugæ MDCCXXVII. III. Id. Jun. St. Vet. / X. Cal. Jul. St. N. Vitam Gloriosissimam Cum Morte Placida Ac Beata Commutavit, Celle 1727; Ernst Ludowig Rathleff, Die Uber den 
triumpl'ed in his reign / His sword glar'd dreadful o'er the Hungarian plain / Witnes, ye troops, thro' whose wide ranks he ran, / Rouz'd the fierce war, and call'd the tumult on. ${ }^{57}$ Umgekehrt sahen diejenigen Autoren, die in Kurhannover die Krönung Georgs II. begrüßten, ganz selbstverständlich eine Verbindung zwischen Kurhannover und Großbritannien, wobei allerdings das Kurfürstentum als solches nicht mit seinem verfassungsrechtlichen Terminus erwähnt, sondern lediglich umschrieben wurde: Lebe! Lebe! Lange lebe! / Allergnädigster Georg. / Landes=Vater / Herr und König. ${ }^{58}$

Aus der Sicht der Autoren war der Königstitel die entscheidende Würde, wie schon 1719 ausführlich festgestellt wurde: [...] Hannover, merckst du nicht was man von ferne spuert? / Die schnellen Rosse, die vor deinen Thoren schnauben. [...] Ey! Was bedeutete das? Der König ziehet ein. ${ }^{59}$ Im Jahr 1740 wurde noch einmal deutlicher formuliert:

unverhofften und gantz Europa Höchst schmertzlichen Tod Ihro Majestät Georg des I. Glorwürdigsten Andenckens Königs von Groß-Britannien, Franckreich und Irrland, Churfürst zu Braunschweig und Lüneburg [et]c. [et]c. [et]c. Geschöpffte Betrübniß / Aber Durch die Erhebung Ihro Majestät Georg des II. Auff den Englischen Thron Wieder hergestellete Freude, Helmstedt, 1727; Johann Heinrich Schrammen, Bittere Klage und süsser Trost, Als der weyland Allerdurchlauchtigste ... Herr Georg der Erste, König von Groß-Britannien, Franckreich und Irrland ... Hertzog zu Braunschweig und Lüneburg ... Auf Dero Reise [...] Die zeitliche Crone mit der Ewigen durch einen ... höchstseeligen Tod verwechselte, Und darauf Die Königliche Leiche den 8ten September zu Hannover anlangete / Und begraben wurde, Hannover 1727; Marquis D’Eireval, Reflexions Morales Et Chretienes Sur L' Inopinee Et Fatale Mort De Sa Majeste Britannique George Ier De Glorieuse Memoire Roi De France, Decede Le 22me De Juin, Dans Le Chateau Episcopal De Monseigneur Eveque D’ Osnabruc, Par Le Tres Zele Tres Soumis Et tres Devoüe Serviteur, Helmstedt 1727; Richard Savage, A poem, sacred to the glorious memory of our late most gracious sovereign lord King George, Dublin 1727; George Woodward, A poem to the glorious memory of His Sacred Majesty King George I, London 1727; Mr. Byles, A poem on the death of His late Majesty King George, of glorious memory. And the accession of our present sovereign King George II. to the British throne, [Boston] [1727].

57 Byles, 1727 (wie Anm. 56), S. ii.

58 Anon., Allerunterthänigstes Freuden-Lied / dem Allerdurchlauchtigsten Großmächtigsten Könige / Churfürsten und Herrn / Herrn Georg dem Andern / Könige von Groß-Britannien, Franckreich und Irrland, Hertzoge zu Braunschweig und Lüneburg ... Bei Dero allerhöchstem ... Eintritt in Seine Stadt Celle Den 17 Augusti im Jahr 1729, [...] abgesungen/ von Ihro Königlichen Majestät der hiesigen Stadt-Schule Choro Symphaniaco, Celle 1729, o. S. Zur Krönung Georgs II. siehe: Anon., Am Freuden-reichen Danck-Feste über die im Seegen vollzogene Königl. Groß-Britannische Crönung Unsers Allerdurchlauchtigsten, Großmächtigsten Königs und Landes-Vaters, Georgs des Andern [...] Und Unsrer Allerdurchlauchtigsten, Großmächtigsten Königin und Landes-Mutter, Carolinen, Königin von Groß-Britannien, [et]c. [et]c. Als am verwichenen 9. Novembr. des 1727. Jahrs, Wurde Aus dem XIII. Cap. I. Chron. v. 18. Das Rechte Gilgal treuer Unterthanen in des Reichs Erneuerung, [...] [S.1.], [ca. 1727]; Richardson Pack, A congratulatory poem to his Majesty George the IId upon his accession to the throne. To which are Prefixed Verses Inscribed to the Right Honourable the Earl of Scarborough, London 1727; Mr. Beckingham, A poem on His most sacred Majesty King George the second. His accession to the throne, London [1727]; Byles, 1727 (wie Anm. 56).

59 Bey Ihro Königl. Maj. Von Groß-Britan[n]ien Und Chur-Fürstl. Durchlauchtigkeit zu Braunschweig-Lüneburg Höchst-erfreulichen Ankunfft In Hannover, So geschahe Im Jahr Christi 1719. den Rieff einer Aus allerunterthänigst-devotestem Hertzen Glück zu dem König! o. O., o. J., S. 2. 


\section{Daß Du von Deinen Thron Dich hast zu uns gewendet, / und dadurch unsern Wunsch und Sehnsucht nun geendet, / Daß uns Dein Gnade=Strahl, daß Deine Purpur Pracht. I Und Deine Gegenwart uns heute glücklich macht. I Es Kann nun jederman durch dieses Gnaden=Zeichen, I Mit allem Rechte sich den Glück- lichsten vergleichen, Weil Deine Königs Huld besonders auf uns strahlt. ${ }^{60}$}

Analog äußerten sich die vielen Autoren, die Lobgedichte für die Begrüßung Georgs II. auf seiner ersten Reise seit seiner Krönung durch das Kurfürstentum veröffentlichten. ${ }^{61}$ Die Schlacht bei Dettingen 1743 war dann Anlass für eine ganze Reihe

60 Martin Hartwig Hoffschläger, Als Der Aller-Durchlauchtigste, Großmächtigste Fürst und Herr, Herr Georg der Ander, König von Groß-Britannien, Franckreich und Irrland ... Hertzog zu Braunschweig und Lüneburg ... Dero Teutsche Provintzen Den 7. Jun. 1740. Mit Deroselben .. Gegenwart erfreuete, Hannover 1740, S. 3 .

61 Anon., Parckmannisches Willkhumme pai dr klickling Ankunfft unners theirn unn liewen Lands- unn Parck-Fotersch Jerg des Annern/ Khinigs fonn Kruß-Brittannien / Franckreich unn Irrland. Wie har am 24. Julius in tiessen laffenden 1729ten Jahrs offs Klaßthol kham / unn uns samtliche Parckleit alt unn junck, kruß und klähn mit Seiner Khiniglichen Kegenwart trfrähte, kemacht in aller Unterthanikhät von uns sämtling Parckleiten, [Clausthal] 1729; Henning Calvör, Allerunterthänigste Addresse Der Clausthalischen Musen: Welche Zur frohen Bewillkommung Des Herrn Georg des Anderen [...] Als Ihro Königl. Majestät ... diesen Hartz-Gebürgen, und Clausthal den 24. Julii dieses 1729. Jahres allergnädigst gönneten, Clausthal 1729; C. B., Dilische Willkommnungs Ode, Als der Allerdurchlauchtigste und Großmächtigste Fürst und Herr, Herr Georg der Andere, König von Groß-Britannien, Im Jahr Christi 1729 den 4ten Juny. In die Residentz Hannover anlangete, Hannover 1729; Anon., Allerunterthänigste Ehren-Bezeigungen, Mit welchen Der Allerdurchlauchtigste ... Herr Georg II. König von Groß-Britannien, [...] Den 29. Julii 1729. demüthigst empfangen wurde In S. Maj. Stadt Göttingen, Göttingen 1729; Rath und Bürgerschafft der Stadt Celle, Allerunterthänigster Glückwunsch, Welchen Dem Allerdurchlauchtigsten, Großmächtigsten Könige, Chur-Fürsten und Herrn, Herrn Georg dem Andern, [...] Bey Dero Gegenwart Den 27. Aug. 1729. in tieffster Submission darbringen sollten, Celle 1729; Anon., As Dei Allerdorchlüchtigste Könning un Heer, Heer Georg de Andere, Den 4. Juny des Sönnavends vor Pingsten tau Middage in Hannauver kam, un drup Den 18. düsses Mahndes im Jahr 1729 [...], Hannover 1729; Anon., Celle 1729 (wie Anm. 53); Johann Christoph Arnemann, Als Der Allerdurchlauchtigste, Großmächtigste Fürst und Herr, Herr Georg der Andere, König von Groß-Britannien, Franckreich und Irrland, durch Ihro glückliche Anherokunfft aus Engelland Ihro Teutsche getreue Unterthanen zum Ersten mahl höchlich erfreueten, Hannover 1729; Johann Just Fahsium, Die erquickte Irene Als / Der Aller-Durchlauchtigste / Großmächtigste König und Herr / Herr Georg der II. König von Groß-Brittannien / Franckreich und Irrland, Anno 1729. im Monath Julio seine teutschen Provinzen höchstbeglückt besuchte, Goslar 1729; I. C. S. H., Allerunterthänigstes Wunsch-Opffer, Als der Allerdurchleuchtigste, Großmächtigste Fürst und Herr, Herr Georg der Andere, [...] am 13ten Julii 1729. nahe bey Hannover, einen grossen Theil der Chur-Hannöverschen Trouppen musterte, Hannover 1729; Johann Christian Bertram, Als Die Hellstrahlende Landes-Sonne, An dem Hannöverischen Firmament auffging, War Der 4te Junius des 1729. Jahrs, Da nach langer Sehnsucht vieler Tausend Seelen, Der ... Fürst und Herr, Herr Georg der Andere, [...] Von Engelland Dero Churfürstl. Erbländer besuchten, und In dero Churfürstl. ResidenceStadt zu Hannover ankahmen., Hannover 1729; Michael Christoph Brandenburg, Die Unaußsprechliche Freude Der Chur-Braunschweig- und Lüneburgischen Länder, Uber Die allerhöchste Gegenwart Des Herrn Georg des Anderen, Königes von Groß-Britannien, Franckreich und Irrland, Hertzoges zu Braunschweig und Lüneburg. In einer Ode entworffen, Lüneburg 1729.; Georg Balthasar Christ, Als Der Allerdurchlauchtigste, Großmächtigste König und Herr, Herr Georg der Andere, König von Groß-Britannien / Franckreich und Irrland am 4ten Junii des 1729ten Jahres aus Engeland in Seine Chur-Fürstl. Residence-Stadt Hannover unter vielen Freudens-Bezeugungen derer getreuen Unterthanen, höchst-glücklich überkommen, Hanno- 
von Lobpreisungen auf Georg II. ${ }^{62}$ Die deutschen Autoren betonten die Verteidigung Kurhannovers, schrieben aber, wie beispielsweise Johann Conrad Hahn, den Erfolg dem König und nicht dem Kurfürsten zu, womit sie die Doppelherrschaft betonten:

So ists, Beherrscher kluger Britten! Du, Deiner Teutschen Heyl und Lust / Des
volcks Trajan des Lands Auge, / Georg, der Freund und Feind durch Seine Macht
bestritten / [... I Monarch! Da mich Dein Glantz entzücket, / So weissagst dieses
meine Brust, / Als die mit Ehrfurchts=voller Luft / Vor Deinem Gnaden=Thron
mit höchster Huld beglücelt. / O Held! Die Hoffnung wincket mir, / Und heisset
mich erstaunt in Dir / Des Reichs und meinen Schutz=Gott ehren. / Was kan,

ver 1729; Johann Martin Ludewig Evers, Als der Allerdurchlauchtigste, Großmächtigste König und Herr, Herr Georg der Andre, König von Groß-Britannien Franckreich und Irrland ... Hertzog zu Braunschweig und Lüneburg, Nach Dero Erhebung auf den Thron, Zum erstenmal Dero Teutsche Länder, Insonderheit die Stadt Celle Den 27. Augusti im Jahr 1729. Allergnädigst besuchten, Celle 1729; Anon., Allerunterthänigster Zuruff, Als der Allerdurchlauchtigste, Großmächtigste Fürst und Herr, Herr Georg der Andere, [...] Den 4. Jun. 1729. [...] zum ersten mahle aus Engelland in Dero Churfürstl. Residentz-Stadt Hannover angelanget, [S.1.] 1729; M. H. Hoffschläger, Allerunterthänigstes Freuden-Opffer, welches Bey Des Allerdurchlauchtigsten Großmächtigsten Fürsten und Herrn, Herrn Georg des Andern, [...] Allerhöchst- und gnädigsten Heimsuchung Dero Chur-Fürstenthums und Teutsche Provintzen, Hannover [1729]; Christoph Friederich Wedekind, Bey der höchst erfreulichen Und Erwünschten Ankunfft Des Allerdurchlauchtigsten Fürsten und Herrn, Herrn Georgens Des Zweyten, [...] Als Dieselben Den [ ] May des ietztlauffenden 1729. Jahrs in Dero Churfürstl. Haupt- und Residentz-Stadt Hannover eintraffen, Helmstedt 1729; August Friedrich von Zanthier, Die Ungemeine Freude Bey Allgemeinen Vergnügen, Als Der Allerdurchlauchtigste / Großmächtigste Fürst und Herr, Herr Georg der Andere, [...] Dero Teutschen Chur- und Erblande Mit längst-erwünschtester Gegenwart Im Jahr 1729. Allergnädigst erfreueten, Hildesheim 1729; Henrich Christian Lemcker, Allerunterthänigste Bewillkommung Getreuer Unterthanen, Als der Allerdurchlauchtigste, Großmächtigste König und Herr, Herr Georg der Andere, [...] Dero teutsche Erb-Länder und insonderheit die Stadt Lüneburg d. 15. Aug. 1729. besuchten, Lüneburg 1729; Rath und Bürgerschafft der Stadt Celle, Allerunterthänigster Glückwunsch, Welchen Dem Allerdurchlauchtigsten, Großmächtigsten Könige, Chur-Fürsten und Herrn, Herrn Georg dem Andern, [...] Bey Dero Gegenwart Den 27. Aug. 1729. in tieffster Submission darbringen sollten, Celle 1729; Ulrich Martin Polon, Dem Allerdurchlauchtigst Großmächtigsten Fürsten und Herrn, Herrn Georg dem Andern, [...] meinem Allergnädigsten Könige und Herrn, überreichet dieses in tieffester Devotion, [ca. 1729].

62 J. E. G. Pott, Die Siegreiche und Höchsterfreuliche Zurückkunft Seiner Königlichen Majestät von Groß-Britannien Georges Andern den 18. October 1743. von der Armee glücklich allhie wiederum eingetroffen Als auch Die Höchstglückliche Verbindung Des Kron-Prinzen von Dännemark Friedrichs mit der Groß-Britannischen Prinzessin Louisen welche den 10. November volzogen worden, Hannover 1743; Siegmund Ferdinand Weißmüller, Des Allerdurchlauchtigst- u. Großmächtigsten Königes und Herrn, Herrn George des Andern Königes von Groß-Britannien, Franckreich und Irrland, Unschätzbare Sorgfalt, Gnädigste Hülffe, Glückliche Siege Bewundert in demüthigster Ehrfurcht Ein allerunterthänigst-treugehorsamster Knecht, Oettingen 1743; Anon., Das Erschreckte Durch Se. Königl. Groß-Brittannische Majestät, Herrn Georg Des Zweyten, Höchste Gegenwart Wieder neu belebte und glückseelige Hanau, [S. 1.], 1743; Johann Conrad Hahn, Uber den Von Seiner Königlichen Majestät, Georg Dem Andern, König von Groß-Brittannien, Franckreich und Irrland [et]c. [et]c. Am 27sten Junii 1743. bey Dettingen glücklich erfochtenen Sieg, Hanau 1743. 
nun Du die Palmen führst / Und Dich mit Sieges=Fahnen zierst, Der Teutschen Wunsch und Glück, der Britten Freude mehren? ${ }^{63}$

Damit setzten diese Autoren andere Akzente als der einleitend zitierte Brandenburg. Geboren 1694, hatte dieser in Rostock und Leipzig studiert, war seit 1722 Pfarrer und wirkte seit 1744 als Assessor des Konsistoriums des Herzogtums Lauenburg. In seinem Werk von 1748 thematisierte er die Verbundenheit der Bewohner des Herzogtums Lauenburg, das 1702 an das Kurfürstentum Braunschweig-Lüneburg gefallen war, mit Georg II., König von Großbritannien und Kurfürst von Hannover. Wie viele andere brachte er den Herrscher sowohl mit dem springenden Ross als Symbol der Welfen als auch mit dem Löwen als Sinnbild für England in Verbindung. Auch knüpfte Brandenburg an Heinrich den Löwen an, der von Braunschweig 1182 und noch einmal 1189 nach England ins Exil ging, denn laut Brandenburg kehrten sowohl Heinrich der Löwe als auch Georg II. als machtvolle Herrscher nach Norddeutschland zurück. Die Janusköpfigkeit, mit der Brandenburg also die Fürsorge des Herrschers für Kurhannover wie für Großbritannien beschrieb, meinte also keine innere Zerrissenheit sondern eine beiden Herrschaftsräumen geltende Aufmerksamkeit. Brandenburgs Allegorie zielte auf die Gleichmäßigkeit in der Aufmerksamkeit des Herrschers ab und spiegelte damit nicht die realpolitischen Umstände wider, da die Voraussetzung einer Position des Herrschers in der Mitte zwischen beiden Territorien nicht gegeben war. Vielmehr erkannte Brandenburg an, dass Georg II. sich vorwiegend in Großbritannien aufhielt und bedauerte, dass er seine Stammlande bald wieder verlassen würde. Zugleich wies er darauf hin, dass der gleich verteilten Aufmerksamkeit des Herrschers die kulturellen und ökonomischen Unterschiede zwischen den Herrschaftsräumen gegenüberstanden: Brandenburg beschrieb die Bewohner zumindest Lauenburgs als „arm“ und charakterisierte die Städte Englands als „reich“.

Ähnlich wie Brandenburg ordnete im Jahr 1750 Hornbostel die Herrschaft Georgs II. zwei Welten zu: Zwo Welten ist Er gros genug. / Er will, so legen sich die Kriege; / Nächst uns liebt Er die ganze Welt; Und reizt Ihn unser Heil zum Siege, / So bleibt er doch ein Friedensheld. ${ }^{64}$ Ähnlich äußerten sich die viele Autoren aus Anlass des Todes von Georg II. ${ }^{65}$

63 Hahn, 1743 (wie Anm. 62), o. S.

64 Hornbostel, Auf die Ankunft Sr. Königl. Majestät von Grosbritannien zu Herrenhausen 1750, Hannover 1750.

65 Ode auf den Tod Seiner Königl: Maiestät Georg des Andern, [S.1.], [1760]; Anon., Klaglied bei der grossen Leiche Sr. Königl. Majestät von Grosbrittanien, und Churfürstl. Durchl. von Braunschweig-Lüneburg, unsers Allergnädigsten Landesherrn, weiland Georg des Andern, als Höchstdieselben den 25ten Oktober 1760 das Zeitliche verliessen und die vergängliche mit der ewigen Krone der Ehren verwechselten, Harburg 1760; Ode auf den Tod Seiner Königl: Maiestät Georg des Andern, [S.1.], [1760]; Anon., The tears of Britannia: an elegiac poem. Occasioned by The Death of his Most Sacred Majesty King George II, London 1760. 
Im Gegensatz zu Brandenburg verfügten andere deutsche Autoren über detaillierte landeskundliche Kenntnisse und gingen daher beispielsweise auf das wachsende britische Reich mit seinen Kolonien ausführlich ein, erst recht, als dieses die britischen Interessen immer stärker bestimmte. Johann Heinrich Steffens, Rektor des Celler Gymnasiums, ließ 1763 zum Ende des Siebenjährigen Krieges die Verdienste Georgs II. beim Ausbau des Empire Revue passieren:

Das Verhängnis fügt es anders, die bezwungene neue Welt / Küsset nun Georgens Zepter, macht, daßjene Hofnung fällt. / So viel Flotten in der See, nie so stark in allen Kriegen / lassen sich an Florida, nicht an Canda begnügen: / Um den Frieden zu erzwingen, muß weit mehr bezwungen seyn, / Wohin das Zepter reicht, Herr der Britten, das ist dein. ${ }^{66}$

In einer zweiten Publikation führte er das Thema etwas weiter aus:

Das Verhängnis fügt es anders, die bezwungne neue Welt / küsset nun Georgens Zepter, macht, daß jene Hofnung fällt. So viel Flotten in der See, nie so stark in allen Kriegen / lassen sich an Florida, nicht an Canada begnügen; / Um den Frieden zu erzwingen, muß weit mehr bezwungen seyn, / [...] Die Gerechtigkeit, ihr Schild, rächet zwar der Britten Ehre; / mit Triumph gebieten sie über beiden Welten Meere; / Aber ihre tapfere Hülfem Millionen hinderns nicht, / Daß die Flamme nicht von neuen über unsere Grenzen bricht. / [...] Was blieb nun noch unversucht, allenthalben durchzubrechen, / Und durch diesen neuen Bund Englands Schutz für uns zu schwächen? / Wenn der Seraph heilige Lieder vor dem Trohn des Höchsten bringt / [...] / Aber Deines Seegens Kraft wirkt bis in die spätesten Zeiten, / Und Ihn wird des Enkels Trohn in Britannien verbreiten. ${ }^{67}$

Die Anzahl der zur Krönung Georgs III. publizierten Lobgedichte war im Vergleich zu seinem Vorgänger eher gering, wobei sich nicht erkennen lässt, ob das Genre an Popularität verlor oder ob dies eine Folge der fehlenden Reisen des Herrschers nach Kurhannover war. ${ }^{68}$ Ähnlich wie sein Vater wurde Georg III. dann 1769 als Friedens-

66 Johann Heinrich Steffens, Nach dem Dankfeste, wegen des von Seiner Königl. Majestät von Grosbritannien, Georg dem Dritten, wieder hergestellten Friedens, suchte einer verehrungswürdigen Versammlung in dem Hörsaale der Zellischen Stadtschule die Größe dieser Wohlthat nebst den überstandenen Gefahren des Krieges durch nachstehende Rede zu schildern den 25ten Januar 1763, Celle 1763, S. 11.

67 Steffens, 1763 (wie Anm. 66), S. 11ff.

68 Johann Ludwig Lev. Gebhard, [De Origine Ducum Serenissimorum Meclenburgicorum] Georgii Tertii Augustissimi Regis Magnæ Britanniæ Franciæ Hiberniæ Defensoris Fidei Ducis Brunsvicensis Et Luneburgensis S. R.J. Archithesaurarii Et Electoris Et Sophiæ Charlottæ Augustissimæ Reginæ Natæ Ducis Meclenburgicæ Connubialia Et Coronationum Sacra. Faustis Gratulationibus Et Piissimis Votis Veneraturos Georgum Fridericum Augustum De Wense Eqvitem Luneburgensem Atque Hartwicum De Bulow Eqvitem Meclenburgicum Indicit Deqve Origine Ducum Serenissimorum Meclenburgicorum, Luneburgi XXII Septembris MDCCLXI, Lüneburg 1761; Anon., Gratulatio Academiae Cantabrigiensis auspicatissimas Georgii III., Magnae Britanniae Regis et Serenissimae Charlottae principis de Mecklenburg-Strelitz nuptias celebrantis, 1761. 
fürst gelobt: So denkt, so thut Georg, der allerbeste König! / Er halt der Waffen Ruhm zu wenig / Für jenen größern Ruhm, ein menschenfreund zu seyn. / [...] Nicht Länder zu verheeren, Nein, zum Schutze seiner Staaten / Führt er das Schwert. ${ }^{69}$ Über viele Jahre wurde nun in Hannover Ende der sechziger und der siebziger Jahre jeweils am Geburtstag des Königs ein Singgedicht aufgeführt, das anschließend gedruckt wurde. ${ }^{70}$ In diesen Gedichten wurde der Monarch jeweils für seine Herrschaft gelobt, ohne dass zwischen den Untertanen Großbritanniens und Kurhannovers differenziert wurde. Vielmehr feierte man Georg III. beispielsweise 1773 als der beste von Europens Fürsten. ${ }^{71}$

Die gemeinsame Verwicklung Kurhannovers und Großbritanniens in die Kriege mit Frankreich hatte etwa zur Folge, dass Johann Hermann Vier, Pastor zu Kehdingbruch im Amt Neuhaus, in seiner Predigt explizit das gemeinsame Schicksal aller Untertanen Georgs III. hervorhob:
Doch es danken alle edle Briten und rechtschaffene Hannoveraner Gott mit Her- zen, Mund und Händen; ja es danke Gott und lobe Dich, Sein Volk in großen Schaaren, daß Du in / Georg, dem Dritten, uns einen König und Landesvater ge- geben hast / [...] Doch für edle Briten und für meine biederen Landsleute bedarf es keiner so weitläufigen Ermunterung. ${ }^{72}$

69 Greve / Winter, Singgedicht welches am 4ten Junius, als an dem höchsterfreulichen Geburtstage unsers allergnädigsten Königs Georgs des Dritten bei der deßwegen im ersten Hörsaale des Gymnasii zu Hannover anzustellenden feierlichen Handlung musikalisch aufgeführet werden soll, Hannover 1769, S. 3.

70 Ballhorn / Winter, Singgedicht, welches wegen des höchsterfreulichen am 4ten Junius eingefallenen Geburtsfestes unsers Allergnädigsten Königs Georgs des Dritten bei der deßwegen am 23ten d. M. Vormittags um 10 Uhr im ersten Hörsaale des Gymnasii zu Hannover anzustellenden öffentlichen Feier musikalisch aufgeführet werden soll, Hannover 1768; Greve / Winter, 1769 (wie Anm. 69); Ballhorn / Winter, Singgedicht, welches zu Bezeugung gerechtester Freude über den am 4ten Junius abermal erlebten höchtgewünschten Geburtstag unsers Allergnädigsten Königs Georgs des Dritten bei der am 5ten d. M. Vormittags um 10 Uhr im ersten Hörsaale des Gymnasii zu Hannover deßwegen anzustellenden öffentlichen Feier musikalisch aufgeführet werden soll, Hannover 1770; Ballhorn / Winter, Singgedicht, welches am 4ten Junius als an dem höchsterfreulichen Geburtstage unsers Allergnädigsten Königs Georgs des Dritten bei der deßwegen im ersten Hörsaale, Vormittags um $10 \mathrm{Uhr}$ zu haltenden feierlichen Rede musikalisch aufgeführet werden soll, Hannover 1772; Ballhorn / Winter, Singgedicht, welches am 4ten Junius als an dem höchsterfreulichen Geburtsfeste unsers Allergnädigsten Königs Georgs des Dritten bei der deßwegen Vormittags um $10 \mathrm{Uhr}$ im großen Hörsaale zu Hannover anzustellenden öffentlichen Feier musikalisch aufgeführet werden soll, Hannover 1773; Schumann / Winter, Singgedicht, welches am 4ten Junius als an dem höchsterfreulichen Geburtsfeste unsers Allergnädigsten Königs Georgs des Dritten bei der im großen Hörsaale zu Hannover Vormittags um 10 Uhr deswegen anzustellenden öffentlichen Feier musikalisch aufgeführet werden soll, Hannover 1774.

71 Ballhorn / Winter, 1773 (wie Anm. 70), S. 3.

72 Johann Hermann Vier, Ehret den König Georg den Dritten! Eine Predigt am Tage der General-Kirchenvisitation den 15ten Jul. 1796 gehalten in der Gegenwart Sr. Magnificenz des Herrn General-Superintendenten Velthusen, Hannover 1797, S. 20-28. 
Die Gesundung Georgs III. 1789 wurde in Kurhannover mit einem von der Regierung verordneten Festtag begangen. ${ }^{73}$ In Großbritannien schrieb beispielsweise Samuel Hayes die Genesung des Herrschers im Wesentlichen den Gebeten der Briten $\mathrm{zu}^{74}$ ähnlich argumentierten auch andere britische Autoren, die ebenfalls Kurhannover und die Gebete der kurfürstlichen Untertanen nicht erwähnten. ${ }^{75}$

Umfassende landeskundliche Kenntnisse flossen in die Lobeshymne für Georg IV. ein, die diesem der Magistrat und die Bürgerschaft der Stadt Göttingen aus Anlass des kurzen Besuchs der Stadt 1821 widmeten:

Dort, wo die Nebelküsten sich erheben, / Eint Brittenliebe sich um Seinen Thron, I Wo Schottlands Berge zu den Wolken streben, / Da huldigt Ihm des Hochlands starker Sohn, / Und wo des Shannons stolze Silberwelle / So grüne Flur, als Felsgeklipp' umzieht, I Da sprudelt Ihm der Liebe frische Quelle, I Da preis't Ihn Irlands Herz und Irlands Lied. I Und wo das Meer mit seinen Riesenwellen / An Herkul's Felsensäuöen schäumend bricht, / Da sieht man Seine Königsbanner schwellen, Und Liebe dienet Ihm in süßer Pflicht; I Ja selbst der wilde Sohn der heißen Wïste / Ist Seinem hohen Zepter unterthan, I Und Kühn nach Indiens entlegner Küste / Brach sich der Britte die verweg'ne Bahn. / So glänzt Sein Diadem in allen Zonen / Und ungemessen ist Sein Königthum, / So schmücken Ihn die schimmerreichsten Kronen, / Und sternenhoch trägt Ihn der schöne Ruhm ; / Und daß Er schirme Seine Insellande, / Reicht Ihm, befreundet und mit mildem Sinn, I Zu ew'ger Herrschaft heil'gem Unterpfande / Der Meeresfürst den mächtigen Dreizack hin. I Und dennoch auf dem reichsten Erdenthrone / Vergaß Er nicht das fromme Ahnenland, Wo einst, noch ohne Schmuck der Königskrone, / Die heil'ge Wiege Seiner Väter stand; Umleuchtet von des Lebens höchstem Schimmer, I

73 Johann Konstantin Eberwein, Worte einer Musik am allgemeinen höchsterfreulichen Dank- und Hohen Jubel-Fest wegen glücklicher Wiedergenesung unseres ... Königs Georg III den 26. April in Lüneburg aufgeführet, Lüneburg 1789; Ders., Komposition der kleinen Lieder des von Rektor Crome zum Dank-Fest für die Wiedergenesung des Königs Georg III gedichteten Schäfer-Idylls, Hamburg 1789; Johann Conrad Eggers, Rede an dem im Herzogthume Lauenburg verordneten Dank-Feste für die Genesung des Königs, Ratzeburg 1789; Johann Gottlieb Burkhardt, Die Verherrlichung der göttlichen Macht [Dankpredigt für Genesung des Königs Georg III. von Großbritannien am 23. April 1789], Hamburg 1789; An dem Feste wegen glücklicher Genesung unsers geliebtesten Königs [Georg III.], Hannover 1789; Gerhard Philipp Scholvin, Der dankbare Unterthan bey der Wiedergenesung des Königs wurde in dem allgemeinen Dankfeste, welches den 26ten April 1789 wegen der Wiedergenesung Sr. Großbritannischen Majestät Georg III. gefeiert wurde, Hannover 1789.

74 Samuel Hayes, Verses on His Majesty's recovery, London 1789.

75 Anon., A thanksgiving appointed to be said for the recovery of our most gracious sovereign King George III, London 1789; James Dore, A sermon on the happy recovery of His Majesty King George the Third. Preached at Maze Pond, Southwark, April 26, 1789, London 1789; R. Formby, A sermon preached at St. George's Church, Liverpool, on Thursday the $23 \mathrm{~d}$ of April, 1789, the day of thanksgiving for His Majesty's recovery, Liverpool 1789. 
Im Sonnenglanz' der königlichen Pracht, / Hat Er mit milder Vaterliebe immer / An Sein getreues deutsches Volk gedacht. ${ }^{76}$

Zweifelsfrei demonstrierte Georg IV. mit seinen Stammlanden Verbundenheit, wenn er das Königtum Hannover 1821 besuchte. ${ }^{77}$ Vieles aber spricht dafür, dass die Lobgedichte des Jahres 1821 Projektionen waren, in die sowohl die lange Abwesenheit des Herrschers, die langjährige Fremdherrschaft als auch die Anglophilie einflossen.

\section{III.}

Die in den Lob- und Herrschergedichten zutage tretende Wahrnehmung der politischen Verhältnisse der Personalunion entsprach den verfassungsrechtlichen Gegebenheiten. Seit Georg I. arrangierten sich die Könige mit den unterschiedlichen politischen Systemen und versuchten die Interessen Kurhannovers und Großbritanniens miteinander in Übereinstimmung zu bringen. Großbritannien wurde in Kurhannover ohne Widerspruch als dominierende Macht wahrgenommen, während umgekehrt das Interesse der britischen politischen Eliten an Angelegenheiten des Kurfürstentums begrenzt war.

Wie andere Personalunionen im 18. Jahrhundert entstand die Britisch-Hannoversche Union aus einer spezifischen politisch-dynastischen Situation, die sich aus der Glorious Revolution von 1688 ergab. Sie führte zu einem völligen Nebeneinander von Kurhannover und Großbritannien. Diese auf ein verfassungsrechtliches Minimum beschränkte Verbundenheit war von englischer Seite her gewollt und wurde von Georg Ludwig spätestens mit seiner Krönung akzeptiert. Besonders Georg II. und Georg III. suchten die sich ihnen im politischen Wechselspiel eröffnenden Spielräume zu nutzen. Verfassungsrechtlich aber blieben einzig die Herrscher das Großbritannien mit Kurhannover verbindende Element. Anders als in den Lob- und Preisgedichten erkennbar, zweifelten Georg I. und Georg II. an der Sinnhaftigkeit der Verbindung, da ihnen die Schwierigkeiten und Unzulänglichkeiten einer Verwaltung auf die Distanz deutlich vor Augen standen. Auch wussten sie um das ökonomische und kulturelle Gefälle und standen immer wieder aufs Neue vor der Aufgabe, die Mitglieder der politisch-administrativen Eliten beider Herrschaftsräume überzeugen zu müssen. Dies war in Großbritannien schwieriger als in Kurhannover, da der Verbindung zu den Stammlanden häufig die mit der globalen Expansion verbundenen Interessen

\footnotetext{
76 Seiner Königlichen Majestät Georg dem Vierten, Könige von Hannover bey Allerhöchstdessen Ankunft in Göttingen am 30sten October 1821 in tiefster Unterthänigkeit gewidmet von dem Magistrate und der Bürgerschaft der Stadt Göttingen, (S. I.) 1821, S. 3f.

77 van den Heuvel, 2013 (wie Anm. 44).
} 
entgegengesetzt wurden. ${ }^{78}$ Die Revolutionskriege jedoch führten zu einem Verstummen der britischen Skeptiker der Personalunion - und auch nach dem Wiener Kongress blieben maßgeblich auf Betreiben Großbritanniens die Dynastien und ihre Verbindungen Grundpfeiler des europäischen Ordnungssystems. Während der gesamten Dauer der Personalunion galt: Hanover and Great Britain were not synonymous - aber die Könige und Kurfürsten verfolgten konsequent eine durchaus konsistente Politik. 


\title{
Die Hannoveraner Könige im Zerrspiegel der britischen Karikatur
}

\author{
Barbara Schaff
}

\section{Die britische Bildsatire im Kontext der literarischen Satire und des künstlerischen Produktionskontextes des 18. Jh.}

Im Zeitalter der Personalunion (1714-1837) erlebten die politische Bildsatire und die literarische Satire in Großbritannien eine in Europa einzigartige Blüte. Deren Mittel in Bild und Text sind oft ausgesprochen drastisch und treffen mit ihren derben skatologischen und sexuellen Anspielungen die Rezeptionsgewohnheiten auch heutiger Leser und Betrachter noch empfindlich. Dass sich die Satire im England des 18. Jh. so ungehindert entfalten konnte, ist im Wesentlichen den Errungenschaften der Glorious Revolution von $1688 \mathrm{zu}$ verdanken. Sie stellte die Souveränität des Parlaments über die Krone und begünstigte die Entstehung einer politischen Öffentlichkeit, in der das Reflektieren über Politik in einem pluralistischen Diskurs stattfand. Seit 1695 war die Licensing Order, die seit 1643 den Druck von allen politisch, religiös und moralisch als anstößig beurteilten Schriften verboten hatte, nicht mehr erneuert worden. Dies hatte zur Folge, dass in England seit dem 18. Jh. faktische Pressefreiheit bestand und die freie Meinungsäußerung immer weniger eingeschränkt wurde. Dadurch konnte die Karikatur zu einem mächtigen Instrument der politischen Propaganda und Agitation werden, das das politische Tagesgeschäft erbarmungslos kommentierte und im Bewusstsein der Stärke des Parlaments und der britischen Werte der Meinungsfreiheit auch vor den Monarchen nicht Halt machte. Nie zuvor in der britischen Geschichte wurden britische regierende Monarchen und deren Familien in ähnlicher Weise diffamiert und obszön entblößt wie die Hannoveraner Könige, insbesondere Georg III. und sein Sohn Georg IV. Für die Blüte der britischen Karikatur während der Regierungszeit Georg III. und Georg IV. (1860-1820) gibt es mehrere Gründe. Zum einen die bereits erwähnte relative Pressefreiheit in der parlamentarischen Demokratie. Dazu kam jedoch noch ein weiterer wichtiger Faktor: Nach einer stabilen Periode von Whig-Regierungen, in denen die Tories kaum eine Rolle spielten, lebte in 
der Regierungszeit von Georg III. die rivalisierende Auseinandersetzung zwischen den beiden Parteien wieder auf. Tories und Whigs machten sich gerne das Instrument der Satire zur Diffamierung des politischen Gegners zunutze, indem sie Karikaturisten beauftragten, zum politischen Tagesgeschäft Stellung zu nehmen.

Als provozierendes Instrument der Wirklichkeitswahrnehmung richtete sich Satire auf Personen des öffentlichen Lebens und entblößte deren moralische Verfehlungen. Als Kompass galten dabei die aufklärerischen Werte der civil society, also Vernunft, common sense und für alle gleichermaßen verbindliche moralische Verhaltensnormen. In den poetologischen Diskursen des 18. Jh. fand eine breite Auseinandersetzung mit Satire statt, und zwar sowohl der literarischen wie der Bildsatire. John Dryden lieferte bereits 1693 mit seiner Schrift „Discourse Concerning the Original and Progress of Satire" den Auftakt: Er definierte die Gattungsmerkmale der Satire und leitete sie historisch aus der griechischen und römischen Antike her. War die Urform der Satire derb, grob und obszön, so ist sie in den Texten von Juvenal und Horaz bei ihrer eigentlichen Aufgabe angelangt, der moralischen Verbesserung des Menschen:

It is an action of virtue to make examples of vicious men. They may and ought to be upbraided with their crimes and follies, both for their own amendment (if they are not yet incorrigible), and for the terror of others, to hinder them from falling into those enormities, which they see are so severely punished in the persons of others. ${ }^{1}$

Nach Dryden ist die zeitgenössische Satire den Idealen der civil society und der politeness verpflichtet: Sie soll den Verstand des Menschen reinigen und ihn in der schonungslosen Bloßstellung menschlicher Laster und schlechter Verhaltensweisen zu einem moralisch guten Menschen erziehen. Als ein erzieherisches Instrument, das auf Grund eines allgemein verpflichtenden moralischen Kompasses operiert, macht sie auch vor den Herrschern nicht halt, wenn diese sich moralisch nicht regelkonform verhalten. Dryden zielte auf eine verfeinerte, hochentwickelte und einheitliche Form der Gattung ${ }^{2}$ und war einem der Ideologie des 18. Jh. entsprechenden Entwicklungsbegriff von Kunst verpflichtet, die nun die kruden Anfänge hinter sich gelassen hat und der stilistischen Vervollkommnung zustrebt. Dies bedeutete, dass obszöne und skatologische Darstellungen - die ja in der Karikatur gang und gäbe sind - nicht zur Gattung der Satire gehörten. ${ }^{3}$

1 John Dryden, A Discourse Concerning the Original and Progress of Satire, in: Ders. (Hg.), Essays of John Dryden, 3 Bde, Bd. 2, New York 1961, S. 80.

2 Vgl. Christina Oberstebrink, Karikatur und Poetik. James Gillray 1759-1815, Berlin 2005, S. 91.

3 Vgl. Dryden, 1961 (wie Anm. 1), S. 51. 
Diese Forderung nach hygienischer Satire wurde jedoch in der Literatur - man denke an die bösartigen Satiren von Jonathan Swift - wie in der Bildsatire im Laufe des 18. Jh. immer wieder unterlaufen. Mit gewagten Anspielungen, mit greller Überzeichnung verweigerten sich die Karikaturen eines Thomas Rowlandson, James Gillray oder George Cruikshank dem Fortschrittsgedanken der Kunst und stellten damit die Entwicklung der Gattung von den barbarischen Anfängen hin zur stilistischen und ästhetischen Vollkommenheit, wie sie Dryden skizzierte, in der Praxis in Abrede. Der aufgeklärten poetologischen Prämisse, zur Vollendung streben zu müssen, wurde von der Karikatur eine eindeutige Absage erteilt. Dies führte in der kunsttheoretischen Debatte der Zeit zu unterschiedlichen Positionsbestimmungen: William Hogarth, der große Satiriker des 18. Jh., suchte in seinen Werken eher universelle Charaktere und Typen denn wiedererkennbare real existierende Personen, wie sie die Karikatur wiedergibt, darzustellen. Hogarths Satiren zielten auf das Bloßstellen der Schwächen der menschlichen Natur, nicht auf Individuen. Er verwahrte sich streng gegen die Bezeichnung Karikaturist, denn er hielt die Karikatur als eine niedere Kunstform gegenüber der komischen Charakterdarstellung:

Now that, which has of late years got the name of caricatura, is, or ought to be, totally divested of every stroke that hath a tendency to good drawing; it may be said to be a species of lines that are produced, rather by the hand of chance, than of skill. ${ }^{4}$

In seinem Sketch „The Bench“, einer satirischen Darstellung der Richterschaft, macht er den Unterschied zwischen Character and Caricature deutlich: Der Character zeigt keinen bestimmten Menschen, sondern einen Typen, der eine menschliche Verhaltensweise oder einen Charakterzug repräsentiert, die Karikatur dagegen verzerrt und verfremdet einen bestimmten Menschen.

Und genau darum geht es ja auch in der politischen Karikatur: Auf Anhieb und mittels weniger Striche einen bekannten Menschen mittels eines überzeichneten Merkmals erkenntlich zu machen - das kann in der grotesken Übertreibung geschehen, aber auch mit sprachspielerischen Mitteln, die in ein Bild übersetzt werden: So wurde beispielsweise in Karikaturen des 18. Jh. der Earl of Bute, Premierminister unter König Georg III., dessen Name ähnlich wie das englische Wort für Stiefel klingt, oft als ein riesiger Stiefel dargestellt oder der Führer der Whig-Partei, James Fox, als Fuchs. Oder man stellte die skandalösen Verfehlungen der Herrschenden mittels Körperkennzeichen dar, in dem man deren moralischen Exzess in Bilder eines physiognomischen Exzess übersetzte: Der lasterhafte Wüstling wird dementsprechend als extrem übergewichtig porträtiert. Mit diesen erfinderischen Bildmetaphern und As-

4 William Hogarth / John Trusler, The works of William Hogarth, in a series of engravings, With descriptions, and a comment on their moral tendency, by John Trusler. To which are added, anecdotes of the author and his works, London 1833, S. 29. 


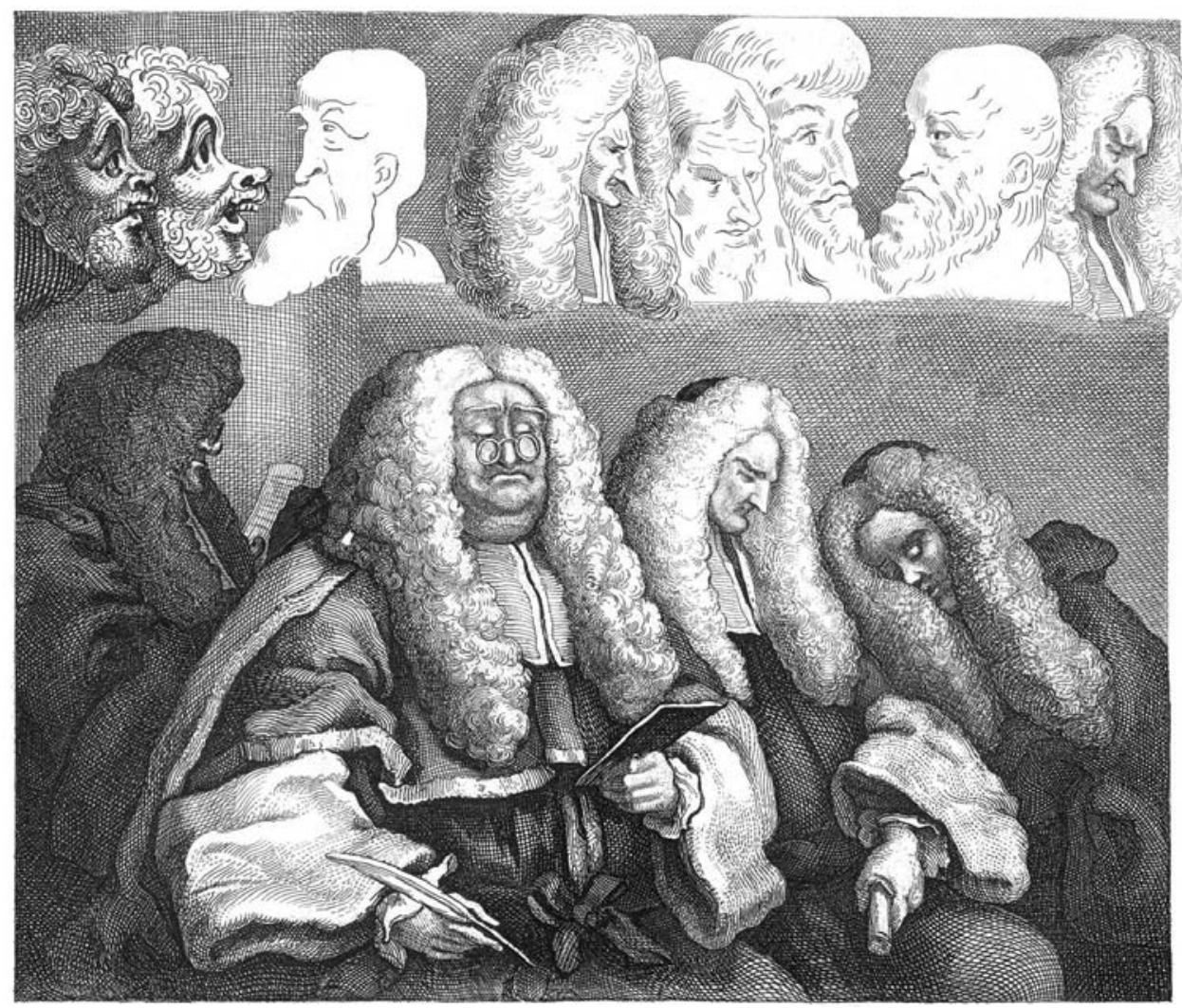

Abb. 1: William Hogarth, The Bench, 1833.

www.gutenberg.org/files/22500/22500-h/22500-h.htm

soziationen unterhielten die Karikaturisten ihr Publikum, das sich an der Entschlüsselung erfreute. Die Anspielungen hatten aber auch einen ganz praktischen Grund: Die indirekte Darstellung machte es den karikierten Personen schwer, die Künstler bei Gericht der Verleumdung zu bezichtigen, da ja eine direkte Darstellung nicht nachgewiesen werden konnte. ${ }^{5}$

In Drydens Schrift findet sich noch ein weiterer Aspekt der Satire, der mit der Gattung intrinsisch verbunden ist: das Moment politischer Freiheit und Demokratie. Dryden beruft sich hier auf Aristoteles, der in seiner Poetik die Urform der Komödie an die Entwicklung der demokratischen Städte anbindet. ${ }^{6}$ Im England des 18. Jh. war die Ansicht, dass Satire erst in demokratischen Verhältnissen möglich ist, weit verbrei-

5 Vgl. Diana Donald, The Age of Caricature. Satirical Prints in the Reign of George III., New Haven, CT u.a. 1996, S. 50.

6 Vgl. Aristotelis, Poetik, Leipzig 1961, S. 26. 
tet. Dank der liberalen Tradition der Pressefreiheit konnte sich diese Verbindung von Demokratie und Satire produktiv entfalten. Im Katalog der Werke James Gillrays, des vielleicht berühmtesten Karikaturisten des späten 18. Jh., wird die Bildsatire als ein genuines, nationaltypisches Charakteristikum der Briten bewertet: The wit of painting is an English invention; it was preceded by literary satire, and satire grew out of liberty, which is Johnny's delight. ${ }^{7}$ Der Englandreisende Wilhelm von Archenholtz, der 1797 einen Bericht seiner Englandreise veröffentlichte, sah den gleichen Zusammenhang zwischen dem Privileg der Pressefreiheit und der Blüte der Satire. Gleichzeitig konstatierte er in England die eindeutige Vorherrschaft der Bildsatire vor der literarischen:

The print shops are real galleries. We must rank in the number of national privileges, the liberty of publishing satyrical engravings, which turn the events of the day into ridicule. The Frenchman chooses rhyme, the duller Dutchman a medal, and the Englishman a print, to give currency to satire. ${ }^{8}$

Seine Eindrücke von der Freiheit, die englische Bürger aufgrund ihrer Verfassung und religiösen Traditionen besitzen, gleichen denen vieler Englandreisender des 18. Jh. Ähnlich formulierte es auch Karl Philip Moritz 1782 in den „Reisen eines Deutschen in England“. Moritz beobachtet in England eine soziale Kohäsion, gegründet auf eine demokratische, verfassungsgestützte Tradition, die in Deutschland fehlt. Er versteht nicht ganz, warum der König - gemeint ist Georg III. - so wenig beliebt ist: Die Verachtung des Volkes gegen den König geht erstaunlich weit. ,Our king is a blockhead!" hab' ich wer weiß wie oft sagen hören; indem man zu gleicher Zeit den König von Preußen mit Lobsprüchen in den Himmel hob. ${ }^{9}$ Dieser Mangel an Respekt und die damit verbundene Macht des Karikaturisten, Herrscher und ihre Familien nicht nur in ihren Eigenheiten und Fehlern bloßzustellen, sondern auch brutal zu diffamieren, ohne dafür Konsequenzen fürchten zu müssen, wird von den meisten Englandreisenden als typisch britisch und nicht auf kontinentale Verhältnisse übertragbar angesehen. Vielleicht war gerade deshalb das deutsche Interesse an diesem Bereich der englischen Kultur besonders groß. Zur Verbreitung der englischen Karikaturen in Deutschland trug vor allem die Zeitschrift „London und Paris“ bei, die als erste regelmäßig erscheinende Karikaturenzeitschrift Europas gelten kann. Sie wurde von dem Weimarer Geschäftsmann Friedrich Johann Justin Bertuch zwischen 1798 und 1815 publiziert und dank einer großen Anzahl französischer und englischer Karikaturen wurde sie

7 zitiert nach: Oberstebrink, 2005 (wie Anm. 2), S. 93. Mit Johnny ist John Bull gemeint, der prototypische Engländer.

8 Johann Wilhelm von Archenholz, A picture of England, containing a description of the laws, customs, and manners of England, Interspersed with curious and interesting Anecdotes Of Many Eminent Persons, Translated from the original German of W. de Archenholtz, Formerly A Captain In The Prussian Service, A new translation, London 1797, S. 146.

9 Carl Philip Moritz, Reisen eines Deutschen in England im Jahre 1782, Berlin 1783, S. 64. 
zu einem bedeutenden Medium europäischen Kulturtransfers. Die von Auslandskorrespondenten an Bertuch gesandten kolorierten Radierungen wurden in Weimar kunstgerecht reproduziert, ausführlich beschrieben und kommentiert. Im Laufe der Jahre wurden hier Dutzende von Arbeiten britischer Karikaturisten reproduziert. Vor allem die Kommentare sind ein wichtiges Zeitdokument der Rezeption, denn die in Deutschland ungewohnte Gattung der politischen Bildsatire, ihr Stil und Kontext, werden ausführlich beschrieben und erläutert. Die Spottbilder auf die politischen Akteure in England und Frankreich - allen voran Napoleon - inspirierten auch die Karikatur in Deutschland als neues Mittel politischer Auseinandersetzung und ermutigten deutsche Künstler in den Befreiungskriegen, ihrerseits den Zeichenstift zum Kampf gegen den französischen Kaiser zu spitzen. Bemerkenswert ist nicht zuletzt die Schnelligkeit, mit der die britischen Karikaturen ihren Weg in das deutsche Journal fanden: Sie wurden oft im gleichen Monat wie in England gedruckt.

Während deutsche Leser mit den Abbildungen der Karikaturen in der Zeitschrift vorlieb nehmen mussten, waren in der Metropole London vor allem die print shops ein Publikumsmagnet, in denen die neuesten Werke in großen Fenstern ausgestellt wurden und damit auch die Menschen in Scharen anzogen, die nicht genügend Geld hatten, die Abzüge zu kaufen. Die satirischen Druckgraphiken - Radierungen und Kupferstiche - waren so teuer, dass sie sich nur die Oberschicht leisten konnte. ${ }^{10}$ Eine exklusive Sammlung von Karikaturen zu besitzen und sie auf Gesellschaften den Gästen zu zeigen war denn im späten 18. Jh. vor allem auch ein Mittel zum Distinktionsgewinn: Damit bewies man nicht nur kulturelles Kapital, also Geschmack und Bildung, sondern auch das Vorhandensein des notwendigen ökonomischen Kapitals. War die Zirkulation der Druckgrafiken auf die Oberschicht beschränkt, bedeutete dies jedoch nicht, dass weniger wohlhabende Menschen sie sich nicht wenigstens anschauen konnten: Karikaturen hatten einen so wichtigen kulturellen Status, dass die Menschen sich in London an den Schaufenstern der zahlreichen print shops, in denen regelmäßig die neuesten Drucke ausgestellt wurden, die Nasen platt drückten. An der anonymen Radierung "The Caricature Shop“ kann man deutlich die soziale Differenzierung sehen: Für Karikaturen interessieren sich wirklich alle, ob Männer oder Frauen, alt oder jung, arm oder reich, schwarz oder weiß, und soziale Differenzen werden - für den Moment wenigstens - im gemeinsamen Lachen getilgt. ${ }^{11}$ In dieser Abbildung des Schauens von Karikaturen auf der Straße ist, ähnlich wie in den von Habermas zitierten Kaffeehäusern ${ }^{12}$ ein Ort erkennbar, in dem sich eine politische

10 Vgl. Monica Glavac, Der Fremde in der europäischen Karikatur. Eine religionswissenschaftliche Studie über das Spannungsfeld zwischen Belustigung, Beleidigung und Kritik, Göttingen 2013, S. 100.

11 Vgl. Mike Goode, The Public and the Limits of Persuasion in the Age of Caricature, in: Todd Porterfield (Hg.), The Efflorescence of Caricature, 1759-1838, Farnham u. a. 2011, S. 117-136, hier: 124.

12 Vgl. Jürgen Habermas, Der Strukturwandel der Öffentlichkeit. Untersuchungen zu einer Kategorie der bürgerlichen Gesellschaft, Frankfurt am Main 1962, S. $89 f$. 
Öffentlichkeit artikuliert. Zugleich ist die Radierung auch ein Metakommentar über diese Öffentlichkeit selbst, in dem die Selbstbeobachtung und die Selbstbeschreibung der britischen Gesellschaft nicht nur zusammenfällt, sondern zudem durch den ökonomischen Ort gerahmt wird, der dem Medium Karikatur die Verbreitung und den kommerziellen Erfolg garantiert: das Geschäft.

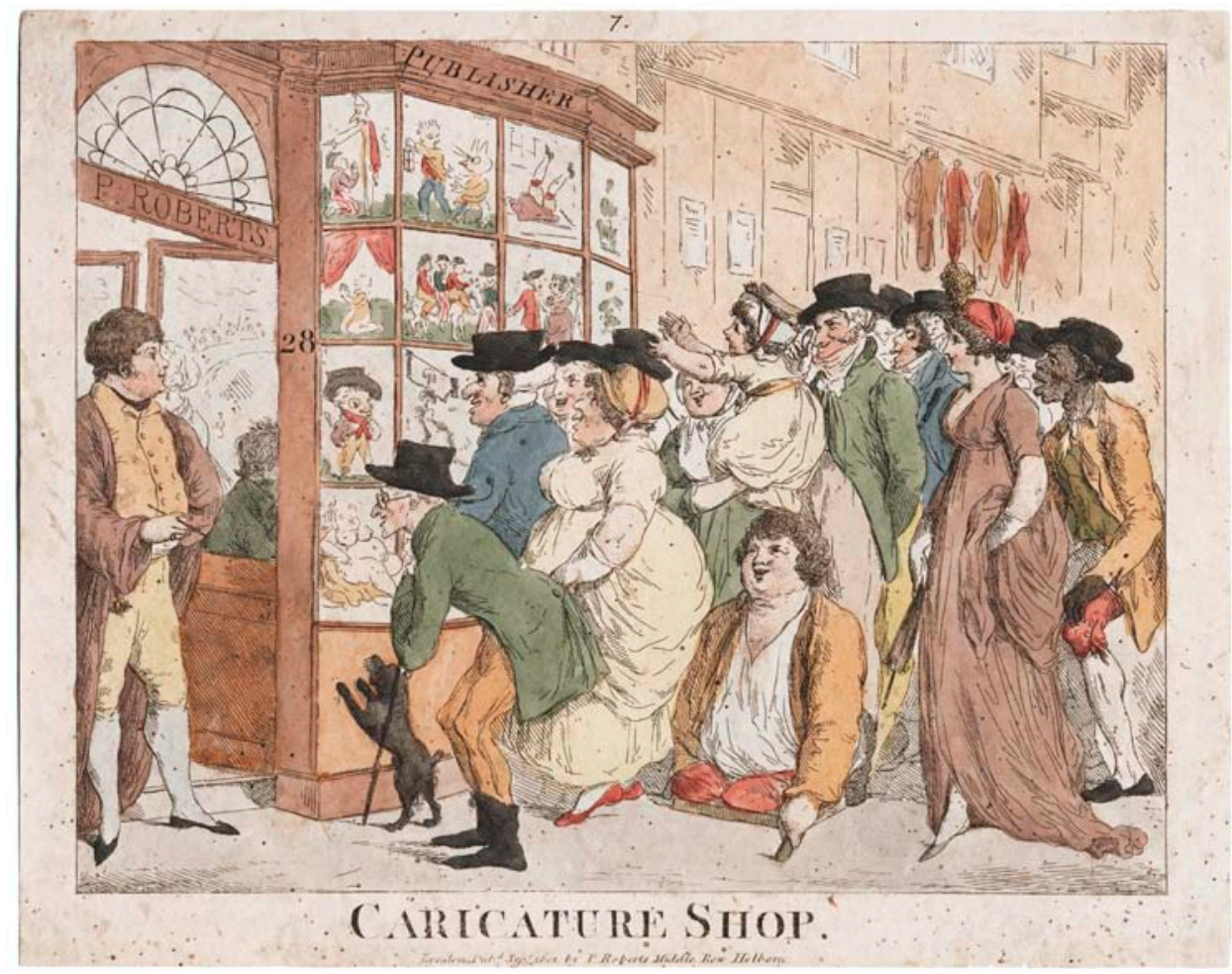

Abb. 2: Anon., The Caricature Shop, 1801.

(c) Courtesy of The Lewis Walpole Library, Yale University

Die Gattung der Karikatur, auch dies zeigt die Radierung, ist eine junge, Aufsehen erregende Kunstform, die der traditionellen Repräsentation von Körpern in Plastik und Malerei eine subversive und ikonoklastische Dynamik entgegensetzt. Im Zeitalter der beginnenden Industrialisierung ist es eine Kunstform, die vom Tempo lebt: sowohl in Bezug auf ihre immer aktuellen Inhalte und tagespolitischen Anspielungen als auch auf die Bedingungen ihrer technischen Produktion, die sich rasant entwickeln. ${ }^{13}$ Den Bann, den Karikaturen über Menschen ausüben können, so dass sie

13 Vgl. M. Dorothy George, English Political Caricature to 1792. A Study of Opinion and Propaganda, Oxford 1959, Kap. 1. 


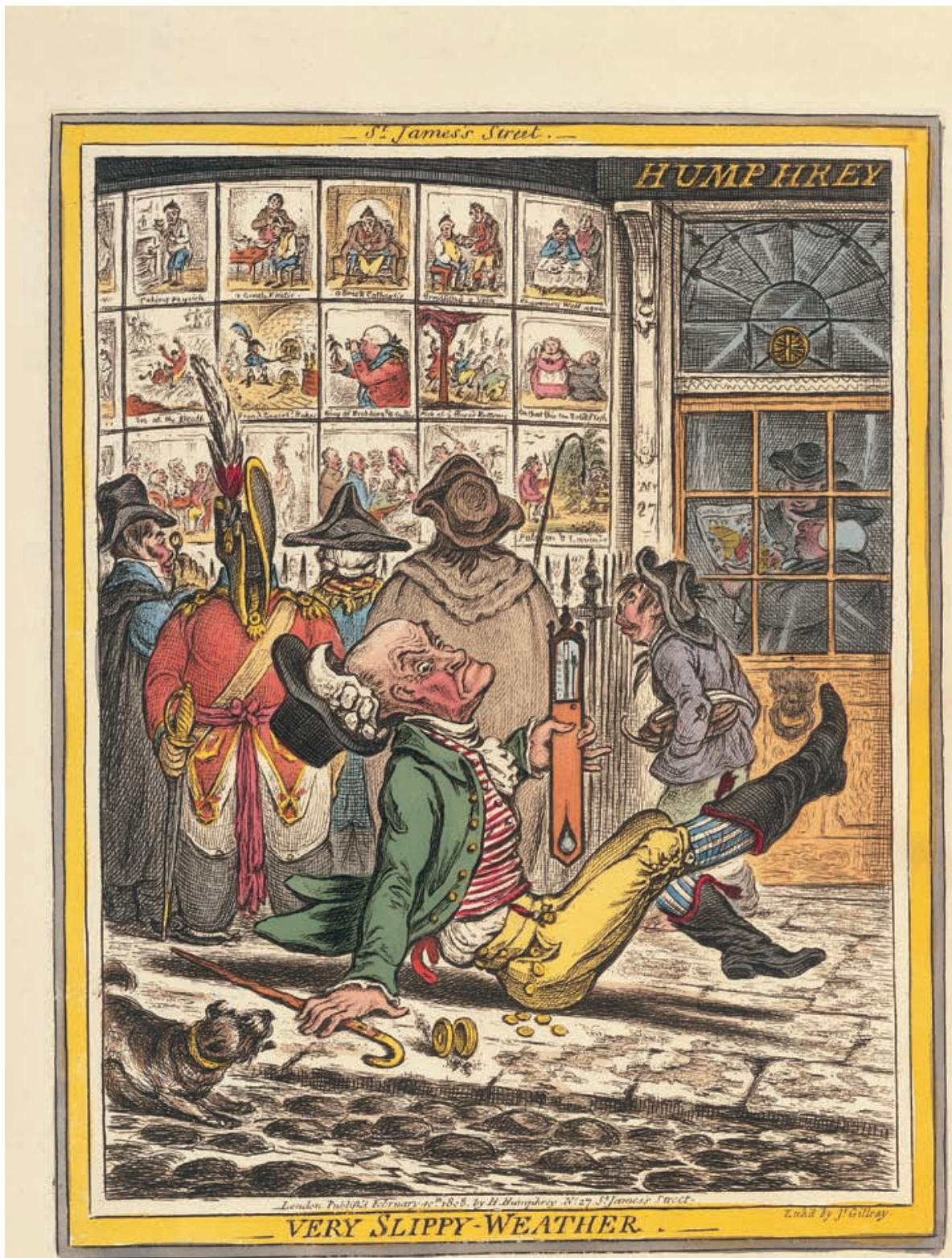

Abb. 3: James Gillray, Very Slippy Weather, 1808.

Wilhelm Busch - Deutsches Museum für Karikatur und Zeichenkunst (C) Archiv der Wilhelm-Busch-Gesellschaft e. V. 
nicht wahrnehmen, was hinter ihnen passiert, thematisiert eine ähnliche Radierung von James Gillray: „Very Slippy Weather“. Auch hier betrachtet eine Gruppe von Menschen interessiert die Auslagen in einem print shop (und werden in der Karikatur selbst zu Betrachteten), während ein Spaziergänger hinter ihnen auf dem nassen Pflaster ausrutscht. Die mit ihren gelben Hosen, der rot gestreiften Weste und dem Spazierstock eindeutig als aufgeblasener Geck gekennzeichnete Figur, die vor dem Karikaturen-Laden zu Fall kommt, symbolisiert die Macht der Karikatur, Menschen zu Fall zu bringen.

Rechts über der Tür ist der Name der Besitzerin des Ladens zu sehen: Hannah Humphrey. Hannah Humphrey war eine selbstständige Verlegerin für satirische Druckgrafik (und damit einer der wenigen selbstständigen weiblichen Unternehmer), die 1779 in der Old Bond Street ihren eigenen Laden eröffnete und mit dem Karikaturisten James Gillray eng zusammenarbeitete. Diese Zusammenarbeit erwies sich als äußerst gewinnbringend für beide: Humphreys Laden war bald der bekannteste und erfolgreichste in ganz London. In „London und Paris“ kommentierte Johann Christian Hüttner 1806:

Die Karikaturläden sind wie immer belagert, aber nur bei der Humphrey, welche Gillrays Sachen verkauft, sieht man Leute von Stand, Geschmack und Kenntnissen hineingehen; diese Frau treibt auch bloß mit ihrer eigenen Ware einen sehr bedeutenden Handel. ${ }^{14}$

Die Bezeichnung Age of Caricature ist vor allem mit den Namen zweier Akteure verbunden: James Gillray (1757-1815) und George Cruikshank (1792-1878). Beide Karikaturisten machten sich auch mit respektlosen Darstellungen der königlichen Familie einen Namen und beherrschten den Markt der satirischen Printmedien für lange Zeit. Gillray erwies sich in ca. 700 Grafiken - die meisten kolorierte Radierungen - als dynamischer und scharfer Kritiker seiner Zeit. Seine Zielscheiben waren immer wieder Georg III., der als einfacher und knauseriger Bauerntölpel dargestellt wurde (im Volk hatte der König den Spitznamen Farmer George) sowie der Premierminister William Pitt der Jüngere und sein Rivale aus der Whig Partei, William Fox. Johann Christian Hüttner ${ }^{15}$ kürte ihn in „London und Paris“ bewundernd zum bedeutendsten Karikaturisten der Zeit:

Die außerordentlichen Vorzüge, welche sich bei Gillray vereinigen, haben sich seit Hogarth schlechterdings in keinem Künstler zusammengefunden. Seine ausgebrei-

14 zitiert nach: Glavac 2013 (wie Anm. 10), S. 98.

15 Zur Bedeutung Johann Christian Hüttners als wichtiger Akteur britisch-deutschen Kulturtransfers um 1800 vgl. Karl S. Guthke, Ein Weltmann aus Deutschland. Johann Christian Hüttner und die große Öffnung in die weite Welt, in: Lessing Jahrbuch XXXVIII, Lessing Society 2008/2009, Göttingen 2010, S. 219-248. 
teten literarischen Kenntnisse jeder Art; seine äußerst richtige Zeichnung; seine Gabe, die Gesichtszüge jeder Person, die er nur einmal zu sehen bekommt, richtig aufzufassen; sein tiefes Studium der Allegorie, die Neuheit seiner Gedanken und die unverrückte durchgängige Hinsicht auf den eigenthümlichen Charakter der Karikatur machen ihn zum ersten lebenden Künstler in seiner Gattung, nicht nur unter den Engländern, sondern auch unter allen europäischen Völkern. Paris darf sich geschickter Männer in der Kunst rühmen, aber unsere Leser wissen, wie abgeschmackt alle Pariser Karikaturen sind, wenn man sie gegen die von Gillray hält. ${ }^{16}$

Der selbstreferentielle Gestus, mit dem Gillray in „Very Slippy Weather“ in den Auslagen von Hannah Humphreys Laden seine eigenen Karikaturen abbildet, zeugt vom Selbstbewusstsein eines Künstlers, der sich seines Status sicher ist. Die kulturelle Bedeutung und die Sichtbarkeit der satirischen Printmedien im öffentlichen Raum des späten 18. Jh., auf die diese beiden Blätter ja ebenfalls verweisen, hatte zur Folge, dass die Zielscheiben der Satire, also Politiker und die königliche Familie, mit Maßnahmen gegen die Karikaturisten und Drucker sehr vorsichtig zu sein hatten: Mit Klagen vor Gericht hätten sie sich nicht nur als Spielverderber erwiesen, sondern ihre Demokratiefähigkeit in Abrede gestellt. Deshalb machten sie denn auch meist gute Miene zum bösen Spiel, indem sie sich selbst als eifrige Sammler von Karikaturen gerierten oder schlimmstenfalls auch einmal eine Auflage aufkauften um sie aus dem Verkehr zu ziehen. ${ }^{17}$

George Cruikshank, dessen Hauptschaffensperiode in die Zeit der napoleonischen Kriege fiel, erlangte mit der Illustration der Satire „The Political House that Jack Built" von William Hone Berühmtheit. Diese Satire thematisierte das Peterloo Massaker vom 16. August 1819, bei dem Milizen auf eine Gruppe unbewaffneter Demonstranten, darunter auch Frauen und Kinder, die auf einem Feld bei Manchester gegen Getreidezölle protestiert hatten, geschossen hatten. Georg IV. war besonders häufig das Ziel von Cruikshanks Karikaturen, und nachdem Cruikshank in einer Zeichnung auf die amourösen Abenteuer des Königs angespielt hatte, zahlte ihm dieser im Juni 1820 die Summe von 100 Pfund mit der Auflage, ihn nie wieder kompromittierend darzustellen. ${ }^{18}$

16 J.C. Hüttner, Die jetzigen Karikaturzeichner in London, in: London und Paris, 1798-1815 18 (1806), S. 7-10, hier: S. 7.

17 Vgl. Donald, 1996 (wie Anm. 5), S. 15.

18 Vgl. Richard A. Vogler (Hg.), The Graphic Works of George Cruikshank, Mineola 1979, S. 135. 


\section{Die Hannoveraner Könige in der Bildsatire}

Welches Bild erhalten wir in diesen Karikaturen von den Hannoveraner Königen, welche ihrer Schrullen, Eigenheiten, politischen Haltungen und merkwürdigen oder abstoßenden Verhaltensweisen standen im Zentrum der Kritik? Wie verhielt sich die politische Karikatur zur Monarchie in den Zeiten, in denen die Öffentlichkeit einen immer stärkeren Einfluss auf die Politik gewann und die beiden großen Parteien, die Whigs und die Tories, um Mehrheiten kämpften, und in denen nationale Identität und damit auch die Stabilität der Monarchie während der amerikanischen und der französischen Revolution vor allem auch von außen herausgefordert wurde? Dass Georg III. und Georg IV. am häufigsten Zielscheibe satirischer Angriffe waren hängt jedoch nicht nur mit den politischen Gegebenheiten ihrer Regierungsperioden, sondern auch mit der künstlerischen Entwicklung des Mediums Karikatur zusammen, dem technischen Fortschritt in Druck und Distribution, und dem sich bildenden Markt für Druckgraphiken im ausgehenden 18. Jh. Doch auch von Georg II. gibt es eine anonyme Karikatur aus dem Jahre 1737, die, wenngleich sie künstlerisch nicht mit dem Werk Gillrays oder Cruikshanks zu vergleichen ist, an satirischer Schärfe kaum zu übertreffen ist: „The Festival of the Golden Rump“. Anders als spätere Karikaturen ist sie noch von einer starken Textabhängigkeit gezeichnet: Sie illustriert einen Text von Henry Fielding - einem erbitterten Gegner der Politik Georg II. und seines Premierministers Robert Walpole. Fielding hatte bereits 1731 in seiner burlesken „Welsh Opera" die königliche Familie verspottet. Sie erscheint hier unter dem Namen „Ap-Shinken“ - Schinken ist sowohl eine Anspielung auf die deutsche Herkunft als auch auf das offensichtlich sehr ausladende Hinterteil des Königs. 1737 veröffentlichte Fielding in der Zeitschrift "Common Sense“ die fiktive Reiseerzählung "The Vision of the Golden Rump“, in der ein Ich-Erzähler in einem Traum in einem fernen Land einer Prozession zu einem Tempel folgt, die das Festival des Golden Rump feiern wollen. Der Golden Rump ist das Oberhaupt dieses Volkes und symbolisiert in Fieldings Satire Georg II.: eine Statue mit einem Holzkopf, Bocksfüßen (mit denen er nach seinen Untertanen tritt) und einem riesigen goldenen Hinterteil. Die Königin, und dies ist Teil des Rituals, verabreicht ihm ein Klistier zur Beruhigung und Linderung seiner Beschwerden, ebenso wie der höchste Hofbeamte (damit ist der Premierminister Robert Walpole gemeint) versucht, den König zu beschwichtigen. Wichtig ist, dass die Figur der Versammlung den Rücken zuweist:

By this description the reader will easily conceive that the Back of the Idol was turned to the Congregation; an Attitude which I do not remember to have observed among the Chinese and Indian Pagods. But my friendly Conductor informed me, that he had placed himself in this Posture upon his first Entrance into the Temple, as well to shew his politeness, as to testify his respect and gratitude to a na- 
tion which had elected him into the number of the Dii Majores or Greater Gods. Here I could not help smiling, to think how widely the custom of this country differed from mine, where the same thing, which passed here for civility, and good manners, would be reckoned a mark of insolence and brutality. ${ }^{19}$

Die Zeitgenossen konnten in dieser Beschreibung unschwer ihren von Hämorrhoiden geplagten König erkennen, der ihnen allzu oft durch die häufigen Reisen ins Kurfürstentum den ,Rücken kehrte - im englischen Sprachgebrauch der Zeit hieß das to rump. Der während der Regierungszeit Georg II. in London gegründete Rumpsteak Club, zu dem auch Fielding und der Prince of Wales gehörten, war demnach auch nicht eine Steakhouse Version des 18. Jh. sondern ein Club von enttäuschten engli-

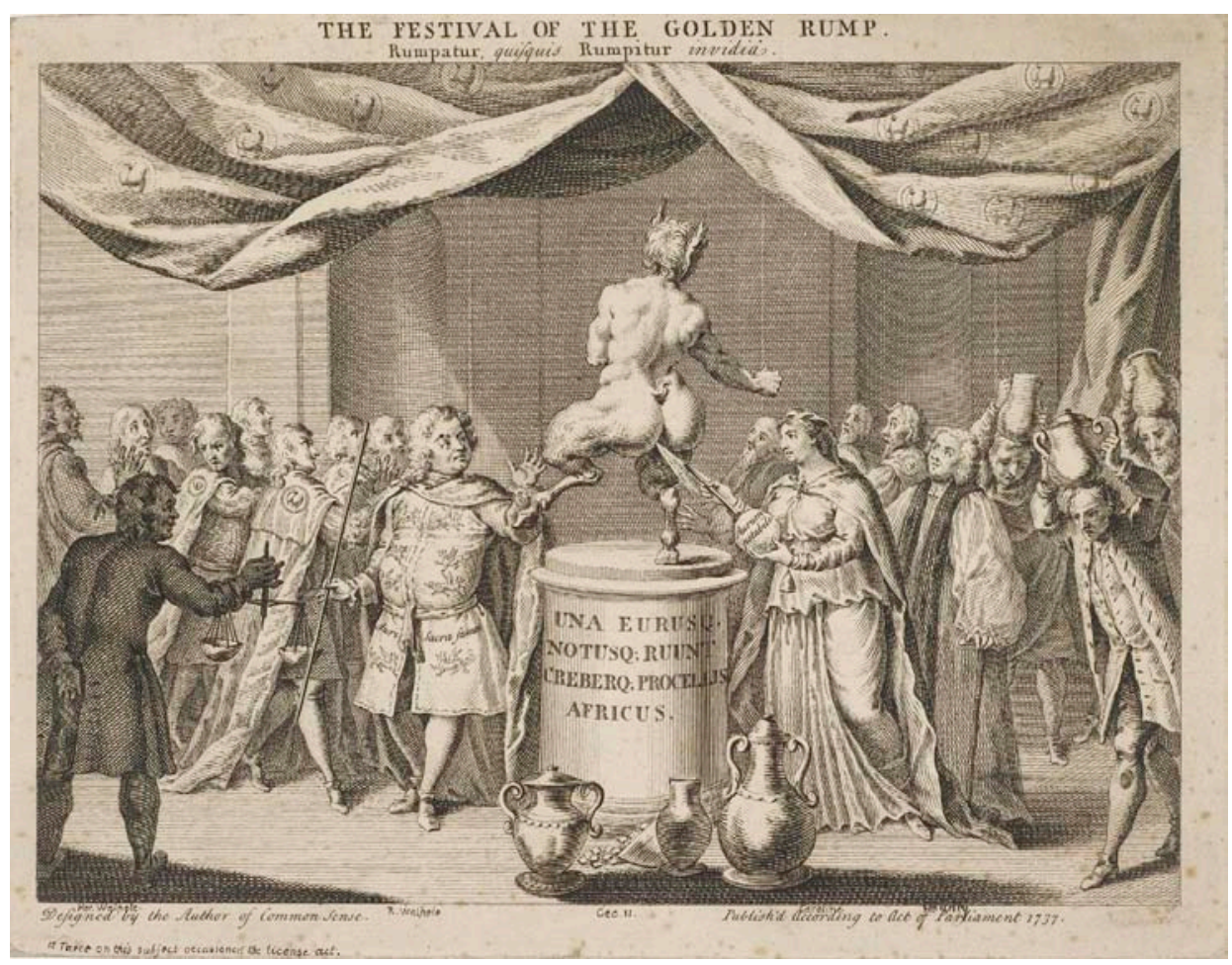

Abb. 4: Anon., The Festival of the Golden Rump, 1837.

British Museum, Number Cc,3.173

(C) Trustees of the British Museum

19 Henry Fielding, The Vision of the Golden Rump, in: Common Sense, or, the Englishman's Journal (March 1837), S. 48-63, hier: S. 49. 
schen Aristokraten, die sich vom König im Stich gelassen fühlten. ${ }^{20}$ Zur Illustration dieser Satire kam kurz darauf eine Karikatur in Umlauf, die die entscheidenden Invektiven des Textes getreu umsetzte.

„The Vision of the Golden Rump“ wäre vielleicht längst vergessen worden, wenn sie nicht für die weitere Entwicklung des englischen Dramas von entscheidender Konsequenz gewesen wäre: Eine heute nicht mehr erhaltene Bühnenversion, von der man nicht weiß, ob sie von Fielding selbst verfasst worden war, hatte den Premierminister Walpole so aufgebracht, dass er am 21. Juni 1737 im Parlament den Theatre Licensing Act durchbrachte. Dieses Gesetz schrieb vor, dass künftig jedes Theaterstück vor der Aufführung dem Lord Chamberlain vorzulegen sei, und dass kommerzielle Theateraufführungen lediglich in Häusern stattfinden dürften, die im Besitz eines königlichen Patents waren. ${ }^{21}$ Aufgrund dieses Gesetzes blieben bis in die Mitte des 20. Jahrhundert hinein (erst 1968 wurde es außer Kraft gesetzt) dem englischen Drama, das sich am Anfang des 18. Jh. durch Witz, Imagination, beißende Sozialkritik und Subversion ausgezeichnet hatte, die Flügel beschnitten.

In der zweiten Hälfte des Jahrhunderts begann sich die Gattung der satirischen Druckgraphik von Textvorlagen zu emanzipieren. Die technischen Entwicklungen führten zu schnellerer Produktion und vermehrt kolorierten Karikaturen ${ }^{22}$, inhaltlich richteten sich die Karikaturen nun häufig auf tagespolitische Ereignisse. Die Regierungszeit Georg III. (1760-1820) war für England eine Zeit der außenpolitischen Herausforderungen und innenpolitischen Krisen. Es war die Epoche der amerikanischen und französischen Revolution, deren Forderungen nach Gleichheit und Freiheit auch in England breites Gehör fanden. Der anfangs populäre König verlor vor allem nach den Belastungen des Volkes durch die Kriege immer mehr an Sympathie. Zwei anonyme, im „Oxford Magazine“ veröffentlichte Karikaturen illustrieren dies: Bei seiner Thronbesteigung 1760 wird Georg III. enthusiastisch gefeiert. Zehn Jahre später sieht niemand mehr aus dem Fenster, wenn die königliche Kutsche vorbeifährt. In diesen Jahren stand das Modell der politischen Repräsentation im Parlament auf dem Prüfstand. Eine exemplarische Figur für das sich in der Bevölkerung breitmachende Gefühl einer tiefgreifenden demokratischen Krise, die Parlament und Krone unter einen immer stärkeren Reformdruck setzten, war der Schriftsteller und Whig-Politiker John Wilkes. Er führte eine Dauerkampagne gegen den Tory Premierminister Earl of Bute ${ }^{23}$ und kämpfte für eine gerechtere Verteilung der Parlamentsmandate und die totale Freiheit der Presse. Wilkes kam dafür ins Gefängnis, hatte jedoch soviel Rückhalt beim Volk, dass er bei der nächsten Wahl wieder von seinem Wahlbezirk als

20 Vgl. Peter Thomson, The Cambridge Introduction to English Theatre 1660-1900, Cambridge 2006, S. 85.

21 Vgl. Thomson, 2006 (wie Anm. 20), S. 88.

22 Vgl. George, 1959 (wie Anm. 13), S. 118.

23 Vgl. John Sainsbury, John Wilkes, the Lives of a Libertine. Aldershot 2006, S. 63f. 
Abgeordneter gewählt wurde. Für die politische Satire und Karikatur war diese Epoche eine Glanzzeit, in der Kritik an Regierungsmitgliedern und Missständen zuhauf in scharfsinnige Texte und Bilder umgesetzt wurde, die einen tiefen Zynismus über das politische Geschehen offenbarten. Vor allem Gillray und Cruikshank perfektionierten die Kunst der politischen Karikatur in bislang ungekanntem Maße. Wichtig ist hierbei die Tatsache, dass sie keineswegs einer bestimmten politischen Richtung verpflichtet waren, sondern vielmehr Auftragsarbeiten von beiden politischen Fraktionen annahmen. Diana Donald beschreibt in ihrem Buch über Karikatur während der Regierungszeit Georg III., wie Gillray im Jahre 1788 zunächst Karikaturen im Dienste der Whig Partei verfasste, später jedoch im Dienste der Tories die Whigs attackierte. ${ }^{24}$ In den 1790er Jahren erhielt er schließlich eine Pension der Regierung, war damit ruhiggestellt und künftig für die Opposition verloren. ${ }^{25}$ George Cruikshank zeigte sich ideologisch kaum weniger flexibel. In den Jahren 1819 und 1820 trat er zugleich als Illustrator des radikalen regierungskritischen Pamphlets „The Political House that Jack Built" von William Hone wie auch als Zeichner loyaler Tory-Satiren in Erscheinung, die die Angst vor dem Wiedererstarken jakobinischer Sympathien ausdrückten.

Im Blackwood's „Edinburgh Magazine“, einer der führenden Zeitschriften des 19. Jh., erscheinen 1832 die „Lectures on the Fine Arts“, in denen der Autor folgende Zeilen über Cruikshank schreibt:

Generally speaking, people consider him as a clever, sharp caricaturist, and nothing more-a free-handed comical young fellow, who will do anything he is paid for, and who is quite contented to dine off the proceeds of a "George IV" to-day and those of a "Hone" or a "Cobbett" tomorrow. He himself, indeed, appears to be the most careless creature alive, as touching his reputation. He seems to have no plan - almost no ambition - and, I apprehend, not much industry. He does just what is suggested or thrown in his way, pockets the cash-orders his beef-steak $[\ldots] \cdot{ }^{26}$

Der Karikaturist als Mietling, der sich prostituiert: Dies war ein häufiges Verdikt der Zeitgenossen, die die Karikatur eben nicht als eigenständige Gattung geschweige denn Kunstform sahen, und deren Produzenten schon gar nicht als Künstler, sondern kommerzielle Zeichner. Hierin wird eine Parallele zu der im 18. Jh. geläufigen Unterscheidung zwischen Autoren und sogenannten hack writers ersichtlich: Mit dem pejorativen Begriff hack writers wurden Journalisten und Schriftsteller bezeichnet,

24 Vgl. Donald, 1996 (wie Anm. 5), S. $26 f$.

25 Vgl. Ian Haywood, The Revolution in Popular Literature. Print, Politics and the People, 1790-186, Cambridge 2004, S. 60.

26 William Blackwood, Lectures on the Fine Arts, in: Blackwood's Edinburgh Magazine 14.78 (1823), S. 18-26, hier: S. 19. 
die sich nicht der hohen Literatur verpflichtet sahen, sondern ihren Lebensunterhalt durch Schreiben verdienen mussten, oft nach Seiten bezahlt wurden und daher eben genau das schrieben, wofür sie Geld bekamen.

Die politisch oft uneindeutige und paradoxe Haltung der Karikaturisten hat jedoch noch einen anderen Grund. Es spiegelt sich darin auch ein in Zeiten der napoleonischen Kriege um England besorgter, loyaler Patriotismus wider, der die Ideale der british liberty und civil society gegen das revolutionäre Pathos der Franzosen verteidigt. Deutlich äußert er sich in vielen napoleonkritischen (und damit monarchiefreundlichen) Karikaturen. Auf der anderen Seite stellen Karikaturisten einen demokratischen Idealen und dem common sense verpflichteten Freiheitssinn aus, der sich eben nicht nur gegen Frankreich, sondern im Inland gegen die Regierung wendet, wenn es darum geht, politische Repressionen und Ausbeutung der Bürger zu kritisieren.

Zwei Karikaturen Gillrays mögen dies verdeutlichen: auf den ersten Blick scheinen sie fast identisch zu sein. In „A Connaisseur Examining a Cooper“ sehen wir den kurzsichtigen König, wie er im Licht einer Kerze eine Miniatur betrachtet, die das Porträt Oliver Cromwells von Samuel Cooper darstellt. Gillray veröffentlichte sie im Jahre 1792, und damit im Kontext der französischen Revolution. Die Miniatur Cromwells kann als Anspielung auf die eigene, blutige republikanische Geschichte Englands verstanden werden: Charles I. war 1649 schließlich durch einen Urteilspruch eines vom Parlament eingesetzten Gerichts zum Tode verurteilt worden. Gillrays Karikatur kann also als Warnung an den König verstanden werden: Könige werden nicht nur in Frankreich enthauptet, die Geschichte könnte sich durchaus wiederholen.

11 Jahre später nimmt Gillray dieses Motiv wieder auf, jedoch mit einer deutlich patriotischen und monarchiefreundlicheren Note. Die Jonathan Swift verpflichtete Karikatur „The King of Brobdingnag and Gulliver“ (1803) projiziert eine Episode aus Swifts Roman „Gulliver's Travels“ (1726) auf das Verhältnis von England zu Frankreich. Der Riesenkönig von Brobdingnag (Georg III) inspiziert den kleinen Gulliver (Napoleon), der ihm von seinem Land und dessen Vorzügen berichtet. In der Sprechblase heißt es:

My little friend Gildrig, you have made a most admirable panegyric upon your country; but from what I can gather from your own relation, and the answers I have with much pain wringed and extorted from you, I cannot but conclude you to be one of the most pernicious, odious little reptiles that nature ever suffered to crawl upon the surface of the earth.

Napoleon als hässliches kleines Reptil - damit trifft Gillray ins Mark der Frankophobie der Jahrhundertwende und verspottet im grotesken Größenverhältnis der Figuren den britischen Größenwahn. Georg III. war jedoch nicht nur als politische Figur, sondern oft auch in seinen Eigenheiten Zielscheibe des Spottes. Der König war als 


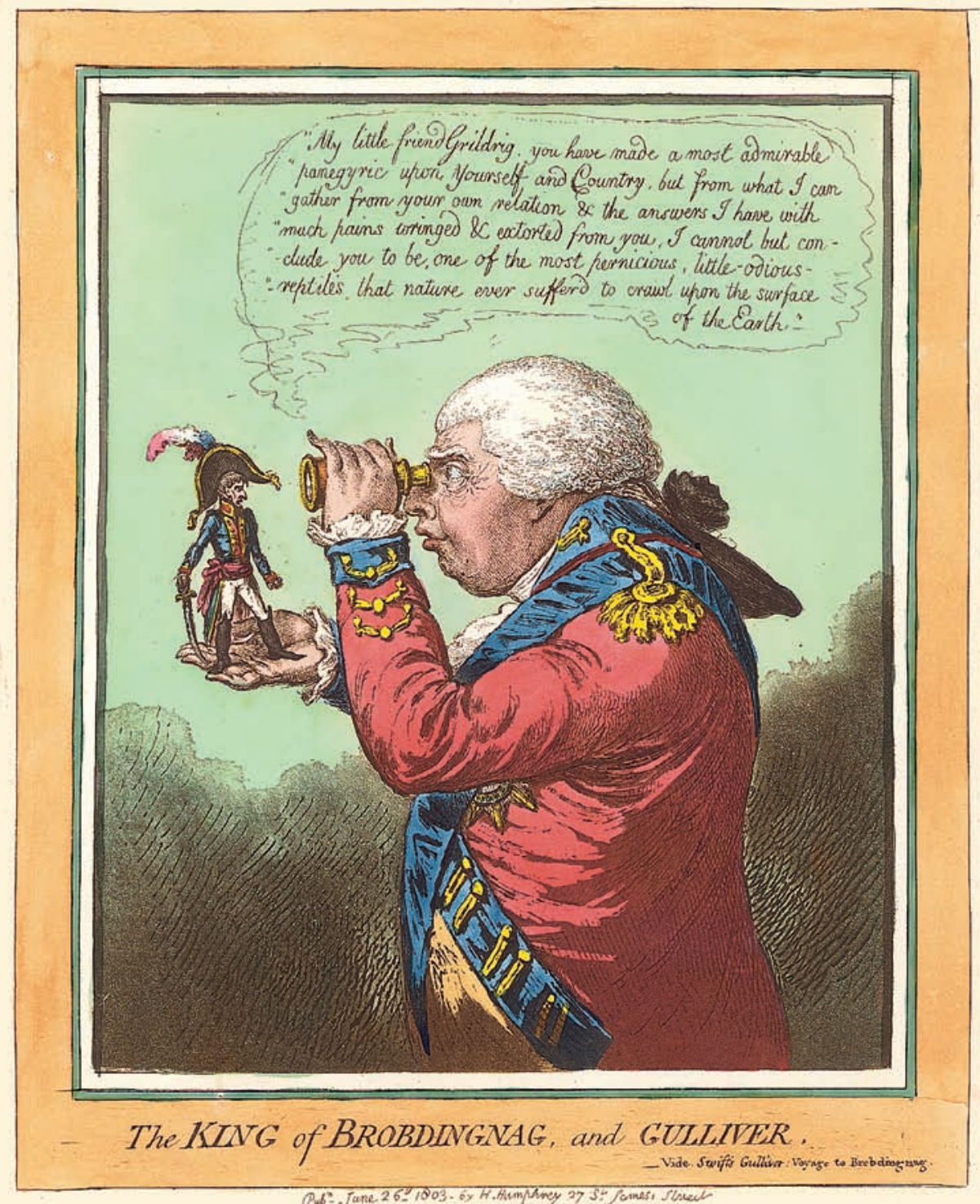

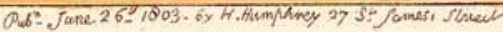

Abb. 5: James Gillray, The King of Brobdingnag and Gulliver, 1803.

Wilhelm Busch - Deutsches Museum für Karikatur und Zeichenkunst.

Dauerleihgabe der STIFTUNG NIEDERSACHSEN

(C) Archiv der Wilhelm-Busch-Gesellschaft e. V. 
sparsamer Mann bekannt, der das einfache Leben auf dem Lande liebte (sein Spitzname in der Bevölkerung war Farmer George) und seine Sparsamkeit war ein beliebtes Thema der Bildsatiren der Zeit. In der politischen Karikatur ist die Darstellung von Essen und Körperumfang ein wichtiges Mittel zur Charakterisierung von Personen und zur Übermittlung von politischen Inhalten: $\mathrm{Zu}$ dicke Menschen sind meist genauso negativ konnotiert wie zu dünne: Der oft dicke John Bull, also der typische Engländer, verzehrt sein Beefsteak und repräsentiert die gesunde Nation, während der dünne, verhungerte Franzose einen schwachen Volkskörper repräsentiert - das zeigte beispielhaft William Hogarth in seinem Gemälde „The Gate of Calais“ (1748). Die häufigen Karikaturen der königlichen Familie, die Essen thematisieren, machen deutlich, dass hier die Balance fehlt. Während Georg III. und seine Frau absoluter Sparsamkeit frönen, pflegt der Prince of Wales ein ausschweifendes Lasterleben. Gillrays Karikatur „Monstrous Craws at a New Coalition Feast“ vom 29. Mai 1787 zeigt den König als alte Frau, eine ausgemergelte Königin und den Prince of Wales vor dem offenen Tor zur königlichen Schatzkammer um eine große Schüssel mit Goldmünzen sitzend. Die Aufschrift ist: John Bull's Blood, also die Steuern, die den armen Briten abgepresst wurden. Alle drei schaufeln gierig die Münzen in sich hinein, aber während die Kröpfe des Königspaars gefüllt sind - dies ist ein Hieb auf dessen notorische Sparsamkeit - ist der des verschwenderischen Prince of Wales leer. Die auffälligen Kröpfe in Form von grünen Geldbeuteln, die der königlichen Familie um den Hals hängen, tauchen auch in anderen Karikaturen Gillrays auf, genauso wie das Motiv des verschwenderischen Monarchen, der sein Volk ausbeutet, im Kontext der französischen Revolution häufig wieder kehrt (z. B. in Gillrays „A New Way to Pay the National Debt“, 1786).

Gillrays Karikatur „Anti-Saccharites: or John Bull and his Family Leaving off the Use of Sugar" (1792) ist im politischen Kontext der Abolitionismus-Debatte der 1790er Jahre situiert. Mit das wichtigste Produkt der Kolonien war Zucker, und deshalb setzten sich viele Abolitionisten in Pamphleten und Gedichten für den Zuckerboykott ein. Gillrays Titel verweist auf die weite Verbreitung der Aktion, denn John Bull steht ja für die ganze Nation. Die Karikatur zeigt das eigentlich politisch korrekte Verhalten des Königspaares: der König findet den Tee ohne Zucker delicious, und den etwas miesepetrig dreinschauenden Töchtern versucht die Königin den Zuckerverzicht schmackhaft zu machen:

Oh Ihr Lieben, versucht es doch. Ihr könnt Euch gar nicht vorstellen, wie gut es ohne Zucker schmeckt! Und dann bedenkt doch, wieviel Arbeit ihr den Schwarzen erspart, wenn ihr aufZucker verzichtet! Und vor allem vergesst nicht, wieviel Auslagen dies Eurem armen Papa ersparen wird! 


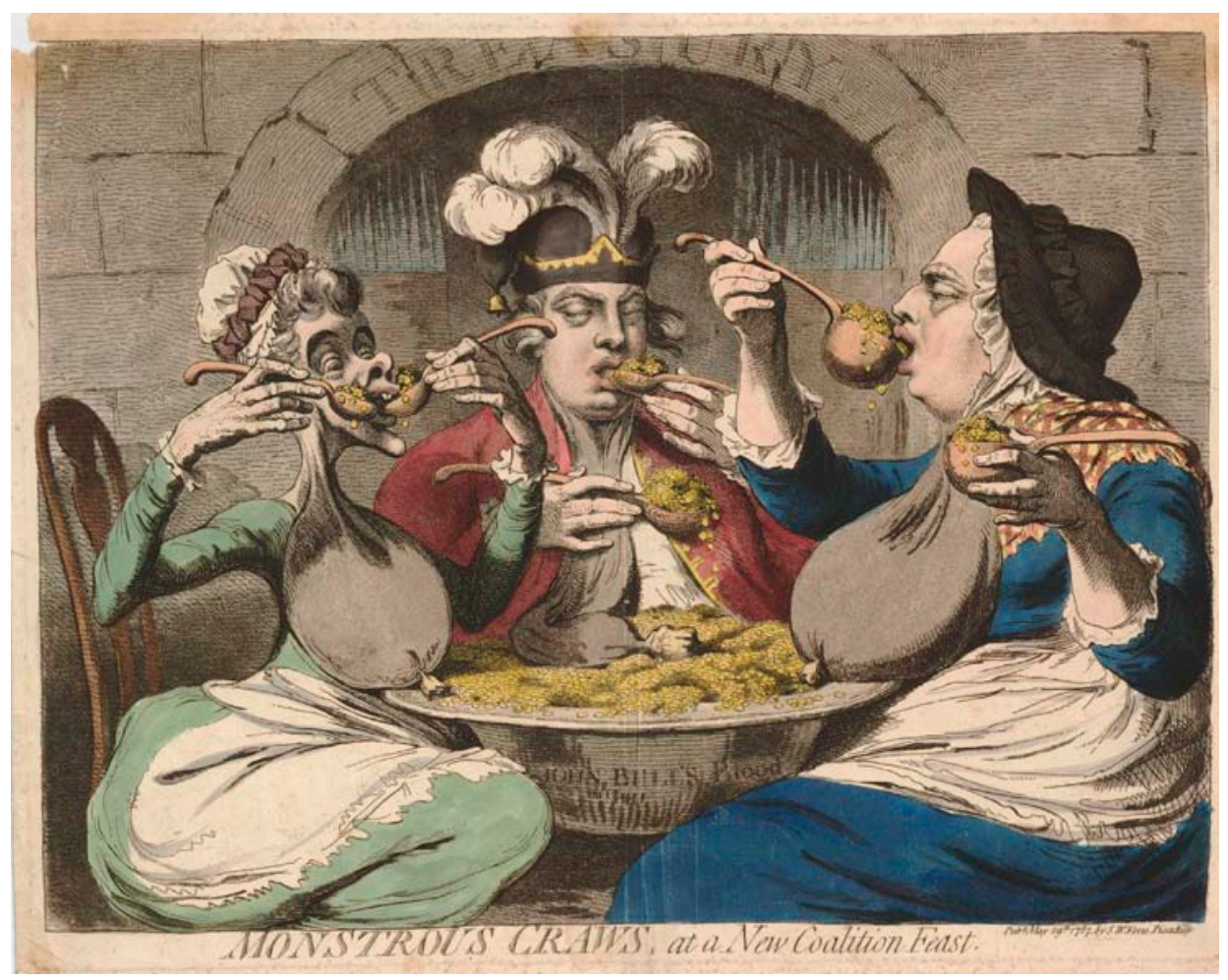

Abb. 6: James Gillray, Monstrous Craws at a New Coalition Feast, 1787.

British Museum, Number 7166.

(C) Trustees of the British Museum

Und damit enthüllt die Königin ihr eigentliches Motiv für den Zuckerboykott: Ihr geht es nicht um die Abschaffung der Sklaverei, sondern um die finanzielle Entlastung des königlichen Haushalts. Noch bevor man diese Sprechblase entziffert hat, haben die dürren Hände der Königin, die prominent im Zentrum des Bildes platziert sind, schon darauf verwiesen, dass Geiz und nicht humanitäre Bedenken der Motor des Boykotts sind. Gillray geht aber noch weiter, indem die Königin als Hauptakteurin im Zentrum der Zeichnung steht und den König an den Rand verweist: dies spielt auf die politisch prekäre Situation des Königs nach dem Ausbruch seiner Porphyrie-Erkrankung an, die ihn zunehmende dement werden ließ.

Auch in "Temperance enjoying a frugal meal“ (1792) richtet sich die Satire auf den Geiz des Königspaares. Der König isst ein gekochtes Ei, die Königin stürzt sich auf eine Schüssel Salat, zu trinken gibt es Wasser. Was heute als vorbildliche Umsetzung des Veggie Day Konzepts angesehen werden kann, bedeutete im Kontext der kuli- 


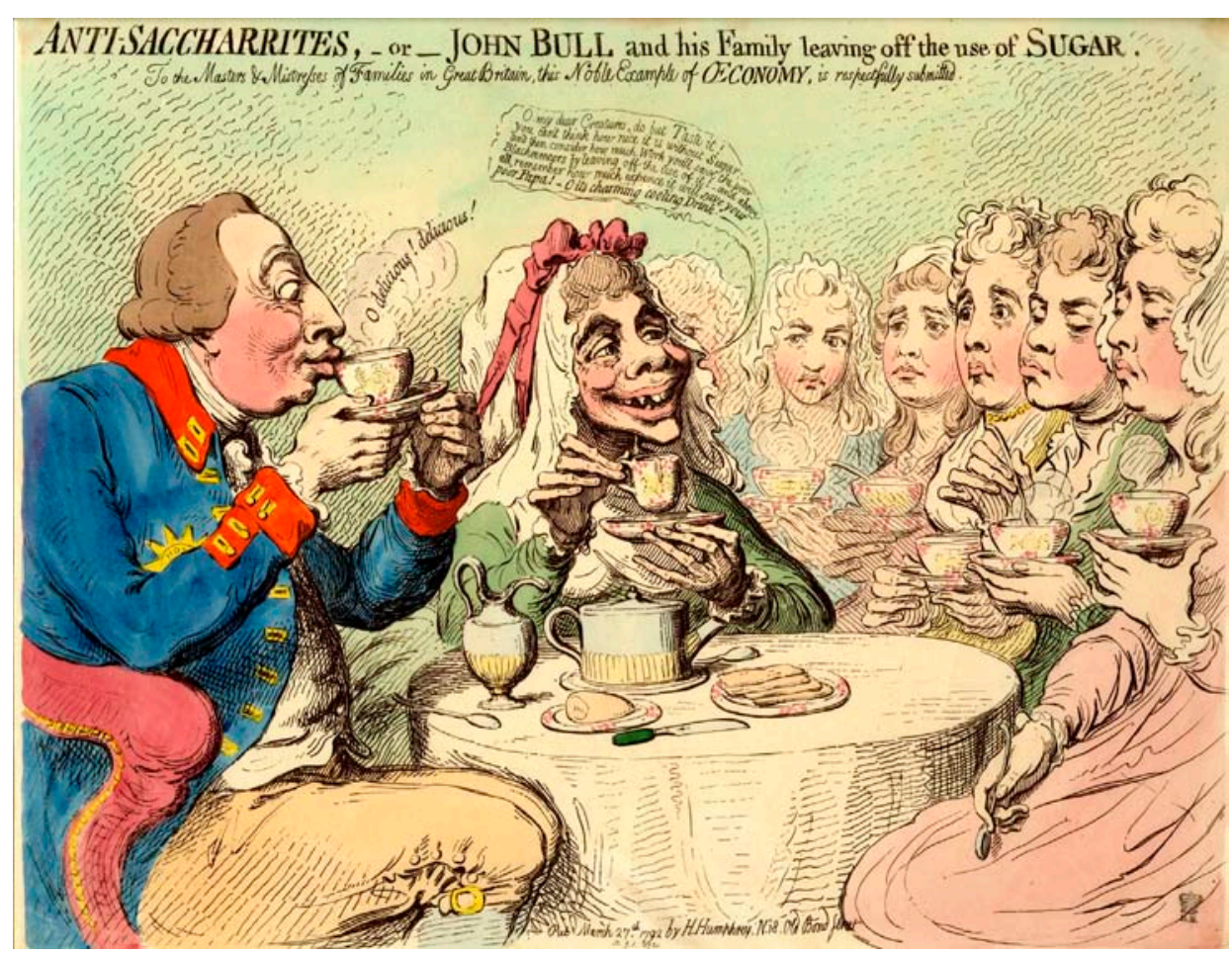

Abb. 7: James Gillray, Anti-Saccharites: or John Bull and his Family Leaving of the Use of Sugar, 1792. British Museum, Number 1851,0901.592.

(C) Trustees of the British Museum

narischen Gepflogenheiten der Aristokratie des 18. Jh. eine Lachnummer. Ähnlich sparsam wie das Menü ist auch die Ausstattung des Salons: An der Wand hängt ein leerer Bilderrahmen, der König trägt geflickte Hosen und sitzt auf einem zerschlissenen Stuhl, der notdürftig mit einem Tuch verhüllt ist.

Gegenstück zu diesem Bild ist die bitterböse Darstellung des Prince of Wales in Gilrays „A Voluptuary under the horrors of Digestion“ (1792). Kein anderer Monarch ist so erbarmungslos von der Presse diffamiert worden wie Georg IV. - als Prince of Wales, als Prinzregent und später als König. Auch erfolgreiche Verleumdungsklagen - der Journalist und Herausgeber der radikalen Whig-Zeitschrift „The Examiner“ Leigh Hunt nannte den Prinzregenten einen fat Adonis of fifty und musste dafür 2 Jahre ins Gefängnis und 500 Pfund Strafe zahlen ${ }^{27}$ - brachten die Presse und Karikaturisten nicht wirklich zum Schweigen. Immer wieder wurde der verschwenderische

27 Vgl. Robert L. Patten, George Cruikshank's Life. Times and Art, Volume 1, 1792-1835, New Brunswick, NJ 1992, S. 117. 


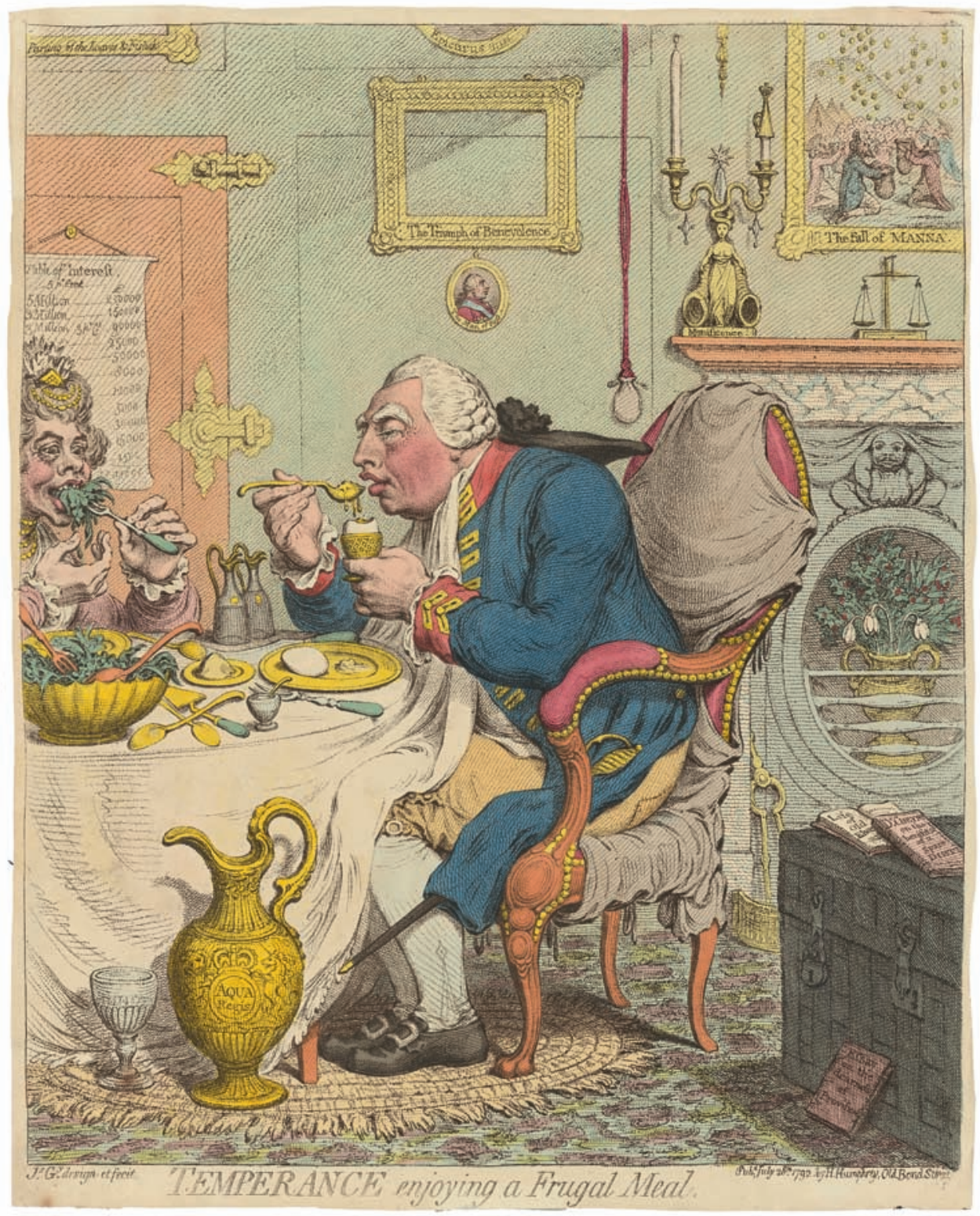

Abb. 8: James Gilray, Temperance enjoying a frugal meal, 1792.

Wilhelm Busch - Deutsches Museum für Karikatur und Zeichenkunst (C) Archiv der Wilhelm-Busch-Gesellschaft e. V. 
Lebensstil des Prinzregenten aufs Korn genommen. Auch das Thema dieser Karikatur ist der Exzess: Der Prince of Wales lehnt nach einem gewaltigen Mahl erschöpft und mit zum Platzen gespannter Weste in seinem Stuhl und holt sich mit der Gabel die Speisereste aus den Zähnen. Der Kerzenleuchter an der Wand zeigt anstelle eines Wappens gekreuzte Messer und Gabel, und hinter dem Stuhl steht ein überschwappender Nachttopf auf einem Stapel unbezahlter Rechnungen - der Nachttopf, ebenso wie die auf dem Boden liegenden Flaschen spielen auf die Inkontinenz des Thronfolgers an. Eines der vielen Fläschchen im Hintergrund hat die Aufschrift For the Piles: auch hier wieder eine Anspielung auf die königlichen Hämorrhoiden als Zeichen eines exzessiven Lebenswandels. Neben kulinarischen Exzessen und Verschwendungssucht wurden auch die sexuellen Eskapaden des Prince of Wales schonungslos dargestellt. Cruikshanks „Merry Making on the Regent's Birthday“ (1812) zeigt den Prinzregenten beim Tanz mit einer sehr ausgelassenen Dame, deren Ehemann ein Papier mit dem Tagesablauf des Prinzregenten in der Hand hält: Nach dem Frühstück ist das Beiwohnen einer Exekution in Newgate an der Reihe, das Abendprogramm beinhaltet ein Diner mit bread, cheese \& kisses, und Flirten und Tanzen. Die Instrumente der beiden Hornisten sind so hinter dem Kopf des Ehemanns arrangiert, dass er als gehörnter Ehemann erscheint. Nicht fehlen darf der Blick nach draußen, der die königlichen Ausschweifungen an der sozialen Realität spiegelt: Galgen, abgerissene Bettler und hungernde Kinder dramatisieren die Kluft zwischen Arm und Reich und setzen das moralische Fehlverhalten des Prinzregenten wirkungsvoll in Szene.

Ein gefundenes Fressen für Karikaturisten war natürlich die Scheidungsaffäre zwischen Georg IV. und Caroline von Braunschweig. Diese Ehe war von Anfang an glücklos gewesen und der König wollte Caroline nicht als Königin anerkennen und strebte sogar einen Hochverratsprozess gegen sie an. Davon konnten ihn seine Berater zwar wieder abbringen, aber die Scheidung war nach englischem Recht nur zu erlangen, wenn einem der beiden Ehepartner die eheliche Untreue nachzuweisen war. Mit Unterstützung des Premierministers beauftragte der König eine finanziell gut ausgestattete Untersuchungskommission damit, kompromittierendes Material über Caroline von Braunschweig zu sammeln. Sein Ansehen bei der Bevölkerung geriet damit auf den Tiefpunkt und das Parlament ließ letztendlich den Scheidungsprozess auch deshalb nicht zu, weil die populäre Königin den Großteil der Presse hinter sich hatte. ${ }^{28}$ Cruikshank fasste diese Auseinandersetzung, während der jede Menge schmutziger Wäsche gewaschen wurde, 1820 in eine anspielungsreiche Zeichnung mit dem Titel „Ah sure such a pair was never seen such so justly form'd to meet by nature“ und dem Untertitel „Old Sherry - dedicated to old bags“. Sie zeigt das Königspaar als groteske Birnenkörper - die Birne verweist nicht nur auf die unförmige Leibesfülle, sondern auch auf das homophone Wortpaar pair und pear im Englischen.

28 Vgl. Linda Colley, Britons. Forging the Nation 1707-1837, London 1992, S. 266. 
Nur ihre Köpfe ragen aus grünen Säcken, die sowohl Gillray wie Cruikshank öfters verwendeten - als Geldsäcke in der oben genannten Karikatur, und hier wohl in der Funktion als Aufbewahrungsbehälter für die Beweisdokumente im Scheidungsprozess. Die Körperhaltung der beiden spricht für die Auseinandersetzung: sie blickt ihn provozierend von der Seite an, er blickt wütend von ihr weg. Unter dem König lugt ein Papier mit der Aufschrift Order to lie on the table, wobei lie durchgestrichen und durch lay ersetzt ist. Hiermit ist natürlich nicht die Korrektur eines Schreibfehlers der Ersatz von liegen durch legen - gemeint, sondern wieder ein phonetischer Witz: das Homonym lie kann sowohl liegen wie lügen bedeuten. Cruikshank attackiert den lockeren Umgang mit der Wahrheit in diesem Prozess, der ja nur dazu dienen sollte, dem König ein Mittel an die Hand zu geben, um seine ungeliebte Frau endlich loszuwerden.

Mit Gillray und Cruikshank hatte die politische Karikatur in England ihren Höhepunkt erreicht. In den 1830er Jahren wurde es mit der neuen Technik der Lithografie möglich, Illustrationen in Zeitschriften und Büchern in großer Zahl herzustellen. Damit wanderte die Karikatur vermehrt in die Zeitschriften ab - der Print Shop hatte als Ort der Ausstellung politischer Kritik ausgedient. Zugleich änderte sich im viktorianischen Zeitalter der Geschmack: Bildsatiren waren nicht länger grell, derb, skatologisch und dem Exzess verpflichtet, sondern wurden milder und passten sich damit den Erfordernissen des Mediums Zeitschrift an, das für die größere Öffentlichkeit gedacht war. Nie wieder hat seitdem die britische Bildsatire mit ähnlich schockierenden Darstellungsstrategien gearbeitet. Die Reformen, die ab 1832 England modernisierten, schwächten die politisch engagierten Radikalen, und die Presse setzte allmählich mehr auf kommerziellen Gewinn denn satirischen Protest ${ }^{29}$. Mit dem Ende der Personalunion war auch die große Tradition der radikalen politischen Karikatur und Satire in England zu Ende.

29 John Strachan, Satirical Print Culture, in: Francis O'Gorman, The Cambridge Companion to Victorian Culture, Cambridge 2010, S. 156-176, hier: S. 171. 


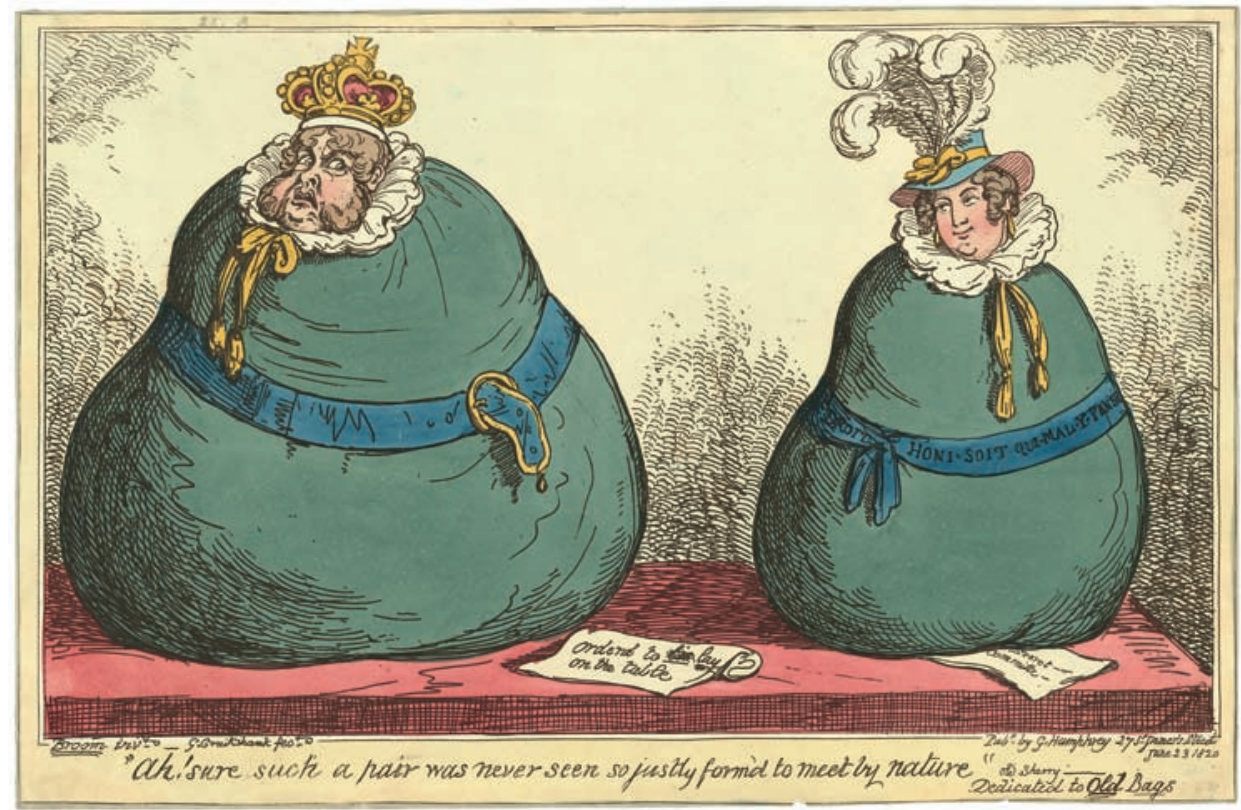

Abb.9: George Cruikshank, Ah sure such a pair was never seen such so justly form'd to meet by nature, 1820 .

Leihgabe der Landeshauptstadt Hannover im Museum Wilhelm Busch Deutsches Museum für Karikatur und Zeichenkunst

(C) Archiv der Wilhelm-Busch-Gesellschaft e. V. 



\title{
Von Georg II. zu George Washington: Überlegungen zur Visualisierung von Legitimität im Übergang von Monarchie zu Demokratie ${ }^{1}$
}

\author{
Volker Depkat
}

\section{Einleitung}

Die Kurfürsten von Hannover waren als Könige von England im Zeitalter der Personalunion auch Herren über ein weitverzweigtes Kolonialreich, dessen Schwerpunkt bis 1776 in Nordamerika lag. ${ }^{2}$ Für die Bewohner der britischen Kolonien in Nordamerika waren Georg I., Georg II. und Georg III. die Oberhäupter eines imperialen Herrschaftsverbandes, in den sie hineinwuchsen, der ihr Alltagsleben strukturierte und der auch ihre koloniale Identität bestimmte. Dabei hatten die nordamerikanischen Kolonisten durchaus ihr Scherflein dazu beigetragen, dass England in einer Reihe von Kolonialkriegen gegen Frankreich bis 1763 zum Herrn über den nordamerikanischen Kontinent aufsteigen konnte, und sie sonnten sich als überzeugte Englishmen nur allzu gerne im imperialen Glanz des britischen Weltreiches. ${ }^{3}$

1 Ich bedanke mich bei Tamara Heger und Katharina Matuschek für die Mithilfe bei diesem Aufsatz.

2 Zum britischen Weltreich hier nur: Peter Wende, Das Britische Empire. Geschichte eines Weltreichs, München 2008; Hermann Wellenreuther, Der Aufstieg des ersten Britischen Weltreiches. England und seine nordamerikanischen Kolonien 1660-1763, Düsseldorf 1987; Ders., Niedergang und Aufstieg. Geschichte Nordamerikas vom Beginn der Besiedlung bis zum Ausgang des 17. Jahrhunderts, Münster 2000; Ders., Ausbildung und Neubildung. Die Geschichte Nordamerikas vom Ausgang des 17. Jahrhunderts bis zum Ausbruch der Amerikanischen Revolution 1775, Hamburg 2001; Alan Taylor, American Colonies. The Settling of North America, New York 2001; Jack P. Green / J. R. Pole, Colonial British North America. Essays in the New History of the Early Modern Era, Baltimore 1984.

3 Zur Rolle der Kolonialkriege und ihre Bedeutung für das Selbstverständnis der Kolonisten: Taylor, 2001 (wie Anm. 2), S. 420-443; Wellenreuther, 1987 (wie Anm. 2), S. 265-298; Fred Anderson, Crucible of War. The Seven Years' War and the Fate of Empire in British North America, 1754-1766, New York 2000. 
Diese imperiale Identität war auch für diejenigen attraktiv, die aus anderen, europäischen Ländern in die nordamerikanischen Kolonien einwanderten. Nehmen wir zum Beispiel Heinrich Melchior Mühlenberg, der, 1711 in Einbeck geboren, im Jahr 1741 von Halle aus als lutherischer Pastor nach Pennsylvania entsandt wurde, um dort die lutherische Kirche aufzubauen, und dies auch sehr erfolgreich tat. Er war Zeit seines Lebens stolz darauf, ein Untertan des Kurfürsten von Hannover und Königs von England zu sein. Dafür musste er im 18. Jahrhundert noch nicht einmal die Dynastie wechseln. ${ }^{4}$

Allerdings war das 18. Jahrhundert auch die Zeit, in der große Teile Nordamerikas für die britische Monarchie verloren gingen, weil sich dreizehn Kolonien am 4. Juli 1776 für unabhängig erklärten und die Vereinigten Staaten von Amerika gründeten, die dann im weiteren Verlauf ihrer Geschichte Großbritannien aus Nordamerika verdrängten und selbst zur Weltmacht wurden. ${ }^{5}$

Die sich während der Regentschaft Georgs III. ereignende Amerikanische Revolution steht am Anfang der politischen Moderne. ${ }^{6}$ Sie realisierte ein rein säkular begründetes Gemeinwesen, das das Volk zum Souverän und Autor einer geschriebenen Verfassung hatte, die alle legitime politische Macht aus der Gesellschaft selbst hervorgehen ließ und die Macht der Herrschenden vom Vertrauen und der Zustimmung des Volkes abhängig machte. Die Begründung und Ausgestaltung dieser politischen Ordnung ist ein sehr aufregender und höchst komplizierter Prozess, der auf verschiedenen Ebenen ablief - und auf jeder gleichermaßen spannend ist.

$\mathrm{Da}$ ist zunächst die verfassungsrechtliche Dimension, bei der es darum ging, die in der Unabhängigkeitserklärung verkündeten politisch-sozialen Prinzipien in eine institutionelle Ordnung zu überführen, die das Grundrecht auf life, liberty and the pursuit of happiness wie eine sich selbst-bewegende Maschine auf alle Ewigkeit garantieren würde. ${ }^{7}$ Auch hatte die Ausgestaltung der amerikanischen Demokratie

4 Zu Mühlenberg: Thomas J. Müller, Kirche zwischen zwei Welten. Die Obrigkeitsproblematik bei Heinrich Melchior Mühlenberg und die Kirchengründung der deutschen Lutheraner in Pennsylvania, Stuttgart 1994; Jürgen Gröschl / Thomas Müller-Bahlke / Claus Veltmann (Hg.), Freiheit, Fortschritt und Verheißung. Blickwechsel zwischen Europa und Nordamerika, Halle an der Saale 2011.

5 Zur Amerikanischen Revolution: Francis D. Cogliano, Revolutionary America, 1765-1815. A Political History, New York 22009; Robert Middlekauff, The Glorious Cause. The American Revolution, 1763-1789, New York 1982; Gordon S. Wood, The Radicalism of the American Revolution, New York 1992; Hermann Wellenreuther, Von Chaos und Krieg zu Ordnung und Frieden. Der Amerikanischen Revolution Erster Teil, 1775-1783, Berlin 2006.

6 Zum Zusammenhang von Aufklärung, Revolution und Moderne: Jonathan I. Israel, A Revolution of the Mind. Radical Enlightenment and the Intellectual Origins of Modern Democracy, Princeton, N. J. 2010; Ders., Democratic Enlightenment. Philosophy, Revolution, and Human Rights 1750-1790, New York 2011; Frank Kelleter, Amerikanische Aufklärung. Sprachen der Rationalität im Zeitalter der Revolution, Paderborn 2002.

7 Zur Verfassungsgeschichte der Amerikanischen Revolution: Richard R. Beeman / Stephen Botein / Edward C. Carter (Hg.), Beyond Confederation: Origins of the Constitution and American National Identity, 
eine soziale Dimension, galt es doch auszuhandeln, welche sozialen Gruppen in einer Ordnung, die auf einem radikalen Gleichheitsgrundsatz aufgebaut war (we hold these truths to be self-evident that all men are created equal), denn nun eigentlich das Sagen haben sollten. ${ }^{8}$ Dann ist da noch die identitätspolitische Ebene, denn der Prozess der Loslösung von England und die Begründung eines neuen, als ideal und exzeptionell antizipierten Nationalstaats beinhaltete auch einen tiefen Wandel in den Köpfen der Bewohner der britischen Kolonien in Nordamerika, die bis weit in die 1770er Jahre hinein von sich als ,Engländer ${ }^{`}$ zu denken geneigt waren und sich nun plötzlich als Amerikaner definieren mussten. What do we mean by the revolution?, fragte John Adams rückblickend in einem Brief an Thomas Jefferson im Jahr 1815. The war? That was no part of the revolution; it was only an effect and consequence of it. The revolution was in the minds of the people, and this was effected from 1760 to 1775, in the course of fifteen years, before a drop of blood was shed at Lexington. ${ }^{9}$ Schließlich ging es bei Gründung und Ausgestaltung der amerikanischen Demokratie auch um die Erfindung einer politischen Kultur, die die revolutionär begründete Verfassungsordnung tragen und stabilisieren würde. Dieser Aspekt steht im Zentrum des vorliegenden Beitrags.

\section{Die Politik des Visuellen - Visuelle Politik}

Unter ,politischer Kultur' soll hier die Gesamtheit aller Symbole, Wertideen und Praktiken verstanden werden, die die Legitimität einer politischen Ordnung sowie die Autorität ihrer Amtsträger begründen und dem politischen Handeln in dieser Ordnung Orientierung geben. ${ }^{10}$ Ein zentrales Feld ,politischer Kultur ${ }^{6}$ ist in diesem Zusammenhang der gesamte Bereich des Visuellen, denn Herrschaftsordnungen können nur dann Legitimität und Gültigkeit für sich beanspruchen, wenn sie sich der normativen, wertideellen Grundlagen bewusst sind, auf denen ihre Autorität und ihre regulativen Funktionen beruhen. Politische Systeme sind deshalb nur solange stabil,

Chapel Hill, N.C. 1987; Gordon S. Wood, The Creation of the American Republic, 1776-1787, Chapel Hill, N. C. 1969; Michael G. Kammen, A Machine that would go of itself. The Constitution in American Culture, New York 1986.

8 Zum egalitären Radikalismus der Amerikanischen Revolution und dem konservativen Impetus der Eindämmung der egalitären Energien insbesondere: Wood, 1992 (wie Anm. 5); Ders., 1969 (wie Anm. 7), S. 471-564.

9 John Adams and Thomas Jefferson, 24. August 1815, in: The Works of John Adams, Second President of the United States. With a Life of the Author, Notes and Illustrations, by his Grandson Charles Francis Adams, Bd. 10, Boston 1856, S. 172.

10 Karl Rohe, Politische Kultur und ihre Analyse. Probleme und Perspektiven der politischen Kulturforschung, in: Historische Zeitschrift 250 (1990), S. 321-346; Barbara Stollberg-Rilinger (Hg.), Was heißt Kulturgeschichte des Politischen?, Berlin 2005; Wolfgang Hardtwig (Hg.), Ordnungen in der Krise. Zur politischen Kulturgeschichte Deutschlands 1900-1933, München 2007. 
wie die Normen und Wertideen, auf denen ihr institutionelles Gefüge beruht, erkennbar sind und sichtbar gemacht werden können. Kurz, politische Systeme müssen die normativen und wertideellen Grundlagen ihrer Ordnung visualisieren können. Das gilt auch - und vielleicht sogar insbesondere - für demokratische Ordnungen, die im Prinzip der Volkssouveränität gründen. ${ }^{11}$

In diesem Zusammenhang nun erhalten Bilder von Politikern - zumal die von Regierungschefs und Staatsoberhäuptern - eine zentrale politische Bedeutung, denn, diese These wird hier jedenfalls vertreten, in diesen Bildern werden die Normen und Wertideen einer politischen Ordnung in besonderem Maße sichtbar gemacht. Dies geschieht entweder in affirmativer Absicht oder aber mit der Absicht der Infragestellung, der Kritik oder der Negation eines normativen Geltungsanspruches. Insofern ordnet sich der vorliegende Beitrag in das Feld einer kulturgeschichtlich erweiterten Politikgeschichte ein, die das Visuelle als integralen Bestandteil von Politik begreift, „Bilder der Macht" analysiert und die „Macht der Bilder“ anerkennt. ${ }^{12}$ Dabei weiß er sich methodisch den Visual Culture Studies verpflichtet, deren wesentliche Prämissen hier in vier Punkten kurz vorgestellt seien. ${ }^{13}$

Bilder sind erstens nicht nur bloße Illustrationen von Texten, sondern eine ganz eigene Form der Ordnung, Interpretation und Aneignung von Welt, die gleichberechtigt neben Texten steht und ihre ganz eigene Dynamik hat. Bilder lassen sich mithin als Akte kultureller Sinnstiftung begreifen, die jene orientierungsgebenden Perspektiven auf die Welt organisieren, ohne die intentionales Handeln in ihr nicht möglich ist. Bilder sind deshalb nicht nur ein gleichsam passiver Spiegel der äußeren Wirklichkeit, sondern sie bringen die Wirklichkeit, die sie darstellen, immer auch ein Stück weit mit hervor. Als solche Repräsentationen von Wirklichkeit sind Bilder zweitens auch als visuelle Argumente zu begreifen, die integrale Bestandteile von denjenigen Prozessen sozialer Kommunikation sind, durch die sich einzelne Gruppen und ganze Gesellschaften über sich selbst und ihren Ort in der Welt verständigen. ${ }^{14}$ Drittens lassen Bilder sich immer auch als Visualisierung von abstrakten Wertideen

11 Wolfram Pyta, Visualizing Democratic Legitimacy and Authority. The Case of the Weimar Republic, in: Volker Depkat / Meike Zwingenberger (Hg.), Visual Cultures - Transatlantic Perspectives, Heidelberg 2012, S. 69-83, hier S. 69f.

12 Stefan Germer / Michael F. Zimmermann (Hg.), Bilder der Macht, Macht der Bilder. Zeitgeschichte in Darstellungen des 19. Jahrhunderts, München 1997.

13 Nicholas Mirzoeff, An Introduction to Visual Culture, New York 22010; Ders., The Visual Culture Reader, London ${ }^{3}$ 2013; Gunther Kress / Theo van Leeuwen, Reading Images. The Grammar of Visual Design, London 22010; Depkat / Zwingenberger, 2012 (wie Anm. 11).

14 Zum Konzept der sozialen Kommunikation: Volker Depkat, Kommunikationsgeschichte zwischen Mediengeschichte und der Geschichte sozialer Kommunikation. Versuch einer konzeptionellen Klärung, in: Karl-Heinz Spieß (Hg.), Medien der Kommunikation im Mittelalter, Stuttgart 2003, S. 9-48; Demnächst auch: Ders., Wege in die Kommunikationsgeschichte des Zeitalters der Personalunion, in: Steffen Hölscher / Sune Schlitte (Hg.), Kommunikation im Zeitalter der Personalunion (1714-1837). Prozesse, Praktiken, Akteure, Göttingen (im Druck). 
und Normen einer Kultur lesen. Sie machen etwas Unsichtbares wie beispielsweise ,die Nation“ oder ,den Staat‘ oder eben auch ,Legitimität‘ oder ,Demokratie“ sichtbar. Dabei folgen sie viertens einer kulturell konditionierten und deshalb auch kulturell spezifischen „visuellen Grammatik“, also einem Regelsystem, das bestimmt, wie Bilder aufgebaut sind. ${ }^{15}$ In diesem Zusammenhang kann man danach fragen, welche Bedeutung den Farben zukommt, welchen Informationsgehalt die verschiedenen Zonen eines Bildes haben, wie Rahmen gesetzt werden, aus welchen Elementen Bilder bestehen und wie diese zueinander in ein Verhältnis gesetzt werden. Die kulturell bestimmte Grammatik des Visuellen freizulegen, heißt Bilder ,lesen zu lernen`.

Auf dieser Grundlage steht der vorliegende Beitrag, der es sich zum Ziel gesetzt hat, eine Auswahl von Porträts der hannoversch-britischen Könige mit denen von George Washington zu vergleichen, der als erster postrevolutionärer Staats- und Regierungschef am Anfang des von Alexis de Tocqueville diagnostizierten „Zeitalters der Demokratie“ steht. ${ }^{16}$ Wie also haben europäische Zeitgenossen Könige gemalt, um königliche Herrschaft zu legitimieren? Wie haben dann die Amerikaner ihre Präsidenten gemalt, um Macht und Autorität eines demokratisch gewählten Staatsoberhaupts und Regierungschefs zu legitimieren? Wie hat - damit einhergehend - die frühe amerikanische Demokratie ihren Anspruch auf Legitimität und Autorität in einem historischen Kontext visualisiert, in dem die Visualität politischer Macht entscheidend von monarchisch-aristokratischen Traditionen geprägt war, in die die Kolonisten Britisch-Nordamerikas selbst hineingewachsen waren?

\section{Die Visualisierung monarchischer Legitimität in der Personalunion}

Wenn die Bewohner der dreizehn britischen Kolonien sich am Vorabend ihrer Revolution vorstellten, wie ,politische Macht' denn aussehe und woran man sie erkenne, dann hatten viele von ihnen ganz bestimmt die Porträts der britischen Könige vor Augen, deren Konterfeis in Form von Gemälden und Stichen auch in den Kolonien überall angebracht waren. Von besonderer Bedeutung waren in diesem Zusammenhang zwei Formen des Monarchenporträts, nämlich zum einen Krönungsbilder, die als offizielle Staatsporträts die Macht des Königs in besonders verdichteter Form repräsentierten, und zum anderen Darstellungen des Monarchen als Feldherren.

15 Zur visuellen Grammatik speziell: Kress / van Leeuwen, 2010 (wie Anm.13).

16 Isaac Kramnick (Hg.), Alexis de Toqueville. Democracy in America and Two Essays on America, übers. von Gerald E. Bevan, London 2003. 
Eines dieser Krönungsbilder befindet sich seit 1837 an der sogenannten Königswand im Aula-Gebäude der Göttinger Universität (Abb. 1). Es ist das lebensgroße Porträt von König Georg II., dem Stifter der Universität, das 1741 vom hannoverischen Hofmaler Gottfried Boy gemalt wurde und zunächst in Hannover hing, bevor es 1746 auf Bitten der Universität nach Göttingen überführt wurde. Dort hing es bis 1837 in verschiedenen Räumen und fand dann mit Eröffnung der neuen Aula seinen endgültigen Platz. ${ }^{17}$

Dieses Bild König Georgs II. ist ein konventionelles Staatsporträt, das die Macht und Legitimität des britischen Königs und Kurfürsten von Hannover vor allem durch den Körper des Königs und die materiellen Objekte im Raum visualisiert. ${ }^{18}$ Werfen wir zunächst einen Blick auf den Körper des Königs, dem seit dem Mittelalter eine zentrale Bedeutung für die Visualisierung königlicher Macht zukam. ${ }^{19}$ Der gemalte Georg II. ist von offensichtlich guter Statur. Er steht aufrecht in voller Beherrschung des eigenen Körpers. Sein Gesicht ist ebenmäßig, fast engelsgleich. Im Körper des Königs sind Selbstbeherrschung, Kraft und auch männliche Schönheit repräsentiert. Dieser Körper ist bekleidet, und zwar mit erkennbar kostbarem Geschmeide in den Farben der Macht. Georg II. trägt einen purpurnen, mit Goldbrokat und Hermelin besetzten Gehrock und einen purpurnen Umhang, dessen Innenseite ganz aus Hermelin ist, dazu silbrig glänzende Schnallenschuhe sowie weiße Strümpfe und eine Allongeperücke. Insgesamt ist der Glanz der Kleidung verschwenderisch. Sie verbindet sich harmonisch mit der Statur des königlichen Körpers, und beides zusammen lässt den Monarchen zu einer nicht mehr ganz irdischen Erscheinung werden.

Genauso wichtig - ja fast noch wichtiger - für die Repräsentation königlicher Macht, sind die im Raum verstreuten, aber doch mit dem Körper des Königs verbundenen materiellen Objekte als Insignien der Macht. Wir sehen die Krone auf dem Tisch links hinter dem König. Er hält ein Zepter in der Hand, und sein Umhang liegt zum Teil auf dem Thronsessel im rechten Bildhintergrund. Alle diese Objekte verweisen auf ,Blut' und ,Gottesgnadentum' als die beiden Quellen monarchischer Legitimität. Hinzu kommt der Habitus des Abgehobenen. Georg II. steht auf einem Podest unter einem Baldachin in einem geschlossenen Raum. Es kommt zu keinem direkten Blickkontakt mit dem Betrachter. Der Monarch schaut aus dem Bild heraus über den Betrachter hinweg auf etwas, das weit in der Ferne liegt. Der König ist buchstäblich entrückt. Er steht in keinem Kontakt mit der Welt da draußen. Er ist nicht

17 Marianne Bergmann / Christian Freigang, Das Aula-Gebäude der Göttinger Universität. Athen im Königreich Hannover, München 2006, S. 43.

18 Zu Georg II. hier nur: Mijndert Bertram, Georg II. König und Kurfürst, Göttingen ${ }^{2} 2004$.

19 Ernst H. Kantorowicz, Die Zwei Körper des Königs. Eine Studie zur politischen Theologie des Mittelalters, übers. von Walter Theimer, Stuttgart 1992; Florentine Mütherich (Hg.), Percy Ernst Schramm, Die deutschen Kaiser und Könige in Bildern ihrer Zeit 751-1190, München 1983. 


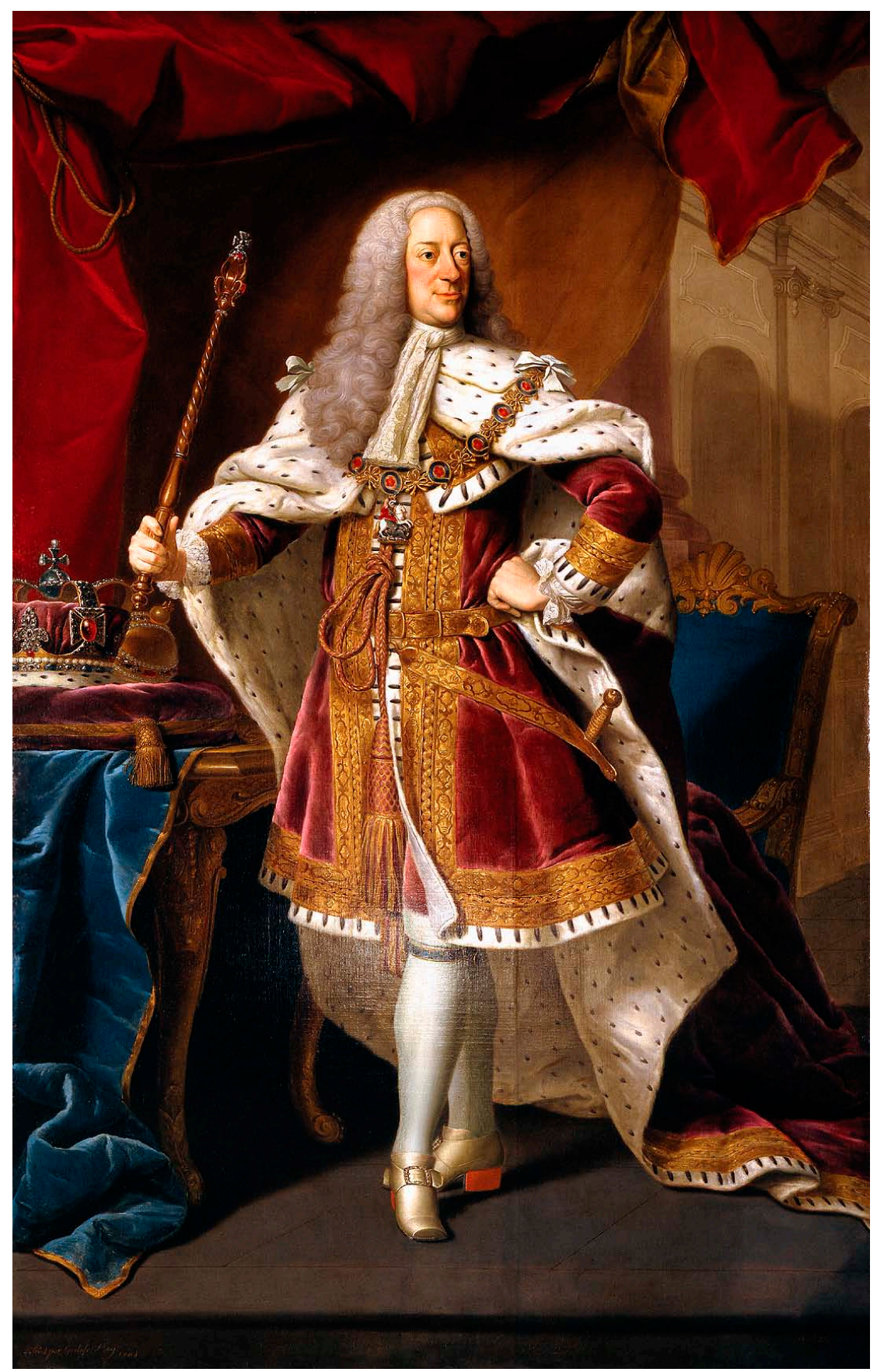

Abb. 1: Gottfried Boy, König Georg II., 1741.

Aula-Gebäude der Göttinger Universität. 
Teil der Gesellschaft, die er regiert, sondern schwebt irgendwo zwischen der irdischen und der göttlichen Sphäre.

So konventionell diese Darstellung des abgehobenen Königs als Quelle aller politischen Macht auch sein mag, sie ist insofern bemerkenswert, als der König in Großbritanniens gemischter Verfassung um die Mitte des 18. Jahrhunderts deutlich an Bedeutung verlor. Zwar war die Macht der Könige weiterhin substantiell, doch gewann die Staatsbürokratie und vor allem der Premierminister in dieser Zeit massiv an Einfluss. Kein Geringerer als Georg II. höchstselbst stellte 1744 resigniert fest, dass die Minister die eigentlichen Könige des Landes seien. ${ }^{20}$ Insofern lässt sich diese Darstellung scheinbar uneingeschränkter königlicher Machtvollkommenheit auch als visuelle Behauptung eines Herrschaftsanspruches lesen, der durch den Aufstieg der modernen Staatsverwaltung im Großbritannien des 18. Jahrhunderts tatsächlich immer problematischer wurde.

Deutet das bislang erörterte Krönungsbild Georgs II. auf ,Blut' und ,Gottesgnadentum' als Quellen königlicher Macht, so verweisen Bilder, die den König als Feldherren darstellen, auf militärisches Charisma als eine weitere wichtige Säule des monarchischen Herrschaftsanspruchs.

Von besonderer Bedeutung sind in diesem Falle Reiterbilder, wie das von Joseph Highmore, ein damals gefragter Porträtist, Maler historischer Szenen und Freund von William Hogarth (Abb. 2). Das Mitte der 1740er Jahre entstandene Reiterbild war offenbar eine Vorstudie für ein geplantes, aber nie realisiertes lebensgroßes Reiterporträt von Georg II. ${ }^{21}$ Diese Darstellung Georgs II. stand in der ikonographischen Tradition des Reiterbildes von Karl I., das Anthony van Dyck 1633 angefertigt hatte, welches wiederum sein Vorbild in Tizians Reiterporträt von Karl V. aus dem Jahr 1548 fand. Das zentrale Thema ist hier das vom König als Feldherren, dessen Autorität und Charisma auf militärischen Erfolgen beruht. Das Bild zeigt Georg II. in voller Ritterrüstung wie er hoch zu Ross unter einem antiken Triumphbogen hervorreitet. In der rechten Hand hält er einen Feldherrenstab als Zeichen seiner Autorität. Hinter dem Pferd des Königs ist ein Page zu sehen, der den gefiederten Helm des Königs trägt, was die Referenzen ans mittelalterliche Rittertum noch verstärkt. Im rechten Bildhintergrund kann man unten Kavalleriesoldaten erkennen, die auf ihren von einer Anhöhe herabreitenden Oberkommandierenden warten. Insgesamt handelt es sich hier um ein antikisierend-mediävistisches Phantasiebild von Georg II. als Feldherrn, das auf die feudalen Grundlagen königlicher Legitimität verweist.

Interessant ist nun, dass Georg II. der letzte britische König war, der tatsächlich noch selbst als Militärmonarch agiert hat: In der Schlacht von Dettingen komman-

20 John Cannon / Ralph Griffith, The Oxford Illustrated History of the British Monarchy, New York 1988, S. 473.

21 Martin Postle, Joseph Highmore. Equestrian Portrait of King George II. https://www.tate.org.uk/art/artworks/highmore-equestrian-portrait-of-king-george-ii-t04944/text-summary (letzte Einsicht: 30.03.2014). 


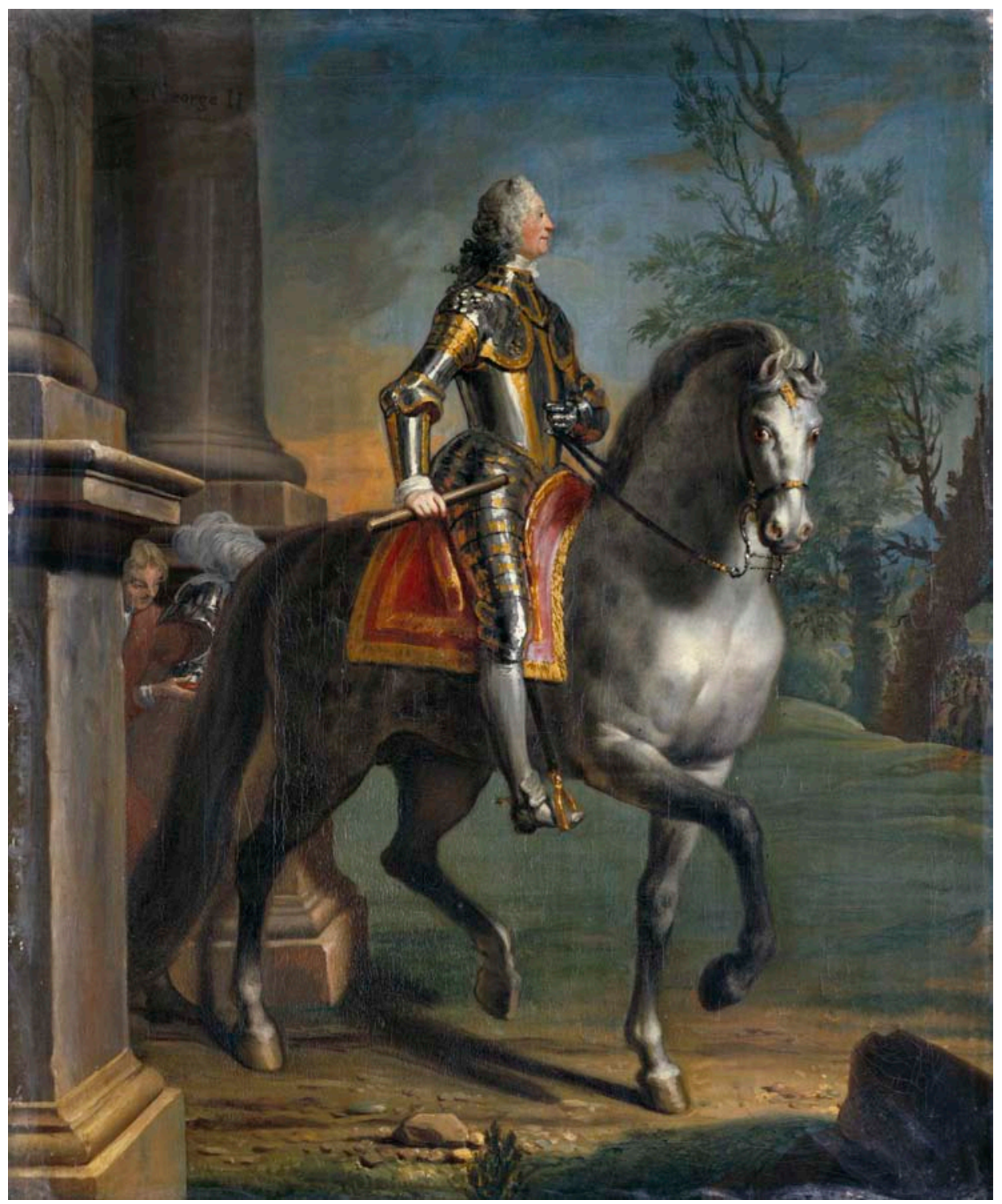

Abb. 2: Joseph Highmore, Reiterporträt von König Georg II., ca. 1743-1745. Tate Gallery, T04944.

dierte er im Jahr 1743 höchstpersönlich die hannoverischen und britischen Truppen zum Sieg über die Franzosen, was ihm bei seinen fremdelnden britischen Untertanen einen großen Popularitätsschub bescherte. Sein Nachfolger, Georg III., spielte die Rolle als Oberkommandierender der Truppen wegen der damit verbundenen Risi- 
ken nicht mehr persönlich, sondern nur noch virtuell. ${ }^{22}$ In der Folge setzte sich die Haltung durch, das Leben des Thronfolgers nicht durch militärische Einsätze zu gefährden und stattdessen den Zweitgeborenen mit der Aufgabe als commander-in-chief der britischen Truppen zu betrauen. In der Ikonographie monarchischer Macht blieb der König als Feldherr - oft in Form eines Reiterstandbildes - jedoch weiterhin sehr präsent.

\section{Der Anti-Monarchismus der Amerikanischen Revolution}

Die Amerikanische Revolution begann nach dem Ende des Siebenjährigen Krieges im Jahr 1763 als Steuerstreit zwischen dem Mutterland und seinen Kolonien, der sich bis Mitte der 1770er Jahre im Rahmen der britischen Verfassung entfaltete. ${ }^{23}$ In diesem Streit ging es um die Frage, wer das Recht hatte, in den Kolonien Britisch-Nordamerikas Steuern zu erheben, das britische Parlament in London oder die in den einzelnen Kolonien lokal gewählten Parlamente. Ausgelöst wurde er durch eine Reihe von Steuergesetzen, die das britische Parlament im Laufe der 1760er Jahre beschloss und sich damit kühl über die bereits im Vorfeld geäußerte massive Kritik der Kolonisten hinwegsetzte. Die Bewohner der nordamerikanischen Kolonien waren nicht bereit, die von London beschlossenen Steuergesetze zu akzeptieren, weil sie der Meinung waren, dass nur die von ihnen selbst gewählten Kolonialparlamente dies dürften. Dabei beriefen sich die nordamerikanischen Kolonisten in ihrem Protest gegen die britischen Steuergesetze auf ihre Rights of Englishmen, auf diejenigen Rechte, die sie ihrer Überzeugung nach als Engländer hatten. Als Engländer, so meinten sie, dürften sie nicht von einem Parlament besteuert werden, in dem sie nicht selbst auch repräsentiert wären. Anfangs protestierten die Bewohner der britischen Kolonien in Nordamerika also als ,Engländer' gegen die britische Regierung in London, die aus ihrer Sicht die angestammte britische Verfassungsordnung verletzte.

Dabei blieb es jedoch nicht. In dem Maße, in dem der Streit eskalierte, weil London sich unversöhnlich zeigte und mit harter Hand gegen die aufsässigen Kolonisten vorging, schwenkten die Kolonisten auf eine neue Linie ein. Die ,revolutionäre Wende' der Amerikanischen Revolution fällt in die Jahre von 1774/76. Das Revolutionäre an dieser Wende ist, dass die amerikanischen Kolonisten in diesen Jahren aus

22 Clarissa Campbell Orr, The Feminization of the Monarchy 1780-1910. Royal Masculinity and Female Empowerment, in: Andrzej Olechnowicz (Hg.), The Monarchy and the British Nation 1780 to the Present, Cambridge 2007, S. 76-107, hier S. 84.

23 Zur Amerikanischen Revolution siehe die in Anm. 5 aufgeführte Literatur. Für das Folgende speziell auch: Volker Depkat, Die Erfindung der republikanischen Präsidentschaft im Zeichen des Geschichtsbruchs. George Washington und die Ausformung eines demokratischen Herrscherbildes, in: Zeitschrift für Geschichtswissenschaft 56 (2008), S. 728-742. 
dem Rahmen der britischen Verfassung ausbrachen und ihren Protest auf eine ganz neue Grundlage stellten: Sie beriefen sich fortan auf einen naturrechtlich begründeten Liberalismus, der ganz in individuellen Grundrechten ankerte, die zu schützen die einzig legitime Verwendung staatlicher Macht war. Damit einher ging der Wandel vom Partikularismus hin zu einem Universalismus: Es waren nicht länger die ,Rechte der Engländer', auf die sich die nordamerikanischen Kolonisten im Streit mit dem Mutterland beriefen, sondern die immer und überall gültigen Menschenrechte.

Das zentrale Dokument der revolutionären Wende ist die Declaration of Independence vom 4. Juli 1776, die in sich selbst ein revolutionäres Dokument ist. ${ }^{24}$ In ihr sind die politisch-sozialen Grundprinzipien niedergelegt, auf die die künftige staatliche Ordnung der Vereinigten Staaten gebaut sein sollte. Die Unabhängigkeitserklärung proklamierte die naturrechtlich begründete Freiheit eines jeden einzelnen Individuums und sah den Schutz der individuellen Grundrechte als einzigen legitimen Staatszweck an. Sie verfügte ferner, dass die Regierungen von der Zustimmung der Regierten abhängig sein sollten und erklärte es zur gesellschaftlichen Pflicht, Herrschaftsordnungen, die den Staatszweck des Grundrechteschutzes nicht länger erfüllten, durch eine andere Ordnung zu ersetzen, die die Grundrechte besser schützen würde, als die bestehende. Damit postulierte die Unabhängigkeitserklärung nicht nur Individualismus, Konstitutionalismus und Volkssouveränität, sondern auch das Recht auf Revolution.

Der revolutionäre Gründungsakt der USA ging einher mit einer anti-monarchischen Wende. Bis zum 4. Juli 1776 hatte sich der Streit zwischen dem Mutterland und den Kolonien als ein Konflikt zwischen Parlamenten entfaltet. In ihm hatten die Kolonisten ihre ganzen Hoffnungen auf den britischen König gesetzt, von dem sie erwarteten, dass er als Sachwalter der angestammten britischen Verfassung eine Art Schiedsrichterrolle spielen würde, um das in ihren Augen außer Rand und Band geratene Parlament in London wieder zur Räson zu bringen. Genau das tat Georg III. jedoch nicht. Er tat vielmehr alles, um die vom Parlament beschlossenen Steuergesetze durchzusetzen und den Widerstand der Kolonisten zu brechen. Nicht zuletzt deshalb wälzten die Amerikaner in ihrer Unabhängigkeitserklärung, die sich in ihrem dritten Teil wie eine Anklageschrift gegen Georg III. liest, die ganze Schuld auf die britische Monarchie ab. Seitdem war die Monarchie in den Augen der Amerikaner eine von Natur aus despotische Herrschaftsform, die Freiheit systematisch zu vernichten trachtete. Mit dem 4. Juli 1776 war nicht nur die Person König Georgs III., sondern die Institution der Monarchie als solche vollständig diskreditiert.

24 Zur Unabhängigkeitserklärung hier nur: Pauline Maier, American Scripture. Making the Declaration of Independence, New York 1997; Israel, 2010 (wie Anm. 6), S. 452-460. 
Das lässt sich in der Entwicklung der revolutionären Festkultur mit Händen greifen. ${ }^{25}$ Bis in die 1770er Jahre hinein hatten die Bewohner der Kolonien in Britisch-Nordamerika in ihren diversen Fast- und Danktagen, Toasts und Ansprachen, Straßentheateraufführungen und Prozessionen zu den Freiheitsbäumen den britischen König als Wächter der britischen Verfassung gefeiert und angerufen. Nach der Unabhängigkeitserklärung etablierte sich rasch ein neuer Festkalender, der von Ritualen der symbolischen Tötung des Monarchen strukturiert war. Nach der Unabhängigkeitserklärung rissen New Yorker Bürger das Reiterstandbild Georgs III. zu Boden und hackten es in Stücke. Anderswo wurden Bilder des Monarchen verbrannt und das traditionelle Königsgeburtstagsfest wurde in die Beerdigung des Königs umfunktioniert.

Was bedeutete diese anti-monarchische Wende der Amerikanischen Revolution, die nicht nur die Monarchie, sondern überhaupt jede Form der Exekutive diskreditiert hatte, für die Ikonographie der Macht in der amerikanischen Demokratie als erste postrevolutionäre Ordnung der Moderne?

Folgen wir dem amerikanischen Schriftsteller Washington Irving, nicht viel. In seiner berühmten Kurzgeschichte „Rip van Winkle“ von 1819 erzählt er die Geschichte eines gleichnamigen Bauern, der zur Zeiten der britischen Kolonialherrschaft in einer niederländischen Siedlung im Hinterland New Yorks lebt. ${ }^{26}$ Eines Tages geht er in den Wald und fällt dort in einen tiefen, zwanzig Jahre währenden Zauberschlaf. Als er wieder aufwacht, ist die Amerikanische Revolution vorüber und Rip van Winkle - ein typisches Märchenmotiv - aus der Zeit gefallen. Er kehrt in sein Dorf zurück und findet alles grundlegend verändert vor. Viele neue Häuser sind in der Zwischenzeit gebaut worden, sein eigenes Haus liegt verfallen da und er sieht kein bekanntes Gesicht mehr. Überall trifft er auf die Zeichen einer neuen demokratisch-egalitären Zeit. Als er zu seinem ehemaligen Lieblingsort der Dorfkneipe kommt, stellt er fest, dass hier eine neues Union Hotel entstanden ist. Der ehemalige große Baum davor ist einem Fahnenmast gewichen, an dem die Stars and Stripes im Wind wehen. All' dieser Wandel ist für Rip Van Winkle schwer zu verstehen, doch dann entdeckt er sehr zu seiner Freude, das ihm zunächst vertraut erscheinende Porträt König Georgs III. Doch auch das ist seit der Amerikanischen Revolution nicht mehr dasselbe. Irving beschreibt das so:

He recognized on the sign, however, the ruby face of King George, under which he had smoked so many a peaceful pipe; but even this was singularly metamorphosed. The red coat was changed for one of blue and buff, a sword was held in the hand

25 David Waldstreicher, In the Midst of Perpetual Fetes: The Making of American Nationalism 1776-1820, Chapel Hill, N.C. 1997, S. 17-52.

26 Washington Irving: Rip van Winkle [1819]. http://www.ibiblio.org/ebooks/Irving/Winkle/Irving_Winkle.pdf (Letzte Einsicht: 30.03.2014). 
instead of a scepter, the head was decorated with a cocked hat, and underneath was painted in large characters, General Washington. ${ }^{27}$

Folgen wir dieser Geschichte, so wurde bei der visuellen Erfindung der amerikanischen Präsidentschaft also nur der rote Mantel des britischen Königs durch einen blau-beigen ausgetauscht, das Zepter durch ein Schwert und die Krone durch ein Dreispitz ersetzt. Der Rest des königlichen Porträts wurde demnach recycelt und mit einer neuen Bildunterschrift versehen.

Ganz so einfach war es freilich nicht, aber womit Washington Irving Recht hat, ist, dass sich die postrevolutionäre Ikonographie exekutiver Macht in der frühen amerikanischen Republik nicht unter dem kompletten Bruch mit der monarchisch-aristokratische Tradition formierte. Vielmehr stellt sich der Prozess der, visuellen Erfindung der amerikanischen Demokratie als ein hoch komplexer Prozess von produktiver Anverwandlung und behutsamer Demokratisierung der monarchisch-aristokratischen Tradition dar. ${ }^{28}$ Diese These möchte ich nun am Beispiel dreier ausgewählter visueller Repräsentationen des ersten amerikanischen Präsidenten diskutieren, wobei es zunächst um die Darstellung George Washingtons als Inhaber des amerikanischen Präsidentenamtes gehen soll und dann um Darstellungen von Washington als General der Kontinentalarmee, die ebenfalls im Bildhaushalt der frühen amerikanischen Republik omnipräsent waren.

\section{Visualisierung Postrevolutionärer Legitimität}

Das Urbild des postrevolutionären Staats- und Regierungschefs im Zeitalter der Demokratie stammt von Gilbert Stuart. Es ist das sogenannte „Landsdowne Portrait“ von George Washington aus dem Jahr 1796. ${ }^{29}$ Dieses Bild, von dem Stuart mehrere Kopien anfertigte, war im April 1796 von Senator William Bingham (Pennsylvania) in Auftrag gegeben und dem britischen Premierminister William Petty Fitz Maurice, $2^{\text {nd }}$ Earl of Shelburne, $1^{\text {st }}$ Marquess of Lansdowne, als Geschenk überreicht worden. In

27 Irving (wie Anm. 26), S. 19 [Hervorhebung im Original].

28 Vgl. für das folgende auch: Volker Depkat, The Grammar of Postrevolutionary Visual Politics. Comparing Presidential Stances of George Washington and Friedrich Ebert, in: Udo J. Hebel / Christoph Wagner (Hg.), Pictorial Cultures and Political Iconographies. Approaches, Perspectives, Case Studies from Europe and America, Berlin 2011, S. 176-197

29 Das Folgende im Kern nach: Volker Depkat, Freiheitsstreben und Ordnungsverlangen. Die Paradoxien der Aufklärung im Lichte visueller Narrative, in: Luise Güth u. a. (Hg.), Wo bleibt die Aufklärung? Aufklärerische Diskurse in der Postmoderne, Stuttgart 2013, S. 17-35, hier S. 28-31; Zu dem „Landsdowne Portrait" Gilbert Stuarts vgl. Carrie Rebora Barratt / Ellen G. Miles, Gilbert Stuart, New York 2004, S. 166-183; Dorinda Evans, The Genius of Gilbert Stuart, Princeton 1999, S. 60-73; Noble E. Cunningham, Popular Images of the Presidency. From Washington to Lincoln, Columbia, MO 1991, S. 130-139. 
Form von Stichen und Drucken war das Bild vielfältig in den USA - aber auch in Europa - präsent. Das zeigt nicht zuletzt der hier abgedruckte Stich „General Washington", der im Jahre 1818 von C. Goodman und B. Piggot in Philadelphia zum Verkauf auf dem damals rasch expandierenden Markt für Stiche angefertigt wurde (Abb. 3).

Washington steht im Zentrum des monumentalen Bildes. Sein Körper ist im halblinken Profil ganz zu sehen, sein rechter Arm ist in Rednergeste ausgestreckt, in seiner linken Hand hält er ein Zierschwert in der Scheide, dessen Spitze auf den Boden zeigt. Das Schwert deutet auf seine in der Vergangenheit liegenden militärischen Verdienste hin, doch bleibt der, General' George Washington in diesem Bild ganz klar der Zivilperson des ,Präsidenten' George Washington untergeordnet. Washington hat einen dunklen Samtanzug an, dessen Jacke mit Stehkragen bis auf seine Knie herab reicht. Dazu trägt er schwarze Strümpfe, schwarze Lederschuhe mit silbernen Schnallen und ein weißes Hemd mit Spitzenborten an Kragen und Ärmeln. Insgesamt ist seine Kleidung von unaufdringlicher Eleganz. Sie ist zwar von erkennbar guter Qualität, aber nicht pompös oder extravagant, sondern eher moderat, zurückgenommen und bürgerlich. Ein schwarzer Hut mit Kokarde, der auf dem Schreibtisch liegt, komplettiert seinen formal korrekten Anzug. Der Hut des Bürgers ist an die Stelle der monarchischen Krone getreten.

Das Gesicht Washingtons ist symmetrisch geformt und ebenmäßig proportioniert. Er wirkt wie eine antike Statue und verrät Milde und Entschlusskraft zugleich. Vor dem Hintergrund physiognomischer Theorie wird sein ,schönes' Gesicht zum Spiegel seiner ,schönen' Seele - und wir wissen, wie sehr Gilbert Stuart sich angestrengt hat, dem in Wirklichkeit sehr viel grobschlächtigeren Gesicht Washingtons die engelsgleiche Ebenmäßigkeit zu geben. ${ }^{30}$ Politisch gewendet heißt das, dass das Gesicht Washingtons den tugendhaften und moralischen Charakter des ersten amerikanischen Präsidenten visualisiert, ohne den im Denken der Zeit ein auf Freiheit und Selbstbestimmung gegründetes Gemeinwesen nicht bestehen konnte. ${ }^{31}$

Betont sei, dass Washington hier als Bürger des Staates dargestellt wird, dem er als Oberhaupt und Regierungschef vorsteht. Der fiktive Raum, in dem er sich befindet, ist offen und transparent. Anders als Georg II. steht George Washington nicht erhöht auf einem Podest, sondern bleibt buchstäblich auf dem Teppich. Seine ausgestreckte Hand scheint anzudeuten, dass er als Redner versucht, sein Publikum zu überzeugen und somit mit der Kraft des besseren Argumentes zu regieren. Dabei ordnet er sich stets der Verfassung als Quelle seiner temporären Macht unter. Das kommunizieren vor allem die Bücher, die unter und auf dem Schreibtisch durcheinander liegen. Eines der Bücher unter dem Tisch heißt „Constitution \& Laws of the United States“, und auf dem Schreibtisch liegen „The Federalist Papers“ und „The

30 Barrat / Miles, 2004 (wie Anm. 29), S. 147-153.

31 Depkat, 2008 (wie Anm. 23), S. $738 f$. 
Journal of Congress“..$^{32}$ All diese Werke sehen benutzt aus; der Präsident arbeitet also mit ihnen. Die Schriftstücke auf dem Schreibtisch und das Tintenfass mit Feder weisen Washington als einen persönlich regierenden Staatsmann aus, der durch seine Tätigkeit die Verfassungsordnung erhält und in die Zukunft sichert.

Individuelle Leistung als Ausweis moralischer Integrität wird somit zum zentralen Kriterium von Washingtons Autorität und Legitimität. Das wird auf dem Bild auf vielfache Weise visualisiert. Zwei der Bücher unter dem Tisch - ein Werk mit dem Titel „American Revolution“ und die von ihm als Oberkommandierenden der Kontinentalarmee erlassenen Tagesbefehle (General Orders) - verweisen direkt auf Washingtons Verdienste um die Amerikanische Revolution und lassen ihn gleichsam zur Personifikation der in der Unabhängigkeitserklärung und der Verfassung von 1787 eingeschriebenen, politisch-sozialen Wertideen erscheinen. Ebenso verweist das Zierschwert auf seine militärischen Erfolge im Amerikanischen Revolutionskrieg. Allerdings entwirft die klare Unterordnung der militärischen unter die zivile Symbolik Washington als Cincinnatusfigur, als einen idealen Republikaner also, der in Zeiten der äußeren Bedrohung seine privaten Interessen hintanstellt und das bedrohte Gemeinwesen unter Einsatz seines Lebens verteidigt, nur um wieder ins Privatleben zurückzukehren, sobald die Gefahr abgewendet ist. ${ }^{33}$

Wenngleich die Darstellung Washingtons als erstes postrevolutionäres Staatsoberhaupt und Regierungschef im „Landsdowne Portrait“ noch unverkennbar viele Elemente der monarchisch-aristokratischen Ikonographietraditionen aufweist, so ist es doch bemerkenswert, dass Gilbert Stuart sich entschloss, Washington ostentativ als ersten Bürger des Staates zu entwerfen, der auch im Amt des Präsidenten stets Teil der Gesellschaft bleibt, die er regiert. Dominant sind Symbole von Staatsbürgerlichkeit und bürgerlicher Respektabilität, die auf persönlicher Bildung, individueller Leistung, Tugend und Moral beruht.

Ungeachtet der prägenden Wirkung, die Stuarts Darstellung des Zivilisten George Washington auf dem „Landsdowne Portrait“ für die visuelle Kultur der amerikanischen Präsidentschaft hatte, gab es in der frühen amerikanischen Republik ungleich mehr visuelle Repräsentationen, die Washington als General und siegreichen Feldherrn darstellten. ${ }^{34}$ Washington war nun einmal erfolgreicher General bevor er Präsident wurde - und er wurde wohl auch nur Präsident, weil er von der überwiegenden Mehrheit der Zeitgenossen wegen seiner in scheinbar selbstlosem Einsatz für die Sache erbrachten militärischen Verdienste als Personifizierung der Amerikanischen

32 Barrat / Miles, 2004 (wie Anm. 29), S. 169.

33 Vgl. dazu Garry Wills, Cincinnatus. George Washington and the Enlightenment, New York 1984; Karsten Fitz, The American Revolution Remembered, 1830s-1850s. Competing Images and Conflicting Narratives, Heidelberg 2010.

34 Mark E. Thistlethwaite, The Image of George Washington. Studies in Mid-Nineteenth-Century American History Painting, New York 1979. 


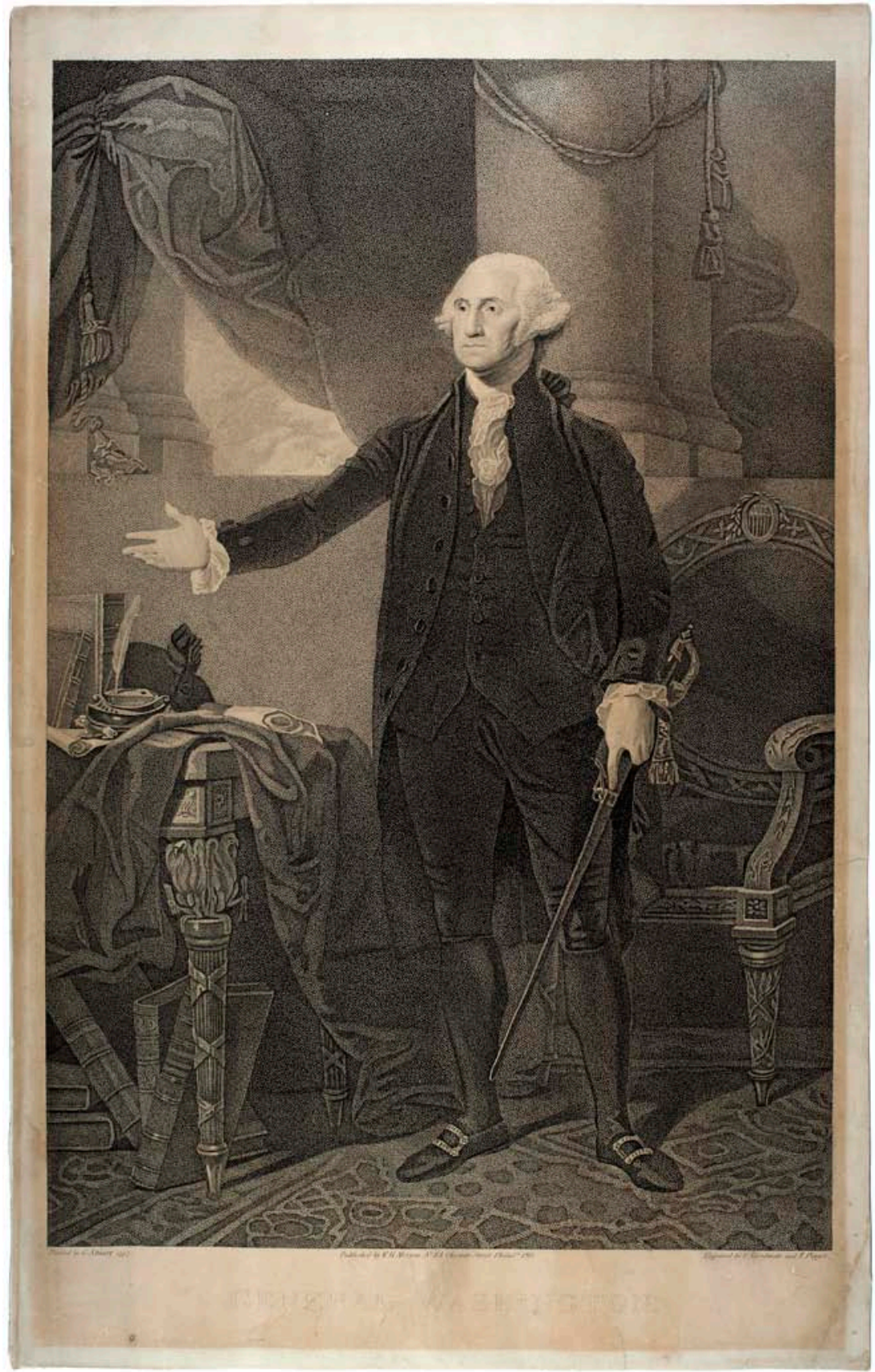

Abb. 3: Gilbert Stuart (Maler)/C. Goodman und B. Piggot (Stecher/Drucker), General Washington, Philadelphia 1818.

American Antiquarian Society, R54 B dr 6 - CAPE. 


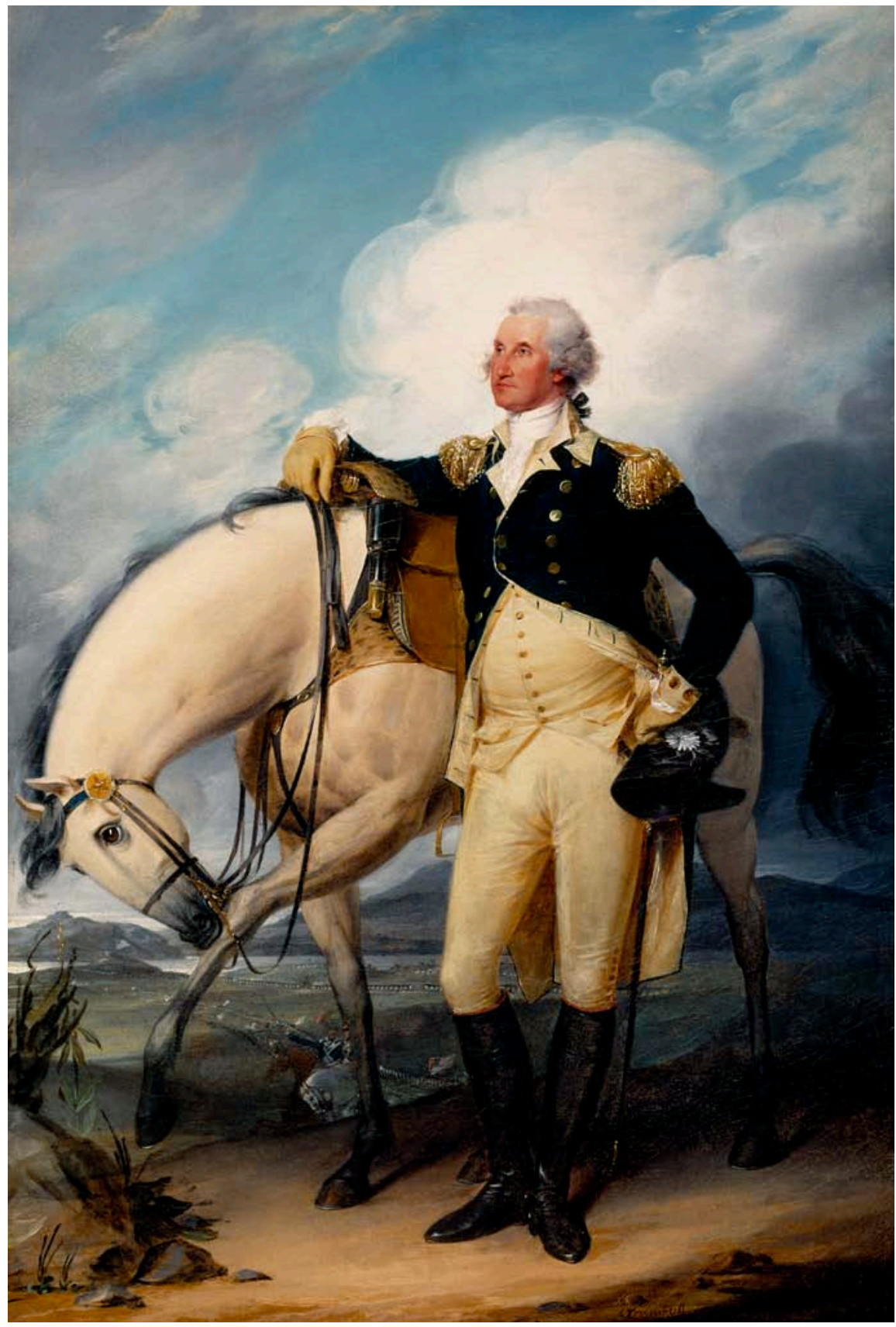

Abb. 4: John Trumbull, Washington at Verplanck's Point, 1790.

Winterthur Museum, 1964.2201. 
Revolution gesehen wurde. ${ }^{35}$ Ein auf militärisches Charisma gestützter Führungsanspruch ist für die ,politische Kultur' der amerikanischen Präsidentschaft bis weit ins 20. Jahrhundert hinein prägend gewesen. Gleichzeitig setzt sich hier eine im Zusammenhang mit Georg II. diskutierte monarchisch-aristokratische Tradition fort, die allerdings im Prozess der Ausgestaltung der amerikanischen Republik demokratisiert wurde. Auch dies hat seinen Niederschlag in der visuellen Kultur der amerikanischen Präsidentschaft gefunden.

Nehmen wir zum Beispiel das Gemälde „Washington at Verplanck's Point“ von John Trumbull aus dem Jahre 1790 (Abb. 4). ${ }^{36}$ Der führende Washington-Porträtist seiner Zeit hat dieses Bild zur Freude und Erbauung von Martha Washington gemalt, die dem Maler in der Vergangenheit zu mehreren Sitzungsterminen mit ihrem Ehemann George verholfen hatte. Auch für dieses Gemälde hatte Washington persönlich Modell gesessen. „Washington at Verplanck's Point“ hing zunächst im New Room von Washingtons Wohnsitz Mount Vernon und ging dann nach dem Tod von Martha Washington in den Besitz der Enkelin Elizabeth Custis Law über. ${ }^{37}$ Gleichwohl zirkulierte dieses Motiv breit in der frühen Republik, weil einerseits Trumbull selbst mehrere Kopien von diesem Bild in Umlauf brachte und weil sich andererseits in der ersten Hälfte des 19. Jahrhunderts ein rasch expandierender Markt für Lithographien etablierte, auf dem sich mit Drucken von George Washington gute Geschäfte machen ließen.

Das Bild zeigt eine Szene aus dem Jahr 1782. General Washington steht in Uniform ohne Kopfbedeckung neben seinem Schimmel. Sein rechter Arm ist abgewinkelt auf den Sattel gelehnt, in der Hand hält er locker die Zügel des sich bewegenden Pferdes, das sich mit dem Maul das linke Bein kratzt oder leckt. Washington ist anmutig und wirkt entspannt, hat aber doch die volle Kontrolle über das Pferd, das merkwürdig klein erscheint. Reiter wissen, dass eine solche, auf das Pferd gestützte lockere Pose ein Ding der Unmöglichkeit ist, was nur zu unterstreichen scheint, dass es Trumbull hier primär um die Visualisierung von Führungskraft und Herrschaft geht.

Washington steht auf einer Anhöhe über dem Tal des Hudson River, von wo er die im Hintergrund des Bildes ablaufenden Vorgänge zu beobachten scheint. Dort

35 Mark E. Thistlethwaite, The Face of the Nation. George Washington's Image and American Identity, in: Depkat / Zwingenberger, 2012 (wie Anm. 11), S. 35-52; Glenn A. Phelps, George Washington and American Constitutionalism, Lawrence, KS 1993, S. 102.

36 Zu Trumbull, dem Maler der Amerikanischen Revolution: Irma B. Jaffe, John Trumbull. Patriot-Artist of the American Revolution, Boston 1975; Dies., Trumbull. The Declaration of Independence, New York 1976; Helen A. Cooper, John Trumbull. The Hand and Spirit of a Painter, New Haven, CT 1982; Stuart A. P. Murray, John Trumbull. Painter of the Revolutionary War, Armonk, NY 2009; J. F. Weir, John Trumbull. A Brief Sketch of His Life, to which is added a Catalogue of his Works, New York 1901.

37 Vgl. Amanda Isaac, Furnishing the New Room: John Trumbull's Portrait of Washington. http://mountvernonnewroom.tumblr.com/post/52946632321/furnishing-the-new-room-john-trumbulls-portrait-of (Letzte Einsicht: 30.03.2014); Cooper, 1982 (wie Anm. 36), S. $118 f$. 
sieht man das Feldlager der amerikanischen Kontinentalarmee am Verplanck's Point, ebenso die von der Schlacht von Yorktown zurückkehrenden französischen Einheiten, die über die Hügel des Flusstales in das Lager der Amerikaner einmarschieren, wo sie freudig begrüßt werden. Wir sehen Washington also als Schlachtensieger nicht lange nach der britischen Kapitulation in Yorktown am 19. Oktober 1781.

Vergleicht man diese Darstellung des siegreichen Generals mit dem oben erörterten Reiterstandbild von Georg II. werden einige Grundmuster der in den USA neu entstehenden Ikonographie der Macht sichtbar. Washington steht neben dem Pferd und sitzt nicht auf ihm. Zwar kontrolliert er das Pferd mit relativer Lässigkeit, doch lässt er ihm zugleich seine Bewegungsfreiheit. Insgesamt erscheint Washington hier nicht als Triumphator, sondern nimmt sich und seine Person sehr zurück. Er wirkt wie ein stiller Genießer der Szene unter ihm. Die Uniform ist eher schlicht, hat nur wenig Dekor, keine Ehrenzeichen oder sonstige Insignien. Insgesamt entwirft Trumbull Washington hier als einen Bürgergeneral, der nun, nachdem das militärische Werk vollendet ist, bald wieder ins Privatleben zurückkehren wird. Washington ist hier ganz gewiss kein Ritter in antikisierend-feudaler Tradition wie Georg II., sondern eher ein römischer Civis, der sich in Zeiten der äußeren Bedrohung selbstlos in den Dienst der Republik gestellt hat, um die Freiheit zu verteidigen. Damit lässt sich das Gemälde „Washington at Verplanck’s Point“ als eine andere Visualisierung des Cincinnatus-Themas lesen, das für die Ausgestaltung der amerikanischen Demokratie allgemein und insbesondere der amerikanischen Präsidentschaft von überragender Bedeutung ist.

Werfen wir deshalb noch einen abschließenden Blick auf eine dreidimensionale visuelle Repräsentation George Washingtons, nämlich die Statue des französischen Bildhauers Jean-Antoine Houdon, die seit 1796 in der Rotunda des State Capitolvon Virginia steht (Abb. 5). ${ }^{38}$ Sie wurde 1784 vom Parlament des Bundesstaates bei Houdon in Auftrag gegeben. Houdon begann mit den Arbeiten im Jahr 1785 und war 1791/92 mit der Skulptur fertig. 1796 lieferte er sie aus. Der französische Bildhauer hatte Washington persönlich getroffen, eine Gesichtsmaske von ihm abgenommen und auch den Körper des Revolutionshelden vermessen. Deshalb gilt diese Statue als eine der akkuratesten Darstellungen George Washingtons.

Die aus Carrara Marmor gefertigte Skulptur zeigt einen stehenden Washington in Lebensgröße. Washington trägt seine Uniform, doch hält er in der rechten Hand einen Spazierstock, während sein linker Arm auf einem Fascis ruht, einem Rutenbündel, das im Römischen Reich das Symbol der höchsten Amtsträger war. An dem

38 Charles H. Hart / Edward Biddle, George Washington, Jean Antoine Houdon, Sculptor. A Brief History of the Most Famous Sculpture Created of America's Immortal Patriot. Issued to Commemorate the Bicentennial of His Birth, 1732-1932, Providence, R.I., 1931; Ronald E. Heaton, The Image of Washington. The History of the Houdon Statue, Norristown, PA 1971; Allgemein zu Houdon: Anne L. Poulet, Jean-Antoine Houdon. Sculptor of the Enlightenment, Washington, DC 2003. 


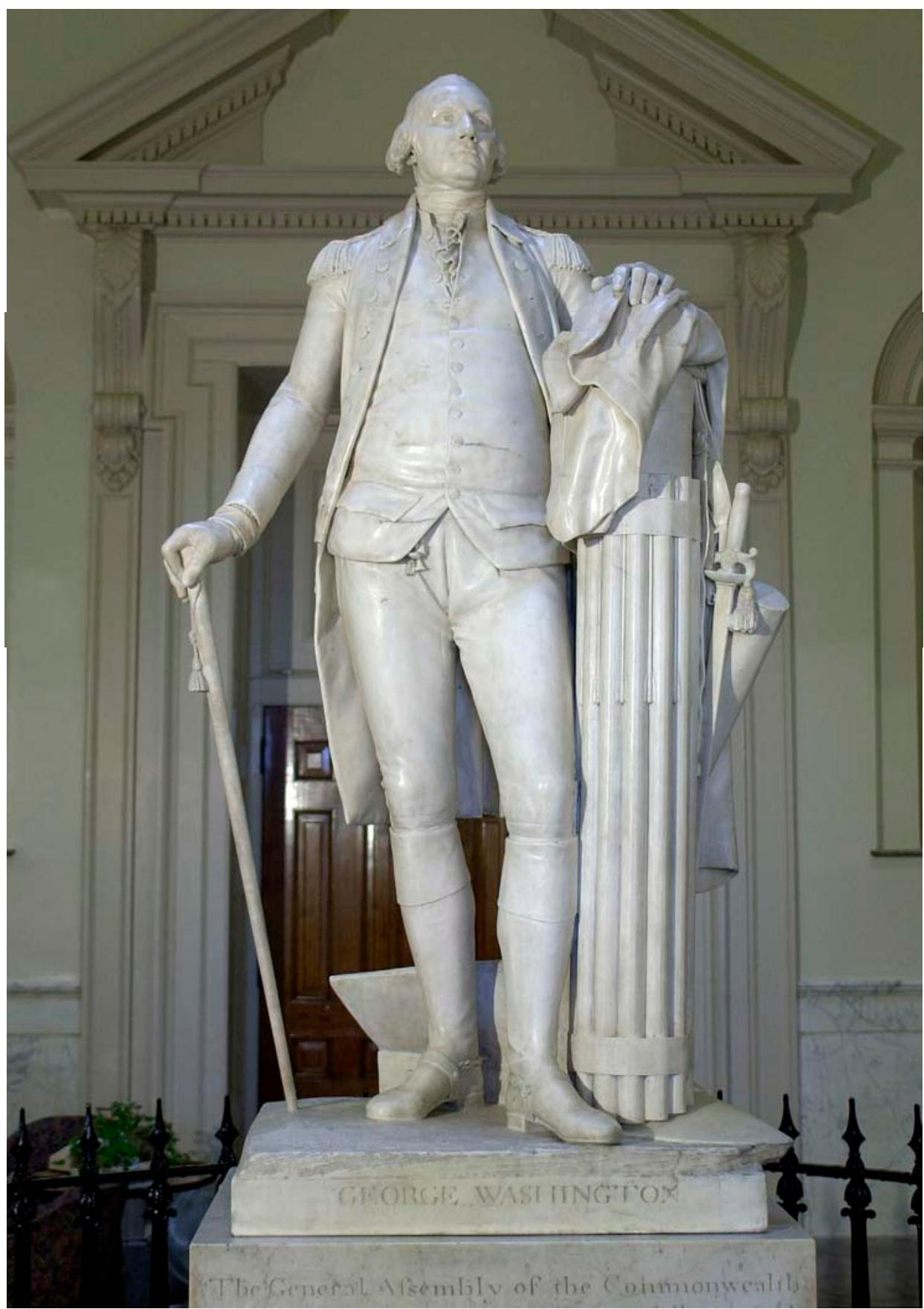

Abb. 5: Jean-Antoine Houdon, George Washington, 1785-1792.

State Artwork Collection, Library of Virginia. www.virginiamemory.com 
Rutenbündel hängen Washingtons Umhang und sein Schwert, und hinter dem Fascis ist ein Pflug zu erkennen. Damit zeigt die Statue Houdons Washington als römischen Bürgersoldaten im Moment des Übergangs von der soldatischen zur zivilen Existenz. Die Ausnahmesituation des Krieges ist vorbei; Washington hat das Schwert buchstäblich an den Nagel gehängt und mit dem Spazierstock schon wieder einen zivilen Gegenstand in der Hand, der ihn zugleich als Gentleman ausweist. Der Pflug im Hintergrund zeigt an, dass Washington eigentlich ein Farmer ist und somit auch in das Leben als Farmer zurückkehrt. Damit liefert diese Statue eine Visualisierung des abstrakten Ideals vom gentleman farmer, der als idealer Republikaner in römisch-antiker Tradition im Moment äußerer Gefahr seinen Pflug gegen das Schwert eintauscht, um die republikanische Freiheit zu verteidigen, und der nun, nachdem die Gefahr abgewendet ist, wieder in sein ziviles Leben als Landwirt zurückkehrt. Die revolutionär begründete amerikanische Demokratie machte in der Ausgestaltung ihrer politischen Kultur mithin produktive Anleihen beim klassisch-römischen Republikanismus, indem sie das Bild vom königlichen Feldherrn in das antik-römische Ideal des Cincinnatus umformte, um die Legitimität exekutiver Macht zu kommunizieren, und das nicht nur visuell. ${ }^{39}$

\section{Schluss}

Wenn die Bewohner der britischen Kolonien in Nordamerika sich vorstellten, wie politische Macht aussehe und woran man sie erkenne, dann hatten viele von ihnen bis zur Revolution mit Sicherheit Bilder der hannoverschen Kurfürsten auf dem englischen Thron vor Augen. Die offiziellen Porträts von Georg I., Georg II. und Georg III. waren in Form von kopierten Gemälden auch in den Kolonien allgegenwärtig und erreichten in Form von Drucken noch ein viel weiteres Publikum, so begrenzt das aus heutiger Sicht auch war. Als Akte visueller politischer Kommunikation vermittelten Krönungsporträts, Reiterbilder und andere visuelle Darstellungen der britischen Könige Vorstellungen von exekutiver Macht und legitimer politischer Herrschaft. Bis zum 4. Juli 1776 war die Ikonographie der Macht in den nordamerikanischen Kolonien des britischen Weltreiches von Herrschaftszeichen der Monarchie und einem aristokratisch-feudalen Symbolhaushalt geprägt.

Die Amerikanische Revolution und ihr radikaler naturrechtlicher Egalitarismus entfalteten sich als totaler Bruch mit der Monarchie als Herrschaftsform. Das am 4. Juli 1776 begonnene Experiment in Demokratie sah sich deshalb einem potentiellen symbolischen Vakuum gegenüber, wenn es darum ging, das historische No-

39 Georg Schild, Res Publica Americana. Romrezeption und Verfassungsdenken zur Zeit der Amerikanischen Revolution, in: Historische Zeitschrift 284 (2007), S. 31-58. 
vum einer flächenstaatlichen Demokratie, die als moderner Verfassungsstaat in allen ihren Teilen auf dem Prinzip der Volkssouveränität gegründet war, auch visuell zu legitimieren. Dabei waren die Befürworter der Verfassung von 1787 gezwungen, die neue Ordnung gleich an zwei Fronten visuell zu verteidigen und ihre Legitimität zu behaupten, und zwar einerseits gegenüber der europäischen aristokratisch-feudalen Tradition und andererseits gegenüber den Kritikern in den USA selbst, die die föderal-repräsentative Verfassung von 1787 als Bruch mit den Idealen der Unabhängigkeitserklärung und ihrem radikal-demokratischen Potential interpretierten. Diese doppelte Frontstellung umreißt das Spannungsfeld, in dem die visuelle Kultur der amerikanischen Präsidentschaft erfunden wurde, wobei hier eine Vielzahl von Akteuren zusammenwirkten: die Präsidenten selbst, die Maler, die Drucker und nicht zuletzt diejenigen Amerikaner, die als Käufer der Präsidentendarstellungen den durchaus lukrativen Markt für die Bilder von amerikanischen Präsidenten definierten.

Insgesamt stellt sich die visuelle Erfindung der amerikanischen Präsidentschaft nicht als abrupter Bruch mit den europäischen Traditionen dar, sondern vielmehr als ein gradueller Umbau europäischer Traditionen, die produktiv adaptiert und neu formuliert wurden. Damit lässt sich die visuelle Erfindung der amerikanischen Präsidentschaft einerseits als Anverwandlung römisch-antiker ikonographischer Traditionen, andererseits als schrittweise Demokratisierung insbesondere der monarchisch-aristokratischen Ikonographie beschreiben, die für die Generation der amerikanischen Revolutionäre unmittelbar durch Georg I., Georg II. und Georg III. konkretisiert wurde. In diesem Zusammenhang lässt sich die Konstruktion einer Ikonographie demokratischer Macht durchaus als europäisch-amerikanisches Gemeinschaftsprodukt begreifen.

Gilbert Stuart war ein in England geborener und ausgebildeter Maler, der, fasziniert von den USA, in den 1790er Jahren ganz bewusst nach Amerika segelte, um Washington als Held der Revolution und erstes postrevolutionäres Staatsoberhaupt zu malen. Jean-Antoinne Houdon, dem wir die wohl wirklichkeitsgetreueste Darstellung George Washingtons verdanken, war Franzose, der sich ebenfalls von den USA begeistert zeigte und seine eigenen Hoffnungen auf eine bessere Ordnung auf sie und insbesondere George Washington projizierte. Damit steht die Ausgestaltung einer Ikonographie demokratischer Macht am Beginn einer viel umfassenderen Entwicklung, in deren Verlauf Amerikaner und Europäer immer wieder gemeinschaftlich Bilder von Amerika entwarfen und Amerika so zusammen erfanden. 


\title{
Zwischen Empire und Reich.
}

\section{Zur Kommunikation des globalen Siebenjährigen Krieges im Raum der Personalunion}

\author{
MARIAN FÜSSEL
}

Betrachtet man die Zeit der Personalunion zwischen Großbritannien und dem Kurfürstentum Braunschweig-Lüneburg als Ausbildung eines transnationalen Kommunikationsraumes, rücken unweigerlich die zahlreichen Kriege des langen 18. Jahrhunderts in den Blick. ${ }^{1}$ Am Beginn der Personalunion stand das Ende des Spanischen Erbfolgekrieges und im Zuge eines „zweiten hundertjährigen Krieges“ zwischen England und Frankreich folgten der Österreichische Erbfolgekrieg, der Siebenjährige Krieg und die Koalitionskriege seit der Französischen Revolution. ${ }^{2}$ Für die britische Politik brachte die Bindung mit dem Kurfürstentum immer wieder die ungeliebte Frage nach einem continental commitment auf. ${ }^{3}$ Weit seltener ist in der Forschung die umgekehrte Variante diskutiert worden, das heißt die Frage, wie man in Hannover die Situation beurteilte, denn unmittelbar betroffen vom Krieg war ja die Bevölkerung im Reich. ${ }^{4}$ Jenseits der jeweiligen Positionierung für oder wider die Han-

1 Vgl. Marian Füssel, Kriege und Kriegserfahrung, in: Katja Lembke (Hg.), Als die Royals aus Hannover kamen. Hannovers Herrscher auf Englands Thron 1714-1837, Ausst. Kat. Niedersächsisches Landesmuseum Hannover / Museum Schloss Herrenhausen, 17.05.-05.10.2014, Dresden 2014, S. 162-169 (im Druck); zum Begriff des Kommunikationsraums vgl. Andreas Koch, Dynamische Kommunikationsräume. Ein systemtheoretischer Raumentwurf, Münster 2004.

2 Arthur H. Buffinton, The Second Hundred Years' War, 1689-1815, New York 1929; Francois Crouzet, The Second Hundred Years War: Some Reflections, in: French History 10 (1996), S. 432-450.

3 Jeremy Black, Continental Commitment. Britain, Hanover and interventionism 1714-1793, London / New York 2005; Tony Hayter, England, Hannover, Preußen. Gesellschaftliche und wirtschaftliche Grundlagen der britischen Beteiligung an Operationen auf dem Kontinent während des Siebenjährigen Krieges, in: Bernhard R. Kroener (Hg.), Europa im Zeitalter Friedrichs des Großen. Wirtschaft, Gesellschaft, Kriege, München 1989, S. 171-192; Uriel Dann, Hannover und England 1740-1760. Diplomatie und Selbsterhaltung, Hildesheim 1986.

4 Vgl. allerdings Hermann Wellenreuther, Die Bedeutung des Siebenjährigen Krieges für die englisch-hannoveranischen Beziehungen, in: Adolf M. Birke / Kurt Kluxen (Hg.), England und Hannover = England and Hanover, München u. a. 1986, S. 145-175; exemplarisch zur Situation vor Ort Marian Füssel, „Die besten Feinde, welche man nur haben kann"? Göttingen unter französischer Besatzung im Siebenjährigen Krieg, in: Göttinger Jahrbuch 60 (2012), S. 137-160. 
noveraner intensivierten die Kriege jedoch unweigerlich den kulturellen Austausch zwischen beiden Territorien, sei es durch die Präsenz britischer Soldaten vor Ort oder die Rezeption von Nachrichten aus der Distanz, die im Folgenden im Mittelpunkt stehen sollen. ${ }^{5}$ Als Momente medialer Verdichtung zeichnen sich bewaffnete Konflikte seit jeher durch eine besondere Konjunktur von Nachrichtenkommunikation aus. Spätestens seit dem Dreißigjährigen Krieg gilt der Krieg als Motor der Medienlandschaft oder wie es 1755 ein Autor ausdrückte als fruchtbare Mutter der Zeitungen. ${ }^{6}$ Neben der Zeit der Reformation und dem Dreißigjährigen Krieg stellte vor allem der Siebenjährige Krieg (1756-1763) eine der frühneuzeitlichen Hochphasen von Flugschriftenpublizistik dar. ${ }^{7}$ Die Kommunikation von Schlachten und Belagerungen als Medienereignissen und ihre Verbreitung als Nachricht konnte Mitte des 18. Jahrhunderts bereits auf ein gut etabliertes System kommunikativer Routinen zurückgreifen. ${ }^{8}$ Neben einlaufenden Depeschen und Zeitungen wurden Siege und Niederlagen auch durch akustische und symbolische Praktiken wie Salutschüsse, Predigten, Glockengeläut oder ein Te Deum Laudamus kommuniziert. ${ }^{9}$

Stärker noch als zuvor bereits der spanische und der österreichische Erbfolgekrieg war der Siebenjährige Krieg allerdings ein Konflikt globalen Ausmaßes. ${ }^{10}$ Die

5 Vgl. Marian Füssel, Der Siebenjährige Krieg in Nordwestdeutschland. Kulturelle Interaktion, Kriegserfahrung und -erinnerung zwischen Reich und Empire, in: Ronald Asch (Hg.), Hannover, Großbritannien und Europa. Erfahrungsraum Personalunion 1714-1837, Göttingen 2014 (im Druck). Aus der älteren Forschung vgl. vor allem Reginald Savory, His Britannic Majesty's Army in Germany during the Seven Years War, Oxford 1966.

6 Zitiert nach Jürgen Wilke, Krieg als Medienereignis - Konstanten und Wandel eines endlosen Themas, in: Kurt Imhof / Peter Schulz (Hg.), Medien und Krieg - Krieg in den Medien, Zürich 1995, S. 21-35, hier: S. 22.

7 Vgl. Wolfgang Adam / Holger Dainat (Hg.), „Krieg ist mein Lied“. Der Siebenjährige Krieg in den zeitgenössischen Medien, Göttingen 2007; Ewa Anklam: Wissen nach Augenmaß. Militärische Beobachtung und Berichterstattung im Siebenjährigen Krieg, Berlin u. a. 2007, S. 189-242; Manfred Schort, Politik und Propaganda. Der Siebenjährige Krieg in den zeitgenössischen Flugschriften, Frankfurt a. M. u. a. 2006; John Cardwell, Arts and Arms. Literature, Politics and Patriotism during the Seven Years War, Manchester 2004.

8 Vgl. exemplarisch Sebastian Küster, Vier Monarchien - Vier Öffentlichkeiten. Kommunikation um die Schlacht bei Dettingen, Herrschaft und soziale Systeme in der Frühen Neuzeit 6, Münster 2004; einen Überblick über frühneuzeitliche Konzepte wie jüngere Forschungen zu Medienereignissen geben Thomas Weißbrich / Horst Carl, Präsenz und Information: Frühneuzeitliche Konzeptionen von Medienereignissen, in: Joachim Eibach/ Horst Carl (Hg.), Europäische Wahrnehmungen. Interkulturelle Kommunikation und Medienereignisse 1650-1850, Hannover 2008, S. 75-98.

9 Vgl. Michèle Fogel, Les ceremonies d'information dans la France du XVIe au milieu du XVIIIe siècle, Paris 1989; Dies., Célébrations de la monarchie et de la guerre. Les Te Deum de victoire en France de 1744 à 1783, in: La Bataille, l'Armée, la Gloire 1745-1871, Bd. 1, Actes du Colloque International de Clermont-Ferrand recueillis et présentés par Paul Viallaneix et Jean Ehrard, Faculté des Lettres et Sciences Humaines de l'Université de Clermont-Ferrand II, Clermont-Ferrand 1985, S. 35-44.

10 Vgl. Marian Füssel, Der Siebenjährige Krieg. Ein Weltkrieg im 18. Jahrhundert, München 2010; Daniel Baugh, The Global Seven Years War 1754-1763, Harlow 2011; Mark H. Danley / Patrick J. Speelman (Hg.), The Seven Years' War. Global Views, Leiden / Boston 2012. Insofern ist der Siebenjährige Krieg ein guter Ansatzpunkt für eine Verflechtungsgeschichte vgl. Michael Werner / Bénédicte Zimmermann, 
Nachrichten kündeten nun nicht mehr allein von europäischen Ereignissen, sondern auch von den Konflikten des britischen Empires und seiner Rivalen in Nord- und Südamerika, der Karibik, Afrika und Südasien. ${ }^{11}$ Was wussten aber die Bewohner des Alten Reiches von den überseeischen Aktivitäten der Briten und Franzosen? Nahmen die Bewohner der Kur-Hannoverschen Territorien den Krieg womöglich anders wahr als Untertanen anderer Reichsteile? ${ }^{12}$ Welche Bilder transportierten die zeitgenössischen Medien? ${ }^{13}$

In Großbritannien selbst lösten die Nachrichten aus Übersee regelmäßig eine landesweite Welle der Begeisterung und öffentlicher Feiern aus. ${ }^{14}$ Wie unter anderem Nicholas Rogers, Kathleen Wilson und Bob Harris betont haben, gewannen diese Feiern vor allem deshalb eine neue Qualität, weil sich nicht mehr allein von der Obrigkeit ausgingen, sondern von der Bevölkerung selbst, genauer gesagt den aufstrebenden städtischen Mittelschichten: professionals, merchants, traders and manufacturers. ${ }^{15}$ Ähnliche Befunde sind für das alte Reich bereits am Beispiel der Friedensfeiern des Jahres 1763 gemacht worden, und wie sich im Folgenden zeigen wird, lässt sich diese Tendenz auch für die Aufnahme der überseeischen Ereignisse während des Krieges bestätigen. ${ }^{16}$ Das Milieu der Nachrichtenrezipienten mit Interesse für die Geschicke

Vergleich, Transfer, Verflechtung. Der Ansatz der Histoire croisée und die Herausforderung des Transnationalen, in: Geschichte und Gesellschaft 28 (2002), S. 607-636; zum Kontext der zunehmenden Globalisierung von Kriegen im 18. Jahrhundert vgl. Marian Füssel, Global Wars in the Eighteenth Century. Entanglement - Violence - Perception, in: Matthias Pohlig / Michael Schaich (Hg.), The War of the Spanish Succession. New Perspectives, Oxford 2014 (im Druck).

11 Zur globalen Ausweitung des militärischen Nachrichtenspektrums vgl. Jürgen Wilke, Krieg als Medienereignis. Zur Geschichte seiner Vermittlung in der Neuzeit, in: Heinz-Peter Preusser (Hg.), Krieg in den Medien, Amsterdamer Beiträge zur neueren Germanistik 57, Amsterdam 2005, S. 83-104, hier S. $91 \mathrm{f}$.

12 Vgl. dazu bereits die Überlegungen von Hermann Wellenreuther, Göttingen und England im 18. Jahrhundert, in: 250 Jahre Vorlesungen an der Georgia Augusta 1734-1984. Akademische Feier aus Anlaß der 250. Wiederkehr des Tages der ersten Vorlesung an der Georgia Augusta am 14. Oktober 1984 in der Aula der Georg-August-Universität Göttingen, Göttingen 1985, S. 30-63, hier S. 44-49.

13 Vgl. die Hinweise zur Rezeption des french and indian war im süddeutschen Raum bei Rainald Becker: Nordamerika aus süddeutscher Perspektive. Die neue Welt in der gelehrten Kommunikation des 18. Jahrhunderts, Stuttgart 2012.

14 Vgl. etwa zur Aufnahme der Nachricht der Einnahme Cape Bretons im Jahr 1758 Bob Harris, "American Idols": Empire, War and the Middling Ranks in Mid-Eighteenth-Century Britain, in: Past and Present 150 (1996), S. 111-141, hier: S. 115-118. Zu den Feiern der Erfolge des Annus mirabilis 1759 vgl. Huw V. Bowen, British Conceptions of Global Empire, 1756-1783, in: Journal of Imperial and Commonwealth History 26 (1998), S. 1-27, hier S. 1ff.; vgl. ferner Frank McLynn, 1759. The year Britain became master of the world, London u. a. 2004.

15 Harris, 1996 (wie Anm. 14), S. 112; Ders., Politics and the nation: Britain in the mid-eighteenth century, Oxford u. a. 2002, S. 113ff.; Nicholas Rogers, Whigs and cities. Popular politics in the age of Walpole and Pitt, Oxford u.a. 1989; Kathleen Wilson, The sense of the people. Politics, culture and imperialism in England, 1715-1785, Cambridge u.a. 1998.

16 Im Reich waren die Feierlichkeiten obrigkeitlich verordnet und hatten von den städtischen Magistraten umgesetzt zu werden. Dennoch zeigt das Engagement, mit dem die Bevölkerung der Aufforderung nach- 
des britischen Empire geht über die traditionelle Verfassergruppe der Dorfpfarrer und geistlichen Chronisten deutlich hinaus. Ein Hannoveraner Bäckermeister, ein Göttinger Professor, ein Krefelder Tuchhändler, ein Celler Garnisonsauditeur oder ein Weinhändler aus Herzberg - sie alle waren Teil des kleinstädtischen Mittelschichtsmilieus, welches die britische Forschung als treibende Kraft hinter der kulturellen Resonanz der imperialen Erfolge ausgemacht hat. ${ }^{17}$ Im Folgenden gehe ich in drei Schritten vor und stelle zunächst Praktiken der Nachrichtenrezeption aus Zeitungsmeldungen vor (1.), gehe dann auf die Verarbeitung der Kriegserfolge des britischen Empire in privaten Chroniken ein (2.), um drittens auf performative Praktiken der Siegesbekundung zu sprechen zu kommen (3.).

\section{Zeitung lesen: Nachrichten aus Übersee}

Auch im Reich diskutieren Zeitungen und Wochenschriften, wie der in Augsburg herausgegebene „Apotheker" die Vorgänge in Übersee. ${ }^{18}$ Der „Apotheker" sieht sogar die Ursache des gesamten Konflikts in den Auseinandersetzungen in Nordamerika begründet. 1762 heißt es in einem Artikel: Durch dich [Amerika] entbrannten unsre Staaten. / Du machtest Bauern zu Soldaten, / Und zwangst die Bürger zum Gewehr. / Das Feuer, das aus dir gestammet, / Hat breite Meere überflammet, / und tobet durch mein Deutschland her. ${ }^{19}$ Mit ähnlicher Brand-Metaphorik deutet im gleichen Jahr auch der dreizehnte Band des „Neueröfneten Historischen Bilder-Saals“ die Entwicklung des Krieges:

kam, dass es hier um mehr als eine lästige Pflichterfüllung ging, vgl. Gertrud Angermann, „Friedenstücher“ und Friedensfeiern zum Ende des siebenjährigen Krieges (1756-1763), in: Westfalen. Hefte für Geschichte, Kunst und Volkskunde 77 (1999), S. 299-337, hier S. 323-332; Siegrid Westphal, Festkultur zwischen städtischer Identitätsstiftung und Reichsbekenntnis. Das Hubertusburger Friedensfest von 1763 in der Reichsstadt Nordhausen, in: Beiträge zur Heimatkunde aus Stadt und Kreis Nordhausen 22 (1997), S. 126-140, hier S. 139f.; Kurt Jäger, Friedensfeiern im preußischen Krefeld des Jahres 1763, in: Die Heimat [Krefeld] 51 (1980), S. $90 \mathrm{ff}$.

17 Zum deutschen Lesepublikum vgl. Martin Welke, Die Legende vom „unpolitischen Deutschen“. Zeitungslesen im 18. Jahrhundert als Spiegel des politischen Interesses, in: Jahrbuch der Wittheit zu Bremen 25 (1981), S. 161-188.

18 Nicole Waibel, Nationale und patriotische Publizistik in der Freien Reichsstadt Augsburg: Studien zur periodischen Presse im Zeitalter der Aufklärung (1748-1770), Presse und Geschichte, Neue Beiträge 31, Bremen 2008, S. 312-325. Vgl. u. a. die Artikel „Eine Heldenode“, 13 St., 1762, S. 193-195; „Sehnsucht nach einem allgemeinen Frieden“, 16 St., 1762, S. 241-244, „Schutzschrift für den unschuldiger Weise verfolgten Krieg“, 6 St., 1762, S. 89-96; „Von dem Unterschiede der alten und neuen Art, Krieg zu führen“, 34 St., 1763, S. 531-536 u. 36 St., 1763, S. $563 f f$. und ein weiterer Artikel 33 St., 1763, S. 512-526.

19 „Sehnsucht nach einem allgemeinen Frieden“, in: Der Apotheker, 16 St., 1762, S. 242, zitiert nach Waibel, 2008 (wie Anm. 18), S. 315. 
Der Krieg, den Frankreich und Engeland schon A. 1755 miteinander führten, und der den 18 May zu Londen förmlich erklärt wurde, der bloß einige Streitigkeiten in Acadien und America anbetraf, hatte sich unglücklicher Weise nach Europa gezogen, und in Deutschland waren die Funken bereitet, in eine Flamme auszuschlagen. $^{20}$

Der „Bildersaal“ liefert bereits eine narrative Synthese der einzelnen Zeitungsnachrichten und unterscheidet in seiner Gliederung zwischen Land- und Seekrieg.

Wie die Nachrichten aus aller Welt jedoch bereits zeitnah verarbeitet wurden, zeigt der Blick in einige zeitgenössische Tagebücher. Zu den besonders eifrigen Nachrichtenrezipienten im kurhannoverschen Raum zählten der Göttinger Professor für morgenländische Sprachen Andreas Georg Wähner (1693-1762) und der Celler Garnisonsauditeur Johann Philipp Schowart (1707-1783). ${ }^{21}$ An ihnen lässt sich relativ gut die Registratur vor allem aus Nordamerika eintreffender Nachrichten nachvollziehen. Nachdem beispielsweise James Abercrombie am 8. Juli 1758 einen erfolglosen und verlustreichen Angriff auf das französische Fort Ticonderoga unternommen hat, notiert Schowart dies am 31. August als Nachricht aus der Withhaler Zeitung (der Whitehall Evening Post), während Wähner leicht verzögert am 2. September aus der Hamburger Zeitung weiß, daß der General Abercrombie, als er die Franzosen in ihrem verschanzten Lager angreiffen wollen, eine Nase geholet. ${ }^{22}$ Ein Jahr darauf, am 16. September 1759, kann Wähner aus seinem Brief an John Thompson (1693-1768), seit 1751 außerordentlicher Professor für englische Literatur an der Göttinger Universität und ein häufiger Gewährsmann Wähners, von der erfolgreichen Einnahme des Forts berichten. ${ }^{23}$ Die britische Einnahme von Louisbourg am 26. Juli 1758 ist bei Schowart am 25. August 1758 Thema, bei Wähner übermittelt durch Thompson

20 Andreas Lazarus von Imhoff, Des neueröfneten Historischen Bilder-Saals Dreyzehender Theil, In welchem die allgemeine Welt-Geschichte besonders der zwischen Frankreich und Engelland entsponnene, und sich nach Deutschland ausgebreitete Krieg von dem Jahr 1756 bis 1760 beschrieben ist. Mit den darzu schicklichen Kupfern und dem Register, Nürnberg 1762, S. 1.

21 Zur jeweiligen Biographie vgl. Sigrid Dahmen, Andreas Georg Wähner (1693-1762). Professor für morgenländische Sprachen in Göttingen, in: Göttinger Jahrbuch 60 (2012), S. 109-135; Jens Mastnak / Michael-Andreas Tänzer (Hg.), Celle im Siebenjährigen Krieg. Das Tagebuch des Garnisonsauditeurs Johann Philipp Schowart, Forschungen zur Hannoverschen Militärgeschichte 1, Celle 2010, S. 41-50.

22 Mastnak / Tänzer, 2010 (wie Anm. 21), S. 166; Andreas Georg Wähner, Tagebuch aus dem Siebenjährigen Krieg. Bearbeitet von Sigrid Dahmen, Quellen zur Geschichte der Stadt Göttingen 2, Göttingen 2012, S. 41. Zu Ticonderoga vgl. William R. Nester, The epic battles for Ticonderoga, 1758, Albany 2008; zur Hamburger Presse vgl. Holger Böning, Periodische Presse. Kommunikation und Aufklärung. Hamburg und Altona als Beispiel, Bremen 2002.

23 Wähner, 2012 (wie Anm. 22), S. 112. Zu Thompson vgl. Theodor Wolpers, Göttingen als Vermittlungszentrum englischer Literatur im 18. Jahrhundert, in: Rainhard Lauer (Hg.), Philologie in Göttingen. Sprach- und Literaturwissenschaft an der Georgia Augusta im 18. und beginnenden 19. Jahrhundert, Göttinger Universitätsschriften, Serie A, 18, Göttingen 2001, S. 91-136, hier S. $99 f$. 
einen Tag später am 26. August. ${ }^{24}$ Am 2. September berichtet Wähner auch über die militärischen Siegesfeiern für die Eroberung Louisbourgs: Nachricht eingelanget, daß $d[\mathrm{en}] 24$. bey unsrer armée wegen Louisbourg victorie geschossen sey. ${ }^{25}$

Schowart und Wähner notieren als einige wenige Zeitgenossen auch Ereignisse aus Indien. Am 9. Oktober 1759 hält Schowart beispielsweise fest: Die Engländer haben in Ost Indien Surrate erobert, und den Nabab nach Bombay gefangen geführet, worauf die Frantzosen Bombay aber vergebens belagert. Cliver [Robert Clive] hat an einen Ort die Frantzosen gäntzlich geschlagen. ${ }^{26}$ An Donnerstag dem 18. Dezember 1760 notiert Wähner: Ganz sichere Briefe von Hannover geben, daß Pondicherie an die Engeländer über sey. ${ }^{27}$

Besonders aufschlussreich ist die Kommunikation des Ausgangs der Belagerung von Quebec während der Schlacht auf den Plains of Abraham am 13. September 1759, mit der sich der Krieg in Nordamerika endgültig zu Gunsten der Briten entschied. ${ }^{28}$ Am Dienstag, dem 16. Oktober 1759, erreichte die Nachricht von der Einnahme Quebecs London und wurde in einer Gazette Extraordinary verbreitet. ${ }^{29}$ Am gleichen Tag erhält Wähner zunächst die Frankfurter Zeitung mit der gegenteiligen Nachricht, aus Paris melde man am 5. Oktober, dass Briefe aus Amerika geben, daß die Engeländer bey Quebeck von den Franzosen geschlagen und durch einen starken Sturmwind ihre Flotte auf dem Laurenzflusse zerstreuet worden. ${ }^{30}$ Der wahre Sieger wird erst neun Tage später an Donnerstag, dem 25. Oktober, kommuniziert. Ein Kurier unserer Armee überbringt die Nachricht: Quebeck sey an die Engländer über. Weitere zwei Tage später treffen detailliertere Nachrichten ein. Am Samstag, dem 27. Oktober, notiert Wähner: Altonaer Zeitung: Es hat seine völlige Richtigkeit daß Quebeck d[en] 18. Septemb[er] durch das eng[lische] Wolfische Corps allein ist erobert worden. Der eng[lische] Gen[eral] Wolf und der franz [ösische General] Monkalm sind beyde dabey ums Leben gekommen. ${ }^{31}$

24 Mastnak / Tänzer, 2010 (wie Anm. 21), S. 165; Wähner, 2012 (wie Anm. 22), S. 39. Zur Belagerung und Einnahme von Louisbourg vgl. Hugh Boscawen, The capture of Louisbourg, 1758, Norman, Okla. 2011; Andrew J. B. Johnston, Endgame 1758. The promise, the glory, and the despair of Louisbourg's last decade, Lincoln, Neb. u. a. 2007.

25 Wähner, 2012 (wie Anm. 22), S. 41.

26 Mastnak / Tänzer, 2010 (wie Anm. 21) S. 184.

27 Wähner, 2012 (wie Anm. 22), S. 166.

28 Vgl. zuletzt Matthew C. Ward, The battle for Quebec 1759. Britain's conquest of Canada, Stroud 2005; Dan Snow, Death or victory. The battle of Quebec and the birth of an empire, Toronto 2010; Phillip A. Buckner (Hg.), Revisiting 1759. The conquest of Canada in historical perspective, Toronto u. a. 2012.

29 Bowen, 1998 (wie Anm. 14), S. 22 mit Anm. 1.

30 Wähner, 2012 (wie Anm. 22), S. 114.

31 Am gleichen Tag erfahren auch die preußischen Untertanen aus den Berliner Nachrichten von der Eroberung Quebecs vgl. Berlinische Nachrichten, Anno 1759, No. 129, Sonnabend, den 27. October, S. $537-$ 539. Das „Wiener Diarium“ hingegen bestätigte erst am 7. November die Nachricht des französischen Verlustes, nachdem es noch am 31. Oktober eine gegenteilige Meldung gebracht hatte vgl. Wienerisches Diarium, Num., 87, Mittwoch dem 31. Octobris 1759 und Num. 89, Mittwoch den 7. Novembris 1759. 
Charakteristisch für Wähners prüfenden Umgang mit der Evidenz von Nachrichten ist, dass die Feststellung des Kommunikationsweges genauso viel Raum einnimmt wie das kommunizierte Ereignis selbst:

$D$ [en] 21. Sept[ember] ist mit dieser Nachricht ein eng[lischer] offcier von Quebeck an den $H[\mathrm{err}] n$ Pitt abgefertiget. $D[\mathrm{en}]$ 16. oct [obris] ist dieser officier $z u$ London angelanget. $D[\mathrm{en}] 17$. Octob[er] ist diese Nachricht von London nach dem Haag spediret: woselbst er in der Nacht zwischen d[em] 19.-20. Octob[er] angelanget. ${ }^{32}$

Bezeichnenderweise tritt nun wieder Thompson als vertrauenswürdiger Informant auf.

$H[\mathrm{err}]$ Proflessor] Tompson: Ich habe vor einer halben Stunde einen Brief von Hannover, und auch die eng[lischen] Zeitungen erhalten, mit der zuverlässigen Nachricht, daß Quebeck d[en] 18. Sept [ember] erobert worden. Gott Lob! - Der eng[lische] Gener[al] Wolf ist bald im Anfang der bataille gefallen. Worauf der Gen[eral] Monkton das commando genommen. Und als auch dieser durch die Brust geschossen worden, ist es endlich an den gen[eral] Townsend gekommen. Der Französische Gen [eral] Vaudrevil ist gleichfalls geblieben. ${ }^{33}$

In der darauffolgenden Woche notiert Wähner dann die Nachrichten des offiziellen victorie schiessens für den Sieg bei Quebec bei der Armee Herzog Ferdinands.

In Celle registriert Schowart die Siegesnachricht von Quebec bereits am Mittwoch den 24. Oktober, also einen Tag vor Wähner:

Ein Englischer Courier hat in Hannover, die Nachricht gebracht, daß Quebec über sei und vernahm man nachgehens, daß solches d. 18. Sept. mit Capitulation geschehen, nach dem am 13 vorher nahe dabei blutig Treffen gewesen, so die Engländer ohngeachtet der feindlichen Obermacht zwar gewonnen, jedoch ihren braven General Wolff, so wie die Franzosen den General Montcalm verloren, daß also beide commandirende Generale im Treffen geblieben. ${ }^{34}$

Am folgenden Montag trägt Schowart noch weitere Details des Sieges nach:

Im Treffen bei Quebec den 13 haben die Franzosen 1500 die Engländer aber kaum halb soviel verlohren, auch die Engländer 348 M. [...] darunter 14 Off-

32 Wähner, 2012 (wie Anm. 22), S. 115.

33 Wähner, 2012 (wie Anm. 22), S. 115.

34 Mastnak / Tänzer, 2010 (wie Anm. 21), S. 184 f. 
ciere zu Gefangenen gemacht in Quebec. Haben die Engländer allein 241 Canonen [...] Mörser und Haubitzen bekommen. ${ }^{35}$

In Emmerich am Niederrhein registriert der Krefelder Abraham ter Meer am 24. Oktober in seinem Tagebuch: Wir besuchten dort unsere Freunde und lasen in der Harlemer Zeitung, daß die Engländer Quebeck erobert hätten. ${ }^{36}$

Nachrichten aus Nordamerika brauchten zu dieser Zeit nur noch rund einen Monat und verbreiteten sich im Reich entlang einiger Anlaufzentren, wie in diesem Fall Hamburg oder Hannover, von denen aus sie weiter diffundierten. Ihre Aufnahme in den Tagebüchern bleibt nah am Zeitungsstil und wurde möglichst durch andere Quellen, denen man vertraute, abgesichert. Fällt für die Bewohner des Alten Reiches die Aufnahme der Nachrichten über Siege und Niederlagen, die Zahlen der Verluste und erbeuteten Waffen oder die Wege der Information noch relativ nüchtern aus, so kommt es bei Thomas Turner (1729-1793), einem Ladenbesitzer aus dem Dorf East Hoathly in Sussex, zudem zu einer patriotischen Emphase. Turner liest am Samstag, den 20. Oktober, die extraordinary Gazette vom vorigen Mittwoch, rekapituliert kurz den Ausgang der Belagerung, den Tod Wolfes und Montcalms sowie die Verletzung General Moncktons und schreibt dann voller Begeisterung:

Oh, what a pleasure is it to every true Briton to see with what success it pleases Almighty God to bless His Majesty's arms with, they having success at this time in Europe, Asia, Africa and America, and I think in this affair our generals, offccers and common men have behaved with uncommon courage and resolution, having many and great difficulties to encounter before they could bring the city to surrender. ${ }^{37}$

Es zeichnet sich damit bereits ab, dass der Tod Wolfes zu der entscheidenden Chiffre für die Eroberung Quebecs wird. ${ }^{38}$ Turner, der eine Art Ikone für die britische Medienrezeptionsforschung zum 18. Jahrhundert darstellt, las regelmäßig den lokalen

35 Mastnak / Tänzer, 2010 (wie Anm. 21), S. 185.

36 „Nous y vimmes nos amis et y lument dans la gasette de Harlem que les Anglois avoient fait la conquete de Quebeck". Gottfried Buschbell (Hg.), Das Tagebuch des Abraham ter Meer (1758-1769), Krefeld 1936, S. 78f. Zu Ter Meer als Zeitungsleser vgl. Miriam Müller, On dit. Die Nachrichtenrezeption des Krefelders Abraham ter Meer im Siebenjährigen Krieg, in: Annalen des Historischen Vereins für den Niederrhein insbesondere das alte Erzbistum Köln 215 (2012), S. 73-96.

37 David Vaisey (Hg.), The Diary of Thomas Turner 1754-1765. Oxford / New York 1985, S. 191. Die Identifikation als „britisch“ im Gegensatz zu „englisch“ war dabei keineswegs selbstverständlich, vgl. Stephen Conway, War and National Identity in the Mid-Eighteenth-Century British Isles, in:The English Historical Review 116, No. 468 (2001), S. 863-893, hier S. 872 und 874.

38 Zur Geschichte der medialen Inszenierung von Wolfe als Kriegshelden vgl. Alan McNairn, Behold the Hero. General Wolfe \& The Arts in the Eighteenth Century, Liverpool 1997. 
Sussex Weekly Advertiser und die London Gazette. ${ }^{39}$ Das Spektrum der von ihm registrierten Ereignisse des Krieges reicht vom Verlust Minorcas (1756) über die Schlacht bei Rossbach (1757) bis zur Eroberung Montreals (1760). ${ }^{40}$ Ein ausgeprägtes Interesse für die Situation Hannovers oder der britischen Soldaten im Westen des Alten Reiches lässt sich jedoch nicht ausmachen. Lediglich die Schlacht von Krefeld 1758 findet kurz Erwähnung, tritt aber deutlich zurück gegenüber der Begeisterung für den Erfolg Friedrichs II. bei Rossbach. ${ }^{41}$

Die Nachrichtenübermittlung aus Übersee war jedoch keine kommunikative Einbahnstraße nach Europa. Wie etwa aus der Korrespondenz des protestantischen Pastors Heinrich Melchior Mühlenberg (1711-1787) aus Pennsylvania hervorgeht, der seit 1742 in Amerika lebte, las man auch in den Kolonien eifrig Zeitung und verfolgte die Ereignisse in Europa mit teilweise noch größerem Interesse als dessen Bewohner jene in Nordamerika. ${ }^{42}$ In einem Brief aus Providence an den Pastor Krome in Einbeck vom 27. Februar 1759 schreibt Mühlenberg:

Wie es vergangenen Sommer und Herbst bis zur Ausgange des Novembris in Preußen, Pommern, Brandenburgischen, in Schlesien, Heßen, Hannöverischen, Sachsen und besonders vor Dresden, Torgau, Leipzig, Halle etc: zuletzt ergangen, das haben wir mit Wehmuth in den hiesigen Gazetten gelesen. ${ }^{43}$

Im Postskriptum des Briefes heißt es weiter mit Blick auf das heutige Südniedersachsen: Wie die Zeitung hier vermeldet en passant, so muß es vergangenen Herbst recht betrübt bey Eimbeck, Göttingen, Nordheim, Münden etc. etc. hergegangen seyn! bitte mit Gelegenheit speciellere Nachricht. ${ }^{44}$ Das Bewusstsein von den globalen Dimensionen des Krieges war bei Missionaren wie Mühlenberg traditionell stark ausgebildet, hatte er doch das Schicksal einer weltumspannenden Gemeinde im Hinblick. An Samuel Theodor Albinus schreibt Mühlenberg am 1. November 1756 angesichts des sich ausweitenden Krieges mit Blick auf die Missionare im südindischen Tranquebar: Unsere armen Mitbrüder in den Englischen Colonien in Ostindien werden gleichfals Noth, Gefahr und Trübsal haben. ${ }^{45}$

39 Vaisey, 1985 (wie Anm. 37), S. 347.

40 Vaisey, 1985 (wie Anm. 37), S. 55 (Minorca 1756), S. 99 (Prag 1757), S. 124f. (Rossbach 1757), S. 155ff. (Krefeld 1758), S. 161 (Louisbourg 1758), S. 191f. und 194f. (Quebec 1759), S. 212 (Montreal 1760).

41 Zur Aufnahme der preussischen Siege bei Leuthen und Rossbach in England vgl. Manfred Schlenke, England und das friderizianische Preussen: 1740-1763. Ein Beitrag zum Verhältnis von Politik und öffentlicher Meinung im England des 18. Jahrhunderts, Freiburg u.a. 1963, S. 234-253.

42 Kurt Aland (Hg.), Die Korrespondenz Heinrich Melchiors Mühlenbergs: aus der Anfangszeit des deutschen Luthertums in Nordamerika, Bd. 2: 1753-1762, Berlin u. a. 1987. Zur kolonialen Presselandschaft vgl. David A. Copeland, Colonial American newspapers. Character and content, Newark u.a. 1997.

43 Aland, 1987 (wie Anm. 42), Nr. 185, S. 364-371, hier S. 368.

44 Aland, 1987 (wie Anm. 42), Nr. 185, S. 370.

45 Aland, 1987 (wie Anm. 42), Nr. 172, S. 300ff., hier S. 301. 
Eine fiktionale Variante dieser ,amerikanischen' Perspektive auf Europa hat Johann Heinrich Gottlob von Justi 1759 in seiner pro-preußischen Propagandaschrift „Untersuchung, ob etwa die heutigen europäischen Völker Lust haben möchten, dereinst Menschen-Fresser, oder wenigstens Hottentotten zu werden" inszeniert, die im Untertitel ihren Verfasser einen ehemaligen Europäer kennzeichnet, welcher sich nach America begeben hat, weil er dereinst seine Nachkommen mit stinkenden Schaafs-Därmen nicht gerne ausgezieret wißen möchte. Nachfahren dieses Europäers befinden sich im Jahre 1759 in Amerika, wohin die gesunde Vernunft und die Wissenschaften höchst wahrscheinlich ihren künftigen Aufenthalt finden werden. Eines Tages trifft eine Zeitungsnachricht ein, in der ein Kapitän Bohn aus Europa berichtet, wo zu diesem Zeitpunkt nur noch wilde Völker leben, die sich in Bärenheute und Federn kleiden und keinerlei höhere Kultur mehr besitzen. ${ }^{46}$ Justi spielt hier mit einer Verschränkung von Raum- und Zeitperspektive. Während die Nachfahren der zivilisierten Europäer aus der neuen in die alte Welt zurückblicken, bekommt der Leser gleichzeitig einen Einblick in eine Zukunft, in der nach den Verheerungen des gegenwärtigen Krieges in Europa jegliche Zivilisation verschwunden ist. Bemerkenswert daran ist weniger der eurozentrische Blick auf eine in jedem Fall als ,primitives' Anderes gewertete indigene Kultur, als vielmehr die raum-zeitliche Verschiebung der Perspektive, gingen doch, wie gezeigt, viele der Bewohner des alten Reiches von einer ,Entflammung' des Krieges in Amerika aus.

Man sollte den Umfang des globalen Wissens der Nachrichtenrezipienten im Reich jedoch auch nicht überschätzen. Die Einnahme der westafrikanischen Insel Gorée durch die Briten Ende Dezember des Jahres 1758 findet in allen vorgestellten Selbstzeugnissen Erwähnung, jedoch meist nur mit einem Satz. ${ }^{47}$

Die Eroberung der Insel Gorea ist durch d[en] H[err]n v[on] Werpup bekräftiget. [...] Gorea sey erobert; und darin 300 Franzosen ohne die vielen Negers zu Kriegsgefangenen gemacht, auch 94 Canonen, 11 Steinstücke und 4 Mörser genommen. Laut der Hofzeitung vom 29. Januar. ${ }^{48}$; Le 4me la gasette d'harlem nous dit que les Anglois ont pris l'isle et le fort goeré. ${ }^{49}$ Der englische Admiral

46 Johann Heinrich Gottlob von Justi, Untersuchung, ob etwa die heutigen europäischen Völker Lust haben möchten, dereinst Menschen-Fresser, oder wenigstens Hottentotten zu werden [...] Philadelphia in Pensilvanien [i.e. Schwerin] [1759], S. 7f.; auf die Flugschrift folgte prompt eine Gegenschrift: [Anonym], Beweis daß derjenige, der schon ein Hottentotte ist, nicht erst einer werden dürfe, zur Antwort auf das Pensilvanisirten Preußen witzige Frage: Ob etwan die heutigen Europ. Völker Lust haben möchten, dereinst Menschen-Fresser, oder wenigstens Hottentotten zu werden [...], Frankfurt a. M. 1760; vgl. dazu Schort, 2006 (wie Anm. 7), S. $392 \mathrm{ff}$.

47 Vgl. Baugh, 2011 (wie Anm. 10), S. 330ff.; A. J. Marsh, The Taking of Goree, 1758, in: Mariner's Mirror 51 (1965), S. 117-130.

48 Wähner, 2012 (wie Anm. 22), S. 71 f.

49 Buschbell, 1936 (wie Anm. 36), S. 49. 
Keppell hat denen Franzosen die Insul Gorée weggenommen und 94 Kanonen, 4 Mörser und 2 Schiffe bekommen. ${ }^{50}$ Die Expedition wider das Fort und die Insel Gorre in Africa hatte unter der Anführung des Chefs der Escadre Keppel, einen glücklichen Ausgang. ${ }^{51}$

In London erschien 1759 ein Einblattdruck mit dem Titel „The Bold Sawyer“, der in Reimform die Einnahme der Insel by true british boys pries. ${ }^{52}$ Als Einzelinformation wird die Einnahme Goreés ,roh' in ein gewohntes Rezeptionsschema aufgenommen, aber nicht notwendig in Wissen transformiert. ${ }^{53}$ Wie eine einzelne Information jedoch in einen größeren Sinnzusammenhang aufgehoben werden konnte, macht wiederum Schowarts Tagebuch deutlich. Aus einer angeblich am 18. Oktober 1759 vor dem englischen König gehaltenen Rede von Richard Howe weiß Schowart die für England glücklich ausgehaltene [n] Begebenheiten des Annus Mirabilis in zehn Punkten resümierend zu berichten:

Die eroberung des Forts du Quesne am Ohio. 2. Die von Goreé in Africa 3. Von Guadeloupe und den dazu gehörigen Plätzen in West-Indien 4. Die Niederlage der ganzen Französichen Armeé durch eine Handvoll Infanterie bei Minden 5. Die Einnahme von Niagara 6. Die von Ticonderago 7.Crown Point. 8. Das siegreiche Seetreffen bei Cap Lagos (gegen la clue) 9. Die über die Feinde in Ost-Indien erhaltene Vorteile 10. Die Einnahme von Quebec hier zu ist dann noch d. 21. Nov gekommen der Sieg den Hawke gegen den französischen Admiral Conflans bei Bel Isle erfochten. ${ }^{54}$

Mit dieser Liste zeichnet sich bei Schowart schon eine Art des Überblicks ab, der als Motivation auch für andere Zeugnisse charakteristisch ist.

50 Johann Georg Fülling, Die Isthaer Chronik des Pfarrers Johann Georg Fülling. Zur Geschichte Niederhessens im siebenjährigen Kriege, hg. von G. Bätzing, M. 2 Karten u. 2 Abb., Kassel 1957, S. 36.

51 Eberhard Jürgen Abelmann, Hannover im Siebenjährigen Krieg. Hannoverisches Kriegsdenkmal. Das Kriegsgeschehen in Stadt und Kurfürstentum, dokumentiert von einem Bäckermeister, hg. von Hans Hartmann, Hameln 1995, S. 207.

52 Cardwell, 2004 (wie Anm. 7), S. 229.

53 Zur heuristischen Unterscheidung von Information als ,roh` und Wissen als, gekocht` vgl. Peter Burke, Papier und Marktgeschrei. Die Geburt der Wissensgesellschaft, Berlin 2001, S. 20; weiterführend vgl. Arndt Brendecke / Markus Friedrich / Susanne Friedrich, Information als Kategorie historischer Forschung. Heuristik, Etymologie und Abgrenzung vom Wissensbegriff, in: Dies. (Hg.), Information in der Frühen Neuzeit. Status, Bestände, Strategien, Münster 2008, S. 11-44.

54 Mastnak / Tänzer, 2010 (wie Anm. 21), S. 185 f. 


\section{Ordnen: Chronisten des globalen Krieges}

Einen eher resümierenden Zugang zu den Ereignissen in Übersee wählt der Hannoveraner Bäckermeister Eberhard Jürgen Abelmann (geb. 1703). ${ }^{55}$ In seinem „Hannoverischen Kriegesdenkmal“ widmet er ,Englands Eroberungen in Übersee' ein eigenes, chronologisch geordnetes Kapitel, ähnlich wie es zeitgleich auch Druckerzeugnisse, wie der „Historische Bildersaal“ tun. ${ }^{56}$ Abelmann ist ebenfalls ein fleißiger Zeitungsleser, zu seinen besonderen Informationsquellen zählen die „Hannoverische[n] Beyträge zum Nutzen und zum Vergnügen“, einem Vorläufer des „Hannoverschen Magazins“. So verweist er seine Leser explizit auf weiterführende Artikel zur ,Beschaffenheit und Handlung der Stadt Quebec oder verschiedener Karibikinseln. ${ }^{57}$ Die „Hannoverischen Beyträge" druckten während des Krieges eine ganze Serie von Artikeln, die die Bewohner Kurhannovers über die neuen von den Briten eroberten Territorien informierten. Den Anfang machte 1758 ein Artikel der „Nützlichen Sammlungen“ über ,Kap-Breton' und Louisbourg, gefolgt von Artikeln über Gorée (1759), Quebec (1760), Grenada, St. Vincent und St. Lucia (1762) oder Florida, New Orleans und Manila (1763)..$^{58}$ Abelmanns Perspektive ist deutlich von den „Beyträgen“ geprägt, indem er vor allem auf die wirtschaftliche Nutzbarkeit der überseeischen Territorien eingeht: America gehöret größtentheils Spanien und hat viel Gold und Silber-Gruben, Potosi sind die reichsten in der Welt. Die größte Eroberung aber, die England während diesem Kriege gemacht hat ist für Abelmann jedoch eindeutig, dass die tapfern Briten

55 Abelmann, 1995 (wie Anm. 51), S. 42 f.

56 Abelmann, 1995 (wie Anm. 51), S. 149-154.

57 Abelmann, 1995 (wie Anm. 51), S. 151 und 153.

58 Von 1755-1758 erschienen die „Nützlichen Sammlungen“, deren Nachfolger waren von 1759-1762 die „Hannoverischen Beyträge“, ihnen folgte von 1763-1790 wiederum das „Hannoverische Magazin“, vgl. J[ohann] H[inrich] Pratje, Nachricht von Kap-Breton und Louisbourg, und von dem Stockfischfange daselbst, in: Nützliche Samlungen, 1758, Sp. 1105-1116; [Johann Hinrich Pratje], Nachricht von der Insel Goree, und von dem derselben abhängenden Handel, in: Hannoverische Beyträge, 36tes Stück, Freytag, den 4ten May 1759, Sp. 569-600 (als Informationsgrundlage dienten die ersten Bände von Johann Joachim Schwabe, Allgemeine Historie der Reisen zu Wasser und zu Lande; oder Sammlung aller Reisebeschreibungen [...] 21 Bde., Leipzig 1747-1774); Joh. Franz Wagner, Nachricht von Quebek, in: Hannoverische Beyträge 6tes Stück, Montag, den 21ten Januarius 1760, Sp. 81-96; J[ohann] T[obias] Röhler, Kurze Beschreibung der von der Großbrittanischen Seemacht in America ohnlängst eroberten Inseln Grenada, St. Vincent und St. Lucia, in: 52tes Stück, Montag, den 28ten Junius 1762, Sp. 817-832 u. 53tes Stück, Freytag, den 2ten Julius 1762, Sp. 833-848; J[ohann] T[obias] Köhler, Beschreibung des Landes Florida in dem nördlichen Amerika, welches durch den neulichen glorreichen Frieden von Spanien an Großbritannien abgetreten worden, in: Hannoverisches Magazin 1763, 27tes Stück, Montag, den 4trn April 1763, Sp. 417-460; [Anonym], Beschreibung von Neu-Orleans, welches den Franzosen im Frieden verbleibet, ebd., 41 tes Stück, Montag, dem 23ten May 1763, Sp. 649-654; J[ohann] T[obias] Köhler, Beschreibung der philippinischen oder manilischen Eylande in Ostindien, besonders aber von Manila, der vornehmsten unter denselben und ihrer Hauptstadt, wie auch von dem reichen Handel, der von daraus mit den Gallionen nach Acapulco getrieben wird, ebd., 46tes Stück, Freytag, den 10ten Junius 1763, Sp. 721-766. 
die Insel Cuba unter ihre Bothmäßigkeit brachten..$^{59}$ Die Bewohner der hannoverschen Territorien hatten in mancherlei Hinsicht eine direktere Verbindung nach London, wie sich etwa am Beispiel der "Göttingischen Anzeigen von gelehrten Sachen“ zeigt, die regelmäßig über Neuerscheinungen aus Großbritannien berichteten. ${ }^{60}$ Während des Krieges erscheint beispielsweise 1761/62 eine kurze Besprechung der fortlaufend im „London Magazine“ veröffentlichten „History of the origin and progress of the present war", die dem Rezensenten vor allem deswegen als lesenswert erscheint, weil sie einem Deutschen wenigstens dazu dienen [kann], sich von dem Kriege in den andern Welttheilen einen vollständigen Begriff zu machen. Von diesem gibt sie wirklich manches, so einem Deutschen aus den Zeitungen nicht bekannt seyn kann. ${ }^{61}$ Nicht so einverstanden ist man allerdings mit der entschieden gegen das continental commitment gerichteten Position des Verfassers: ein misvergnügter aber kluger Engländer, der Deutschland nicht kennet, hat verdriesliche Stunden gehabt. ${ }^{62}$

Mochte der Blick auf die Weltpolitik des britischen Empire für einen Hannoveraner oder Göttinger noch besonders nahe gelegen haben, so zeigen auch die Chroniken anderer Regionen, dass die Zeitgenossen sehr wohl ein Bewusstsein von den globalen Ausmaßen des Konfliktes besaßen. So schaltet etwa der hessische Pfarrer Johann Georg Fülling (1721-1779) in seiner Chronik regelmäßig Informationen über die Situation in Europa wie in Übersee ein. ${ }^{63}$ Während die Nachrichten aus der Region sehr ausführlich sind, werden die weltpolitischen Vorgänge allerdings meist nur mit einem Satz gewürdigt. ${ }^{64}$ Für 1758 tritt mit der Nachricht von der Eroberung Cap Bretons zum ersten Mal ein überseeischer Schauplatz in der Chronik auf. Im Bericht für das Jahr darauf folgt die Meldung der Eroberung des Forts von Niagara und der Insel Gorée vor Afrika, und im Jahresbericht für 1760 erscheint die Nachricht von der Eroberung ganz Kanadas und Louisianas durch General Amherst. Erst im Jahresbericht für 1761 werden die Informationen etwas ausführlicher: Den 27. Juli bekam die alliierte Armee Nachricht, dass die Engländer anfangs dies Jahres Pondicherry und St. Dominique und einer ungemeinen Beute an Artillerie, Geld und Waren sich bemächtiget. Des Weiteren erfahren wir über den Kriegseintritt Spaniens:

Da Frankreich in diesem Jahre ein Bündnis mit Spanien schlossen, welches beide Kronen einen Familientraktat nennten, so begehrte der englische Gesandte zu

59 Abelmann, 1995 (wie Anm. 51), S. 153.

60 Vgl. Jennifer Willenberg, Distribution und Übersetzung englischen Schrifttums im Deutschland des 18. Jahrhunderts, München 2008, S. $144 \mathrm{f}$.

61 [Johann David Michaelis], [Rez.] History of the origin and progress of the present war, in: London magazine, June 1761, in: Göttingische Anzeigen von gelehrten Sachen Jg.1761/1762, Bd. 1, S.170ff., hier S. 171.

62 Michaelis, 1761/62 (wie Anm. 61), S. 172.

63 Fülling, 1957 (wie Anm. 50).

64 Vgl. Fülling, 1795 (wie Anm. 50) 1757: S. 12f. (noch keine außereuropäischen Ereignisse); 1758: S. 26ff.; 1759: S. 36f.; 1760: S. 50ff.; 1761: S. 63ff.; 1762: S. $81 \mathrm{ff.}$ 
Madrid eine Kopie davon mit dem Bedeuten, dass, wann ihm solches verweigert würde, er Befehl habe, Madrid zu verlassen. Der König von Spanien hat geantwortet, dass er diesen Antrag vor eine förmliche Kriegerklärung annehme und er nichts weiter zu tun hatte, als vor den englischen Gesandten Graf von Bristol die nötigen Pässe ausfertigen ließe. Den 25. Dezembris hat dies der spanische Gesandte Grafvon Fuentes in London bekannt gemacht und den Staatssekretär Graf von Egremont wissen lassen, dass er ohne Abschiedsaudienz wegziehen würde. ${ }^{65}$

1762 weiten sich mit dem neuen Kriegsgegner Spanien nun die Schauplätze, von denen wir erfahren, weiter aus. Kuba und verschiedene karibische Inseln werden mehrfach erwähnt. Auch in den habsburgischen Territorien werden diese Nachrichten rezipiert, mitunter jedoch mit einiger Verzögerung. Der junge Karl Graf von Zinzendorf etwa erfährt am 15. Oktober in Wien aus der „Gazette de France“ von der Einnahme Havannas durch die Briten. ${ }^{66}$ Erst am Mittwoch, den 20. Oktober, bringt das „Wiener Diarium “ dann die ausführliche Nachricht, datiert aus London vom 1. Oktober. ${ }^{67}$

Eine ungewöhnliche Variante der Verarbeitung präsentiert der Pfarrer Georg Schatz aus Wollbrandshausen, einem Dorf im Eichsfeld rund 20 Kilometer östlich von Göttingen. Im 1766 niedergeschrieben Teil seiner Chronik, welche die Zeit des Siebenjährigen Krieges behandelt, skizziert er den Krieg eingangs als globalen Konflikt zwischen Briten und Franzosen, berichtet im Folgenden dann aber allein über den Kriegsverlauf im Alten Reich:

anno 1755. Haben die französischen und englischen kaufmänner drey schiffe einander visitiret, und verschiedene contrebande waaren vorgefunden, weßwegen die könige beyder nationen zu wasser und zu lande krieg einander angekündiget. Frankreich thäte den engländeren die insul minorca den 28. Juny unter anführung des duc de richelieu abnehmen, wohingegen die engländer den franzosen das berühmte Fort Lovie undt fuß S. Laurenty mit allen colonien in America abnahmen und überall den meister spieleten, ohnerachtet die spanier Frankreich zu hülffe eyleten, muste gleichwohl Spanien wieder willen sehen wie ihnen ihre goldgruben, die stadt Havanna in America ebenfalls entzogen wurde. Ich will nun beyde partheyen auf den wässeren kreutzen und durch 7 jahr pro und contra sich schlagen lassen, mich indessen hier in Deutschland festen Fusses setzen. ${ }^{68}$

65 Fülling, 1957 (wie Anm. 50), S. 65f.

66 Maria Breunlich/Marieluise Mader (Hg.), Karl Graf von Zinzendorf. Aus den Jugendtagebüchern 1747, 1752 bis 1763, Veröffentlichungen der Kommission für neuere Geschichte Österreichs 84, Wien 1997, S. $305 f$.

67 Wienerisches Diarium, Num. 84, Mittwoch den 20. Octobris 1762.

68 Gerhard Rexhausen, Das Eichsfeld im Siebenjährigen Krieg: die Chronik des Pfarrers Schatz aus Woll- 
Auch der Weinhändler Johann Philipp Zellmann aus Herzberg trifft in seinem Tagebuch eher resümierende Aussagen, jedoch auf Grundlage eingehender Nachrichten. So notiert er etwa: Die Engländer fahren fort, mit ihren Flotten brav zu thuen und assistiren den König von Preußen mit ihren Sterlingspfunden. ${ }^{69}$ Im Jahr 1761 notierte er:

Den 15. Januarii bekamen die Engländer Pondichery und mit diesem Hauptplatz alles, was die Frantzosen in Ost-Indien haben. Diese Zeitung kam zugleich mit der glücklichen action in Westphalen vom 16. Julii an, zugleich auch, daß die Engländer die Insel Dominique in West-Indien erobert; und da jetzt zugleich die Mecklenburg-Strelitz'sche Prinzessin zur Hochzeit nach London gebracht wird, wie mag nicht das übermüthige London jauchzen, August $1761 .^{70}$

Und im September gleichen Jahres heißt es dann endgültig: Indessen, daß unser Land so mißhandelt wird, jauchzen die Engländer über ihre conquêten; mit dem Verlust unsrer Würste haben sie denen Frantzosen alles in Asia, Africa und America abgenommen. ${ }^{71}$ Zellmann geht sprachlich auf Distanz zu den Engländern, deren Freude er registriert, aber auch vor ,Übermut' warnt. Die Verluste der Franzosen waren ihm eine größere Genugtuung, als die Siege der Briten, litt er doch ganz konkret vor Ort unter der französischen Besatzung.

Wie sich an dem Hannoveraner Bäckermeister Abelmann zeigte, wurden nicht nur Zeitungen, sondern auch Wochenschriften als Informationsquellen genutzt. Der Markt an Printmedien differenzierte sich während des Krieges immer weiter aus und versuchte möglichst auch den ,gemeinen Mann' als Käufer und Leser zu gewinnen. Ein Projekt, an dem dies exemplarisch deutlich wird, ist eine von dem Merseburger Verleger Johann Georg Laitenberger von August 1757 bis September 1758 herausgegebene zeitungsähnliche Wochenschrift mit dem Titel „Der mit einem Sächsischen Bauer von jetzigem Kriege redende Französische Soldat“, die auch über die Vorgänge in Übersee berichtet. ${ }^{72}$ Was diese Publikation so besonders macht, ist weniger die Form des Dialogs zwischen dem Soldaten und dem Bauern, wie man sie etwa aus den „Gesprächen im Reiche derer Todten“ kennt, als vielmehr die bewusste Vulgarisierung der verwendeten Sprache. Ob dies tatsächlich im Sinne der Volksaufklärung zur

brandshausen, in: Eichsfeld-Jahrbuch 13 (2005), S. 125-154, hier S. 130.

69 Aus schwerer Zeit. Tagebuch des Johann Philipp Zellmann zu Herzberg am Harz aus der Zeit des siebenjährigen Krieges. Mitgeteilt aus einer Familienchronik von Dr. K. Zellmann (Separatabdruck aus der Zeitschrift des Harzvereins für Geschichte u. Altertumskunde Jg. 33. Heft 2), Wernigerode 1900, S. 26.

70 Zellmann, 1900 (wie Anm. 69), S. 45.

71 Zellmann, 1900 (wie Anm. 69), S. 52.

72 Lutz Voigtländer, Krieg für den „gemeinen Mann“: „Der mit einem Sächsischen Bauer von jetzigem Kriege redende Französische Soldat“. Eine neue Form der Berichterstattung in einer Wochenschrift des 18. Jahrhunderts; zugleich eine kleine Geschichte des Siebenjährigen Krieges zwischen Kolin und Zorndorf, Bremen 2006, Zitat S. 13, zum See- und Kolonialkrieg vgl. S. 271-276. 
Adressierung der ländlichen Gesellschaft und städtischer Unterschichten oder eher zur Belustigung städtischer Mittelschichten diente, die sich von dem hier repräsentierten Milieu abgrenzte, bleibt dahingestellt, denn über die Rezeption dieses Organs ist kaum etwas bekannt. Breiten Raum nimmt etwa die Einnahme von Louisbourg 1758 ein, die den französischen Soldaten sagen lässt: Fürwahr, eine solche Nachricht verursacht bey uns mehr Schrecken, als wenn wir 2 der stärcksten Bataillen in Deutschland verlohren hätten. ${ }^{73}$

\section{Hannover siegt, der Franzmann liegt. Performative und materielle Siegeskommunikation}

Neben den Zeitungen dürfte einer der wichtigsten Informationsmultiplikatoren das öffentliche Salutschiessen der jeweiligen Truppen für ihre Siege in Übersee gewesen sein. ${ }^{74}$ Auch hierüber erhalten wir wiederholt Informationen in Selbstzeugnissen. Der britische Colonel James Adolphus Oughton etwa berichtet in seinem Journal, das er 1758 auf dem westlichen Kriegsschauplatz des alten Reiches führte, am 24. August 1758 über ein Freudenfeuer anlässlich der Eroberung Louisbourgs:

A Feu de Joye of all the Army and Detached Corps for the taking of Louisbourg beginning with 42 Guns of the Hannoverian Park of Artillery, then the Battalion Guns, and lastly the Small Arms beginning with the Cavalry on the right of the 1st Line \& ending with those on the right of the $2 d$. repeated 3 times, Drums beating \& Trumpets sounding, and Solemn thanksgieving order'd to be returned to Almighty God for this great an important Event. The Cavalry fired their Pistols only; it Thundered Lightened \& rained excessively hard the whole time. ${ }^{75}$

Ganz ähnliches berichtet auch der hessische Hauptmann Georg Ernst von und zu Gilsa (1740-1798) in seinem Tagebuch. Am 16. September 1759 notiert er, dass die Armee unter dem Herzog von Holstein, Prinz von Bevern und von Wangenheim ausrückte und ein dreymahligen Lauf-und Freudenfeuer sowobl über die von die Engländer

73 Voigtländer, 2006 (wie Anm. 72), S. 276.

74 Zur akustischen Dimension militärischer Kommunikation vgl. Marian Füssel, Zwischen Schlachtenlärm und Siegesklang. Zur akustischen Repräsentation von militärischer Gewalt im Siebenjährigen Krieg (1756-1763), in: Stefanie Stockhorst (Hg.), Krieg und Frieden im 18. Jahrhundert, Hannover 2014 (im Druck).

75 James Adolphus Oughton, By dint of labour and perseverance. A Journal recording two Months in Northern Germany kept by Lieutenant Colonel James Adolphus Oughton, commanding 1st Battalion, 37th Regiment of Foot, 1758, transcribed, with an introd. biogr. essay and footnotes by Stephen Wood, London 1997, S. 49. 
gewonnene See-Bataille als auch die Eroberung des Forths Niagara veranstalteten. ${ }^{76}$ Gut eine Woche später am 24. September macht die Armée sowohl als auch die detachirten Corps nach vorhero gehaltenen Gottesdienst und angesungen Te Deum ein Freudenfeuer über die Einnahme der Stadt Quebeck als auch über die von die Engländer gewonnenen bataille am 13ten September. ${ }^{77}$ Am 4. Juli des folgenden Jahres hören wir noch einmal von Erfolgen in Quebec:

des Abends gegen 6 Uhr, fande sich die gantze Armée unter dem Gewehr, um über die Vortheile, so die Engländer bey der Stadt Quebeck über die Frantzosen erhalten, auch der englische Admiral Mylord Kolby sämbtliche sich in Fluß St. Lorent befindlichen feindlichen Schiffe ruinirt hatte, ein dreymahliges Lauf-und Freudenfeuer zu machen. ${ }^{78}$

Von überseeischen Ereignissen des Jahres 1761 berichtet der britische Corporal William Todd (1724-1791) aus seinem Lager nahe Erwitte südlich von Lippstadt im Juli 1761. Am 28. Juli erreichten ihn the great and good News of the Surrender of Pondicherry \& the Isle of Dominico to his Majestys Arms. ${ }^{79}$ Drei Tage darauf, am 31. Juli, stellte sich die Armee bei Büren früh morgens in ordre de bataille auf und schoss ein Freudenfeuer für diese Eroberungen in Indien und der Karibik: At 70 Clock in the Morning our whole Army \& Detach'd Corps drew out in Order of Battle, of fired a few de Joye [feu de Joie] for the taking of Pondicherry \& the Isle of Dominico. ${ }^{80}$ Besondere Begeisterung löste dann später am Tage die Ausgabe von Half a pint of Brandy per Man für die Teilnehmer an der Schlacht von Vellinghausen zwei Wochen zuvor aus. ${ }^{81}$

Diese in soldatischen Selbstzeugnissen vielfach überlieferten performativen Praktiken der Siegesbekundung konnte eine ganze Reihe von Funktionen erfüllen. Zunächst konnten sie zur Motivation und Repräsentation der eigenen Truppen dienen, zweitens konnten sie Kriegsgefangene einschüchtern, drittens kommunizierten sie den Anwohnern der Gegend die Information eines Erfolgs, und viertens konnten auch in der Nähe lagernde gegnerische Truppen in manchen Fällen das Siegesfeuer wahrnehmen. Angesichts der Tatsache, dass viele Schlachten keineswegs mit einem eindeutigen Sieger endeten - Beispiele wären Lobositz, Hastenbeck, Zorndorf oder

76 Holger Th. Gräf/Lena Haunert/Christoph Kampmann (Hg.), Adliges Leben am Ausgang des Ancien Régime. Die Tagebuchaufzeichnungen (1754-1798) des Georg Ernst von und zu Gilsa, Marburg 2010, S. 78.

77 Gräf / Haunert / Kampmann, 2010 (wie Anm. 76), S. 79.

78 Gräf / Haunert / Kampmann, 2010 (wie Anm. 76), S. $113 f$.

79 Andrew Cormack / Alan Jones (Hg.), The Journal of Corporal Todd 1745-1762, Publications of the Army Records Society 18, London 2001, S. 174. Die Besatzung von Pondicherry hatte sich am 15. Januar 1761 ergeben, die der Insel Dominica am 7. Juni 1761.

80 Andrew Cormack / Alan Jones, 2001 (wie Anm. 79), S. 175.

81 Andrew Cormack / Alan Jones, 2001 (wie Anm. 79), S. 175. 
Torgau - artikulierte das Freudenfeuer auch symbolisch einen Geltungsanspruch auf einen eindeutigen Sieg. ${ }^{82}$

Nicht zuletzt angesichts des noch hinzukommenden hohen Grades an Geheimhaltung innerhalb der militärischen Kommunikation sind viele Soldaten grundsätzlich skeptisch gegenüber Gerüchten. Major Richard Davenport (1719-1760) etwa schreibt aus einem Lager bei Bramsche im April 1760 an seinen Bruder in England: I never believe anything till I see it in the Gazette from Whitehall. ${ }^{83}$ Die Zeitung gilt in diesem Fall als vertrauenswürdiger Beweis, ausgestattet mit der Autorität der eigenen Krone.

Eine musikalische Umsetzung fand der globale Krieg zwischen Großbritannien und Frankreich bei Georg Philipp Telemann, der wahrscheinlich 1763 eine Kantate mit dem Titel „Hannover siegt, der Franzmann liegt“ (TWV 13:20) komponierte. ${ }^{84}$ Im Gegensatz zur älteren Forschungsmeinung es handle sich um eine Arbeit zu den Schlachten bei Krefeld (1758), Minden (1759) oder Vellinghausen (1761), ist das Stück tatsächlich wohl erst anlässlich des Friedensschlusses 1763 entstanden. Von den sieben Sätzen der Kantate stellt vor allem der Text des siebten - mit "Gassenhauer“ betitelten - Satzes einen deutlichen Bezug zu den überseeischen Erfolgen der Briten her, wenn es heißt Senegal und Cape Breton, zwo sehr tiefe Wunden, trägt der Franzen Reich davon.

$\mathrm{Zu}$ den für den Siebenjährigen Krieg sehr typischen Gattungen von Artefakten, mit Hilfe derer die Bewohner des alten Reiches sich mit den Erfolgen ihrer Kriegsparteien identifizierten, zählten die sogenannten Iserlohner Tabaksdosen. Sie erschienen recht zeitnah mit Motiven von Schlachten und politischen Ereignissen und wurden zu Preisen um einen Taler gehandelt. Im Hinblick auf die Personalunion und die globalen Schauplätze des Krieges fällt das überlieferte Angebot an Motiven jedoch eher mager aus. Während sechs unterschiedliche Dosen Georg II. abbilden, existieren nur zwei militärische Motive aus Übersee, zum einen das Seegefecht vor Cartagena 1758 und zum anderen die Eroberung der Insel Martinique im Februar 1762. ${ }^{85}$

82 Zum Medienduell um Zorndorf vgl. Marian Füssel, Das Undarstellbare darstellen. Das Bild der Schlacht im 18. Jahrhundert am Beispiel Zorndorf (1758), in: Gabriela Signori / Birgit Emich (Hg.), Kriegs / Bilder in Mittelalter und Früher Neuzeit, ZHF Beiheft 42, Berlin 2009, S. 317-349.

83 Charles Walter Frearson (Hg.), “To Mr. Davenport”. Being Letters of Richard Davenport (1719-1760) to his Brother during Service in the 4. Troop of Horse Guards and 10. Dragoons, 1742-1760, London 1968, S. 79.

84 Carsten Lange, Telemann und England, in: Friedhelm Brusniak/ Annemarie Clostermann (Hg.), Aspekte der englisch-deutschen Musikgeschichte im 17. und 18. Jahrhundert, Sinzig 1997, S. 111-140, hier S. 131ff.; Werner Menke, Das Vokalwerk Georg Philipp Telemann's. Überlieferung und Zeitfolge, Leipzig 1941, S. $114 \mathrm{f}$.

85 Vgl. Wolf-Dieter Könenkamp, Iserlohner Tabaksdosen. Bilder einer Kriegszeit, Münster 1982, zu Georg vgl. S. 113 und zu Cartagena und Martinique S. 74 f. 


\section{Fazit}

Der Krieg kann als eine Art Indikator sowohl für Zustand und Qualität der Personalunion gelesen werden, als auch für übergreifende strukturelle Prozesse der Politisierung, Medialisierung und Globalisierung. Prozesse, die insgesamt wesentlich zum Laborcharakter des Siebenjährigen Krieges beigetragen haben. ${ }^{86}$ Informationen wurden ebenso zu einem begehrten Konsumgut wie zum Motor einer medialen Globalisierung. Eine Nachricht zwischen Nordamerika und Europa brauchte im hier untersuchten Zeitraum zwischen vier und sechs Wochen, eine zwischen Europa und Indien zwischen sechs und sieben Monaten. Die Teilhabe an der politisch-militärischen Ereignisgeschichte durch die Rezeption von Nachrichten und die aktive Identifikation durch Memorabilia wie Tabakdosen, Porzellan oder Vivatbänder eröffnete breiteren Teilen der Bevölkerung einen neuen Grad von emotionsgeladener Politisierung, egal welcher Seite sie sich verbunden fühlten. Für die Rezeptionsgeschichte militärischer Ereignisse keine Besonderheit, aber an den vorgestellten Quellen exemplarisch gut nachvollziehbar, ist die Feststellung, dass die Bedeutung einzelner Ereignisse erst ex post aus größerer historischer Distanz konstruiert wird. Die beiden heute als entscheidend für die weitere Entwicklung auf dem indischen Subkontinent angesehenen Schlachten der Briten bei Plassey 1757 und Wandiwash 1760 finden überhaupt keine Erwähnung, während eine inzwischen als vergleichsweise unbedeutend angesehene Eroberung, wie die der Insel Gorée 1758, in den meisten Zeugnissen Erwähnung fand. Betrachtet man den globalen Wahrnehmungshorizont der untersuchten Selbstzeugnisse, so fällt auf, dass der atlantische Raum bis Afrika und der Karibik sehr präsent ist, während der südasiatische Kriegsschauplatz bis auf wenige Ausnahmen kaum in den Blick tritt. Innerhalb der britischen Öffentlichkeit existierte spätestens seit den Erfolgen der Jahre 1758/1759 ein Bewusstsein von dem weltumspannenden Ausmaß des militärischen Erfolgs. Formulierungen der Glückwunschadressen wie in every quarter of the globe, in every quarter of the world, in so many different parts of the globe oder in every part of the known world sprechen eine deutliche Sprache. ${ }^{87}$ Angesichts der Nachricht von der Eroberung Havanas räsoniert in Reich etwa der Augsburger „Apotheker“ über die Risiken einer globalen Vormachtstellung der Briten: Und der Größe deiner Werke / scheint die Erde fast zu klein. Und dann konkret: Auch Havana ist gefallen, / Und demüthigt sich vor dir. Dieß erwekt dir Ruhm bei allen / Aber Sorgen auch bei mir. / Dieser Streich war allzu prächtig / Allzu reich, zu missgunstvoll / England, du wirst allzu mächtig / als dass man dich dulten soll. ${ }^{\beta 8}$

86 Vgl. Füssel, 2010 (wie Anm. 10), S. 109-116.

87 Bowen, 1998 (wie Anm. 14), S. 3.

88 „Eine Heldenode“, in: Der Apotheker, 13 St., S. 194, zitiert nach Waibel, Publizistik (wie Anm. 18), S. 317. 
Was die Frage nach der Gestalt der Personalunion als Kommunikationsraum angeht, liefert gerade der Kriegszustand ein eindeutiges Ergebnis. Nicht territoriale Grenzen spannen den Kommunikationsraum auf, sondern die einzelnen kommunikativen Akte. Besonders plastisch tritt das in den Siegesbekundungen innerhalb der Armeen zu Tage, so konnte der Raum sich auch auf Hessen, Westfalen oder Quebec erweitern, je nachdem wo die kommunizierenden Akteure sich gerade befanden. Die Kriegsberichterstattung brachte den Bewohnern des alten Reiches, und darunter zweifellos besonders denen des Kurfürstentums Braunschweig-Lüneburg, die umkämpften Einflusszonen der Europäer in Übersee näher. So hatte der Helmstedter Stadtschulrektor Wagner in den „Hannoverischen Beyträgen “ wohl Recht, als er schrieb, dass seine Bemühungen, den wißbegierigen Lesern [...] einige historische Nachrichten über die von Engländern eroberten Orte zu geben, manchen angenehm gewesen sind ${ }^{89}$ Dennoch nahmen die Bewohner der kurhannoverschen Territorien, diese Eroberungen nicht als ihre, sondern als die der Engländer war. In aller Deutlichkeit formulierte das etwa der Göttinger Professor Samuel Christian Hollmann in seinem „Lob des Krieges“, einer Schrift, die bereits während des Krieges verfasst wurde, jedoch erst nach dessen Ende erschien:

Des Königs Teutsche Unterthanen haben daher zum Theil, nebst ihren Alliirten, den armen Hessen, fast mit Haut und Haar für die Engelländer bezablen müssen. Wie billig wäre es daher, daß sie auch an den, von den Engelländern in diesem Kriege eroberten, großen Vortheilen Theil hätten! Sie, dieser gantze Krieg weiter nichts anging, als daß ibr Landesherr zugleich ein Herr der Engelländer war, die diesen Kaufmanns-Krieg in America angefangen, und also auch daselbst fortzusetzen hatten..$^{90}$

Die amerikanischen Händel im Rahmen einer blue water policy stießen auf Unverständnis bei den Bewohnern Kurhannovers, die sich unnötigen Leiden ausgesetzt sahen für ein imperiales Kalkül, das ihnen weitgehend fremd war. ${ }^{91}$ Eine patriotische Emphase war hier also nicht zu erwarten; spielten solche Gefühle unter den Bewohnern der nordwestdeutschen Reichsterritorien eine Rolle, dann gegenüber dem gegen die Franzosen siegreichen Prinzen Ferdinand von Braunschweig.

89 Wagner, 1760 (wie Anm. 58), Sp. 81.

90 [Samuel Christian Hollmann], Lob des Krieges: in einigen Gesprächen entwickelt, Teil 2, Frankfurt u.a. 1770, S. 412f., vgl. dazu bereits Wellenreuther, 1985 (wie Anm. 12), S. 45-49.

91 Vgl. Wellenreuther, 1986 (wie Anm. 4), S. 173. Zur Entwicklung der "blue water policy" vgl. Daniel A. Baugh, Great Britain's 'Blue-Water' Policy, 1689-1815, in: The International History Review 10/1 (1988), S. 33-58. 
Wenn eine militärische Identifikationsfigur in der gesamteuropäischen Öffentlichkeit erfolgreich war, dann war das der roi connétable Friedrich II. ${ }^{92}$ Die überseeischen Schauplätze machten in England zwar Männer wie Robert Clive oder James Wolfe zu gefeierten Kriegshelden, auf die Bewohner des Kontinents übertrug sich dies jedoch während des Krieges noch nicht. ${ }^{93}$ Auf der anderen Seite wurden auch in der britischen Öffentlichkeit bis 1762 eher ambivalente Gefühle im Hinblick auf Hannoveraner artikuliert, die bis zu radikalem Spott reichten. ${ }^{94}$ Bei aller Begeisterung der jüngeren Forschung für eine globale Verflechtungsgeschichte darf man demnach auch die Dissoziationsprozesse und Formen wechselseitigen Unverständnisses in der Personalunion nicht ignorieren, auf die bereits Hermann Wellenreuther in verschiedenen Arbeiten zu Recht hingewiesen hat. ${ }^{95}$ Der Siebenjährige Krieg bildete eine Phase kommunikativer Verdichtung im globalen Maßstab, zeigte aber auch deutlich die Grenzen der Gemeinsamkeiten zwischen Reich und Empire auf.

92 Marian Füssel, Der roi-connétable und die Öffentlichkeit, in: Bernd Sösemann/Gregor Vogt-Spira (Hg.), Friedrich der Große in Europa. Geschichte einer wechselvollen Beziehung, 2 Bde., Stuttgart 2012, hier Bd. 2, S. 199-215.

93 Zu Wolfe, vgl. McNairn, 1997 (wie Anm. 38); zu Clive vgl. Marian Füssel, Händler und Krieger? Robert Clive, die East India Company und die Kapitalisierung des Siebenjährigen Krieges in Indien, in: Markus Meumann / Matthias Meinhardt (Hg.), Die Kapitalisierung des Krieges. Kriegsunternehmer in Spätmittelalter und Früher Neuzeit, Berlin 2014 (im Druck).

94 Vgl. Bob Harris, Hanover and the public sphere, in: Brendan Simms / Torsten Riotte (Hg.), The Hanoverian dimension in British history, 1714-1837, Cambridge u.a. 2007, S. 183-212; Frauke Geyken, Gentlemen auf Reisen. Das britische Deutschlandbild im 18. Jahrhundert, Frankfurt/Main u. a. 2002.

95 Vgl. Hermann Wellenreuther, Von der Interessenharmonie zur Dissoziation. Kurhannover und England in der Zeit der Personalunion, in: Niedersächsisches Jahrbuch für Landesgeschichte 67 (1995), S. 23-42. 



\title{
Die Formierung der anglo-schottisch-irischen Union im 18. Jahrhundert
}

\author{
JÜRGEN ELVERT
}

Mit seinen 1689/90 erschienenem Werk "Two Treatises on government" hatte sich der Philosoph, Erzieher und Arzt John Locke im ausgehenden 17. Jahrhundert Einlass in den Kreis der führenden staats- und verfassungsrechtlichen Theoretiker seiner Zeit verschafft. Locke war im Gefolge Wilhelm von Oraniens nach jahrelangem holländischem Exil wieder in seine Heimat zurückgekehrt. In den Niederlanden war er über die philosophischen Schriften Spinozas und die natur- und verfassungsrechtlichen Überlegungen Grotius' mit dem Gedankengut der holländischen Aufklärung in Berührung gekommen, die sein weiteres Leben und Wirken nachhaltig beeinflussten und ihn zu einem der Väter des englischen enlightenment werden ließen. Bereits vor seinem Zwangsaufenthalt auf dem Kontinent hatte er sich als ein finanziell unabhängiger, nicht korrumpierbarer und politisch unbequemer Denker erwiesen, für den das göttliche Recht königlicher Herrschaft keine Selbstverständlichkeit war, der sich aber auch entschieden gegen den von Thomas Hobbes in seinem „Leviathan“ (1651) eher weltlich definierten Staatsabsolutismus aussprach. Insgesamt bot er in seinem Werk einen auf die damals aktuellen Verhältnisse in England zugeschnittenen Verfassungsentwurf, als dessen wichtigstes Kriterium die Teilung der Macht in zwei Gewalten gilt, in die Legislative des Parlaments und die dem Parlament unterstellte Exekutive der Krone. ${ }^{1}$

Mit den „Treatises“ erschienen in England noch weitere sowie insgesamt 19 Neuauflagen älterer staatsrechtlicher Schriften. ${ }^{2}$ Dies sind Indizien dafür, wie sehr in der Blütephase der Aufklärung die Frage nach neuen Rahmenbedingungen staatlicher Herrschaft und Verfassung die Zeitgenossen bewegte. Mit der glorious revolution war die entscheidende staatsrechtliche Weichenstellung vorgenommen worden, durch die

1 Zu Locke vgl. z. B. Richard Ashcraft, Revolutionary Politics \& Locke's Two Treatises of Government, Princeton 1986.

2 Vgl. Conal Condren, George Lawson's Politica and the English revolution, Cambridge 1989, S. 151. 
das ehemals göttliche Recht der Krone der Souveränität des Parlaments unterworfen wurde, das fortan - wenigstens theoretisch - die Krone samt ihrer Rechte und Pflichten wie ein gewöhnliches Staatsamt vergeben konnte. Zwar blieben in der Regierungspraxis der kommenden Jahrzehnten bedeutende königliche Prärogativrechte wie die Wahl der Minister und die Zielvorgaben der, Großen Politik', besonders der Außenpolitik, weiterhin erhalten, doch bildete sich im Verlauf des 18. Jahrhunderts ein System der Checks and Balances zwischen der Krone, dem Oberhaus und dem Unterhaus heraus, das die staatliche Herrschaft beim ,König im Parlament' sah.

In Irland erwartete die protestantische Oberschicht vom Souverän dieselben Rechte und Machtbefugnisse, die die Bill of Rights der englischen nobility und gentry zugestand. Bei Anerkennung der Krone als Ausdruck anglo-irischer Gemeinsamkeit ging man dort von einer Neuverteilung der Kompetenzen nach englischem Vorbild zu Gunsten des Parlaments und zu Lasten des Vizekönigs oder seines Statthalters aus. Allerdings waren die der ,glorreichen Revolution' folgenden zwei Jahrzehnte in Irland von der Suche nach einer Neudefinition des anglo-irischen Verhältnisses geprägt. Dabei kristallisierten sich zwei grundsätzlich unterschiedliche Standpunkte heraus. Der eine, den J.G. Simms als „kolonialen Nationalismus “ bezeichnete, ${ }^{3}$ sah Irland als ein unabhängiges Königreich mit einem eigenen Parlament und eigenen funktionsfähigen staatlichen Organen. Dem englischen Parlament wurden nur wenige, eng begrenzte Mitspracherechte zugestanden. Einer der führenden irischen Denker der Zeit, William Molyneux ${ }^{4}$, fasste in seiner im Jahre 1698 erschienenen Schrift „The case of Ireland's being bound by acts of parliament in England, stated" die Argumente dieser Fraktion zusammen. Dabei leitete er den Unabhängigkeitsanspruch für Irland bereits aus den Verhandlungen ab, die seinerzeit zwischen den irischen Königen und Heinrich II. geführt worden waren. Einige allgemeinere Aussagen der Streitschrift, die sich mit der grundsätzlichen Gleichberechtigung der Menschen im Verhältnis zueinander und der Frage nach der freiwilligen Unterwerfung der Menschen unter Rechtsnormen als Charakteristikum einer zivilisierten Gesellschaft befassen, zeigen den großen Einfluss, den die Schriften John Lockes auch in Irland ausübten. ${ }^{5}$ Molyneux zählte zu einer relativ kleinen, aber an der Wende vom 17. zum 18. Jahrhundert gesellschaftlich einflussreichen Gruppe von Intellektuellen, der Dublin Philosophical Society ${ }^{6}$, zu deren Mitgliedern neben anderen politische Denker und Philosophen wie Robert Molesworth, John Toland und Jonathan Swift gehörten, der aber auch der

3 J.G. Simms, The establishment of protestant ascendancy, 1691-1714, in: T.W. Moody/W.E. Vaughan (Hg.), A New History of Ireland, Bd. 4: Eighteenth-Century Ireland 1691-1800, Oxford 1986, S. 5.

4 Zu Molyneux vgl. z. B.: J. G. Simms, William Molyneux of Dublin. A Life of the seventeenth-century Political Writer and Scientist, Dublin 1982.

5 Molyneux zum Beispiel führte eine intensive Korrespondenz mit Locke.

6 K. Theodore Hoppen, The Common Scientist of the Seventeenth Century. A Study of the Dublin Philosophical Society, Bd. 15: 1683-1708, London 2013. 
junge George Berkeley nahestand. In England stieß diese Interpretation auf heftigen Widerspruch. Eine Reihe von mehr oder weniger polemischen Gegendarstellungen versuchte, die Unhaltbarkeit der Argumente von Molyneux zu beweisen, auch sah sich das Unterhaus zu einer Resolution genötigt, die eine Bestandsgefährdung des Königreiches für den Fall vorhersagte, dass sich solche und ähnliche Überlegungen jenseits der Irischen See durchsetzten. Für eine Mehrheit im House of Commons bestand kein Zweifel daran, dass Irland ein von England abhängiges und untergeordnetes Königreich war. Mit dieser Einschätzung wussten sich die Abgeordneten in Übereinstimmung mit dem anderen in Irland vertretenen Standpunkt. Dieser sah das Land als ein von der Krone erobertes Territorium, das von der protestantischen Macht, die als eine Art zivilisatorischer Brückenkopf diente, für die Krone gehalten würde. Im Rahmen solcher Überlegungen gab es selbstverständlich auch kein gleichberechtigtes irisches Parlament, es musste stattdessen der englischen Herrschaft untergeordnet sein. Die Unvereinbarkeit der beiden Interpretationen verhinderte jahrelang eine sinnvolle $\mathrm{Zu}$ sammenarbeit zwischen den Vizekönigen und ihren irischen Statthaltern, die kraft Amtes den englischen Standpunkt zu vertreten hatten, und dem Parlament in Dublin, das mehrheitlich die Molyneux'sche Sichtweise unterstützte.

Stattdessen erzeugten ständige Dispute zwischen Legislative und Exekutive beiderseits der Irischen See Reibungsverluste, die die Klärung manches wichtigen politischen Problems über Gebühr verzögerte oder gar gänzlich verhinderte. Wie problematisch die ungeklärten Beziehungen sich auch auf das innerenglische Verhältnis zwischen König und Parlament auswirken konnten, zeigt die Kritik Westminsters an der Entscheidung Wilhelms, nach dem Frieden von Rijswijk (1697) gegen den erklärten Willen der Legislative nicht alle seine Söldnerheere aufzulösen, sondern Teile nach Irland zu verlegen. Das Parlament sah darin einen Versuch des Königs, sich außerhalb des unmittelbaren parlamentarischen Zuständigkeitsbereichs eine nur schwer kontrollierbare Machtbasis aufbauen zu wollen.

Für das irische Parlament bedeutete das eine Niederlage. Unmittelbar nach dem Sieg Wilhelms über Jakob hatten einflussreiche irische Protestanten sich ein ehrgeiziges Ziel gesteckt: die Vollendung der Union des irischen mit dem englischen Königreich. Zunächst waren dies Einzelmeinungen gewesen, doch vor dem Hintergrund der Diskussion um die konstitutionelle Stellung Irlands im Herrschaftsbereich der englischen Krone wurden nach dem Tod Wilhelms solche Forderungen immer öfter vorgetragen, im Jahre 1703 hatte das irische Unterhaus dann förmlich an Königin Anna appelliert, eine Union der beiden Königreiche herbeizuführen. Die Unionsdebatte wurde in enger Verbindung mit der Frage nach weitergehenden Rechten für das irische Parlament geführt. Schon Molyneux hatte in seiner Schrift dieses Junktim hergestellt, als er darauf hinwies, dass dem englische Parlament nur dann ein Mitspracherecht in irischen Angelegenheiten eingeräumt werden dürfe, wenn irische Abgeordnete in Westminster mit in den Abstimmungsprozess einbezogen würden. 
Und in der Folgezeit hatten irische Parlamentarier ebenso wie politische Theoretiker gern betont, dass eine Union mit England stets nur die zweitbeste Lösung nach einer konstitutionellen Absicherung der eigenen Entscheidungsfreiheit unabhängig vom englischen Parlament sein könne.

Trotz der unbestreitbaren Vorteile, die eine Vereinigung der beiden Königreiche den Angehörigen der protestantischen Elite Irlands, der sog. Protestant Ascendancy bot - es hätte die protestantische Minderheit des Landes aus der relativen sozialen Isolation im Lande befreit und die von ihr dominierte irische Wirtschaft enger an das englische ökonomische System gebunden - bleibt festzuhalten, dass sich in der protestantischen Oberschicht Irlands zu Beginn des 18. Jahrhunderts eine eigenständige kolonial-nationale Identität herauszubilden begann. Diese Entwicklung blieb nicht auf Irland beschränkt, sondern beeinflusste in den Folgejahren die politischen Entwicklungen auch außerhalb der engen Grenzen der Britischen Inseln. Vergleichbare Überlegungen jenseits des Atlantiks gipfelten im amerikanischen Unabhängigkeitskampf. Nachweislich waren die Schriften von Molyneux, Molesworth, Toland und einiger anderer verwandter politischer Denker im Verlauf des 18. Jahrhunderts in den nordamerikanischen Kolonien mit großem Interesse rezipiert worden. So konnten die Gedanken Lockes den amerikanischen Unabhängigkeitskampf auf zweifache Weise beeinflussen: Einmal indirekt über die irisch-protestantischen Staatstheoretiker, zum anderen direkt über die Rezeption durch die Vordenker der Revolution, die sich selbst oft und gerne auf Locke beriefen.

Es verwundert daher nicht, wenn die Nachricht vom Zusammenschluss Englands und Schottlands zum United Kingdom of Great Britain unter Auslassung des Königreichs Irland im Jahre 1707 die politischen Entscheidungsträger in Dublin nicht allzu sehr betrübte. Zwar verfasste Swift unter dem Eindruck der soeben vollzogenen anglo-schottischen Union die „Story of the injured lady“, in der Irland als ein junges Mädchen erscheint, das von einem Verehrer schmählich zu Gunsten einer hässlichen Rivalin sitzen gelassen wird - doch verzichtete er später auf eine Veröffentlichung dieser Allegorie. Und auch wenn sich das irische Parlament noch nicht ganz damit abfinden wollte - zwei Jahre später suchte das Oberhaus noch einmal um Vollzug der Union mit Großbritannien nach - scheint beiderseits der Irischen See das tatsächliche Interesse am Zusammenschluss der Königreiche nicht allzu groß gewesen zu sein. ${ }^{7}$

Trotz der Distanz, auf die das irische Parlament in der Frage des Verhältnisses zu Großbritannien gegangen war, wirkten sich die dortigen politischen Entwicklungen auch weiterhin unmittelbar auf Irland aus. Hier wie dort gab es Whigs und Tories, wenngleich in Dublin die Trennungslinien zwischen den politischen Lagern aufgrund der mehrheitlichen Sympathien für den kompromisslos anti-katholischen Kurs der

7 Bei Simms, 1986 (wie Anm. 3), S. 2ff., werden einige Hinweise darauf gegeben, die sich zum Beispiel auf bewussten Verzicht der irischen Exekutive in Bezug auf die Einbringung von Haushaltsentwürfen beziehen, die fortan vom Unterhaus vorgelegt wurden. 
britischen Whigs anders verliefen als in London. So standen die irischen Whigs dem anglikanischen Protestantismus der königstreuen britischen Tories beispielsweise näher als dem teils fundamentalistisch-sektiererischen Protestantismus vieler britischer Whigs. Die besonderen Rahmenbedingungen der protestant ascendancy Irlands, die sich ihrer Rolle als Minderheit in einer grundsätzlich immer noch feindlich eingestellten und mehrheitlich katholischen Gesellschaft durchaus bewusst war, bedingten folglich ungewöhnliche politische Konstellationen, die wiederum die Differenzen zur britischen Politik deutlich hervortreten ließen.

In den 1720er Jahren war der koloniale Nationalismus der protestant ascendancy ausgereift genug, um vor einer Auseinandersetzung mit der Krone nicht mehr zurückzuschrecken, wenngleich diese auch stellvertretend mit dem britischen Kronrat und dem Vizekönig geführt wurde. Schon bald entwickelte sich der Disput zu einer Grundsatzdebatte um die Entscheidungsgewalt des irischen Parlaments. Einer der Wortführer in der Debatte auf irischer Seite war Jonathan Swift, der sich in vier seiner „Drapier's letters“, publiziert zwischen Februar und Oktober 1724, jede britische Einflussnahme in irische Angelegenheiten verbat und statt dessen, wenn auch noch verschleiert, die völlige Unabhängigkeit des Königreichs Irland einforderte. ${ }^{8}$ Nur dank einer geschickten Regie der britischen Regierung in Verbindung mit dem irischen Vizekönig und dem irischen Parlaments gelang es, einen Ausweg aus der Verfassungsdebatte zu finden: Die protestant ascendancy akzeptierte die Obergewalt des britischen Parlaments, dieses verzichtete im Gegenzug für über zwanzig Jahre nahezu völlig darauf, seine Hoheitsrechte auch tatsächlich auszuüben.

Ohnehin waren die Jahre zwischen 1725 und 1750 durch ungewöhnliche politische Ruhe und Stabilität überall auf den britischen Inseln gekennzeichnet. In Irland hatten sich die protestantischen Grundherren spätestens nach dem Ausgleich mit London endgültig als führende gesellschaftliche Gruppe etablieren können. Aus einer derart saturierten Position heraus konnten sie es sich nun auch leisten, auf eine allzu harte Verfolgung von Andersdenkenden wie Katholiken oder Presbyterianern zu verzichten. Das war in den ersten Jahrzehnten des Jahrhunderts durchaus nicht selbstverständlich gewesen. Nach 1691 hatte in Irland eine kleine Minderheit protestantischer Landbesitzer einer katholischen Mehrheit gegenübergestanden. Exakte Zahlenangaben über das proportionale Verhältnis gibt es nicht, doch haben Berechnungen für die 30er Jahre des Jahrhunderts eine geschätzte Einwohnerzahl von zirka 3,1 Millionen mit einem katholischen Anteil von etwa 70\% ergeben. Damit hatte sich das absolute Verhältnis zwischen Katholiken und Protestanten seit den Tagen der glorious revolution kaum verändert, doch während sich 1688 noch etwa $22 \%$ des Landes in katholischer Hand befunden hatten, waren dies im Jahre 1703 nur noch

8 Vgl. Oliver W. Ferguson, Jonathan Swift and Ireland, Champaign 1962. 
14\%, bis 1776 ging dieser Anteil auf unter 5\% zurück, die restlichen 95\% gehörten ungefähr 5.000 protestantischen Grundbesitzern.

Die 50er Jahre des 18. Jahrhunderts sind in Bezug auf das Verhältnis der irischen Katholiken zur protestantischen Herrschaft von einem grundlegenden Stimmungsumschwung gekennzeichnet. Viele irische Katholiken, besonders Angehörige der katholischen gentry und der Kaufmannschaft, begannen, sich im Zeitalter der langsam entstehenden Geschichtswissenschaft mit der Suche nach der eigenen Identität zu beschäftigen. Dieses neu erwachte Interesse an der eigenen Vergangenheit lässt sich zwar durchaus mit geistesgeschichtlichen Entwicklungen anderswo in Europa vergleichen, doch besaß die irische Variante eine Besonderheit. Die Erinnerung an die eigene keltisch-irische Kultur konnte über eine Befriedigung rein historischer Neugierde hinaus trefflich als Beweis für die Daseinsberechtigung eigener keltisch-irisch-katholischer Werte innerhalb des protestantisch dominierten Irland dienen. Ohne es wissen zu können, eröffneten sie damit eine Debatte, die einige Jahrzehnte später den irischen Nationalismus des 19. und frühen 20. Jahrhunderts maßgeblich mit beeinflussen sollte.

Die offensichtliche Suche vieler irischer Katholiken nach einem Arrangement mit der protestant ascendancy setzte nicht unbedingt die Akzeptanz des politischen Status quo voraus. Dazu waren die Lebensbedingungen unter den Zwängen der penal laws entschieden zu schlecht. Nach wie vor jedoch hofften sie, sich des königlichen Wohlwollens durch die demonstrative Loyalität zur Krone zu versichern und dadurch möglicherweise einen größeren Handlungsspielraum gegenüber den irischen Protestanten zu gewinnen. So boten sie im Jahre 1762, als sich Großbritannien im Siebenjährigen Krieg einer französisch-österreichisch-spanischen Koalition gegenüberstand, der Londoner Regierung die Bildung eines irisch-katholischen Regiments an, das in der Armee des mit Großbritannien verbündeten Portugal kämpfen sollte. Doch die Dubliner Regierung protestierte energisch gegen die Bildung einer bewaffneten ,papistischen' Macht auf irischem Boden, und der Plan wurde rasch wieder fallengelassen.

Dennoch stand die Frage nach dem Verhältnis der einzelnen Reichsgebiete zueinander und zum Mutterland auf der politischen Tagesordnung in vielen Teilen des Empire. In den nordamerikanischen Kolonien hatte der britische Sieg über die Franzosen eine jahrelange Bedrohung beseitigt, die lange Zeit nur dank der militärischen Hilfe des Mutterlandes abgewehrt werden konnte. Nun war die Schutzmacht vor den imperialen Ambitionen Frankreichs überfüssig geworden, stattdessen gerieten die anglo-amerikanischen Beziehungen in eine tiefe Krise, ausgelöst durch zwei gegensätzliche Entwicklungen beiderseits des Atlantiks. In Nordamerika hatte sich wie in Irland ein koloniales Nationalbewusstsein entwickelt. Dieses bestimmte in zunehmendem Maße die Entscheidungen der politisch tragenden Schicht, also in erster Linie der Nachfahren der frühen Siedler, die sich in ihrer Argumentation und in 
der Definition ihrer politischen Ziele zumindest zu Beginn der Auseinandersetzung oftmals am irischen Modell orientierten. Ausgangspunkt des anglo-amerikanischen Disputs war die Unzufriedenheit in den Kolonien über die Form ihrer Repräsentation im Parlament von Westminster, wo nur eine kleine Gruppe nordamerikanischer Parlamentsabgeordneter vertreten war. Als in Großbritannien die Rechnungen aus dem Siebenjährigen Krieg fällig wurden, versuchte die Regierung zunächst, den zusätzlichen Finanzbedarf durch Steuer- und Abgabenerhöhungen zu decken. Die Vertreter und Sprecher der nordamerikanischen Kolonien indes verknüpften nach der Veröffentlichung dieser Absichten ihre Zustimmung dazu mit der Forderung nach verbesserter parlamentarischer Repräsentation - no taxation without representation wurde schnell zum Schlachtruf der frühen Unabhängigkeitskämpfer. Die Antwort aus London ließ nicht lange auf sich warten: In Erinnerung an die Auseinandersetzung mit den kolonialen Nationalisten der irischen protestant ascendancy erhielt das britische Parlaments per Gesetz die letztendliche Zuständigkeit für die nordamerikanischen Kolonien. Der Text dieses Gesetzes indes war in den entscheidenden Passagen identisch mit der „Declatory Act“ von 1719/20. Während das irische Parlament damals von vornherein lediglich versucht hatte, dessen Vorschriften durch Missachtung zu unterwandern und letztlich einen Kompromiss mit Westminster erreichen konnte, sollte sich diesmal daran ein Funke entzünden, der nur zehn Jahre später, am 4. Juli 1776, zur Unabhängigkeitserklärung der 13 ehemaligen nordamerikanischen Kolonien Großbritanniens führte.

Die wachsenden Spannungen jenseits des Atlantiks wurden in Irland aufmerksam verfolgt. Seit dem frühen 18. Jahrhundert war ein steter, wenn auch nicht allzu starker, Strom von Emigranten, hauptsächlich aus Ulster, in die nordamerikanischen Kolonien geflossen und hatte auf diese Weise persönliche transatlantische Bindungen entstehen lassen, die entscheidend dazu beitrugen, dass die nordamerikanischen Siedler von vielen Iren als Schicksalsgenossen betrachtet wurden - dies umso mehr, als ihnen die Motive der amerikanischen Unabhängigkeitsbewegung wohlbekannt waren. Seit Ausbruch der Unruhen in den Kolonien hatten daher fast alle gesellschaftlichen Gruppen des Landes Solidaritätsadressen an die Amerikaner verabschiedet. Zahlreiche Zeitungen forderten zudem von der Dubliner Legislative und Exekutive, auf König Georg III., seine Regierung und das Parlament von Westminster dahingehend einzuwirken, den Konflikt mit friedlichen Mittel beizulegen. Allerdings wurde ein aktives irisches Eingreifen zugunsten der rebellierenden Amerikaner kaum gefordert im Gegenteil: Als sich der Konflikt durch das Eingreifen von Frankreich und Spanien auszuweiten drohte, stellte sich die politische Führung Irlands fast geschlossen hinter die britische Politik.

Die Einflüsse des amerikanischen Unabhängigkeitskrieges auf die irische Wirtschaft, Gesellschaft und Politik waren beträchtlich. Das im Jahre 1776 verhängte Exportverbot für Nahrungsmittel ließ nur noch Ausfuhren nach Großbritannien und 
in die nicht an der Rebellion beteiligten Kolonien zu. Damit versuchte die britische Regierung, die zur Versorgung der Truppen in Nordamerika Nahrungsmittel in großem Umfang einkaufen musste, die Preise so stabil wie möglich zu halten. Viele Produzenten in Irland protestierten anfangs energisch gegen solche Eingriffe und bezeichneten sie als den verfassungswidrigen Versuch, unliebsame Konkurrenz auszuschalten. Doch waren ihre Sorgen nur teilweise begründet, denn trotz aller Anstrengungen der britischen Regierung ließ die große Nachfrage nach Nahrungsmitteln die Preise kontinuierlich ansteigen, so dass die Absatzeinbußen wieder annähernd ausgeglichen werden konnten. Weit nachhaltigere Auswirkungen hatten die Rufe vieler britischer Grundbesitzer, die protektionistische Maßnahmen gegen irische Produkte zum Schutze der eigenen Erzeugnisse forderten. Sie belebten in Irland die Unabhängigkeitsdebatte neu, die, auch vor dem Hintergrund der aktuellen Ereignisse in Nordamerika, für die nächsten Jahre wieder das grand thème der heimischen Politik sein sollte. Im irischen Parlament mehrten sich erneut die Stimmen, die unverblümt die völlige irische Unabhängigkeit forderten. Sie sammelten sich um eine ursprünglich eher lose Verbindung von protestantischen Abgeordneten kolonial-nationaler Provenienz, die sich selbst den Namen Patriots gegeben hatten. Die Argumente, die sie benutzen, waren durchaus fundiert, hatte doch die britische Regierung in den vergangenen Jahren mehrfach heimische Interessen irischen Wünschen vorgezogen, gleichzeitig jedoch keine Zweifel an der Entschlossenheit aufkommen lassen, die Fäden politischer Macht in Irland auch künftig fest in den eigenen Händen halten zu wollen.' Im Umkehrschluss folgerten nun viele Angehörige der protestant ascendancy, dass die irische Unabhängigkeit die beste Voraussetzung für eine wirklich gedeihliche Zusammenarbeit mit Großbritannien sein würde - diese wurde selbst nicht in Frage gestellt, sondern als Grundlage der eigenen politischen Macht vorbehaltlos anerkannt. Prominentester Wortführer dieser Gruppe war der 1775 zum Führer der Patriots gewählte Unterhausabgeordnete Henry Grattan ${ }^{10}$.

Der Kriegsverlauf lieferte den irischen ,Patrioten' zusätzliche Argumente und förderte nachhaltig die Verbreitung ihrer politischen Ideen. Seit Ausbruch der Unruhen in den amerikanischen Kolonien, also seit Beginn der 70er Jahre, waren ständig Truppen aus Irland abgezogen worden. Dies schien durchaus vertretbar gewesen zu sein, da sich die innenpolitischen Verhältnisse des Landes wesentlich stabilisiert hatten und auch die irischen Katholiken offensichtlich den Status quo akzeptierten. Doch der Kriegseintritt Frankreichs und Spaniens änderte die strategische Lage Irlands und Britanniens grundlegend. Beiderseits der Irischen See erwachten lang vergessene Invasionsängste neu. Um einen wirkungsvollen Schutz vor Überfällen von

9 Vgl. dazu die detaillierte Schilderung der politischen Entwicklungen in den 60er und 70er Jahren in: R. B. McDowell, Ireland in the Age of Imperialism and Revolution, 1760-1801, Oxford 1979, dort bes. S. 209-274.

10 Zu Grattan vgl. R. B. McDowell, Grattan. A life, Dublin 2001. 
außen zu haben und über einen ausreichend großen Sicherheitsapparat im Falle von inneren Unruhen verfügen zu können, wurden mindestens 12.000 Soldaten benötigt. Im Jahre 1778 jedoch standen nur noch etwa 8.000 Mann in Irland unter Waffen. Die Gefahr einer Landung französischer Truppen in Großbritannien oder Irland war durchaus gegeben, zumal sich die meisten Einheiten der britischen Flotte in Übersee befanden und Frankreich, wenigstens zeitweilig, die Seeherrschaft im Kanalgebiet und in der Irischen See wiedererlangt hatte. Auch operierten in diesen Jahren einige amerikanische Kaperschiffe in den Gewässern rund um Irland, die dort relativ ungestört und erfolgreich Jagd auf britische Handelsschiffe machten. Die protestantischen Grundherren reagierten diesmal ungewöhnlich schnell auf die Herausforderung. Da die Regierung in Dublin nicht mehr über genügend Truppen verfügte, um die Küstenverteidigung aus eigener Kraft sicherzustellen, entstanden innerhalb weniger Wochen überall im Lande größtenteils aus privater Initiative der jeweiligen regionalen Magnaten oder kleinerer Gruppen von Grundbesitzern bewaffnete Milizverbände. Bei den Angehörigen dieser Verbände handelte es sich überwiegend um Freiwillige aus den Reihen der Pächter und der Kaufmannschaft, sie nannten sich daher schlicht Volunteers.

Deren fast ausnahmslos protestantisches Offizierskorps entstammte zumeist der gentry, während Unteroffiziere und Mannschaften überwiegend Landpächter, Kaufleute und Handwerker, also allesamt Angehörige der damaligen Mittelklasse waren. Obwohl die katholische Bevölkerung mehrfach versucht hatte, ihre Loyalität zum Staat zu beweisen, schreckten die meisten protestantischen Grundherren noch immer vor einer Aufnahme von katholischen Freiwilligen zurück, abgesehen davon, dass sich viele Katholiken eine Mitgliedschaft bei den Volunteers gar nicht leisten konnten, da diese für ihre Ausrüstung und Verpflegung selbst aufkommen mussten. So blieben die Angehörigen der ascendancy überwiegend unter sich. Doch da in den Korps die sozial einflussreichsten Schichten vertreten waren, wurde die Mitgliedschaft in einem der Korps schnell zur gesellschaftlichen Ehrensache.

1782 zählten die verschiedenen Freiwilligenverbände landesweit bereits über 100.000 Mitglieder. Sie verkörperten die Enttäuschung weiter Teile der Bevölkerung über die politischen Verhältnisse der Zeit, besonders über die Abhängigkeit des irischen vom britischen Parlament. Die britische Regierung und der Vizekönig in Dublin hatten keine andere Wahl - sie mussten die neu entstandene außerparlamentarische Kraft in Irland zur Kenntnis nehmen, wollten sie nicht riskieren, dass die Spannungen kulminierten und die Unzufriedenheit der kolonialen Nationalisten Irlands in eine Unabhängigkeitserklärung nach amerikanischem Vorbild mündete. Angesichts des britischen Engagements jenseits des Atlantiks reichten die Heimattruppen bei weitem nicht aus, um der neuen Herausforderung erfolgreich mit militärischen Mitteln begegnen zu können. Die Regierung entschloss sich daraufhin, einigen zentralen Forderungen der irischen protestant ascendancy nach größerer poli- 
tischer und wirtschaftlicher Unabhängigkeit von London stattzugeben. ${ }^{11}$ Diese Maßnahmen wurden in Irland überwiegend wohlwollend, zum Teil sogar begeistert aufgenommen. Schließlich schienen auf den ersten Blick alle Wünsche nach politischer und wirtschaftlicher Unabhängigkeit in Erfüllung gegangen zu sein. Der Eindruck wurde durch die Einrichtung eines eigenen irischen Postwesens und einer irischen Nationalbank noch unterstrichen. Doch trotz der weitreichenden Zugeständnisse besaß London nach wie vor erhebliche, wenn auch überwiegend informelle, Mitspracherechte in irischen Fragen. Zwar war es nun das verbriefte Exklusivrecht des Parlaments in Dublin, Gesetze für Irland zu erlassen, doch Rechtswirksamkeit erhielten sie erst durch das Siegel des britischen Lordkanzlers, der wiederum vor der Besiegelung die Zustimmung des britischen Kabinetts einzuholen hatte. Ferner wurden der Vizekönig und sein Stellvertreter nach wie vor von der Krone ernannt und gehörten auch nach 1782 der jeweiligen britischen Regierung an. Trotz dieser offensichtlichen Defizite war die Mehrheit der irischen Parlamentarier indes mit dem Erreichten ebenfalls zufrieden, schließlich konnte man der britischen Krone nun Loyalitätsadressen zukommen lassen, ohne einen Gesichtsverlust im Lande fürchten zu müssen. Auch war es weiterhin möglich, an dem im Einzelfall oftmals durchaus profitablen Patronagesystem der Krone teilzuhaben.

Die Reformen sorgten dafür, dass die 1780er Jahre für die anglo-irischen Beziehungen ein relativ ruhiges Jahrzehnt sein sollten. In Irland wie in Großbritannien schien der Wunsch nach einer Atempause zur Erholung von den stürmischen Ereignissen, die den äußeren Rahmen ebenso wie die inneren Strukturen des Empire so nachhaltig verändert hatten, das politische Leitmotiv dieser Jahre zu sein. Dennoch blieben viele Fragen, besonders in Bezug auf die Gestaltung der wirtschaftlichen Zusammenarbeit, offen. Die Notwendigkeit einer Überarbeitung der handelspolitischen Beziehungen zwischen beiden Ländern waren schon in den frühen 80er Jahren festgestellt worden, als in Folge einer Missernte in Irland Stimmen laut wurden, die protektionistische Maßnahmen gegen britische Agrarerzeugnisse verlangten. Diese Reaktion forderten jene Kräfte in beiden Hauptstädten heraus, die sich der Schaffung föderaler Reichsstrukturen ohne Handelsschranken verschrieben hatten. Sie erkannten, dass ein solches Ziel nur durch ein Vertragswerk erreicht werden konnte, in das die gegenseitigen Wirtschaftsbeziehungen ebenso wie Sicherheitsfragen mit einbezogen sein würden. ${ }^{12}$

Der irische Hauptgesprächspartner bei den Entwurfsverhandlungen war Henry Grattan, zu dieser Zeit immer noch Sprecher der Patriots, mittlerweile jedoch die dominierende Persönlichkeit im irischen Unterhaus schlechthin. Es gelang ihm, den

11 Vgl. Tony Claydon / Ian McBride (Hg.), Protestantism and National Identity. Britain and Ireland, c. 1650c. 1850, Cambridge 1999.

12 Vgl. Liam de Paor, The Peoples of Ireland. From Prehistory to Modern Times, New York 1986, S. 206. 
Briten noch zwei weitere Konzessionen abzuringen: Bei Inkrafttreten des Vertrages wäre dem irischen Parlament ein unabhängiges Kontrollrecht der Beträge zum Ausbau der Royal Navy vorbehalten worden, womit es ein direktes Mitbestimmungsrecht in Verteidigungsangelegenheiten erhalten hätte. Ferner sollte das Abkommen zunächst das irische Parlament passieren, bevor es in Westminster zur Entscheidung vorgelegt worden wäre. Die erste Hürde bereitete keinerlei Schwierigkeiten, doch in Westminster verursachte der Entwurf eine wahre Welle der Entrüstung und Empörung. Besonders die britischen Händler und Manufakturbetreiber wandten sich energisch gegen die Zugeständnisse an die irische Konkurrenz. Dabei nutzten sie alle ihnen zur Verfügung stehenden Mittel und Möglichkeiten aus, einschließlich einer intensiven und kostenaufwendigen Pressekampagne. Nachdem die Parlamentarier zwanzig Änderungsvorschläge formuliert hatten, wurde der so überarbeitete Entwurf mit der denkbar knappen Mehrheit von 20 Stimmen angenommen, nur um diesmal am 15. August 1785 nach der Rückverweisung im irischen Unterhaus zu scheitern.

Inhalt und letztliches Scheitern des geplanten Abkommens spiegeln den Stellenwert wieder, der beiderseits der Irischen See dem Verbleib Irlands im britischen Empire beigemessen wurde, sie reflektieren aber auch die grundsätzlich unterschiedlichen Auffassungen von der Art des Verbleibs. Premierminister Pitt setzte zunächst mit guten Gründen auf freiwillige Kooperation. Nach dem Ausscheiden der ehemaligen nordamerikanischen Kolonien aus dem Reichsverbund stellte Irland aufgrund seiner unmittelbaren geographischen Nähe zum Mutterland des Empire den Prüfstein für die weitere Funktionsfähigkeit imperialer Zusammenarbeit und für die Durchsetzungskraft Großbritanniens im imperialen Verbund dar. Ein Ausscheiden des unmittelbaren Nachbarn hätte auf die überseeischen Territorien eine deutliche Signalwirkung ausgeübt und diese vielleicht dem nordamerikanischen und irischen Beispiel folgen lassen. Es wäre ferner von rivalisierenden europäischen Mächten mit imperialen Ambitionen wie zum Beispiel von Frankreich, Spanien oder den Niederlanden zu Recht als ein Zeichen der Schwäche interpretiert worden und hätte möglicherweise bewaffnete Konflikte in Übersee um dortige Besitzungen nach sich gezogen, denen London nach dem kräftezehrenden Kampf in Nordamerika noch nicht gewachsen war. Ein im beiderseitigen Einverständnis geschlossener Vertrag jedoch, der den freiwilligen Verzicht auf bestimmte Hoheitsrechte kodifiziert hätte, wäre international als Symbol für die Handlungsfähigkeit des British Empire gewertet worden. Aus reichs- und außenpolitischer Perspektive sind die weitgehenden Zugeständnisse, mit denen die britische Regierung die kolonialen Nationalisten in Irland zum Verbleib im Empire bewegen wollte, also durchaus nachvollziehbar. Der heftige Protest, auf den der Vertragsentwurf im Londoner Parlament stieß, war hauptsächlich Ausdruck der Angst vieler britischer Unternehmer und Kaufleute vor einem Verlust liebgewonnener Privilegien, die sie massiven Druck auf Westminster ausüben ließ. Dieser Druck war indes durchaus willkommen, hätte die Akzeptanz des Abkom- 
mens doch einen realen Machtverlust beider Häuser zur Folge gehabt. Darauf indes brauchten die Mitglieder des House of Commons bei den Nachbesserungen nun nicht mehr explizit hinzuweisen.

Angesichts des prononcierten Kolonialnationalismus in Irland barg die starre Haltung Westminsters das verhältnismäßig große Risiko in sich, eine Sezessionserklärung des irischen Parlaments zu provozieren, wo mittlerweile die meisten Abgeordneten den Patriots Henry Grattans zuzurechnen waren. Dieses Risiko war freilich kalkulierbar, hatte doch das Verhalten der irischen Parlamentarier in den zurückliegenden Jahren stets darauf schließen lassen, dass sie nicht daran dachten, den konstitutionell festgelegten Handlungsrahmen zu überschreiten. Zwar hatten Grattan und seine Patriots nach dem Scheitern des anglo-irischen Abkommens noch einmal nachdrücklich darauf hingewiesen, dass sie, vor die Wahl gestellt, zwischen Empire und Freiheit entscheiden zu müssen, stets für die Freiheit votieren würden, doch gelang es ihnen in den folgenden Jahren nicht, jene Integrationskraft zu entwickeln, die nötig gewesen wäre, um die gespaltene irische Gesellschaft hinter sich zu vereinen. Stattdessen erhielten am Rande der kolonialnationalen Bewegung solche Kräfte größeren Zulauf, die zu einem radikaleren Vorgehen auf dem Weg zur Unabhängigkeit von Großbritannien bereit waren. Doch für London schloss, schon die imperiale Raison eine irische Unabhängigkeit von vornherein aus. Nachdem die Vertragsinitiative gescheitert war, nahm Premierminister Pitt daher eine grundsätzliche Neuorientierung seiner Irlandpolitik vor, die allerdings mit den im irischen Parlament und in der irischen Gesellschaft entwickelten Vorstellungen über das bilaterale Verhältnis nicht mehr vereinbar war.

Die Wellen, die die revolutionären Entwicklungen in Frankreich schlagen ließ, trieben auch in Irland die Frage nach einer Neudefinition des irischen Selbstverständnisses schneller als bislang voran, möglicherweise dort aufgrund der jahrhundertealten guten familiären, religiösen, kulturellen und ökonomischen franko-irischen Beziehungen sogar noch schneller und radikaler als in anderen Teilen des Kontinents. Auch auf der irischen Insel lösten sie eine heftige Debatte über politische Grundsatzfragen aus, in denen die liberalen Kräfte nach Analogien zwischen den französischen Ereignissen und der glorious revolution suchten, während die Konservativen eher vor den Gefahren eines völligen Zusammenbruchs staatlicher Autorität warnten.

Vor diesem Hintergrund verbesserten sich die Beziehungen zwischen den Patriots im Dubliner Parlament und den Whigs im britischen House of Commons signifikant. ${ }^{13}$ Daraus entstand in der Folgezeit eine Art Kooperation, die bis zur Übernahme bestimmter, schon seit längerem von der britischen Opposition gestellter Forderungen durch Grattan und seine Mitstreiter führte. Diese bezogen sich zumeist auf Kritik

13 Vgl. dazu die entsprechenden Ausführungen bei: Clemens Körte, Rechtsbewusstsein und Verrechtlichung in der irischen Agrargesellschaft 1760-1850, Göttingen 2006. 
an der bestehenden Form parlamentarischer Repräsentation, an der Form der Patronage, der Ämtervergabe und anderer Mittel, die die Regierungspartei anwandte, um die Sitzmehrheit zu erhalten. Damit jedoch wurden auch die Bindungen der Patriots an das britische politische System wieder gestärkt, so dass sich Grattan im Sommer 1790, als die Spannungen zwischen Großbritannien und Spanien aufgrund rivalisierender Gebietsansprüche an der nordamerikanischen Westküste sich bedrohlich verstärkten und ein neuer Krieg nicht mehr ausgeschlossen werden konnte, zu einer öffentlichen Erklärung entschloss, in der er betonte, dass die Interessen Großbritanniens und Irland nicht voneinander zu trennen seien.

Dies stieß bei vielen engagierten irischen Kolonialnationalisten auf heftige Kritik. So veröffentlichte beispielsweise Theobald Wolfe Tone, ${ }^{14}$ ein junger protestantischer Dubliner Rechtsanwalt, daraufhin eine Flugschrift, in der er darauf hinwies, dass sich Irland nicht in einem Konflikt mit Spanien befinden würde und dass der Hinweis auf die Notwendigkeit irischer Hilfe für Großbritannien zum Wohle des Empire, den Grattan in seiner Loyalitätsadresse gegeben hatte, eine trügerische und hohle Phrase gewesen sei. In seiner berühmt gewordenen Schrift mit dem Titel „An argument on behalf of the catholics in Ireland" folgerte er im darauffolgenden Jahr, dass die einzige Möglichkeit, dem britischen Einfluss auf irische Angelegenheiten begegnen zu können, eine Parlamentsreform sei, die nur durch eine enge Zusammenarbeit der irischen Katholiken und der radikalen Protestanten erreicht werden könne. Tones Forderungen entsprachen den Ansichten vieler aufgeklärter Liberaler und radikaler Protestanten in Irland, sie wurden gleichfalls von den Führern der organisierten Katholiken nachdrücklich begrüßt. Überall im Lande trafen sich unter maßgeblicher Beteiligung der verschiedenen lokalen und regionalen Volunteer-Korps aufgeklärte Protestanten und Katholiken, um nach Wegen zu suchen, auf denen die geteilte irische Gesellschaft unter Berücksichtigung der Ideale der - zwischenzeitlich offensichtlich nicht mehr kontrollierbaren - französischen Revolutionäre zu einer, freien, gleichen und gerechten Gemeinschaft geführt werden sollte.

Besonders beliebt für solche Treffen waren die Jahrestage des Sturms auf die Bastille, und so wurden dann auch erstmals am 14. Juli $Z$ auf einer Bürgerversammlung in Belfast Überlegungen die Gründung einer politischen Vereinigung betreffend angestellt, in der gleichermaßen Protestanten wie Katholiken vertreten sein sollten. Die Ulster-Metropole, zu dieser Zeit ein etwa 20.000 Einwohner zählender aufstrebender Industriestandort, bot sich für ein solches Treffen besonders an, da im irischen Nordosten im Gegensatz zum eher staatskirchlich-konservativ orientierten Dubliner Verwaltungssitz aufgeklärtes Unternehmertum presbyterianischer Provenienz dominierte, das sich von der Bildung einer neuen Gesellschaft auf der Grundlage gemein-

$14 \mathrm{Zu}$ Tones Bedeutung bei der Formierung der United Irishmen vgl. Sean Cronin, Irish Nationalism. A History of Its Roots and Ideology, Dublin 1980. 
samer katholischer und presbyterianisch-protestantischer Interessen die Ablösung der alten Herrschaftsstrukturen erhoffte. Nur wenige Wochen später, am 14. Oktober 1791, wurde das Statut der Belfast Society of United Irishmen verabschiedet, an dessen Formulierung Theobald Wolfe Tone maßgeblich beteiligt war. ${ }^{15}$

Der starke Zulauf, den die United Irishmen mit ihrem konfessionsübergreifenden Ansatz verbuchen konnten, erweckte manche Organisationen zu neuem Leben, die längere Zeit kaum an die Öffentlichkeit getreten waren, sich nun aber mit ähnlich lautenden Forderungen wieder an die Öffentlichkeit wandten. Nach langen Jahren relativer Stabilität hatte der Reformprozess somit in kurzer Zeit eine brisante Gemengelage aus divergierenden politischen und sozialen Interessen entstehen lassen. Zwar verfügten die liberalen Abgeordneten um Henry Grattan nach wie vor über großen Einfluss im Parlament, doch ihre Bereitschaft zu weiteren Konzessionen an die Katholiken und zu einer moderaten Parlamentsreform, mit denen sie einen gesamtgesellschaftlichen Konsens erreichen wollten, stieß auf wachsende Kritik beiderseits der Irischen See. In London weckten überdies seit Anfang 1794 vertrauliche Hinweise auf Kontakte zwischen den United Irishmen und Repräsentanten des revolutionären Frankreichs alte Invasionsängste zu neuem Leben.

Diese Ängste und Sorgen waren nicht unbegründet. Aus Enttäuschung über den ihrer Meinung nach allzu langsamen Fortschritt des Reformprozesses hatten in der Tat einige führende Vertreter der United Irishmen, unter ihnen Tone, im April 1794 Verbindung mit dem französischen Nationalkonvent aufgenommen und diesem eine Liste von Bedingungen übergeben, unter denen sie eine Landung französischer Truppen in Irland unterstützen würden. Die Regierung war durch eigene Agenten über jede Phase dieser Konspiration informiert, konnte Jackson daher vor seiner Rückkehr nach Frankreich verhaften lassen und damit auch die Überbringung der Bedingungen verhindern, doch besaß sie außer dem begründeten Verdacht keinerlei Beweise, die gegen die irischen Verschwörer verwendet werden konnten. Diese nutzten ihre guten Kontakte zur vizeköniglichen Administration in Dublin, um einen allseits akzeptablen Ausweg aus dem Dilemma zu finden. Der Kompromiss sah vor, dass Tone alle Verantwortung an dem Treffen auf sich nahm, dafür nach Nordamerika ins Exil gehen durfte und die Regierung als Gegenleistung auf eine weitere Verfolgung von Angehörigen der - durch den Verlust eines fähigen Organisators und ausgewiesenen politischen Publizisten nun erheblich geschwächten - United Irishmen in dieser Angelegenheit verzichtete. ${ }^{16}$

In Ulster, besonders in der Grafschaft Armagh, schlossen sich zur selben Zeit Protestanten zu bewaffneten Geheimbünden, den sogenannten fleets zusammen. ${ }^{17}$

15 Vgl. Jürgen Elvert, Geschichte Irlands, ${ }^{4} 2003$, Kapitel 5.

16 Vgl. Tom Dunne, Rebellions. Memoir, Memory and 1798, Dublin 2004.

17 Zur Formierung von Geheimgesellschaften im revolutionären Irland vgl. Jürgen Elvert, Geheimbünde und 
Damit verstießen sie zwar gegen geltendes Recht, doch sah sich die ohnehin krisengeschüttelte Dubliner Regierung nicht in der Lage, dagegen einzuschreiten. Die Mitglieder einer dieser Verbände nannten sich selbst in Erinnerung an Wilhelm von Oranien Orange Boys. Aus dieser Gruppe sollte sich wenig später der Loyal Orange Order, die bis heute wirksamste außerparlamentarische anti-katholische pressure-group Ulsters herausbilden. ${ }^{18}$ Die Protestanten beriefen sich bei ihren Aktionen, die vornehmlich gegen katholische Pächter oder Weber gerichtet waren, auf das immer noch geltende Verbot des Waffenbesitzes für Katholiken. Dieses Gesetz würde, so hieß es, durch die Zugehörigkeit zu den Milizverbänden systematisch unterlaufen und sei eine permanente Bedrohung der eigenen Sicherheit. Die Reaktion der Katholiken ließ nicht lange auf sich warten. In kurzer Zeit entstanden landesweit eigene Geheimbünde, die sogenannten Defenders, die durch ein wirksames Netzwerk von Verbindungen eng miteinander kooperierten und sich nötigenfalls gegenseitig schnelle Hilfe zukommen lassen konnten. Im Gegensatz zu den protestantischen Gruppen besaßen die katholischen Geheimbünde sogar so etwas wie eine politische Programmatik. Diese jedoch war wenig differenziert und offensichtlich populistisch - man forderte niedrigere Pachtsätze, höhere Löhne für Landarbeiter sowie die Reduktion oder gänzliche Abschaffung des Zehnten. In ihren oftmals brutalen Methoden unterschieden sie sich indes nicht von ihren protestantischen Widersachern: anonyme Drohbriefe, öffentliche anonyme Verunglimpfung missliebiger Personen, Angriffe auf Haus und Hof der Gegner sowie Überfälle zur Beschaffung von Waffen.

Zunächst hielt sich die sektiererische Gewalt in Grenzen und war oftmals eher das Ergebnis zufälliger Aufeinandertreffen, während sich der alltägliche protestantisch-katholische Antagonismus in Ulster hauptsächlich im Wettstreit um gutes Ackerland, auf Viehmärkten oder auch, dann eher sportlich, bei Hahnenkämpfen zeigte. Das Jahr 1795 markiert indes einen Wendepunkt, denn von nun an wurde die Auseinandersetzung gezielter, planmäßiger und mit weitreichenderen Konsequenzen ausgetragen. So gelang es einer gut organisierten Gruppe protestantischer Peep-o'Day Boys im Jahre 1795 binnen weniger Wochen, in Nordarmagh etwa tausend Katholiken aus ihren Häusern zu vertreiben und zur Auswanderung in weniger dicht besiedelte Regionen, hauptsächlich nach Connacht, zu zwingen, ohne dass die Magistrate der betroffenen Gemeinden dagegen eingeschritten wären oder die Dubliner Regierung Truppen zum Schutz der nun existentiell bedrohten Katholiken in Marsch gesetzt hätten. Die Reaktion der Defenders ließ nicht lange auf sich warten. Im September terrorisierte eine Gruppe von ihnen wochenlang protestantische Farmen im Norden der Grafschaft. Es kam, wie es kommen musste: Die bedrohten Farmer riefen

kolonialer Nationalismus in Irland von der Mitte des 18. Jahrhunderts bis zum Vollzug der anglo-irischen Union von 1801, in: Volkhard Huth (Hg.), Geheime Eliten?, Frankfurt/ Main 2014, S. 345-362.

18 Vgl. Sean J. Connolly, Divided kingdom. Ireland, 1630-1800, Oxford 2008, S. 432. 
die Peep-o'-Day Boys um Hilfe, diese kamen nur zu gerne und stellten die katholische Sektierer in der Nähe von Loughgall an einem Ort namens The Diamond. ${ }^{19}$ Die besser ausgebildeten und ausgerüsteten Protestanten verließen das Schlachtfeld als Sieger und ließen über 30 tote Defenders zurück. In den folgenden Wochen und Monaten verstärkten sich die Übergriffe protestantischer Gangs auf unbeteiligte katholische Bewohner der Grafschaft, denen nun keine, Verteidiger' mehr zur Hilfe kommen konnten. Erneut sahen die Regierungsvertreter sowie ortsansässige landlords mehr oder weniger tatenlos zu. Nach wie vor verfügten sie selbst nicht über genügend Mittel, um diese Übergriffe zu verhindern, doch nicht ohne Grund befürchteten viele von ihnen, sollten sie trotzdem gegen einzelne fleets vorgehen, einen Übergriff des protestantischen Protestes auf andere Grafschaften Ulsters.

Zwischenzeitlich hatten sich sowohl die politischen Ziele als auch die organisationalen Strukturen der United Irishmen erheblich verändert. Sie mussten erkennen, dass weder die Regierung in Dublin, noch Regierung, Krone oder Parlament in London bereit waren, auf ihre umfassenden Reformpläne einzugehen. Stattdessen strebten sie nun die Errichtung einer Irischen Republik an, die mit französischer Hilfe erfolgen sollte. Unter dem Druck des neuen Versammlungsgesetzes von 1793 war es seither nicht mehr möglich gewesen, nach bewährtem Muster Versammlungen abzuhalten, auf denen die Ziele öffentlich diskutiert und dadurch in der Bevölkerung verbreitet werden konnten. Im Verlauf des Jahres 1795 vereinigten sich überdies United Irishmen und Defenders zu einer radikalrepublikanischen Bewegung in Irland, die auch über einen eigenen paramilitärischen Apparat verfügte.

Der Verbindungsmann der Organisation zum Direktorium in Paris war Theobald Wolfe Tone. Auch aus seinem nordamerikanischen Exil hatte er enge Kontakte nach Irland aufrechterhalten können und war schließlich aufgefordert worden, persönlich nach Frankreich zu reisen, um ,vor Ort' die Interessen der United Irishmen wahrzunehmen. Nachdem am 5. April 1795 französische und preußische Unterhändler in Basel Friedensbedingungen ausgehandelt hatten, war eine der großen Mächte aus der europäischen Anti-Revolutions-Koalition ausgeschieden. Aufgrund der verbesserten strategischen Lage Frankreichs konnte nun eine militärische Unterstützung der irischen Republikaner durchaus gewährt werden. Ohne die Aussicht auf auswärtige Militärhilfe wären alle Erhebungspläne der irischen Radikalen aufgrund der Kräfteverhältnisse im Lande von vornherein nur Makulatur gewesen. Es galt daher, diese Botschaft auf allen verfügbaren Kanälen dem Adressaten zu übermitteln. So reisten im Mai des Jahres zwei Mitglieder ihres Führungsrates nach Hamburg, um auch dort mit einem Agenten des Direktoriums die Bedingungen für eine französische Intervention in Irland zu erörtern. Zur selben Zeit war Tone bereits in Paris eingetroffen. Seine Eloquenz und sein Charisma öffneten ihm in kurzer Zeit die Türen zu einigen

19 Sean J. Connolly, Oxford Companion to Irish History, Oxford 2007, S. 434. 
maßgeblichen Angehörigen der französischen Regierung. Als besonders wichtig für den weiteren Verlauf der Planungen erwiesen sich bald seine Kontakte zum amtierenden Verteidigungsminister Lazare Carnot, der sich nach anfänglichem Zögern im Frühjahr 1796 den Argumenten des Iren anschloss. Dieser hatte stets den strategischen Nutzen betont, den Frankreich aus einer Landung in Irland ziehen könnte, zumal, laut Tone, $80 \%$ der irischen Bevölkerung, Katholiken und Presbyterianer, der Dubliner Regierung ablehnend gegenüberstünden. Zweifellos waren die Zahlen des irischen Gesandten zumindest geschönt, auch konnte er nicht garantieren, dass die irische Bevölkerung nach einer Landung französischer Truppen tatsächlichem ,mit fliegenden Fahnen' ins republikanische Lager wechseln würde, doch bot ein entschlossen durchgeführtes französisches Landungsunternehmen in Irland, das wenigstens nicht auf den offenen Widerstand der Bevölkerung treffen würde, in der Tat interessante militärstrategische Perspektiven. Schließlich hätte Großbritannien mit einem Abfall Irlands eine wichtige Nachschubbasis verloren, auch wäre von irischem Boden aus ein Angriff auf die relativ ungeschützte britische Flanke an der Irischen See leichter gewesen als im stark befestigten Südengland.

Dieser Erkenntnis konnten sich auch die übrigen Mitglieder des Direktoriums nicht widersetzen. Im Juni 1796 fiel die Entscheidung zugunsten der Entsendung eines Expeditionskorps nach Irland. ${ }^{20}$ Bald danach begann Carnot in Zusammenarbeit mit Lazare Hoche, einem der jungen und ehrgeizigen Generäle, die die Revolution hervorgebracht hatte, die konkreten Planungen und Vorbereitungen, die schnellstmöglich abgeschlossen sein sollten. Doch zögerte ein mangelhaftes Kommunikationssystem zwischen Paris und der Provinz die Aufstellung der Truppe sowie die Ausrüstung der notwendigen Schiffe über Gebühr hinaus, so dass das 15.000 Mann starke Korps erst im Dezember des Jahres einsatzbereit war. Anstatt besseres Wetter abzuwarten, entschloss sich Hoche zur sofortigen Durchführung der Operation. Schnell erwies sich dies als ein verhängnisvoller Fehler. Zwar gelang es der Royal Navy nicht, die französische Flotte nach dem Auslaufen aus Brest abzufangen, doch wurde diese von heftigen Winterstürmen auseinandergerissen. Lediglich ein Drittel der Schiffe gelangte bis in die Bantry Bay, nur um nach wenigen Tagen feststellen zu müssen, dass widrige Witterungsverhältnisse eine Landung der Truppen ausschlossen. Unverrichteter Dinge mussten die Schiffe schließlich in ihren Ausgangshafen zurückkehren.

Auch wenn diese Operation letztlich kläglich gescheitert war, zogen die britische Regierung und die Dubliner Administration energische Konsequenzen. Der Durchbruch der französischen Flotte hatte die Mängel des bisherigen Blockadesystems der kontinentalen Häfen offengelegt. Die Admiralität in London reagierte rasch

20 Zur geplanten Landung französischer Truppen in Irland vgl. Thomas Pakenham, The Year of Liberty. The Story of the Great Irish Rebellion of 1798, London 2000. 
und verstärkte die für die Blockade eingesetzten Schiffseinheiten sowie deren Taktik so nachhaltig, dass die französische Marine die Britischen Inseln bis zur endgültigen Niederlage Napoleons nicht mehr unmittelbar bedrohen konnte. Die enge Kommunikation zwischen den United Irishmen und dem Pariser Direktorium hatte ferner die Gefährlichkeit der irischen Radikalen für die bestehende Ordnung des Landes gezeigt. Eine Reihe von Notstandsverordnungen schränkte die erst vor kurzem gewährten Bürgerrechte wieder ein und erleichterte den Staatsorganen die Kontrolle verdächtiger Personen.

Die Aufstände des Jahres 1798, denen sich noch vereinzelte isolierte Revolten in den folgenden Monaten anschlossen, kosteten etwa 50.000 Menschen das Leben. Doch so blutig die Erhebungen auch waren und so viele nationalirisch inspirierte Mythen und Legenden später um diese Ereignisse gewebt werden mochten, die dadurch in den Rang eines einheitlichen und zentral gelenkten Aufstandes erhoben werden sollten, ändert das nichts an den historisch belegbaren Rahmenbedingungen. Es waren spontane Proteste, die zumeist von ehemaligen Anhängern der liberalen Politik Henry Grattans der späten 80er und frühen 90er Jahre des Jahrhunderts geführt wurden, denen die erreichten Reformen nicht genügten und deren radikale republikanische Ideale in der Auseinandersetzung mit einer zur Bewahrung des Status quo entschlossenen Staatsmacht chancenlos waren. Wesentlich größere Tragweite für den weiteren Verlauf der irischen Geschichte hatte denn auch eine politische Entscheidung des britischen Premierministers, an der dieser vermutlich schon seit einigen Jahren arbeitete, deren Realisierung indes letztlich erst vor dem Hintergrund des Sommers 1798 verständlich wird: dem Vollzug der Union. ${ }^{21}$ Er maß dem Verbleib Irlands im Empire, wie er seit seinem Amtsantritt im Jahre 1784 immer wieder betont hatte, eine erhebliche symbolische Bedeutung für den Bestand des britischen Weltreiches an sich bei. Besonders nach dem Abfall der amerikanischen Kolonien hätte die Unabhängigkeit Irlands einen Präzedenzfall für andere Teile des Reiches bieten können. Nachdem seine Initiative zur Schaffung eines einheitlichen anglo-irischen Wirtschaftsraumes bei gleichzeitiger Anerkennung bestimmter Formen nationaler Unabhängigkeit 1785 an den Parlamenten in London und Dublin gescheitert war, musste nun eine andere Lösung gefunden werden. Die politischen Entwicklungen und Verwicklungen nach Ausbruch der französischen Revolution hatten zwar zwischenzeitlich das irische Problem überlagert, angesichts einer drohenden, pointiert anti-britischen franko-irischen Republikanerallianz trat es nun umso deutlicher wieder hervor.

Doch auch wenn vor dem Hintergrund der zurückliegenden Ereignisse die Notwendigkeit einer engen anglo-irischen Kooperation in Sicherheitsfragen von den meisten Angehörigen des Dubliner Parlaments nicht bestritten wurde, wenn diese

$21 \mathrm{Zu}$ Pitts Unionsplänen und deren Durchführung vgl. z. B. Michael J. Turner, Pitt the Younger. A Life, London 2005. 
die Kooperation darüber hinaus auch aus ökonomischen Erwägungen gar nicht in Frage stellen wollten, stand die weitaus größte Mehrheit des irischen Parlaments dem Vollzug einer Union, also der Auflösung einer eigenständigen irischen Legislative, ablehnend gegenüber. Sicher: Pitt besaß einige Verbündete jenseits der Irischen See, besonders unter den konservativen Protestanten, die sich von der Union einen verbesserten Schutz protestantischer Privilegien erhofften, schließlich hätten sich die Protestanten dann nicht mehr in einer Minderheitsposition befunden, sondern wären, wie die Mehrheit der Bevölkerung, Angehörige der Staatskirche gewesen. Auch sprachen viele ökonomische Argumente für die Vereinigung der beiden Königreiche, wäre es unter einem einheitlichen staatlichen Dach doch beispielsweise für viele potentielle britische Investoren leichter gewesen, ihr Geld auch in Irland anzulegen, was fraglos zu einer Verbesserung des irischen Lebensstandards beigetragen hätte. Doch war dies im Dubliner Parlament noch die Meinung einer (wenn auch starken) Minderheit, die Mehrheit, das stand spätestens im Februar 1799 fest, als das irische Parlament erstmals das Für und wider einer Union mit Großbritannien erörterte, teilte diese Meinung nicht, denn der Entwurf wurde mit 109 zu 104 Stimmen abgelehnt. Charles Cornwallis, seit 1798 Vizekönig in Irland, erhielt daher vom Premierminister den Auftrag, nachhaltige Überzeugungsarbeit zu leisten und, wenn diese keinen Erfolg haben sollte, nötigenfalls auch mit großzügigen Geldmitteln und der Aussicht auf weitere persönliche Vorteile um Unterstützung für die Unionspläne zu werben.

Die vizekönigliche Behörde musste in den folgenden Wochen auf vielen Ebenen um Sympathien für die Pläne Pitts werben, die zwischenzeitlich auch die Zustimmung des britischen Parlaments gefunden hatten. Erste Zielgruppe waren natürlich die Abgeordneten des irischen Parlaments, ohne deren Zustimmung eine Union nicht möglich gewesen wäre. Darüber hinaus galt es, sich möglichst großer Unterstützung durch die Bevölkerung zu versichern, von der man sich nachhaltige Rückwirkung auf die Haltung der Parlamentarier erhoffte. Dies jedoch wussten auch die entschiedenen Unionsgegner, so dass beide Gruppen mit beachtlichem Aufwand die Bürger des Landes über die Vor- und Nachteile eines Vereinigten Königreiches von Großbritannien und Irland informierten. In großem Umfang nutzten sie dabei die vorhandenen Publikationsorgane sowie Flugblätter und Plakate. Daneben boten sie allen Interessierten die Gelegenheit, sich auf Versammlungen und anderen öffentlichen Veranstaltungen zu informieren. Die Wirkung dieser Kampagnen war zweifellos groß, dennoch sind auch nur annähernd zuverlässige Schätzungen ihres tatsächlichen Wirkungsgrades nicht möglich, dazu waren die Einflüsse regionaler, sozialer oder ökonomischer Partikularinteressen zu unterschiedlich. Lediglich einige allgemeine Stimmungstrends sind anhand von zeitgenössischen Stimmungsberichten und anderen Aufzeichnungen nachvollziehbar. ${ }^{22}$

22 Zur Abstimmung über die Union vgl.: Elvert, 2003 (wie Anm. 15), Kap.5. 
So scheinen sich die Bürger Dublins, um die herausragende Rolle der Stadt als Metropole eines eigenen Königreiches besorgt, mehrheitlich gegen eine Union ausgesprochen zu haben, während die Stimmung in Cork und Belfast in dieser Frage eher geteilt war. Hier beeinflussten offensichtlich Überlegungen über die Vor- und Nachteile einer engeren ökonomischen Kooperation das Stimmungsbild. Die Protestanten waren in der Unionsfrage tief gespalten. Während viele Anhänger der Staatskirche die Sicherheit zu schätzen wussten, die ihnen im Rahmen eines Vereinten Königreiches geboten werden konnte, fürchteten die Presbyterianer mehrheitlich den Verlust von Handlungsfreiheiten, die sich im Laufe der Zeit in ihren Hauptsiedlungsgebieten, vorwiegend im irischen Norden, erstritten hatten. Auf den ersten Blick erstaunlich sind die überlieferten katholischen Reaktionen. Einmal abgesehen von den wenigen Radikalrepublikanern, die die Aufstände des Sommers 1798 und die anschließenden Verfolgungen durch die Staatsmacht überlebt hatten, und ferner abgesehen von einigen engagierten Anhängern des liberal-nationalen Kurses Henry Grattans waren die Ansichten in der Unionsfrage durchaus differenziert. Offenbar stießen die Hinweise des Vizekönigs auf die Gewährung völliger Gleichberechtigung nach Verabschiedung des Unionsgesetzes gerade bei vielen kirchlichen Würdenträgern auf großes Interesse. Bei ihnen waren die Erinnerungen an die Ausschreitungen gegen katholische Priester im revolutionären Frankreich noch in sehr guter Erinnerung, die Tausenden das Leben gekostet hatten. Angesichts der immer noch virulenten Bedrohung der Britischen Inseln durch Frankreich schien die relative Sicherheit im Rahmen eines gestärkten Großbritannien mit möglicher Aussicht auf Gleichberechtigung eine bessere Perspektive zu bieten als die relative Unsicherheit in einem revolutionär-republikanischen System.

Andere Mittel mussten zur Umstimmung der Abgeordneten angewendet werden. Da der Entwurf der Unionsakte im Unterhaus 100 (von 658), im Oberhaus 32 Sitze für die Repräsentanten Irlands vorsah, bedeutete dies für drei von vier Mitgliedern der beiden irischen Häuser zunächst den Abschied von der Tätigkeit als Parlamentarier. Auch wenn sich nur wenige der Betroffenen von solchen Überlegungen leiten ließen, erlaubten die knappen Mehrheitsverhältnisse kein Risiko. Der Vizekönig und seine Bevollmächtigten prüften jeden Einzelfall, garantierten stets die soziale Absicherung und in besonders hartnäckigen Fällen sogar noch einen Profit für den Fall, dass die Unionsakte angenommen werden würde. Es gab also bei dem Verfahren um das anglo-irische Unionsgesetz einige Fälle von Bestechung. Allerdings muss rückblickend festgestellt werden, dass sich die meisten Abgeordneten des Dubliner Parlaments bei ihrer Entscheidung für oder gegen das Vereinigte Königreich von Großbritannien und Irland letztlich doch in erster Linie von ihrer Überzeugung leiten ließen, so dass die Abstimmungsergebnisse der zweiten (118:73) und dritten Lesung (158 : 87) in etwa die tatsächlichen Meinungsverhältnisse im Parlament repräsentierten. Dafür spricht auch das Tempo, mit dem man in Irland nach Inkrafttreten der 
Unionsakte am 1. Januar 1801 wieder zur politischen Tagesordnung überging und mit dem sich die neuen Abgeordneten in Westminster in ihren Rollen zurechtfanden. Offensichtlich hatte die irische Bevölkerung in ihrer großen Mehrheit kein Interesse mehr an irgendwelchen radikalrepublikanischen Umsturzplänen, sondern erhoffte sich nach langen Jahren politischer und ökonomischer Instabilität von der Union mit Großbritannien nunmehr inneren und äußeren Frieden, Freiheit und Wohlstand. Zum Zeitpunkt des Vollzugs der Union konnte allerdings niemand ahnen, dass es bis dahin noch ein sehr weiter Weg sein würde. 



\title{
Continental European Involvement in the Eighteenth-Century British Empire
}

\author{
Stephen Conway
}

This lecture brings together historical approaches usually pursued separately, or even antagonistically. Recent scholarship attempting to place eighteenth-century Britain in a wider context has tended to take one of two paths: the imperial or the European, the latter often linked to a new interest amongst British historians in the Hanoverian connection. ${ }^{1}$ One of my objectives is to demonstrate that the imperial and the European need not be seen as alternative perspectives. An obvious if easily overlooked point is that empire and Europe overlapped: Ireland was both part of the metropolitan core and a colony, while the Mediterranean outposts of Gibraltar and Minorca were as much imperial possessions as the North American provinces, the West Indian islands, and the Asian holdings of the East India Company. ${ }^{2}$ But the complementarity of Europe and empire perhaps comes most clearly into focus when we consider continental European involvement in British territories across the globe. ${ }^{3}$

1 For the imperial, see, e.g., Kathleen Wilson, The Island Race. Englishness, Empire, and Gender in the Eighteenth Century, London 2002; Kathleen Wilson (Hg.), A New Imperial History. Culture, Identity, and Modernity in Britain and the Empire, 1660-1840, Cambridge 2004; Miles Ogborn, Global Lives. Britain and the World, 1550-1800, Cambridge 2008; Emma Rothschild, The Inner Life of Empires. An Eighteenth-Century History, Princeton 2011; For the European turn, see, e.g., Andrew C. Thompson, Britain, Hanover, and the Protestant Interest, 1688-1756, Woodbridge 2006; Brendan Simms / Torsten Riotte (Hg.), The Hanoverian Dimension in British History, 1714-1837, Cambridge 2007; Marie Peters, Early Hanoverian Consciousness, Empire or Europe?, in: English Historical Review 122 (2007), S. 632-668; Tony Claydon, Europe and the Making of England, 1660-1760, Cambridge 2007; Stephen Conway, Britain, Ireland, and Continental Europe in the Eighteenth Century. Similarities, Connections, Identities, Oxford 2011.

2 For the influence of the European parts of the empire on the governing of newly conquered Canada, see Stephen Conway, The Consequences of the Conquest. Quebec and British Politics, 1760-1774, in: Phillip Buckner / John G. Reid (Hg.), Revisiting 1759. The Conquest of Canada in Historical Perspective, Toronto 2012, S. 141-165.

3 Continental European is used here as a short-hand for all non-British and non-Irish Europeans. It includes inhabitants of islands such as Minorca and Corsica, even though they were not, strictly speaking, continental. 
Historians are beginning to appreciate the similarities between the different $\mathrm{Eu}$ ropean overseas empires, and even their interconnectedness. ${ }^{4}$ But no scholar - as far as I know - has attempted to bring out the European character of Britain's empire by systematically exploring the many ways in which other Europeans contributed to its expansion, consolidation, and defence. The first section of the lecture accordingly surveys the various continental European inputs in the second half of the eighteenth century, where possible conveying an impression of their scale. The choice of period is deliberate: historians often claim that from the seventeen-fifties the British became more nationally and imperially conscious; ${ }^{5}$ I want to demonstrate that an empire usually depicted as a great national enterprise, and the focus of much national pride, depended to a remarkable degree on continental European assistance.

While this is a transnational story, we cannot understand it without looking at the actions and attitudes of national politicians and administrators. Enthusiasts for transnational history often present it as an antidote to narrowly national history; again, I want to show that divergent approaches can fruitfully be brought together. In the second part of the lecture I hope to establish that British governments saw no inconsistency in encouraging some forms of continental European involvement in the empire and attempting to block or limit others. Their decisions about which forms of involvement should be encouraged, and which should not, reflected the political and economic orthodoxy of the time, usually described by historians as mercantilism. Despite long-running debates about whether the concept obscures more than it reveals, mercantilism remains a useful shorthand term for a wide range of government measures - going far beyond trade regulation - designed to promote national prosperity and power by preserving and enhancing resources to compete more effectively with other states. ${ }^{6}$

4 A pioneer in this respect is Holden Furber, Rival Empires of Trade in the Orient, 1600-1800, Oxford 1976; for more recent examples, see J. H. Elliott, Empires of the Atlantic World. Britain and Spain in America, 1492-1830, New Haven 2006; Eliga H. Gould, Entangled Histories, Entangled Worlds. The English-Speaking Atlantic as a Spanish Periphery, in: American Historical Review 112 (2007), S. 764-786; Jack P. Greene / Philip D. Morgan (Hg.), Atlantic History. A Critical Appraisal, New York 2009.

5 See, e. g., P. J. Marshall's essays, Cornwallis Triumphant, War in India and the British Public in the Late Eighteenth Century, in: Lawrence Freedman / Paul Hayes / Robert O’Neill (Hg.), War, Strategy, and International Politics. Essays in Honour of Sir Michael Howard, Oxford 1992, S. 57-74; P. J. Marshall, A Nation Defined by Empire, 1755-1776, in: Alexander Grant / Keith J. Stringer (Hg.), Uniting the Kingdom? The Making of British History, London 1995, S. 208-222; Linda Colley, Britons, Forging the Nation, 1707-1837, New Haven 1992, chs. 2 and 3; Kathleen Wilson, The Sense of the People. Politics, Culture, and Imperialism in England, 1715-1785, Cambridge 1995; Eliga H. Gould, The Persistence of Empire. British Political Culture in the Age of the American Revolution, Chapel Hill 2000; Bob Harris, Politics and the Nation. Britain in the Mid-Eighteenth Century, Oxford 2002.

6 For scepticism, see, e. g., D. C. Coleman, Eli Heckscher and the Idea of Mercantilism, in: D. C. Coleman (Hg.), Revisions of Mercantilism, London 1969, S. 92-117; for recent emphasis on division over political economy, see Steve Pincus, Rethinking Mercantilism. Political Economy, the British Empire, and the Atlantic World in the Seventeenth and Eighteenth Centuries, in: William \& Mary Quarterly, 3rd series, 69 


\section{I.}

We begin, then, with a brief survey of continental European involvement in the empire. Capital investment is perhaps an appropriate place to start. The British national debt supported far more than imperial defence and expansion, but as an increasingly large portion of the British armed forces were deployed in the extra-European world from the middle of the century, we can reasonably say that the national debt underwrote a good deal of British imperial activity. ${ }^{7}$ Between 1760 and the late seventeen-eighties, according to a recent calculation, more than $£ 20$ million were put in British public funds by overseas investors, or about sixteen per cent of the total. ${ }^{8}$ This proportion was probably smaller than earlier in the century, when the Dutch stake alone amounted to about fifteen per cent, but even by the seventeen-nineties foreign investment was still far from negligible. ${ }^{9}$ Another piece of detailed scholarship reveals that European holdings in the stock of the British East India Company were particularly impressive: in the seventeen-sixties they amounted to some thirty per cent of all accounts. ${ }^{10}$ Nor was continental European investment confined to the public funds and the great chartered companies. Private individuals, trying to secure profits in British overseas possessions, also sought European backing. Dutch financiers, such as Hope and Co., of Amsterdam, lent money to British West Indian planters. ${ }^{11}$

European commodities also played a significant part. British slave traders on the west coast of Africa almost certainly used Dutch gunpowder and muskets. ${ }^{12}$ In Asia, senior officers of the British East India Company's army preferred to equip their cavalry with swords of German manufacture rather than comparable British products. ${ }^{13}$ A study of the cargoes of British ships sailing for India has revealed that they often contained continental European manufactures as well as domestically produced ones:

(2012), S. 3-34.

7 For deployments, see J. A. Houlding, Fit for Service. The Training of the British Army, 1715-1795, Oxford 1981, S. 409-413 (Appendix B).

8 J. F. Wright, The Contribution of Overseas Savings to the Funded National Debt of Great Britain, 1750-1815, in: Economic History Review, 2nd series, 50 (1997), S. 657-674.

9 P. G. M. Dickson, The Financial Revolution in England. A Study in the Development of Public Credit, 1658-1756, London 1967, S. 322.

10 H. V. Bowen, From Supranational to National. Changing Patterns of Investment in the British East India Company, 1750-1820, in: Bob Moore / Henk van Nierop (Hg.), Colonial Empires Compared. Britain and the Netherlands, 1750-1850, Aldershot 2003, S. 131-144.

11 Marten Gerbertus Buist, At Spes Non Fracta, Hope \& Co., 1770-1815, Merchant Bankers and Diplomats at Work, The Hague 1974, S. 20 .

12 This, at least, is the inference of John Roberts letter to Arthur Conran of Rotterdam, written from London on 1 Sept. 1752, The National Archives of the United Kingdom, Kew (henceforth TNA), Treasury Papers (Royal African Company), T 70/1478, fo. 3.

13 National Archives of Scotland, Edinburgh, Miscellaneous Gifts and Deposits, Campbell of Inverneill Papers, GD 1/6/2/2, Archibald Campbell to Directors of the East India Company, 2 Dec. 1786. 
smuggled goods detected on board East Indiamen between 1762 and 1771 included foreign textiles, wines, guns, steel, lead, iron, and copper, taken onto the ships at various points in their voyage to Asia - in the Channel, at continental ports such as Lisbon and Cadiz, and at Madeira, Tenerife, or the Cape Verde Islands. ${ }^{14}$

Commodities from continental Europe probably arrived in the largest quantities in Britain's North American and West Indian territories. Some entered the British colonies by unofficial routes, brought directly from northern European ports such as Amsterdam and Hamburg, or as a result of illicit trade between the North American mainland and the foreign West Indies, or of exchanges between British and other European islands in the Caribbean. ${ }^{15}$ Others arrived on British or colonial ships, after having passed first through a British port, in the manner prescribed by the seventeenth-century trade regulations known as the Navigation Acts. Many text-book statistical snapshots obscure the importance even of legal trade: continental European re-exports are often subsumed in the official figures for British exports. ${ }^{16}$ If we focus on the items in the list of re-exports that almost certainly came from continental Europe and add the value of these together, we can see that the European proportion of total official English exports to America and Africa in 1772-1774 was probably somewhere around a fifth. ${ }^{17}$ The quantity of illegally imported continental goods is impossible to calculate, though contemporary accounts nearly all suggest that it was considerable. $^{18}$

Textiles and clothing were prominent amongst the continental European commodities imported into the Atlantic colonies. "An Account of all Foreign Goods and Produce" legally imported into British North America during 1769, drawn up for the chancellor of the exchequer, includes German, Dutch, and Russian linens, Silesian and Dutch lawns, and Italian silks. ${ }^{19}$ Colonial records similarly demonstrate that continental European textiles and clothing items had penetrated British imperial markets. A few examples should suffice. Governor James Glen of South Carolina noted in 1749 the large numbers of Linnens of all kinds consumed in his colony, many of

14 H.V. Bowen, Privilege and Profit. Commanders of East Indiamen as private Traders, Entrepreneurs and Smugglers, 1760-1813, in: International Journal of Maritime History 19 (2007), S. 43-88, hier S. 63ff.

15 For examples of this trade early in the century, see Christian J. Koot, Empire and Periphery. British Colonists, Anglo-Dutch Trade, and the Development of the British Atlantic, 1621-1713, New York 2011, ch. 6. For the mid-century, see Huntington Library, San Marino, California, Invoice-book of Brand and Schuyler, 1744-53, HM 637, S. 17, 46, 50, 53f., 84ff. und $162 \mathrm{f}$.

16 See, e. g., Edwin J. Perkins, The Economy of Colonial America, New York 1980, S. 25-28, (Tables 2.1-2.3).

17 Jacob M. Price, The Imperial Economy, 1700-1776, in: P. J. Marshall (Hg.), The Oxford History of the British Empire, volume 2: The Eighteenth Century, Oxford 1998, S. 78-104, S. 102 (Table 4.5).

18 See, e. g., the view of Thomas Whately, a treasury secretary in the early 1760s, The Regulations Lately Made Concerning the Colonies, and the Taxes Imposed upon Them, Considered, London 1765, S. 92.

19 Bodleian Library, Oxford, MS North c. 83, fos. 17-24. 
them German, and also the considerable quantitys of the fine Laces of Flanders, the finest Dutch Linnens \& French Cambricks. ${ }^{20}$ James Pinnock, a barrister on Jamaica, purchased Three $p^{r}$ French ribbed Silk Stockings at the end of December 1766, and a French Silk \& Silver Waistcoat in December 1769. ${ }^{21}$ A farmer in Chester County, Pennsylvania, included 4 Holland Shirts amongst the goods seized or destroyed when the British army passed through his neighbourhood in September 1777.22 The following year, a New York merchant sold a quantity of what he described as Oznebrigs, a British corruption of Osnabrücks, or German linens. ${ }^{23}$

Some of these items might not have been what they seemed. Textiles described as Oznebrigs or Osnaburgs were not always the Westphalian originals; Scottish and Irish linen-makers produced their own imitations. ${ }^{24}$ Even so, we can be confident that foreign linens sold well across the Atlantic. In 1753, according to a contemporary account, 6.8 million yards of them were re-exported from Britain, mainly to the colonies in North America and the West Indies. ${ }^{25}$ Nine years earlier, in 1744, William Beckford, a prominent Jamaican planter, had testified before the House of Commons that large quantities of German linens were consumed in the British Caribbean islands. Merchants from many different German states established themselves in London in the second half of the eighteenth century at least partly to facilitate access to British colonial markets. ${ }^{26}$

Nor were textiles and clothing the only continental goods sent to North America and the West Indies. Colonial sources such as diaries, letters, inventories, and adverts in newspapers refer to items such as German steel and Dutch crockery. ${ }^{27}$ The soap used in the British Caribbean, according to one account, came mainly from Marseilles, smuggled into the British islands from the neighbouring French possessions. British soap, the same source tells us, melted in the heat, and became totally

20 British Library, London (henceforth BL), King's MS 205, fos. 292-3, Glen's responses to questions asked by the board of trade.

21 BL, Cash-Account-book of James Pinnock, 1758-1810; Add. MS 33, 317, fos. 64 and 74.

22 Historical Society of Pennsylvania, Philadelphia, Chester County Miscellaneous Papers, Depredation Claim of Joel Bailey of West Bradford, 11 Sept. 1777.

23 New-York Historical Society, New York City, Bancker Papers, Account-book Blotter, Feb. 1778.

24 See, e.g., Bristol Record Office, Ashton Court Collection, Woolnough Papers, AC/WO 16 (4) b, Jamaica Accts 31 Decr 1747, which refers to 11 Scotch Oznab. 778 Yds. For Irish and Scottish linen exports to America and the West Indies, see Price, 1998 (wie Anm. 17), S. 87f.

25 BL, Walpole (Wolterton) Papers, Add. MS 74,053, fo. 148.

26 Margrit Schulte Beerbühl / Klaus Weber, From Westphalia to the Caribbean. Networks of German Textile Merchants in the Eighteenth Century, in: Andreas Gestrich / Margrit Schulte Beerbühl (Hg.), Cosmopolitan Networks in Commerce and Society, 1660-1914, German Historical Institute, Supplement No. 2, London 2011, S. 53-98, hier S. 57 und 59-74.

27 See, e.g., for German steel, Connecticut Courant, 13 May 1765; for Delftware, see Boston Public Library, Boston, Massachusetts, CH M.1.10.147, Account of damages to the Estate of John Hancock by the British Army during the siege of Boston, 26 Feb. 1777. 
unserviceable. ${ }^{28}$ Fruits, almost certainly of Mediterranean provenance, appear to have been imported into the colonies in large quantities from Britain. ${ }^{29}$ In about 1766, Peter Hasenclever, a German who had recently arrived in New Jersey from England, reported to the British government that imports from Spain, Portugal and Italy and the whole Mediterranean were chiefly Fruit, though he added oil, salt, and wine as other important items. ${ }^{30}$

Wine deserves particular note. Affluent colonials, rather than rely on locally produced rum, drank copious quantities of Portuguese wine, given preferential access to British colonial markets in recognition of the long-standing Anglo-Portuguese alliance. Lisbon wine was popular; ${ }^{31}$ but for those who purchased it, Madeira was more than just a drink; it was a status symbol. ${ }^{32}$ German and Spanish wines also circulated freely; according to a visitor to Philadelphia in 1750, they were obtainable in all taverns. ${ }^{33}$ French wines, despite their expense, seem to have reached colonial consumers, too. Newspaper adverts demonstrate the ready availability of claret, the English name for red Bordeaux; ${ }^{34}$ and the personal diaries and journals of many members of the colonial elite testify to its even readier consumption. ${ }^{35}$

But the main European contribution to Britain's empire came in human rather than material form. Continental European experts played an important role. The General Survey of North America, undertaken after the Seven Years War to map out the recently enlarged British possessions, was directed by two surveyor generals, both of whom came from continental Europe. Samuel Johannes Holland, a Dutchman, was in charge of the northern department, while Wilhelm Gerhard von Brahm, a former Bavarian officer, born in Coblenz, supervised the survey work in the south. Many of those who served under Holland and Brahm also came from continental Europe, such as the Prussian Charles (or Carl) Blaskowitz, and Bernhard Romans, a native of the Dutch Republic. ${ }^{36}$

28 BL, West Papers, Add. MS 34,736, fo. 205, Petition of Willoughby Marchant, n.d., but probably 1756.

29 Bodleian Library, MS North C. 83, fo. 22.

30 William L. Clements Library, Ann Arbor, Michigan, Shelburne Papers, Thoughts concerning America by Mr Hasenclever, $c .1766$.

31 See George Francis Dow (Hg.), The Holyoke Diaries, Salem, Mass. 1911, S. 22; for consumption at Harvard College in 1760.

32 David Hancock, Oceans of Wine. Madeira and the Emergence of American Trade and Taste, New Haven 2009.

33 Oscar Handlin / John Clive (Hg.), Journey to Pennsylvania by Gottlieb Mittelberger, Cambridge, Mass. 1960, S. 37.

34 See, e. g., Connecticut Courant, 6 May 1765, 3 March 1766.

35 See, e. g., Mabel L. Webber (ed.), Journal of Robert Pringle, 1746-1747, in: South Carolina Historical and Genealogical Magazine 26 (1925), 21, 22; Jack P. Greene (ed.), The Diary of Colonel Landon Carter of Sabine Hall, 1752-1778, 2 vols., Charlottesville 1965, ii. 671 and 737.

36 For Holland, see Stephen Hornsby, Surveyors of Empire. Samuel Holland, J.F. W. Des Barres, and the 
Another example of where continental expertise was used to support British imperial efforts is the presence of the German naturalists Johann Reinhold Forster and his son Georg on James Cook's second voyage of discovery in the Pacific in 1772-1775. To add to the European flavour of the enterprise, Forster senior took on as an assistant the Swedish naturalist Anders Sparrman when Cook's vessels docked at Cape Town. Johann Reinhold had already published work in English on the animals, birds, and insects of North America, and when father and son returned from Cook's voyage, Georg produced a massive two-volume account, based on the detailed records of their travels, published with a British readership in mind.$^{37}$ Some of the Forsters' specimens collected on the voyage were sent to Oxford in January 1776, and subsequently displayed in the Ashmolean Museum. Forster senior's Scottish ancestry, and his coming to England in the seventeen-sixties, admittedly made him an ambiguous figure; he described himself as appertaining equally to the Brittish \& the German nation. ${ }^{38}$ Even so, Forster's German credentials were clear; born in Prussia, he was an ordained Lutheran pastor, educated at Berlin and Halle.

More significant, at least numerically, were the continental European sailors who served on British ships. Royal Navy vessels took on board trained mariners, regardless of their nationality. In the War of American Independence, the Danish consul in London complained of the great Number of our Seamen pressed. ${ }^{39}$ Muster lists suggest that Swedes, Dutchmen, Germans, and Portuguese as well as Danes helped to crew British warships. But we should not exaggerate the numbers involved: most ships had only a relatively small continental European contingent on board; probably no more than about six per cent, if a sample of ships' musters at the time of the American war is an accurate guide. ${ }^{40}$

Continental sailors were much more numerous on trading ships, especially in wartime, when merchant captains sought to replace British and Irish crew members transferred into the navy. ${ }^{41}$ As mariners' wage rates rose, large numbers of foreign

Making of The Atlantic Neptune, Toronto 2011. For the survey as a whole, see Alexander James Cook Johnson, Charting the Imperial Will. Colonial Administration and the General Survey of British North America, 1764-1775, University of Exeter PhD dissertation, 2012.

37 Georg Forster, A Voyage around the World, in His Majesty's Sloop, Resolution, Commanded by Capt. James Cook, during the Years 1772, 3, 4, and 5, 2 vols., London 1777.

38 National Library of Scotland, Edinburgh, Robertson-MacDonald Papers, MS 3943, fo. 55, Forster to [William Robertson], 16 Dec. 1777.

39 TNA, Admiralty Papers, ADM 1/5118/21, fo. 520.

40 Stephen Conway, The British Isles and the War of American Independence, Oxford 2000, S. 36. Unfortunately, comparable data is not available for earlier in the century.

41 David J. Starkey, War and the Market for Seafarers in Britain, 1736-1792, in Lewis R. Fischer / Helge W. Nordvik (Hg.), Shipping and Trade, 1750-1950. Essays in International Maritime Economic History, Pontefract 1990, S. 25-42, hier S. 34f.; Peter Earle, Sailors. English Merchant Seamen, 1650-1775, London 1998, S. 203. 
sailors flocked to British ports from Scandinavia, the Dutch Republic, and north Germany. A good many of them were probably employed on routes with which they were familiar - particularly on the short crossing from southern England to the Low Countries, and on voyages on the North Sea and into the Baltic. But continental Europeans also joined the crews of ships sailing across the Atlantic. The wages-book for the Clifton, a merchant vessel whose sailors were discharged in Devon in the spring of 1762, after a trip to Barbados, includes names that are clearly not British. Eric Ferdinand Pape and Matthew Thesia, probably Germans, both left the ship at Barbados. The man described as Godfrey Strag was almost certainly German, too; when he signed the book to acknowledge receipt of his pay, he wrote his name as Gott Fried Strag. ${ }^{42}$

Settlement of the British colonies in North America relied heavily on Europeans from beyond the British Isles. By the end of the seventeenth century, parts of New England were already densely populated by people who could trace their origins back to the first English colonists; but further south, in the middle and southern provinces, development depended upon attracting large numbers of immigrants. Some non-British Europeans were already in the colonies when the eighteenth century began: Dutch descendants of the original New Netherland settlers, Swedish-speakers whose forefathers had established New Sweden, and French Huguenots, who had arrived in New York and South Carolina after the Revocation of the Edict of Nantes in 1685.43

But it was in the eighteenth century that continental European migration to North America took off. The middle colonies, especially Pennsylvania, were the most popular destination for incomers, but other areas attracted significant numbers. In the seventeen-thirties, Protestants from Salzburg founded Ebenezer, in Georgia, and Swiss Protestants established themselves at Purrysburg, South Carolina. ${ }^{44}$ The end of the War of the Austrian Succession in 1748 saw another surge of continental European Protestants coming to America, from Nova Scotia in the north to Georgia in the south. After the Seven Years War, British promoters of settlement in newly acquired Florida, ceded by Spain, encouraged Greeks, Corsicans, Italians, and Minorcans to come to the infant British colony. New Smyrna, a settlement on the Atlantic coast of East Florida, had a short-lived existence as a Greek enclave between 1768 and 1777.45

42 Bristol Record Office, Ashton Court Collection, Munckley Papers, AC/MU 1 (9).

43 For the Huguenots, see Paula Wheeler Carlo, Huguenot Refugees in Colonial New York, becoming American in the Hudson Valley, Brighton 2005; and Bertrand van Ruybeke, From Babylon to Eden. The Huguenots and their Migration to Colonial South Carolina, Columbia SC 2006.

44 For the Salzburgers, see Thompson, 2006 (wie Anm. 1); for Purrysburg, Arlin C. Migliazza, To Make This Land Our Own. Community, Identity and Cultural Adaptation in Purrysburg Township, South Carolina, 1732-1865, Columbia SC 2007.

45 Bernard Bailyn, Voyagers to the West. Emigration from Britain to America on the Eve of the Revolution, 
French Protestants, from near Bordeaux, whom the governor of East Florida hoped to lure to his province, ended up settling in South Carolina. ${ }^{46}$

The largest number of continental European arrivals in the North American colonies, both before and after the Seven Years War, came from Germany. They comprised but a small part of the outward flow of people from the Holy Roman Empire; more went in other directions - north, east, and south within Europe, or to Asia in the service of the Dutch East India Company - than went west to settle across the Atlantic. ${ }^{47}$ But Germans made up a significant proportion of the migrants coming to British North America. So great were the numbers over the course of the century that German-speakers formed about ten per cent of the settler population by the eve of the American Revolution. They were particularly concentrated in Pennsylvania, where a third of the white people were of German origin. ${ }^{48}$

Yet the most important European human contribution to British imperial activity arguably came in military form. ${ }^{49}$ Most of the common soldiers in the East India Company's European forces were British or Irish, though scattered contemporary testimony suggests that a far from negligible number were from other European countries. ${ }^{50}$ We know that Swiss troops served the East India Company in the seventeen-fifties, under the command of their own officers. ${ }^{51}$ Nearly thirty years later, in 1782, two Hanoverian regiments sailed to India to reinforce the beleaguered royal and company troops, who were facing a powerful enemy in the form of Haidar Ali of Mysore, supported by a French expeditionary army. The Hanoverians were still on the subcontinent ten years later; and when their regiments were recalled some of the

London, 1987, S. 451-461.

46 Haines Hill, Berkshire, Colleton, Garth, and Godsal Family Papers, Box 23, Charles Garth letter-books, Garth to South Carolina Assembly's Committee of Correspondence, 24 Oct., 20 Nov. [1763]; National Archives of Scotland, Macpherson Grant of Ballandalloch Papers, GD 494/1/2, James Grant to John Savage, 12 July 1765 .

47 See David Eltis, Introduction, in: Eltis (Hg.), Coerced and Free Migration. Global Perspectives, Stanford CA. 2002, esp. S. 17, for every German that moved to the Americas, nine migrated in the opposite direction.

48 A. G. Roeber, The Origins of Whatever Is Not English among Us. The Dutch-speaking and German-speaking Peoples of Colonial British America, in: Bernard Bailyn / Philip D. Morgan (Hg.), Strangers within the Realm. Cultural Margins of the First British Empire, Chapel Hill 1991, S. 220-283, hier S. 244.

49 For more on this, see Stephen Conway, Continental European Soldiers in British Imperial Service, c.1756-1792, English Historical Review, 129 (2014), S. 79-106.

50 BL, India Office Records, E/1/55, fo. 406, Richard King to Peter Michell, 18 April 1771; and the comments of Lord Cornwallis, in November 1786, ibid., Home Misc./389, p. 319. For British enlistments, see H. V. Bowen, The East India Company and Military Recruitment in Britain, 1763-71, Bulletin of the Institute of Historical Research 59 (1986), S. 78-90; for the Irish contribution, see Thomas Bartlett, The Irish Soldier in India, 1750-1947, in: Michael Holmes / Denis Holmes (Hg.), Ireland and India. Connections, Comparisons, Contrasts, Dublin 1997, S. 12-28, hier S. 14 (Table 2.1).

51 See, e. g., BL, India Office Records, E/4/861, S. 67, 218, 333, Directors of the East India Company to the President and Council at Fort St George, 19 Dec. 1753, 24 Jan. and 29 Nov. 1754. 
soldiers volunteered to transfer into company service. ${ }^{52}$ When they first arrived in India, the two battalions of Hanoverians joined seven British army infantry battalions and a cavalry regiment. The Hanoverian battalions, each of 1,000 officers and men, were stronger than the British, so we can assume that the Germans comprised well over twenty per cent of the non-company forces in India at that time. ${ }^{53}$

At the beginning of the War of American Independence, George III in his capacity as elector also lent Hanoverian regiments to help garrison Minorca and Gibraltar, freeing up British regiments for service elsewhere. Proportionately, German soldiers made a much bigger contribution in the Mediterranean than in India; in 1776, five Hanoverian battalions garrisoned Gibraltar and Minorca, together with a total of six British. ${ }^{54}$ British military capacity benefited from continental European manpower in North America, too. German, Swiss, and Dutch officers obtained commissions in the Royal American Regiment, raised in 1756 after the British Parliament gave a special dispensation from the requirements of the Act of Settlement of 1701, which debarred all but the crown's subjects from holding civil or military office. ${ }^{55}$ In the Seven Years War, and in the subsequent peace, the regiment's rank and file included many Germans recruited in Germany. ${ }^{56}$ When the American rebellion broke out in 1775, German enlistment into the Royal Americans was pursued again with vigour. ${ }^{57}$ At the same time, German military entrepreneurs agreed to provide recruits to fill other understrength British regular infantry battalions; the most important of these contractors, the Hanoverian Lieutenant-Colonel Georg Heinrich Albrecht von Scheither, eventually supplied nearly 2,000 soldiers for various British regiments serving in North America. ${ }^{58}$

The most substantial German military contribution, however, both in the American war and more generally, came in the form of the established units hired from a variety of German states. Known generically as the Hessians, these German auxiliaries

52 Ibid., E/4/879, S. 255. See also Chen Tzoref-Ashkenazi, German Voices from India. Officers of the Hanoverian Regiments, in: East India Company Service, South Asia. Journal of South Asian Studies 32 (2009), S. 189-211.

53 For the royal forces in India, see P. J. Marshall, The Making and Unmaking of Empires. Britain, India, and America, c.1750-1783, Oxford 2005, S. 220.

54 For the British troops, see Houlding 1981 (wie Anm. 7); for the Hanoverians, see Rodney Atwood, The Hessians. Mercenaries from Hessen-Kassel in the American Revolution, Cambridge 1980, S. 25.

55 Augustine Prévost, e.g., who became a major in the Royal Americans, had been a captain in a Swiss regiment in the Dutch army, see National Army Museum, Chelsea, 6106-40-1-2. Other French-speaking Swiss Protestants included Prévost's brother Jacques-Marc, Henri Bouquet, and Frederick Haldimand.

56 For German recruits arriving at New York from Hamburg in 1756, see Huntington Library, Loudoun Papers, LO 1607. For the raising of 300 Germans in 1766, see Joseph Redington (Hg.), Calendar of Home Office Papers of the Reign of George III, 1766-1769, London 1879, S. 54.

57 For one contractor's account, see John Savage, The Case of Major John Savage, London 1785.

58 TNA, War Office Papers, WO 4/99, S. 198. For Scheither's contract generally, see the documents collected in WO 43/405. 
came not only from Hessen-Kassel and Hessen-Hanau, but also from Brunswick and Waldeck, and later from Anhalt-Zerbst and Ansbach-Bayreuth. Initially, the British government intended to use the Hessian and Brunswick units in the same way as they employed the Hanoverians sent to Gibraltar and Minorca - to relieve British troops for service in America. Lord North, the prime minister, planned to send the Germans to Ireland, and dispatch British regiments in Ireland across the Atlantic. But, fearing Protestant Irish objections, he decided instead to use the Germans in North America. ${ }^{59}$ Originally they seem to have been earmarked for garrison duties, freeing up the maximum number of British soldiers to fight the rebels; but very quickly this idea was abandoned, and most of the German auxiliaries were employed as a field force, alongside the British regulars. By the closing years of the war, the Hessians comprised some thirty-seven per cent of the British army in North America. ${ }^{60}$

\section{II.}

How did decision-makers in London view continental European participation in the empire? Some forms of involvement were beyond their oversight, or even took place without their knowledge. But in many areas the British state sought to shape and control continental European penetration of its overseas possessions. Mercantilist ideas about how to achieve national advantage led British governments to seek to limit the quantity of continental European products entering imperial markets. A good example of this is the attempt made - without great success - to reduce colonial consumption of continental European textiles, especially linens, after the Seven Years War.

The seventeenth-century Navigation Acts envisaged colonies as appendages of the national community, established to boost national prosperity and national power. The 1663 Navigation Act stipulated that continental European products could be sent to the English colonies only once they had passed through an English port. The intention was partly to levy customs duties that would provide the crown with an income, but also to increase the cost of the items for colonial consumers, and so incline the settlers to purchase similar English manufactures instead. During the course of the eighteenth century, import duties on foreign textiles steadily rose, especially in wartime, when the state needed extra revenue. A five per cent increase was imposed in 1748, at the end of the War of the Austrian Succession, and another five per cent added in 1759, during the Seven Years War. ${ }^{61}$ But cheaply produced German linen

59 TNA, State Papers Ireland, SP 63/437B, fos. 36-7, 39, 46.

60 Atwood, 1980 (wie Anm. 54), S. 257 (Appendix D).

61 See N. B. Harte, The Rise of Protection and the English Linen Trade, 1690-1790, in: Ders. / K. G. Ponting (Hg.), Textile History and Economic History, London, 1973, S. 74-112, hier S. 75-84. 
exports to North America and the West Indies continued to thrive, partly because many were smuggled into the colonies without coming through a British port and paying duties, and partly because foreign linens that reached the colonies via Britain were subject to a drawback, or repayment of part of the import duty, which British merchants could claim if they re-exported the linens.

British politicians appear to have considered removing the drawback at various points in the eighteenth century. The mercantile community divided on the issue, but those who opposed ending the drawback seem to have had the most influence, at least until the end of the Seven Years War. In the seventeen-fifties, for instance, Dennys de Berdt, a prominent London merchant, argued that the drawback served British interests. Without it, he claimed, smuggling to North America and the West Indies would probably increase. Revenue would be lost on the import of foreign linens. And, most importantly, foreigners would earn less for their linens and therefore be unable to buy so many British woollen goods. They might even start producing more woollens of their own, and sell these across the Continent, reducing the consumption of British wool products still further. ${ }^{62}$

British politicians were less persuaded by such arguments after the Seven Years War, when access to European markets became more restricted as a result of new tariffs imposed by continental governments. ${ }^{63}$ To successive post-war ministries, the colonies were the one reliable market for British manufactures; it followed that foreign competition should be strongly discouraged. Historians mainly remember George Grenville's Revenue Act of 1764 for its changes to the duty on foreign molasses (semi-refined sugar) entering the North American colonies; but besides increasing the money coming into the government's coffers, the act was designed to limit the flow of continental European linens entering North America and the West Indies. The new legislation ended the re-export drawback and imposed new duties on foreign cloth sent to the colonies.

Grenville's Revenue Act attracted some opposition, but almost exclusively on the issue of the most appropriate rate for the molasses duty. Very few MPs questioned Grenville's attempt to reduce foreign linen sales in America, and most of those who did express concern were not regular opponents of the government. Richard Glover, who had important mercantile connections, was probably the most vocal critic of Grenville's proposal to remove the drawback, and yet he was usually a supporter of the ministry. He argued, as de Berdt had done in the seventeen-fifties, that smuggling would be inadvertently boosted and, in a new point, that colonial manufacture

62 BL, Walpole (Wolterton) Papers, Add. MS 74,053, fos. 48 and 113-14, de Berdt to Horatio Walpole, 27 Feb. and 9 April 1755.

63 De Berdt continued to put the case for the drawback, and the dangers of removing it, see Huntington Library, Stowe Collection, Grenville Papers, STG Box 21, de Berdt to [Thomas Fonnereau], 21 March 1764. 
of linens would be encouraged. ${ }^{64}$ But politicians associated with the parliamentary opposition tended to agree with the government, at least on the case for reducing foreign linen consumption in the colonies. William Baker, a supporter of the out-ofoffice Duke of Newcastle, effectively endorsed Grenville's approach. So, too, did John Huske, another MP associated with the opposition, who argued that the removal of the drawback on foreign linens was a bounty to our own manufactures. ${ }^{65}$

The next government, led by the Marquis of Rockingham, set about reversing many of Grenville's initiatives. Most famously, the new administration repealed Grenville's American Stamp Act, which had caused enormous uproar in the colonies and threatened to bring transatlantic trade to a stand-still. At the same time, Rockingham and his colleagues undertook a radical overhaul of the 1764 Revenue Act, reducing the charge on foreign molasses entering the North American colonies and introducing free ports in the West Indies. But in one important respect Grenville's regulatory edifice was left intact. The new government's Revenue or Plantation Duties Act of 1766 did not overturn the previous ministry's attempts to reduce colonial consumption of continental European manufactures. The drawback on foreign linen re-exports was not restored, and the 1766 act maintained Grenville's new duties on linens imported into the colonies.

Two very different governments, then, had very much the same perspective on the need to keep the colonies as captive markets for British manufactures. Their immediate successors took the same view. Charles Townshend, chancellor of the exchequer in the government led by the Duke of Grafton, toyed with the idea of making it easier for southern European fruit, oil, and wine to enter the colonies. Townshend planned to impose a duty on these imports, but at the same time reduce their price to colonial consumers by allowing them to be shipped directly to North America, rather than come through a British port. ${ }^{66}$ In the end, Townshend retreated in the face of parliamentary opposition. But even if he had proceeded with his original plan, his liberality was distinctly limited. Fruit, oil, and wine were not direct competitors for British manufactures. At no stage does Townshend appear to have contemplated any change in the duty chargeable on German and other continental textiles imported into British America. Lord North, chancellor of the exchequer after Townsend died, also made no attempt to reduce the fiscal discrimination against foreign linens intro-

64 Hampshire Record Office, Winchester, Malmesbury Papers, 9M73/G713, S. 116, Parliamentary Diary of James Harris, 23 March 1764. For earlier indications of Glover's opposition to the removal of the drawback, see S. 100 und 102.

65 P. D. G. Thomas (Hg.), The Parliamentary Diaries of Nathaniel Ryder, 1764-7, Royal Historical Society, Camden Miscellany 23, 4th series, volume 7, London 1969, S. 236 und 238.

66 Thomas (Hg.), 1969 (wie Anm. 65), S. 344; Dalkeith House, Midlothian, Buccleuch and Queensberry Muniments, Townshend Papers, Box VIII, bundle 31, includes documents on Proposed duties on wine, oil, \& fruit imported into America. 
duced in 1764 and confirmed in 1766. Indeed, while North was first minister, the discrimination increased; in 1771 the subsidy on the export of certain types of British linens, introduced in 1743 , was extended to new sorts of fabric, providing an added advantage to British products in colonial markets. ${ }^{67}$

Given these efforts to exclude foreign manufactures, it might seem odd that British governments generally welcomed continental European manpower. An exclusionary approach in one area might be expected to have encouraged the same in others. After all, many Britons outside government circles were far from comfortable about the presence of continental Europeans in the empire. Benjamin Franklin, in an essay written in 1751, famously criticized the large number of German settlers in Pennsylvania, which he claimed was losing its English character. ${ }^{68}$ Other commentators doubted the reliability of outsiders. Captain James Douglas of the Royal Navy, for instance, reported from the Caribbean in 1760 that the deserters from his vessel were all Foreigners, who were now serving in the Enemy's Privateers. ${ }^{69}$ In the next war, British critics readily attributed the overwhelming Hessian defeat at Trenton in December 1776 to the German-ness of the auxiliary troops. ${ }^{70}$

Ministers and administrators in London no doubt had their own prejudices, but these are not readily apparent in the official record. The one exception to this general rule is religious rather than national. Before and during the Seven Years War, British governments regarded continental Catholics as unsuitable, at least as settlers or soldiers, fearing that they would be tempted to support their French and Spanish co-religionists. After 1763, when the Protestant cause seemed to have triumphed in Europe and Catholicism appeared less threatening, even official hostility to Catholic involvement diminished. In general, both before and after the Seven Years War, British governments took the view that national sentiment should be subordinated to national interests; if the state needed manpower, it had no hesitation in turning to the rest of Europe to provide it.

Consider the case of continental European mariners. Dutch, German, and Scandinavian sailors, as we have seen, flocked to serve on board British merchant ships in wartime, attracted by the high wages. But we should not suppose that their recruitment was simply a natural consequence of the workings of an international free market in maritime labour. The British state tightly regulated the manning of merchant vessels to promote national advantage. The Navigation Act of 1660 stipulated that only English ships could carry goods between English territories and that

67 Harte, 1973 (wie Anm. 61); S. 98f..

68 Leonard W. Labaree u. a. (Hg.), The Papers of Benjamin Franklin (39 vols. to date), New Haven, 1959-, S. iv. 234.

69 National Maritime Museum, Greenwich, Sir James Douglas Papers, DOU/4, Douglas to John Clevland, 14 Dec. 1760.

70 See, e. g., New-York Historical Society, Andrew Elliot Letters, Andrew Elliot to his brother, 3 Jan. 1777. 
three-quarters of the crew must be subjects of the crown. The aim was to secure a great reserve of trained mariners, who could be conscripted into the Royal Navy in time of war. Eighteenth-century British governments, however, recognized that if British sailors were transferred into the navy, then the needs of the merchant marine had to be met from elsewhere. Large numbers of foreign seamen were able to join British ships in wartime only because the government secured parliamentary approval for a temporary suspension of the manpower requirements of the 1660 Navigation Act at the beginning of every conflict in which Britain was a participant. ${ }^{71}$

In the case of the merchant marine, British governments called on foreign help only in wartime; once hostilities ended, the restrictions of the 1660 Navigation Act came back into force. By contrast, ministers and officials in London believed that they had to offer more consistent encouragement to secure foreign assistance in settling British North America. A good deal of the movement of people across the Atlantic, it should be said, owed little or nothing to the actions of the British state. Most Germans who made the journey to the middle colonies arrived as a result of private engagements between colonial landowners and employers on the one hand and recruiting agents and ships' captains carrying the migrants on the other. ${ }^{72}$ Colonial governments also played a part. South Carolina's assembly passed a tax on slave sales in 1741, the revenue from which was devoted to subsidizing the settlement of continental European Protestants in the colony. ${ }^{73}$ The same assembly later underwrote the expenses of a Charleston merchant house that shipped in French Protestant refugees. ${ }^{74}$

But governments in London did not rely on private or local initiatives; they offered their own inducements. In 1740, a Naturalization Act, sponsored by the ministry, gave foreign Protestants who had resided in the North American colonies for seven years the same rights as the king's natural-born subjects, so long as the migrants swore an oath of allegiance to their new monarch. ${ }^{75}$ The intention was clearly to encourage further foreign migration. In the early seventeen-fifties, the British government even paid for the voyage of German and Swiss settlers to Nova Scotia, and then provided them with provisions on their arrival. ${ }^{76}$ The expense proved so considerable

71 See the following Acts of Parliament, 13 Geo. II, c.3, $\$ 1$ (1740); 28 Geo. II, c. 16 (1755); 16 Geo. III, c. 20 (1776); 33 Geo. III, c. 26 (1793).

72 See, e. g., Günter Moltmann, The Migration of German Redemptioners to North America, 1720-1820, in: P. C. Emmer (Hg.), Colonialism and Migration. Indentured Labour before and after Slavery, Dordrecht 1986, S. 105-122.

73 See TNA, Colonial Office Papers, CO 5/373, fos. 206-11, An Account of Cash Receiv'd and Paid by John Dart Commissary General by the Appropriation Law for Settling of Poor foreign Protestants in the Townships of South Carolina, 1743-50, which suggests more than $£ 25,000$ was spent for the purpose. A revision of the law in 1752 lowered the bounty, due to concerns about the cost (CO 5/374, fo. 60).

74 Ibid., CO 5/378, fo. 38, William Bull to the Lord Commissioners of Trade and Plantations, 24 Oct. 1764.

7513 Geo. II, c. 7.

76 See, e. g., Journal of the Commissioners for Trade and Plantations from January 1749-1750 to December 
that this scale of generosity was not repeated, but after the Seven Years War, government money was again used to help cover the costs of bringing French Huguenots to South Carolina and Greeks and other Mediterranean peoples to East Florida. ${ }^{77}$ In the case of the Greeks, the government even agreed to loan a de-commissioned naval vessel to the private projector who appealed for help to transport his migrants to America. ${ }^{78} \mathrm{~A}$ more usual subsidy was the forgoing of potential tax income: British governments routinely allowed new settlers to pay no quit rents - a form of royal revenue - for up to ten years after their arrival. ${ }^{79}$

Why did British governments offer such encouragement to European migrants? Part of the explanation lies in the need to settle sparsely populated areas of the colonies. The British state had no need to stimulate German migration to Pennsylvania, which attracted large numbers of incomers, but the mid-eighteenth-century population of Nova Scotia in the north and Georgia in the south remained very small. In the former, most of the inhabitants were Mik'maq Indians or French Acadians; apart from the British military garrison, no more than a few hundred British colonists lived in the province. ${ }^{80}$ Georgia's trustees reckoned about the same time that its white population was a mere 1,700 strong. ${ }^{81}$ Even in neighbouring South Carolina, an English colony since the sixteen-sixties, the governor thought in 1749 that there were no more than 25,000 settlers. $^{82}$

Increasing the settler population would improve the security of the colonies. The government's decision to subsidize foreign Protestant settlement in Nova Scotia owed much to a desire to make the colony more defensible in the case of a French attack. Security was an important consideration elsewhere. In many places, natives posed a threat on the frontier; additional settlers would reduce that threat. ${ }^{83}$ In the southern plantation colonies, slave insurrection was a constant white anxiety. The introduction of rice cultivation into South Carolina at the very end of the seventeenth century created a great surge in slave numbers. By 1708 the colony had a black majority; hence the keenness of the local assembly to promote the settlement of foreign

1753, London 1932, S. 42, S. 46, S. 50f., S. 66, S. 72, S. 82, S. 183, S. 194, S. 204, S. 210, S. 221, S. 247 , S. 392 .

77 See TNA, Colonial Office Papers, CO 5/540, fo. 12, for the French Huguenots; and ibid., CO 5/548, fos. $158-162$, for the Greeks.

78 Ibid., CO 5/548, fos. 154-156.

79 See, e. g., TNA, CO 5/145, fo. 56, John Robinson to John Pownall, 16 July 1772.

80 For lists of the settlers receiving provisions in 1749 and 1750, see ibid., Treasury Papers, T 1/336/42-5 and T 1/337/83. For Nova Scotia more generally, see Geoffrey Plank, An Unsettled Conquest, The British Campaign against the Peoples of Acadia, Philadelphia 2001.

81 TNA, Colonial Office Papers, CO 5/656, fo. 201, Georgia Trustees' memorial to the king, n.d., but c. 1750.

82 BL, King's MS 205, fo. 296.

83 See, e.g., South-Carolina Gazette, 27 Sept. 1752, report of Gov. James Glen's speech to the assembly. 
Protestants, who would reduce the racial imbalance. Hence, in part, too, we can surmise, the British government's willingness to encourage French, Swiss, and German migration to the colony.

British governments also recognized that many foreign settlers had qualities that made them particularly suitable for developing the colonies. The British state's subsidizing the costs of bringing Mediterranean peoples to East Florida can be explained by the settlers' reputed skills in cotton and silk production. ${ }^{84}$ The French Protestants from near Bordeaux who went to South Carolina in the seventeen-sixties offered knowledge of viticulture as well as silk manufacturing. ${ }^{85}$ Around the same time, a British secretary of state was well disposed to a project for settling in East Florida former gun-makers from Liege, on the grounds that they could establish a Manufactory of small Arms in their new American home. ${ }^{86}$ British sources rarely identify German settlers as having specialist skills, but they routinely describe them as industrious. ${ }^{87}$ According to a report drawn up for the government in 1771, the German settlers in the back country of South Carolina supplied Charleston with large quantities of flour and produced more than enough hemp for the cordage used on the province's merchant ships. ${ }^{88}$ Settlers of this kind would increase colonial production, which would benefit the metropolitan economy both by sending to Britain valuable raw materials and foodstuffs and by earning the export credits to afford an increasing quantity of British manufactured goods in return.

Foreign migrants had another great advantage in the eyes of British politicians and officials. They allowed the colonies to be populated without depleting Britain's own human capital reserves. A central tenet of mercantilist thought was that countries with large populations were stronger than countries with small populations. In this sense, Britain was at a great disadvantage compared with France, which throughout the eighteenth century had a population roughly double that of Britain and Ireland combined. During and just after wars, British ministers' awareness of this demographic deficit unsurprisingly increased. In 1762, when the South Carolina assembly was keen to encourage migration into the colony, its agent in London wrote that the British government was reluctant to see any new settlers come from its own country,

84 TNA, Colonial Office Papers, CO 5/548, fos. 156-8.

85 Haines Hill, Colleton, Garth, and Godsal Family Papers, Box 23, Charles Garth Letter-books, Garth to the South Carolina Assembly's Committee of Correspondence, 9 July 1763.

86 TNA, Colonial Office Papers, CO 5/540, fo. 74, Earl of Sandwich to the Lords Commissioners of Trade and Plantations, 13 July 1764.

87 See, e. g., National Archives of Scotland, Macpherson Grant of Ballandalloch Papers, GD 494/1/2, James Grant to Thomas Thoroton, 1 Sept. 1766; John Huddlestone Wynne, A General History of the British Empire in America, volume 2, London 1770, S. 307; Francis Harper (Hg.), Travels in Georgia and Florida, 1773-74. A Report to Dr John Fothergill, Transactions of the American Philosophical Society 33, Pt. II (1943), S. 136.

88 BL, King's MS 210, fo. 3. 
which was so drain'd of men by the Seven Years War that we have hardly sufficient for the Manufacture and Husbandry of this Island. He added that for internal security reasons the government in Dublin was even more unwilling to see any diminution in the Protestant population of Ireland. ${ }^{89}$

Similar manpower considerations encouraged London governments to look favourably on the recruitment of Swiss, Dutch, and above all German soldiers for service in the British Empire. Britain's manpower supplies were limited, especially compared with France's, even after the Scottish Highlands and then Catholic Ireland had been subjected to increasingly heavy recruiting. Nevertheless, we would be mistaken if we concluded that the British state welcomed continental European soldiers simply because it had no alternative source of manpower to tap. Imperial populations provided a considerable reinforcement to British and Irish military resources in the wider world, particularly in the form of provincial regiments in the American colonies, or the much more numerous native contribution to the manning of the East India Company's army. If it were just a question of numbers, these imperial troops could provide the support that British military forces needed. But as with foreign settlers, quality was as important to British governments as quantity. Foreign Protestant officers brought into the Royal American Regiment offered the language skills necessary to recruit German settlers in the colonies, but also technical expertise as engineers and cartographers. Several went on to glittering careers as imperial soldiers and administrators; the Swiss-born Frederic Haldimand, for instance, became governor of Quebec. British ministers probably saw Germans troops in particular as a valuable addition to British strength. If German settlers were industrious, German soldiers were solidly reliable. ${ }^{90}$ They were European professionals, who used the same tactics as British regular soldiers, and shared with them the same military culture; they were the most natural supplement, in other words, to British military forces deployed across the empire. ${ }^{91}$

89 Haines Hill, Colleton, Garth, and Godsal Family Papers, Box 23, Charles Garth Letter-books, Garth to the South Carolina Assembly's Committee of Correspondence, 30 Sept. 1762.

90 See, e. g., Frauke Geyken, The German Language is Spoken in Saxony with the Greatest Purity, or English Images and Perceptions of Germany in the Eighteenth Century, in: Joseph Canning / Hermann Wellenreuther (Hg.), Britain and Germany Compared. Nationality, Society, and Nobility in the Eighteenth Century, Goettingen 2001, S. 37-70, hier S. $48 f$.

91 See, e. g., Stephen Conway, The British Army. Military Europe, and the War of American Independence, William \& Mary Quarterly, 3rd series, 67 (2010), S. 69-100; Conway, 2011 (wie Anm. 1). 


\section{III.}

Continental European involvement in the eighteenth-century British Empire, then, was greater than most imperial historians acknowledge. That involvement was not simply a consequence of the inability of the British state to maintain an exclusionary empire for national advantage. The limited reach of London governments did indeed contribute to the ready availability of many continental manufactured goods in the Atlantic colonies; despite the best efforts of ministers and officials, illegal trade simply could not be curbed. But other forms of European involvement stemmed not from the failure of the British state to impose its will, but at least partly from its success. Continental manufactures might have been unwelcome to British governments, but continental human capital was not. Foreign experts, sailors, settlers, and soldiers all played a significant part in the making of the British Empire, and with the active encouragement of ministers and officials in London. British governments had no qualms about using transnational means to secure national imperial ends. 



\title{
Zwischen Union und Devianz. Der Transfer religiöser Ideen im Raum der Personalunion
}

\author{
Manfred Jakubowski-Tiessen
}

I.

Am Anfang ging es um die Religion; genauer: um die Konfession. Es ging um die Frage, wie eine protestantische Erbfolge auf dem englischen Thron sicher gestellt werden könnte. Als Queen Anne nach achtzehn Fehl- oder Totgeburten im Jahre 1700 auch ihren einzigen noch lebenden Sohn im Alter von 11 Jahren infolge einer Pockenerkrankung verlor, war abzusehen, dass mit ihrem Tod die protestantische Linie des Hauses Stuart erlöschen würde. Aus diesem Grunde legte das englische Parlament $1701 \mathrm{im}$ Act of Settlement fest, dass nach dem Tod der Königin Anne das Recht der Thronfolge auf Sophie von der Pfalz, der protestantischen Kurfürstin von Hannover, übergehen sollte. Sophie stammte mütterlicherseits von den Stuarts ab; ihre Mutter Elisabeth war die Tochter Jakobs I. von England. Kurfürstin Sophie starb jedoch wenige Wochen vor Eintritt des Erbfalls, so dass 1714 ihr Sohn, Kurfürst Georg Ludwig, als Georg I. den britischen Thron bestieg und damit die 123-jährige Personalunion zwischen Großbritannien und Kurhannover begründete. Wie wichtig die konfessionelle Komponente bei dieser Erbfolge war, zeigt sich nicht zuletzt darin, dass die Thronfolge im Jahr 1714 von den englischen Zeitgenossen nicht als Hanoverian succession, sondern vornehmlich als Protestant Succession angesehen wurde. ${ }^{1}$

Mit der Thronfolge von 1714 kam England nun in den Besitz der Welfen, einer Dynastie, welche sich als Verfechterin protestantischer Interessen in den Jahrzehnten vor dem Act of Settlement nicht gerade hervorgetan hatte. Herzog Johann Friedrich, der Onkel des späteren Königs Georg I., war im Alter von 26 Jahren in Assisi zum Katholizismus konvertiert; allerdings verzichtete er nach Übernahme der hannoverschen Regierung im Jahr 1665 auf das ius reformandi, die Rekatholisierung seines Landes, weil er den Widerstand der Landstände fürchtete. Diese politische Rücksichtnahme

1 Vgl. Andrew C. Thompson, Britain, Hanover and the Protestant Interest, 1688-1756, Studies in early modern cultural, political and social history 3, Woodbridge 2006, S. 60, 167. 
hinderte ihn jedoch nicht daran - wenn auch sehr vorsichtig und nicht öffentlich die Pläne des römisch-katholischen Bischofs und kaiserlichen Gesandten Cristobal Royas y Spinola zu unterstützen, der sich um eine Reunion der Konfessionen, d.h. die Rückführung der Protestanten in die katholische Kirche bemühte und entsprechende Gespräche in Hannover führte. ${ }^{2}$ Mit dem Tod Johann Friedrichs schien aus kaiserlicher und römischer Sicht die Hoffnung auf eine weitere Ausbreitung des Katholizismus in Norddeutschland zunächst zu schwinden.

In gleicher Weise hatte Johann Friedrichs Bruder Ernst August, seit 1662 lutherischer Fürstbischof in Osnabrück und ab 1679 als Nachfolger seines Bruders Herzog von Braunschweig-Calenberg, bereits während seiner Osnabrücker Zeit über einen Konfessionswechsel mit dem kaiserlichen Hof verhandelt. Anders als bei seinem Bruder hatte der avisierte Übertritt zur katholischen Kirche bei Ernst August ausschließlich politische Motive. Er wäre zu einer Konversion bereit gewesen, wenn dadurch das Alternat auf dem Osnabrücker Bischofssitz, also die wechselnde Herrschaft zwischen katholischem und protestantischem Fürstbischof, aufgehoben und das Hochstift Osnabrück rechtsverbindlich in welfischen Besitz überführt worden wäre; wozu es allerdings nicht kam, weil der Kaiser dieses Ansinnen ablehnte. Nach Übernahme der hannoverschen Regierung hat Ernst August die von Spinola ausgehenden Reunionsgespräche weiterhin gefördert. Es sei ihm, wie er sich äußerte, dasjenige, was zu beforderung des Unions-Werks dienen mag, nicht misfällig. ${ }^{3}$ Mit diesen Gesprächen federführend beauftragt war auf hannoverscher Seite der Konsistorialrat und Abt von Loccum Gerard Wolter Molanus, ein Schüler des Helmstedter Theologieprofessors Georg Calixts, des wichtigsten Vertreters einer irenischen Theologie im lutherischen Protestantismus des 17. Jahrhunderts. ${ }^{4}$ Auch Gottfried Wilhelm Leibniz beteiligte sich an diesen kirchenpolitischen und theologischen Gesprächen, in denen teilweise äußerst subtile theologische Materien erörtert wurden. ${ }^{5}$ Herzog Ernst August konnte

2 Zu den Reunionsgesprächen siehe Hans Otte / Richard Schenk (Hg.), Die Reunionsgespräche im Niedersachsen des 17. Jahrhunderts. Rojas y Spinola - Molan - Lebniz (Studien zur Kirchengeschichte Niedersachsens 37), Göttingen 1999; zu den konfessionellen Interessen der welfischen Herzöge im 17. Jahrhundert siehe Hans Otte, Glaubenswechsel, Reichpolitik und Wiedervereinigung der Kirchen. Der Beginn der Reunionsverhandlungen in Hannover und die Interessen der welfischen Herzoge, in: Ebd., S. 56-84.

3 Zit. nach Otte, 1999 (wie Anm. 2), S. 79.

4 Heinz Weidemann, Gerard Wolter Molanus, Abt zu Loccum. Eine Biographie, Bd. 2, Göttingen 1929; zu Georg Calixt siehe die Artikel von Inge Mager, in: Religion in Geschichte und Gegenwart. Handwörterbuch für Religion und Geschichtswissenschaft, Bd. 2,Tübingen 42008, Sp. 12f. und von Johannes Wallmann, in: Theologische Realenzyklopädie, Bd. 7, S.552-559; Martin Ohst, Gerard Wolter Molanus und seine Stellung zum Projekt einer kirchlichen Reunion, in: Heinz Duchhardt / Gerhard May (Hg.), Union - Konversion - Toleranz. Dimensionen der Annäherung zwischen den christlichen Konfessionen im 17. und 18. Jahrhundert (Veröffentlichungen des Instituts für Europäische Geschichte Mainz, Beiheft 50), Mainz 2000, S. 171-197.

5 Weidemann, 1929 (wie Anm. 4), S. 76ff, 142; Hartmut Rudolph, Bemerkungen zu Leibniz' Reunionskonzept, in: Duchhardt / May, 2000 (wie Anm. 4), S. 227-242. 
an diesen seit 1688 neu aufgenommenen Gesprächen nur gelegen sein, sekundierten sie doch die Verhandlungen seiner Geheimen Räte in Wien, welche sich dort zur selben Zeit um die Erlangung der Kurwürde für Hannover bemühten. Im Gegensatz zu Molanus und Leibniz war Ernst August an den theologischen Inhalten der Unionsgespräche aber in keiner Weise interessiert, ihm ging es ausschließlich um politische Vorteile für seine Dynastie und sein Territorium. Um seine Aussichten auf die neunte Kur zu erhöhen, hatte Ernst August wohl zeitweilig sogar einen Konfessionswechsel ins Auge gefasst, zumindest wurde dieser in Wien als möglich angenommen. ${ }^{6}$ Politische Zugeständnisse an den Kaiser waren zwar notwendig, wie zum Beispiel die Zusage, bei künftigen Kaiserwahlen stets für den Habsburger Kandidaten zu stimmen, eine Konversion jedoch nicht. ${ }^{7}$ Im Dezember 1692 wurde Ernst August von Kaiser Leopold I. zum Kurfürsten erhoben. ${ }^{8}$

Weniger aus politischen denn aus Vernunft- und Toleranzgründen hat die gebildete Kurfürstin Sophie den Reunionsbestrebungen, wie sie zu ihrer Zeit in Hannover diskutiert wurden, etwas abgewinnen können. ${ }^{9}$

Ich hoffe, alle Christen werden bald eins sein [...]. In jener Welt wird man uns nicht fragen, von welcher Religion wir gewesen sein, sondern was wir Gutes und Böses getan haben; daran ist wohl am meisten gelegen, das andere ist ein Pfaffengezänk, das bei den Fürsten stehet zu akkordieren. ${ }^{10}$

Und an anderer Stelle betont die in Glaubensfragen tolerante Sophie: Die Uneinigkeit der Christen sei eine Schande. Bei ihr diene ein Türke, der wolle erst ein Christ werden, wenn wir in unserem christlichen Glauben eins seien. ${ }^{11}$ Sophie hatte auch keine Bedenken, ihrer Nichte Lieselotte von der Pfalz zwecks Heirat des Herzogs Philipp von Orléans, des Bruders Ludwig XIV., den Übertritt zum Katholizismus zu empfehlen. ${ }^{12}$

Am Hofe in Hannover herrschte eine Kirchlichkeit aus Staatsräson. Ernst August besuchte wohl regelmäßig den Gottesdienst, las aber während der Predigt durchaus

6 Georg Schnath, Geschichte Hannovers im Zeitalter der neunten Kur und der englischen Sukzession 1674-1714, Bd. 1, Hildesheim 1938, S. 488.

7 Zu den Verhandlungen über die hannoversche Kurwürde siehe Schnath, 1938 (wie Anm. 6), S. 592-650, bes. 633-535.

8 Die Zustimmung des Reichstags ließ allerdings noch auf sich warten.

9 Mathilde Knoop, Kurfürstin Sophie von Hannover (Niedersächsische Biographien 1), Hannover 1999, S.139-145.

10 Brief an die Raugräfin Luise (1661-1733), die Tochter ihres Bruders Karl Ludwig aus zweiter, morganatischer Ehe, in: Robert Geerds (Hg.), Die Mutter der Könige von Preußen und England: Sophie von Hannover. Memoiren und Briefe, übersetzt von dems., München / Leipzig 1913, S. 219.

11 Eduard Bodemann (Hg.), Briefe der Kurfürstin Sophie von Hannover an die Raugräfinnen und Raugrafen zu Pfalz, Leipzig 1888, S. 91.

12 Ragnhild Hatton, Georg I. Ein deutscher Kurfürst auf Englands Thron, Frankfurt/Main 21985, S. 74. 
auch Komödien, und manchmal so laut, dass sich seine Frau Sophie gestört fühlte beim Briefeschreiben. ${ }^{13}$ Bei einer solch indifferenten Einstellung zur Religion verwundert es nicht, dass der Kurfürstin Sophie der Gedanke eher fern lag, das englische Erbe aus konfessionellen Gründen anzutreten. Wie ihren Briefen zu entnehmen ist, schien ihr das Erbe ohnehin nicht von jedem Makel ganz frei zu sein. Den Pretender Jakob III., dessen Porträt bei ihr im Schloss in Hannover hing, schien sie zuweilen wohl doch als rechtmäßigen Erben des britischen Königreichs anzusehen. Wenn sie dem englischen Erbe überhaupt etwas abgewinnen konnte, dann war es die Aussicht auf machtpolitischen Zugewinn für ihre Nachkommen und ihr Haus. ${ }^{14}$

Nachdem die hannoversche Kurwürde gesichert war und schließlich auch der Reichstag 1708 der Erhebung Hannovers in den Kurfürstenstand zugestimmt hatte, musste auf Rom und den Kaiser keine besondere Rücksicht mehr genommen werden. Vielmehr galt es nun, da die englische Sukzession in greifbare Nähe gerückt war, alle möglichen Irritationen im Vorfeld zu vermeiden. Solche waren noch einmal aufgetreten, als Maximilian Wilhelm, der Bruder Georg Ludwigs und dritte Sohn Ernst Augusts, gerade in jener Zeit zum Katholizismus konvertierte, als in England über die hannoversche Thronfolge verhandelt wurde. Die hannoverschen Gesandten in Den Haag und London empfahlen deshalb, Hannover müsse sich jetzt stärker protestantisch zeigen, um die Thronfolge der Welfen in England nicht zu gefährden. ${ }^{15}$

Georg Ludwig, an dessen Hof, wie es heißt. „die frivolen Kurtisanen den Ton bestimmten " ${ }^{16}$ präsentierte sich fortan öffentlich als Verteidiger des Protestantismus und antizipierte damit gewissermaßen, was bei einer Thronbesteigung in England von ihm erwartet wurde. Jetzt wurde keine besondere Toleranz gegenüber den Katholiken mehr geübt wie noch bei seinen beiden Vorgängern Johann Friedrich und Ernst August. ${ }^{17}$ Vielmehr erließ er am 25. April 1713 ein Religionsedikt, das den Status der Katholiken im Kurfürstentum rechtlich regelte und die Ausübung ihrer Religion stark einschränkte. ${ }^{18}$

13 Eduard Bodemann, Herzogin Sophie von Hannover, in: Wilhelm Maurenbrecher (Hg.), Historisches Taschenbuch, Sechste Folge, Siebenter Jahrgang, Leipzig 1888, S. 29-86, hier: S. 81.

14 Gerd van den Heuvel, „Kein Königreich ist mit einer guten Gesundheit zu vergleichen.“ Liselotte von der Pfalz kommentiert die hannoversche Sukzession, in: Heide Barmeyer (Hg.), Hannover und die englische Thronfolge (Hannoversche Schriften zur Regional- und Lokalgeschichte 19), Bielefeld 2005, S. 141-156, hier: S. 153.

15 Hatton, 1985 (wie Anm. 12), S. 74.

16 Joachim Lampe, Aristokratie, Hofadel und Staatspatriziat in Kurhannover: die Lebenskreise der höheren Beamten an den kurhannoverschen Zentral- und Hofbehörden 1714-1760, Göttingen 1963, S. 134.

17 Hans-Georg Aschoff, Die Reunionsgespräche zwischen Katholiken und Protestanten im 17. Jahrhundert, in: Barmeyer, 2005 (wie Anm. 14), S. 179-197, hier: S. 179f.

18 Aschoff, 2005 (wie Anm. 17), S. 180. 
II.

Als Kurfürst Georg Ludwig den englischen Thron bestieg, war er für die Engländer ein weitgehend unbeschriebenes Blatt. Aus ihrer Sicht handelte es sich um einen Fürsten aus einem eher unbedeutenden deutschen Territorium, mit dem sie eigentlich nur eines verband: der Protestantismus. But now, God be prais'd, though our present most gracious Sovereign is a Foreigner, yet is he a Protestant.$^{19}$ So heißt es in einer anonymen Schrift aus dem Jahr seines Regierungsantritts. Der Protestantismus war, wie Frauke Geyken formuliert, „das Brennglas, durch das das Bild Georgs Formen annahm“. ${ }^{20}$ Auf jeden Fall gehörte es fortan zur Selbststilisierung des englischen Königs, sich als Retter und Wahrer protestantischer Interessen darzustellen, und so wurde seinen Titeln der des Defender of Faith hinzugefügt. ${ }^{21}$

Da Georg I. den Gegnern der hannoverschen Sukzession anfangs kaum Angriffsflächen bot, geriet nun seine Konfession in den Fokus der Kritik. ${ }^{22}$ Gewiss, der neue König war ein Protestant, aber er war ein Lutheraner. Konnte aber ein Lutheraner das Oberhaupt der Kirche von England werden?

Kurz nach der Thronbesteigung entstand eine öffentliche Debatte über diese Frage, die auf zwei Ebenen geführt wurde. ${ }^{23}$ Zum einen wurde gefragt, ob die theologischen Grundpositionen der anglikanischen und der lutherischen Kirche überhaupt übereinstimmten; zum anderen wurden die äußere Form des Gottesdienstes und die Ausgestaltung des Kirchenraums verglichen, um dadurch Unterschiede oder Ähnlichkeiten zwischen den beiden Konfessionen festzustellen. Während die Befürworter der hannoverschen Sukzession betonten, dass die Lutheraner wahre Protestanten seien, es eine Gemeinsamkeit in fundamentalen Glaubensartikeln gäbe und die Verwandtschaft zwischen der lutherischen und der anglikanischen Liturgie überaus deutlich sei, hoben die Kritiker gerade signifikante Unterschiede hervor; und einige dieser Kritiker sahen gar eine gewisse Nähe der lutherischen Kirche zum Katholizismus. Letzteres war eine gefährliche Sichtweise, weil damit den Jakobiten ein Argument in die Hände gespielt wurde, welches den Ausschluss der katholischen Stuarts von der Erbfolge wieder in Frage zu stellen vermochte. Deshalb sah sich der lutherische Pre-

19 Zit. nach Frauke Geyken, Gentlemen auf Reisen: das britische Deutschlandbild im 18. Jahrhundert, Frankfurt/Main 2002, S. 135.

20 Geyken, 2002 (wie Anm. 19), S. 136.

21 Geyken, 2002 (wie Anm. 19), S. 200; Andrew C. Thompson, The confessional dimension, in: Brendan Simms (Hg.), The Hanoverian dimension in British History, Cambridge 2007, S. 161-182, hier: S. 170.

22 Geyken, 2002 (wie Anm. 19), S. 208.

23 Hannah Smith, Georgian Monarchy. Politics and Culture, 1714-1760, Cambridge 2006, S. 48 weist auf diese Debatte hin. Etwas ausführlicher geht Andrew Spicer, Introduction: Lutheran Churches and Confessional Identy, in: Ders. (Hg.), Lutheran Churches in Early Modern Europe, Ashgate 2012, S. 1-4, auf diese Debatte ein. 
diger an der Londoner Trinitatiskirche und spätere Hofprediger in Hannover, Balthasar Mentzer, veranlasst, eine Schrift zur Verteidigung der lutherischen Lehre gegen den Vorwurf der Papisterei herauszugeben. ${ }^{24}$ Diese kurz nach der Thronbesteigung Georg I. entstandene Debatte zeitigte jedoch keine nachhaltige Wirkung; denn die Kritiker verstummten recht bald. Georg I. hielt sich - wie es für ihn verpflichtend war - aus Gründen der Staatsräson an die anglikanische Kirche.

\section{III.}

Die hannoversche Sukzession in England hat eine weitere, zu Beginn des 18. Jahrhunderts nur noch glimmende religions- und kirchenpolitische Debatte neu zu entfachen vermocht. Im Jahr 1714 erschien in London in zweiter Auflage die Übersetzung des "Jus feciale divinum“ von Samuel Pufendorf. ${ }^{25}$ Pufendorf wirkte seit 1688 als Hofhistoriograph und Geheimer Rat am brandenburg-preußischen Hof in Berlin. Dass dieses von Theophilus Dorrington ${ }^{26}$ ins Englische übersetzte Buch Pufendorfs, dessen erste Auflage bereits 1703 in England erschienen war, ${ }^{27}$ gerade zu diesem Zeitpunkt erneut herausgegeben wurde, war kein Zufall. Der veränderte Titel der zweiten Auflage gibt nicht nur das Anliegen des Buches wieder, nämlich die Prinzipien des Luthertums im Hinblick auf deren Vereinbarkeit mit der englischen Kirche zu untersuchen, sondern nennt auch den Anlass: die Thronbesteigung Georgs I. Der Titel der Schrift lautete: „A View of the principles of the Lutheran churches, shewing how far they agree with the Church of England: being a seasonable essay towards the uniting of Protestants upon the accession of His Majesty King George to the throne of these kingdoms. “28 Die Tatsache, dass ein Lutheraner nun zum Oberhaupt der anglikani-

24 Balthasar Mentzer, A vindication of the Lutheran Religion, from the charge of Popery, London 1720 . Zu Mentzer siehe Religion in Geschichte und Gegenwart. Handwörterbuch für Religion und Geschichtswissenschaft, Bd. 5, Tübingen 42002, Sp. 1104; Rudolf Steinmetz, Die Generalsuperintendenten von Calenberg, in: Zeitschrift der Gesellschaft für Niedersächsische Kirchengeschichte 13 (1908), S. 25-267, hier: S. $153-166$.

25 Zur Entstehung und zum Kontext des Jus feciale divinum siehe die Einleitung von Detlef Döring in der von ihm herausgegebenen historisch-kritischen Edition dieser Schrift im Rahmen der Gesammelten Werke Samuel Pufendorfs: Bd. 9: Jus feciale divinum, Berlin 2004.

26 Zu Dorringtons Kontakten nach Deutschland und zu dessen Übersetzung der Pufendorf-Schrift siehe Alexander Schunka, Zwischen Kontingenz und Providenz. Frühe Englandkontakte der Halleschen Pietisten und protestantische Irenik um 1700, in: Pietismus und Neuzeit. Ein Jahrbuch zur Geschichte des neueren Protestantismus 34 (2008), S. 82-114, hier: S. 91-94, $106 f$.

27 Samuel Pufendorf, The divine feudal law: or, covenants with mankind, Represented. Together with means for The uniting of Protestants. In which also the principles of the Lutheran Churches are stated and defended, By Samuel Baron Pufendorf. Translated from the Latin by Theophilus Dorrington, London 1703. Schon diese erste Übersetzung war im Kontext der erwarteten hannoverschen Sukzession erschienen.

28 London 1714. 
schen Kirche geworden war, und er damit in seiner Person gewissermaßen eine innerprotestantische Union verkörperte, beflügelte die Anhänger des Unionsgedankens zu verstärktem Engagement, nachdem in den Jahrzehnten zuvor erste entsprechende Initiativen im Sande verlaufen waren.

In Europa hatte sich um 1700 im Protestantismus ein Gefühl der Bedrohung verbreitet, veranlasst durch die zunehmende Bedrängung der Protestanten in den habsburgischen Ländern, durch die Aufhebung des Edikts von Nantes 1685, die zu einer Massenauswanderung der Hugenotten aus Frankreich führte, durch die Konversion des sächsischen Kurfürsten zum Katholizismus 1697 und schließlich durch den von Ludwig XIV. ausgelösten neunjährigen Krieg, der eine Rekatholisierung der von den Franzosen besetzten Gebiete zur Folge hatte. Vor dem Hintergrund dieser Entwicklungen gab es Kräfte in allen protestantischen Konfessionen, die für einen engeren politischen und vor allem kirchenpolitischen Zusammenschluss der Protestanten plädierten. Der Bischof von Lincoln, William Wake ${ }^{29}$, betonte in einer Predigt anlässlich des ersten Jahrestages der Thronbesteigung am 1. August 1715 vor König Georg I. die Notwendigkeit einer Union zwischen den protestantischen Kirchen und Staaten, wobei die anglikanische Kirche seiner Ansicht nach als the head of the Protestant interest die Führungsrolle zufalle. ${ }^{30}$ Als Wake ein Jahr später zum Erzbischof von Canterbury berufen wurde, ergriff er selbst die Initiative und suchte Mitstreiter für seine Unionspläne. ${ }^{31}$ In Hannover fand er diese im Abt von Loccum, Gerard Wolter Molanus, und in Gottfried Wilhelm Leibniz. Beiden war die Einheit der Christenheit - und wie bereits erwähnt, durchaus auch unter Einschluss des Katholizismus - seit Jahren ein Anliegen; es ging ihnen nun vor allem um eine Wiedervereinigung der infolge der Reformation entstandenen Kirchen. Mit dem reformierten Hofprediger Daniel Ernst Jablonski in Berlin hatten Molanus und Leibniz schon intensiv, allerdings vergeblich über eine innerprotestantische Union verhandelt. ${ }^{32}$ Große Hoffnungen ruhten nun auf dem Erzbischof von Canterbury, der über den einflussreichen hannoverschen Minister Andreas Gottlieb von Bernstorff, ${ }^{33}$ dem ersten Leiter der

29 Norman Sykes, William Wake. Archbishop of Canterbury 1657-1737, 2 Bde, Cambridge 1957.

30 Sykes, 1957 (wie Anm. 29), Bd. 2, S. 1.

31 Sykes, 1957 (wie Anm. 29), Bd. 2, S. 3-22; Wolf-Friedrich Schäufele, Erzbischof William Wake von Canterbury (1657-1737) und die Einigung der europäischen Christenheit, in: Duchhardt / May, 2000 (wie Anm. 4), S. 301-314.

32 Weidemann, 1929 (wie Anm. 4), Bd. 2, S. 130-147.

33 Hermann Kellenbenz, Andreas Gottlieb von Bernstorff, in: Neue Deutsche Biographie, Bd. 2, Berlin 1955, S.137f.; Hartwig Graf von Bernstorff, Andreas Gottlieb von Bernstorff 1649-1726. Staatsmann, Junker, Patriarch. Zwischen deutschem Partikularismus und europäischer Politik, Bochum 1999. 
Deutschen Kanzlei in London, Einfluss auf Georg I. zu nehmen versuchte. ${ }^{34}$ Trotz wiederholter Bemühungen gelang es Wake jedoch nicht, konkrete Ergebnisse zu erzielen und mit Bernstorffs Rückkehr nach Hannover verlor er schließlich seinen wichtigsten Mittelsmann zum König. Dass die Unionsbefürworter ihre Hoffnung auf Wake gesetzt hatten, geschah wohl in Verkennung seiner wahren kirchenpolitischen Position. Denn für Wake war die anglikanische Kirche die vollkommenste protestantische Kirche und an diese sollten sich die anderen Kirchen anpassen. Eine Einigung zwischen der anglikanischen Kirche und den protestantischen Kirchen auf dem Kontinent war auch deshalb sehr schwierig, weil die Kirche von England auf ihre Episkopalverfassung und die apostolische Sukzession nicht verzichten wollte. ${ }^{35}$ Gewissermaßen als kleine Lösung einer solchen Union wurde die Vereinigung der Kirchen innerhalb der Personalunion kurzzeitig ins Auge gefasst. Dem Vorbild des hannoverschen Königs folgend könnten, so der Vorschlag, doch zumindest die anglikanische Kirche Englands und die lutherische Kirche Hannovers sich vereinen und damit eine einheitliche Staatskirche im Raum der Personalunion geschaffen werden. ${ }^{36}$ Das war allerdings eine Idee, die am Londoner Hof niemals ernsthaft in Erwägung gezogen wurde.

Parallel zu diesen über einzelne Personen laufenden Bemühungen um eine innerprotestantische Union nahmen sich seit 1717, dem Jahr des Reformationsjubiläums, ebenfalls Gesandte des Corpus Evangelicorum auf dem immerwährenden Reichstag in Regensburg der Sache der Protestanten an. ${ }^{37}$ Mit dem hannoverschen Reichstagsgesandten Johann Rudolf von Wrisberg, der die Interessen Hannovers und Georgs I. auf dem Reichstag in Regensburg vertrat, standen sowohl der Erzbischof von Canterbury als auch der Abt von Loccum in Briefwechsel..$^{38}$ Nach langen Verhandlungen, bei denen die Gesandten der beiden aufstrebenden protestantischen Mächte Brandenburg-Preußen und Hannover den Takt vorgaben, einigten sich die Gesandten der protestantischen Länder im Februar 1722 auf ein „Conclusum wegen näherer Zusammensetzung oder Vereinigung der Protestierenden“. Diese Vereinbarung sah die gegenseitige Anerkennung von Lutheranern und Reformierten als Glaubensbrüder vor. Sie fand allerdings keineswegs den Beifall aller lutherischen Kirchen. Den

34 Sykes, 1957, (wie Anm. 29), Bd. 2, S. 69-72; William O’Reilly, Protestantische Kultur in England und Irland im 17. und 18. Jahrhundert, in: Peter Claus Hartmann (Hg.), Religion und Kultur im Europa des 17. und 18. Jahrhunderts (Mainzer Studien zur Neueren Geschichte 12), Frankfurt/Main u.a. 2004, S. 57-72, hier: bes. S. 57-61.

35 O’Reilly, 2004 (wie Anm. 34), S. 10f.; Schäufele, 2000 (wie Anm. 31), S. 213.

36 Sykes, 1957 (wie Anm. 29), Bd. 2, S. $61 \mathrm{f}$.

37 Wolf-Friedrich Schäufele, Christoph Matthäus Pfaff und die Kirchenunionsbestrebungen des Corpus Evangelicorum 1717-1726 (Veröffentlichungen des Instituts für Europäische Geschichte Mainz 172), Mainz 1998, S. 87-123.

38 Schäufele, 1998 (wie Anm. 37), S. 195. 
heftigsten Widerstand leistete die Hamburger Geistlichkeit, allen voran der dortige Hauptpastor Erdmann Neumeister, dessen Pamphlete in ganz Deutschland Aufsehen erregten. ${ }^{39}$ Einige Verse aus dem „Neumeisterlichen Madrigal auf die Union“ (1722) seien im Folgenden zitiert: ${ }^{40}$

Was vor ein Wunder-Ding will allererst entstehn?

Des Teuffels Mutter soll anjetzo schwanger gehn,

Man sagt daßsie ihr Wochen-Bette

$\mathrm{Zu}$ Regensburg längst aufgeschlagen hätte

Und wäre schon im Kreissen.

Gebiert sie einen jungen Sohn,

So soll er Syncretismus heissen,

Wirds aber eine Tochter seyn,

So heists sie Union;

Jedoch geräth das Werck nicht etwa noch ins Stecken,

So schwör ich Stein und Bein:

Es wird die Mutter sammt der Brut verrecken.

Das Werk geriet, wie Neumeister hoffte, tatsächlich ins Stecken. In den folgenden Jahren zeigte sich, dass weder der König noch die hannoverschen Minister an dem Einigungswerk wirklich interessiert waren. ${ }^{41}$ Infolgedessen verzichtete man in Hannover auf dessen Ratifizierung, worauf diese dann auch in Preußen und anderen protestantischen Territorien unterblieb. ${ }^{42}$ Die innerprotestantischen Unionsbestrebungen waren damit auch auf dem Reichstag zu Regensburg endgültig gescheitert.

Die Verabschiedung des Act of Settlement, die darauf folgende hannoversche Sukzession in England und die sich daran anschließenden religions- und kirchenpolitischen Debatten und Gespräche zeigen, welche Bedeutung selbst drei Generationen nach dem Westfälischen Frieden die Religion als Faktor der Politik noch hatte, wenn auch zunehmend nur noch als rhetorisches Mittel zur Durchsetzung politischer Interessen und zur Legitimierung politischen Handelns. ${ }^{43}$ Religion bleibt als Faktor innenwie außenpolitischer Maßnahmen auch noch im 18. Jahrhundert, wie Andrew C.

39 Schäufele, 1998 (wie Anm. 37), S. 302. Zu Erdmann Neumeister siehe die Artikel von Johannes Wallmann in: Religion in Geschichte und Gegenwart, Bd. 6, Tübingen 42003, Sp. 231 und Wolfgang Miersemann in: Neue Deutsche Biographie, Bd. 19, Berlin 1999, S. 170f.

40 Zit. nach Schäufele, 1998 (wie Anm. 37), S. 321.

41 Schäufele, 1998 (wie Anm. 37), S. $284 f$.

42 Schäufele, 1998 (wie Anm. 37), S. 287.

43 Vgl. Manfred Schlenke, England blickt nach Europa. Das konfessionelle Argument in der englischen Politik in der Mitte des 18. Jahrhunderts, in: Paul Kluke/ Peter Alter (Hg.), Aspekte der deutsch-britischen Beziehungen im Laufe der Jahrhunderte (Veröffentlichungen des Deutschen Historischen Instituts London 4), Stuttgart 1978, S. 24-45. 
Thompson zu Recht betont, eine „soft power“ im politischen Geschäft. ${ }^{44}$ Schließlich bleibt zu betonen, dass die Reunionsbemühungen zwischen Katholiken und Protestanten wie auch die innerprotestantischen Gespräche über eine Union nur ein erstes Wetterleuchten einer neu anbrechenden Zeit größerer Toleranz darstellten. Der Weg von einer tolerantia ecclesiastica zu einer wirklichen Union bzw. Reunion der durch die Reformation getrennten Kirchen ist - sehen wir einmal von der preußischen Union des 19. Jahrhunderts $\mathrm{ab}$ - allerdings bis heute eine noch weitgehend unbewältigte Aufgabe geblieben.

\section{IV.}

Der religiösen Indifferenz der beiden ersten hannoverschen Könige auf dem englischen Thron ist es wohl vor allem zuzuschreiben, dass sich am Hof in London, im Zentrum der aufstrebenden Weltmacht, eine religiöse Eigenkultur etablieren konnte, ${ }^{45}$ wie es am Hof in Hannover zu jener Zeit nicht möglich gewesen wäre. Georg von Dänemark, der Ehemann der späteren Königin Anne, hatte 1700 in London eine lutherische Hofkapelle gegründet, die mitten im St James Palace eingerichtet wurde. Die Aufsicht über diese Kapelle lag in der Hand des Bischofs von London, welcher auch die vom König ernannten Hofprediger einsetzte. Bei jeder Thronbesteigung mussten diese vom König jeweils neu bestätigt werden. ${ }^{46}$ Auf Empfehlung des Sekretärs des Prinzen Georg, Heinrich Wilhelm Ludolf, wurde als erster Hofprediger der aus der Grafschaft Waldeck gebürtige Anton Wilhelm Böhme berufen. Böhme war ein Pietist hallescher Provenienz, ein Schüler August Hermann Franckes. ${ }^{47}$ Mit seiner Berufung hatte die pietistische Bewegung, welche die größte Frömmigkeitsund Erneuerungsbewegung innerhalb des Protestantismus seit der Reformation war, einen ersten festen Stützpunkt in der angelsächsischen Welt erlangt. Dieser Schritt war von Bedeutung, weil der Hallesche Pietismus weitgespannte Zielsetzungen verfolgte. August Hermann Francke ging es, wie er in einer programmatischen Schrift schrieb, um eine reale Verbesserung in allen Ständen in und ausserhalb Teutschlands, ja in Europa und allen übrigen Theilen der Welt. ${ }^{48}$ Weltverwandlung durch Menschen-

44 Thompson, 2007 (wie Anm. 21), S. 170.

45 Manfred Jakubowski-Tiessen, Eigenkultur und Traditionsbildung, in: Hartmut Lehmann (Hg.), Geschichte des Pietismus, Bd. 4: Glaubenswelt und Lebenwelten, Göttingen 2004, S. 195-210.

46 Daniel L. Brunner, Halle pietists in England. Anthony William Boehm and the Society for Promoting Christian Knowledge (Arbeiten zur Geschichte des Pietismus 29), Göttingen 1993, S. 49.

47 Zu Böhme siehe Brunner, 1993 (wie Anm. 46); Arno Sames, Anton Wilhelm Böhme (1673-1722). Studien zum ökumenischen Denken und Handeln eines hallischen Pietisten (Arbeiten zur Geschichte des Pietismus 26), Göttingen 1990.

48 So der nicht ganz vollständige Titel des sogenannten „Universalprojekts“, in: Erhard Peschke (Hg.), 
verwandlung war das Ziel des Pietismus. ${ }^{49}$ Welcher Ort hätte im 18. Jahrhundert als Ausgangspunkt derartiger globaler Zielsetzungen besser geeignet sein können als die Weltstadt London.

Bemerkenswert ist, dass Georg I. bei seinem Regierungsantritt den deutschen Hofprediger Böhme trotz seiner pietistischen Gesinnung in seinem Amt bestätigte. In Halle wurde dies als ein ermutigendes Zeichen gedeutet. Nur kurze Zeit später bekam Böhme von dort einen Vorschlag, auf welche Weise er den englischen König möglicherweise dazu bewegen könne, dem Hallischen Pietismus künftig besondere Förderung zu erweisen. Böhme solle auf das Beispiel des preußischen Königs und dessen Protektion für die Halleschen Unternehmungen hinweisen. Wenn Böhme bei seinem Vorgehen erfolgreich wäre, würde es, wie betont wurde, nicht allein ein Segen für England sein, sondern auch der pietistischen Sache in Hannover helfen. Georg I. erwies sich für ein solches Ansinnen wie für pietistische Anliegen überhaupt als wenig zugänglich; derartige Bemühungen scheiterten vor allem an seinem religiösen Desinteresse. ${ }^{50}$

Als Böhme 1722 verstarb und damit die Stelle des deutschen Hofpredigers vakant wurde, war den halleschen Pietisten klar, dass für dessen Nachfolge nur ein Theologe aus dem Kurfürstentum Hannover in Frage käme. Wie konnte man dennoch die pietistische Tradition in der Londoner Hofkapelle sichern? Dies könne nur gelingen, wie August Hermann Francke sehr wohl wusste, wenn man einen Pietisten aus dem Kurfürstentum finden würde, der für dieses Amt die notwendige Qualifikation mitbrächte. In einer geheim gehaltenen Aktion gelang es Francke über das pietistische Netzwerk in die entscheidenden Gremien in London und Hannover den Namen eines pietistischen Kandidaten zu lancieren, der dann auch als Nachfolger Böhmes berufen wurde: ${ }^{51}$ Es war Friedrich Michael Ziegenhagen, seit 1718 Kabinettsprediger des Grafen Ernst August von Platen (1674-1726) in Linden bei Hannover. ${ }^{52}$ Im November 1722 trat Ziegenhagen sein Amt als Hofprediger in London an, ein Amt, das er über 50 Jahre bis zu seinem Lebensende 1776 innehatte. Wie sein Vater so hatte auch Georg II. bei seinem Regierungsantritt den deutschen Hofprediger in seinem Amt belassen. Auf diese Weise konnte der hallesche Pietismus in den folgenden Jahrzehnten im Schatten der englischen Weltmacht seine Beziehungsnetze von London

August Hermann Francke, Werke in Auswahl, Berlin 1969, S. 108-115.

49 Manfred Jakubowski-Tiessen, Von Spener zu Francke - Der Pietismus im 17. und 18. Jahrhundert in seiner europäischen Dimension, in: Holger Zaunstäck / Thomas Müller-Bahlcke / Claus Veltmann (Hg.), Die Welt verändern. August Hermann Francke. Ein Lebenswerk um 1700, Halle 2013, S. 29-39.

50 Brunner, 1993 (wie Anm. 46), S. 56.

51 Brunner, 1993 (wie Anm. 46), S. 57.

52 Zur Biographie Friedrich Michael Ziegenhagens siehe Christina Jetter-Staib, Halle, England und das Reich Gottes weltweit - Friedrich Michael Ziegenhagen (1694-1776). Hallescher Pietist und Londoner Hofprediger (Hallesche Forschungen 34), Halle 2013. 
aus bis in die außereuropäische Welt spannen. Die lutherische Hofkapelle mit dem Hofprediger Ziegenhagen und seinen ebenfalls pietistischen Mitarbeitern wurde zur wichtigsten Schaltstelle für alle von Halle ausgehenden Missionsaktivitäten in Nordamerika und Indien. ${ }^{53}$ Hier wurden die auszusendenden Missionare und Prediger, wie etwa auch Heinrich Melchior Mühlenberg, ${ }^{54}$ vor ihrer Abreise betreut und auf den Dienst in den fremden Kontinenten vorbereitet. ${ }^{55}$ Über Ziegenhagen lief nahezu alle Post zwischen Halle, England, Indien und Nordamerika. Die lutherische Hofkapelle war zugleich der Ort, an dem sich eine Schar religiös Gleichgesinnter aus dem Kreis der in London ansässigen Deutschen versammelte, um eine pietistische Gemeinschaft zu gegenseitiger Erbauung und religiöser Stärkung zu pflegen. ${ }^{56}$ Ziegenhagens Ziel war es, diesen Kreis frommer deutscher Landsleute durch seine regelmäßige Predigttätigkeit und Seelsorge zusammenzuhalten und möglichst zu erweitern. ${ }^{57}$

In den fünf Jahrzehnten seines Londoner Wirkens nahm Ziegenhagen eine Schlüsselstelle ein für die Verbindung zu einflussreichen Kreisen in England, die bereit waren die missionarischen Aktivitäten Halles finanziell zu unterstützen. Besonders wichtig war seine Verbindung zu der 1698 gegründeten Society for Promoting Christian Knowledge, einer Institution, die ähnliche Anliegen wie die Pietisten vertrat, nämlich die Menschen durch christliche Unterweisung zu einer religiösen und moralischen Erneuerung zu führen. ${ }^{58}$ In dieser Gesellschaft, der die beiden Hofprediger Böhme und Ziegenhagen eng verbunden waren, fanden die pietistischen Unterneh-

53 Norman J. Threinen, Friedrich Ziegenhagen: the London Connection to India and America, in: Hans-Jürgen Grabbe (Hg.), Halle Pietism, Colonial North America, and the Young United States (USA-Studien 15), Stuttgart 2008, S. 113-134. Über die Mitarbeiter Ziegenhagens und das Umfeld der Hofkapelle siehe Jetter-Staib, 2013 (wie Anm. 52), S. 87-90, S. 136-144. Nachfolger Ziegenhagens wurde sein Mitarbeiter, der Lektor Friedrich Wilhelm Pasche, ebenfalls Hallischer Pietist, der u. a die transatlantische Korrespondenz fortsetzte.

54 Jetter-Staib, 2013 (wie Anm. 52), S. 348-370; zu Mühlenberg siehe den jüngst erschienen Sammelband Hermann Wellenreuther / Thomas Müller-Bahlcke / A. Gregg Roeber (Hg.), The Transatlantic World of Heinrich Melchior Mühlenberg in the Eighteenth Century (Hallesche Forschungen 35), Halle 2013.

55 Jetter-Staib, 2013 (wie Anm. 52), S. 217-225.

56 Die gründliche Erforschung der deutschen Hofkapelle und ihrer Gemeinde bleibt ein wichtiges Desiderat der Forschung.

57 Die vor ihrem Ehemann geflüchtete Gräfin Johanna Sophie von Schaumburg-Lippe, die mit der kurfürstlichen Familie 1714 nach London übersiedelte und dort bis 1728 bei der Prinzessin Wilhelmine Karoline, der Frau des Kurprinzen, als Oberhofmeisterin diente, hat der pietistischen Gemeinschaft der deutschen Hofkapelle in London angehört und dort ein Bekehrungserlebnis gehabt. Nach dem Tod ihres Ehemannes, des Grafen Friedrich Christian, und der Übernahme der Regierung durch ihren Sohn Albrecht Wolfgang, kehrte Johanna Sophie nach Schaumburg-Lippe zurück und hat dort mit großem Engagement die pietistische Bewegung gefördert. Siehe Manfred Jakubowski-Tiessen, Religiosität in Krisenzeiten. Der Pietismus in Schaumburg-Lippe, in: Helge Bei der Wieden (Hg.), Die Ausstrahlung der Reformation. Beiträge zu Kirche und Alltag in Nordwestdeutschland (Studien zur Kirchengeschichte Niedersachsens 43), Göttingen 2011, S. 73-86.

58 Zur Society for Promoting Christian Knowledge siehe Brunner, 1993 (wie Anm. 46), S. 101-197. Sowohl Böhme als auch Ziegenhagen waren in führenden Positionen in dieser Missionsgesellschaft. 
mungen auf den außereuropäischen Missionsfeldern immer wieder hilfreiche Förderung. Ziegenhagen wurde zu einer wichtigen Instanz innerhalb des internationalen pietistischen Netzwerkes und wusste seine herausgehobene Stellung, die noch durch seinen direkten Zugang zur Königsfamilie eine zusätzliche Aufwertung erfuhr, für die Sache des Pietismus zu nutzen. ${ }^{59}$ In England und am Hof wurde er durchaus als ein Vertreter des Halleschen Pietismus wahrgenommen. Obwohl er selbst weder in Indien noch in Amerika gewesen war, empfand er seine Londoner Tätigkeit stets als einen Beitrag zur Ausbreitung des Reichs Gottes auf Erden.

\section{V.}

Während den Pietisten am Hofe in London weitgehende Freiheiten für ihre religiösen Ambitionen eingeräumt wurden, wurde der Pietismus im Kurfürstentum Hannover von Regierung und kirchlicher Oberbehörde als deviante religiöse Bewegung beurteilt, die es zu bekämpfen galt. Bereits unter dem Kurfürsten Georg Ludwig war 1703 ein erstes Edikt gegen den Pietismus erlassen worden, das sich gegen Leute richtete, welche mit sogenannten pietistischen auch anderen neuerlichen Irrthümern in Religions-Sachen behafftet sind. ${ }^{60}$ Das Edikt verbot jegliche Separation vom öffentlichen Gottesdienst und vom Abendmahl. Vier Wochen später wurde zur Erläuterung des Edikts an alle Geistlichen ein von Molanus entworfenes Konsistorialschreiben versandt, worin die Merkmale der Pietisterey im Einzelnen beschrieben werden. ${ }^{61}$ Nachrichten über eine neu entstandene radikalpietistische Bewegung im Harz, die inzwischen an das Konsistorium in Hannover gelangt waren, ${ }^{62}$ haben den Inhalt dieses Konsistorialschreibens wohl mit bestimmt. Molanus wollte in seinem Konsistorialschreiben vermutlich vor allem die Merkmale des separatistischen Pietismus beschreiben; seine „Notae charactericae pietisticae“ wurden vom hannoverschen Konsistorium aber zur allgemeinen Charakterisierung des Pietismus, eben auch des kirchlichen herangezogen. Molanus fehlte, wie sein Biograph Heinz Weidemann betont, eine

59 Jetter-Staib, 2013 (wie Anm. 52), S. 436.

60 Rudolf Ruprecht, Der Pietismus des 18. Jahrhunderts in den Hannoverschen Stammländern, Göttingen 1919, S. 18f.; Manfred Jakubowski-Tiessen, Der Pietismus in Niedersachsen, in: Martin Brecht / Klaus Deppermann (Hg.), Geschichte des Pietismus, Bd. 2: Der Pietismus des 18. Jahrhunderts, Göttingen 1995, S. 428f.

61 Ruprecht (wie Anm. 60), S. 19f.; Jakubowski-Tiessen, 1995 (wie Anm. 60), S. $428 f$.

62 Ruprecht, 1919 (wie Anm. 60), S. 16ff., 28f.; Manfred Jakubowski-Tiessen, Religiöse Konflikte und soziale Proteste. Bergarbeiterunruhen und radikalpietistische Bewegungen im Oberharz im 18. Jahrhundert, in: Jahrbuch der Gesellschaft für Niedersächsische Kirchengeschichte 94 (1996), S. 123-138. 
seelsorgerische Gabe; deshalb habe er „die Tiefe dieser Bewegungen nicht zu begreifen vermocht, sondern allein vom grünen Tische aus sein Urteil über sie gefällt" ${ }^{63}$

Die radikalpietistischen separatistischen Bewegungen im Harz, die zu ersten Auseinandersetzungen mit den kirchlichen Instanzen führten, haben das Bild des Pietismus in den welfischen Ländern in den folgenden Jahrzehnten hauptsächlich geprägt und immer wieder staatliche Reaktionen hervorgerufen. Die zum Teil harten staatlichen Maßnahmen gegen diese religiösen Bewegungen erklären sich teilweise daraus, dass die nach primär absolutistischen Grundsätzen herrschende Regierung des Kurfürstentums durch die separatistischen Bewegungen das einheitliche landesherrliche Kirchenwesen gefährdet sah. Diese Sorge kommt in dem Pietistenedikt vom 15. Mai 1711 zum Ausdruck, in dem der regelmäßige Besuch des Gottesdienstes unter Androhung der Landesverweisung zur Pflicht erklärt und die Konventikel bei Gefängnisstrafe erneut verboten wurden. Die Berufung auf den inneren Christus könne, wie es in dem Edikt ferner heißt, letztlich alle Ordnungen der Kirche aufheben, Tür und Tor für mancherlei Irrtümer öffnen und dazu führen, daß ein jeder nach seinem Gutdüncken und Wahn sich eine Religion fingiren möge. ${ }^{64}$ Die Regierung hat das Verhalten der Harzer Pietisten schließlich „als Ungehorsam gegen staatliche Ordnungen gebrandmarkt und demgemäß als Aufruhr gegen den Staat bestraft “ ${ }^{65}$

Dass sich ein kirchlicher Pietismus trotz des schroff antipietistischen Kurses des Konsistoriums und der harten antipietistischen Edikte dennoch im Kurfürstentum hat entwickeln können, lag vor allem daran, dass einige einflussreiche Adlige des Kurfürstentums sich der pietistischen Bewegung angeschlossen hatten. Seit 1727 fanden die Hallischen Pietisten in dem Staatsminister Gerlach Adolph von Münchhausen (1688-1770), den Begründer der Göttinger Universität, einen Protektor in der Hannoverschen Regierung. ${ }^{66}$ Als König Georg II. 1727 auf den Thron gelangte, berief er Münchhausen in das Geheime Ratskollegium und ernannte ihn 1732 zugleich zum Großvogt der cellischen Amtsvogteien. Münchhausen plädierte für Toleranz in religiösen Fragen, lehnte fundamentalistische Positionen ab und versuchte stets eine Vermittlerrolle in Religionsstreitigkeiten einzunehmen. ${ }^{67}$ Er war zwar selbst kein Pietist,

63 Weidemann, 1929 (wie Anm. 4), Bd. 1, S. 98.

64 Ruprecht, 1919 (wie Anm. 60), S. 39.

65 Ruprecht, 1919 (wie Anm. 60), S.40.

66 Walter Buff, Gerlach Adolph Freiherr von Münchhausen als Gründer der Universität Göttingen, Göttingen 1937.

67 An die Theologische Fakultät der neu gegründeten Universität in Göttingen wollte A. G. v. Münchhausen nur solche Theologen berufen, die sich in den Auseinandersetzungen zwischen der lutherischen Orthodoxie und dem Pietismus nicht besonders exponiert hatten. Die Fakultät sollte eine irenische theologische Ausrichtung bekommen. Emil F. Rössler, Die Gründung der Universität Göttingen. Eine Sammlung bisher ungedruckter Entwürfe, Berichte und Briefe, Göttingen 1855, S. 422ff. 
zeigte aber eine gewisse Aufgeschlossenheit gegenüber den Pietisten, ${ }^{68}$ was wohl nicht zuletzt daran lag, dass seine Frau Wilhelmine Sophie, geb. von Wangenheim (17031750), eine bekennende Pietistin war. Sie hielt in ihrem Haus regelmäßig pietistische Konventikel und pflegte weit gespannte Beziehungen zu führenden Pietisten ihrer Zeit. ${ }^{69}$ Besonders intensiv waren ihre Kontakte nach Halle und Wernigerode. Zwar nahm ihr Ehemann an den Konventikeln in seinem Haus nicht teil, war jedoch für die erweckten Besucher seiner Frau stets zu sprechen und unterhielt sich auch bei den gemeinsamen Mahlzeiten gern mit ihnen über erbauliche Themen. Sein Wohlwollen für die Pietisten brachte ihn in eine gewisse Opposition zum orthodoxen Konsistorium. ${ }^{70}$

Dennoch gelang es dem pietistenfeindlichen Konsistorium im Jahr 1740, König Georg II. davon zu überzeugen, den ihrer Ansicht nach immer noch virulenten Harzer Separatismus mit einem weiteren scharfen Edikt zu bekämpfen. Das noch im selben Jahr erlassene Pietisten-Edikt stellte den letzten Versuch zur Bekämpfung der separatistischen Bewegung im Harz dar. ${ }^{71}$ Noch einmal wurden lokale Untersuchungen und Maßnahmen gegen einzelne Pietisten eingeleitet. Zu jener Zeit hielten viele Pfarrer der Harzregion das Edikt jedoch für unnötig und eher kontraproduktiv, da die radikalpietistische Bewegung bereits am Abklingen war und es ihnen nun vor allem darum ging, die Separatisten unter das Dach der Kirche zurückzuholen.

Während der pietistischen Bewegung unter den hannoverschen Königen Georg I. und Georg II. in London relativ große Entfaltungsmöglichkeiten eingeräumt wurden, sahen sich die Pietisten in Kurhannover starken staatlichen und kirchlichen Repressalien ausgesetzt. Wie lässt sich dieses asymmetrische obrigkeitliche Handeln gegenüber dem Pietismus im Raum der Personalunion erklären? Zunächst ist zu bedenken, dass die beiden ersten hannoverschen Könige religiösen Fragen und theologischen Erörterungen kein allzu großes Gewicht beigelegt haben. Religion war zwar noch ein Faktor der Politik und diente durchaus noch zur Legitimierung politischen Handelns, aber die eigenen Glaubenswelten der Könige blieben davon zumeist unberührt. Ihre religiöse Indifferenz und ihr Desinteresse an theologischen Materien zeitigte ein eher geringes Engagement in kirchlichen Angelegenheiten. Der dadurch entstandene Spielraum wurde in London und Hannover auf unterschiedliche Weise genutzt. Die deutschen Hofprediger Böhme und Ziegenhagen und ihre Mitarbeiter in der deutschen Hofkapelle nutzten diesen, um die pietistische Bewegung mit ihrem globalen Missionsanliegen zu fördern. In Hannover dagegen hat das Konsistorium sich diesen Spielraum zunutze gemacht und sich aller ihm zur Verfügung stehenden

68 Buff, 1937 (wie Anm. 66), S. 15.

69 Ruprecht, 1919 (wie Anm. 60), S. 135 f.

70 Ruprecht, 1919 (wie Anm. 60), S. 137.

71 Ruprecht, 1919 (wie Anm. 60), S. $96 f f$. 
Möglichkeiten bedient, um die Pietisten und den Pietismus in Kurhannover zu bekämpfen, weil es in der pietistischen Bewegung eine große Gefahr für die evangelische Kirche sah.

Als weitere Ursache für die Divergenz im obrigkeitlichen Verhalten gegenüber dem Pietismus in London und Hannover sind die unterschiedlichen religionspolitischen Verhältnisse in diesen Ländern zu berücksichtigen. Im Unterschied zu England, wo sich auf der Grundlage der Bill of Rights ein parlamentarisches Regierungssystem herausgebildet hatte, herrschten in Kurhannover noch absolutistische Strukturen vor. Dabei bildete die konfessionelle Uniformität eine zusätzliche ideologische Klammer für das absolutistische Herrschaftssystem. In England hatte sich dagegen eine konfessionelle Pluralität entwickelt, seitdem der 1689 unter Wilhelm von Oranien vom Parlament verabschiedete Toleration Act den englischen Freikirchen die freie Religionsausübung gestattete. Auch ausländischen Religionsgemeinschaften war die freie Religionsausübung in London erlaubt. In England war dadurch eine religiöse Vielfalt entstanden, die gegenseitige Toleranz erforderte und einen höheren Grad an Freiheit gewährte, was auch der deutschen Hofkapelle und ihren Predigern zu Gute kam, die keiner hannoverschen Oberbehörde, sondern dem Bischof von London unterstanden.

Und schließlich war die von Ziegenhagen unterstützte missionarische Tätigkeit der Pietisten auf den fernen Missionsfeldern in Indien und Nordamerika für das expandierende Britische Weltreich eine wohl eher willkommene als unerwünschte Aktivität, flankierte sie doch die politische, wirtschaftliche und kulturelle Expansion in den außereuropäischen Besitzungen, selbst wenn die Königsfamilie „nur zu begrenzten Unterstützungsleistungen für die Mission bereit" war und Bitten um Spendenbeiträge sogar ablehnte. ${ }^{72}$

\section{Epilog}

Trotz seiner jahrzehntelangen erfolgreichen Mitarbeit am Aufbau des Reichs Gottes auf Erden musste auch Ziegenhagen erfahren, dass es auch für den Pietismus Grenzen des Wachstums gab. Nicht jede Person, die sich ihm anvertraute, konnte er für die Sache des Pietismus gewinnen. Um Ostern 1741 kam beispielsweise der später berühmte Göttinger Professor der Orientalistik, Johann David Michaelis, aus Halle mit einer Empfehlung zu Ziegenhagen nach London. Ziegenhagen scheint einige Hoffnungen auf diesen jungen begabten Theologen gesetzt zu haben, der während seines etwa siebzehnmonatigen Aufenthalts in London auf Bitten Ziegenhagens vierzehntägig die Nachmittags- und manchmal auch die Morgenpredigten in der Hofkapelle

72 Jetter-Staib, 2013 (wie Anm. 52), S. 248. 
übernahm. Nach Michaelis eigener Aussage habe er bei seinem dortigen Aufenthalt von Ziegenhagens theologischen Kenntnissen sehr profitieren können, obgleich dieser, wie Michaelis in seiner Lebensbeschreibung hervorhebt, ein Pietist und noch dazu ein ziemlich eifriger war. ${ }^{73}$ Schon in der Zeit seines Englandaufenthalts registrierten Ziegenhagen und sein Kollege Samuel Theodor Albinus bei Michaelis mit einiger Sorge eine gewisse Beeinflussung durch die Bibelwissenschaft des englischen Deismus. Etwa fünfzehn Jahre später äußerte Albinus, dass er einen sehr betrübten Begriff von der Universität Göttingen und inspecie von dem vormals so redlichen M. Mich[aelis] gewonnen hätte. Er könne kaum glauben, so stellte Albinus in einem Brief mit großer Verwunderung fest, daß Michaelis ein Religions-Spötter solte worden seyn. ${ }^{74}$ Aber das war natürlich eine Beurteilung aus pietistischer Perspektive.

73 Johann David Michaelis, Lebensbeschreibung von ihm selbst abgefaßt, mit Anmerkungen von Hassencamp, Rinteln / Leipzig 1793, S. 36.

74 Albinus an Sebastian Andreas Fabricius, dem Organisator der Missionsabteilung in Halle, 8.9.1756, Archiv der Franckeschen Stiftungen: I D 4:42.2; zit. bei Jetter-Staib, 2013 (wie Anm. 52), S. 182. 



\title{
William Hogarth in Göttingen: Wendungen eines Kultur- und Medientransfers
}

\author{
Christian Scholl
}

William Hogarth in Göttingen: die Wirkung der Arbeiten des zwischen den 1720er und 1760er Jahren in London tätigen Künstlers in der niedersächsischen Universitätsstadt der Aufklärungszeit stellt geradezu ein Paradebeispiel für Kommunikation und Kulturtransfer in der Personalunion dar. Aus Göttinger Sicht steht dabei selbstredend Georg Christoph Lichtenberg im Zentrum, der zwischen 1784 und 1785 seine Erklärungen „Ueber die Hogarthischen Kupferstiche" im „Göttinger Taschen Calender" sowie ab 1794 bis zu seinem Tod im Jahre 1799 die „Ausführlichen Erklärungen der Hogarthischen Kupferstiche“ publiziert hat. ${ }^{1}$ Indem Lichtenberg Texte zu Bildern verfasste, geht es bei dem hier zu verhandelnden Kulturtransfer zugleich um einen Medientransfer - und das mit allen Schwierigkeiten, die eine derartige Übertragung mit sich brachte. Das Thema ,Hogarth in Göttingen' geht aber noch darüber hinaus, denn die Rezeption dieses Künstlers fand im direkten Göttinger Umfeld Lichtenbergs auch innerhalb der bildkünstlerischen Medien statt: in den Nachstichen des Ernst Ludwig Riepenhausen. ${ }^{2}$ Dabei gibt es bei Riepenhausen verschiedene Modi der Hogarth-Rezeption, auf die im Folgenden noch einzugehen sein wird.

1 Wolfgang Promies (Hg.), Lichtenbergs Hogarth. Die Kalender-Erklärungen von Georg Christoph Lichtenberg mit den Nachstichen von Ernst Ludwig Riepenhausen zu den Kupferstich-Tafeln von William Hogarth, München/Wien 1999; Georg Christoph Lichtenberg, Ausführliche Erklärung der Hogarthischen Kupferstiche, mit verkleinerten aber vollständigen Copien derselben von E. Riepenhausen, 1.-5. Lieferung, Göttingen 1794-1799. Nach Lichtenbergs Tod folgten bis 1835 noch Lieferung 6-14, deren Text zu beträchtlichen Teilen von anderen Verfassern stammt - vgl. die Übersicht in: Ulrich Joost / Gerd Unverfehrt (Hg.), Hogarth und die Nachwelt. Von Lichtenberg bis Hrdlicka, Ausst.-Kat. Kunstsammlung der Universität Göttingen, 13. November-18. Dezember 1988, Göttingen 1988, S. 104f. Zu den späteren Verfassern gehört auch der Göttinger Kunsthistoriker Johann Dominicus Fiorillo - vgl. Claudia Schrapel, Johann Dominicus Fiorillo. Grundlagen zur wissenschaftsgeschichtlichen Beurteilung der „Geschichte der zeichnenden Künste in Deutschland und den vereinigten Niederlanden“, Hildesheim u. a. 2004, S. 429-449.

2 Vgl. hierzu Max Kunze, Zwischen Antike, Klassizismus und Romantik. Die Künstlerfamilie Riepenhausen. Ausst.-Kat. Winkelmann-Museum Stendal, 20. Mai-22. Juni 2001, Mainz 2001, S. 1-5 und 11-22. 
Zudem beginnt das Problem des Medientransfers bei Hogarth nicht erst mit der schriftlichen und bildlichen Rezeption. Vielmehr erweisen sich dessen Bilder selbst bei genauerer Betrachtung als intermedial. Es sind visuelle Gebilde, in denen Texte immer wieder eine integrative Rolle spielen. Für einen Transfer macht sie dies eher noch fragiler und erklärungsbedürftiger - und das in einer Zeit, die zunehmend sensibel für die Eigengesetzlichkeit von Texten und Bildern wurde. ${ }^{3}$ Insofern hat man es im Falle von Hogarth mit einem potenzierten Kultur- und Medientransfer zu tun, bei dem sich interkulturelle Übertragungsprobleme innerhalb des von der Personalunion abgesteckten politischen Raumes immer wieder mit medialen Übertragungsschwierigkeiten überkreuzen. Dies macht die entsprechenden Kunstwerke in ihrer Göttinger Rezeption so kompliziert, aber auch so interessant.

Um sich diesem komplizierten, glücklicherweise aber auch ausgesprochen unterhaltsamen Thema zu nähern, soll im Folgenden ein ausgewähltes Bild von Hogarth in seinem Weg durch die Medien verfolgt werden. Die Wahl fiel dabei ganz pragmatisch auf dasjenige Werk, von dem ein Stich vom Künstler selbst in der Kunstsammlung der Universität Göttingen vorhanden ist: „Strolling Actresses dressing in a barn“, übersetzt: Wander-Schauspielerinnen, die sich in einer Scheune ankleiden Abb. 1). ${ }^{4}$

Der querformatige, $428 \times 539 \mathrm{~mm}$ messende Stich zeigt das Innere einer Scheune. Balken und Dachschrägen suggerieren, dass der Blick tiefenräumlich in Richtung einer Giebelwand geht. Diese tiefer im Bildraum liegende Wand kann man jedoch nur im oberen Bereich des Bildes sehen, während im unteren Bereich bildparallel eine Bretterwand eingezogen ist, welche die Bühne für das figuren- und requisitenreiche Geschehen im Vorder- und Mittelgrund bietet. Dabei trifft die Bezeichnung ,Bühne' beinahe auch im wörtlichen Sinne zu, da es sich bei den dargestellten Personen um Schauspieler (bzw. überwiegend um Schauspielerinnen) handelt. Allerdings werden diese nicht bei der Aufführung eines Bühnenstücks gezeigt, sondern bei den geschäftigen Vorbereitungen, die dieser Aufführung vorausgehen. Hieraus ergeben sich eine Vielzahl von Brüchen zwischen der Höhenlage, die das Bühnenstück mit seinen Göttinnen und Heldinnen und den Requisiten einer möglichst perfekten Illusion einerseits beansprucht, und den desillusionierend profanen Tätigkeiten, denen die Akteure hier nachgehen. Ein erheblicher Teil des Witzes dieses Blattes besteht darin, dass Hogarth diesen Tätigkeiten selbst etwas Theatralisches verleiht, wie er ja die Schauspielerinnen bereits weitgehend kostümiert auftreten lässt. Insofern erscheint

3 Vgl. Moritz Wullen, Bild und Text. Hogarths Medienmix, in: Martina Dillmann / Claude Keisch (Hg.), Marriage a-la-mode. Hogarth und seine deutschen Bewunderer, Ausst.-Kat. Altes Museum Berlin, 18. Dezember 1998 - 28. Februar 1999, Städelsches Kunstinstitut und Städtische Galerie Frankfurt a. M., 25. März - 20. Juni 1999, Berlin 1998, S. 11-15.

4 William Hogarth, Strolling Actresses dressing in a barn, 1738, Radierung und Kupferstich, 428 x 539 mm, Kunstsammlung der Georg-August-Universität Göttingen. Vgl. auch Ronald Paulson, Hogarth's Graphic Works, New Haven / London 21970, Bd. 1, S. 182f.; Berthold Hinz / Hartmut Krug (Hg.), William Hogarth. Das vollständige druckgraphische Werk, Gießen ${ }^{3} 1988$, S. $73 f$. 


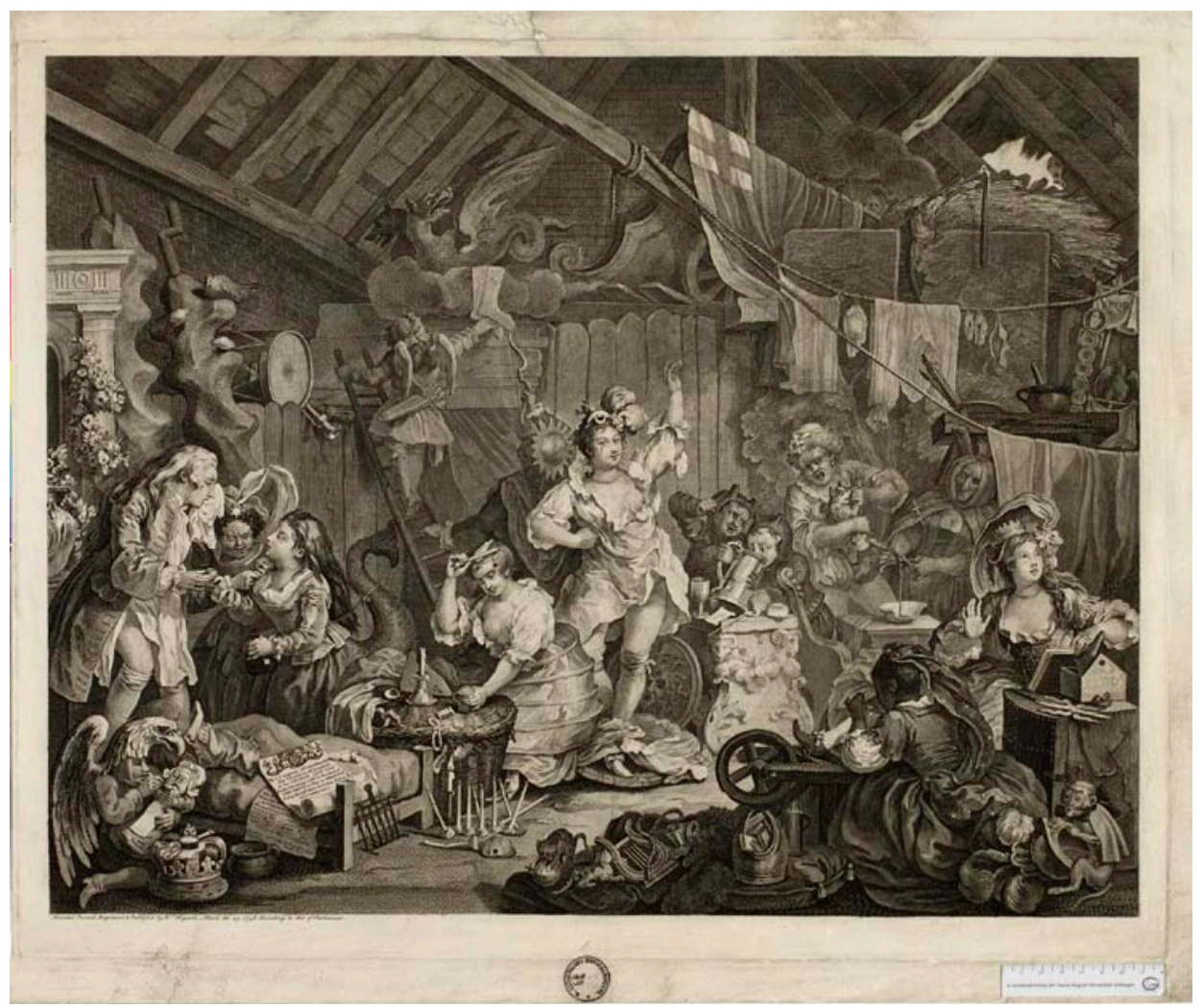

Abb. 1: William Hogarth: Strolling Actresses dressing in a barn, 1738, Radierung und Kupferstich, $428 \times 539$ mm;

Kunstsammlung der Georg-August-Universität Göttingen, Foto: Kristina Bohle

die formale Gestaltung des Raumes als Bühne - mit Kulissen, einem regelrechten Schnürboden und einer Art Hinterbühne - durchaus konsequent.

Das schauspielerhafte Agieren der Personen zeigt sich vor allem an der frontal dargestellten Figur im Zentrum des Blattes. Die Darstellerin der Mondgöttin Diana bewegt sich in ihrem derangierten Kleid in einer Art und Weise, die für Schauspieler und Tänzer der ersten Hälfte des 18. Jahrhunderts charakteristisch war. ${ }^{5}$ Links zu ihren Füßen talgt sich eine weitere Akteurin mit Krinoline das Haar, wobei sie einen Korb als Tisch benutzt. Direkt hinter ihr befindet sich - in Rückenansicht gezeigt -

5 Vgl. u. a. Margit Legler, Reinhold Kubik, Prinzipien und Quellen der barocken Gestik, in: Bert Siegmund (Hg.), Gestik und Affekt in der Musik des 17. und 18. Jahrhunderts. XXVIII. Internationale wissenschaftliche Arbeitstagung Michaelstein, 19. bis 21. Mai 2000, Michaelsteiner Konferenzberichte 63, Dössel 2003, S. 43-63. 
die Darstellerin einer Gottheit mit einer Sonne hinter dem Kopf. ${ }^{6}$ Sie gibt mit einem Bogen einem Kind, das als geflügelter Amor verkleidet ist, Anweisungen. Dieses ist auf eine Leiter hinaufgestiegen, um Strümpfe, die an einer Wolkenkulisse zum Trocknen angehängt sind, zu prüfen oder herunterzuholen. Darüber erkennt man auf dem Dachboden einen Drachenwagen, während links an die Bretterwand weitere Kulissenelemente gelehnt sind: Vor allem bewegliche Meereswellen, auf denen Hühner sitzen. Darunter tritt vom linken Bildrand her eine gestisch und mimisch leidend dargestellte Person ins Bild, der eine als Sirene mit Fischschwanz verkleidete Frau ein Getränk reicht. Eine ältere Darstellerin der Aurora ist derweilen damit beschäftigt, der Sirenen-Darstellerin an der Schulter einen Parasiten auszudrücken. In der linken unteren Ecke hockt eine als Adler verkleidete Frau, die ihr Kind füttert - der dazugehörige Breitopf ist auf einer Krone abgestellt.

Wendet man sich der rechten Bildhälfte zu, so sieht man links neben der Diana-Darstellerin zwei als Teufel verkleidete Kinder, die sich an einem antikisierenden Altar um einen Maßkrug balgen. Rechts daneben wird ein Tisch wirklich zum Opferaltar: Eine Frau hält eine Katze fest, der eine andere ein Stück vom Schwanz abschneidet, um daraus Theaterblut zu gewinnen. Davor schiebt sich in der rechten unteren Bildecke eine große Repoussoirgruppe. Ganz rechts arbeitet eine sitzende Schauspielerin offenbar daran, ihren Text zu repetieren. An ihren Beinen ist ein als Rückenfigur dargestelltes Mädchen damit beschäftigt, Strumplöcher zu schließen. Rechts davor hockt ein Affe mit einem Helm. Die dunkel gehaltene Repoussoirgruppe läuft etwa in der Bildmitte mit einem umgestürzten Karren, einer mit Büchern vollgestopften Bischofsmütze und zwei Katzen, die mit einem Reichsapfel und einer Lyra spielen, aus.

Ganz oben rechts sind auf dem Stich zwischen gut bestückten Wäscheleinen römische Heereszeichen zu entdecken. Eine Person schaut durch ein Loch in der Decke, während die Köpfe zweier weiterer Personen auf dem Dachboden hervorlugen.

\section{Von London nach Göttingen: Wendungen eines Medientransfers}

Die Umstände, unter denen die Blätter des in London geborenen und dort wirkenden Künstlers William Hogarth in die Hände des Göttinger Professors Georg Christoph Lichtenberg gelangten, sind von der Forschung bereits gut erschlossen worden. ${ }^{7} \mathrm{Zu}$

6 Die ikonographische Deutung wird frühzeitig diskutiert: Lichtenberg denkt in seinen Kalender-Erklärungen zunächst an Phöbus: Promies, 1999 (wie Anm. 1), S. 28. In der Ausführlichen Erklärung von 1794 deutet er sie unter Bezug auf weitere Quellen als Jupiter: Lichtenberg, 1794-1799 (wie Anm. 1), 1. Lieferung, S. 15.

7 Vgl. hierzu u. a. Ulrich Joost, Lichtenbergs Bilderklärungen, in: Joost/Unverfehrt, 1988 (wie Anm. 1), S. 14-22; Karl Arndt, „Orbis pictus“: Zu Lichtenbergs Hogarth-Erklärungen, in: Niederdeutsche Beiträge 
ihren Voraussetzungen gehört, dass Hogarth schon zuvor in Kreisen der Aufklärung kein Unbekannter war. Namentlich seine 1753 erschienene Schrift „The Analysis of beauty “ wurde in Deutschland intensiv diskutiert. ${ }^{8}$ Auch für Lichtenberg ist dementsprechend eine frühzeitige Kenntnis des Schaffens dieses Künstlers überliefert.

Entscheidend wurde für den Göttinger Gelehrten schließlich eine Reise, die ihn 1774 bis 1775 nach London führte. Dort erwarb Lichtenberg von der Witwe Hogarths, wie er selbst schreibt, zwey vollständige Exemplare der Werke, eines für einen Freund in Deutschland, und eines für mich. ${ }^{9}$ Damit sind die druckgraphischen Reproduktionen gemeint - die Gemälde scheint Lichtenberg nicht gesehen zu haben. ${ }^{10}$ Für das Thema ,Medientransfer' ist dieser Umstand überaus bedeutsam, denn nahezu alle Stiche von Hogarth gehen auf Gemälde desselben Künstlers zurück. Leider ist das entsprechende Bild für "Strolling Actresses dressing in a barn “ 1874 verbrannt. ${ }^{11}$ Blickt man aber auf andere Beispiele wie etwa die erhaltene Gemäldeserie zu „Marriage à la Mode“, so rückt ein Sachverhalt in den Fokus, der für Reproduktionsgraphik keineswegs ungewöhnlich ist: Die Stiche geben die Gemälde seitenverkehrt wieder. ${ }^{12}$ Mit einer solchen, gleichsam buchstäblichen Wendung im Medientransfer muss man auch bei den „Strolling Actresses" rechnen.

Mit dem Gemälde ist das künstlerisch vermutlich bedeutende Anfangsglied der medialen Kette von „Strolling Actresses“ für immer verloren. Rezeptionsgeschichtlich waren die Stiche freilich von vornherein wirksamer. Sie waren es auch, die Lichtenberg veranlassten, sich verstärkt mit dem künstlerischen Schaffen von Hogarth auseinanderzusetzen. Zurück in Göttingen, sammelte er Material zu den Blättern und entwickelte den Plan, Kommentare zu verfassen. Aus finanzieller Not sah er sich allerdings 1782 gezwungen, die Stiche an die Göttinger Universitätsbibliothek zu verkaufen. Immerhin erbat er sich, daß ich meinen Alten Freund zu weilen wieder auf meine Stube kommen lassen darf. ${ }^{13}$

zur Kunstgeschichte 33 (1994), S. 113-140; Ders., „....anschauende Kenntnis des Menschen in allen Ständen..." Georg Christoph Lichtenberg als Dolmetsch von William Hogarth, in: Dillmann/Keisch, 1999 (wie Anm. 3), S. 108-123; Hans-Georg von Arburg, Kunst-Wissenschaft um 1800. Studien zu Georg Christoph Lichtenbergs Hogarth-Kommentaren, Lichtenberg-Studien 11, Göttingen 1998, S. $13 \mathrm{f}$.

8 Vgl. Arndt, 1994 (wie Anm. 7), S. 114.

9 Promies, 1999 (wie Anm. 1), S. 157. Zu der Frage, welche Blätter in diesen „vollständigen Exemplare[n]“ enthalten waren, vgl. Arndt, 1994 (wie Anm. 7), S. 113f.

10 Vgl. Arndt, 1994 (wie Anm. 7), S. 108.

11 Vgl. Paulson, 1970 (wie Anm. 4), Bd. 1, S. 182.

12 Dies gilt für alle Stiche der Serie „Marriage à la mode“: vgl. Dillmann/Keisch, 1998 (wie Anm. 3), S. 52-65 mit Paulson, 1970 (wie Anm. 4), Bd. 2, Tafeln 268-273.

13 Georg Christoph Lichtenberg an Christian Gottlob Heyne, den 6. Mai 1782, in: Ulrich Joost/Albrecht Schöne (Hg.), Georg Christoph Lichtenberg. Briefwechsel. Bd. 2: 1780-1784, München 1985, S. 319 (Nr. 909). Vgl. auch Arndt, 1994 (wie Anm. 7), S. 115. 
Seit 1778 war Lichtenberg für den von Johann Christian Dieterich herausgegebenen „Göttinger Taschen Calender" tätig. Für diesen schrieb er ab dem Jahrgang 1784 regelmäßig „Ueber die Hogarthischen Kupferstiche“ - eine Serie, die bis 1795 fortgesetzt wurde. ${ }^{14}$ Der Text zu „Herumstreifende Comödianten, die sich in einer Scheune ankleiden“, erschien gleich im ersten Jahrgang. ${ }^{15}$ Das ist mediengeschichtlich insofern von Bedeutung, als dieser Beitrag noch nicht von druckgraphischen Reproduktionen zu Hogarth-Stichen begleitet wird, sondern als reine Text-Publikation publiziert wurde. In seiner Einleitung äußert sich Lichtenberg hierzu:

Der Verfasser gegenwärtigen Aufsatzes hofft, den Lesern des Calenders einen Dienst zu erzeigen [...] wenn er einige Züge aus den Werken dieses unsterblichen Mannes, die nicht jedem verständlich seyn mögten, hier aufsammelt und erklärt, er wird gröstentheils ohnehin nur solche wählen, die auch noch ohne die Abbildung dabey zu haben, unterhalten können. ${ }^{16}$

Auch wenn Lichtenberg am Ende seiner Einleitung erörtert, wo und zu welchem Preis man die entsprechenden Druckgraphiken erwerben könne, ${ }^{17}$ entwickelt er zunächst einmal eine bildlose Beschreibung. Man hat es also mit einem wirklichen Medientransfer zu tun, bei dem ein Text das absente Bild ersetzen soll. Umso bemerkenswerter ist, wie Lichtenberg diesen Transfer umsetzt.

Selbst wenn es ausgesprochen verlockend erscheint, Lichtenberg ausführlich zu zitieren, sei hier doch zu einem eher abstrakten Mittel gegriffen, um dessen Gang der Beschreibung nachzuvollziehen (Abb. 2): Anhand von Pfeilen lässt sich erkennen, wie sich Lichtenberg in seinem Text am Bild entlangschreibt. Dabei fällt auf, dass er tatsächlich am linken Bildrand beginnt und sich dann in Schleifen allmählich nach rechts vorarbeitet. Im Großen und Ganzen ,scannt` er das Bild gleichsam von links nach rechts ab. Bezeichnenderweise folgt er dabei der Leserichtung. Dass man dieses Bild auch ganz anders beschreiben kann, konnte oben mit einer eigenen Beschreibung demonstriert werden, die von der Hauptfigur im Zentrum der Komposition ausging. Bei Lichtenberg wird zudem nicht zuerst der Aktionsraum charakterisiert, sondern vielmehr das Bild von links nach rechts Objekt für Objekt durchbeschrieben. Erst in der rechten Bildhälfte verliert dieser Vorgang an Systematik. Dabei scheint der Sprung durch das Sujet motiviert: Lichtenberg gelangt nämlich von der Katze, welcher der Schwanz gekürzt wird, zu den beiden Katzen, die im Vordergrund mit

14 Promies, 1999 (wie Anm. 1). Vgl. Arndt, 1994 (wie Anm. 7), S. 115-118; Arburg, 1998 (wie Anm. 7), S. 1315.

15 Promies, 1999 (wie Anm. 1), S. 27-30.

16 Promies, 1999 (wie Anm. 1), S. 8.

17 Promies, 1999 (wie Anm. 1), S. 8. 


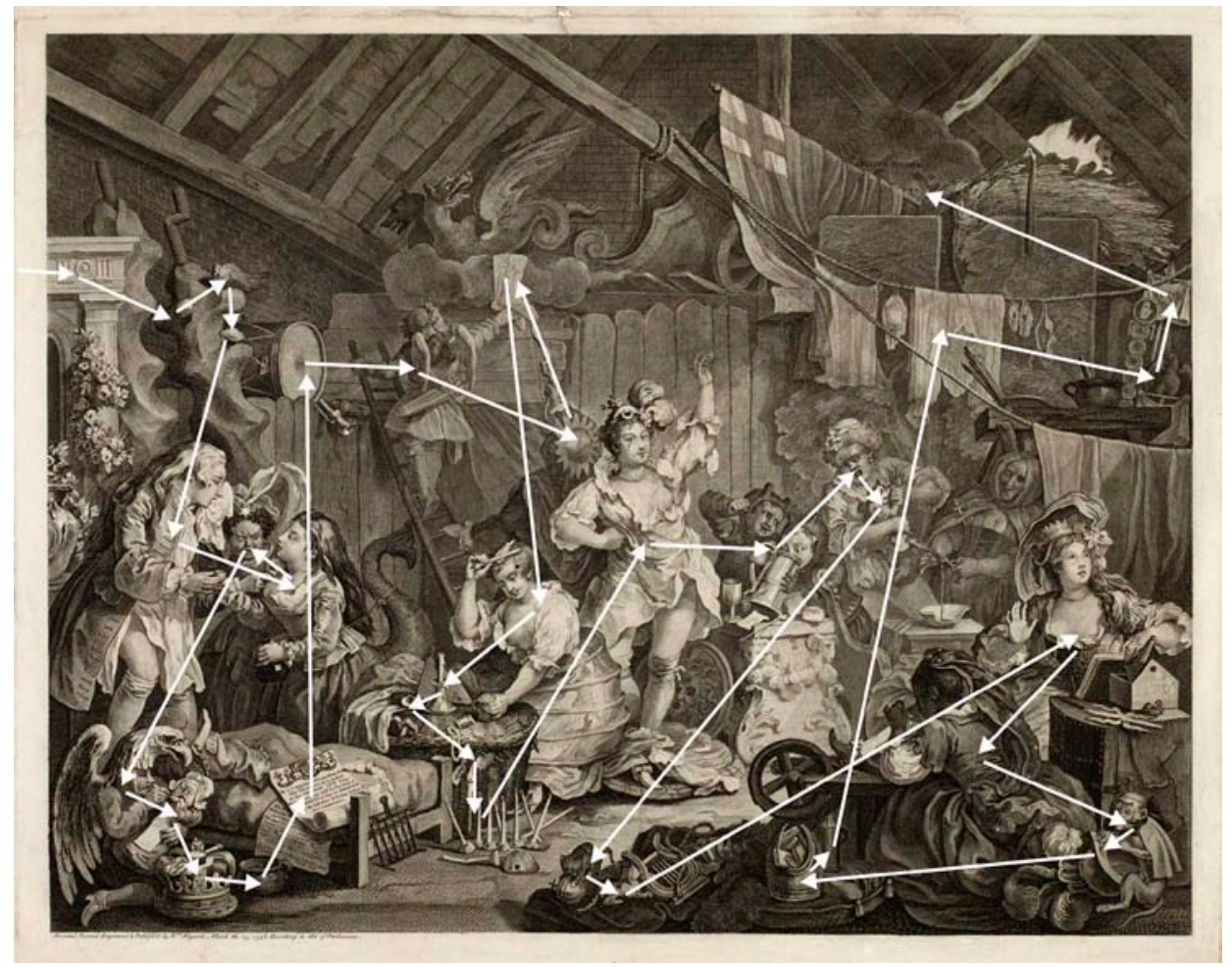

Abb. 2: William Hogarth: Strolling Actresses dressing in a barn mit graphischer Darstellung der Beschreibungsrichtung durch Georg Christoph Lichtenberg;

Kunstsammlung der Georg-August-Universität Göttingen, Foto: Kristina Bohle

Reichsapfel und Lyra spielen. ${ }^{18}$ In Folge dieses ,Katzensprungs' wird die bis dahin ausgesprochen kontinuierliche Bilderschließung zugunsten einer sich stärker zwischen den Ebenen hin- und herbewegenden Schilderung aufgegeben.

Sieht man sich bei den anderen Texten Lichtenbergs um, so erscheint das zumindest in der linken Bildhälfte relativ strikt durchgehaltene Beschreiben von links nach rechts eher als eine Besonderheit, die vermutlich mit der Fülle des auf diesem Blatt Dargestellten zusammenhängt. In diesem Falle wäre sie gerade kein Indiz für ein eher literarisches Vorgehen Lichtenbergs, sondern vielmehr eine Reaktion auf die spe-

18 Promies, 1999 (wie Anm. 1), S. 29: Neben dem Altar steht eine lautschreyende Frauensperson, die eine Katze hält, von der sie gebissen wird, weil man ihr die Spitze des Schwanzes abschneidet, um Blut fürs Trauerspiel zu erhalten; der übrige Stamm des Schwanzes bleibt stehen, für eine nächste Erndte, [...]. Ein junger Anflug von Katzen für den jungen Anflug von Trauerspielen, spielt fürs erste sein zeitiges Lustspiel unten vor der bisincta Diana; die eine mit einem Reichsapfel, und die andere lockt, oder ist im Begrif zu locken, Katzentöne aus der goldenen Leyer. 
zifische visuelle Erscheinung dieses konkreten Blattes. Tatsächlich ging der Verfasser ausgesprochen differenziert mit den Bildern Hogarths um.

Wie bereits erwähnt, war Lichtenbergs Bilderklärung im „Göttinger Taschen Calender“ von 1784 als Bildersatz gedacht. Ganz anders verhält es sich bei der „Ausführlichen Erklärung der Hogarthischen Kupferstiche", die in mehreren Lieferungen ab 1794 publiziert wurde. ${ }^{19}$ Diese erschien, wie der Untertitel deutlich macht, mit verkleinerten aber vollständigen Copien derselben von E. Riepenhausen. Damit ist der Göttinger Kupferstecher Ernst Ludwig Riepenhausen gemeint, der in den Jahrgän-

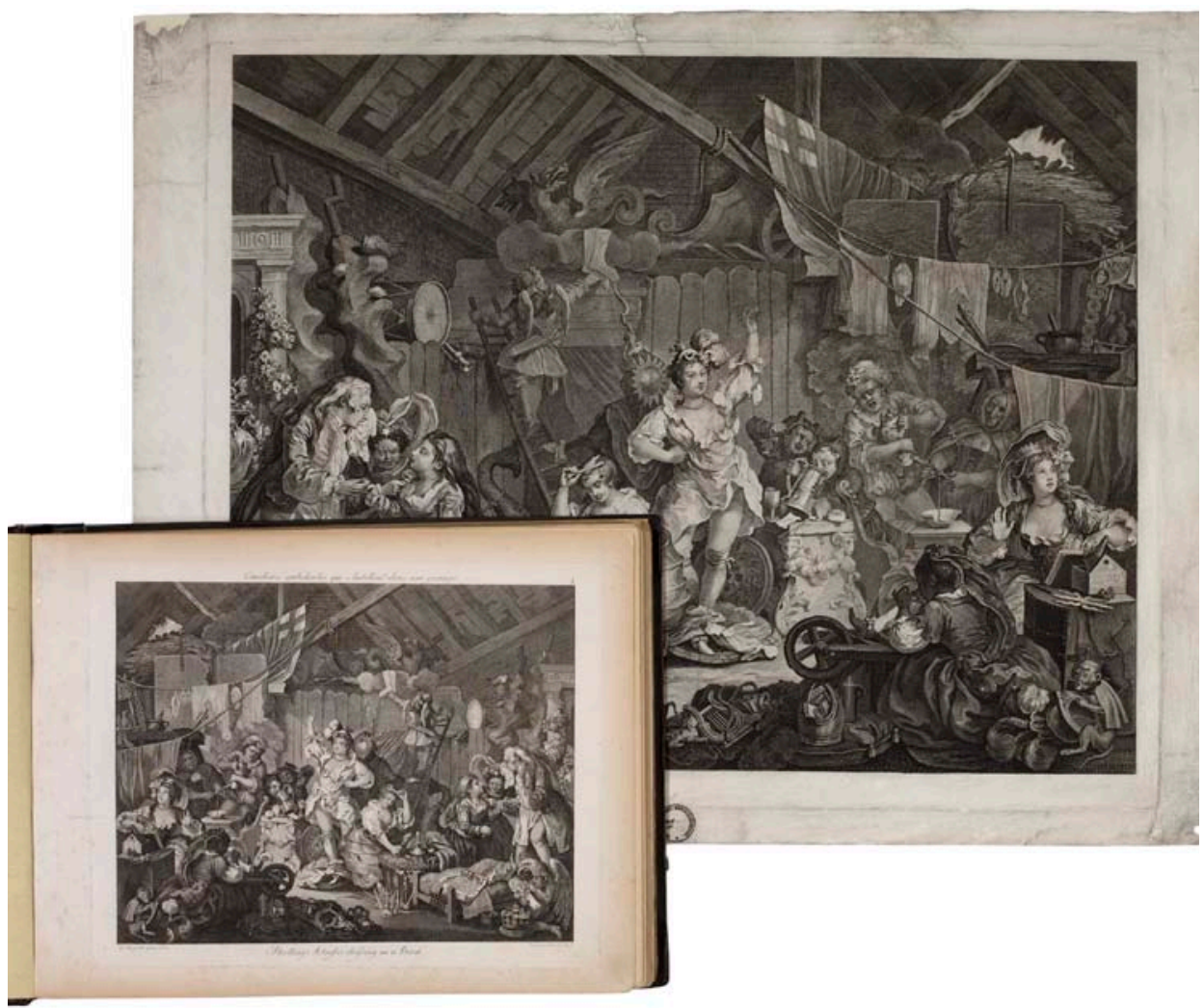

Abb. 3: Ernst Ludwig Riepenhausen nach William Hogarth: Strolling Actresses dressing in a barn, Kupferstich, 234 x 295 mm;

Kunstsammlung der Georg-August-Universität Göttingen, im Größenvergleich mit der Stichvorlage von Hogarth (wie Abb. 1), Foto: Kristina Bohle

19 Vgl. Joost, 1988 (wie Anm. 7), S. 16-19; Arburg, 1998 (wie Anm. 7), S. 15f.; Arndt, 1994 (wie Anm. 7), S. 118-121. 
gen ab 1785 für Lichtenberg bereits das Kupfer für den „Taschen Calender“ geliefert hatte. ${ }^{20}$ Das Bild „Herumstreichende Komödiantinnen“ ist das erste Werk überhaupt, das in der „Ausführlichen Erklärung “ besprochen wird. ${ }^{21}$

Vergleicht man Riepenhausens Nachstich mit Hogarths Originalstich, so fällt zunächst einmal der Größenunterschied ins Auge (Abb. 3). Da es vor allem darum ging, handlichere und sicher auch preisgünstigere Reproduktionen für das deutsche Publikum zu erstellen, sind die Riepenhausen-Drucke erheblich kleiner. Eine weitere augenfällige Differenz betrifft die Ausrichtung: Der Riepenhausen-Stich ist gegenüber der Hogarth-Vorlage wiederum seitenverkehrt. In diesem Fall hängt dies nicht damit zusammen, dass hier erneut einfach nur nach der Vorlage (hier: der Stichvorlage) gearbeitet wurde, die durch den Druck gespiegelt wurde. Gegen eine solche Erklärung sprechen andere Beispiele, bei denen Riepenhausen den Stich so angelegt hat, dass die Vorlage am Ende seitenrichtig wiedergegeben wurde. ${ }^{22}$ Vielmehr liegt hier eine bewusste Entscheidung vor, die Lichtenberg in seiner „Ausführlichen Erklärung“ auch entsprechend begründet hat:

Herr Riepenhausen hat Hogarth's Copie dieses Mal nicht umgezeichnet, und das, wie mich dünkt, mit sehr vielem Recht. Denn erstlich fällt nun das Licht wieder von der Linken ein, wie es sich gehört; zweitens schneidet nun die alte Frau an der Katze mit der rechten Hand, und drittens näht die Göttin der Nacht mit der Rechten. Hätte man auch annehmen wollen, Hogarth hätte bei der Alten seine Absichten gehabt, ihr die Scheere in die Linke zu geben; so war er doch gar der Mann nicht, der von einem so sehr mittelmäßigen Einfall zweimal auf einem und demselben Blatt Gebrauch hätte machen können, und viertens kommen nun Ganymed's Knopflöcher auch wieder an die linke Seite. Wollte man auch da sagen, der Rock wäre ein gewendeter. Lieber Himmel! Was für Unsinn ließe sich nicht durch eine solche Hermeneutik rechtfertigen! ${ }^{23}$

Mit der Existenz eines preiswerten, dem Publikum zugänglichen Nachstiches konnte Lichtenberg auch seine Beschreibungsstrategie ändern. Er stellte seine Schilderung jetzt unter die leitende Fragestellung, wie sich der Titel „Strolling Actresses“ mit den zum Teil maskulin wirkenden Figuren vereinen lässt, und ging generell auf sehr viel freiere Weise mit der Beschreibung des Blattes vor. Ganz offensichtlich ist

20 Zu Riepenhausens Stichen für die „Ausführliche Erklärung“ vgl. Ausst. Kat. Stendal, 2001 (wie Anm. 2), S. 11-22.

21 Lichtenberg, 1794-99 (wie Anm. 1), 1. Lieferung, 1794, S. 3-30.

22 Tatsächlich gibt der Großteil der Riepenhausen-Nachstiche die englischen Stiche von bzw. nach Hogarth seitenrichtig wieder. Umso mehr erscheint das seltene Spiegeln der Vorlagen bewusst eingesetzt worden zu sein. So sind bei den Vier Tageszeiten die Blätter „Morning“ und „Evening" gespiegelt, die übrigen hingegen nicht. Bei der Serie „A Rake’s Progres““ sind Blatt 3, 4 und 8 gespiegelt. Die Serie „Marriage à la Mode“ ist komplett gespiegelt, ebenso die Einzelblätter „Columbus Breaking the Egg“, „Scholars at a Lecture“, "Southwark Fair", „The Politician“ sowie „Before“ (aber nicht „After").

23 Lichtenberg, 1794-99 (Anm. 1), 1. Lieferung, 1794, S. 29. 
dies eine Beschreibung, die damit rechnet, dass die Leser das Blatt vor sich haben. ${ }^{24}$ So zeigt sich gerade im Vergleich der Beschreibungen die Sorgfalt und Umsicht, mit der Lichtenberg mit diesen Bildern umgeht. Man kann, um einen modernen Begriff zu wählen, geradezu von ,Medienkompetenz'sprechen.

Von eindrucksvoller Qualität sind im übrigen auch die Nachstiche von Lichtenbergs bildkünstlerischem Mitstreiter Riepenhausen. Bei einer Bewertung ist die unterschiedliche Bildgröße in Betracht zu ziehen, welche dem Stecher manche Feinheit verwehrt hat. Wie genau er unter diesen Bedingungen die Hogarthsche Vorlage übertragen hat, ist durchaus beachtlich. So darf man in diesem Falle wohl tatsächlich von einem gelungenen Medientransfer sprechen, der hier sowohl von Bild zu Text als auch von Bild zu Bild zwischen London und Göttingen vollzogen wird.

\section{Von England nach Deutschland: Aspekte eines Kulturtransfers}

Nun geht es bei der Übertragung der Bilder Hogarths von London nach Göttingen nicht allein um einen Medientransfer, sondern auch um das Überspringen kultureller Differenzen. Von Beginn an reflektiert Lichtenberg im „Göttinger Taschen Calender“ über die Möglichkeiten und Schwierigkeiten des von ihm betriebenen Kulturtransfers. Er tut dies ganz grundlegend, indem er die Kunst Hogarths zu charakterisieren sucht. Einerseits stilisiert er diesen dabei zu einem universal wirksamen Künstler. Andererseits muss er aber eingestehen, dass eine Vielzahl von Details in dessen Bildern vom Betrachter ein Zusatzwissen erfordert. So schreibt er im Vorwort „Ueber die Hogarthischen Kupferstiche“ über Hogarth:

Den allgemeinen Beyfall hat er, wie große Schriftsteller den ihrigen, der Darstellung allgemeiner menschlichen Natur, und der Sprache zu danken, die man in Lissabon so gut versteht als in Moskau. Allein ausser diesen Zeichen, die seinen

24 Thomas Althaus diagnostiziert bei Lichtenbergs „Ausführlicher Erklärung“ eine zunehmende Eigenwertigkeit des Textes gegenüber den Bildern. Er konstatiert, dass die Hogarth-Kommentare „mit ihren ausgestellten Worten beginnen, eigene Geschichte zu erzählen, gegen den Bezugshorizont, in den sie gestellt sind. Der wäre dann wie der Bezugshorizont jedes literarischen Textes, der etwa entstehungsgeschichtlich auszumachen ist, im letzten nichts weiter als die Veranlassung des Schreibens. Die Bewegung der Entfernung von ihrem Anlaß ist an diesen Texten genau zu beobachten; sie zeigen sich noch in der Arbeit daran, zeigen den Prozeß ihrer Metaphorisierung an den ausgestellten Worten vor und machen ihn sich so selbst zum Thema“. - Thomas Althaus, Das Uneigentliche ist das Eigentliche. Metaphorische Darstellung in der Prosa bei Lessing und Lichtenberg, Literatur als Sprache. Literaturtheorie - Interpretation - Sprachkritik 8, Münster 1991, S. 255. Abgesehen davon, dass diese Diagnose tendenziell überzogen ist - vgl. auch Arburg, 1998 (wie Anm. 7), S. 39 - macht ein Vergleich der jeweiligen Medienkonstellation bei der „Ausführlichen Erklärung“ und den Kalender-Erklärungen deutlich, dass sich Lichtenberg gerade da von der Bildvorlage löst, wo er diese nicht mehr „ersetzen“ und Ekphrasis leisten muss, indem diese nunmehr selbst als Nachstich verfügbar ist. Insofern kann die Lösung von der Vorlage gerade als Reaktion auf deren im Bild gesicherte Präsenz verstanden werden. 


\begin{abstract}
Werken die Verständlichkeit versichern, so lange als sie dauern werden, bedient er sich, um denselben einen Reiz für sein Zeitalter besonders zu geben, einer Menge anderer, die mit der Zeit verlöschen werden, und wohl zum Theil schon verloschen sind; auch selbst die allgemein verständlichen sind öfters so angebracht, daß sie nicht jeder gleich für wichtig hält, und also einen Gedanken entbehrt, den er sogleich würde gefunden haben, wenn er nur das Zeichen für wichtig gehalten hätte. ${ }^{25}$
\end{abstract}

Lichtenberg argumentiert auf der Basis aufklärerischer Semiotik, indem er zwischen universal wirksamen und konventionellen, der Erklärung bedürftigen Zeichen unterscheidet. ${ }^{26}$ Anders als bei rigideren Kunsttheoretikern seiner Zeit, welche Werke der bildenden Kunst weitgehend auf den Gebrauch natürlicher Zeichen einschränken wollten, ${ }^{27}$ fällt sein Urteil allerdings ausgesprochen positiv aus. Die Folgen hieraus übernimmt er selbst als Schriftsteller: Lichtenberg erklärt Hogarth. Dabei hat ein erheblicher Teil seiner Erörterungen damit zu tun, dass der Künstler für ein britisches Publikum mit einem spezifischen Vorwissen gearbeitet hat, das eines Transfers bedarf. ${ }^{28}$

Was dies bedeutet, lässt sich anhand des Blattes „Herumstreifende Schauspielerinnen, die sich in einer Scheune ankleiden“" sehr gut erörtern. Tatsächlich gewinnt die hier gezeigte Szene nämlich erheblich an Aussagekraft und Schärfe, wenn man die vom Künstler selbst in das Bild integrierten Texte zu deuten weiß. In der linken unteren Ecke des Hogarth-Stiches (beim Riepenhausen-Stich ist es die rechte) sieht man neben der als Adler verkleideten Frau mit dem Kleinkind eine Krone. Auf dieser ist das Breipfännchen abgestellt, aus dem das Kind gefüttert wird. Zwischen Krone und Breipfanne ist ein Blatt abgelegt, auf dem zu lesen ist: „The Act against strolling Play-

25 Promies, 1999 (wie Anm. 1), S. 7.

26 Grundlage ist die etwa von Theoretikern wie Christian Wolff, Alexander Gottlieb Baumgarten, Johann Jacob Bodmer, Johann Jacob Breitinger, Moses Mendelssohn oder Gotthold Ephraim Lessing vorgenommene Differenz zwischen ,natürlichen' und ,willkürlichen' Zeichen - vgl. u. a. Bengt Algot Sørensen, Symbol und Symbolismus in den ästhetischen Theorien des 18. Jahrhunderts und der deutschen Romantik, Kopenhagen 1963, S. 32-40.

27 Die weitgehende Festlegung der Bildkünste auf den Gebrauch ,natürlicher ' Zeichen verbindet sich mit der Utopie einer unmittelbar anschaulich wirkenden Kunst und manifestiert sich im ausgehenden 18. Jahrhundert insbesondere in der Allegoriekritik - vgl. Sørensen, 1963 (wie Anm. 26), S. 33-40.

28 In seiner „Ausführlichen Erklärung der Hogarthischen Kupferstiche“ unterscheidet Lichtenberg zwischen einem prosaischen und einem poetischen Weg, Hogarths Werke zu erklären, und reklamiert für sich selbst den zweiten. Als gemeinsamen Nenner bezeichnet er jedoch die Vermittlung der erforderlichen Sachinformationen: Man sagte, was die Dinge bedeuten, und machte besonders auf solche aufmerksam, die jemand, der nicht mit dem Lande des Künstlers, oder auch nicht mit dessen Genie bekannt ist, entweder ganz übersehen, oder wenn er sie auch bemerkt hätte, doch nicht gehörig verstanden haben würde. (Lichtenberg, 1794-99 (wie Anm. 1), 1. Lieferung, 1794, S. IV). In diesem Zusammenhang verweist Lichtenberg mehrfach auf seinen häufigen Umgang mit Engländern (ebd., S. VIII, XIII). Tatsächlich baute er sich ein regelrechtes Netzwerk auf, um die Stiche interpretieren zu können - vgl. Arburg, 1998 (wie Anm. 7), S. 17. 
ers“. Dieser Hinweis führt zu einem konkreten historischen Dokument: 1737 wurde ein Gesetz erlassen, welches Theateraufführungen auf bestimmte Aufführungsstätten (die Theater Drury Lane, Covent Garden, die City von Westminster sowie den Aufenthaltsort des Königs) beschränkt. ${ }^{29}$ Daraus folgt, dass für die Schauspielertruppe, die Hogarth in seinem Stich beim Umkleiden in einer ländlichen Scheune zeigt, ein Existenzverlust unmittelbar bevorsteht. Der daneben auf dem Bett dargestelle Theaterzettel vertieft dies: By a Company of Comediens from the Theatres at London at the GEORGE INN This Present Evening will be Presented THE DEVIL to Pay in HEAVEN Being the last time of Acting Before the Act Commences. Es geht folglich um die letzte Vorstellung, welche diese Theatertruppe geben kann, bevor das Gesetz greift und derartige Vorstellungen verboten werden.

Von diesen schriftlich wiedergegebenen Sachinformationen hängt die Deutung des Bildes in nicht unerheblichem Maße ab. Dementsprechend geht auch Lichtenberg ausführlich hierauf ein. So schreibt er etwa in der „Ausführlichen Erklärung der Hogarthischen Kupferstiche" von 1794:

Bald wird es also vorbei seyn, gesetzt auch, daß sie, wie in Deutschland gewöhnlich ist, drei bis viermal hinter einander zum letzten Male spielen. Diese armen Teufel wird schwerlich etwas retten können, auch die feinste Sylbenstecherei englischer Rechtshändler nicht. Sagte die Acte, wie etwa im Deutschen, bloß against strolling actors (gegen herumstreichende Comödianten), so dürften sie nur sagen: wir streichen zwar, aber wir sind Comödiantinnen: so wären sie einstweilen so sicher in ihren Scheunen, als auf ihren Londonschen Theatern. So aber heißt es against strolling players, und gegen dieses Wort käme selbst eine Bande Hermaphroditen nicht auf. Aber wer weiß was sie dennoch thun. So wahr ist es überall, aber nirgends mehr als in England: um Recht zu thun in der Welt, braucht man nur sehr wenig zu wissen, allein um mit Sicherheit Unrecht thun zu können, muß man die Rechte studiren. ${ }^{30}$

Auffällig ist, wie Lichtenberg hier immer wieder zwischen Verweisen auf England und auf Deutschland hin- und herpendelt, während er gleichzeitig die Leitfrage nach dem Geschlecht der „Actresses“ weiterspinnt. Genau darin zeigt sich sein Bemühen um einen Kulturtransfer.

Die Konsequenz aus der ganz unmittelbaren Bedrohung der Schauspieler sieht er in einem anderen Bilddetail verwirklicht. Unter dem Korb mit der Aufschrift „Jewels“, an dem sich eine Schauspielerin die Haare talgt, befindet sich eine Kerze, deren Flamme bereits den Korb erfasst:

29 Vgl. Frederick Antal, Hogarth und seine Stellung in der europäischen Kunst, Dresden 1962, S. 90f.; Paulson, 1970 (wie Anm. 4), Bd. 1, S. 182; Ronald Paulson, Hogarth. His Life, Art, and Times, New Haven $/$ London 1971, Bd. 1, S. 395.

30 Lichtenberg, 1794-99 (wie Anm. 1), 1. Lieferung, 1794, S. 6. 
Ein brennendes Licht, das vermuthlich zum Anzünden der übrigen bereit steht, ist so nachlässig hingestellt, daß die Flamme desselben das Stroh, worein die Juwelen im Malter-Cassettchen gepackt sind, ergreift, und nicht allein die Juwelen (denn nach den neuesten Versuchen verfliegt der Demant im Feuer), sondern dieses ganze Pantheon mit allen seinen Herrlichkeiten aufliegen machen wird, wenn es die Göttinnen nicht bald gewahr werden. Also hier glimmt schon die Rechtskräftigkeit der Parlaments-Acte, von dem Schicksal selbst angefacht. ${ }^{31}$

So deckt Lichtenberg Bildstrategien auf, die für Hogarth ausgesprochen charakteristisch sind. Dabei gewinnt seine Erklär-Arbeit dadurch an Bedeutung, dass die vom Künstler angewandten Strategien im ausgehenden 18. Jahrhundert zunehmend in Verruf gerieten, indem das Ideal selbstevidenter Bilder propagiert wurde. ${ }^{32}$ Hogarths erklärungsbedürftige Medienkombination war insofern alles andere als unproblematisch.

\section{Von Kunstwerk zu Kunstwerk: Zur Kommunikation des künstlerischen Anspruchs}

Umso erstaunlicher erscheint es, wie Lichtenberg die künstlerische Gültigkeit von Hogarth beschwört. Dabei greift er gleich zu Beginn seiner Kalendererklärungen „Über die Hogarthischen Kupferstiche“ zum Höchsten, zu dem man als kunstverständiger Verfasser im ausgehenden 18. Jahrhundert überhaupt greifen kann - zu Raffael:

Es wird nicht leicht unter uns, oder überhaupt in der gesitteten Welt, einen Mann von Geist und Geschmack geben, der den Namen Hogarth nicht kennt. Auch ist der Mann in seiner Art gewißs so einzig, als Raphael in der seinigen, so verschieden auch die Wege seyn mögen, die beyde zu ihrem Ruhm betreten haben. ${ }^{33}$

31 Lichtenberg, 1794-99 (wie Anm. 1), 1. Lieferung, 1794, S. 12.

32 Man kann hier etwa auf Johann Wolfgang Goethes Weimarischen Kunstfreund Johann Heinrich Meyer verweisen, der in seinem Aufsatz „Über die Gegenstände der bildenden Kunst“ das Ideal eines sich selbst erklärenden Bildes propagiert hat - Johann Heinrich Meyer, Ueber die Gegenstände der bildenden Kunst, in: Propyläen. Eine periodische Schrifft 1,1 (1798), S. 20-54, hier S. 21: Man fordert von einem jeden Kunstwerke, daß es ein Ganzes für sich ausmache, und von einem Werke der bildenden Kunst besonders, daß es sich selbst ganz ausspreche. Es muß unabhängig seyn, die vorgestellte Handlung, der Gegenstand muß, im Wesentlichen, ohne äussere Beyhülfe, ohne Nebenerklärung, die man aus einem Dichter oder Geschichtschreiber schöpfen müßte, gefaßt und verstanden werden.

33 Promies, 1999 (wie Anm. 1), S. 7. 
Die Aussage, dass Hogarth in seiner Art so einzig sei als Raphael in der seinigen, erstaunt nicht zuletzt deshalb, weil Raffael in der Kunsttheorie dieser Zeit nicht als Spezialist galt, sondern als universaler Künstler. Noch mehr überrascht, dass Lichtenberg ausgerechnet einen Künstler wie Hogarth, dessen Werke klassische Idealvorstellungen immer wieder verletzen und nicht selten karikaturistisch überzeichnet erscheinen, mit Raffael in Beziehung setzt, dessen Kunst geradezu als Inbegriff des klassischen Ideals angesehen werden kann. ${ }^{34}$

Nun gehört es zu den besonders bemerkenswerten Facetten von Hogarths Schaffen, dass es selbst von einer intensiven Auseinandersetzung mit Werken und Bildtypen der Kunstgeschichte geprägt ist. ${ }^{35}$ Auch dies lässt sich am Beispiel des Bildes „Strolling Actresses dressing in an Barn" exemplarisch demonstrieren. Als künstlerische Referenz figuriert dabei tatsächlich kein Geringerer als Raffael selbst. Wie Frederick Antal plausibel machen konnte, lassen sich die beiden als Teufelchen verkleideten Kinder, die sich hinter einem antikisierenden Opferaltar um einen Bierkrug rangeln, als Zitate zweier Kinderfiguren in Raffaels Karton „Das Opfer zu Lystra“ deuten (Abb. 4). ${ }^{36}$ Hogarth hat die Kartons zu Wandteppichen in der Sixtinischen Kapelle in Rom, die zu den wertvollsten Kunstschätzen in England gehörten, zweifellos gekannt. Zu seinen Lebzeiten wurden sie (bis 1763) im Hampton Court Palace gezeigt. ${ }^{37}$ Dabei sind aus Raffaels lieblich dreinblickenden (und dreinfötenden) Ministranten bei Hogarth zwei ausgesprochen derbe Gesellen geworden, die ihre Teufelskostüme durchaus mit Leben erfüllen.

Die Art und Weise, wie sich Hogarth hier auf Raffael bezieht, hat also einen ausgesprochen parodistischen Charakter. Dies spricht gerade nicht für eine ernsthafte Berufung auf diesen Künstler, sondern eher für eine Distanzierung von dessen Idealismus. Man kann daraufhin sogar die Frage stellen, ob nicht sogar Lichtenbergs Einleitung selbst mit ihrem Loblied auf Hogarth als Distanzierung von dem idealistischen Kunstkonzept zu verstehen ist, wie man es um 1800 in Raffael verkörpert sah.

Tatsächlich ist der Sachverhalt aber wohl doch komplizierter - und dies sowohl bei Hogarth als auch bei Lichtenberg. So hat Hogarth ebenso versucht, sich als Maler ernster Historien in der Tradition Raffaels zu etablieren. ${ }^{38}$ Dieses - insgesamt eher er-

34 Zur Frage nach dem Karikaturenhaften von Hogarths Kunst und dessen Rezeption bei Lichtenberg vgl. Arburg, 1998 (wie Anm. 7) S. 182-194.

35 Vgl. hierzu insbesondere Werner Busch, Nachahmung als bürgerliches Kunstprinzip. Ikonographische Zitate bei Hogarth und in seiner Nachfolge, Studien zur Kunstgeschichte 7, Hildesheim/ New York 1977.

36 Antal, 1962 (wie Anm. 29), S. 90.

37 Vgl. John Shearman, Raphael's Cartoons in the Royal Collection of Her Majesty the Queen and the Tapestries for the Sistine Chapel, London 1972, S. 149-153.

38 William Hogarth: „Paul before Felix“, 1747/48, London, Lincoln’s Inn - vgl. u. a. Paulson, 1971 (wie Anm. 29), Bd. 2, S. 51-54; Werner Busch, Das sentimentalische Bild. Die Krise der Kunst im 18. Jahrhundert und die Geburt der Moderne, München 1993, S. 31-36. Bezeichnenderweise publizierte Hogarth eine Graphik mit dem Titel „Paul before Felix Burlesqued“, laut Bildunterschrift „Design’d and scratch’d 


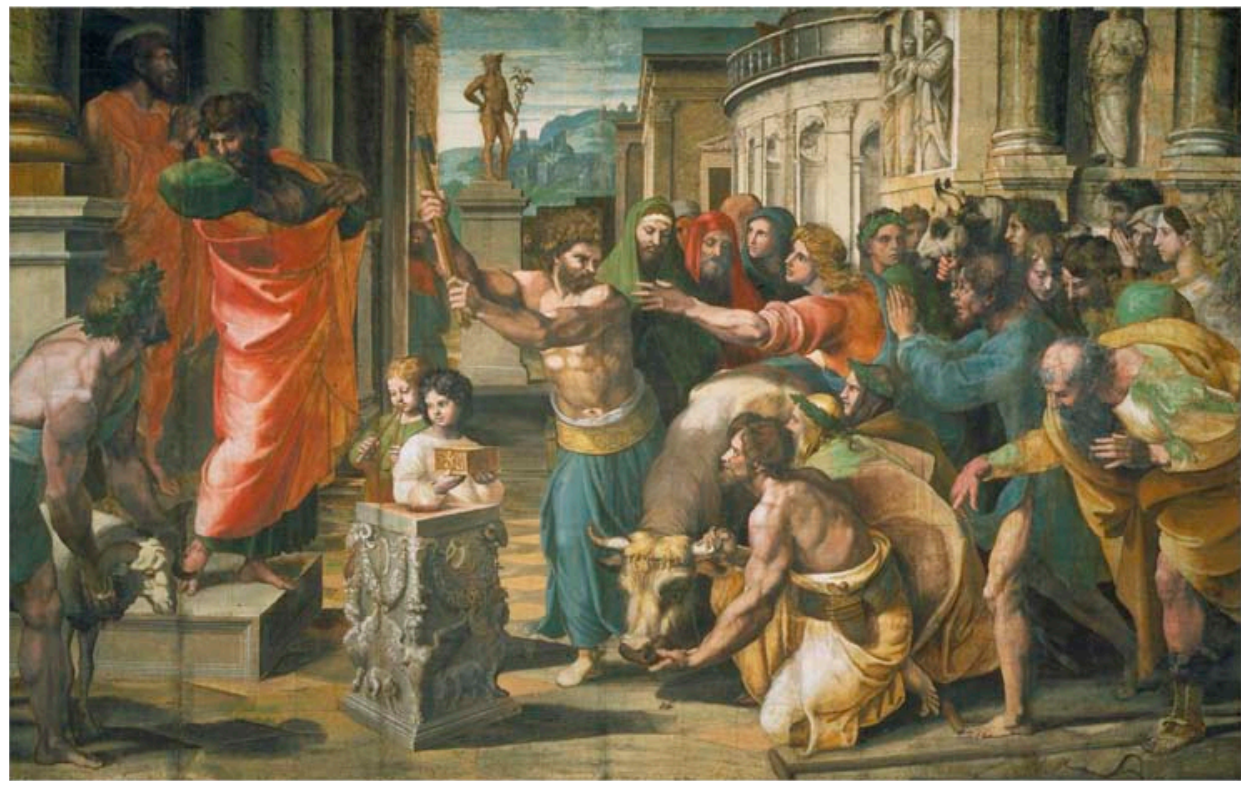

Abb. 4: Raffael: Das Opfer zu Lystra, 1514/15, schwarze Kreide und Tempera auf mehreren übereinandergeleimten und auf Leinwand kaschierten Papierbögen, 342 x $442 \mathrm{~cm}$, London, V\&A Images Victoria and Albert Museum

folglose - Bestreben muss durchaus ernst genommen werden. Einen wichtigen Beleg für sein Kunstverständnis bietet die Graphik „Characters and Caricatures“, die 1743 als Subskriptionsblatt für die Serie „Marriage à la Mode“ gedruckt wurde (Abb. 5). ${ }^{39}$ Im unteren Bereich kontrastiert sie - durch einen Riss getrennt - anhand älterer Beispiele aus der Kunstgeschichte Charakterdarstellungen mit karikaturistisch überzeichneten Kopfdarstellungen nach Annibale Carracci, Pier Leone Ghezzi und Leonardo da Vinci. ${ }^{40}$ Die - positiv konnotierten - Charakterköpfe stammen von Raffael. Einer davon ist aus dem Karton „Das Opfer zu Lystra“ übernommen, den Hogarth in „Strolling actresses“ parodiert. Betrachtet man das Blatt insgesamt, so bietet es ein Panorama dessen, was Hogarth physiognomisch und pathognomisch in seinem Werk ausgebreitet hat. Hogarth selbst inszeniert sich also zumindest hier als Charakterisierer und nicht als Karikaturist, wobei er sich unmissverständlich auf Raffael bezieht. Dass er ihn vorher parodiert hat, ändert ebensowenig an diesem Selbstverständnis wie

in the true Dutch taste“, um die Distanz zwischen der Höhenlage seines Historiengemäldes und einem niederen Stil in der Art holländischer Malerei zu demonstrieren - vgl. Werner Busch, 1993 (wie Anm. 38), S. 35f.; Paulson, 1970 (wie Anm. 4), Bd. 1, S. 215 f.

39 William Hogarth, Characters and Caricatures, 1743, Radierung, 206 × 200 mm; vgl. Paulson, 1970 (wie Anm. 4), Bd. 1, S. 188f.

40 Siehe die Beschriftung des Blattes - vgl. ebd. 


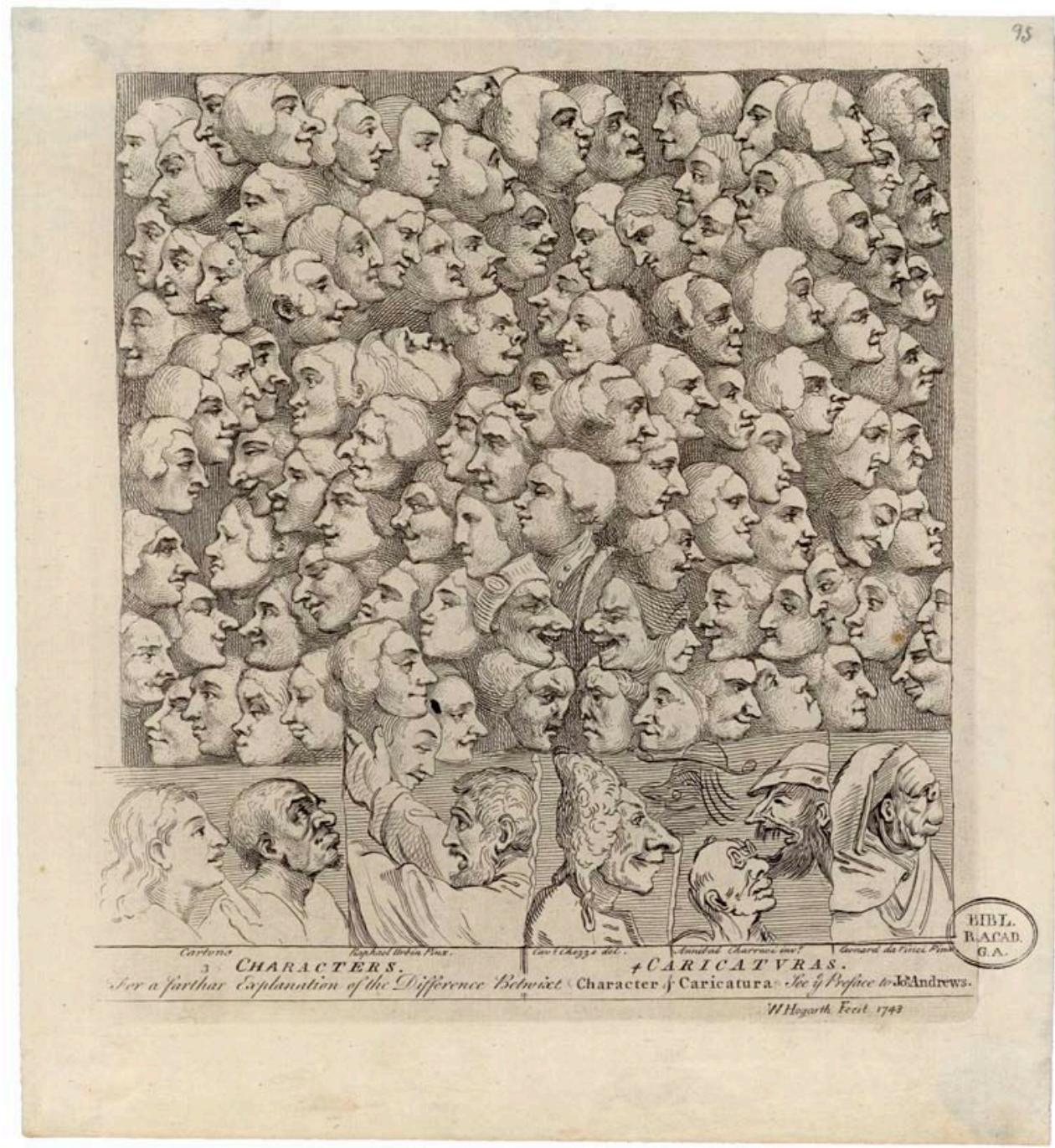

Abb. 5: William Hogarth: Characters and Caricatures, 1743, Radierung, 231 x 206 mm, Göttingen, Staats- und Universitätsbibliothek, gr. $2^{\circ}$ Art. plast. VI, 25 Rara: Abb. Nr. 21; mit freundlicher Unterstützung der Göttinger Staats- und Universitätsbibliothek 
die Frage, ob ihm die Umsetzung dieser Differenzierung - d.h. die Wahrung eines Abstands zur Karikatur - immer gelungen ist. ${ }^{41}$

Als Charakterisierer reiht sich Hogarth bei aller Spezifik, mit der er etwa auch gesellschaftskritische Themen umgesetzt hat, in eine breite und facettenreiche künstlerische und kunsttheoretische Tradition ein, welche von der Frühen Neuzeit bis ins 19. Jahrhundert hinein reicht. Es würde den Rahmen dieses Beitrags sprengen, hier eine angemessene Verortung des Künstlers zu bieten. Angedeutet sei hier nur, dass sich die Fähigkeit, Personen physiognomisch und pathognomisch zu charakterisieren, gerade für die Hochkunst der Historie mit dem Anspruch verband, Ausdrucksgehalte auf differenzierte Weise visualisieren zu können und damit etwas zu leisten, was den Sprachkünsten ebenbürtig sei.

Dass Georg Christoph Lichtenberg genau diese Fähigkeit bei Hogarth sah und besonders schätzte, zeigt sich an einer Ebene des Medientransfers, die bislang noch nicht zur Sprache gekommen ist, weil sie bei den "Strolling Actresses“ nicht vorkommt: Die kleinformatigen, von Ernst Ludwig Riepenhausen ab 1785 gestochenen Illustrationen zum „Göttinger Taschen Calender" konzentrieren sich nämlich nur auf die Köpfe der Personen, auf welche mit Zahlenverweisen im Text eingegangen wird.

Es ist wohl in erster Linie diese Charakterisierungskunst, der William Hogarth das große Lob Lichtenbergs zu verdanken hat: Den allgemeinen Beyfall hat er, wie große Schriftsteller den ihrigen, der Darstellung allgemeiner menschlicher Natur, und der Sprache zu danken, die man in Lissabon so gut versteht als in Moskau. ${ }^{42}$ Genau darin bestand das Ziel des Charakterisierens: In der Befähigkeit zum idealerweise allgemein-menschlich wirksamen Darstellen. Dass Hogarths Werk gleichwohl immer erklärungsbedürftig blieb und bleiben wird, war Lichtenberg nichtsdestoweniger klar und bildete sicher einen Hauptanlass für seine eindrucksvollen Leistungen im englisch-deutschen Kultur- und Medientransfer. Letztlich erscheint dieses Eingeständnis ehrlicher als das wohl von vornherein utopische Ziel einer unmittelbar und voraussetzungslos wirksamen Kunst. So braucht also die Kunst die Literatur, aber eben auch die Kunstgeschichte.

41 Vgl. Arburg, 1998 (wie Anm. 7), S. $188 f$.

42 Promies, 1999 (wie Anm. 1), S. 7. Vgl. auch Arburg, 1998 (wie Anm. 7), S. 195-210. 



\title{
Musik als Wissenschaft im Raum der Personalunion
}

\author{
Andreas WaczKat
}

Am 23. Juni 1733 vermerkt die Londoner Tageszeitung „The Bee“:

Great Preparations are making for Mr. Handel's Journey to Oxford, in order to take his Degree of Musick; a Favour that University intends to compliment him with, at the ensuing Publick Act. The Theatre there is fitting up for the Performance of his Musical Entertainments, the first [of] which begins on Friday Fortnight the $6^{\text {th }}$ of July. We hear that the Oratorios of Esther and Deborah, and also a newer one never performed before, called Athaliah, are to be represented two Nights each; and the Serenata of Acis and Galathea as often. ${ }^{1}$

Keine Frage: spricht man über Musik im Raum der Personalunion, zieht die Person Georg Friedrich Händels die mit Abstand größte Aufmerksamkeit auf sich. Dass der vormalige hannoversche Hofkapellmeister indes auch - zumindest in gewisser Weise - für die Geschichte und das Verständnis der Musik als Wissenschaft im Raum der Personalunion zentral ist, belegt dieses Ereignis aus dem Jahr 1733. Die Universität Oxford, begründet im 12. Jahrhundert und damit eine der ältesten Universitäten Europas, beabsichtigte, Händel den akademischen Grad eines Doctor Musicae - D.Mus. - zu verleihen; ein Grad, der wie auch der des Baccalaureus Musicae - B.Mus. - wohl seit dem frühen 16. Jahrhundert vergeben worden war. Händel sollte anlässlich dieser Ehrung, so berichtet es „The Bee“, und so bestätigen es die Zeitungen aus Oxford, seine Oratorien Esther, Deborah und die eigens zu diesem Anlass komponierte Athalia aufführen, ebenso die unterhaltende kleine Seranata Acis und Galathea. Händel hatte dazu, so berichtet "The Bee“ weiter, auch die entsprechenden Gesangssolisten aus London in die wohl eine Tagesreise entfernte Universitätsstadt mitgenommen: die

1 Zitiert nach: Walter Eisen (Hg.), Händel-Handbuch, Bd. 4, Dokumente zu Leben und Schaffen, Leipzig 1985, S. $215 f$. 
Sopranistinnen Anna Strada und Mrs. Wright, die beiden Tenöre Thomas Salway und Philip Rochetti sowie den Bass Gustavus Waltz.

Die Aufführungen fanden allgemeines Lob, und sie überstiegen die Anforderungen, die die Universität Oxford an die Verleihung der akademischen Grade des Baccalaureus oder des Doctor Musicae geknüpft hatte, bei weitem. Der Baccalaureus Musicae konnte solchen Personen verliehen werden, die sich sieben Jahre nachweislich dem Studium und der Praxis der Musik verschrieben hatten und ein fünfstimmiges Canticum zum Examen vorlegten, das auch in der School of Music der Universität Oxford mit Vokalstimmen und Instrumenten aufzuführen war. ${ }^{2}$ Mit einem solchen Canticum ist ein einsätziges geistliches Werk gemeint, etwa ein einfaches Anthem, wie es im Rahmen einer gottesdienstlichen Feier in der anglikanischen Kirche vorkommt. Für die sehr viel seltenere Verleihung des Doctor Musicae bedurfte es fünf weiterer Jahre der praktischen oder theoretischen Auseinandersetzung mit der Musik; das vorzulegende Canticum wurde nun sechs- oder achtstimmig erwartet. ${ }^{3}$ Mit den insgesamt zwölf Jahren des Studiums der Musik ist freilich keine universitäre Ausbildung gemeint: Die Musik war kein Studienfach an den Universitäten. Vielmehr hatten die Kandidaten für diesen Titel ihre jeweilige Beschäftigung mit der Musik durch geeignete Nachweise zu belegen. William Croft beispielsweise, dem der Titel des Doctor Musicae im Jahr 1713 verliehen worden war, konnte das leicht tun: Nachdem er einige Jahre als Chorknabe in der Chapel Royal gesungen hatte, wurde er im Jahr 1700 Organist an der St. Anne's Church in London, später Musiklehrer an der Chapel Royal, 1708 schließlich Organist an der Westminster Abbey. ${ }^{4}$ In dieser Stellung komponierte er 1714 - also schon als Doctor Musicae - sowohl die Musik für die Begräbnisfeierlichkeiten von Queen Anne als auch die Musik für die Krönungszeremonie für den hannoverschen Kurfürsten Georg Ludwig zum King George I. Croft steht auf diese Weise an führender Stelle, wenn es um Musik im Raum der Personalunion geht. Er hatte also schon 13 Jahre einer professionellen Karriere hinter sich, und auch das Canticum, mit dem er sich der Prüfung unterzog, ist bekannt: Das Anthem This is the day, komponiert anlässlich des Friedens von Utrecht im Jahr 1713, ${ }^{5}$ für den auch schon Händel das Utrechter Te Deum geschaffen hatte.

Im Vergleich zu Händels abendfüllendem Oratorium Athalia ist Crofts Promotionsanthem ein klein dimensioniertes Werk, und bei aller souveränen Beherrschung des Kompositionshandwerks fehlt es Crofts Kompositionen doch an jenem zündenden Feuer, mit dem die Händelschen Oratorien so schnell für sich einnehmen, wofür

2 Susan Wollenberg, Music in 18th-Century Oxford, in: Proceedings of the Royal Music Association 108 (1981/82), S. 69-99, hier S. 70.

3 Wollenberg, 1981/82 (wie Anm. 2), S. 71.

4 Watkins Shaw, William Croft, in: Ludwig Finscher (Hg.), Die Musik in Geschichte und Gegenwart (im Folgenden MGG), Personenteil 5, Kassel 22001, Sp. 120-122, hier Sp. 120.

5 Shaw, 2001 (wie Anm. 4). 
auch Athalia ausgezeichnete Beispiele parat hält. Händel hatte also alle Bedingungen für die Verleihung des Doctor Musicae erfüllt - und lehnte den Titel dennoch ab. Was war passiert? Über die Gründe lassen sich nur Mutmaßungen anstellen, denn in den zahlreichen Dokumenten, die im Zusammenhang mit dieser Titelverleihung einschlägig sind, ${ }^{6}$ finden sich dazu keine Hinweise. Immer wieder einmal wird daher gemutmaßt, dass Händels Bescheidenheit ihn zur Ablehnung des Titels geführt haben könnte, ${ }^{7}$ doch beruht das wohl auf einer biographischen Projektion. Der einzige Komponist, dem schon zu Lebzeiten ein Denkmal gesetzt worden ist, nämlich die 1737/38 von Louis François Roubiliac für die Vauxhall Gardens geschaffene Statue, hat es ja auch akzeptiert, dabei als Apollo dargestellt zu werden.

Wahrscheinlicher sind damit zwei andere Gründe: Zum Einen wird angeführt, dass Händel die Prüfungsgebühr in Höhe von $£ 100$ zu hoch gewesen sein könne, ${ }^{8}$ was zwar denkbar, angesichts des von der Norwich Gazette am 21. Juli 1733 berechneten Reingewinns von $£ 2.000^{9}$ aus den in Oxford gegebenen Konzerten aber nicht sehr überzeugend ist. Zum Anderen war der Doctor Musicae 1715 auch an den Organisten Maurice Greene verliehen worden, der seit 1730 Professor der Musik an der Universität Oxford war. Greene allerdings trat um 1715 auch für Händel die Bälge, wenn dieser an der Orgel der St. Paul's Cathedral spielte. Auf Augenhöhe mit Händel stand der Herr Professor Greene also sicherlich nicht, wenngleich er gewiss auch ein solider Komponist war.

Für das Nachdenken über Musik als Wissenschaft im Raum der Personalunion steckt diese Episode allerdings schon ganz wesentliche Punkte des Rahmens ab. Nicht die Residenzstädte sind es, die die Aufmerksamkeit auf sich ziehen, sondern die Universitäten Oxford und Göttingen. Und es geht um die Entdeckung der Beschäftigung mit Musik als theoretischer Disziplin eigenen Rechts, wie es sich beispielsweise auch an der Verleihung des Oxforder Doctor Musicae an Samuel Arnold im Jahr 1773 ablesen lässt. Zwar hatte auch Arnold, der später noch Hofkomponist, Direktor der Academy of Ancient Music sowie Organist an der Westminster Abbey werden sollte, ${ }^{10}$ eine professionelle Karriere als Musiker noch vor sich, doch wesentlich in Erscheinung getreten ist er als Herausgeber der ersten Gesamtausgabe der Werke Händels,

6 Eisen, 1985 (wie Anm. 1), S. 218-221.

7 Eisen, 1985 (wie Anm. 1), S. 220, jedoch ohne Nennung spezifischer Biographen. Der mutmaßlicherweise früheste Beleg für Händels angebliche Bescheidenheit findet sich bei Friedrich Chrysander, G. F. Händel, Leipzig 1858, S. 87. Allerdings spielen die Umstände der Oxforder Promotion bei Chrysander keine Rolle.

8 Eisen, 1985 (wie Anm. 1), außerdem Hans-Joachim Marx, Georg Friedrich Händel, in: Ludwig Finscher (Hg.), MGG, Personenteil 8, Kassel 22002, Sp. 509-638, hier Sp. 529.

9 Eisen, 1985 (wie Anm. 1), S. 221.

10 Robert Hoskins, Samuel Arnold, in: Ludwig Finscher (Hg.), MGG, Personenteil 1, Kassel 21999, Sp. 1002-1008, hier Sp. 1003. 
was von Robert Hoskins als „hauptsächlich wissenschaftliche Arbeit ${ }^{\text {"11 }}$ charakterisiert wird.

Diese Entwicklung hat eine ebenso lange Vor- wie Nachgeschichte. In Oxford bietet es sich an, zunächst in das Jahr 1626 zurückzuschauen, denn in diesem Jahr wurde von William Heather die Professur für Musik gestiftet, deren als nicht miteinander vereinbar angesehene Aufgaben in der Theorie und Praxis der Musik von zwei Personen wahrgenommen wurden: einem Chorleiter, der die allwöchentlichen Proben des Universitätschors zu leiten hatte, und einem Lektor, der in Fortsetzung der mittelalterlichen und frühneuzeitlichen Tradition die theoretische Beschäftigung mit der Musik im Rahmen des Quadriviums anzuleiten, mithin Musiktheorie als Zahlwissenschaft zu betreiben hatte. ${ }^{12}$ Dabei zeigt schon das Gehalt der beiden Personen die klare Hierarchie auf: Der Lektor bezog $£ 3$ jährlich, der Chorleiter mit $£ 13$ aber mehr als das Vierfache. Noch im 17. Jahrhundert blieb die Position des Lektors dauerhaft vakant, während der Chorleiter seit dem frühen 18. Jahrhundert schon den Titel Professor trug. Hier allerdings liegt auch der Grund dafür, dass der Baccalaureus und der Doctor Musicae ohne vorangegangenes Universitätsstudium verliehen werden konnten, wenn nicht mussten: Der Professor of Music hielt gar keine Vorlesungen.

Und so waren die meisten Träger eines der musikalischen akademischen Grade in Oxford Organisten, Chorleiter und Komponisten. Zum Doctor Musicae ernannt wurde beispielsweise neben den bereits erwähnten William Croft und Maurice Greene im Jahr 1713 Johann Christoph Pepusch, ein Pfarrerssohn aus Berlin, der sich schon seit 1704 in London als Komponist etabliert hatte; er ist auch einer der Mitbegründer der Academy of Ancient Music in London. 1729 wurde John Stanley zum Doctor Musicae promoviert, ein blinder Organist und Geiger, Schüler von Maurice Greene und später Direktor des Londoner Foundling Hospital. 1785 erwarb Friedrich Hartmann Graf diesen Titel. Graf war eigentlich Kantor und Musikdirektor in Augsburg, in den 1780er-Jahren indes Dirigent der von dem Mannheimer Komponisten Johann Wilhelm Cramer ins Leben gerufenen Professional Concerts in London, wo sich Graf offenbar einer sehr großen Wertschätzung erfreuen konnte. 1794 erhielt der zu diesem Zeitpunkt gerade 18-jährige William Crotch den Titel eines Doctor Musicae. Das Kriterium einer bereits zwölf Jahre umfassenden professionellen Karriere scheint hier zunächst schwer erfüllbar, doch soll Crotch schon als Zweijähriger auf einer Orgel die britische Nationalhymne gespielt haben, und schon seit 1779, als Vierjähriger, konzertierte er täglich öffentlich. ${ }^{13}$ Der britische Musikhistoriker

11 Hoskins, 1999 (wie Anm. 10).

12 Wollenberg, 1981/82 (wie Anm. 2), S. 70.

13 Jonathan Rennert, William Crotch, in: Ludwig Finscher (Hg.), MGG, Personenteil 5, Sp. 135-140, hier Sp. 136. 
Charles Burney referierte am 18. Februar 1779 vor der Royal Society über diese außergewöhnliche Frühbegabung. ${ }^{14}$

Charles Burney, Doctor Musicae der Universität Oxford seit 1769, war 1726 in Shrewsbury in den West Midlands als Sohn eines Porträtmalers geboren worden. ${ }^{15}$ Nach dem Besuch der Public School in Chester wurde er 1744 Schüler des Komponisten Thomas Arne in London; hier spielte Burney auch Violine und Viola in jenem Orchester, mit dem Händel seine Oratorienaufführungen bestritt. 1749 wurde er Organist an der St. Dionis Backchurch. Nachdem er sich 1751 aus gesundheitlichen Gründen nach Norfolk zurückgezogen hatte, kehrte er mit seiner Familie, zu der auch seine erste Tochter Esther als begabte Cembalistin gehörte, 1760 nach London zurück, wo er zunächst vornehmlich als Konzertveranstalter, aber auch als Komponist wirkte.

1774 verfolgte Burney den Plan der Gründung einer Music School, 1783 wurde er zum Organisten am College in Chelsea ernannt, wo er 1814, ausgestattet mit einer Staatspension starb. Nachdem er den Oxforder Doctor Musicae erhalten hatte, bereiste er ab 1770 Frankreich, Italien, Deutschland und die Niederlande, um Material für ein großes Vorhaben zu sammeln, das ihn wohl schon seit den 1750er-Jahren beschäftigt hatte: Burney wollte eine Geschichte der Musik schreiben. Aus seinen Reisen resultierte jedoch weit mehr: Im Jahr 1771 erschien sein Buch „The Present State of Music in France and Italy ", ${ }^{16}$ im Jahr 1773 folgte Burneys zweibändige Abhandlung „The Present State of Music in Germany, the Netherlands, and United Provinces "17; alle drei Teile wurden von Christoph Daniel Ebeling und Johann Joachim Christoph Bode als „Carl Burney's der Musik Doctors Tagebuch seiner Musikalischen Reisen " übersetzt und noch im selben Jahr gedruckt. ${ }^{18}$ Auch die projektierte Geschichte der Musik ließ nicht sehr lange auf sich warten, 1776 erschien der erste Teil einer insgesamt vierteiligen „General History of Music from the Earliest Ages to the Present Period“, deren folgende drei Teile von 1782 bis 1789 herauskamen. ${ }^{19}$ Aus

14 Charles Burney, Account of an Infant Musician, London 1779.

15 Jürgen Mainka, Charles Burney, in: Ludwig Finscher (Hg.), Personenteil 3, Sp. 1319-1326, hier Sp. 1319 ff.

16 Charles Burney, The Present State of Music in France and Italy or, the Journal of a Tour through those Countries, undertaken to collect Materials for a General History of Music, London 1771.

17 Charles Burney, The Present State of the Music in Germany, the Netherlands and the United Provinces or, the Journal of a Tour through those Countries, undertaken to collect Materials for a General History of Music, 2 Bde London 1773.

18 Carl Burney's der Musik Doctors Tagebuch einer musikalischen Reise durch Frankreich, Italien, Flandern, die Niederlande und am Rhein bis Wien, durch Böhmen, Sachsen, Brandenburg, Hamburg und Holland 1772/1773, welche er unternommen hat um zu einer allgemeinen Geschichte der Musik Materialien zu sammlen, Hamburg 1772-1773.

19 Charles Burney, A General History of Music From the Earliest Ages to the Present Period, London 17761789. 
dem ersten Band erlebte der vorangestellte Abschnitt über die Musik der Antike auch eine deutsche Übersetzung in Gestalt von „Dr. Karl Burney’s Abhandlung über die Musik der Alten“, die Johann Joachim Eschenburg, Professor für Englische Sprache am Braunschweiger Collegium Carolinum für den Leipziger Verlag Schwickert angefertigt hatte. ${ }^{20}$ Eschenburg übersetzte auch noch eine zweite Schrift Burneys, nämlich dessen „Account of the musical performances in Westminster Abbey and Pentheon in commemoration of Handel", ${ }^{21}$ in der Burney die Feierlichkeiten anlässlich von Händels 25. Todestag ausführlich beschreibt und kommentiert: vornehmlich die Aufführung von Händels Oratorium Messiah in Anwesenheit der königlichen Familie mit nicht weniger als 513 Mitwirkenden.

Mit seiner "General History of Music“ freilich hat Burney eine Arbeit vorgelegt, die ungeachtet zahlreicher Fehler im Detail der theoretischen Beschäftigung mit Musik eine neue Perspektive erschlossen hat, nämlich die historische. Burney ist dabei sicherlich in vielerlei Hinsicht beeinflusst gewesen von dem Gedanken, der auch vielen anderen Schriften des 18. Jahrhunderts zugrunde liegt, die unter Titeln wie „General History of the World“ - z. B. von William Guthrie 1764-1767 publiziert $^{22}$ - oder „History of Mankind“ - z. B. von James Dunbar $1780^{23}$ - erschienen sind. Während diese genannten Schriften aber allesamt mehr oder weniger zahlreiche Vorläufer haben, war Burney in gewisser Weise Pionier. Einzig der italienische Franziskaner-Mönch Giovanni Battista Martini hatte mit seiner „Storia della Musica“, die zwischen 1757 und 1781 in Bologna verlegt wurde,${ }^{24}$ sowie der Londoner Jurist John Hawkins mit seiner 1776 in gleich fünf Bänden erschienenen „A general history of the science and practice of music" 25 traten hier, allerdings annähernd gleichzeitig, hervor. Gemeinsam ist diesen Schriften nicht allein die historische Perspektive und die grundsätzliche Erkenntnis, dass Musik überhaupt ein Gegenstand ist, der sich historisch fassen und untersuchen lässt, sondern auch, dass die gewählten Methoden bis in die Gegenwart hinein immer noch einen Teil des Methodenbestands musikwis-

20 Dr. Karl Burney's Abhandlung über die Musik der Alten. Aus dem Englischen übersetzt, und mit einigen Anmerkungen begleitet von Johann Joachim Eschenburg, Leipzig 1781.

21 Charles Burney, An Account Of The Musical Performances In Westminster-Abbey, And The Pantheon [...] 1784, in: Commemoration Of Handel, London 1785. Übersetzt als: Dr. Karl Burney's Nachricht von Georg Friedrich Händel's Lebensumständen und der ihm zu London im Mai und Juni 1784 angestellten Gedächtnißfeyer. Mit Kupfern aus dem Englischen übersetzt von Johann Joachim Eschenburg, Berlin / Stettin 1785.

22 William Guthrie, A General History of the World from the Creation to the Present Time, 12 Bde, London 1764-1767. Guthries General History of the World ist die gewissermaßen konsequente Ausweitung seiner dreibändigen General History of England, London 1744-1751, wie auch seiner zehnbändigen General History of Scotland, London 1767-1768.

23 James Dunbar, Essays on the History of Mankind in Rude and Cultivated Ages, London 1780.

24 Giovanni Battista Martini, Storia della Musica, 3 Bde, Bologna 1757-1781.

25 John Hawkins, A General History of the Science and Practice of Music, 5 Bde, London 1776. 
senschaftlicher Forschung ausmachen, insofern Textquellen herangezogen werden, die nach philologischen Kriterien im Hinblick auf die enthaltenen Informationen über die Geschichte der Musik befragt werden. Dass dabei von Martini, Burney und Hawkins im Streben nach Universalität der Darstellung auch Kapitel geschrieben worden sind, die nahezu frei von Tatsachen sind, hat Alexander Rehding unlängst am Beispiel von Burneys Darstellung der Musik im alten Ägypten gezeigt; ${ }^{26}$ dies mindert jedoch nicht den Wert der grundsätzlichen Einsicht, dass es auch im alten Ägypten eine Musik gegeben hat, über die sich berichten lässt, um damit einen Beitrag zum allgemeinen Weltwissen zu leisten.

John Hawkins trat mit seiner "General history of the science and practice of music" gleichzeitig mit Burney in Erscheinung, wobei Hawkins vier Monate später als Burney allerdings schon seine komplette Abhandlung veröffentlichte, während von Burneys „General History“ zunächst nur der erste Teil in die Buchhandlungen gekommen war, der die Musik im alten Ägypten, im alten Israel, im antiken Griechenland sowie im antiken Rom behandelt. Hawkins war allerdings nicht zuletzt persönlich in einer günstigeren Position. Geboren 1719 in London, hatte er Jura studiert und im Anschluss bis 1753 als Rechtsanwalt und Richter in verschiedenen Ämtern gearbeitet. ${ }^{27}$ In diesem Jahr aber heiratete er Sidney Storer, eine sehr wohlhabende Frau, deren Vermögen es Hawkins erlaubte, sich aus allen Ämtern zurückzuziehen und als Privatier wohl über 16 Jahre hinweg an seiner „General History of the Science and Practice of Music" zu schreiben. 1772 in den Adelsstand erhoben, starb er 1789 in London wenige Wochen bevor die letzten Bände von Burneys „General History“ aus der Druckerei kamen. Allerdings: den Doctor Musicae der Universität Oxford hat er nie erhalten. Hawkins war musikalischer Laie, ein Amateur im besten Sinn des Wortes, der zwar Mitglied in einer singing society war, jedoch nicht in der Lage gewesen wäre, ein Canticum zu komponieren.

Doch das ist sicher nicht der einzige Grund, warum schon damals Burneys „General History" eindeutig vorgezogen und auch sehr viel besser verkauft wurde. Burney hatte Europa zumindest in Teilen bereist und Informationen aus erster Hand von Gewährspersonen gesammelt, wo Hawkins all sein Wissen am Schreibtisch aus anderen Büchern bezog. Schon Burney selber verspottete Hawkins Konkurrenzprodukt in einer bösen, allerdings damals ungedruckt gebliebenen Satire:

Around Apollo's radiant throne, a crowd

Has late assembled, clamorous and loud;

Complaining of a certain scribe malign

26 Alexander Rehding, Die ägyptische Spieldose, in: Sandra Danielczyk u. a. (Hg.), Konstruktivität von Musikgeschichtsschreibung, Hildesheim 2012, S. 11-33, hier S. 13 f.

27 Bernhard Schrammek, Sir John Hawkins, in: Ludwig Finscher (Hg.), MGG, Personenteil 8, Kassel 22002, Sp. 895-898, hier Sp. 895f. 
Unlicens'd by the God, or Muse divine;

Unauthoriz'd by Judgment, Talents, Taste

Unprincipl'd in present Lore or past;

Without an Ear to hear, or soul to feel,

Without a mask his malice to conceal. ${ }^{28}$

Die Rivalität von Burney gegen Hawkins - in anderer Richtung ist davon nichts zu erkennen - spiegelte sich aber ohnehin in vielen Kontexten. So ist ein damals populärer Kanon - ein catch, eine besondere Form der musikalischen Satire - bekannt, in der ganz typisch mit Wortspielen die Komik transportiert wird:

Sir John Hawkins

Burn 'is History

How d'ye like him?

Burn 'is History

Burney's History pleases me. ${ }^{29}$

Gerecht wird man Hawkins und seiner „General History“ mit diesen Versen sicher nicht, und so hat Robert Stevenson schon 1950 in einem Aufsatz formuliert:

"Hawkins deserves a better reputation than they bestowed upon him; and students of his career nowadays rate him among the three great pioneers of modern musicology. A century before musicological endeavor flowered, Sir John by some proleptic insight grasped the basic principles of a discipline that has only now come into its own." 30

Dass die historischen Perspektiven the basic principles der Musikwissenschaft seien, war zwar selbst in der britischen Sichtweise um 1950 kein eindeutiger Konsens und ist es heutzutage noch um ein Vielfaches weniger, doch worauf Stevenson in seiner apologetischen Würdigung nicht zu Unrecht hinweist, ist die Bedeutung der grundsätzlichen Erkenntnis, dass Musik ein historischer Gegenstand ist.

Daran allerdings haben Burney und Hawkins gleichermaßen Anteil. Wer aber ist für Stevenson der dritte Pionier der modernen Musikwissenschaft? Es ist nicht Martini mit seiner „Storia della Musica“, sondern es ist der Göttinger akademische Musikdirektor Johann Nikolaus Forkel. Forkel, geboren 1749 in Meeder bei Coburg, war für kurze Zeit Schüler des Lüneburger Johanneums gewesen, bevor er schon als 17-Jähriger zum Präfekt des Schweriner Domchors berufen wurde. 1769 stattete

28 Zitiert nach Robert Stevenson, “The Rivals" - Hawkins, Burney, and Boswell, in: The Musical Quarterly 36 (1950), S. 67-82, hier S. 72.

29 Stevenson, 1950 (wie Anm. 28), S. 74 f.

30 Stevenson, 1950 (wie Anm. 28), S. 82. 
ihn sein Dienstherr, der mecklenburgische Herzog Friedrich, genannt der Fromme, mit einem Stipendium aus, mit dem Forkel in Göttingen Jura studieren sollte. Forkel betrieb diese juristischen Studien wohl nur mit begrenztem Engagement. Wenngleich der Mecklenburgische Herzog ihn bereits für den Hofdienst in Schwerin bzw. Ludwigslust bestimmt hatte, schien sich Forkel an der Göttinger Universität schnell etablieren zu wollen: Schon von 1770 an verwaltete er für zunächst drei Jahre das Organistenamt an der Universitätskirche. ${ }^{31}$

Der junge Student Forkel interessierte sich freilich nicht nur für die Praxis der Musik. In seiner späteren „Allgemeinen Litteratur der Musik“, einer 1792 erschienenen Bibliographie des musikalischen Schrifttums, bekundete Forkel, bereits in diesen Jahren um 1770 eine Kenntnis der wichtigsten musikalischen Schriften über seinen kleinen Büchervorrat,

worunter sich außer den meisten deutschen und einigen ausländischen Lehrbüchern, auch der erste Band von der Storia della Musica des P. Martini, Walthers mus. Lexicon, Adlungs Anleitung zur mus. Gelahrtheit, nebst den bekannten Zeitschriften von Mattheson, Mitzler, Marpurg und Hiller befanden, ${ }^{32}$

erlangt zu haben. Mit diesem nach eigenem Bekunden defizitären Wissen ausgestattet, wagte sich Forkel schon drei Jahre nach seiner Immatrikulation an ein ambitioniertes Projekt: Im Winterhalbjahr 1772 kündigte er privatim Vorlesungen über die Theorie der Musik an. Diese Vorlesungen verstanden sich als wissenschaftliche Veranstaltungen, für die das akademische Umfeld der Universität Göttingen günstige Voraussetzungen bot; tatsächlich hatte Forkel hier Gegebenheiten und Gelegenheiten passgenau zueinander gebracht und etwas getan, was noch anderthalb Jahrhunderte später so vertraut schien, dass Heinrich Edelhoff in seiner 1935 in Göttingen gedruckten, jedoch in Freiburg entstandenen Dissertation ${ }^{33}$ Forkel zum „Begründer der Musikwissenschaft als einer modernen Hochschuldisziplin“ erklärte, und auch Axel Fischer würdigte Forkels Vorlesungen noch als „Keimzelle der musikwissenschaftlichen Universitätslehre “. ${ }^{34}$

Diese Sichtweise hat Manches für sich. Forkel war offenbar ein weitsichtiger und vielseitig interessierter Denker, der sich, ohne sich dabei auf allzu viele Vorbilder berufen zu können, für viele Arbeitsbereiche engagierte, die heute der Musikwissenschaft zugerechnet werden, und der zudem in seinen einschlägigen Schriften auch

31 Axel Fischer, Johann Nikoslaus Forkel, in: Ludwig Finscher (Hg.), MGG, Personenteil 6, Sp. 1458-1468, hier Sp. 1458ff.

32 Johann Nikolaus Forkel, Allgemeine Literatur der Musik, Leipzig 1792, S. V.

33 Heinrich Edelhoff, Johann Nikolaus Forkel. Ein Beitrag zur Geschichte der Musikwissenschaft, Göttingen 1935, S. 102.

34 Fischer, 2001 (wie Anm. 31), Sp. 1462. 
theoretisch über die Fragestellungen und Methoden reflektierte. Zu seinen Tätigkeitsfeldern zählten die Musikhistoriographie ebenso wie die Komponistenbiographik, die Lexikographie und die Editionsphilologie. Forkel übersetzte musikbezogene Schriften aus dem Italienischen, dem Französischen und dem Lateinischen, er rezensierte umfangreich die aktuellste Forschungsliteratur für die „Göttingischen Anzeigen von gelehrten Sachen“.

Im Februar 1779 wurde Forkel zum Akademischen Musikdirektor der Universität ernannt. Zu seinen Aufgaben gehörten die Leitung des Collegium Musicum und die Organisation der Akademischen Winter-Concerte. Anlässlich des 50jährigen Stiftungsjubiläums der Göttinger Universität wurde ihm 1787 die Ehrendoktorwürde verliehen - den Titel eines Doctor Musicae gab es hier nicht. Nachdem sich Forkel 1789 erfolglos um die Nachfolge Carl Philipp Emanuel Bachs als Musikdirektor der Hamburger Hauptkirchen beworben hatte, blieb er der Universität als Musikdirektor bis zu seinem Tod 1818 erhalten.

In den Anfängen seiner akademischen Lehrtätigkeit ging Forkel noch einen anderen Weg der Auseinandersetzung mit Musik als Burney, Hawkins oder der von Forkel auch erwähnte Martini. Die gedruckte Einladungsschrift zu Forkels Vorlesung über die Theorie der Musik gibt darüber Auskunft. Forkel behandelte

die physikalische Klanglehre,

die mathematische Klanglehre,

musikalische Grammatik mit ihren Teildisziplinen,

der musikalischen Zeichenlehre,

den musikalischen Tonarten,

der Lehre von der Harmonie,

und der Rhythmodie,

die musikalische Rhetorik mit ihrer Teildisziplin,

der musikalischen Periodologie, und schließlich

die musikalische Kritik. ${ }^{35}$

Dass dieser Theorie der Musik auch eine Geschichte der Musik an die Seite wuchs, war gewissermaßen konsequent, denn Forkel reagierte damit auf das erwachende Interesse an allgemeiner Musikgeschichte auch in Göttingen, wo August Ludwig Schlözer mit seiner „Vorstellung einer Universal-Historie“ 1772 einen ähnlichen Grund legte, ${ }^{36}$ wie ihn auch Burney und Hawkins in Großbritannien gefunden hatten. Die Göttinger Universität als Universität der Personalunion ermöglichte hier eine sehr

35 Johann Nikolaus Forkel, Ueber die Theorie der Musik, insofern sie Liebhabern und Kennern nothwendig und nützlich ist. Eine Einladungsschrift zu musikalischen Vorlesungen, Göttingen 1777, S. 12-28.

36 Ludwig August Schlözer, Vorstellung seiner Universal-Historie, 2 Bde, Göttingen 1772-1773; zum Einfluss Schlözers auf Forkel vgl. auch Frank Hentschel, Modularisierte Musikgeschichte, in: Sandra Danielczyk u. a. (Hg.), Konstruktivität von Musikgeschichtsschreibung, Hildesheim 2012, S. 241-260, hier S. 243. 
enge Anlehnung, denn die einschlägigen englischen Schriften waren schnell auch in der Göttinger Universitätsbibliothek verfügbar: Die „General Histories“ von Hawkins und Burney sogar schon unmittelbar nach ihrem Erscheinen.

Dem Vorwort in der späteren „Allgemeinen Literatur der Musik“ zufolge begann sich Forkel zwischen 1776 und 1777 besonders für die Geschichte der Musik zu interessieren. ${ }^{37}$ Das ist also genau die Zeit vor seiner zweiten und dann dauernden Vorlesungstätigkeit an der Göttinger Universität und dem Erscheinen der „General Histories" von Hawkins und Burney, die Forkel ausweislich des Registers der Universitätsbibliothek vielfach ausgeliehen hat. ${ }^{38}$

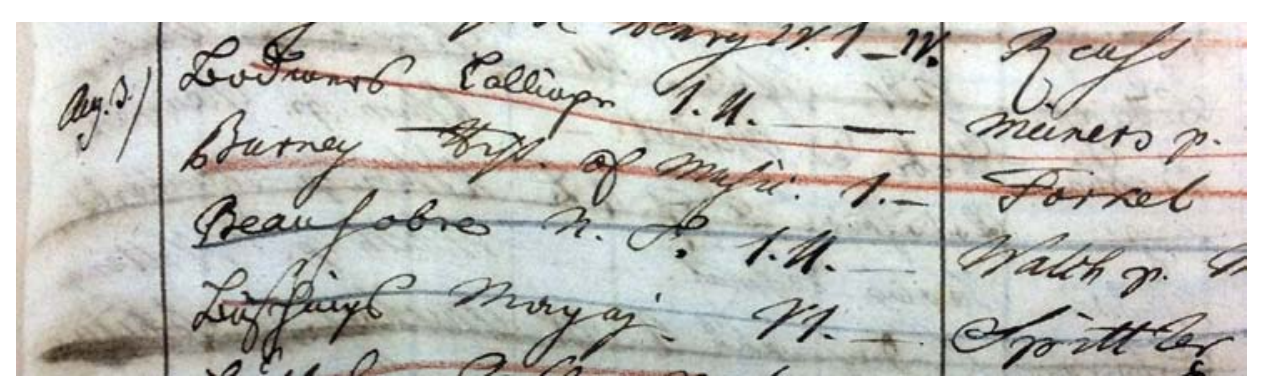

Abb. 1: Archiv der Niedersächsischen Staats- und Universitätsbibliothek, Ausleihregister Ostern 1783-Ostern 1784, Eintrag vom 3. August 1783: Forkel leiht zum wiederholten Mal den ersten Band von Burneys „General History of Music" aus.

Seit 1779 arbeitete Forkel dann an seiner eigenen Darstellung, einer „Allgemeinen Geschichte der Musik“, deren erster Band 1788 herauskam. Schon zehn Jahre zuvor, nämlich 1778, hatte Forkel im zweiten Band seiner „Musikalisch-kritischen Bibliothek" Hawkins „General History“, im dritten Band von 1779 Burneys Pendant einer sehr ausführlichen Rezension unterzogen: Für das weitgehend uneingeschränkte Lob von Hawkins „General History“ braucht Forkel 63 Seiten, für einen vorgeblichen Verriss von Burneys erstem Band seiner Darstellung sogar 74 Seiten. ${ }^{39}$

Dieser Verriss allerdings hat seinen Gegenstand in Burneys „Tagebuch seiner musikalischen Reise", nach dem Forkel attestiert:

Schon aus dem erwähnten Tagebuch einer musikalischen Reise, welches gleichsam als ein Vorläufer der allgemeinen Geschichte der Musik von unserm Verfasser, an-

37 Forkel, 1792 (wie Anm. 32), S. V. Forkel schreibt hier, er habe vor 15 oder 16 Jahren begonnen, sich für die historische Kenntniß der Musik zu interessieren, woraus nach dem Erscheinungsjahr der Allgemeinen Literatur zurückzurechnen ist.

38 NSuUB Göttingen, Bibl.-Arch. Ausleihregister.

39 Johann Nikolaus Forkel, Musikalisch-kritische Bibliothek, Bd. 2, Gotha 1788, S. 166-229 (Hawkins) und Bd. 3, Gotha 1779, S. 117-191 (Burney). 
gesehen werden mußte, konnte man leicht bemerken, daß die wirkliche Erscheinung des Werks mehr zu fürchten, als zu wünschen war. Die ganze Art, in der ein für unsere Kunst so wichtiges Unternehmen behandelt wurde, und die Menge von nicht nur übereilten, sondern gänzlich falschen dort befindlichen Urtheilen, verrieth nicht nur schon zum voraus, daß Hr. Burney für sein Unternehmen zu arm an wahren gründlichen musikalischen Kenntnissen sey, sondern gab auch binlänglichen Grund zu befürchten, daß er einen großen Nebel von gewissen $\mathrm{Na}$ tionalvorurtheilen noch nicht genug vertrieben haben möchte, um im Stande zu seyn, wenigstens aus demjenigen Theil seiner Geschichte, welcher die neuere Zeit, und insbesondere uns Deutsche angeht, etwas besseres als eine ärgerliche Chronik zu machen. ${ }^{40}$

Diese Aussage ist in doppelter Hinsicht mutig. Denn zum Einen ist diese neuere Zeit noch gar nicht Gegenstand des ersten Bandes von Burneys "General History“, zum Anderen zeigt ein Blick in Forkels „Allgemeine Geschichte der Musik“, dass er Burneys „General History“ nicht nur als Anregung, sondern sogar als Vorlage verstanden hat. Forkel beginnt seine „Allgemeine Geschichte“ wie Burney seine „General History" bei den ältesten Zeiten: Nämlich den alten Egyptiern und führt sie bis zum Beginn des lateinischen Mittelalters: Augustinus, Boëthius, Cassiodor. Und in vielen Details der Darstellung reicht die Anlehnung so weit, dass Oliver Wiener diesen ersten Teil von Forkels „Allgemeiner Geschichte“ als ein weiträumiges Plagiat von Burneys erstem Band beschreiben kann, wobei Wiener auf rund 50 Seiten Forkels Abhängigkeit von Burney bis in einzelne Formulierungen hinein aufzeigt. ${ }^{41}$

Es wäre ein Leichtes, Forkels akademische Karriere damit zu Fall zu bringen. Doch würde man Forkels Rolle, die auch die eines Vermittlers ist, damit nicht vollständig gerecht. Wie Burney und Hawkins geht auch Forkel in seiner „Allgemeinen Geschichte der Musik“ über eine reine Chronik von Ereignissen hinaus und deutet die Musikgeschichte mit einem bestimmten Narrativ aus. Und dieser Narrativ ist einer, der, bei Burney allerdings sehr viel stärker als bei Hawkins, vom Gedanken einer historischen Evolution der Geschichte ausgeht und letztlich auf eine musikalische Heroengeschichte abzielt. Während bei Hawkins und Burney die Musikgeschichte aber ihre eigentliche Vollendung im Schaffen Händels findet, ist Forkels Held Johann Sebastian Bach, dessen Biographie Forkel 1802 im Druck erschienen ließ.42

Der Narrativ einer historischen Evolution wird in der „Allgemeinen Geschichte der Musik" unweigerlich deutlich beim Blick auf die methodische Grundlegung der

40 Forkel, 1779 (wie Anm. 39), Bd. 3, S. $118 \mathrm{f}$.

41 Oliver Wiener, Apolls Musikalische Reisen. Zum Verhältnis von System, Text und Narration in Johann Nikolaus Forkels Allgemeiner Geschichte der Musik (1788-1801), Mainz 2009, S. 229-241.

42 Johann Nikolaus Forkel, Ueber Johann Sebastian Bachs Leben, Kunst und Kunstwerke, Leipzig 1802. 
Musikgeschichte, deren anthropologische Grundlagen Forkel als Prozess zunehmender Komplexität zeichnet: Vom ersten Zustand des Menschen an, in dem dieser noch keine Unterschiede zwischen Tönen bemerken kann, wird zunächst der Rhythmus als Mittel erkannt, Töne unterhaltend zu machen; ein Zustand, der Forkel zufolge noch bei vielen Völkern seiner Gegenwart andauere. ${ }^{43}$ Die in Forkels Gegenwart zu erkennende Ausdifferenzierung der Musik lässt sich dann mit Methoden beschreiben, die sicherlich nicht zufällig jenen entsprechen, die Forkel in seinen Vorlesungen zur Theorie der Musik bereits dargelegt hat: der musikalischen Grammatik und der musikalischen Rhetorik. ${ }^{44}$

Im zweiten Band von Forkels „Allgemeiner Geschichte der Musik“, der übrigens zu keiner Zeit unter dem Verdacht eines Plagiats steht, lässt sich dann sehr deutlich die Tendenz zur Heroengeschichtsschreibung erkennen. Nahezu jeder einzelne Paragraph der Darstellung nennt eine bedeutende Person bereits in der Überschrift: Vom Mailänder Kirchenvater Ambrosius und seinen Gesängen spannt sich so ein Bogen, der über Papst Gregor bis hin zu Josquin, Jean Mouton und Heinrich Isaac führt. Ein dritter Band der „Allgemeinen Geschichte der Musik“, der bis in Forkels Gegenwart führen sollte, ist zwar angekündigt, jedoch allen Indizien zufolge niemals auch nur ernsthaft begonnen worden. ${ }^{45}$ Dennoch wäre es müßig, schon anhand der ersten beiden Bände im Detail nachweisen zu wollen, welche der Forkelschen Darstellungen bis in die gegenwärtige Musikwissenschaft hinein überlebt haben; Forkel hat musikhistorisches Wissen kanonisiert und den Kunstwert von Musik als Maßstab für die Relevanz des lauten Nachdenkens über Musik etabliert, eine Sichtweise, von der sich auch die gegenwärtige Musikwissenschaft noch keineswegs überall entschieden distanziert.

Festzuhalten aber bleibt: Die Personalunion ist ein Raum, in dem das theoretische Nachdenken über Musik an einen Punkt der Beschäftigung führt, an dem aus dem Doctor Musicae - dem Doktor der praktisch verstandenen Musik - der Universität Oxford der Doctor scientiae musicae - der Doktor der Musikwissenschaft - wird; ein seltener, aber auch heute noch verliehener und in Deutschland offiziell anerkannter akademischer Titel. In der Person des Göttinger akademischen Musikdirektors Forkel verbinden sich dabei zwei Perspektiven: die theoretische, die ihre Wurzeln nicht zuletzt auch im Musikunterricht der deutschen Lateinschulen hat, und die historische, die von Großbritannien aus nach Göttingen gefunden hat. Für den umgekehrten Weg der theoretischen Perspektive gibt es bislang keine ganz so klar

43 Johann Nikolaus Forkel, Allgemeine Geschichte der Musik, Bd. 1, Leipzig 1788, S. 5 f.

44 Forkel, 1788 (wie Anm. 43), S. $36 f$.

45 F. L. Cr., Johann Nikolaus Forkel, in: Zeitgenossen. Ein biographisches Magazin für die Geschichte unserer Zeit 4 (1819), S. 123-136, hier S. 136. 
erkennbaren Konturen: Hier sind noch in erheblichem Maße Forschungsarbeiten zu leisten.

Der Blick auf die Musik als Wissenschaft im Raum der Personalunion bliebe freilich in jedem Fall unvollständig ohne einen Blick auf diejenige Person, die es Forkel mutmaßlicherweise überhaupt erst ermöglicht hat, die Schriften von Hawkins und Burney zu lesen. Wenn die Universität Göttingen als Universität der Personalunion auch einen starken Bezug zur englischen Sprache hatte, gibt es doch Anlass zu zweifeln, ob Forkel im Englischen sattelfest genug für die Lektüre war. Ins Spiel kommt damit Margareta Dorothea - genannt Meta - Liebeskind, geborene Wedekind, Tochter des Göttinger Philosophieprofessors Rudolf Wedekind, seit 1778 Forkels Klavierschülerin, seit 1782 seine Ehefrau, von der er sich 1794 nach sehr turbulenten Ehejahren wieder scheiden ließ. ${ }^{46}$ Meta Liebeskind war ohne Zweifel in der englischen Sprache sehr begabt. Sie übersetzte für Georg Forster zahlreiche Bände in einer Geschwindigkeit, die die in der Sekundärliteratur vertretene Aussage, sie sei der Simultanübersetzung fähig, als durchaus plausibel erscheinen lässt. Zur Turbulenz der Forkelschen Ehe gehört, dass Meta eher selten in Göttingen anwesend war; es dauerte nach der Eheschließung sogar eine erhebliche Zeit, bis das Ehepaar überhaupt eine gemeinsame Wohnung beziehen konnte. Legt man nun aber die Zeiten von Metas Anwesenheit in Göttingen und das Ausleihregister der Universitätsbibliothek nebeneinander, zeigt sich recht deutlich, dass Forkel die „General Histories“ von Hawkins und Burney nur dann ausgeliehen hat, wenn Meta in Göttingen war - vielleicht war sie also seine Übersetzerin. Und vielleicht liegt darin auch ein Grund, warum Forkels während der Ehe entstandener erster Band der „Allgemeinen Geschichte der Musik" ein so weiträumiges Plagiat von Burneys erstem Band der "General History“ sein konnte, während der zweite Band nicht nur kein Plagiat mehr ist, sondern auch einem anderen Konzept der Darstellung folgt. Ohne die Anregung des Doctor Musicae der Universität Oxford Charles Burney hätte Forkel demnach nicht zu einer historischen Beschäftigung mit Musik gefunden, die ihn in den Stand versetzte, zum Doctor honoris causa der Universität Göttingen werden zu können. Ohne die starke Frau an seiner Seite aber möglicherweise auch nicht.

46 Andreas Waczkat, Forkel's Muse. Meta Forkel-Liebeskind and how Johann Nikolaus Forkel Read Works in English, in: Göttinger Händel-Beiträge 15 (2014) S.196-205.. 


\section{Kooperation oder Konkurrenz? \\ Die Göttinger Königliche Gesellschaft der Wissenschaften und die Royal Society im 18. Jahrhundert}

\section{Peter Aufgebauer}

Georg Christoph Lichtenberg berichtet im April 1770 von seiner ersten Englandreise in einem Brief aus London an Christian Gottlob Heyne in Göttingen auch über ein Gespräch mit dem Earl of Marchmont, Großsiegelbewahrer von Schottland:

Ich habe mich mit Lord Marchmont über allerley Gegenstände unterredet. Man hält ihn hier für einen der grösten Staatsmänner und Köpfe in Engelland, er ist dabey ein groser Liebhaber der Mathematik und Physick, und hält außerordentlich viel auf Göttingen und die Deutschen. Mit der hiesigen Königlichen Societät ist er gar nicht zufrieden und sagt, daß gemeiniglich die unbeträchtlichsten Sachen abgelesen würden, er wollte nicht einmal, daß ich hinein gehen solte. Als ich ihn nach der Ursache dieses Verfalls fragte, so antwortete er mir mit einem Achselzucken. ${ }^{1}$

Für Christian Gottlob Heyne, seit wenigen Monaten ständiger Sekretär der „Göttinger Sozietät der Wissenschaften“, dürfte beides von Interesse gewesen sein, die Hochschätzung Göttingens und der Deutschen wie die drastische Äußerung über die ältere und vermeintlich ehrwürdige Schwester, die „Royal Society for Improving of Natural Knowledge“.

Die Royal Society ${ }^{2}$ entstand um 1660 als zunächst privater Zusammenschluss eines kleinen Kreises in London, der an den Naturwissenschaften und allgemein an naturkundlichen Fragen interessiert war. Als Motto wählte man die Devise ,Niemandes Worte - ,nullius verba'.

1 Ulrich Joost/Albrecht Schöne, Georg Christoph Lichtenberg. Briefwechsel, Bd. 1: 1765-1779, München 1983, Nr. 13, S. 22.

2 Rosemary Hildegarde Syfret, The Origins of the Royal Society, in: Notes and Records of the Royal Society of London (1948), S. 75-137; Thomas Thomsen, History of the Royal Society from its Institution to the End of the Eighteenth Century, London 1812, S. 1-16. 
„Niemandes Worte` sollten eine höhere Autorität haben als das Experiment und der empirische Beweis; damit war die Emanzipation der modernen Naturwissenschaften heraus aus der traditionellen philosophischen und theologischen Deutungshoheit der Antrieb und das zentrale Anliegen der Gesellschaft.

Privilegien Charles II., der auch das Patronat übernahm, gaben der Society eine Verfassung und feste Regularien und verliehen ihr ein Wappen. ${ }^{3}$ Der Architekt Christopher Wren, der spätere Erbauer der St. Pauls Cathedral, und der Physiker und Chemiker Robert Boyle zählten zu den Gründungsmitgliedern. Das königliche Patronat und die Prominenz mancher Mitglieder der ersten Generation machten die Society rasch attraktiv, und das seit 1665 erscheinende Publikationsorgan, die gegenwärtig im 371. Jahrgang stehenden „Philosophical Transactions“, war die erste ausschließlich den Naturwissenschaften gewidmete Zeitschrift, zählte rasch zu den international beachteten Wissenschaftsjournalen und bestimmte vielfach den Diskurs in den Naturwissenschaften. ${ }^{4}$ Ein Übriges für das Renommee tat die Reihe von wissenschaftlich herausragenden oder wissenschaftspolitisch einflussreichen Präsidenten wie Christopher Wren, Isaac Newton, Hans Sloane, John Pringle oder Joseph Banks. ${ }^{5}$ International berühmte Autoren und Gelehrte wie Gottfried Wilhelm Leibniz (aufgenommen 1673) oder Voltaire (aufgenommen 1743) vermehrten Ansehen und Einfluss der Royal Society.

Bald nach der Stiftung der Georgia Augusta wurde auch einer der Göttinger Gelehrten in die Royal Society aufgenommen, nämlich Albrecht von Haller im Jahre $1739{ }^{6}$

$\mathrm{Zu}$ dieser Zeit wurde hier in Göttingen und zwischen der Regierung in Hannover und der Universität seit längerem das Projekt einer, Gelehrten Gesellschaft ${ }^{c}$ neben der Universität erörtert, unter führender Beteiligung Albrechts von Haller. ${ }^{7}$ So wie Gerlach Adolf vom Münchhausen der eigentliche Schöpfer der Georg-August-Universität war, so kann Albrecht von Haller als der eigentliche spiritus rector der "Göttinger Societät der Wissenschaften“ gelten, der heutigen Göttinger Akademie der Wissenschaften. Die ersten Überlegungen zur Gründung einer gelehrten wissenschaftlichen Gesellschaft an oder neben der Universität reichen bis in die Anfangs-

3 Thomsen, 1812 (wie Anm. 2), Appendix Nr. I und II.

4 David A. Kronick, A History of Scientific and Technical Periodicals, New York 21976; William Dampier, A History of Science and Its Relations with Philosophy and Religion, London 81971, S. 146ff.

5 Thomsen, 1812 (wie Anm. 2), S. 13.

6 Royal Society Archive, Certificates of Election and Candidature 1739/09, https://collections.royalsociety. org/DServe.exe?dsqIni=Dserve.ini\&dsqApp=Archive\&dsqCmd=ImageView.tcl\&dsqDb=Catalog\&dsq Image=EC_1739_09.jpg (letzte Einsicht: 05.06.2014).

7 Vgl. zum folgenden Rudolf Smend, „Ein Academiste muß erfinden.“ Haller und die Königliche Societät der Wissenschaften, in: Norbert Elsner / Nicolaas A. Rupke (Hg.), Albrecht von Haller im Göttingen der Aufklärung, Göttingen 2009, S. 143-165. 
jahre der Georgia Augusta, also die frühen dreißiger Jahre des 18. Jahrhunderts, zurück. ${ }^{8}$ Aus verschiedenen, auch finanziellen und nicht zuletzt persönlichen Gründen wurden die Pläne erst um 1750 so konkret, dass man zum Jahresbeginn 1751 in den „Göttingischen Zeitungen von gelehrten Sachen“ den Ausblick auf das bevorstehende wissenschaftliche Jahr mit folgender Ankündigung beschloss:

Endlich wird auch mit der nächsten Oster eine Gesellschafft hiesiger Gelehrter näher zusammentreten, und theils in monatlichen Versammlungen, theils in auszuarbeitenden und jährlich an Tag zu gebenden Abhandlungen, in der Naturlehre, der Mathematic, der Geschichte und den schönen Wissenschaften, ihre Bemühungen zur Aufnahme dieser edlen Künste vereinigen. Man wird auch dem besten Ausschuß der jungen Gelehrten und der academischen Jugend einen Zugang zu diesen Versamlungen eröfnen, und ihnen Gelegenheit verschaffen, sowohl mit Zuhören und mit freundschafftichem Umgange mit den Lehrern, als durch eigene Ausarbeitungen ihre Gaben zu zeigen und anzuwenden. Die Königliche Regierung wird diese Gesellschaft auf eine besondere Art schützen und belohnen, und man wird mit eigenen Preisen die ausländischen und die einheimischen Gelehrten aufmuntern, schwere Aufgaben aus den oben benannten Wissenschaften aufzuklären. ${ }^{9}$

Am 23. April 1751 trat die Gesellschaft zum ersten Mal zusammen, und zwar in der Wohnung Albrecht von Hallers in der Unteren Karspüle; der 23. April war der Tag des Hl. Georg, des Namenspatrons König Georgs II. Die offizielle Einweihung der wissenschaftlichen Gesellschaft fand am 10. November, dem Geburtstag des Königs statt, und im ersten Jahresbericht, der zu Silvester 1751 erschien, wurde sie dann als „Königliche Gesellschaft der Wissenschaften“ bezeichnet: Die Königl. Gesellschaft der Wissenschaften, die wir im vorigen Jahr nur noch gehoft haben, ist im itzigen schon zur Würksamkeit, und zur öffentlichen Einweihung erwachsen, und ibre ersten Arbeiten werden in kurzer Zeit ans Licht tretten. ${ }^{10}$

Beständiger Präsident wie es hieß, war Albrecht von Haller, Sekretär der Orientalist Johann David Michaelis; der Gesellschaft gehörten sieben Ehrenmitglieder an, darunter der Hannoversche Staatsminister August Wilhelm von Schwicheldt und der Geheime Rat Friedrich Carl Freiherr von Hardenberg, ferner der Kanzler der Georgia Augusta, der Theologe und Historiker Johann Lorenz von Mosheim.

Untergliedert wurde die Gesellschaft in drei Klassen, eine mathematische, eine physische und eine historische, der zunächst je ein Professor der Universität

8 Johannes Joachim, Die Anfänge der Königlichen Sozietät der Wissenschaften zu Göttingen (Abhandlungen der Gesellschaft der Wissenschaften zu Göttingen, Phil.-Hist. Klasse, III,19), Berlin 1936.

9 Smend, 2009 (wie Anm. 7), S. 143; digitalisierte Ausgabe: http://gdz.sub.uni-goettingen.de/dms/load/ toc/? PPN=PPN319732576\&IDDOC=65999 (letzte Einsicht: 05.05.2014).

10 Smend, 2009 (wie Anm. 7), S. 144. 
als ordentliches Mitglied angehörte; dies waren Johann Andreas von Segner, Samuel Christian Hollmann und Johann Matthias Gesner; daneben gab es je einen weiteren Göttinger Professor pro Klasse als außerordentliches Mitglied, nämlich Tobias Mayer, Johann Georg Röderer und Gottfried Achenwall, und schließlich gehörten der Societät als auswärtige Mitglieder aus dem nicht-hannoverschen Ausland je drei weitere Gelehrte pro Klasse an, insgesamt also eine anfängliche personelle Grundausstattung von 24 Gelehrten. Hinzu kamen noch 11 sogenannte ordentliche Zubörer.

Den Kern des Akademie-Auftrags beschrieb Albrecht von Haller in einer bei der feierlichen Einweihung durch den Sekretär Michaelis verlesenen Grundsatzrede in Abgrenzung zum Amt eines Universitätslehrers wie folgt: Das Amt eines Universitätsprofessors führe diesen nicht darauf,

daß er die Wissenschaften mit neuen Wahrheiten bereichern soll. Er muß gleichsam einerley Weg Jahr aus Jahr ein von neuem gehen, und einen kurzen Auszug seiner Wissenschaft deutlich und ordentlich vortragen, den er nach und nach mit den neuen Erfindungen anderer Gelehrter zu bereichern hat: nie aber kann er sich in seinen Vorlesungen in eine ausführliche Betrachtung eintzeler Stücke einlaßen, ohne andere nöthige Theile seiner Wissenschaft zu versäumen [...] Hingegen ist der Endzweck gelehrter Gesellschaften, daß ein jedes Mitglied einzelne und kleine Feldern der Gelehrsamkeit genau untersuchet, und etwas an das Licht bringet, daß seinen übrigens gleichfalls gelehrten Mitgliedern unbekannt gewesen war. Kleine Ausarbeitungen, die etwas neues enthalten, werden in ihren Schriften gesammelt, und für die Nachwelt bewahret: zweifelhafte Erfahrungen durch ihr vereinigtes Zeugniß und angestellte Versuche mit Gewißheit bestätiget oder verworfen: schwere Aufgaben, die sie allen Gelehrten vorlegen, von sovielen Gelehrten zugleich erwogen, und oft glücklich gelöset, und dadurch die Anzahl der Wahrheiten vermindert, die das menschliche Geschlecht noch suchet, ohne sie gefunden zu haben. ${ }^{11}$

Für die hier genannten Ergebnisse der genauen Untersuchungen einzelner und kleiner Felder wurde eine neue Schriftenreihe ins Leben gerufen, die „Kommentare der Königlichen Gesellschaft der Wissenschaften zu Göttingen "12, eröffnet mit einer Huldigungsadresse an den Patron, Georg II. In dieselbe Richtung wie das Postulat kleiner Ausarbeitungen, die Neues enthalten, geht die berühmt gewordene Formulierung in dem ebenfalls von Haller 1751 verfassten „Allgemeinen Plan der Königlichen Gesellschaft der Wissenschaft in Göttingen": Ein bloßer Lehrer kann mit elementaren Wissenschaften und einem guten Vortrage die Liebe der Jugend erwerben und sich selbst

11 Smend, 2009 (wie Anm. 7), S. $148 f$.

12 Commentarii Societatis Regiae Scientiarum Gottingensis, Tomus I, ad Annum MDCCLI, Göttingen 1752; Digitalisat: http://gdz.sub.uni-goettingen.de/dms/load/toc/?PPN=PPN352829796_0001 (letzte Einsicht: 05.06.2014). 
zufrieden stellen. Ein Academiste muß erfinden oder verbessern oder seine Blöße unvermeidlich verrathen. ${ }^{13}$

Wie das konkret aussah, lässt sich am Beispiel des ordentlichen und des außerordentlichen Mitglieds der nicht ohne Grund als erste genannten, also der mathematischen Klasse, Johann Andreas von Segner und Tobias Mayer, illustrieren. ${ }^{14}$

Segner hatte eine Professur für Mathematik und Naturlehre inne, lehrte bald nach seiner Berufung zusätzlich auch Medizin, befasste sich daneben auch mit Chemie und Physik, hier vor allem der Hydrodynamik. Er entwickelte 1750 ein Wasserrad, den Vorläufer der Turbine. Den erstmaligen Besuch König Georgs II. an seiner neuen kurhannoverschen Landesuniversität im Jahre 1748 nutzte Segner zu einem Vorstoß, um Genehmigung und Mittel zur Begründung einer Sternwarte zu erlangen - mit Erfolg, und schließlich wurde er ihr erster Direktor. Ein vielseitiger, tüchtiger Mann, freilich auch eitel, ehrgeizig und von notorischer Streitsucht. Er publizierte zahlreiche Monographien zu medizinischen und physikalischen Fragen und veröffentlichte eine vielfach neu aufgelegte „Einführung in die Naturlehre“. In den Schriften der Akademie erschienen aus seiner Feder Studien über die Oberflächen flüssiger Körper und über die Funktion der Fadenkreuze in den Okularen astronomischer Fernrohre und ihre Verbesserung - das war in der Tat das genaue Beackern einzelner und kleiner Felder, wie Haller es von einem Akademiemitglied erwartete.

Tobias Mayer wurde 1750 auf den Lehrstuhl für Ökonomie berufen; er las über ,praktische Geometrie', die sich u.a. mit geometrischer Projektion und mathematischem Zeichnen, etwa im Zusammenhang der Kartographie, befasste; außerdem behandelte er Militärarchitektur, die sogenannte Fortifikation, die Anlage militärischer Festungen, verbunden mit Pyrotechnik und Ballistik; drittens trug er Algebra und Analysis vor, apostrophiert als ,reine und angewandte Mathematik'; und schließlich lehrte er auch noch Mechanik, nämlich die Lehre von der Konstruktion und dem Gebrauch der Maschinen.

Seine eigenen Forschungen im Sinne des Akademieauftrags aber lagen im Bereich der Astronomie. Mit dem Hauptinstrument der Sternwarte, dem vom König geschenkten Birdschen Mauerquadranten, womit die Göttinger Sternwarte ebenso qualitätsvoll ausgestattet war wie das königliche Observatorium in Greenwich, vermaß er die Örter von rund 1100 Sternen des Tierkreises und die Bewegung des Mondes durch den Tierkreis und leitete aus diesen Beobachtungen und Daten eine Theorie der Mondbewegung ab, die es gestattete, mit Hilfe seiner Tabellen und der aktuellen Position des Mondes die geographische Länge eines Schiffes auf See zu bestimmen - das war in der Tat, um noch einmal mit Albrecht von Haller zu reden, die

13 Smend, 2009 (wie Anm. 7), S. 149.

14 Vgl. zum folgenden Peter Aufgebauer, Die Anfänge der Sternkunde in Göttingen, in: Göttinger Jahrbuch 50 (2002), S. 75-92. 
glückliche Lösung einer schweren Aufgabe, durch die die Anzahl derjenigen Wabrheiten vermindert [wird], die das menschliche Geschlecht noch suchet, ohne sie gefunden zu haben. Mehr als zwanzig Studien kleineren und mittleren Umfangs aus seiner Feder sind in den Schriften der Akademie veröffentlicht worden.

Diese beiden Beispiele aus der mathematischen Klasse zeigen: Das an der Georgia Augusta von Beginn an verankerte Prinzip der weitgehenden Lehrfreiheit und der Zensurfreiheit erhielt mit Begründung der Societät der Wissenschaften einen starken Antrieb im Hinblick auf Forschungsfreiheit, verbunden mit den erforderlichen Publikationsmöglichkeiten.

Die enge Verbindung von Universität und Societät in Göttingen war neu in der europäischen Wissenschaftslandschaft; die älteren gelehrten Gesellschaften in Paris, London, Wien, München oder Berlin waren an Residenzstädten angesiedelt und nicht mit einer Universität verbunden, oder sie waren, wie die Leopoldina, überhaupt nicht ortsfest, sondern wechselten mit dem jeweiligen Präsidenten an dessen Wohnsitz. ${ }^{15}$

Hier liegt auch einer der Unterschiede zwischen der Royal Society und der Göttinger Königlichen Societät. Ein weiterer ist die fachliche Ausrichtung; während die Royal Society erklärtermaßen zur Erweiterung naturkundlicher und naturwissenschaftlicher Kenntnisse gegründet worden war, for Improving of Natural Knowledge, richteten sich Interesse, Zuständigkeit und Kompetenz der Göttinger Societät auf alle an der Georgia Augusta vertretenen Fakultäten und Disziplinen einschließlich der Theologie und der Philologien, ausgenommen allein die Rechtslehre, der man die Eigenschaft einer forschungsorientierten Wissenschaft noch längere Zeit absprach.

Die für Göttingen charakteristische Verbindung von Universität und Societät zeigt sich auch in einem weiteren Merkmal: Der Kurfürst von Hannover bzw. König von England war der nominelle Rektor der Georgia Augusta und wurde beispielsweise auf jeder Promotionsurkunde als Rektor genannt; nun war er auch von Beginn an Patron der Societät der Wissenschaften.

Bei allen Unterschieden haben also die Royal Society und die Göttinger Königliche Societät der Wissenschaften denselben Patron in der Gestalt des englischen Königs, solange die politische Personalunion bestand; mit Georg II., Georg III., Georg IV. und Wilhelm IV. blicken uns hier in der Aula nicht nur die Rektoren unserer Universität, sondern auch die Patrone sowohl der Royal Society als auch der Göttinger Akademie an. Allein Ernst August, der erste hannoversche König nach dem Ende der Personalunion, war nicht mehr Patron der Royal Society, sondern nur noch deren

15 Rudolf Smend, Die Göttinger Gesellschaft der Wissenschaften, in: Festschrift zur Feier des zweihundertjährigen Bestehens der Akademie der Wissenschaften in Göttingen, Berlin/Göttingen / Heidelberg 1951, S. V-XIX; Rudolf Vierhaus, Etappen der Göttinger Akademiegeschichte, in: Nachrichten der Akademie der Wissenschaften zu Göttingen, Philologisch-Historische Klasse 2 (2003), S. 50-57. 
Royal Fellow, neuer Patron wurde 1838 Queen Victoria. ${ }^{16}$ Ernst August und seine Nachfolger waren aber Patrone der Göttinger Societät.

Für unser Thema ergibt sich hier die Frage, ob die sozusagen wissenschaftliche Personalunion in der Person des königlichen Patrons beider Forschungseinrichtungen eher zu Wettstreit und Konkurrenz, etwa um Reputation oder Einfluss bei Hofe, um Ressourcen und Ausstattung, um gesteigertes öffentliches Ansehen geführt hat, oder ob der gemeinsame Patron verstärkt zu wechselseitigen Kooptationen führte und dazu, dass wissenschaftliche Projekte und Unternehmungen gemeinsam konzipiert und durchgeführt werden konnten und vielleicht auch durchgeführt wurden.

Wendet man sich mit solchen Fragen den Quellen zu, stößt man allerdings zunächst auf Äußerungen, die nationale, um nicht zu sagen nationalistische Vorbehalte und Vorurteile artikulieren.

Georg Christoph Lichtenberg charakterisiert seinen früheren akademischen Lehrer und nunmehrigen älteren Kollegen, den Mathematiker und Physiker Abraham Gotthelf Kaestner als einen notorischen Englandhasser. Derselbe Georg Christoph Lichtenberg, der ein großer Freund und Bewunderer Englands und des Englischen war, unterstellt den Engländern einen grundsätzlichen Ausländerhass; dem ihm befreundeten Universitätszeichenlehrer und nachmals berühmten Kupferstecher Joel Paul Kaltenhofer empfiehlt Lichtenberg im Jahre 1773, auch einmal nach England zu reisen, rät ihm aber davon $\mathrm{ab}$, sich dauerhaft dort niederzulassen:

In Ihren Jahren - Kaltenhofer ist zu diesem Zeitpunkt 57 Jahre alt - sein Vaterland mit einem andern gantz zu vertauschen ist nicht rathsam. Man bequemt sich in diesen Jahren nicht mehr so nach den Sitten der Länder; ein ruhiges Alter läßt sich in England, das doch nun ein mal gewiss die Ausländer hasst, für einen Fremden nicht hoffen, allein England ist ein vortreffliches Land sich Güter zu erwerben, das ruhige Alter im Vaterland zu genießen. ${ }^{17}$

Der erste berühmte Astronom der Georgia Augusta, Tobias Mayer, wollte sich mit seinen bahnbrechenden Forschungen zur Längenbestimmung auf See auf der Basis einer empirisch ermittelten Mondtheorie nicht an einem entsprechenden Wettbewerb beteiligen, den das englische Parlament mit einem Preis von 20.000 Pfund ausgeschrieben hatte, weil er die Engländer für parteiisch, missgünstig und neidisch hielt. Der Sekretär der Societät, Johann David Michaelis, hatte alle Mühe, ihm schließlich das Manuskript fast gewaltsam zu entreißen, um es in London einzureichen. An den

16 The Royal Society (Hg.), List of Fellows of the Royal Society 1660-2007. A complete listing of all Fellows and Foreign Members since the foundation of the Society. Library and Information Service, London 2007, S. 111, S. 363.

17 Ulrich Joost / Albrecht Schöne (Hg.), Georg Christoph Lichtenberg, Briefwechsel, Bd. 1: 1765-1779, München 1983, Nr. 131, S. 235. 
Privatsekretär des englischen Königs, William Philipp Best, der ein entfernter Vetter war, schrieb Michaelis:

So gleichgültig ich dabey sein kann, ob mein Ehrbarer College 20000 Pfund bekommt, wenn ich nichts habe und nur etwas mehr als ein Bettler bin, sosehr finde ich die Aestimation unsrer Societät, Universität, der Deutschen Lande des Königs, dabei interessiret, ob er dies große Poblema gefunden hat, oder nicht. Es kommt darauf an, daß in England darüber gesprochen wird, und zwar von solchen, die den Rubm einem Deutschen nicht misgönnen. Nach der Gnade, die seine Majestät vor dero Land und Vaterland haben, würde es wohl Höchst Denenselben zu einem allergnädigsten Wohlgefallen gereichen, wenn einer von Dero deutschen Unterthanen sich so signalisirte, und zwar das vor den Augen der Engeländer. ${ }^{18}$

Vor den Augen des gemeinsamen Patrons und vor der wissenschaftlichen Öffentlichkeit, vor allem der englischen, sieht sich die jüngere Schwester, die Göttinger Societät, unter dem Zwang einer besonderen Profilierung.

In der wechselseitigen Aufnahmepolitik der beiden Institutionen ist allerdings von Vorbehalten, Missgunst oder gar national geprägten Hass nichts zu finden. Die Vorschlags- und Wahlprotokolle der Royal Society gestatten einen detaillierten Einblick in das Aufnahmeverfahren und die Begründung des jeweiligen Wahlvorschlags.

Bereits zwei Jahre nach der feierlichen Inauguration der Georgia Augusta 1737 werden zwei ihrer Professoren zu Foreign Fellows der Royal Society gewählt, Haller und Segner.

Bei Albrecht von Haller wird sein Rang als Königlicher Hofarzt zu Hannover, seine Position als öffentlicher ordentlicher Professor an der Göttinger Universität mit der Denomination Medizin, Anatomie, Chirurgie und Botanik, seine Mitgliedschaft in der Schweizer wissenschaftlichen Gesellschaft hervorgehoben. ${ }^{19}$ Die Begründung nennt dann seine tiefen Kenntnisse in der Mathematik und vielen Bereichen der Naturkunde, erwähnt das breit publizierte Oeuvre, darunter auch zahlreiche Texte, die bereits der Royal Society vorgelegt worden waren und unterstreicht die Erwartung, dass in ihm ein sehr nützliches Mitglied der Society gewonnen werde. ${ }^{20}$ An der Spitze

18 Aufgebauer, 2002 (wie Anm. 14), S. 83f.; Michaela Kipp, Patronage, Wissenstransfer und Stiftungspolitik. Beiträge zur Geschichte der Astronomie unter der Personalunion zwischen Großbritannien und Hannover (1714-1837), in: Arnd Reitemeier / Uwe Ohainski (Hg.), Aus dem Süden des Nordens. Studien zur niedersächsischen Landesgeschichte für Peter Aufgebauer zum 65. Geburtstag (Veröffentlichungen des Instituts für Historische Landesforschung der Universität Göttingen 58), Bielefeld 2013, S. 271-284.

19 Royal Society Archive, Albrecht von Haller 1739: D. Albertus Haller, MD, Archiater Regius Hannov., Med. Anat. Chirurg. et Botan. in Acad. Georg. August. Gotting. Prof. Publ. Ordin. et Soc. Scient. Svec. Sodalis, https://collections.royalsociety.org/DServe.exe?dsqIni=Dserve.ini\&dsqApp=Archive\&dsqDb=Catalog\&d sqSearch $=$ RefNo==\%27EC\%2F1739\%2F09\%27\&dsqCmd=Show.tcl (letzte Einsicht: 05.06.2014).

20 Royal Society Archive, Albrecht von Haller 1739 (wie Anm. 19), A Gentleman very Skillfull in Mathematicks and Natural knowledge, particularly in the Several branches of his Profession, in which he has published Several 
der Proposers, sämtlich Fellows of the Royal Society, und damit als Initiator der Zuwahl Albrecht von Hallers erkennbar, steht Johann Georg Steigerthal, prominenter Mitunterzeichner ist Hans Sloane. ${ }^{21}$

Steigerthal stammte aus Nienburg, hatte in Helmstedt, Leiden und Utrecht Medizin studiert, wurde 1703 Professor der Medizin in Helmstedt und war ab 1715 Hof- und Leibmedicus in Hannover. Als königlicher Leibarzt begleitete er Georg I. nach London und auch auf die zunächst fast jährlichen Reisen ins Kurfürstentum. ${ }^{22}$

Hans Sloane, Mediziner und Botaniker, vor allem weitgereister leidenschaftlicher Sammler naturkundlicher Relikte und Artefakte, war seit 1727 in direkter Nachfolge Newtons Präsident der Royal Society; später wurde er der eigentliche Begründer des Britischen Museums, in das er seine umfänglichen Sammlungen als Grundstock einbrachte. ${ }^{23}$

Prominente Fürsprecher also aus der Royal Society mit enger Verbindung zum Königshof, schlagen einen wissenschaftlich namhaften Repräsentanten der noch ganz jungen Göttinger Universität zur Aufnahme vor.

Ähnlich liegt der Fall bei einem anderen Göttinger, der sogar schon zwei Jahre zuvor, 1737, dem Jahr der Eröffnung der Universität, in die Royal Society aufgenommen wurde, der aus Ungarn stammende Mediziner Johann Andreas Segner. Auch hier ging die Initiative vom königlichen Leibarzt in London, Georg Steigerthal, aus, und der Präsident der Royal Society, Hans Sloane, tritt dem Vorschlag bei. In der Begründung wird auf die mathematischen und die Kenntnisse in den experimentellen Naturkundlichen Disziplinen abgestellt. Ausdrücklich ist hervorgehoben, dass Segner eine Professur für Mathematik, Naturphilosophie und Physik in his Majesties new University of Gottinghen ${ }^{24}$ habe - erkennbar gab es in London um Steigerthal und Hans Sloane eine Gruppe von Naturkundlern, Medizinern und Wissenschaftsmana-

Learned Treatises and Dissertations, many whereof he has lately presented to the Royal Society \& being desirous to become a Member of the Said Society, https://collections.royalsociety.org/DServe.exe?dsqIni=Dserve. ini\&dsqApp=Archive\&dsqDb=Catalog\&dsqSearch $=\mathrm{RefNo}==\% 27 \mathrm{EC} \% 2 \mathrm{~F} 1739 \% 2 \mathrm{~F} 09 \% 27 \& \mathrm{dsqCmd}=$ Show.tcl (letzte Einsicht: 05.06.2014).

21 Royal Society Archive, Albrecht von Haller 1739 (wie Anm. 19).

22 Dirk Böttcher, Johann Georg Steigerthal, in: Hannoversches biographisches Lexikon, Hannover 2002, S. 347.

23 Arthur McGregor, Sir Hans Sloane. Collector, scientist, antiquary, founding father of the British Museum, London 1994; Eric St. John Brooks, Sir Hans Sloane. The great collector and his circle, London 1954.

24 Royal Society Archive, Johann Andreas Segner 1738, This Gentleman was formerly Professor in the University of Jena \& is now Professor in Mathematicks, Natural Philosophy \& Physick in his Majesties new University of Gottinghen, \& being desirous to become a Fellow of the Royal Society: he is recommended in a certificate Sign'd by John Geo. Steigertabl, Aug. Joh. Hugo and Paul Gottleib Werlhof, FRS as a person skillfull in Mathematical \& Experimental knowledge; \& we whose names are underwritten, do likewise recommend him, as a person every way qualified to be a usefull Member of this Society https://collections.royalsociety.org/DServe.exe?dsqIni=Dserve. ini\&dsqApp=Archive \&dsqDb=Catalog \&dsqSearch $=$ RefNo= $=\% 27 \mathrm{EC} \% 2 \mathrm{~F} 1737 \% 2 \mathrm{~F} 10 \% 27 \& \mathrm{~d} s q \mathrm{Cmd}=$ Show.tcl (letzte Einsicht: 05.06.2014). 
gern, die den Lehrkörper der Georgia Augusta von Anfang an - vor allem über die zahlreichen einschlägigen Publikationen in lateinischer Sprache - im Blick hatten und im Blick behielten.

Allerdings wurden im Vorfeld derartiger Vorschläge strenge Maßstäbe angelegt, und die Wahl zum Fellow of the Royal Society blieb die große Ausnahme, auch nach der Gründung der Göttinger Societät 1751. Nur selten und zumeist im höheren Lebensalter erfolgten einige weitere Zuwahlen des 18. Jahrhunderts.

Als Johann David Michaelis 1789 aufgenommen wurde, war er bereits 72 Jahre alt. Fast 50 Jahre zuvor, 1741, hatte er einige Zeit in London und Oxford zugebracht und zählte seither zu den Englandfreunden und Englandexperten der Georgia Augusta; dass er erst im hohen Alter zugewählt wurde, erklärt sich wohl aus seinen Forschungsfeldern Orientalistik, Theologie und orientalische Geschichte. ${ }^{25}$ Initiator des Vorschlags war Anthony Hamilton, ein vielseitig interessierter Theologe, der in den siebziger Jahren Archidiakon von London gewesen war; ein anderer der Unterzeichner, William Marsden, war Orientalist und Sprachforscher und stand seit längerem im wissenschaftlichen Austausch mit Michaelis, und Edward Whittaker Gray schließlich war Botaniker und hatte das Amt eines Sekretärs der Royal Society inne.

Der Vorschlag hebt denn auch allgemein seinen Ruhm und das breite publizistische Oeuvre hervor. ${ }^{26}$

Im selben Jahr wie Michaelis wurde auch Abraham Gotthelf Kaestner in die Royal Society gewählt, der daraufhin seinen Englandhass fürs erste vergaß. Auch er war bereits ein älterer Herr von 70 Jahren und hatte im Laufe der Jahrzehnte soviel publiziert, unter anderem regelmäßig Rezensionen der "Philosophical Transactions“ in den „Göttingischen Gelehrten Anzeigen“, dass es hier genügte, auf seinen Ruhm und das breite publizistische Oeuvre hinzuweisen. ${ }^{27}$ Initiator des Vorschlags war Nevil Maskelyne, seit den sechziger Jahren der Royal Astronomer von Greenwich. ${ }^{28}$ Maskelyne hielt seit langem Kontakte zur Göttinger Sternwarte und den hier tätigen Mathe-

25 Friedrich Smend, Johann David Michaelis und Johann Gottfried Eichhorn. Zwei Orientalisten am Rande der Theologie, in: Bernd Moeller (Hg.), Theologie in Göttingen (Göttinger Universitätsschriften A,1), Göttingen 1987, S. 58-81.

26 Royal Society Archive, Johann David Michaelis 1789: John David Michaelis, Knight, Professor of Philosophy at the University of Gottingen well known to the learned world, by his important and numerous publications, being desirous of admission into the Royal Society of London on the foreign List: We whose Names are underwritten, do from our Knowledge of Him, of His writings, recommend Him as a Gentleman well worthy of the honor, He Sollicit, https://collections.royalsociety.org/DServe.exe?dsqIni=Dserve.ini\&dsqApp=Archive\&ds$\mathrm{qDb}=$ Catalog\&dsqSearch $=\mathrm{RefNo}==\% 27 \mathrm{EC} \% 2 \mathrm{~F} 1788 \% 2 \mathrm{~F} 27 \% 27 \& \mathrm{dsqCmd}=$ Show.tcl (letzte Einsicht: 05.06.2014).

27 We the underwritten do recommend for election into the Royal Society on the Foreign list Abraham Gotthelf Kaestner, Aulic Counsellor to His Britannic Majesty, \& Professor of Mathematics in the University of Gottingen, as a Gentleman of distinguished reputation in the Republic of Letters, and whose admission we are persuaded will do credit to the Society.

28 Derek Howse, Nevil Maskelyne. The Seaman’s Astronomer, Cambridge 1989. 
matikern und Astronomen wie Kästner und Lichtenberg. Bereits 1771 hatte ihn die Göttinger Societät als auswärtiges Mitglied aufgenommen. ${ }^{29}$

Der königliche Astronom Nevil Maskelyne ergriff auch vier Jahre später die Initiative, um den 51-jährigen Georg Christoph Lichtenberg, der hier irrtümlich Gottfried Charles Lichtenberg heißt, als auswärtiges Mitglied in die Royal Society aufnehmen zu lassen. ${ }^{30} \mathrm{Zu}$ den prominenten Mitunterzeichnern gehören der Komponist und königliche Hofkapellmeister William Parsons und der Mathematiker, Astronom, Teleskopbauer und Musiker William Herschel ${ }^{31}$, der wenige Jahre zuvor, 1781, durch seine Entdeckung eines neuen Planeten berühmt geworden war; er hatte ihn nach dem englischen König Georg III. „Georgsstern“ genannt, später erhielt er den Namen Uranus. Herschel war seit 1786 korrespondierendes Mitglied der Göttinger Societät der Wissenschaften. ${ }^{32}$

Bei den Göttinger Zuwahlen von auswärtigen Mitgliedern spielen Mitglieder der Royal Society zahlenmäßig keine prominente Rolle, was sich zum Teil aus dem engeren, auf Naturkunde und empirische Wissenschaften beschränkten Interessenbereich der Royal Society erklärt. Bis zum Ende des 18. Jahrhunderts, also in den ersten 50 Jahren ihres Bestehens, hat die Göttinger Societät etwa ein Dutzend englische Gelehrte, die Fellows der Royal Society waren, als auswärtige Mitglieder aufgenommen, darunter allerdings etliche Prominente: ${ }^{33}$

1752 Hans Sloane, ausw. Mitglied, Mediziner und Botaniker, 1727 Präsident der Royal Society

1753 George Charles Parker 2nd Earl of Macclesfield, Ehrenmitglied, Astronom, 1752 Präsident der Royal Society

1765 John Wilkinson, Physiker (FRS 1764)

1766 John Pringle, Mediziner (FRS 1745), 1772 Präsident der Royal Society

1779 Joseph Banks, Botaniker, seit 1778 Präsident der Royal Society

29 Holger Krahnke, Die Mitglieder der Akademie der Wissenschaften zu Göttingen 1751-2001 (Abhandlungen der Akademie der Wissenschaften zu Göttingen, Philologisch-Historische Klasse, Folge 3, 246; Mathematisch-Physikalische Klasse, Folge 3, 50), Göttingen 2001, S. 161.

30 Royal Society Archive, Georg Christoph Lichtenberg 1793: Gottfried Charles Lichtenberg Professor of Natural Philosophy in the University of Gottingen, a Gentleman eminent for his superior knowledge in the various branches of the Science he professes, is hereby recommended as a Candidate for election on the foreign list, as likely to become a very useful \& valuable Member. https://collections.royalsociety.org/DServe.exe?dsqIni=Dserve.ini \&dsqApp $=$ Archive $\&$ dsqDb $=$ Catalog $\&$ dsqSearch $=$ RefNo= $=\% 27 \mathrm{EC} \% 2 \mathrm{~F} 1793 \% 2 \mathrm{~F} 02 \% 27 \& \mathrm{dsqC}-$ $\mathrm{md}=$ Show.tcl (letzte Einsicht: 05.06.2014).

31 Royal Society Archive, Georg Christoph Lichtenberg 1793 (wie Anm. 30).

32 Krahnke, 2001 (wie Anm. 29), S. 112.

33 Zum folgenden Krahnke, 2001 (wie Anm. 29), S. 272-277; für biographische Informationen vgl. Charles Coulston Gillispie / Frederic Lawrence Holmes (Hg.), Dictionary of scientific biography, Bde 1-18, (American Council of Learned Societies), New York 1970-1990. 
1787 William Blizard, Chirurg und Sozialreformer (1787 FRS)

1789 William Cullen, Repräsentant der Edinburgh Medical School, Leibarzt des Königs für Schottland (1777 FRS)

1791 John Bruce, Mitglied der Royal Society of Edinburgh, naturkundlicher und philosophischer Autor (1791 FRS)

Fasst man die gegenseitige Aufnahmepolitik der beiden wissenschaftlichen Gesellschaften im 18. Jahrhundert zusammen, gewinnt man den Eindruck eines eher lockeren und fachbezogenen Beziehungsgeflechtes denn eines straff geknüpften engmaschigen Netzwerkes. Freilich ist die Mitgliedschaft in Akademien nur ein Indiz für Reputation, Austausch und wissenschaftliche Kontakte. Die Korrespondenzen, der Schriftentausch, die Rezensionen und Empfehlungen wären weitere Indizien, doch damit eröffnete sich in der Tat ein weites Feld: Die Bibliographien allein von Abraham Gotthelf Kaestner, Albrecht von Haller oder Johann David Michaelis umfassen einschließlich der Rezensionen jeweils etliche tausend Nummern.

Wenden wir uns zum Schluss noch einem Beispiel für ein wissenschaftliches Großprojekt zu, bei dem die Royal Society die Initiative ergriffen hat, und das so recht ihrem Verständnis von empirischer Naturforschung mit dem Ziel nachprüfbarer Ergebnisse entspricht - ein astronomisches Großereignis des 18. Jahrhunderts.

Der Astronom Edmund Halley hatte 1714 in einem Aufsatz in den „Philosophical Transactions" darauf hingewiesen, dass ein sehr seltenes, aber periodisch wiederkehrendes Phänomen angesichts der in den letzten hundert Jahren entwickelten Teleskope, Messinstrumente, verlässlichen Uhren und der Kenntnis der Gesetze der Himmelsmechanik erstmals die Chance eröffnen würde, die Dimensionen des Sonnensystems exakt zu ermitteln. ${ }^{34}$ Bei dem Phänomen handelte es sich um den Vorübergang der Venus vor der Sonnenscheibe, der paarweise im Abstand von acht Jahren einmal pro Jahrhundert eintritt. Halley hatte für das18. Jahrhundert das Paar 1761 und 1769 vorausberechnet, das nächste Paar würde 1874 und 1882 ein, das dann folgende und vorerst letzte war 2004 und 2012, das nächste wird 2117 und 2125 sein.

Nach Halleys Vorschlag sollten weltweit möglichst viele Astronomen möglichst weit sowohl nach Norden als auch nach Süden aufbrechen, um den zeitlichen Ablauf des Ereignisses von den optischen Kontakten der Venus mit den äußeren und inneren Rändern der Sonne zu messen, woraus man bei den bekannten Koordinaten der Beobachtungsorte die Entfernungen Erde-Venus, Venus-Sonne und Erde-Sonne errechnen konnte und schließlich auf der Basis dieser Entfernungen bei den bekannten Umlaufzeiten der übrigen Planeten auch deren Entfernung zur Sonne nach dem dritten Keplerschen Gesetz ermitteln konnte; die Beobachtungsergebnisse der

34 Edmund Halley, Methodus Singularis Qua Solis Parallaxis Sive Distantia a Terra, ope Veneris intra Solem Conspiciendae, Tuto Determinari Poterit, in: Philosophical Transactions 29 (1714), S. 454-464. 
Expeditionen versprachen also, überhaupt zum ersten Mal die Dimensionen unseres Sonnensystems zuverlässig und präzise zu ermitteln. ${ }^{35}$

Dies war das erste Projekt einer übernational und weltweit organisierten naturwissenschaftlichen Unternehmung in der Zeit der Aufklärung; es beteiligten sich englische, französische, russische, schwedische, amerikanische und deutsche Astronomen. Auch wenn die Überlegungen und Planungen erheblich vor die fünfziger Jahre zurückreichten, lag doch gerade die intensivste Phase der Vorbereitungen und dann vor allem die Durchführung der Beobachtungen an weltweit insgesamt mehr als einhundert Stationen zeitlich mitten im Siebenjährigen Krieg, den die jüngere Forschung als einen „Weltkrieg im 18. Jahrhundert“ apostrophiert hat. ${ }^{36}$ Den Beitrag der Göttinger Societät lieferte Tobias Mayer auf der ersten Göttinger Sternwarte; er publizierte seine Daten in den „Göttingischen Anzeigen von Gelehrten Sachen “.37

Aus verschiedenen, teils organisatorischen, teils technischen Gründen blieben die Beobachtungsergebnisse des Transits von 1761 disparat. ${ }^{38}$ Daraufhin beschloss die Royal Society unter der Führung des königlichen Astronomen Nevil Maskelyne für den acht Jahre später folgenden Transit von 1769, nicht nur die Astronomen der Welt zu neuen Expeditionen aufzufordern, sondern eine eigene Expedition in die Südsee auszurüsten. Maskelyne richtete einen entsprechenden Förderantrag im Umfang von 4000 Pfund an König Georg III. ${ }^{39}$ Nicht nur wegen des zu erwartenden Ruhms für England und die Royal Society, sondern auch, weil Georg III. selbst astronomisch sehr interessiert und versiert war und die wissenschaftliche Bedeutung des Projektes inhaltlich verstand, schien dieser Antrag aussichtsreich. Drei Wochen später gab Georg III. die Zusage über 4000 Pfund aus seiner Privatschatulle - die Royal Society konnte ein eigenes Schiff erwerben, umrüsten und ausstatten und schließlich unter einem astronomisch versierten Kapitän mit fachkundigen Begleitern rechtzeitig zur Südhalbkugel der Erde schicken. König Georg III. ließ sich nach einem Besuch des Royal Observatory in Greenwich eine kleine Privatsternwarte im Park Richmond and Kew errichten, wo er dann zusammen mit seiner Frau und vier Astronomen den Transit der Venus beobachtete.

Alle großen europäischen Nationen beteiligten sich erneut an diesem Projekt, mehr als 250 Beobachter an über 130 Orten der Erde richteten ihre Instrumente

35 Nick Lomb, Transit of Venus. 1631 to the present, Sydney 2011; Andrea Wulf, Die Jagd auf die Venus und die Vermessung des Sonnensystems, München 2012.

36 Marian Füssel, Der Siebenjährige Krieg. Ein Weltkrieg im 18. Jahrhundert, München 2010.

37 Göttingische Anzeigen von Gelehrten Sachen, Jg. 1761/1762, S. 57f.; die Philosophical Transactions 52 (1761), S. 173ff. versammeln die Berichte englischer, französischer und italienischer Astronomen.

38 So erreichte der nachmalige Royal Astronomer Nevil Maskelyne seinen vorgesehenen Beobachtungsort St. Helena verspätet und zudem bei schlechtem Wetter; Wulf 2012 (wie Anm. 35), S. 159ff.; Thomsen 1812 (wie Anm. 2), S. $350 f$.

39 Wulf 2012 (wie Anm. 35), S. $192 \mathrm{f}$. 
auf die Sonne, und die Ergebnisse des Venustransits von 1769 führten zur präzisen Ermittlung der Entfernung Erde-Sonne, die im Mittel 149597870,700 Kilometer beträgt und seither als sogenannte Astronomische Einheit die wichtigste astronomische Maßeinheit neben dem Lichtjahr ist. ${ }^{40}$ Auf der Sternwarte der Göttingischen Sozietät der Wissenschaften nahmen Abraham Gotthelf Kaestner, Jöns Matthias Ljungberg und Georg Christoph Lichtenberg am weltweit ausgespannten Netz der Beobachtungen teil - ihre Messungen wurden allerdings durch den tiefen Stand der Sonne am westlichen Abendhimmel beeinträchtigt; in den „Göttingischen Anzeigen von Gelehrten Sachen“" erschien zwei Wochen später ihr Bericht aus der Feder von Kaestner. ${ }^{41}$

Das von Georg III. finanzierte, von der Royal Society und dem königlichen Astronomen ausgestattete Expeditionsschiff war die Endaevor, Kapitän ein gewisser James Cook, der seine ersten Meriten als Expeditionsleiter und Forschungsreisender dem Planeten Venus verdankte, an dessen Beobachtung er sich beteiligte, wie den „Philosophical Transactions“ zum Jahre 1769 zu entnehmen ist. ${ }^{42}$ Der entsprechende Band der „Transactions“ wurde umgehend in den „Göttingischen Anzeigen von Gelehrten Sachen" annotiert.

40 D. W. Kurtz (Hg.), Transits of Venus. New Views of the Solar System and Galaxy. Proceedings of the 196th Colloquium of the International Astronomical Union 2004, Cambridge 2005, bes. S. 163-179.

41 Göttingische Anzeigen von Gelehrten Sachen, Jg. 1769, S. 665-667.

42 Philosophical Transactions 61 (1769), S. 410. 


\title{
Ein König - viele Wege zum Bücherwissen. Die Göttinger Universitätsbibliothek im Kontext der deutschen und britischen Bibliothekslandschaften 1734-1820
}

\author{
Wilfried Enderle
}

Im ersten Kapitel von Jürgen Osterhammels „Die Verwandlung der Welt. Eine Geschichte des 19. Jahrhunderts“, in dem er über Erinnerungshorte, Wissensschätze und Speichermedien schreibt, stößt man - nur auf den ersten Blick etwas überraschend - auch auf die Bibliothek der Universität Göttingen. Diese galt im 18. Jahrhundert, wie Osterhammel lakonisch bemerkte, „eine Weile [...] als die am besten organisierte Bibliothek der Welt. "1 Nicht ihren Bestand, ihre Größe oder den Besitz besonders wertvoller Handschriften und alter Drucke hob Osterhammel hervor, sondern den banalen Aspekt der guten Organisation - und implizit die gute Benutzbarkeit der Göttinger Bibliothek. Damit steht er freilich in einer langen Tradition. Bereits 1765 hat Johann Stephan Pütter in seinem „Versuch einer academischen Gelehrten-Geschichte von der Georg-Augustus-Universität zu Göttingen“ betont, daß auch die Einrichtung und Ordnung einen der wesentlichsten und seltensten Vorzüge dieser Bibliothek ausmacht. ${ }^{2}$ Und in dasselbe Horn stieß 1802 Ernst Brandes: Eben so allgemein bekannt ist es, daß die Göttingische Bibliothek die gemeinnützigste und die am meisten benutzte Bibliothek in der Welt ist. ${ }^{3}$ Drei Zitate, drei Superlative - das ist das Bild, das sowohl die zeitgenössischen Göttinger Gelehrten als auch die Historiker von der Göttinger Bibliothek im 18. Jahrhundert vermitteln.

Nur wenige Jahrzehnte nach ihrer Gründung war es der Universität ganz offensichtlich gelungen, ihre Büchersammlung im Bewusstsein der gebildeten Zeitgenossen zu einem Ereignis von gleichsam europäischem Rang zu stilisieren. Schon 1787 hatte ein anonymer Autor im „Journal aller Journale“ einen Brief aus Göttingen veröffentlicht, in dem zu lesen war: In einer Beschreibung der göttingischen Universität

1 Jürgen Osterhammel, Die Verwandlung der Welt. Eine Geschichte des 19. Jahrhunderts, München 2009, S. 34.

2 Johann Stephan Pütter, Versuch einer academischen Gelehrten-Geschichte von der Georg-Augustus-Universität zu Göttingen. Erster Theil, Göttingen 1765, S. 220.

3 E[rnst] Brandes, Ueber den gegenwärtigen Zustand der Universität Göttingen, Göttingen 1802, S. 196. 
muß man, glaube ich, bei der Bibliothek anfangen, als welche das Hauptrad ist, die die ganze Maschine treibt. ${ }^{4}$ Aus Briefen, Reisebeschreibungen oder Journalen, insbesondere in den Jahrzehnten nach 1780, könnte man unschwer noch weitere, ähnliche Äußerungen zitieren. ${ }^{5}$ Dabei dürfte das Geschick, mit dem die zeitgenössische Öffentlichkeitsarbeit der Göttinger Universität die Werbetrommel rührte, eine nicht zu unterschätzende Rolle gespielt haben. Nicht ohne Grund hat Wolfgang Schmitz vor einigen Jahren einen Aufsatz unter dem Titel publiziert: „Ein wenig Pralerey und Charlatanerie.' Die propagandistische Selbstdarstellung der Universität Göttingen und ihrer Bibliothek in der Ära Münchhausen ". ${ }^{6}$ Pütter hatte mit seiner bereits erwähnten Beschreibung der Universität, die vom Kurator der Universität, Gerlach Adolph von Münchhausen, bewusst als Werbeschrift für die Universität angeregt worden war, ${ }^{7}$ den ersten großen Aufschlag gemacht. 1788 folgte bereits die zweite, aktualisierte Auflage. ${ }^{8} 1804$ publizierte der Göttinger Gelehrte Christoph Meiners in den „Göttingischen akademischen Annalen“ eine erste Geschichte der Universitätsbibliothek. ${ }^{9}$ Und 1810, zwei Jahre vor seinem Tod, schrieb Christian Gottlob Heyne, Direktor der Bibliothek von 1764 bis 1812, für die „Göttingischen Gelehrten Anzeigen" einen Beitrag, in dem er die Konzeption der Göttinger Universitätsbibliothek erläuterte und der rasch gleichsam kanonischen Charakter erhielt. ${ }^{10}$ Pütter, Meiners und insbesondere Heyne haben mit ihren Arbeiten und der darin postulierten Ex-

4 Briefe aus Göttingen, in: Journal aller Journale, Juni 1787, S. 125.

5 Vgl. Wilhelm Ebel, Briefe über Göttingen. Aus den ersten 150 Jahren der Georgia Augusta, Göttingen 1975, S. 39, 68f., 80 und 84; István Futaky (Hg.), „Selige Tage im Musensitz Göttingen“. Stadt und Universität in ungarischen Berichten aus dem 18. und 19. Jahrhundert, Göttingen 1991, S. 44ff.; Anne Saada, La communication à l'intérieur de la République des Lettres observée à partir de la bibliothèque universitaire de Göttingen, in: Ulrich Johannes Schneider (Hg.), Kultur der Kommunikation. Die europäische Gelehrtenrepublik im Zeitalter von Leibniz und Lessing, Wolfenbütteler Forschungen 109, Wiesbaden 2005, S. 243-254, hier S. 243, verweist auf Erwähnungen in zeitgenössischen französischsprachigen Journalen. Auch Friedrich Gedeke betonte 1789, dass die Universität einen großen Theil ihrer Celebrität der Bibliothek zu verdanken habe; nach Hartmut Boockmann (Hg.), Mehr als irgend eine andere in Deutschland bekannt. Die Göttinger Universität im Bericht des „Universitätsbereisers“ Friedrich Gedike aus dem Jahr 1789, Göttingen 1996, S. 22.

6 Wolfgang Schmitz, „Ein wenig Pralerey und Charlatanerie“. Die propagandistische Selbstdarstellung der Universität Göttingen und ihrer Bibliothek in der Ära Münchhausen, in: Bibliothek und Wissenschaft (41) 2008, S. 17-43.

7 Dass Münchhausen diese Publikation angeregt hatte, behauptet Pütter in seiner Autobiographie; vgl. Johann Stephan Pütter, Selbstbiographie zur dankbaren Jubelfeier seiner 50jährigen Professorstelle in Göttingen, Bd. 2, Göttingen 1798, S. 464.

8 Pütter, Versuch einer academischen Gelehrten-Geschichte. Zweyter Theil von 1765 bis 1788, Göttingen 1788.

9 Beyträge zur Geschichte unserer Universitäts-Bibliothek, in: C[hristoph] Meiners (Hg.), Göttingische Akademische Annalen, Bd. 1, Hannover 1804, S. 1-96.

10 Göttingische Gelehrte Anzeigen, 31. Mai 1810, S. 849-855. Auch in: Karl Julius Hartmann (Hg.), Vier Dokumente zur Geschichte der Universitäts-Bibliothek Göttingen (Chr. G. Heyne 1768. 1810. Jakob Grimm 1829. 1833), Hainbergschriften 4, Göttingen 1937, S. 14-18. 
zeptionalität der Göttinger Bibliothek ein Interpretationsgerüst aufgebaut, das bis heute den Diskurs über die Bibliothek trägt. So war, um nur ein Beispiel aus der neueren Forschung zu nennen, für Bernhard Fabian „die Konzeption der Bibliothek [...] so neu und umwälzend [...], daß im historischen Rückblick mit der Gründung der Göttinger Bibliothek ein neuer Abschnitt in der Geschichte der Bibliotheken begann.“ Die Göttinger Bibliothek war für ihn „die erste wissenschaftliche Universalbibliothek der Welt". ${ }^{11}$ Auch andere Bibliotheken haben im 18. Jahrhundert versucht, die gelehrte Öffentlichkeit auf sich aufmerksam zu machen, sei es über den Druck ihrer Kataloge oder andere Publikationen. Keiner ist es aber gelungen, in der öffentlichen Wahrnehmung den Eindruck ihrer Singularität, ihrer Ausnahmefunktion im Vergleich zu anderen Bibliotheken so zu verankern wie der Universitätsbibliothek Göttingen.

Dass die Bibliothek im 18. Jahrhundert zu einem Alleinstellungsmerkmal Göttingens unter den europäischen Universitäten stilisiert werden konnte, hatte freilich ein fundamentum in re. Denn der Aufbau der Göttinger Universitätsbibliothek im 18. Jahrhundert war in der Tat eine in vielerlei Hinsicht erstaunliche, fast phänomenale Geschichte. Bereits um 1760, nur knapp drei Jahrzehnte nach ihrer Gründung, zählte der Bestand über 50.000 Bände, um 1800 dürften es bereits ca. 130.000 Bände gewesen sein. ${ }^{12}$ Die Göttinger Bibliothek war damit als einzige deutsche Universitätsbibliothek in die Liga der großen europäischen Bibliotheken aufgestiegen. Erstaunlich ist diese Geschichte, weil universitäre Büchersammlungen noch in der ersten Hälfte des 18. Jahrhunderts in der Regel klein waren und einige tausend Bände oft nicht überschritten. ${ }^{13}$ Verwaltet wurden sie im Nebenamt von einem Professor. Der Etat war gering und bestand häufig nur aus einem Teil der Gebühren, die die Studenten bei der Einschreibung oder bei Prüfungen zu entrichten hatte.

11 Bernhard Fabian, Die Göttinger Universitätsbibliothek im 18. Jahrhundert, in: Göttinger Jahrbuch 1980, S. 110. Vgl. auch Ders., Göttingen als Forschungsbibliothek im 18. Jahrhundert, in: Paul Raabe (Hg.), Öffentliche und private Bibliotheken im 17. und 18. Jahrhundert. Raritätenkammern, Forschungsinstrumente oder Bildungsstätten?, Wolfenbütteler Forschungen 2, Bremen / Wolfenbüttel 1977, S. 209-240.

12 Zur Geschichte der Universitätsbibliothek Göttingen im 18. Jahrhundert ist immer noch grundlegend: Karl Julius Hartmann / Hans Füchsel (Hg.), Die Geschichte der Universitäts-Bibliothek Göttingen, verfaßt von Göttinger Bibliothekaren, Göttingen 1937; vgl. ferner Christine Kind-Dörne, Die Niedersächsische Staats- und Universitätsbibliothek Göttingen. Ihre Bestände und Einrichtungen in Geschichte und Gegenwart, Beiträge zum Buch- und Bibliothekswesen 22, Wiesbaden 1986; Helmut Kind, Die Bestände der Göttinger Universitätsbibliothek im 18. Jahrhundert, in: Göttinger Jahrbuch 1987, S. 157-166.

13 So auch noch Manfred Komorowski, Bibliotheken, in: Ulrich Rasche (Hg.), Quellen zur frühneuzeitlichen Universitätsgeschichte. Typen, Bestände, Forschungsperspektiven, Wolfenbütteler Forschungen 128, Wiesbaden 2011, S. 57f. Eine neuere Gesamtdarstellung zur Geschichte der Universitätsbibliotheken in Deutschland im 18. Jahrhundert ist ein Desiderat. Hugo Kunoff, The Foundations of the German Academic Library, Chicago 1982, bietet diese nicht. Vgl. daher das einschlägige Kapitel bei Ladislaus Buzas, Deutsche Bibliotheksgeschichte der Neuzeit (1500-1800), Elemente des Buch- und Bibliothekswesens 2, Wiesbaden 1976, S. 32-47. 
Dass Bibliotheken an Universitäten in der Frühen Neuzeit keine große Rolle spielten, ist nur aus heutiger Sicht erstaunlich. Die Professoren brauchten sie nicht, denn es war Usus, dass sie für ihr gelehrtes Werkzeug selbst sorgten. Mit anderen Worten, jeder Professor besaß zumeist eine umfangreiche eigene Bibliothek, ja, er musste eine eigene Bibliothek besitzen, um überhaupt arbeitsfähig zu sein, da sich in der Regel die Bibliothek seiner Universität darauf beschränkte, nur teure und wertvolle Werke zu sammeln, die sich die Gelehrten vor Ort nicht selber leisten konnten. ${ }^{14}$ Auch in Göttingen war man bei der Gründung der Universität noch von diesen Prinzipien der nebenamtlichen Verwaltung, der Finanzierung über Gebühren und der Beschaffung ausgewählter teurer Werke ausgegangen. ${ }^{15}$ Und diese Prinzipien funktionierten auch in Göttingen wie andernorts. Um 1800 betrug der Bestand der Göttinger Professorenbibliotheken zusammen über 200.000 Bände, ${ }^{16}$ von der Universität in Königsberg ist die Zahl von 100.000 Bänden überliefert; ${ }^{17}$ und man kann davon ausgehen, dass es an anderen Universitäten im Reich - je nach Größe - ähnlich ausgesehen haben dürfte.

Wie kann man vor diesem Hintergrund den Aufbruch der Göttinger Bibliothek erklären? Wie ihre von der Forschung bislang postulierte singuläre Rolle? Die bisherige Forschung hat - völlig zu Recht - auf die besondere Rolle des Kurators Münchhausen sowie das neue Wissenschaftskonzept der Universität selbst verwiesen, das die eigene Forschung der Professoren in den Mittelpunkt rückte. ${ }^{18}$ Bernhard Fabian hat in einem die Forschung bis heute maßgeblich bestimmenden Aufsatz die Bedeutung der Entwicklung der Wissenschaft und des gelehrten Publikationswesens, vor allem auch des Aufschwungs gelehrter Zeitschriften, in den Jahrzehnten nach 1700 betont. ${ }^{19}$ Dazu

14 Paul Raabe, Gelehrtenbibliotheken im Zeitalter der Aufklärung, in: Werner Arnold / Peter Vodosek (Hg.) Bibliotheken und Aufklärung, Wolfenbütteler Schriften zur Geschichte des Buchwesens 14, Wiesbaden 1988, S. 103-122.

15 Emil F. Rössler, Die Gründung der Universität Göttingen. Eine Sammlung bisher ungedruckter Entwürfe, Berichte und Briefe von G. A. v. Münchhausen, J. L. v. Mosheim, Alb. v. Haller, G. C. Gebauer, J. H. Böhmer und anderen Zeitgenossen. Zur Geschichte des deutschen wissenschaftlichen Lebens im XVIII. Jahrhundert, Göttingen 1855, S. 11: 1732 wurde geplant, daß jeder Student bei der Inskription einen halben Taler der Bibliothek verehren solle und damit kan selbige nach und nach schon in guten Stand kommen. Nach ebd., S. 485, vertrat Gruber 1734 noch das Prinzip, dass die Universitätsbibliothek vor allem teure Bücher erwerben soll. Vgl. auch Meiners, Beyträge, 1804 (wie Anm. 9), S. 22ff., wonach bis 1748 der reguläre Etat nur 250 Taler betrug.

16 Gerhard Streich, Die Privatbibliothek als Handwerkszeug des Gelehrten im 18. Jahrhundert, dargestellt am Beispiel Göttingens, in: Paul Raabe (Hg.), Öffentliche und private Bibliotheken im 17. und 18. Jahrhundert. Raritätenkammern, Forschungsinstrumente oder Bildungsstätten?, Wolfenbütteler Forschungen 2, Bremen / Wolfenbüttel 1977, S. 241-299, hier S. 253.

17 Komorowski, 2011 (wie Anm. 13), S. 58.

18 So vor allem Georg Leyh, Die deutschen Bibliotheken von der Aufklärung bis zur Gegenwart, in: Ders. (Hg.), Handbuch der Bibliothekswissenschaft, Bd. 3.2, Wiesbaden 21957, S. 116ff.; vgl. auch Ders., Die Göttinger Bibliothek in den Grundzügen ihrer Entwicklung, in: Nordisk Tidskrift för Bok- och Biblioteksväsen, 36 (1949), S. 69-89.

19 Fabian, 1977 (wie Anm. 11), S. 211 f. 
kam in dieser Zeit, worauf Martin Gierl hinwies, der Boom der Literärgeschichte, der historia literaria, der natürlich bei der Konzeption einer neuen Universität eine Rolle spielen musste und dies in Göttingen auch tat. ${ }^{20}$ Vom Thema der Erschließung des Wissens und der Erarbeitung neuen Wissens als zentralem Modernitätskriterium für die neue Universität in Göttingen ausgehend, sieht Anne Saada die Bibliothek als einen Baustein eines rational kalkulierten Gesamtkonzepts, bestehend aus der Königlichen Gesellschaft der Wissenschaft, der Universität, den „Göttingischen Anzeigen gelehrter Sachen“ und der Bibliothek ${ }^{21}$ - ein schon von Heyne 1810 formuliertes Argument, das auch Reimer Eck in den Vordergrund rückte. ${ }^{22}$ Es fällt indes auf, dass der bibliothekshistorische Kontext kaum zur Erklärung herangezogen wurde. Bei der Herausstellung der Singularität der Göttinger Bibliothek wurde zumeist nur der Vergleich zu anderen Universitäten gezogen. Gerne wurde dabei auf Halle verwiesen, das 1694, also nur wenige Jahrzehnte vor Göttingen gegründet wurde, und wo die Bibliothek noch 1760 nur einige wenige tausend Bände umfasste; oder auf die Universitätsbibliothek Cambridge, die um 1750 erst 30.000 Bände gezählt haben soll. ${ }^{23}$ Damit bleibt man freilich einer erst im Laufe des 19. Jahrhunderts geläufigen Typisierung wissenschaftlicher Bibliotheken verhaftet, die den Zeitgenossen des 18. Jahrhunderts noch eher fremd gewesen war. Denn die zeitgenössische Bibliothekstheorie unterschied damals nur zwischen zwei Typen von Bibliotheken: der bibliotheca privata und der bibliotheca publica. ${ }^{24}$ Oeffentliche Bibliothecken nenne ich diejenigen, die grosse Her-

20 Martin Gierl, Bestandsaufnahme im gelehrten Bereich. Zur Entwicklung der „Historia literaria“ im 18. Jahrhundert, in: Klaus Anselm Vogel (Hg.), Denkhorizonte und Handlungsspielräume. Historische Studien für Rudolf Vierhaus zum 70. Geburtstag, Göttingen 1992, S. 76ff.; Ders., Bauen an der festen Burg der Aufklärung. Historia literaria von Heumann bis Eichhorn und die Göttinger Universität als reale und fiktive Bibliothek, in: Hans Erich Bödeker / Anne Saada (Hg.), Bibliothek als Archiv, Veröffentlichungen des Max-Planck-Instituts für Geschichte 221, Göttingen 2007, S. 281-296.

21 Anne Saada, La construction du réseau universitaire de Göttingen. Un observatoire exemplaire pour les circulations internationals, in: Pierre-Yves Beaurepaire / Pierrick Purchasse (Hg.), Les Circulations internationales en Europe, années 1680-années 1780, Rennes 2010, S. 349-360, hier S. 352; Dies., Économie institutionelle. Consommation et production culturelles à la bibliothèque universitaire de Göttingen au XVIIIe siècle, in: Vincent Milliot / Philippe Minard / Michel Porret (Hg.), La Grande Chevauchée. Faire de l'histoire avec Daniel Roche, Genf 2011, S. 395-413.

22 Reimer Eck, Das magische Dreieck. Gelehrte Zeitung, Bibliothek und Societät, in: Norbert Elsner / Nicolaas A. Rupke (Hg.), Albrecht von Haller im Göttingen der Aufklärung, Göttingen 2009, S. 167-182.

23 So auch noch Saada, 2011 (wie Anm. 21), S. 395, wobei sie dieses Argument übernimmt von: Heinz-Joachim Müllenbrock / Theodor Wolpers, Englische Literatur in der Göttinger Universitätsbibliothek des 18. Jahrhunderts, Arbeiten aus der Niedersächsischen Staats- und Universitätsbibliothek Göttingen 14b, Göttingen 1988, S. 12.

24 So zum Beispiel bereits 1688 Daniel Morhof. Vgl. Colette Nativel, Bibliotheca selon Morhof, in: Marc Fumaroli / Marianne Lion-Violet (Hg.), Les premiers siècles de la République européenne des Lettres. Actes du colloque international, Paris, Decembre 2001, Collections La République européenne des lettres, La République européenes des arts 100, Paris 2005, S. 428-448, hier S. 433. 
ren, Städte, Universitäten, Gymnasia, oder gelehrte Gesellschaften errichtet haben ${ }^{25}$, kann man in Johann David Köhlers 1762 posthum veröffentlichter Anweisung für reisende Gelehrte lesen.

Im Folgenden soll daher versucht werden, die Entwicklung der Göttinger Bibliothek in diesen breiteren Kontext der bibliotheca publica, so wie Köhler sie definiert hat, zu stellen. In einem ersten Schritt soll die Aufbauphase der Göttinger Bibliothek von 1734 bis 1770 mit dem zeitgleich stattfindenden Aufbau der Bibliothek des Grafen Heinrich von Bünau in Dresden kontrastiert werden (1), um dann überzugehen auf die Entwicklung, großer Bibliotheken' im 18. Jahrhundert (2) mit einem kurzen Exkurs zur ,welfischen Bibliothekspolitik' (3). Abschließend soll auf die von 1770 bis in die 1820er Jahre dauernde Blütezeit der Universitätsbibliothek Göttingen, die grob der Amtszeit von Heyne entspricht, im Kontext der Entwicklungen an anderen Universitäten eingegangen werden (4).

\section{Die Gründungsphase der Universitätsbibliothek Göttingen 1734-1770 im Vergleich mit dem Aufbau der Bünauschen Bibliothek in Dresden}

Als 1761 Johann Matthias Gesner, erster Professor für Eloquenz und erster Bibliothekar der Universität Göttingen starb, war innerhalb von 27 Jahren eine große Bibliothek von 50.000 Bänden aufgebaut worden. Eine Bibliothek, deren Ruhm sich in der gelehrten Welt in den folgenden Jahrzehnten rasch etablieren sollte. Genau zur selben Zeit hatte in Dresden Heinrich Graf von Bünau eine große Gelehrtenbibliothek begründet, die bei seinem Tod 176342.000 Bände zählte, also fast so groß war wie die in Göttingen; die aber heute nur noch Kennern des 18. Jahrhunderts ein Begriff sein dürfte. ${ }^{26}$ Bereits dieses Beispiel zeigt, dass Göttingen nicht das einzige Mekka für Bibliothekare im 18. Jahrhundert war. ${ }^{27}$ Und es ist vielleicht kein Zufall, dass Christian Gottlob Heyne, Leiter der Göttinger Bibliothek von 1764 bis 1812, aus Dresden kam, wo er vor seinem Ruf 1763 nach Göttingen auf eine Professur für klassische Philologie als schlechtbezahlter Kopist an der Bibliothek des Grafen von

25 Johann David Köhler, Anweisung für Reisende Gelehrte, Bibliothecken, Münz=Cabinette, Antiquitäten=Zimmer, Bilder=Säle, Naturalien = und Kunst=Kammern, u.d.m. mit Nutzen zu besehen, Frankfurt / Leipzig 1762, S. 5.

26 Die nachfolgenden Angaben zur Bünauschen Bibliothek beruhen auf der detaillierten Studie von Torsten Sander, Ex Bibliotheca Bunaviana. Studien zu den institutionellen Bedingungen einer adligen Privatbibliothek im Zeitalter der Aufklärung, Aufklärungsforschung 6, Dresden 2011.

27 So auch bereits Alfred Hessel, Heyne als Bibliothekar, in: Zentralblatt für Bibliothekswesen 45 (1928), S. 455-470, hier S. $458 f$. 
Brühl in Dresden gearbeitet hatte $;^{28}$ der zweiten großen Bibliothek in Dresden, denn Heinrich Graf von Brühl, seit 1746 Premierminister beim sächsischen Kurfürsten, hatte eine 70.000 Bände umfassende repräsentative Bibliothek aufbauen lassen, eine typische adlige Prestigesammlung, deren Wert vor allem in einer Vielzahl seltener Handschriften und Drucke lag. ${ }^{29}$

Interessanter als die Brühlsche Bibliothek sind im Vergleich zu Göttingen indes die Aktivitäten des Grafen von Bünau. Denn Bünau hatte anders als Brühl primär gelehrte Interessen. Er arbeitete an einer umfangreichen Geschichte des Heiligen Römischen Reiches deutscher Nation, die auch unter dem Titel „Genaue und umständliche teutsche Kayser- und Reichs-Historie“ ${ }^{\text {30 }}$ erschien. Dafür hatte er bereits seit Mitte der 1720er Jahre begonnen, eine Bibliothek aufzubauen, doch sein Sammeleifer überschritt im Laufe der Jahre die Grenzen seiner eigenen gelehrten Interessen. $\mathrm{Da}$ andere Gelehrte die Möglichkeit hatten, die Bünausche Bibliothek zu nutzen, kann man sie mit Abstrichen als eine von einem adligen Herrn gegründete bibliotheca publica verstehen. ${ }^{31}$ Vergleicht man die Entwicklung der Bünauschen Bibliothek mit der in Göttingen, so zeigen sich eine ganze Reihe von Parallelen. Initiator war in beiden Fällen ein Adliger. Hier der Graf von Bünau, in Göttingen Gerlach Adolph von Münchhausen. Die konkrete Arbeit überließ Bünau einem Gelehrten, den er als Bibliothekar eingestellt hatte, Johann Michael Francke. Münchhausen delegierte dies an einen seiner Mitarbeiter in Hannover, Philipp August Schlüter. Denn - und das ist bemerkenswert - die Bibliothek der Universität Göttingen wurde bis zum Tode Münchhausens 1770 nicht primär in Göttingen aufgebaut, sondern in Hannover. Dort wurde der größere Teil der Erwerbungen getätigt und über Sondermittel finanziert; und dort wurden auch die Akzessionskataloge geführt und Schlüter sichtete selbst auch Auktionskataloge und machte für Münchhausen Erwerbungsvorschläge auch wenn natürlich die Göttinger Professoren selbst Bücher zur Bestellung vorschlagen konnten bzw. auch sollten. ${ }^{32}$ Für das Verständnis der Göttinger Bibliothek ist

28 Arn[old] Herm[ann] Lud[wig] Heeren, Christian Gottlob Heyne, Göttingen 1813, S. 36f. Zu Heyne vgl. Helmut Rohlfing, Christian Gottlob Heyne und die Göttinger Universitätsbibliothek, in: Balbina Bäbler / Heinz-Günther Nesselrath (Hg.), Christian Gottlob Heyne - Werk und Leistung nach zweihundert Jahren, Berlin 2014 [Druck in Vorbereitung]; an älterer Literatur vgl. Hessel, 1928 (wie Anm. 27); Christian Gottlob Heyne (1729-1812). Ausstellung anlässlich seines 250. Geburtstages, Göttingen 1979; weitere Literaturhinweise bei: Fee-Alexandra Haase, Christian Gottlob Heyne (1729-1812). Bibliographie zu Leben und Werk. Gedruckte Veröffentlichungen, zeitgenössische Schriften zu seiner Rezeption, Forschungsliteratur, Heidelberg 2002.

29 Christel Hebig, Bibliotheca Brühliana, in: Zentralblatt für Bibliothekswesen 103 (1989), S. 71-76.

30 Heinrich von Bünau, Genaue und umständliche teutsche Kayser- und Reichs-Historie, 4 Bde, Leipzig 17281743.

31 Auch Sander, 2011 (wie Anm. 26), S. 178, konstatiert, dass man bei Adelsbibliotheken nicht pauschal entscheiden kann, ob sie privaten oder öffentlichen Charakter hatten. Zur öffentlichen Nutzung der Bünauschen Bibliothek ebd., S. 181f.

32 Hartmann, 1937 (wie Anm. 10), S. $28 f$. 
das ein Aspekt ersten Ranges. Denn einerseits war sie organisiert wie jede andere Universitätsbibliothek auch: Es gab nur einen kleinen Etat und ein Professor, eben Gesner, leitete sie im Nebenamt. Auf der anderen Seite aber gab es Münchhausen, der in Hannover energisch den massiven Ausbau der Bibliothek betrieb und aus eigener Vollmacht Mittel bereitstellte, die den regulären Etat um ein Vielfaches überschritten.

Deutliche Parallelen zwischen der Göttinger Bibliothek und der Bünauschen zeigen sich auch bei der Praxis der Erwerbungen. Denn wie schaffte man es im 18. Jahrhundert innerhalb weniger Jahrzehnte eine große Bibliothek aufzubauen? Die Methode war relativ einfach: Man erwarb als Grundstock eine oder mehrere vollständige Privatbibliotheken, um diese dann weiter auszubauen. Bünau hatte 1744 die Bibliothek des Berner Stadtbibliothekars Samuel Engel gekauft. ${ }^{33}$ In Göttingen war es Münchhausen bereits 1734, drei Jahre vor der offiziellen Gründung der Universität, gelungen, die fast 9.000 Bände zählende Bibliothek des Großvogts Joachim Hinrich von Bülow zu erwerben. Zusammen mit der Bibliothek des Göttinger Gymnasiums und Dubletten der Hofbibliothek in Hannover zählte die Bibliothek der Universität bei ihrer Gründung ca. 12.000 Bände und hatte bereits damit eine Größe erreicht, die den Büchersammlungen schon länger existierender Hochschulen nicht nachstand und sie in einigen Fällen sogar übertraf. Dazu kam, dass schon 1736 mit dem als Privatsammler renommierten Frankfurter Patrizier Johann Friedrich Armand von Uffenbach vereinbart worden war, dass nach dessen Tod seine Bücher an die Göttinger Universität kommen sollten ${ }^{34}$ - eine Sammlung, über deren Bedeutung „für den Aufschwung der Geistesgeschichte der 1720er und 1730er Jahre" Martin Mulsow zufolge ein eigenes Buch geschrieben werden könnte. ${ }^{35}$ Neben dem Erwerb ganzer Privatbibliotheken bedienten sich sowohl Bünau wie Münchhausen des holländischen Auktionsmarkts sowie natürlich des örtlichen Buchhandels. Erwähnenswert ist, dass Bünau neben Kontakten zu Gelehrten auch die zu auswärtigen Gesandten nutzte, um an Bücher aus England und Frankreich zu gelangen. ${ }^{36}$ Auch das unterschied sich nicht so sehr von dem Vorgehen Münchhausens, der für Erwerbungen aus England die Mitarbeiter der Deutschen Kanzlei in London einspannte. ${ }^{37}$

Für Bünau wie für die Göttinger Universität war die Bibliothek ein Arbeitsinstrument, doch nicht minder wichtig scheint in beiden Fällen auch der Prestigewert gewesen zu sein, den eine große Sammlung mit sich brachte. Für Bünau bot das Sammeln die Option, eine nach außen wirkende, repräsentative Bibliothek aufzubauen,

33 Sander, 2011 (wie Anm. 26), S. 43.

34 Hartmann, 1937 (wie Anm. 10), S. $18 f f$.

35 Martin Mulsow, Prekäres Wissen. Eine andere Ideengeschichte der Frühen Neuzeit, Berlin 2012, S. 289.

36 Sander, 2011 (wie Anm. 26), S. 46.

37 Graham Jefcoate, Wilhelm Best und der Londoner Buchhandel. Ein deutscher Diplomat im Dienst der Universitätsbibliothek Göttingen im 18. Jahrhundert, in: Leipziger Jahrbuch zur Buchgeschichte 6 (1996), S. $199-210$. 
um sich damit in der gelehrten wie der adeligen und höfischen Welt positionieren zu können. Um dieses Kapital auch wirksam einzusetzen, musste natürlich auch für die Sammlung geworben werden. Das damals probate Mittel war, einen Katalog erstellen und drucken zu lassen. Genau dies tat im Auftrag Bünaus sein Bibliothekar, Johann Michael Francke. ${ }^{38}$ Von 1750 bis 1756 erschienen sechs Bände. ${ }^{39}$ Obwohl der Katalog damit nicht abgeschlossen war, fand er unter den Gelehrten der Zeit weite Verbreitung und Anerkennung. Hätte es bereits im 18. Jahrhundert ein Bibliotheksranking gegeben, hätte um 1760 die Bünausche Bibliothek vielleicht sogar vor Göttingen rangiert. Denn einen gedruckten Katalog konnte die Göttinger Bibliothek nicht aufweisen, obwohl Zeitgenossen einen solchen immer wieder eingefordert haben. ${ }^{40}$ Göttingen hatte allerdings ein auf lange Sicht gesehen sogar besseres Substitut: Die „Göttingischen Anzeigen von gelehrten Sachen“. ${ }^{41}$ Die dort rezensierten neuen Bücher landeten in der Regel alle im Bestand der Göttinger Bibliothek und damit waren die Anzeigen auch ein Katalog oder präziser ein Mitteilungsblatt der Neuerwerbungen. Die gesamte gelehrte Welt konnte so regelmäßig erfahren, was in Göttingen gesammelt und gelesen wurde.

Doch zurück zum Vergleich mit der Bibliothek Bünaus. Natürlich gab es auch signifikante Unterschiede zwischen der Sammlung Bünaus und der der Universität Göttingen, insbesondere bei der Art und Intensität der Nutzung sowie der institutionellen Kontinuität. Doch entscheidend für die vorliegende Fragestellung ist, dass die deutliche Parallelität beim Aufbau beider Bibliotheken vor allem eines zeigt: Die Bibliothek der Universität Göttingen war, das Paradoxon sei erlaubt, im Grunde überhaupt keine Universitätsbibliothek. Ihr Aufbau lief nicht in den für deutsche Universitätsbibliotheken üblichen engen Etatgrenzen, sondern entsprach der Vorgehensweise, wie sie Bünau als adliger Mäzen pflegte. So wie Bünau als Adliger eine gleichsam öffentliche Bibliothek aufgebaut hatte, so hatte in Göttingen Münchhausen gewirkt. Er agierte als Stellvertreter für den britischen König und hannoverschen Kurfürsten und baute in dessen Auftrag eine große öffentliche Bibliothek auf, deren Öffentlichkeit er über seine' Universität in Göttingen organisieren ließ. Und damit wird erkennbar, dass man die Göttinger Bibliothek nur dann angemessen beurteilen

38 Zu Francke vgl. Hans Lülfing, Art: Francke, Johann Michael, in: Neue Deutsche Biographie 5 (1961), S. 327f.; Hans Henning, Aus dem Leben und Wirken Johann Michael Franckes. Die Tätigkeit des Bibliothekars der Bünauschen Sammlung in den Jahren 1753-1775 auf Grund neuer Quellen dargestellt, in: Zentralblatt für Bibliothekswesen 72 (1958), S. 273-298.

39 Johann Michael Francke, Catalogus Bibliothecae Bunauianae, 3 Bde, Leipzig 1750-1756.

40 Vgl. Hessel, 1928 (wie Anm. 27), S. 465.

41 Wilfried Enderle, Britische und europäische Wissenschaft in Göttingen. Die Göttingischen Anzeigen von gelehrten Sachen als Wissensportal im 18. Jahrhundert. In: Elmar Mittler (Hg.), „Eine Welt allein ist nicht genug“. Großbritannien, Hannover und Göttingen 1714-1837, Göttinger Bibliotheksschriften 31, Göttingen 2005, S. 161-184. 
und in ihrer Eigenart verstehen kann, wenn man sie im Kontext der großen öffentlichen Bibliotheken ihrer Zeit verortet.

\section{Der take-off der, großen öffentlichen Bibliotheken' im 18. Jahrhundert}

Dass sich die Zeitgenossen sehr bewusst waren, in welcher Liga die Göttinger Bibliothek spielte, zeigt auch Ernst Brandes, der in seiner Schrift „Ueber den gegenwärtigen Zustand der Universität Göttingen“"von 1802 zunächst feststellte: Diejenige öffentliche Anstalt, die ihrer allgemeinen Wichtigkeit wegen zuerst genannt werden muß, ist die Bibliothek. Und er schrieb dann weiter:

Ob sie die zahlreichste Bibliothek in der Welt sey, daran liegt im Ganzen wenig. [...] Wahrscheinlich mußjetzt die Pariser Nationalbibliothek die zahlreichste in der Welt seyn. Die Kaiserliche Bibliothek in Wien wird auf 300000 Bände geschätzt. Die Königl. Bibliothek in Copenhagen auf 250000. Höchst vermuthlich ist die Göttingische Bibliothek sehr nahe an 200000 Bände stark. ${ }^{42}$

Diese letzte Zahl dürfte etwas zu hoch gegriffen sein, doch entscheidend ist, welche Bibliotheken Brandes als Vergleichsobjekte zu Göttingen einfielen: die großen Hofbzw. Nationalbibliotheken Europas.

Betrachtet man die Geschichte der großen Bibliotheken im Europa der Frühen Neuzeit etwas genauer, so fällt ein nicht uninteressantes Phänomen auf: Bis ins 18 . Jahrhundert hinein gab es eine signifikante Differenz zwischen der Entwicklung des zeitgenössischen Buchmarktes und derjenigen der Bibliotheken. Allein im deutschsprachigen Raum wurden im 16. Jahrhundert über 130.000 Bücher verlegt, im 17. Jahrhundert waren es bereits, trotz des dreißigjährigen Krieges, deutlich über 300.000 Titel; für das geplante Verzeichnis der deutschen Drucke des 18. Jahrhundert kalkuliert man mit 600.000 Titeln. ${ }^{43}$ Rechnet man die für die gelehrte Welt wichtigen italienischen, französischen und englischen Buchmärkte hinzu ${ }^{44}$ so wird erkennbar, dass wir für diese Länder in der Frühen Neuzeit ein Publikationsvolumen haben, das - ganz grob kalkuliert - um die 2 Millionen Titel changierte. ${ }^{45}$

42 Brandes, 1802 (wie Anm. 3), S. $196 f$.

43 Die Zahlenangaben nach Heiner Schnelling, Die Verzeichnisse der im deutschen Sprachraum erschienenen Drucke des 16., 17. und 18. Jahrhunderts, in: Bibliothek und Wissenschaft 43 (2010), S. 199-211.

44 Allein der English Short Title Catalogue umfasst für die Zeit von 1476 bis 1800 ca. 460.000 Titel: http:// estc.bl.uk (letzte Einsicht: 26.05.2014). Vgl. auch Michael F. Suarez, Towards a bibliometric analysis of the surviving records, 1701-1800, in: Michael F. Suarez / Michael L. Turner (Hg.), The Cambridge History of the Book in Britain, Bd. 4: 1695-1830, Cambridge 2009, S. 39-65.

45 Die Gesamtzahl der in der Frühen Neuzeit publizierten Titel dürfte bei 3 Millionen gelegen haben. So 
Nun gab es aber im 16. und 17. Jahrhundert und auch noch zu Beginn des 18. Jahrhunderts - von einigen Ausnahmen abgesehen - kaum große Bibliotheken oder Sammlungen, die 50.000 Bände oder mehr zählten. ${ }^{46}$ Natürlich gab es die Vaticana und größere Hofbibliotheken in den Zentren der damaligen Großmächte, im Paris der Bourbonen und im Wien der Habsburger. ${ }^{47}$ Und es gab die höfische Ausnahmebibliothek par excellence, diejenige in Wolfenbüttel, wo Herzog August zu Braunschweig-Lüneburg sich persönlich als Bibliothekar betätigte und bis 1666135.000 Titel in 35.000 Bänden erworben hatte. ${ }^{48}$ Doch das waren, wie gesagt, Ausnahmen. Bibliotheken in nennenswerter Zahl, die in repräsentativer und systematischer Auswahl kontinuierlich das publizierte Wissen der Zeit sammelten, gab es nicht. Es gab indes einen gut funktionierenden Buchmarkt wie die Zahl der publizierten Titel belegt. Wo blieben also all die gedruckten Bücher? Wer sammelte sie? Es war im Wesentlichen die Landschaft der bibliotheca privata, der Privatbibliotheken, für die der Buchmarkt agierte; Bibliotheken von Gelehrten und Sammlern, die meist nur einige tausend Bände umfassten, die aber in ihrer Streuung neben den Klosterbibliotheken die umfassendste Bibliothekslandschaft der Frühen Neuzeit darstellten. ${ }^{49}$

Im Laufe des 18. Jahrhunderts begann sich indes die Diskrepanz zwischen dem Buchmarkt und der Zahl und Größe der bibliotheca publica zu verändern. Spätestens seit der Mitte des Jahrhunderts kam es gleichsam zu einem take-off der großen öffentlichen Bibliotheken. ${ }^{50}$ Dresden war neben Göttingen einer der zentralen Orte. Denn dort wurde sowohl die Bünausche als auch die Brühlsche Bibliothek vom sächsischen Kurfürsten für seine Hofbibliothek erworben, die damit auf einen Schlag zu einer der größten Bibliotheken im Reich avancierte - um 1800 zählte sie ca. 220.000 Bände.

umfasst die Heritage of the Printed Book Database, c.1455-c.1830 mittlerweile über 3 Mio. Titeldaten: http://www.cerl.org/resources/hpb/main (letzte Einsicht: 26.05.2014).

46 Auch David McKitterick, Old Books, New Technologies. The Representation, Conservation and Transformation of Books since 1700, Cambridge 2013, S. 20, weist darauf hin, dass es im 17. Jahrhundert umfassende Sammlungen mit nationalem Anspruch noch nicht gab.

47 Vgl. Simon Balayé, La Bibliothèque Nationale des origines à 1800, Histoire des idées et critique littéraire 262, Genf 1988; Josef Stummvoll (Hg.), Geschichte der Österreichischen Nationalbibliothek, Bd. 1: Die Hofbibliothek (1368-1922), Museion. Veröffentlichungen der Österreichischen Nationalbibliothek N.F. 3,1, Wien 1968.

48 Zuletzt dazu Werner Arnold, Identität durch Bücher. Fürstenbibliotheken in der Frühen Neuzeit, in: Wolfenbütteler Notizen zur Buchgeschichte 36,2 (2011), S. 91-108.

49 Vgl. Wilfried Enderle, Bibliotheken und die Genese der Sammlungskultur in der Frühen Neuzeit, in: Klaus-Rainer Brintzinger / Ulrich Hohoff (Hg.), 101. Deutscher Bibliothekartag in Hamburg 2012. Bibliotheken: Tore zur Welt des Wissens, Hildesheim / Zürich / New York 2013, S. 303-316, hier S. $313 f$.

50 Jonathan I. Israel, Radical Enlightenment. Philosophy and the Making of Modernity 1650-1750, Oxford 2001, S. 119-127, bezeichnet die Zeit von 1670 bis 1750 als die klassische Phase der Universalbibliothek, die aber vor allem durch Privatbibliotheken realisiert wurde. Große öffentliche Universalbibliotheken waren in dieser Phase indes selten und auch Israel konstatiert, dass es um 1750 insofern eine Wende gab, als jetzt zunehmend klar war, dass nur noch Regenten, große Institutionen oder allenfalls sehr vermögende Personen in der Lage waren, Bibliotheken mit universalem Sammelanspruch aufzubauen und zu unterhalten. 
Mit Francke verfügte sie zeitweise über einen der profiliertesten Bibliothekare und seit 1787 war sie auch für die Öffentlichkeit zugänglich. ${ }^{51}$ Nicht minder ehrgeizig waren die bibliothekarischen Ambitionen des württembergischen Herzogs Karl Eugen, der seit den 1760er Jahren die Gründung einer öffentlichen Bibliothek vorantrieb, die seit 1765, zunächst in Ludwigsburg und ab 1777 in Stuttgart öffentlich zugänglich war. ${ }^{52} 1781$ hatte er sogar persönlich Göttingen besucht und einen ganzen Nachmittag lang die Bibliothek besichtigt. ${ }^{53}$ Der Herzog selbst kümmerte sich aktiv um den Ausbau seiner Sammlung und brachte die Bibliothek bis zu seinem Tod 1793 auf einen Bestand von gut 100.000 Bänden. ${ }^{54}$ Vergleichbar rasch war der Aufbau am Hof im benachbarten Mannheim bei den pfälzischen Wittelsbachern verlaufen: 1756 gegründet, war sie um 1800 ebenso groß wie das württembergische Pendant. ${ }^{55}$ In Berlin investierte Friedrich II. nach dem Ende des Siebenjährigen Krieges in die von ihm bis dahin eher vernachlässigte Hofbibliothek auf einen Schlag erhebliche Mittel und ließ sogar ein eigenes Bibliotheksgebäude dafür errichten. ${ }^{56}$ In Stuttgart, Mannheim und Berlin fand der Auf- und Ausbau der höfischen Bibliotheken übrigens im Kontext von bestehenden oder neugegründeten Akademien oder - im Falle Stuttgarts - der hohen Karlsschule statt - und erklärt damit bis zu einem gewissen Grad das jeweilige Interesse. Doch nicht nur in den größeren Residenzstädten gab es ehrgeizige Bibliotheksprojekte. 1782 besuchte Pütter, zu dieser Zeit schon einer der renommiertesten Rechtsgelehrten im Reich, das Augustinerstift Polling in Oberbayern, und berichtete in seiner Autobiographie: Am meisten hatte ich Ursache, die Bibliothek zu bewundern, sowohl wegen ihrer äußerlichen zweckmäßigen Einrichtung, als wegen Auswabl ihrer Bücher, worunter viele von protestantischen Schriftstellern waren. ${ }^{57} \mathrm{Ob}$ es nun die Verwunderung darüber war, dass die Pollinger Mönche auch Bücher protestantischer Autoren sammelten, oder ob Pütters positive Meinung vor allem daher rührte, dass er mit Befriedigung feststellen konnte, dass auch seine eigenen Bücher in der Pollinger Bibliothek vorhanden waren, ${ }^{58}$ sei dahingestellt. Faktum war, dass die im Laufe des

51 Vgl. Leyh, Die deutschen Bibliotheken, S. 43ff; Karl Assmann, Die Anfänge der Sächsischen Landesbibliothek, in: Ders. (Hg.), Sächsische Landesbibliothek Dresden 1556-1956. Festschrift zum 400-jährigen Bestehen, Leipzig 1956, S. 15-25; immer noch grundlegend: Friedrich Adolf Ebert, Geschichte und Beschreibung der königlichen öffentlichen Bibliothek zu Dresden, Leipzig 1822, hier v.a. S. 87-114.

52 Karl Löffler, Geschichte der Württembergischen Landesbibliothek, Leipzig 1923, S. 6-10.

53 Pütter, Selbstbiographie, Bd. 2, S. $712 \mathrm{ff}$.

54 Vgl. Leyh, 1957 (wie Anm. 18), S. 48ff.; Löffler, 1923 (wie Anm. 52), S. 22-39.

55 Vgl. Leyh, 1957 (wie Anm. 18), S. 50 f.

56325 Jahre Staatsbibliothek in Berlin. Das Haus und seine Leute. Buch und Ausstellungskatalog, Berlin 1986, S. 77ff.; Horst Kunze / Werner Dube, Zur Vorgeschichte der Deutschen Staatsbibliothek, in: Deutsche Staatsbibliothek 1661-1961, Bd. 1: Geschichte und Gegenwart, Leipzig 1961, S. 10ff. u. 14ff; Leyh, 1957 (wie Anm. 18), S. $41 \mathrm{ff}$.

57 Pütter, 1798 (wie Anm. 7), S. 741.

58 Pütter, 1798 (wie Anm. 7), S. 742. 
18. Jahrhunderts, insbesondere unter Abt Franz Töpsl, der von 1744 bis 1796 amtierte, die auf 80.000 Bände ausgebaute Bibliothek des Klosters eine der bedeutendsten Sammlungen ihrer Art im Alten Reich war. ${ }^{59}$

Dieser bibliothekarische take-offfand nicht nur in Deutschland statt. In London wurde ebenfalls Mitte des 18. Jahrhunderts mit dem Aufbau zweier großer Bibliotheken begonnen: der des British Museums und der Privatbibliothek Georgs III. 1753 wurde das British Museum durch einen Beschluss des Parlaments gegründet, dessen Bibliothek in den nächsten Jahrzehnten mit Mitteln des Parlaments immer wieder größere Privatsammlungen erwerben konnte. Damit lag der Schwerpunkt zunächst auf dem Erwerb wertvoller Manuskripte und Sammlungen älterer Drucke. ${ }^{60}$ Doch wurde die Bibliothek des British Museum in gewisser Weise ergänzt durch die von Georg III. gegründete Privatbibliothek, der später sogenannten King's Library. Denn sie war als Gebrauchsbibliothek für Gelehrte angelegt, hier ging es nicht vorrangig um den Erwerb rarer Drucke, sondern um die zeitgenössische Literatur, die für Gelehrte von Belang war. ${ }^{61}$ Von 1760 bis 1820 gab Georg III. ein Fünftel seines Privatvermögens für seine Bibliothek aus, die zuletzt ca. 65.000 Bände umfasste. Ein gedruckter Katalog, der nicht öffentlich verlegt, aber anderen Herrschern sowie ausgewählten Bibliotheken geschenkt wurde, ${ }^{62}$ dokumentierte den Umfang und die Bedeutung dieser Sammlung, die zwar als private Bibliothek gegründet, von Anfang an aber als nationale Ressource verstanden wurde und in der Regel Gelehrten auch offenstand. ${ }^{63} \mathrm{Als}$ sie Georg IV. der Bibliothek des British Museum überließ, war sie endgültig integraler Teil der zentralen nationalen Sammlungseinrichtung. ${ }^{64}$

59 Fridolin Dreßler, Die Pollinger Bibliothek: Neuorganisation einer Klosterbibliothek aus dem Geist des 18. Jahrhunderts, in: Ders. / Ladislaus Buzas / Hermann Wiese (Hg.), Zur Geschichte der Pollinger Bibliothek, Pollinger Drucke 4, Murnau 1978, S. 7-14. Zum Kontext vgl. Ludwig Hammermayer, Das Augustiner-Chorherrenstift Polling und sein Anteil an Entstehung und Entfaltung von Aufklärung und Akademie- und Sozietätsbewegung im süddeutsch-katholischen Raum (ca. 1717 - 1787), Schriftenreihe der Akademie der Augustiner-Chorherren von Windesheim 2, Paring 1997; Alois Schmid, „Religioni, scientiis, artibus dedicatum". Oberdeutsche Klosterbibliotheken des Barock, in: Bibliothek und Wissenschaft 45 (2012), S. 11-37.

60 P. R. Harris, A History of the British Museum Library 1753-1973, London 1998.

61 John Brooke, The Library of King George III., in: The Yale University Library Gazette 52 (1978), S. 33-45; Graham Jefcoate, 'Most curious, splendid and useful'. The King's Library of George III., in: Kim Sloan / Andrew Burnett (Hg.), Enlightenment. Discovering the World in the Eighteenth Century, London 2003, S. 38-45. Georg III. nutzte dafür auch seine bibliothekarischen Ressourcen im Kurfürstentum Hannover, ließ er sich doch von Heyne jährlich Listen mit neueren deutschen Publikationen schicken (Heeren, 1813 (wie Anm. 28), S. 342). Auch der Bibliothekar der Hofbibliothek in Hannover, Johann Georg Jung, arbeitete ihm zu (Werner Ohnsorge, Zweihundert Jahre Geschichte der Königlichen Bibliothek zu Hannover (1665-1866), Veröffentlichungen der Niedersächsischen Archivverwaltung 14, Göttingen 1962, S. 54).

62 Frederic Aug. Barnard, Bibliothecae Regiae Catalogus, 5 Bde, London 1820-1829.

63 Jefcoate, 2003 (wie Anm. 61), S. 42.

64 Harris, 1998 (wie Anm. 60), S. 31 f. 
Die Göttinger Bibliothek war, wenn man sie im Kontext anderer großer Bibliotheken betrachtet, also alles andere als eine Ausnahmeerscheinung. Sie war kein singulärer Fall, im Gegenteil, sie war Teil eines allgemeinen take-offs großer Bibliotheken, eines bis dahin beispiellosen bibliothekarischen Aufbruchs. Jetzt erst entstanden in Europa große, universale Bibliotheken, die dafür sorgten, dass nicht nur das ältere Schrifttum, sondern auch die aktuellen Publikationen systematisch gesammelt wurden. Jetzt erst wurde der Grundstock für eine umfassende Überlieferung des publizierten Wissens gelegt, indem zum einen Sammlungen aus der Landschaft der Privatbibliotheken in den Bereich der öffentlich finanzierten großen Bibliotheken übernommen wurden; und diese zum anderen begannen, selbst kontinuierlicher die neue, aktuelle Literatur zu sammeln. Die zunehmende Dynamik der Wissenschaftsbewegung des 18. Jahrhunderts, die Bedeutung die Wissen, insbesondere neues Wissen erhielt, dürfte einer der wesentlichen Gründe für diesen bibliothekarischen take-off gewesen sein, der sich in der Herausbildung großer Bibliotheken von überregionaler Bedeutung manifestierte. Organisatorisch getragen wurden sie in der Regel von den administrativen Zentralinstanzen eines Landes. Sie hatten damit von vorneherein eine Ausstrahlung, die über den jeweiligen Ort selbst hinausreichte. Wenn Heyne 1810 von der Göttinger Bibliothek sprach, so war es für ihn ein nicht bloß academische[s], sondern National-Institut. ${ }^{65}$ Und Jeremias David Reuß, der Nachfolger Heynes, nannte in den 1820er Jahren die Bibliothek mitunter ein vaterländisches literarisches Institut. ${ }^{66}$ Bei beiden klingt damit das Selbstverständnis der Göttinger Bibliothekare an, das Bewusstsein, zu der Liga der großen bibliotheca publica von nationaler Bedeutung zu gehören. Es gehörte freilich zu den Spezifika Göttingens, dass diese große öffentliche Bibliothek Institut einer Universität war - und sich in dieser Hinsicht deutlich von der Mehrheit der anderen großen Bibliotheken unterschied. Dazu hatte bis zu einem gewissen Grade auch die besondere Situation der Personalunion beigetragen.

\section{Exkurs: Die „welfische Bibliothekspolitik“ oder die „Royal Library at Goettingen“}

Als Georg I. 1714 nach London ging, ließ er in Hannover eine Hofbibliothek zurück, die mit Leibniz zwar einen berühmten Bibliothekar hatte, aber von diesem fast wie eine Privatbibliothek geführt wurde. Von einer öffentlichen Nutzung durch andere Gelehrte konnte damals jedenfalls keine Rede sein. ${ }^{67}$ Der Hof in London

65 Göttingische Gelehrte Anzeigen, 1810, S. 850.

66 SUB Göttingen, Cod. Ms. philos. 169:3, Bl. 9r; Geschichte der Göttinger Universitäts-Bibliothek, 1937, S. 184.

67 Ohnsorge, 1962 (wie Anm. 61), S. 26-31 und 35. Vgl. auch Thomas Fuchs, Barocke Wissensordnung und aufgeklärter Denkstil. Leibniz und die Bibliotheken in Göttingen und Hannover, in: Bibliothek und 
wiederum hatte im Unterschied zu den kontinentalen Höfen keine eigenen großen Sammlungen aufgebaut. Es gab keine höfische Kunst- und Wunderkammer ${ }^{68}$ und die Hofbibliothek, die es gab, war klein und bestand vorwiegend aus wertvollen älteren Handschriften und alten Drucken, wurde aber nicht weiter gepflegt. ${ }^{69}$ Das hieß nun aber nicht, dass die Förderung von Bibliotheken nicht zum mäzenatischen Programm der Höfe in London oder Hannover gehört hätte. Sie floss nur nicht primär in den Aufbau klassischer, zentraler und repräsentativer Hofbibliotheken. Bereits 1715, ein Jahr nach seinem Regierungsantritts in London, kaufte Georg I. die berühmte Privatbibliothek von John Moore, des Bischofs von Ely, mit knapp 30.000 Bänden eine der bedeutendsten Gelehrtenbibliotheken der Zeit, und schenkte sie der Bibliothek der Universität Cambridge ${ }^{70}$ - ein politisches Zeichen übrigens, hatte sich Cambridge doch anders als die Tory- und Jakobiten-Hochburg Oxford von Anfang an auf die Seite des neuen Königshauses geschlagen. ${ }^{71}$ Folgt man dem Urteil David McKittericks, dem derzeit besten Kenner britischer Buch- und Bibliotheksgeschichte, so stieg die Universitätsbibliothek von Cambridge in England damit zu einer Bibliothek von nationaler Bedeutung auf. ${ }^{72}$ Georg II. interessierte sich bei seinen regelmäßigen Besuchen in Hannover durchaus für den Ausbau seiner dortigen Hofbibliothek ${ }^{73}$ - und er ließ, wie wir wissen, seinem ersten Minister freie Hand beim großzügigen Ausbau der Bibliothek in Göttingen. Als vom Parlament das British Museum begründet worden war, zeigte sich der König ebenfalls großzügig: die bis dahin bestehende Bibliothek

Wissenschaft 41 (2008), S. 3-16, hier S. 9: „Er betrieb im Erwerb nicht den Aufbau einer höfischen, sondern einer wissenschaftlichen, man könnte sagen, Privatbibliothek." Zu Leibniz als Bibliothekar vgl. Karin Hartbecke (Hg.), Zwischen Fürstenwillkür und Menschheitswohl - Gottfried Wilhelm Leibniz als Bibliothekar, Zeitschrift für Bibliothekswesen und Bibliographie 95, Frankfurt am Main 2008.

68 Die einschlägige Literatur zu frühneuzeitlichen Kunst- und Wunderkammern verweist immer wieder darauf, dass in London eine zu kontinentaleuropäischen Höfen vergleichbare Entwicklung fehlt, was zumindest teilweise auch an den Folgen des englischen Bürgerkriegs lag. Vgl. Ken Arnold, Cabinets for the Curious. Looking Back at Early English Museums, Aldershot / Burlington 2006, S. 21; Arthur MacGregor, The Cabinet of Curiosities in Seventeenth-Century Britain, in: Oliver Impey / Arthur MacGregor (Hg.), The Origins of Museums. The Cabinet of Curiosities in Sixteenth- and Seventeenth Century Europe, Oxford 1985, S. 147.

69 T.A. Birrell, English Monarchs and their Books. From Henry VII. to Charles II., London 1987; Harris, 1998 (wie Anm. 60), S. 6.

70 David McKitterick, Cambridge University Library. A History. The Eighteenth and Nineteenth Centuries, Cambridge u. a. 1986, S. 50f.

71 Heather Ellis, Generational Conflict and University Reform. Oxford in the Age of Revolution, History of Science and Medicine Library 31, Leiden / Boston 2012, S. 22 f.

72 McKitterick, 1986 (wie Anm. 70), S. 17.

73 Ohnsorge, 1962 (wie Anm. 61), S. 39f. Die Situation der Hofbibliothek in Hannover begann sich unter den Nachfolgern von Leibniz zwar etwas zu ändern - ab 1720 war die Bibliothek auch öffentlich zugänglich. Georg II. ließ die Bibliothek durch Münchhausen auch fördern und visitierte sie selbst zweimal, es blieb aber ein Bestandsschwerpunkt auf der welfischen Hausgeschichte. Und für Münchhausen stand nach der Gründung der Göttinger Universität die dortige Bibliothek im Zentrum. 
des Hofes in London wurde 1757 an die neue Einrichtung gegeben. ${ }^{74}$ Und Georg III. schuf, wie bereits erwähnt, aus seinem Privatvermögen die King's Library.

Eine ,welfische Bibliothekspolitik' im eigentlichen Sinne gab es natürlich nicht. Doch gehörte die Förderung von Bibliotheken auch bei den Welfen zum klassischen mäzenatischen Programm einer regierenden Dynastie. Aufgrund der spezifischen Situation in London, der fehlenden großen Hofbibliothek, fokussierte sich ihre Bibliothekspolitik jedoch auf die Förderung gelehrter Sammlungen außerhalb des Hofes. In England war es die Universität in Cambridge und die Bibliothek des British Museum, die davon profitierten, in Kurhannover die Universität Göttingen. Auch aus dieser Perspektive zeigt sich, dass Göttingen nicht dem gängigen Muster einer Universitätsbibliothek entsprach, sondern nur über ihre enge Verbindung zum Hof, in diesem Fall repräsentiert durch die Geheimen Räte in Hannover, verstanden werden kann. Für den Drucker des königlichen Printing Office in London scheint die Sache jedenfalls klar gewesen zu sein: Wenn er Bücher für die Göttinger Bibliothek packte, adressierte er sie schlicht und einfach an die „Royal Library at Goettingen“.75

\section{IV. „Organisation ist alles“ _ Die Blütezeit der Universitätsbibliothek Göttingen 1770-1820}

Nach dem Tode Münchhausens im Jahre 1770 geschah ein kleines bibliothekarisches Wunder. Die großzügige Förderung der Göttinger Bibliothek durch die Geheimen Räte in Hannover wurde fortgesetzt. Jetzt hieß der Mäzen der Regierung Georg Friedrich Brandes - aus Sicht der Göttinger Bibliothek eine Idealbesetzung, war Brandes doch selbst ein leidenschaftlicher Büchersammler. ${ }^{76}$ Die Arbeitsteilung sah nun so aus, dass Heyne selbst die Auswahl und Bestellung der Bücher vornahm, die Rechnungen aber nach Hannover schickte. ${ }^{77}$ Auch jetzt war es, wie in der Ära Münchhausen, wieder eine enge persönliche Beziehung, diesmal von Brandes und Heyne, welche die Grundlage für die special relationship zwischen dem Kollegium der Geheimen Räte und der Göttinger Bibliothek bildete. Dass Heyne 1777 in zweiter

74 Harris, 1998 (wie Anm. 60), S. 3.

75 SUB Göttingen, 4 Cod. Ms. philos. 169:4, 23. Jan. 1824, Bl. 144: H. M. Arthur presents his [...] compliments to Sir Lewis Moeller, and acquaints him that there is no new Publication by the Commissioner of Public Records since the last Delivery of Books from them to the Royal Library at Goettingen.

76 Zu Brandes vgl. Gabriele Crusius, Aufklärung und Bibliophilie. Der Hannoveraner Sammler Georg Friedrich Brandes und seine Bibliothek, Beihefte zum Euphorion 54, Heidelberg 2008; Dies., Sammelkultur im Geist der Aufklärung. Die Bibliothek des Hannoveraner Beamten Georg Friedrich Brandes in der Landesbibliothek Oldenburg, Schriften der Landesbibliothek Oldenburg 51, Heidelberg 2010.

77 Hartmann, 1937 (wie Anm. 10), S. 75. 
Ehe eine Tochter von Brandes heiratete, unterstreicht nur, wie eng öffentliche Geschäfte und private Verbindungen miteinander verquickt waren. ${ }^{78}$

Der Ruf, den sich die Bibliothek unter den Zeitgenossen erwarb, geht im Wesentlichen auf die Ära von Heyne zurück. Auch wenn die Göttinger Bibliothek kein Einzelfall war, sondern Teil eines allgemeinen take-offs großer öffentlicher Bibliotheken, so nahm sie doch unter diesen eine besondere Stellung ein. Denn Göttingen war eine große öffentliche Bibliothek an einer Universität; einer Universität zudem, die von ihren Kuratoren gezielt zu einer der ersten in Deutschland ausgebaut wurde. ${ }^{79}$ Für die Bibliothek bedeutete dies, dass sie in einem höheren Maße als andere große Bibliotheken funktionsfähig sein musste, brauchbar für die Bedürfnisse der Gelehrten wie der Studenten. Und das hieß konkret: Der große Bestand an Büchern musste effektiv administriert werden; und vor allem musste die Wissensbasis, die er darstellte, für den gelehrten Betrieb erschlossen werden. Beides, Administration und Wissen, hing unmittelbar und untrennbar zusammen. Wissen bedurfte - und bedarf - vor allem guter Organisation.

Die effiziente Administration einer großen Bibliothek hatte bereits im 18. Jahrhundert viele Facetten, wie nicht zuletzt die Preisfrage der Königlichen Sozietät der Wissenschaften zu Göttingen von 1773 zeigt, hinter der vermutlich Heyne als deren Sekretär steckte. Sie lautete: Wie vielerley Arten von Insekten giebt es, die den Urkunden und Büchern in Archiven und Bibliotheken schädlich sind ${ }^{80}$ Die Insekten waren natürlich nicht das zentrale Problem für Heyne. Die größte Herausforderung bestand in der praktischen Organisation eines Bestandes von über 60.000 Büchern, der jährlich um ca. 2.000 weitere anwuchs. Nun gab es aber kaum Vorbilder dafür, wie Bibliotheken, die 50.000 Bände und mehr umfassten, in der Praxis effizient organisiert werden sollten. Natürlich hatte die zeitgenössische Bibliothekstheorie eine Vorstellung davon, wie eine große Universalbibliothek beschaffen und organisiert werden sollte. ${ }^{81}$

78 Vgl. Heeren, 1813 (wie Anm. 28), S. 181f.; Michel Espagne, Leseerfahrungen in Hannover und Göttingen. Die Korrespondenz zwischen Brandes und Heyne 1764-1774, in: Hans Erich Bödeker / Philippe Büttgen / Michel Espagne (Hg.), Die Wissenschaft vom Menschen in Göttingen um 1800. Wissenschaftliche Praktiken, institutionelle Geographie, europäische Netzwerke, Veröffentlichungen des Max-Planck-Instituts für Geschichte 237, Göttingen 2008, S. 47-68.

79 Notker Hammerstein, Göttingen. Eine deutsche Universität im Zeitalter der Aufklärung, in: Alexander Patschovsky / Horst Rabe, Die Universität in Alteuropa, Konstanzer Bibliothek 22, Konstanz 1994, S. 169-182, hier S. 173; Anne Saada, Assurer l'excellence d'une communauté universitaire. L'exemple de Göttingen au 18e siècle, in: Dix-Huitème Siècle 41 (2009), S. 305ff.

80 Hannoverisches Magazin 12 (1774), S. 1457. Angenommene Antwortschriften sind gedruckt in Hannoversches Magazin 12 (1774), S. 1457-1502; 13 (1775), S. 177-212 und S. 433-462.

81 So sollte sie systematisch aufgestellt sein, damit die Bibliothek als Ganzes ein Bild des in ihr enthaltenen Wissens darstellen konnte. Der in der Bibliothek dokumentierte Fortschritt des Wissens sollte zudem durch einen sogenannten Realkatalog, einen systematischen Katalog, abgebildet werden, der neben dem als grundlegendem Erschließungsinstrument unabdingbaren alphabetischen Katalog vor allem in Deutschland eine hohe Wertschätzung genoss. Das höchste Ziel einer guten Bibliothek war dabei, wenn sie einmal 
Dieses theoretische Modell, das im Wesentlichen bereits im 17. Jahrhundert ausgearbeitet worden war, war freilich das eine, die Praxis in den großen Bibliotheken, die ab 1750 aufgebaut wurden, häufig etwas anderes. Der organisatorische Schwachpunkt war dabei der Katalog. Dieser war unabdingbar, um die einzelnen Wissensobjekte der sich formierenden großen Sammlungen zu verwalten. Genau dafür fehlte aber die Erfahrung; und oft darüber hinaus das geeignete Personal. Als praktisches Hindernis erwies sich vor allem, dass das Ideal des angestrebten Katalogs eine gedruckte Ausgabe oder zumindest ein handschriftlicher Bandkatalog war. War ein solcher Katalog einmal erstellt, war es schwierig, ihn aktuell zu halten. Das Resultat war, dass alle großen Bibliotheken immer wieder umfangreiche Bestände hatten, die nicht katalogisiert und damit nur eingeschränkt benutzbar waren. Ständig gab es daher neue Katalogprojekte, um Abhilfe zu schaffen, die dann aber ebenso rasch veralteten wie ihre Vorgänger. ${ }^{82}$ Es gab mit anderen Worten in der zweiten Hälfte des 18. Jahrhunderts noch kein Modell, keine Routine, wie man mit dem Phänomen der großen und oft in Schüben ausgebauten Bibliotheken organisatorisch umgehen sollte. Große Wissensbasen von 50.000 bis 200.000 Objekten zu verwalten war ein Novum.

so erschlossen worden war, den Katalog drucken zu lassen, um damit allen Gelehrten den Wert der Sammlung demonstrieren zu können. Wesentliche Merkmale dieses Konzepts sind bereits ausgebildet bei Gabriel Naudé, Advis pour dresser une bibliothèque, Paris 1627 (deutsche Übersetzung: Gabriel Naudé, Anleitung zur Einrichtung einer Bibliothek, Berlin 1978). Vgl. auch Dieter Schmidmaier, Die deutsche bibliothekswissenschaftliche Literatur in der Frühaufklärung. Versuch einer bibliographischen Auswertung, in: Werner Dube (Hg.), Über Bücher, Bibliotheken und Leser. Gesammelte Beiträge zum 60. Geburtstag von Horst Kunze, Leipzig 1969, S. 138-148; Ders., Die Entstehung der bürgerlichen Bibliothekswissenschaft. Versuch einer Würdigung aus der Literatur von 1600-1760, Veröffentlichungen des wissenschaftlichen Informationszentrums der Bergakademie Freiberg 55, Freiberg 1974; Kathrin Paasch, Die Ordnungen der Bücher in den Bibliotheken des 18. Jahrhunderts, in: Bodo-Michael Baumunk, Frühmoderne Bücherwelten. Die Bibliothek des 18. Jahrhunderts und das hallesche Waisenhaus, Katalog der Franckeschen Stiftungen 19, Halle 2007, S. 65-73.

82 Dies zeigt sich deutlich bei der Geschichte einzelner Bibliotheken. Die Bibliothek des British Museum in London legte 1787 den ersten gedruckten Katalog vor, der aber bereits bei Erscheinen als veraltet galt, so dass bereits 1819 der nächste gedruckt werden musste. Mit durchschossenen Blättern diente er dann für die nächsten 30 Jahre als Arbeitskatalog (vgl. Harris, 1998 (wie Anm. 60), S. 13 und 45ff.). Auch an der Hofbibliothek in Wien wurde, vor allem nach der Öffnung der Bibliothek unter Karl VI., das Fehlen eines Gesamtkataloges der Bestände schmerzhaft empfunden. Es dauerte bis 1772, bis ein als Provisorium verstandener zusammenfassender Bandkatalog der Druckwerke auf der Grundlage der Einzelrepertorien angelegt wurde, der dann bis 1825 benutzt wurde. 1780 wurde mit einem neuen Katalogprojekt begonnen, dem Josephinischen Katalog, einem im Grunde gescheiterten Katalogprojekt, da zwar die Bestände verzettelt wurden, die Absicht, daraus einen Bandkatalog zu erstellen, aber nicht mehr realisiert wurde. Unfreiwillig wurde aus dem gescheiterten Projekt damit der erste Zettelkatalog der Bibliotheksgeschichte (Geschichte der österreichischen Nationalbibliothek, S. 241; Markus Krajewski, Zettelwirtschaft. Die Geburt der Kartei aus dem Geiste der Bibliothek, copyrights 4, Berlin 2002, S. 45f. und 51ff.). In Dresden wurde nach der Integration der Bünauschen und der Brühlschen Bibliothek zunächst ohne Gesamtkatalog gearbeitet, der dann, nach der Öffnung der Bibliothek 1787 für die Öffentlichkeit, in Angriff genommen, aber erst von 1798 bis 1800 als Bandkatalog mit 53 engbeschriebenen Folioseiten fertiggestellt wurde. Die Arbeit an den Realkatalogen begann erst danach (Ebert, 1822 (wie Anm. 51), S. 111f.). Zusammenfassend zum Thema der Katalogproblematik vgl. Leyh, 1957 (wie Anm. 18), S. 121-131. 
Auch die Göttinger Bibliothek hatte daher, was oft übersehen wird, zunächst ihre Schwierigkeiten. In der Aufbauphase der 1740er und 1750er Jahre wurde nach dem klassischen Konzept der Bibliothekstheorie und der Praxis, wie man sie aus anderen Universitätsbibliotheken kannte, verfahren. Es gab keine Bibliothekare, sondern nur Gelehrte, Professoren, die sich nebenbei um die Bibliothek kümmern mussten. Und rasch mit dem Arbeitsanfall haderten. In Göttingen klagte Gesner schon 1746:

\section{Hätte ich gewußt, das zu der hiesigen Bibliotheckverwaltung etwas mehreres von Rechnungssachen, als eine simple Recognition des Empfangenen und eine Attesta- tion der Zettel gehörte, so würde gleich anfangs das Bibliothecariat in Unterthä- nigkeit deprecirt haben. ${ }^{83}$}

Aus heutiger Sicht war die Entwicklung der Bibliothek im 18. Jahrhundert eine kontinuierliche Erfolgsgeschichte. Für die Zeitgenossen war das Bild differenzierter. Die ersten Jahrzehnte waren immer wieder durch kleinere und größere Krisen geprägt, die sich im Laufe der 1760er Jahre verschärften. 1761 waren sowohl Gesner als auch Schlüter, der Mitarbeiter Münchhausens in Hannover, gestorben. Die Leitung der Bibliothek wurde dem Theologen und Orientalisten Johann David Michaelis, einem der renommiertesten Gelehrten der Universität, übertragen, der dazu aber keine rechte Neigung hatte. 1763 berief Münchhausen daher Heyne als dessen Vertreter nach Göttingen und dieser erhielt sofort den Auftrag, einen Bericht über den Stand der Bibliothek und Verbesserungsvorschläge zu erarbeiten. 1764 wurde Heyne, der sich mit seiner Denkschrift das Vertrauen Münchhausens erworben hatte, zum ersten Bibliothekar ernannt. Doch auch die Lösungsansätze Heynes griffen nicht sofort. 1776, zwölf Jahre nach seinem Amtsantritt, musste Heyne in einer weiteren Denkschrift zugeben, dass der alphabetische Katalog gänzlich unbrauchbar geworden sei. Bereits seit 1772 stockten die Einträge in den Realkatalog. Bis 1785 wuchsen die Rückstände auf 33.000 Bände. ${ }^{84}$ Die Göttinger Bibliothek steckte in einer Krise; einer Krise, wie sie für fast alle großen Bibliotheken der Zeit typisch war. In Göttingen gelang es indes und das war nicht typisch - der Probleme Herr zu werden. Die Wende leitete 1783 die Berufung von Jeremias David Reuß aus Tübingen ein, der als Professor für Literärgeschichte und Kustos der Bibliothek eingestellt wurde. ${ }^{85}$ Er war der erste Gelehrte in Göttingen, der seine Arbeitszeit weitgehend der Bibliothek und der Erschließung ihrer Bestände widmete - und innerhalb weniger Jahre die organisatorischen Defizite

83 Hartmann, 1937 (wie Anm. 10), S. 38f.

84 Hartmann, 1937 (wie Anm. 10), S. 129-138.

$85 \mathrm{Zu}$ Reuß vgl. Wilfried Enderle, Der Gelehrte als Bibliothekar im Netzwerk der Wissenskommunikation. Jeremias David Reuß (1750-1837) und die Bibliothek der Universität Göttingen, in: Steffen Hölscher / Sune Schlitte (Hg.), Kommunikation im Zeitalter der Personalunion (1714-1837). Prozesse, Praktiken, Akteure, Göttingen 2014 [Druck in Vorbereitung]. 
beseitigte. ${ }^{86}$ Jetzt erst stimmte das Diktum Osterhammels; jetzt erst war Göttingen in der Tat für einige Jahrzehnte die am besten organisierte Bibliothek der Welt.

Diese gute Organisation, die ab Mitte der 1780er Jahre erreicht wurde, hatte weitreichende Folgen. Sie sorgte dafür, dass Göttingen die erste unter den großen Bibliotheken des 18. Jahrhunderts war, deren Bestand, deren Wissensbasis nicht nur vollständig erschlossen worden war, sondern auch kontinuierlich weiter erschlossen wurde. Für die Gelehrten vor Ort war die Bibliothek damit mehr als ein Bücherschatz, sie war gleichsam eine große Suchmaschine des Wissens ihrer Zeit geworden. Das war eine nicht leicht zu überschätzende Leistung. Denn für die Gelehrten des 18. Jahrhunderts war die Beherrschung der Fülle des publizierten Wissens ein ebenso drängendes Thema wie es das heute ist. Wissen zu erschließen, den einmal erreichten Stand des Wissens zu dokumentieren, Wissenslücken zu kartieren, sich kontinuierlich über neues Wissen zu informieren - für all diese Aufgaben hatten die Gelehrten seit dem Ende des 17. Jahrhunderts zunehmend neue Instrumente entwickelt. ${ }^{87}$ Schon im 17. Jahrhundert hatten die Gelehrten sich Gedanken darüber gemacht, wie Wissen rational und systematisch organisiert und nutzbar gemacht werden könnte. Vor allem aufgrund der Rationalisierung und zunehmenden Verwissenschaftlichung des gelehrten Diskurses kam es auch zu Lösungen und zwar zu einer Vielzahl unterschiedlicher Versuche. Zwei der wichtigsten Instrumente, die genutzt wurden, waren Enzyklopädien und Periodika. Enzyklopädien und Lexika boten die Möglichkeit, Wissen zusammenzufassen, zu verdichten und den bis dato erreichten Stand zu dokumentieren. „Das Grosse vollständige Universal-Lexicon aller Wissenschaften und Künste“, der Zedler, wie die „Encyclopédie“ von Diderot und d'Alembert waren die berühmtesten Beispiele, aber bei weitem nicht die einzigen. ${ }^{88}$ Ein anderes Instrument, um Wissen zu organisieren, waren die gelehrten Zeitschriften. ${ }^{89}$ Das „Journal

86 Der alphabetische Katalog wurde vollständig neu geschrieben. Und auch der Realkatalog wurde neu begonnen. Das war zunächst nichts Neues, denn mit dieser Methode, die Kataloge von Zeit zu Zeit immer wieder neu zu erstellen, arbeiteten damals alle großen Bibliotheken. Was Reuß indes in Göttingen einführte, war etwas sehr Einfaches: ein Geschäftsgang, der dafür sorgte, dass kontinuierlich neue Bücher nach einem bestimmten System in alle Kataloge eingetragen wurden, die wiederum so angelegt worden waren, dass bei der Katalogisierung neuer Autoren jeweils ein neues Blatt eingelegt wurde, so dass der Bandkatalog gleichsam wie ein Zettelkatalog funktionierte. Vgl. Hartmann, 1937 (wie Anm. 10), S. $137 f$.

87 Vgl. Peter Burke, Papier und Marktgeschrei. Die Geburt der Wissensgesellschaft, Berlin 2001. Hinweise zu neuerer Literatur bei Marian Füssel, Auf dem Weg zur Wissensgesellschaft. Neue Forschungen zur Kultur des Wissens in der Frühen Neuzeit, in: Zeitschrift für historische Forschung 34 (2007), S. 273-289; Markus Völkel, ,Lob des Blüthenstaubs' oder ,musivisches Werk'? Neuerscheinungen auf dem Gebiet der Wissensgeschichte, in: Archiv für Kulturgeschichte 89 (2007), S. 191-216.

88 Vgl. Hans-Jürgen Lüsebrink, Enzyklopädismus und Kulturtransfer im Aufklärungszeitalter. Fallbeispiele und transkulturelle Perspektiven, in: Stefanie Stockhorst (Hg.), Epoche und Projekt. Perspektiven der Aufklärungsforschung, Das achtzehnte Jahrhundert 17, Göttingen 2013, S. 263-284; Ulrich Johannes Schneider (Hg.), Seine Welt wissen. Enzyklopädien in der Frühen Neuzeit, Darmstadt 2006.

89 Vgl. Thomas Habel, Gelehrte Journale und Zeitungen der Aufklärung. Zur Entstehung, Entwicklung und Erschließung deutschsprachiger Rezensionszeitschriften des 18. Jahrhunderts, Presse und Geschichte - 
des Savants“ und die „Philosophical Transactions“ der Royal Society in London, die beide seit 1665 erschienen, begründeten dieses Genre. Vor allem die zeitgenössischen Rezensionszeitschriften dokumentieren den Anspruch, die Erschließung aktuellen Wissens kontinuierlich zu organisieren. ${ }^{90}$

Die zeitgenössischen Bibliothekskataloge ordnen sich in diese Versuche, Wissen zu erschließen, ein. Genau hier, an diesem zentralen Bedürfnis der Gelehrten, setzte die Göttinger Universität an. Der Ruf der Göttinger Bibliothek gründete nicht zuletzt darin, dass es dank der einmal erreichten effizienten Organisation gelang, ein System zu implementieren, die eigene große Wissensbasis umfassend zu erschließen und der gelehrten Welt zu vermitteln. ${ }^{91}$ Wie dieses Göttinger System der Wissenserschließung aussah, hat Heyne 1810 in den „Göttingischen Gelehrten Anzeigen“ beschrieben, wonach Göttingen ein Palladium der gesammten wissenschaftlichen Gelehrsamkeit bleiben muß, so lange es seine Bibliothek und seine Societät, mit den Commentationen und gelehrten Anzeigen, [...] in gutem Zustande behält. ${ }^{22}$ Drei wissenserschließende Instrumente benennt Heyne: Die Bibliothek bildet den Ausgangspunkt, sie liefert die Wissensbasis, die durch ihre Aufstellung und die Kataloge von Reuß erschlossen und gut organisiert waren. Die wöchentlich erscheinenden „Göttingischen Gelehrten Anzeigen" erschlossen kontinuierlich die Auswahl der wichtigsten Erwerbungen der Bibliothek oder, anders formuliert, des wichtigsten, neu publizierten Wissens für die gesamte gelehrte Welt. Und was taten bzw. waren die „Commentationen“?

Sie waren eine besondere Leistung von Reuß. Denn er nutzte die Wissensbasis der Bibliothek, um das in Periodika und Akademieschriften enthaltene Wissen zu erschließen. ${ }^{93}$ Sein bibliographisches Hauptwerk war ein Verzeichnis der Schriften von Akademien und gelehrten Gesellschaften, das in sechzehn Bänden von 1801 bis 1821

Neue Beiträge 17, Bremen 2007.

90 Mit den „Göttingischen Anzeigen von gelehrten Sachen“ gelang es in Göttingen auch, nach dem Vorbild der seit 1715 in Leipzig erscheinenden „Neuen Zeitung von gelehrten Sachen“ eine Rezensionszeitschrift zu begründen, die in Deutschland neben der „Allgemeinen Deutschen Bibliothek“ des Berliner Verlegers Friedrich Nicolai in der zweiten Hälfte des 18. Jahrhunderts eine dominierende Stellung einnahm. Vgl. Enderle, 2005 (wie Anm. 41), S. 170.

91 Vgl. dazu auch Saada, 2011 (wie Anm. 21), S. 405f.

92 Göttingische Gelehrte Anzeigen, 1810, S. 860.

93 Er begann mit einem Verzeichnis englischer Autoren und ihren Werken, das 1791 und in erweiterter Fassung 1804 unter dem Titel „Das gelehrte England oder Lexikon der jetztlebenden Schriftsteller in Großbritannien, Irland und Nord-Amerika“ erschien. Vgl. dazu Bernhard Fabian, Die erste Bibliographie der Englischen Literatur des achtzehnten Jahrhunderts. Jeremias David Reuß’ Gelehrtes England, in: Ders. (Hg.), Selecta Anglicana. Buchgeschichtliche Studien zur Aufnahme der englischen Literatur in Deutschland im Achtzehnten Jahrhundert, Veröffentlichungen des Leipziger Arbeitskreises zur Geschichte des Buchwesens. Schriften und Zeugnisse zur Buchgeschichte 6, Wiesbaden 1994, S. 239-265 (ursprünglich in: Bertram Haller (Hg.), Festschrift für Gerhard Liebers, Bd. 1: Erlesenes aus der Welt des Buches. Gedanken, Betrachtungen, Forschungen, Wiesbaden 1979, S. 16-43). 
erschienene „Repertorium commentationum a societatibus litterariis editarum ${ }^{.94} \mathrm{Da}$ auf Praxis, auf das Nützliche fokussierte Forschung im 18. Jahrhundert stärker an Akademien angesiedelt war als an Universitäten, ist evident, dass ein solches Verzeichnis darauf abzielte, den Kernbestand des innovativen Wissens der Zeit zu erschließen. Die Wissensbasis des Bestandes der großen Göttinger Bibliothek, erschlossen durch die Kataloge und ihre systematische Aufstellung, die in Göttingen in systematischer Vollständigkeit gesammelten Akademieschriften, die Reuß in seinem Repertorium erschlossen hatte sowie als Drittes die von der Sozietät, der königlichen Gesellschaft der Wissenschaften, herausgegebenen „Göttingischen Gelehrten Anzeigen“ bildeten zusammen ein wissenserschließendes System, wie es in den Jahrzehnten um 1800 an keinem anderen Ort existierte. ${ }^{95}$ Und das letztlich mit den Ruhm der Göttinger Bibliothek wie der Universität begründete und deutlich macht, warum die Bibliothek das Hauptrad ist, die die ganze Maschine treibt. ${ }^{96}$ Dass sich ein solches wissenserschließendes System gerade in Göttingen ausgebildet hatte, lag entscheidend am Zusammentreffen einer großen, vom Landesherrn geförderten öffentlichen Bibliothek mit den Bedürfnissen einer neuen Universität.

Trotz der besonderen Rolle Göttingens aufgrund der Kombination große Bibliothek und Universität sollte man indes nicht übersehen, dass auch andere Universitätsbibliotheken in je unterschiedlicher Weise vom bibliothekarischen take-off seit den 1750er Jahren tangiert wurden. Und Göttingen war unter den europäischen Universitätsbibliotheken auch nicht die einzige große Bibliothek. Eine Universität, deren Bibliothekslandschaft in gewisser Weise eindrücklicher war als die Göttinger, war die der Universität in Oxford. Oxford und Cambridge haben als Universitäten bei den Historikern keinen guten Ruf. ${ }^{97}$ Diesen schlechten Ruf sollte man indes nicht einfach auf die Bibliotheken übertragen..$^{98}$ Beide Universitäten besaßen im 18. Jahrhundert eine durchaus eindrückliche Bibliothekslandschaft. Denn anders als in Göttingen gab

94 Vgl. dazu Enderle, 2014 (wie Anm. 85).

95 Zur Bedeutung der Verbindung von Universität, Göttingischen Gelehrten Anzeigen und Bibliothek und der strategischen Planung von Göttingen als Wissensort vgl. Enderle, 2005 (wie Anm. 41), S. 171f.; Eck, 2009 (wie Anm. 22), S. 171; Saada, 2010 (wie Anm. 21), S. 352; Dies., 2011 (wie Anm. 21), S. 395.

96 Briefe aus Göttingen, 1787 (wie Anm. 4), S. 125.

97 Vgl. Michael Maurer, Die Universitäten Englands, Irlands und Schottlands im 18. Jahrhundert. Intellektuelle, soziale und politische Zusammenhänge, in: Notker Hammerstein (Hg.), Universitäten und Aufklärung, Göttingen 1996, S. 243-272.

98 Charles Benson, Libraries in university towns, in: Giles Mandelbrote / K.A. Manley (Hg.), The Cambridge History of Libraries in Britain and Ireland, Bd. 2: 1640-1850, Cambridge 2006, S. 102-121, hier S. 103: "The libraries were one part of the universities which showed considerable improvements. The period was marked by an abundance of bequests and donations along with irregular purchases. Numerous catalogues were published; several imposing buildings were constructed and many others extended, and legal deposit was introduced." 
es dort nicht nur eine Bibliothek der Universität, sondern auch noch Bibliotheken der Colleges, die bei einem Vergleich immer mit zu berücksichtigen sind.

Besonders eindrücklich war im 18. Jahrhundert die äußere Entfaltung der Bibliotheken in Oxford. ${ }^{99}$ Für die Colleges von Christ Church $^{100}$ und All Souls ${ }^{101}$ entstanden neue, repräsentative Bibliotheksgebäude, dazu kam als markantester Bau die 1749 fertiggestellte Radcliffe Camera, die auf eine Stiftung von John Radcliffe zurückging. Mit der Bodleian Library besaß die Universität zudem auch eine bereits im 17. Jahrhundert renommierte Bibliothek, die 1714 ca. 30.000 Bände besaß, dazu einen Schatz von ca. 6.000 Handschriften. Ein Jahrhundert später waren es um die 150.000 Bände. ${ }^{102}$ Zählt man hierzu noch die Bestände der Collegebibliotheken hinzu, so konnte sich die Universität mit den großen Bibliotheken des Kontinents durchaus messen. ${ }^{103}$ Freilich, und hierin liegt ein entscheidender Unterschied zur Göttinger Konzeption, gingen in Oxford wie in Cambridge Repräsentation vor Organisation. In dieser Hinsicht bildete sich doch der Zustand der Universitäten in ihren Bibliotheken ab. Wenn man im 18. Jahrhundert in Großbritannien gut organisierte Bibliotheken suchte, musste man nach Edinburgh gehen, dem Zentrum der schottischen Aufklärung, wo es mit der Bibliothek der Universität und der Advocates Library zwei durchaus gut verwaltete und auf die Bedürfnisse der Gelehrten ausgerichtete Bibliotheken gab. ${ }^{104}$ Freilich reichten hier die Mittel nicht aus, um sie in die erste Liga der großen Sammlungen zu befördern.

Die fehlenden Mittel waren im Kern auch das entscheidende Problem und Handicap der Universitätsbibliotheken in Deutschland. ${ }^{105}$ Sieht man sich deren Entwicklung etwas genauer an, so zeigt sich aber durchaus, dass es nicht nur in Göttingen

99 Peter Freshwater, Books and universities, in: Giles Mandelbrote / K.A. Manley (Hg.), The Cambridge History of Libraries in Britain and Ireland, Bd. 2: 1640-1850, Cambridge 2006, S. 345-370; J. N. Myres, Oxford Libraries in the Seventeenth and Eighteenth Centuries, in: Francis Wormald / C.E. Wright (Hg.), The English Library before 1700. Studies in its History, London 1958, S. 236-255; Albert Predeek, Die englischen Bibliotheken seit der Reformation, in: Georg Leyh (Hg.), Handbuch der Bibliothekswissenschaft, Bd. 3.2: Geschichte der Bibliotheken, Wiesbaden 21957, S. 628-774.

100 Judith Curthoys, The Cardinal's College. Christ Church, Chapter and Verse, London 2012, S. 141, 183.

101 Edmund Craster, The History of All Souls College Library, London 1971.

102 Alex Noel-Tod, The Bodleian Library in the Eighteenth Century with Reference to Oxford College Libraries and the Radcliffe Library, Aberystwyth 1980; Ian Philip, The Bodleian Library in the Seventeenth and Eighteenth Centuries, Oxford 1983; Freshwater, 2006 (wie Anm. 99), S. 347.

103 Strickland Gibson, Some Oxford Libraries, Oxford 1914, S. 110: "Of the accumulate treasures in Oxford Libraries, treasures which are surpassed by those contained in but a few of the capital cities of Europe, this is not the place to speak at length."

104 C.P. Finlayson / S.M. Simpson, The History of the Library 1710-1837, in: Jean R. Guild / Alexander Law (Hg.), Edinburgh University Library 1580-1980. A Collection of Historical Essays, Edinburgh 1982, S. 55-66; Christine Shepherd, The Inter-Relationship between the Library and Teaching in the Seventeenth and Eighteenth Centuries, in: Jean R. Guild / Alexander Law (Hg.), Edinburgh University Library 1580-1980. A Collection of Historical Essays, Edinburgh 1982, S. 67-86.

105 Zur Literaturlage siehe Anm. 13. 
Gelehrte gab, die versuchten, ihre Bibliothek zu reorganisieren, die sich des bibliothekarischen take-offs der 1750er Jahre und der Bedürfnisse einer Universität nach der Organisation und Vermittlung von Wissen bewusst waren, denen aber die Universität oder der jeweilige Landesherr die nötige finanzielle Hilfe versagten. Ein Beispiel dafür, dass ein Gelehrter parallel zu Göttingen die Zeichen der Zeit erkannt hatte, bietet Johann Carl Dähnert, seit 1747 Professor für Wissenschaftsgeschichte und Bibliothekar an der Universität Greifswald. Er baute die dortige kleine Bibliothek von 5.000 Bänden, die er 1747 übernommen hatte, um das Vierfache aus, vor allem aber erschloss er sie in einem vorbildlichen Katalog, den er freilich mangels finanzieller Unterstützung durch die Universität auf eigene Kosten drucken ließ. ${ }^{106}$ Wie entscheidend für eine Bibliothek die Förderung der Universität durch den jeweiligen Landesherrn war, belegt auch das Beispiel der Universität in Kiel, wobei sich hier die 1773 erfolgte Übertragung des holsteinischen Landesteils an Dänemark positiv auswirkte. Denn die Regierung in Kopenhagen, der leitende dänische Minister Andreas Peter Bernstorff und der Kurator Detlev Reventlou, kümmerten sich, ähnlich wie Münchhausen und Brandes in Göttingen, aktiv und direkt um die Belange der Bibliothek und förderten deren Ausbau zeitweise mit Sondermitteln. ${ }^{107}$

Anders als bei Dähnert in Greifswald ist bei Kiel nicht auszuschließen, dass die Göttinger Bibliothek bereits eine gewisse Vorbildfunktion hat. ${ }^{108}$ Wir wissen von anderen Universitäten, dass seit den 1770er Jahren bei Reformen Göttingen als Vergleichsfolie eine große Rolle spielte. ${ }^{109}$ Wie sehr das Göttinger Modell auch als Konkurrenz und Ansporn wirken konnte, lässt sich besonders schön am Beispiel der Universität Jena zeigen. Vor der Gründung Göttingens war Jena die größte Universitätsbibliothek in Deutschland gewesen. Das lag nicht unwesentlich daran, dass die Bibliothek der Universität zugleich auch als Hofbibliothek für vier kleine sächsische

106 Siegfried Ulber, Johann Carl Dähnerts „Catalogus auctorum et Repertorium reale universalis“, in: Artur Bethke (Hg.), Johann Carl Dähnert (1719-1785). Bibliotheksgeschichtliche Beiträge anläßlich seines 200. Todestages, Veröffentlichungen der Universitätsbibliothek 17, Greifswald 1986, S. 35-42.

107 Rudolf Bülck, Geschichte der Kieler Universitätsbibliothek, Eutin 1960, S. 75-80. 1792 umfasste die Bibliothek dann immerhin bereits 40.000 Bände.

108 Spätestens in einem Gutachten von 1791 wird ausdrücklich auf das Göttinger Vorbild Bezug genommen. Vgl. Friedrich Adolf Schmidt-Künsemüller, C.F. Cramer und die Kieler Universitätsbibliothek, in: Alfred Kamphausen (Hg.), Schleswig-Holstein und der Norden. Festschrift für Olaf Klose zum 65. Geburtstag, Neumünster 1968, S. 193-201, hier S. 198.

109 So zum Beispiel von der Universität Freiburg. Vgl. Peter Schmidt, Die Universität Freiburg i.Br. und ihre Bibliothek in der zweiten Hälfte des 18. Jahrhunderts, Schriften der Universitätsbibliothek Freiburg im Breisgau 12, Freiburg 1987, S. 3 und 8. Vgl. generell auch Notker Hammerstein, Die deutsche Universitätslandschaft im ausgehenden 18. Jahrhundert, in: Gerhard Müller / Klaus Ries / Paul Ziche (Hg.), Die Universität Jena. Tradition und Innovation um 1800, Pallas Athene. Beiträge zur Universitäts- und Wissenschaftsgeschichte 2, Stuttgart 2001, S. 15; Gerrit Walther, Das Ideal: Göttingen. Ruf, Realität und Kritiker der Georgia Augusta um 1800, in: Gerhard Müller / Klaus Ries / Paul Ziche (Hg.), Die Universität Jena. Tradition und Innovation um 1800, Pallas Athene. Beiträge zur Universitäts- und Wissenschaftsgeschichte 2, Stuttgart 2001, S. 33. 
Fürstentümer fungierte. 1763 war die Bibliothek mit 50.000 Bänden, was den Bestand anging, für eine Universitätsbibliothek noch durchaus konkurrenzfähig, doch in den folgenden Jahrzehnten stagnierte die Entwicklung. ${ }^{110}$ Bereits 1785 gab es erste Überlegungen, wie man die Bibliothek wieder konkurrenzfähiger machen könnte, ohne die begrenzten Ressourcen des kleinen Sachsen-Weimar zu überdehnen. Fahrt nahm diese Idee indes erst auf, als sich 1801 der Geheime Rat von Goethe selbst einschaltete. So berichtete in diesem Jahr der neuberufene Jenaer Bibliothekar Johann Samuel Ersch dem Senat über eine Konferenz mit Goethe über Bibliotheksangelegenheiten. Sie betraf vorzüglich eine virtuelle Vereinigung der öffentlichen Bibliotheken zu Jena und Weimar, vermittelst eines gemeinschaftlichen, durchaus alphabetisch geordneten, Catalogs, der [...] auf einmal übersehen läßt, was in diesen Bibliotheken vorhanden ist. ${ }^{111}$ Der springende Punkt dieser Idee einer virtuellen Vereinigung war dabei, dass auf diese Weise unser Catalog einen solchen Umfang gewänne, daßer sich mit den Catalogen anderer Bibliotheken messen läßt. ${ }^{112}$ Und man kann vermuten, dass Goethe als Kenner und Nutzer der Göttinger Bibliothek genau diese im Blick hatte. ${ }^{113}$ Goethe engagierte sich in den folgenden Jahren auch intensiv für die Reorganisation der Universität Jena und ihrer Bibliothek, das Projekt des gemeinsamen Katalogs blieb freilich unvollendet und wurde 1824 ad acta gelegt. ${ }^{114}$

\section{Conclusio}

Selbst bei den in der Literatur so häufig geschmähten Universitätsbibliotheken kann man also bei genauerem Hinsehen gegen Ende des 18. Jahrhunderts Bewegung erkennen. Und richtet man den Blick über die Universitätsbibliotheken hinaus, so wird deutlich, dass man seit den 1750er Jahren, vor allem in Deutschland und Großbritannien, einen take-off großer öffentlicher Bibliotheken erkennen kann. Die Bibliothek der Göttinger Universität war mithin kein singuläres Ereignis, sondern Teil eines allgemeinen Trends. Freilich nahm sie bei diesem Trend eine besondere Stellung ein.

110 Othmar Feyl, Die neuzeitlichen Anfänge der Universitätsbibliothek Jena, in: Karl Bulling (Hg.), Geschichte der Universitätsbibliothek Jena 1549-1945, Weimar 1958, S. 141-224.

111 Karl Bulling / Georg Karpe, Die Universitätsbibliothek in der klassischen und nachklassischen Zeit 1800-1870, in: Karl Bulling (Hg.), Geschichte der Universitätsbibliothek Jena 1549-1945, Weimar 1958, S. 293-482, hier S. 307.

112 Bulling / Karpe, 1958 (wie Anm. 111), S. 308.

113 Helmut Rohlfing, „In der Gegenwart eines großen Capitals, das geräuschlos unberechenbare Zinsen spendet.“ Goethe und die Göttinger Bibliothek, in: Elmar Mittler / Elke Purpus / Georg Schwedt (Hg.), „Der gute Kopf leuchtet überall hervor." Goethe, Göttingen und die Wissenschaft, Göttingen 1999, S. 53-65.

114 Bulling / Karpe, 1958 (wie Anm. 111), S. 422ff. Zum Kontext vgl. Gerhard Müller, Perioden Goethescher Universitätspolitik, in: Gerhard Müller / Klaus Ries / Paul Ziche (Hg.), Die Universität Jena. Tradition und Innovation um 1800, Pallas Athene. Beiträge zur Universitäts- und Wissenschaftsgeschichte 2, Stuttgart 2001, S. 135-153. 
Und zwar dadurch, dass hier erstmals die Ressourcen eines Territoriums gezielt für den Aufbau einer großen Bibliothek an einer Universität und nicht am Hof selber eingesetzt wurden. Aus dieser Verbindung lassen sich auch die spezifischen Leistungen der Göttinger Universitätsbibliothek erklären: ihre gute Organisation, die sowohl die Benutzbarkeit des Bestandes durch die Gelehrten und Studenten vor Ort gewährleistete, als auch ihre wissenserschließenden Aktivitäten über die Kataloge vor Ort sowie die „Göttingischen Gelehrten Anzeigen“ und das Repertorium der Akademieschriften von Reuß. Damit ragte sie nicht nur unter den Universitätsbibliotheken ihrer Zeit hervor, sondern auch unter den anderen großen Bibliotheken, selbst wenn deren Bestände ansehnlicher waren als die in Göttingen. Diese Außenwirkung ihrer wissenserschließenden Aktivitäten nutzte die Göttinger Universität freilich auch gezielt, um das Bild einer Bibliothek zu vermitteln, deren rationaler und systematisch kalkulierter Bestandsaufbau in einmaliger Weise das relevante Wissen der Welt erschlossen hätte und gerade deswegen einen Schatz, eine Wissensbasis von nationaler Bedeutung darstellte.

Bei der Erfolgsgeschichte der Göttinger Bibliothek sollte man indessen nicht übersehen, dass es bis in die 1780er Jahre gedauert hatte, ehe es gelungen war, ein tragfähiges organisatorisches Konzept zu implementieren. Das Bild von der Bibliothek als der eine Weile am besten organisierten der Welt gilt im Grunde nur für die Jahrzehnte von 1780 bis 1820 .

Nach dem Ende des kurzlebigen Königreichs Westfalen gelang es der Universität nicht mehr, an das alte Modell der Sonderfinanzierung, das bis 1806 die Grundlage für den Erfolg der Bibliothek gebildet hatte, anzuknüpfen. Mit der Reduktion der Bibliothek auf ihren regulären Etat ging die Blütezeit der Bibliothek allmählich zu Ende. Es fällt auf, dass der damalige Leiter der Bibliothek, Jeremias David Reuß, in den 1820er Jahren sehr genau beobachtete, wie andere, konkurrierende Bibliotheken agierten. Als die königliche Bibliothek in Berlin in London intensiv Bücher erwarb, ließ er sich von der Deutschen Kanzlei darüber genau Bericht erstatten. ${ }^{15}$ Und 1830 schrieb er an Franz von Reden, damals Gesandter Hannovers in Berlin: Der Gedanke, und die Aussicht, daß die Königl. Bibliothek in Berlin die hiesige überflügeln möchte, macht mir oftmalen traurig-wehmütige Stunden. ${ }^{16}$ Göttingen hatte einen Beitrag ersten Ranges zur Etablierung und Modernisierung großer Bibliotheken beigetragen. Jetzt rezipierten die großen Hofbibliotheken wie auch andere Universitätsbibliotheken dieses Beispiel für ihre eigene Modernisierung. Es sollte freilich nicht die königliche Bibliothek in Berlin sein, welche im 19. Jahrhundert die Göttinger Bibliothek

115 SUB Göttingen, 4 Cod Ms Philos. 169, Bd. 4, Bl. 132f., 188f. und $203 f$.

116 SUB Göttingen, 4 Cod Ms Philos. 169, Bd. 5, Bl. 93v. 
als die in ihrer Art herausragende Einrichtung ablösen sollte, sondern die des British Museums in London. ${ }^{117}$

117 Zur Beziehung der Göttinger Bibliothek zur Bibliothek des British Museum vgl. Graham Jefcoate, „Not a Library for Research“. Antonio Panizzi und die Universitätsbibliothek Göttingen, in: Bibliothek und Wissenschaft 41 (2008), S. 45-55. Zur Geschichte der Bibliothek des British Museum im 19. Jahrhundert Harris, 1998 (wie Anm. 60); Edward Miller, Prince of Librarians. The Life and Times of Antonio Panizzi of the British Museum, London 1967. 



\title{
Im Netz der Dinge. \\ Kulturen des gelehrten Sammelns in der Personalunion
}

\author{
Dominik Collet
}

Frühe Museen haben in den letzten Jahren eine radikale Neuinterpretation erfahren. Wurden sie früher als obskure Sammelsurien betrachtet, interpretiert man sie heute als zentrale Wissensräume. Die neue Kulturgeschichte des Wissens versteht frühneuzeitliche Sammlungen als contact- oder trading-zones, die zentrale Akteure und Ideen trotz großer geographischer Distanzen miteinander in Berührung brachten. Die Exponate dieser Sammlungen lassen sich in diesem Zusammenhang als boundary objects auffassen, die den Austausch über soziale, religiöse, territoriale oder disziplinäre Grenzen hinweg organisierten. ${ }^{1}$ Diese Neubewertung ist heute so populär, dass eine rekonstruierte Kunst- und Naturalienkammer auch im Zentrum des Berliner Humboldtforums, des größten zeitgenössischen Kulturprojekts in Deutschland geplant ist. Sie soll dort andere, offenere Formen des Austauschs zwischen Deutschlands und der Welt illustrieren und materialisieren. ${ }^{2}$

Folgt man dieser Neubewertung, sollten Sammlungen und ihre Objekte auch für den Austausch innerhalb anderer transnationaler Netzwerke, wie etwa der Personalunion von Großbritannien und Kurhannover, ein vielversprechendes Untersuchungsfeld darstellen. Anhand der zwischen den beiden Territorien zirkulierenden Objekte lassen sich möglicherweise intensivere Formen des Austausches beobachten,

1 James Clifford, Museums as Contact Zones, in: Ders. (Hg.), Routes. Travel and translation in the late twentieth century, Cambridge, Mass. 1997, S. 188-219; Peter Galison, Image \& Logic. A Material Culture of Microphysics, Chicago 1997; Susan Starr / James R. Griesemer, Institutional Ecology, Translations and Boundary Objects. Amateurs and Professionals in Berkeley's Museum of Vertebrate Zoology, 1907-39, in: Social Studies of Science 13 (1989), S. 387-420; Daniela Bleichmar (Hg.), Collecting across cultures. Material exchanges in the early modern Atlantic world, Philadelphia 2011.

2 Vgl. zu der „Kunstkammer“ im Berliner Humboldtforum und der von ihr erhofften Umdeutung der früheren Berliner Kolonialmuseen in „Weltmuseen“: Friedrich von Bose, The making of Berlin's Humboldt-Forum. Negotiating history and the cultural politics of place, in: Darkmatter 11 (2013). http:// www.darkmatter101.org/site/category/journal/issues/11-afterlives/ (zuletzt aufgerufen am 1.11.2013). Für einen weniger politisierten, britischen Versuch, museale Objekte als Medien des globalen Wissenstransfers zu befragen, vgl. Neil MacGregor, A history of the world in 100 objects, London 2010. 
als sie von der politischen Ebene bekannt sind. Zudem werden eventuell auch jene bisher kaum erfassten Transfers sichtbar, die vom kleineren Landesteil Hannover aus in die britische Zentrale führten, wenn man das Untersuchungsfeld von Hof und Administration auf den lebhafteren Bereich von materieller Kultur und Wissen(schaft) erweitert. ${ }^{3}$

Allerdings verdeckt die neue Begeisterung für alte Sammlungen leicht, dass auch objektzentrierte Austauschprozesse mit gravierenden Herausforderungen einhergingen - insbesondere dann, wenn sie in den stratifizierten Gesellschaften des 17. und 18. Jahrhunderts stattfanden. Das Sammeln stellte eine außergewöhnlich gesellige Wissenspraxis dar. Es brachte notwendigerweise eine breite Gruppe von Agenten, Händlern, Informanten, Reisenden und Besuchern miteinander in Kontakt. Die Beteiligung solch unterschiedlicher Akteure besitzt sicherlich das Potential, unser Verständnis darüber zu erweitern, wer in der Personalunion neben dem Hofstaat die Träger von Austauschprozessen waren. Das Aufeinandertreffen einer derart heterogenen Gruppe von Akteuren barg aber auch ein hohes Konfliktpotential. Hinzu kommt, dass der Austausch im musealen Raum nicht nur die Übersetzung zwischen unterschiedlichen sozialen Sphären nötig machte, sondern auch eine Übersetzung zwischen unterschiedlichen Medien: Objekten, Bildern und Texten. Solche komplizierten Transferprozesse laden regelmäßig zu Verzerrungen und Voreingenommenheit ein. Deshalb möchte ich den vielen Formen von Kulturkontakten innerhalb der Personalunion eine weitere, oft unterschätzte Variante hinzufügen: die des ,kreativen Missverständnisses‘.

Da Museen schon ihrer Funktion und Intention nach konservative Gebilde darstellen, setzt die Untersuchung bereits in der Phase vor der Personalunion (1714-1837) ein. Dieser Rückgriff erlaubt es, die Potentiale und Probleme des kulturellen Austausches im musealen Raum anhand von zwei eng miteinander verbundenen Fallstudien zu illustrieren: der Londoner Royal Society des späten 17. Jahrhunderts und der Wiederholung und Emulation des Londoner Projektes durch Göttinger Akademiker während der Personalunion einhundert Jahre später. Beide Beispiele fügen sich nur bedingt in die Erfolgsgeschichte der musealen contact zone. Stattdessen illustrieren sie, dass für historische Austauschprozesse soziale Distanz oftmals von größerem Gewicht

3 Jüngere Forschungen zur Hanoverian dimension britischer Politik haben die Deutung der Union als weitgehend folgenlose dynastische Zwecklösung hinterfragt und sie stattdessen in die europäische Tradition des composite state eingeordnet. Vgl. etwa: Brendan Simms / Torsten Riotte (Hg.), The Hanoverian Dimension in British History 1714-1837, Cambridge 2007; Jeremy Black, Continental Commitment. Britain, Hanover and interventionism 1714-1793, London / New York 2005; Stephen Conway, Continental Connections. Britain and Europe in the Eighteenth Century, in: History 90 (2005), S. 353-374; Nicholas B. Harding, Hanover and the British Empire 1700-1837, London 2007. Diese Neubewertungen sind eng mit der lebhaften Forschung zu interkulturellem Austausch und histoires croisées in transnationalen Netzwerken verbunden, bleiben aber weitgehend auf das Feld der Politik beschränkt. Für eine breitere Anwendung dieser Konzepte auf die Personalunion vgl. Steffen Hölscher / Sune Schlitte (Hg.), Kommunikation im Zeitalter der Personalunion (1714-1837). Prozesse, Praktiken, Akteure, Göttingen 2014. 
war als die geographische Entfernung und dass die Wissenspraktiken, die solche Austauschprozesse flankierten, oft nicht in direkten Transfers resultierten, sondern in unintendierten, aber deshalb nicht weniger wirksamen Formen des Austausches.

\section{Ein Empire der Dinge. Das Museum der Royal Society}

Sammler und klassische Gelehrte verstanden einander über lange Zeit nicht als Partner, sondern als Gegenspieler. Während des 17. Jahrhunderts war das Sammeln häufig durch eine kritische Haltung zur universitären Gelehrsamkeit motiviert und wurde von sozialen Gruppen außerhalb der klassischen Bildungstraditionen getragen. Virtuosi und Connaisseurs verstanden das Sammeln als einen Raum der Freundschaft, der sich durch Konsens und Geselligkeit deutlich von den notorischen Streitereien an den Universitäten abhob. Umgekehrt betrachteten viele Professoren die Aktivitäten der Sammler als naiv und oberflächlich und beklagten deren Bereitschaft Form über Substanz und visuellen Reiz über gründliche Analysen zu stellen. Dass diese scharfen Grenzziehungen zumeist nur in der Imagination der beteiligten Akteure existierten und tatsächlich zahlreiche persönliche und institutionelle Überschneidungen bestanden, bedeutet nicht, dass sie keine praktischen Auswirkungen besaßen. Wie die folgenden Fallbeispiele zeigen, barg ihre Überschreitung für die Grenzgänger ein durchaus reales Risiko, das durch eine ausgeprägte ,soziale Geschmeidigkeit' der Vermittler aufgefangen werden musste.

Als die Royal Society for the Improving of Natural Knowledge 1660 in London gegründet wurde, standen ihre Mitglieder fest auf der Seite der Sammler. Im Anschluss an Francis Bacon favorisierten sie direkte Beobachtung anstelle philosophischer Spekulationen und überliefertem Textwissen. Die Errichtung eines Museums stand daher ganz oben auf ihrer Agenda. Sie verstanden die Sammlung als zentrales Instrument, um eine neue Wissenschaft zu begründen, die sich auf materielle Fakten anstatt auf philosophische Gedankenspiele gründen sollte. Sie hofften zudem, dass die physische Präsenz der realen Objekte helfe, jene Streitereien zu vermeiden, welche die Wissenschaft ihrer Zeit und die englische Nach-Bürgerkriegsgesellschaft insgesamt prägten. ${ }^{4}$

Die ersten Fellows hegten die ambitionierte Vorstellung, ihre Sammlung als ,Kontaktraum' zu nutzen, in dem unmittelbar, ungefilterte Beobachtungen möglich wären - ein Unterfangen, das sich explizit gegen die paper techniques der zeitgenössischen Wissenschaft richtete. Der Kurator der Objekte, Robert Hooke, verkündete programmatisch: Bücher seien

4 Michael Hunter, Science and the shape of orthodoxy. Intellectual change in late seventeenth-century Britain, Woodbridge 1995, S. 135-150; Dominik Collet, Die Welt in der Stube. Begegnungen mit Außereuropa in Kunstkammern der Frühen Neuzeit, Göttingen 2007, S. 269-314. 
for the most part [so] superficial, and the Descriptions so ambiguous, that they create a very imperfect Idea of the true Nature and Characteristick of the thing described [...]. It were therefore much to be wisht for and indeavoured that there might be and kept in some repository as full and compleat a Collection of all varieties of Natural Bodies as could be obtain'd, where an Inquirer might be able to have recourse, where he might peruse, and turn over, and spell, and read the Book of Nature, and observe the Orthography, Etymologia, Syntaxis, and Prosodia of Natures Grammar [...].5

Hookes Vision bestand darin, die Praktiken des Lesens in Büchern auf das Lesen der Natur zu übertragen. Sein Ziel war es, die etablierten Texte seiner Zeit im Museum kritisch zu überprüfen und mit aus direkten Observationen gewonnenem Wissen zu ersetzen - ein Ansatz, der sich auch im stolzen Motto der Gesellschaft „nullius in verba" widerspiegelte.

Solch einen object turn in die Praxis umzusetzen, erwies sich allerdings als äußerst kompliziert. 1660, als die Fellows sich um den Aufbau einer Sammlung bemühten, war England aufgrund des Bürgerkrieges lange Zeit vom blühenden Sammlungswesen auf dem Kontinent abgeschnitten gewesen. Den Grundstock für ihr Museum mussten sie daher von einem deutschen Entrepreneur namens Robert Hubert erwerben. Hubert hatte seine Raritäten zunächst an wechselnden Orten im deutschsprachigen Raum gegen Entrichtung eines Eintrittsgeldes präsentiert, war nach dem 30jährigen Krieg aber nach England übersiedelt, wo er in London ein aufgeschlossenes und zahlungskräftiges Publikum für das hier noch kaum bekannte Medium des Museums gefunden hatte. ${ }^{6}$ Auf dem Kontinent blickten solche Sammlungen bereits auf eine über einhundertjährige Geschichte zurück und hatten zahlreiche eigene Traditionen entwickelt, darunter einen ausgefeilten Kanon sammelnswerten Materials. Nach dem Ankauf von Huberts populärer Sammlung fanden die Fellows daher an Stelle der erwarteten Materialien vor allem wundersame Kuriositäten vor, darunter die Rippe eines „Meermanns“, die Knochen eines „syrischen Riesen“ oder ein Nest of a Bird made like the secret parts of a man. ${ }^{7}$ Diese Raritäten konfrontierten ihre hoffnungsvollen Betrachter unmittelbar mit der komplizierten Aufgabe Objekte zu lesen, die ihres ursprünglichen Kontextes vollständig entkleidet worden waren. Die Fellows entschlossen sich daher notgedrungen, den Erwerb der Objekte selbst in die Hand zu nehmen. Dazu griffen sie auf ein bewährtes Mittel zurück, um Wissenschaft

5 Richard Waller (Hg.), The posthumous works of Robert Hooke. Containing his Cutlerian lectures and other discourses, read at the meetings of the illustrious Royal Society, London 1705, S. 365.

6 Zu Huberts deutschem Hintergrund, vgl. Collet, 2007 (wie Anm. 4), S. 278.

7 Robert Hubert, A Catalogue of Many Natural Rarities [...], London 1664, S. 1, 8 und 26. 
über große Distanzen hinweg zu betreiben: den Fragebogen. ${ }^{8}$ In einem ambitionierten Unternehmen wandten sie sich an renommierte Persönlichkeiten in der ganzen bekannten Welt und schickten ihnen ausführliche Inquiries. Darin listeten sie die Objekte mitsamt den begleitenden Informationen auf, die sie sich aus den jeweiligen Regionen wünschten. Die Verantwortung für dieses anspruchsvolle Projekt übertrugen die Fellows einem weiteren Deutschen, dem Sekretär der Gesellschaft Henry Oldenburg. Er exzerpierte lange Listen von interessanten Objekten aus Reiseberichten, übersetzte sie in verschiedene Sprachen, druckte sie in den Philosophical Transactions, koordinierte ihre Verteilung und sammelte den Rücklauf ein. Nahezu einhundert dieser Listen haben sich erhalten. Sie gingen an respektable Kontaktpersonen in den britischen Kolonien und die Stützpunkte anderer europäischer Staaten in Übersee. In wenigen Jahren gelang es Oldenburg von London aus ein einzigartiges weltumspannendes Netzwerk aufzubauen. ${ }^{9}$

Angesichts der schwierigen politischen und logistischen Bedingungen zur Mitte des 17. Jahrhunderts stellt schon allein diese Tatsache eine bemerkenswerte Leistung dar. Allerdings fand ein über den bloßen Kontakt hinaus gehender Austausch nur sehr begrenzt statt. Die Anzahl der Objekte, die das Londoner Museum erreichten, blieb gering. Zumeist bestanden die Sendungen nur aus tendenziös ausgewählten, fragmentarischen Stücken ohne nennenswerte Dokumentation. Auch die begleitenden schriftlichen Auskünfte halfen kaum, diese Defizite aufzufangen. Die Korrespondenten orientierten sich am etablierten Kanon sammelnswerter Objekte. Sie konzentrierten sich auf bizarre Stücke, die die Andersartigkeit der fernen Welten illustrierten und verwiesen darauf, dass die begleitenden Informationen aus gelehrten Büchern kompiliert werden könnten, deren Autorität sie weit höher einschätzten als ihre eigene. Die so übermittelten Exotika verweisen darauf, dass die Londoner und ihre Korrespondenten nicht nur eine räumliche sondern auch eine soziale Distanz trennte. Die wissenschaftlichen Codes der Sammler und ihrer Zulieferer stammten aus ganz unterschiedlichen Lebenswelten. ${ }^{10}$

Einige Korrespondenten wussten diese Distanz gezielt zu instrumentalisieren. Als Philippo Vernatti, ein Faktor der niederländischen Ostindienkompanie, die Fragen der Londoner erhielt, antwortete er mit etablierten Kuriositäten - „Steine“ aus Schlangenköpfen, die wirksam gegen Gifte seien, ostindisches „Stinkholz“, das die

8 Zum Gebrauch des Fragebogens als Kontroll- und Disziplinierungsinstrument, vgl. Arndt Brendecke, Empire und Empirie. Funktion des Wissens in der spanischen Kolonialherrschaft, Köln / Weimar / Wien 2009, S. 270-290 sowie Joan-Pau Rubiés, Instructions for travellers. Teaching the eye to see, in: History and Anthropology 9 (1996), S. 139-190.

9 Collet, 2007 (wie Anm. 4), S. 281-298. Die Listen finden sich heute in den Royal Society Archives, London, CP XIX "Questions and Answers".

10 Dominik Collet, Big sciences, open networks, and global collecting in early museums, in: David Livingstone / Peter Meusburger (Hg.), Geographies of science, Dordrecht 2010, S. 121-138. 
Wilden für heidnische Beschwörungen verwendeten oder an männliche Genitalien erinnernde Vogelnester, die von Chinesen angeblich als Aphrodisiakum genutzt würden. Ging es hingegen um Objekte und Informationen über Handelsgüter, Seekarten oder Bodenschätze, blieb Vernatti bemerkenswert wortkarg. Wie die meisten Korrespondenten war er sich der engen Verbindung von Empire und Empire genau bewusst. Seine Strategie suggestiv (re-)kontextualisierte Objekte als Täuschkörper einzusenden, um die Fellows von sensibleren Themen abzulenken, erwies sich als ausgesprochen erfolgreich. Vernattis faszinierende „Informationen“ und seine Exponate wurden von der Royal Society umgehend als vorbildhaft veröffentlicht. ${ }^{11}$

Zuletzt scheiterten auch noch die Versuche der Fellows, die eingesandten Objekte zur Grundlage experimenteller Überprüfungen zu machen. So hatte Vernatti zwar einen schillernden Bericht und eine Probe des berüchtigten Makassar-Giftes eingesandt - ein Gift von so außergewöhnlicher Potenz, dass es angeblich nur durch die rasche Einnahme der eigenen Exkremente behandelt werden konnte. ${ }^{12}$ Alle Versuche der Fellows, die Wunder-Substanz an Katzen und Hunden zu testen, verliefen jedoch negativ. Angesichts der schlechten Dokumentation der Proben und der wachsenden Zahl von einander bestätigenden Reiseberichten, sahen sich die Londoner aber nicht in der Lage, die Geschichte tatsächlich zu widerlegen. Anstatt falscher Texte vermuteten sie vielmehr das „falsche "Objekt vor sich zu haben. ${ }^{13}$ Für den Austausch valider Informationen erwiesen sich die dekontextualisierten Objekte als ebenso ungeeignet wie der Kontakt zwischen Akteuren aus unterschiedlichen sozialen Kontexten.

Schließlich fand sich die Gesellschaft mit dem stolzen Motto „Nach niemandes Worten“ damit ab, in ihren Veröffentlichungen Informationen zu präsentieren, die aus genau jenen Texten kompiliert waren, die sie eigentlich hatte überprüfen wollen. Das Unternehmen kulminierte in Werken wie der voluminösen History of Plants, einem Werk von immenser Gelehrsamkeit, dessen vier gewaltige Foliobände aus nichts als Text bestanden. Eine vollständige, aber kaum nutzbare Übersetzung von Objekten in Schrift. ${ }^{14} \mathrm{Zu}$ Beginn des 18. Jahrhunderts wurde die Hoffnung, die Sammlung als effektives Vehikel gelehrten Austausches zu nutzen, stillschweigend aufgegeben. Das Sammeln hatte sich als big science erwiesen: als Unternehmen, das die Zusammenarbeit einer Vielzahl von Akteuren über gewaltige geographische und soziale Distanzen hinweg nötig machte. Solch ein Unterfangen harmonierte nur schlecht

11 Vgl. Collet, 2010 (wie Anm. 10), S. 126 f. sowie Thomas Sprat, The History of the Royal Society of London. For the Improving of Natural Knowledge, London 1667, S. 158-172.

12 Vgl. Daniel Carey, The political economy of poison. The kingdom of Makassar and the early Royal Society, in: Renaissance Studies 17 (2003), S. 517-543.

13 Anon., On the nature of a certain stone, found in the Indies, in the head of a serpent, in: Philosopical Transactions of the Royal Society 1 (1665), S. 102f. und Collet, 2007 (wie Anm. 4), S. 303-305.

14 John Ray, Historia plantarum species hactenus editas aliasque insuper multas noviter inventas $\&$ descriptas complectens [...], 3 Bde, London 1686-1704. 
mit einer Wissenspraxis, die auf engem persönlichen Kontakt, vertrauenswürdigen Zeugen sowie dem sozialen Status gründete, der aus finanzieller Unabhängigkeit erwuchs. ${ }^{15}$ Stattdessen konzentrierten sich die Fellows allmählich auf die „kleinen Wissenschaften“, die Mathematik, Physik oder Optik, deren besser nachvollziehbare und wiederholbare Resultate vor Ort, in der technisch und sozial besser kontrollierten Umgebung des Labors, erzielt werden konnten. ${ }^{16}$ Das Museum der Royal Society entwickelte sich statt zum Forschungsraum zum Salon. In London stellte es bald eine zentrale Touristenattraktion dar, die aber in der zunehmend auf experimentelle Verfahren festgelegten Royal Society keinen nennenswerten Platz mehr hatte.

Unglücklicherweise versäumten es die Fellows, die sonst jede ihrer Aktivitäten penibel dokumentierten, diese Entwicklung öffentlich zu machen. Sonst hätten sie die Göttinger Gelehrten des zweiten Fallbeispiels vor mancher Enttäuschung bewahren können. Stattdessen publizierten sie einen sorgfältig redigierten Katalog ihrer Sammlung, der mehreren Gelehrtengenerationen als vermeintliches Vorbild diente. ${ }^{17}$ Viele Ideen der Fellows kehren daher im zweiten Beispiel nahezu wortwörtlich wieder.

\section{Emulation und Innovation. Das Akademische Museum der Universität Göttingen}

Auch die Universität Göttingen, 1737 vom britischen König Georg II. gegründet, verstand sich als Reforminstitution. Die neuartige Kombination der Universität mit einer Akademie der Wissenschaften bezog ihre Inspirationen auch aus dem Erfolg der Royal Society. Wie in London bildete auch in Göttingen eine zentrale Forschungssammlung von Beginn an einen integralen Bestandteil der akademischen Konzeption (Abb. 1+2). ${ }^{18}$ Aufgrund finanzieller Engpässe konnten die ursprünglichen Ideen erst 1773 umgesetzt werden. In diesem Jahr wurde - eine weitere Parallele zu London eine bereits bestehende Privatsammlung erworben. Der Ankauf wurde zudem durch den gemeinsamen Schirmherrn von Royal Society und Göttinger Universität, König

15 Collet, 2010 (wie Anm. 10), S. 129-134.

16 Hunter, 1995 (wie Anm. 4), S. 150 und Palmira Fontes da Costa, The culture of curiosity at the Royal Society in the first half of the eighteenth century, in: Notes and Records of the Royal Society 56 (2002), S. 147-166.

17 Nehemiah Grew, Musaeum Regalis Societatis. Or, a catalogue and description of the natural and artificial rarities belonging to the Royal Society and preserved at Gresham Colledge [...], London 1686.

18 Marie Luise Allemeyer / Dominik Collet / Marian Füssel, The "Academic Museum". Göttingen's university collections as a space of knowledge production and cultural heritage, in: Opuscula Musealia 18 (2010), S. 15-22 sowie zum Museumsgebäude: Gunther Beer, Beitrag zur Baugeschichte des Akademischen Museums 1773 bis 1877 mit drei Gebäudeplänen des Akademischen Museums, in: Museumsbrief 29 (2010), S. $2-20$. 


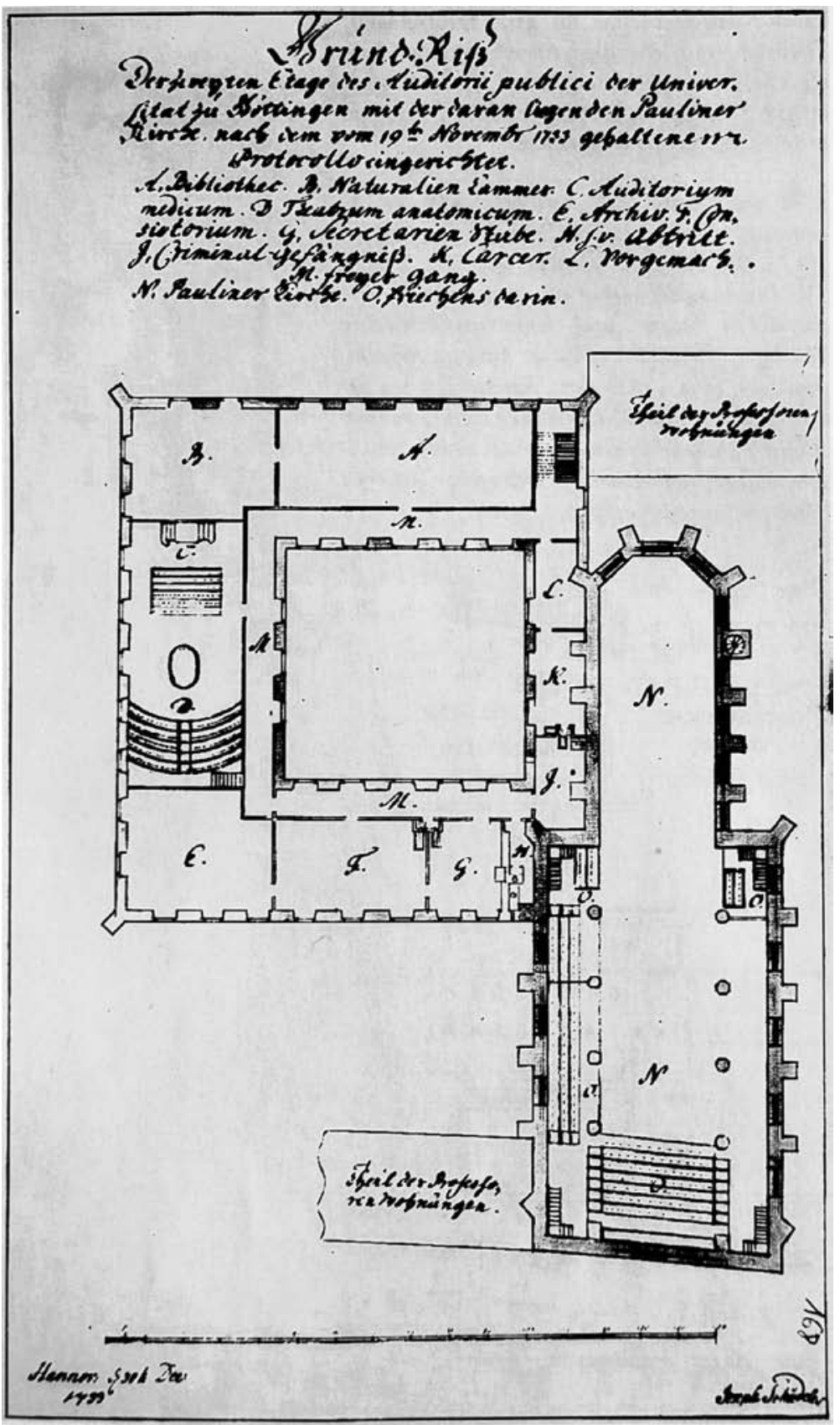

Abb. 1: Bauzeichnung von Joseph Schädeler. Zukünftige Universität in Göttingen mit Raum B „Naturalienkammer“.

NLA Hauptstaatsarchiv Hannover Nr. 23d Göttingen 26pm 


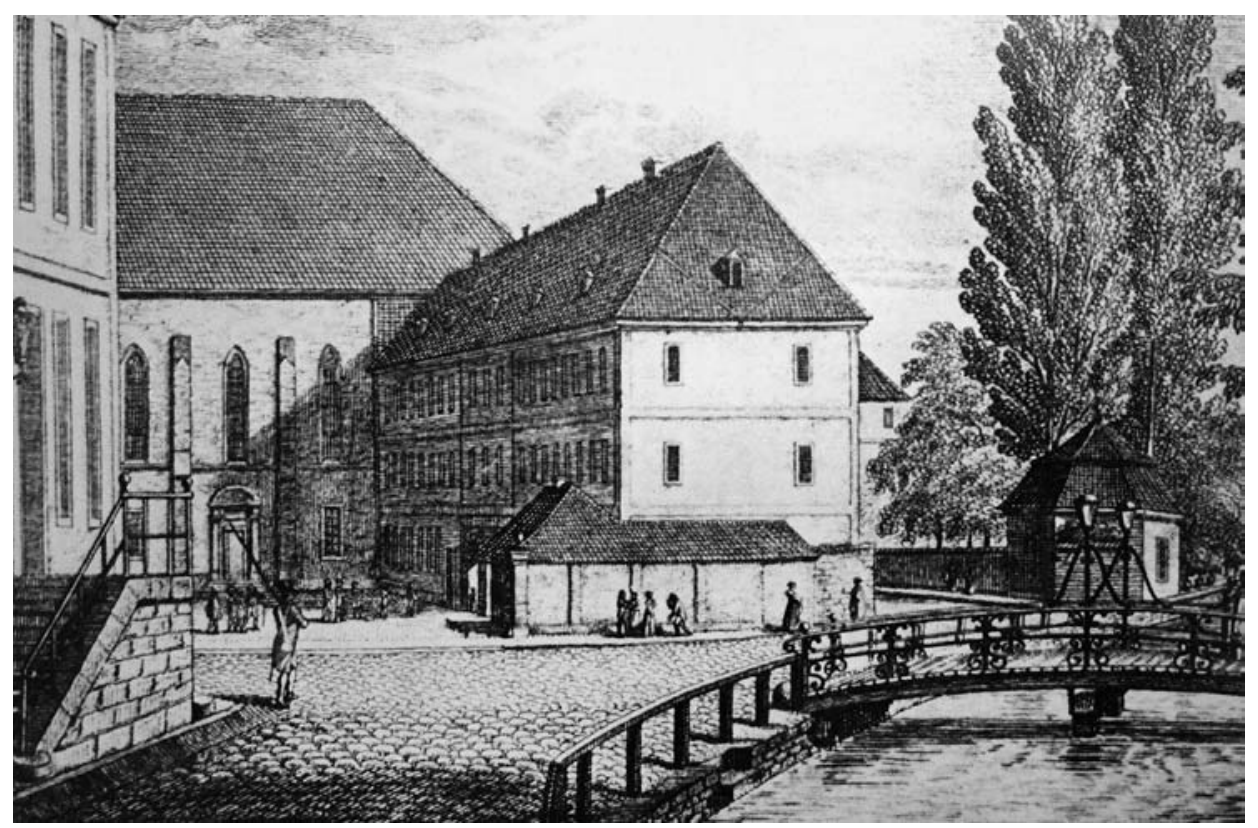

Abb 2: Academisches Museum, Göttingen. Kupferstich um 1800, aus: Alfred Oberndiek, Göttinger Universitätsbauten. Göttingen 1989, S.31

Georg III., finanziert. ${ }^{19}$ Auch die ersten Kommentare der Göttinger Professoren klingen vertraut. Ganz ähnlich wie Robert Hooke verkündete Johann Friedrich Blumenbach, Kurator der Göttinger Sammlung:

Di[e] älteren Sammlungen hatten doch fast durchgehends den Fehler, daß man mehr Seltenheiten als Merkwürdigkeiten der Natur zusammenrafte; [...] Aus dieser letzten Rücksicht werden nun vorzüglich akademische Cabinette wichtig, deren gänzliche Bestimmung dahin abzweckt, dass sie nicht zum Prunck, sondern lediglich zum Gebrauch, zur Untersuchung und zum Unterricht dient [...].

Er fügte stolz hinzu: Göttingen ist die erste Universität in Deutschland, vielleicht in Europa, die mit einem eigentlich akademischen Museum versehen worden; und wir halten uns verpflichtet, von ihm, auch schon als Epochemachenden Phänomen zu sprechen. ${ }^{20}$ Solche Werbeschreiben illustrieren, dass sich mit dem Museum auch noch andere

19 Johann Friedrich Blumenbach, Einige Nachrichten vom academischen Museum zu Göttingen, in: Annalen der Braunschweigisch-Lüneburgischen Churlande 1 (1787), S. 84-99.

20 [Johann Friedrich Blumenbach], Etwas vom Akademischen Museum in Göttingen, in: Georg Christoph Lichtenberg (Hg.), Taschenbuch zum Nutzen und Vergnügen fürs Jahr 1779, Göttingen 1778, S. 45-57, hier S. $47 \mathrm{f}$. 
Hoffnungen verbanden: die Anwerbung vermögender, zumeist adeliger Studierender, die mit den zeitgenössischen Sammlungen gut vertraut waren, sowie die Steigerung des internationalen Renommees der Universität. Sie tragen aber auch der Tatsache Rechnung, dass sich die älteren europäischen Universitäten der objektorientierten Forschung tatsächlich nur langsam und in den Randgebieten ihres Curriculums geöffnet hatten. ${ }^{21}$

Wie die Royal Society erwarben auch die Göttinger Professoren zunächst eine Sammlung, die ihnen in weiten Teilen als planlos und ungeordnet erschien. Es handelte sich um das Kabinett Christian Wilhelm Büttners, über den Goethe später berichtete, dass zu seinen Eigenheiten [...] unbegränzte Neigung zu wissenschaftlichem Besitz, beschränkte Genauigkeitsliebe, und völlige $[\mathrm{r}]$ Mangel an allgemein überschauendem Ordnungsgeiste gehörten. ${ }^{22}$ Auf dieser materiellen Grundlage eigene wissenschaftliche Sammlungspraktiken umzusetzen, erwies sich als äußerst schwierig. Dies galt umso mehr, als die Göttinger Sammlung von Beginn an als öffentliche Institution ausgelegt war und so in einer engen Beziehung zu den fest etablierten Traditionen der privaten Kuriositäten-Liebhaber stand. Auch das Akademische Museum entwickelte sich rasch zu einer zentralen Attraktion für Reisende und zu einer Schnittstelle für den geselligen Austausch von Liebhaberstücken und Kuriositäten - ein Prozess, der eindrucksvoll in einem Besucherbuch dokumentiert ist, das bereits für die erste Dekade über 3.000 Einträge verzeichnet. ${ }^{23}$ Um diesen Entwicklungen zu begegnen, entschlossen sich auch die Göttinger Professoren dazu, Objekte unabhängig vom etablierten Austausch von Kuriositäten zu erwerben. Um dieses Ziel zu erreichen, war die Universität allerdings gezwungen, auf Akteure außerhalb ihrer eigenen Reihen zurückzugreifen Professoren waren für weite und strapaziöse Reisen kaum zu gewinnen. Die Öffnung zur Welt war im allumfassenden Anspruch der Sammlung bereits angelegt. Im universitären Raum aber, in dem Status und Reputation zentrale, beständig umkämpfte Distinktionsmerkmale waren, stellte eine solche personelle und räumliche Ausweitung ein großes Wagnis dar - auch dann, wenn sie sich im privilegierten Rahmen der Personalunion vollzog. Kaum ein Sammler oder Agent teilte die wissenschaftlichen Überzeugungen und Praktiken der Professoren. ${ }^{24}$

21 Marian Füssel, Die Universität der Dinge. Zur universitätshistorischen Verortung des Sammlungswesens, in: Georg-August-Universität Göttingen (Hg.), Dinge des Wissens. Die Sammlungen, Museen und Gärten der Universität Göttingen, Göttingen 2012, S. 52-59.

22 Johann Wolfgang von Goethe, Poetische und prosaische Werke, Bd. 2, Tübingen / Stuttgart 1847, S. 557.

$23 \mathrm{Zu}$ den Besuchern vgl. Christine Nawa, Sammeln für die Wissenschaft. Das Academische Museum Göttingen 1773-1840, M.A. Arbeit, Göttingen 2005, http://webdoc.sub.gwdg.de/master/2010/nawa/nawa. pdf (zuletzt aufgerufen am 1.11.2013).

24 Dominik Collet, Universitäre Sammlungen als contact zone. Gesellige und gelehrte Sammlungspraktiken im Akademischen Museum der Universität Göttingen (1772-1840), in: Traverse 3 (2012), S. 41-52. 
Dieses Konfliktpotential war bereits deutlich geworden, als Albrecht von Haller, Präsident der Göttinger Akademie der Wissenschaften und zugleich auswärtiges Mitglied der Londoner Royal Society, 1752 eine Sammlungsexpedition nach Amerika organisierte hatte. Haller versuchte das Potential der Göttinger Verbindung mit Großbritannien bestmöglich zu nutzen um Naturalien aus allen drey Reichen der Natur zu sammeln. Er sicherte sich die Unterstützung des britischen Königs und verwies ausdrücklich auf das Vorbild der Royal Society. ${ }^{25} \mathrm{Er}$ war sich aber auch der professoralen Vorbehalte seiner Kollegen bewusst. Aus diesem Grund lehnte Albrecht von Haller das Angebot ab, die Sammlungsreise über den Wiener Kaiserhof zu finanzieren. ${ }^{26} \mathrm{Um}$ den betont akademischen Charakter zu wahren, entschied er sich stattdessen für ein Subskriptionsmodell. Dabei gab man wieder an, sich auf englische Vorbilder zu beziehen, die an der britischen Landesuniversität Göttingen besonderes Ansehen genossen:

In England ist mancher wichtige Entwurf durch den Weg der Subscription ausgeführet worden, und so rühmlich dergleichen patriotische Unternehmung dieser großmüthigen Nation sind, eben so viel Ehre wird es jedem Mitgliede dieser Gesellschaft $[\ldots]$ bringen. ${ }^{27}$

Zugleich konnte Haller so an die Erfahrungswelt der Professoren anknüpfen, da ihnen Subskriptionsmodelle aus dem Buchmarkt bereits vertraut waren. Um die textgebundenen Traditionen der Professoren weiter zu bedienen, versprach Haller den Subskribenten neben den Objekten auch exklusive schriftliche Berichte sowie Vorabdrucke etwaiger Reisebeschreibungen. ${ }^{28}$ Ein Risiko musste er in Ermangelung reisewilliger Gelehrter jedoch mit dem Expeditionsleiter eingehen. Angehende Universitätslehrer, wie etwa der junge August Ludwig von Schlözer, standen für ein solch riskantes Unternehmen nicht zur Verfügung. ${ }^{29}$ Hallers Wahl fiel daher auf Christlob Mylius, einen der vielen selbsternannten Experten, die sich im Umfeld der Sammlungen bewegten. Mylius verstand sich allerdings eher auf die Welt der Berliner Salons als auf die Usancen der Universität und sah sich selbst als Journalist, Naturforscher und Dichter.

25 Vgl. die Archivalien zu Hallers Amerika-Expedition, in: Staats- und Universitätsbibliothek Göttingen, Abt. Handschriften und seltene Drucke, 2 H Lit. Biogr. IV 7270.

26 Christlob Mylius, Nachricht von des Herausgebers vorhabenden Reise nach America, in: Physikalische Belustigungen 2 (1773), S. 708-731, hier S. 718. Die Finanzierung sollte unter Vermittlung Gerard von Swietens über das kaiserliche Naturalienkabinett in Wien erfolgen. Möglicherweise spielten auch dynastische Loyalitäten eine Rolle, da das Göttinger Unternehmen bereits von Georg III. unterstützt wurde, wie der Text vermerkt (ebd.).

27 Mylius, 1773 (wie Anm. 26), S. $711 \mathrm{f}$.

28 Mylius, 1773 (wie Anm. 26), S. 711 f. Zu den britischen botanischen Expeditionen, die über Subskriptionen finanziert wurden, vgl. Collet, 2007 (wie Anm. 4), S. 241-243 und 265.

29 Johann Gottlieb Buhle (Hg.), Johann David Michaelis. Literarischer Briefwechsel, 3 Bde, Leipzig 1794-96, hier Bd. 1, S. 192. 
Dies wurde umgehend zu einem Problem, als Mylius während der Reise noch in London verstarb. Verärgerte Professoren begannen umgehend damit, Gerüchte über den zweifelhaften Charakter des Reisenden zu verbreiten. Besonderen Unmut rief dabei die übermäßig lange Zeit hervor, die Mylius in den niederländischen und englischen Amateur-Sammlungen verbracht hatte. Haller selbst befand sich zu dieser Zeit allerdings bereits wieder im heimatlichen Bern und entging so dem Unmut seiner Kollegen. ${ }^{30}$ Vergleichbare chronique scandaleuses finden sich auffällig häufig im Umfeld frühneuzeitlicher Sammlungen. Sie verweisen darauf, dass das Übersetzen zwischen Amateuren und Gelehrten, zwischen unterschiedlichen geographischen Räumen sowie zwischen Objekten und Texten ein heftig umstrittenes Wissenschaftsfeld umriß. ${ }^{31}$

Die Göttinger unternahmen deshalb bei ihrem zweiten Anlauf außergewöhnliche Anstrengungen um ein weiteres Desaster zu vermeiden. Wieder war es einer der ausgesprochenen anglophilen Professoren, von dem die Initiative ausging, nämlich Johann David Michaelis. Als er eine Sammlungsexpedition in den Orient plante, setzte er auf eine lange Reihe von Vorsichtsmaßnahmen. Michaelis wählte potentielle Kandidaten gezielt aufgrund ihrer engen Verbindung mit der universitären Welt aus. Um diese Beziehung noch zu festigen, stellte er sicher, dass die beiden Leiter der Expedition vor ihrer Abreise selbst zu Professoren ernannt wurden. Zudem griff Michaelis, der mit der Royal Society durch seinen Besuch in London 1741 und später auch als Mitglied eng verbunden war, auf das bereits von den Londoner Fellows eifrig benutzte Instrument des Fragebogens zurück. Als die beiden Expeditionsleiter Peter Forskal und Friedrich von Haven aber frühzeitig an Malaria verstarben, löste diese Tragödie umgehend wieder jene persönlichen Angriffe auf die beiden Reisenden aus, die ganz ähnlich schon in Mylius' Fall geäußert worden waren. Die Hoffnung der

30 Vgl. Reimer Eck, Christlob Mylius und Carsten Niebuhr. Aus den Anfängen der wissenschaftlichen Forschungsreise an der Universität Göttingen, in: Göttinger Jahrbuch 34 (1986), S. 11-43, der die Topik der Skandalberichte aber nicht hinterfragt. Zu Mylius' zahlreichen Besuchen von privaten Sammlungen im Tagebuch seiner Reise, vgl. Abraham Gotthelf Kästner, Christlob Mylius, Tagebuch seiner Reise von Berlin nach England 1753. Aus der Handschrift, in: Archiv zur neuern Geschichte, Geographie, Natur- und Menschenkenntnis. Bd. 1 Leipzig 1785, S. 85-167 und Bd. 5, Leipzig 1786, S. 39-140. Zu Mylius' engen Kontakten mit Londoner Virtuosi vgl. seinen aus London an Haller und die Göttinger Akademie gerichteten Artikel: Christlob Mylius, Beschreibung einer neuen Grönländischen Thierpflanze, London 1753. Der Text betonte zwar Mylius' Verbindung zur Royal Society (S. 5), befasste sich aber bezeichnenderweise mit einem liminalen Lebewesen (vermutlich einem Polypen), das mit seinem hybriden Status zwischen Pflanzen- und Tierreich ganz der wissenschaftlichen Episteme der Amateursammler entsprach und von dessen Untersuchung Mylius selbst freimütig bezweifelte, dass sie jemals im Leben einigen Nutzen haben wird (S. 4) - ein Aspekt, der den Göttinger Professoren allerdings besonders wichtig war.

$31 \mathrm{Zu}$ ähnlichen Vorwürfen im Rahmen der Sammlungsreisen Johann Michael Wanslebens in den Orient, Laurentius Rhinhubers nach Äthiopien oder James Reeds, Hugh Jones, William Vernons und David Kriegs nach Amerika, vgl. Collet, 2007 (wie Anm. 4), S. 132-165 und 242ff. Zum Ringen britischer Naturhistoriker wie Joseph Banks und Hans Sloane um Anerkennung in der traditionellen Gelehrtenwelt, vgl. Caspar Hirschi, Men of Sciences versus Macaronies. Die Polemik gegen die Amateur Gentlemen der Royal Society im späten 18. Jahrhundert, in: Frauke Berndt und Daniel Fulda (Hg.), Die Sachen der Aufklärung, Hamburg 2012, S. 193-206. 
Göttinger Gelehrten ruhte nun auf dem letzten Überlebenden, dem Landvermesser und ehemaligen Göttinger Studenten Carsten Niebuhr. Michaelis begann für den Reisenden immer umfassendere Fragebögen zu verfassen, um seine Übersetzung von Natur in Text möglichst umfassend zu kontrollieren und zu disziplinieren. Die sechs bekannten Versionen kulminierten schließlich in einem 400 Seiten umfassenden Fragebogen. Neben seinem nominellen Ziel sollte er auch dazu dienen, sich im Falle weiterer Enttäuschungen vor der europäischen Gelehrtenwelt zu rechtfertigen, weshalb Michaelis seine Fragen an eine Gesellschaft Gelehrter Männer sowohl in deutscher als auch in französischer Sprache drucken ließ. ${ }^{32}$ In seinem Vorwort fasste Michaelis die Schwierigkeiten der disziplinierten Übersetzung von Objekten in Texte folgendermaßen zusammen:

Die Grundlagen der Naturgeschichte, die ich ihr Alphabet nennen möchte, sind doch in der That nur ein Wörterbuch, in eine gewisse Ordnung nach natürlichen Classen gebracht. Daher bestehe ein Mangel darin, daß den Reisenden allein überlassen wird, was sie von auswärtigen Ländern melden sollen, ohne ihnen Fragen vorzulegen und sie zu unterrichten [...]. Sie sehen unzählige Dinge vor Augen, auf die sie nicht merken [dass ein Gelehrter in Europa sie] zu Aufklärung einer Dunkelheit gebrauchen kann.

Dem Professor für orientalische Sprachwissenschaft erschienen die größten Herausforderungen des Wissenstransfers anhand von Objekten dennoch weniger in der geographischen Distanz zu liegen, als darin, Objekte in Text und Amateure in Gelehrte zu verwandeln..$^{33}$

Die professorale Kontrolle forderte - wie schon im Falle der Royal Society einen hohen Preis. Nach seiner Rückkehr benötigte Niebuhr, den die Fragen nach einer abenteuerlichen Reise tatsächlich noch im Feld erreichten, mehr als zehn Jahre, um die Antworten zu verfassen. ${ }^{34}$ Als er sein Werk beendet hatte, ereilte seinen Text ein ähnliches Schicksal wie die History of Lants der Royal Society. Während sein Buch die höchsten Erwartungen erfüllte, endete der Großteil seiner gesammelten

32 Johann David Michaelis, Fragen an eine Gesellschaft Gelehrter Männer die auf Befehl Ihro Majestät des Königs von Dännemark nach Arabien reisen, Frankfurt am Main 1762; Johann David Michaelis, Receuil de Questions, Proposées à une Société de Savans qui par Ordre de sa Majesté Danoise Font le Voyage de l'Arabie, Frankfurt am Main 1763. Eine detaillierte Untersuchung zu den britischen Vorbildern für Michaelis' Fragebogen bietet: Daniel Carey, Arts and Sciences of Travel, 1574-1762. The Arabian Journey and Michaelis's Fragen in context, in: Ib Friis / Michael Harbsmeier / Jørgen Bæk Simonsen (Hg.), Early scientific expeditions and local encounters. New Perspectives on Carsten Niebuhr and The Arabian Journey, Kopenhagen 2013, S. 27-50, hier S. 34-38.

33 Michaelis, 2013 (wie Anm. 32), Vorrede. Michaelis verwies im Vorwort auch auf die Bedeutung von Naturaliensammlungen bzw. „europäischen Cabinettern“ für sein Projekt, gestand aber zugleich, dass seine [a] usfübrlichen Fragen [...] selbst etwas von Antwort enthalten (ebd.).

34 Carsten Niebuhrs Arbeit mündete schließlich in dem vielbeachteten Werk: Beschreibung von Arabien. Aus eigenen Beobachtungen und im Lande selbst gesammelten Nachrichten, Copenhagen 1772. 
Objekte unbeachtet und vernachlässigt im Keller der Kopenhagener Akademie der Wissenschaften. Carl von Linné beklagte sich daher bei Michaelis, die Naturalien selbst seien: mehrentheils ohne gehörige Wartung [geblieben, so] daß der Spiritus verflogen wäre, und dass sie verdürben. Nach ihrer, Übersetzung' in Sprache und ohne ihren ursprünglichen Kontext waren die Dinge stumm und unlesbar geworden. ${ }^{35}$

Mylius' und Niebuhrs Erfahrungen illustrieren die Herausforderungen musealer Kontakte. Solche cultural broker, Vermittler zwischen akademischen und nicht-akademischen Praktiken, zwischen Hannover und dem Empire, zwischen Objekt und Buch begaben sich in ein heftig umstrittenes Feld. Um an Sammlerstücke zu gelangen, mussten sie die Universität verlassen, durften deren soziale und wissenschaftliche Codes jedoch nicht vernachlässigen. Bei Problemen ließ sich ihr Außenseiterstatus leicht gegen sie verwenden, während die erfolgreiche Übersetzung die totale aber nicht immer sinnvolle Übernahme akademischer Wissenspraktiken verlangte. Mylius und Niebuhr stellten dabei keine Einzelfälle dar. Auch berühmte Naturforscher wie Hans Sloane und Joseph Banks, Präsidenten der Royal Society, mussten sich von klassischen Gelehrten aufgrund ihrer als exzentrisch empfundenen Reise- und Sammeltätigkeit weithin als Amateure und Macaronies verspotten lassen (Abb. 3). ${ }^{36}$

Ganz ähnlich wie ihre Londoner Kollegen wurden die Göttinger Professoren durch die Enttäuschungen der Expeditionsunternehmen zu dem Versuch inspiriert, ihre dekontextualisierten Sammlungsobjekte nun aus sich selbst heraus zum Sprechen zu bringen. Da sie für kaum ein Exponat über eine nennenswerte Dokumentation verfügten, erwies sich dies - wie zuvor in London - als ausgesprochen schwierig. Als der dänische König den Göttingern 1781 eine ägyptische Mumie verehrte, bot sich den Professoren eine einmalige Gelegenheit (Abb. 4). Für die überzeugten Aufklärer stellte die Mumie nicht nur ein prominentes Beispiel für zahlreiche Mythen und Aberglauben dar, sie sahen sie auch als Geschenk aus der Welt der sammelnden Amateure und Fürsten. Zwar schätzte man dieses Objekt als Visualisierung der weltweiten Kontakte und der Reputation der Göttinger Universität, zugleich verstand man es aber als Chance, ein Beispiel für eine professionelle Akademisierung vormals aristokratischer Sammlerstücke zu geben. Wie im Falle des Makassar-Giftes kam für die experimentelle Überprüfung des Objektes ein interdisziplinäres Team aus Professoren der Linguistik, Archäologie, Anthropologie und Medizin zusammen, um eine Sektion vorzunehmen, die publizistisch intensiv begleitet wurde. ${ }^{37}$ Die Professoren arbeiteten so gründlich, dass im Inneren der Mumie kaum etwas an seinem Platz blieb. Ihr detailliert veröffentlichter Befund kam allerdings nur zu bescheidenen Er-

35 Michaelis, 1794-1796 (wie Anm. 29), S. 202. Niebuhr schickte auch einige kleinere Objekte an das Göttinger Museum. Eck, 1986 (wie Anm. 30), S. 42.

36 Hirschi, 2012 (wie Anm. 31), S. 193-206.

37 Göttingische Anzeigen von gelehrten Sachen 123 (08.10.1781), S. 985-992. 


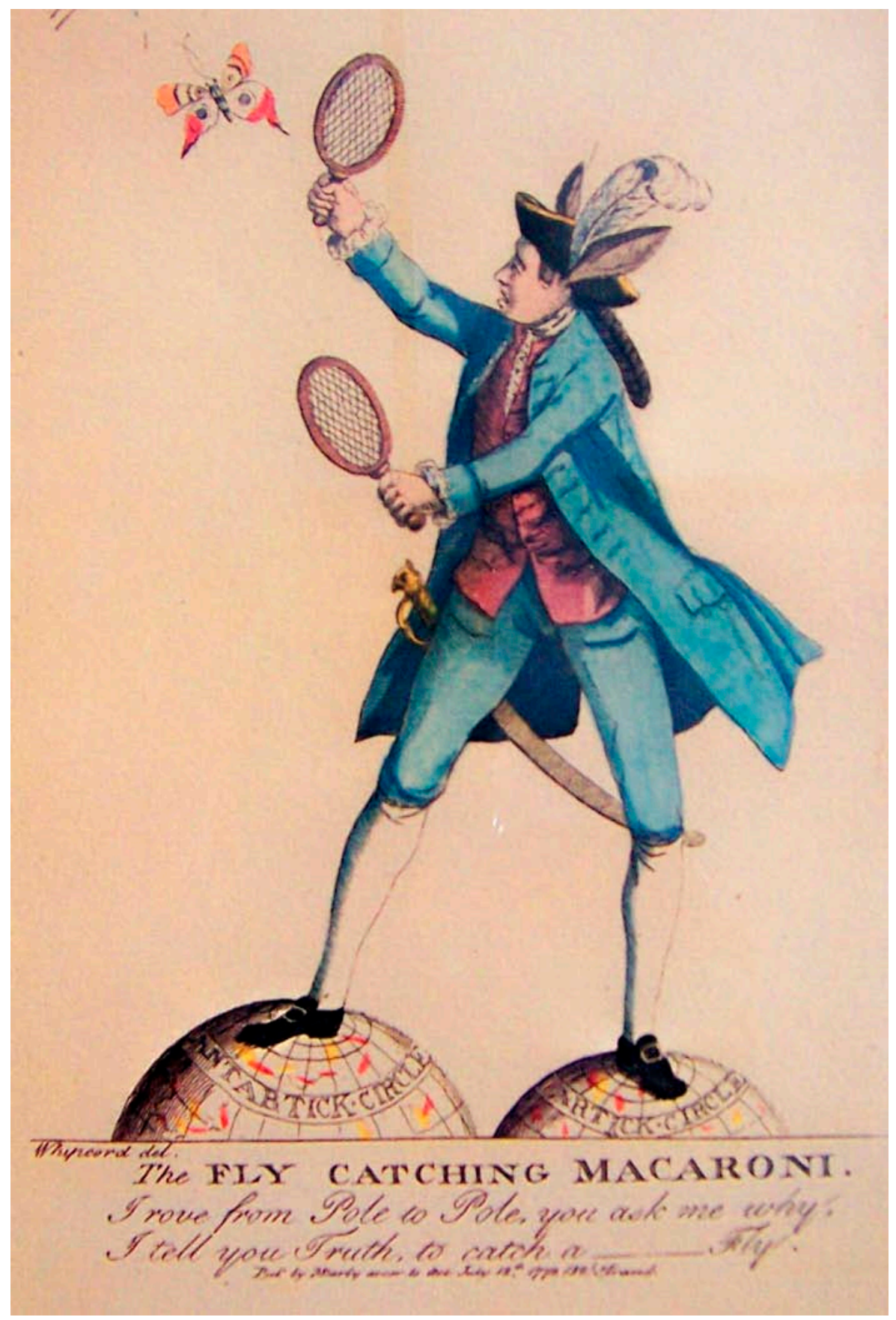

Abb. 3: Karikatur auf Joseph Banks. Kolorierter Kupferstich. M. Darly, The fly catching Macaroni, London 1772. nla.gov.au 


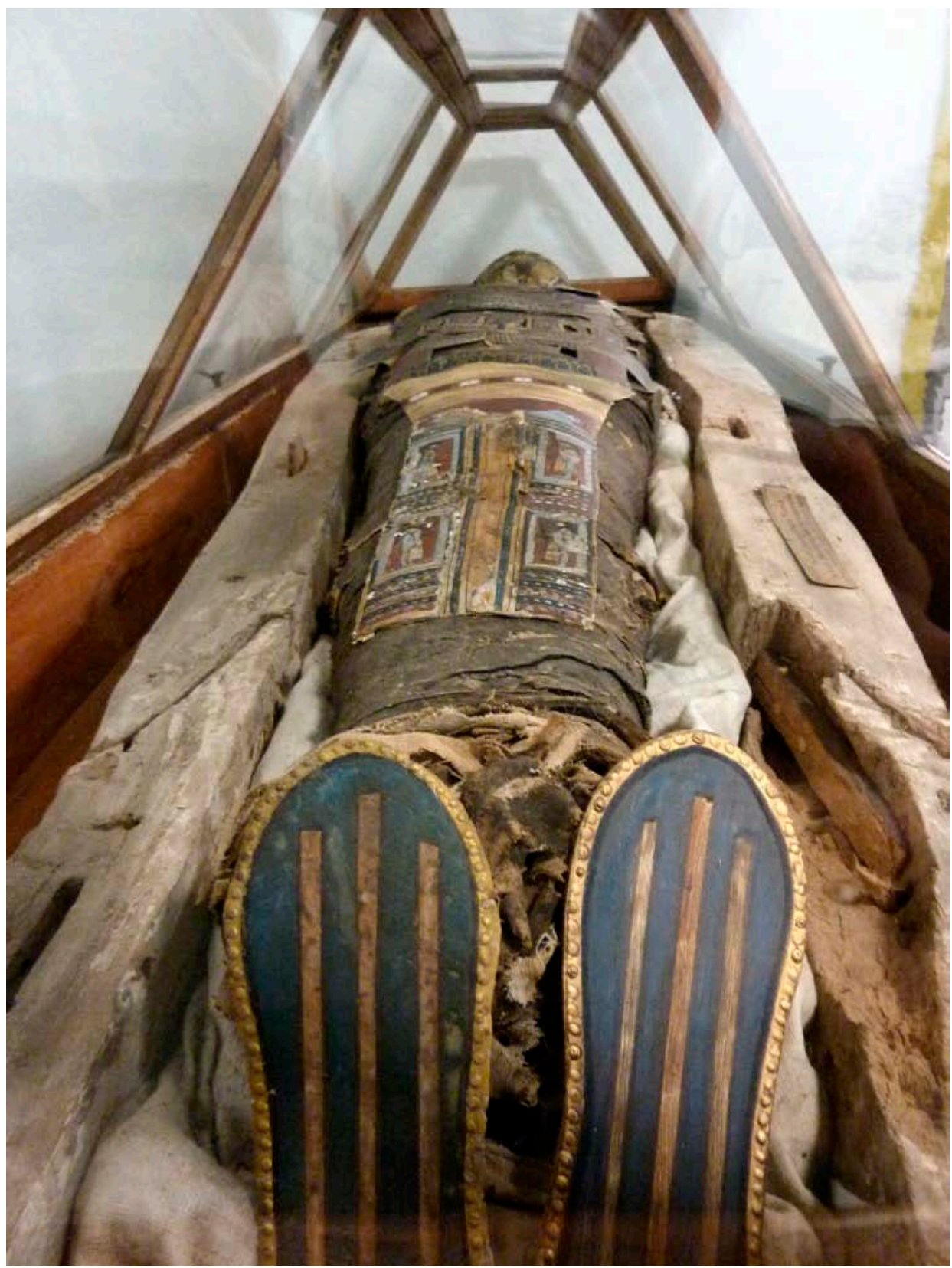

Abb. 4: Ägyptische Mumie des Academischen Museums. Heute Institut für Historische Anthropologie und Humanökologie der Universität Göttingen. Foto: D. Collet 
gebnissen. Niemand konnte ermitteln, woher die Mumie überhaupt stammte, so dass sie ihre Ergebnisse nicht mit bekannten Fakten in Beziehung setzten konnten. Zudem besaßen sie keinerlei Vergleichsmaterial. Bei der einzigen anderen „Mumie“ der Sammlung handelte es sich nur um ein europäisches Schaustellerstück - den weitgehend unverwesten Leichnam eines gewissen Conrad Schachtrupp aus Herzberg, der von einem Totengräber als Nebenerwerb in Wirtshäusern der Göttinger Umgebung vorgezeigt worden war. ${ }^{38}$ Auch als die Göttinger Professoren den Dänischen König später um ein weiteres Exemplar einer echten Mumie baten, war das Ziel nicht, an Vergleichsmaterial zu gelangen. Vielmehr war das erste Geschenk nunmehr so stark beschädigt, dass die Professoren es nicht länger unter dem Namen des königlichen Patrons ausstellen wollten. ${ }^{39}$

Diese Praxis des gutgläubigen Kopierens vermeintlicher britischer Vorbilder blieb nicht ohne Kritik. Mit deutlich größerer Skepsis begegneten ihnen Zeitgenossen, welche angelsächsische Sammlungen mit eigenen Augen gesehen hatten. So verfasste Georg Christoph Lichtenberg, der 1770 und 1775 nach England gereist war, kurz nach der Eröffnung des Göttinger Museums eine bitterböse Satire auf die britischen Museen. In seinem Text verzeichnete er Objekte eines Londoner Sammlers, der unschwer als der in Göttingen verehrte Sir Hans Sloane zu identifizieren war. Laut Lichtenberg enthielt diese Sammlung unter anderem eine

Bettstelle in Form eines Sarges [...] für Methodisten und Betschwestern, eine Suite von Kleidungsstücken für ein Kind mit zwei Köpfen und einen doppelte[n] Kinderlöffel für Zwillinge. ${ }^{40}$

Wie Lichtenberg befürchtete, führte die gewissenhafte Emulation des object turns der Royal Society durch seine Göttinger Kollegen zu vergleichbar ernüchternden Resultaten. Das Akademische Museum spiegelte keineswegs allein die Interessen der Gelehrten wider. Als öffentliche Sammlung reflektierte es ebenso sehr den Geschmack seiner vielen Besucher und Gönner sowie die Schwerpunkte des professionellen Kuriositätenhandels. Auch die gefeierte und bis heute berühmte Sammlung von Objekten der Reisen James Cooks enthielt nicht die von den Professoren ausdrücklich erbetenen Naturobjekte. Ihre Zusammensetzung illustrierte aber auch nicht bloß die repräsentativen Interessen ihres nominellen Spenders, des britischen Königs Georg III. In den

38 Gudrun Schwibbe, Wahrgenommen. Die sinnliche Erfahrung der Stadt, Münster 2002, S. 184. In einer weiteren Parallele zur Londoner Sammlung wurden auch in der Göttinger Sammlung Versuche mit vermeintlich giftigen, exotischen Objekten unternommen, die aber ebenso fruchtlos blieben. Frank William Peter Dougherty, The correspondence of Johann Friedrich Blumenbach, 4 Bde, Göttingen 2006-2012, hier Bd. 3, S. 176ff.

39 Eck, Mylius 1785 (wie Anm. 30), S. 43.

40 Wolfgang Promies (Hg.), Georg Christoph Lichtenberg. Schriften und Briefe, Bd. 3, München 1972, S. 451-457. 
ausgewählten exotischen Ethnographica kamen vielmehr die Vorlieben ganz anderer Akteure zum Ausdruck: die des mit dem Kauf beauftragten Kuriositätenhändlers George Humphreys, die der Virtuosi, für die Humphrey sonst tätig war, und die der Seeleute, welche die Objekte vor Ort gesammelt hatten (Abb. 5). ${ }^{41}$ In einigen Fällen dürften es auch die Gesammelten selbst gewesen sein, die die Zusammensetzung der Sammlung beeinflussten. So finden sich in der Göttinger Sammlung mehrere Schädel von neuseeländischen Maori. Diese weitgereisten Objekte könnte man leicht als eindrückliche Materialisierungen der Personalunion und der Netzwerke des britischen Empires interpretieren - zumal einer als Geschenk der Duchess of Northumberland, Charlotte Percy, und zwei andere über einen deutschen Handwerker am Hof in Windsor, Heinrich Ludwig Goertz, nach Göttingen gelangten. Tatsächlich wurden diese tätowierten, visuell beeindruckenden Schädel aber von den Maori in

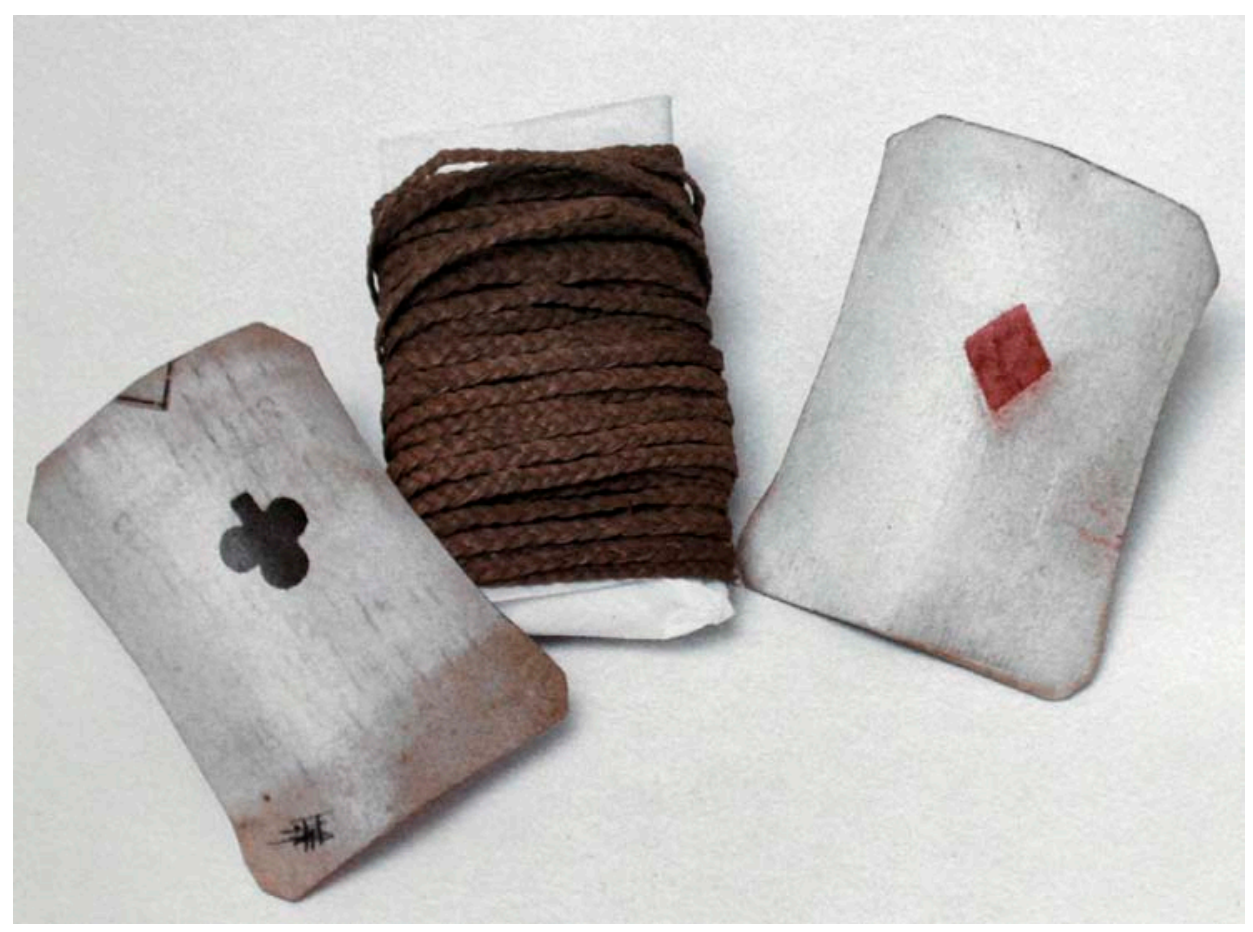

Abb. 5: Geflochtene Schnüre aus Tahiti. Kokosnussfasern auf Spielkarten der Seeleute der James Cook Expedition. Academisches Museum, heute Institut für Ethnologie, Universität Göttingen.

41 Humphreys selektive Vorlieben sind in seinem handschriftlichen Katalog der Sammlung dokumentiert, der heute im Institut für Völkerkunde in Göttingen verwahrt wird. Vgl. auch Thomas Nutz, Varietäten des Menschengeschlechts, Die Wissenschaften vom Menschen in der Zeit der Aufklärung, Köln u. a. 2009, S. $277-281$. 
großen Stückzahlen speziell für den europäischen Markt hergestellt. Sie nutzten das faszinierte Staunen der Europäer, um durch Handel an die begehrten Schusswaffen zu gelangen. In einigen Fällen dienten als Grundlage dieser vermeintlichen Exotika sogar die Schädel getöteter Europäer, die dazu extra eingefärbt und nachträglich tätowiert wurden. ${ }^{42}$ Ethnographische Forschungen waren an solchen, speziell für den europäischen Massengeschmack hergestellten Objekten, kaum durchführbar.

Stattdessen setzte sich auch in Göttingen zunächst wieder eine textbasierte Wissenspraxis durch, welche die Objekte nicht als Quellen sondern als Illustrationen verstand. Dies zeigt sich selbst dort, wo sich tatsächlich intensive, direkte Kontakte im Rahmen der Personalunion nachweisen lassen - etwa im Austausch zwischen dem Präsidenten der Royal Society, Joseph Banks, und dem Leiter des Göttinger Museums, Johann Friedrich Blumenbach. So brachte dieser Kontakt zwar eine große Anzahl von Objekten - vor allem menschliche Schädel - nach Göttingen, die Banks über sein weitgespanntes koloniales Netzwerk akquirieren konnte. Blumenbachs wirkmächtige Theorie über die Entstehung menschlicher Rassen war aber lange zuvor entstanden. ${ }^{43}$ Die Objekte dienten ihm nur mehr zur Illustration seiner zuvor gewonnenen Erkenntnisse, die er anstatt durch Autopsie durch die Lektüre von Reiseberichten gemacht hatte. Auch als Blumenbach 1781 daran ging seine einflussreiche Naturgeschichte zu illustrieren, ignorierte der Direktor des Museums seine eigene Sammlung und wandte sich stattdessen renommierten Büchern zu. Die Instruktionen an seinen Kupferstecher, Daniel Chodowiecki, lauteten daher:

1te Menschen-varietaet. eine Morgenländische Scene edelste Bildung! schlanker
Wuchs [....] Das ganze so viel [wie] möglich feinste Wollust athmend [...] Cos-
tüme etwa aus Niebuhrs Reisen [...]. 2te Menschen-Varietaet Chinesen [...] in
der Ferne ibre bizarren Lusthäusgen [...] wenns angeht auch etwa einige die Thee
trinken wobey etwan DuHaldes dexcription de la Chine nachzusehn. 4te Men-
schen-varietaet Brasilianer [...] wie der Virginier von Wencesl. Hollart (der auch
in Lavaters Physiognomik gut nachgestochen ist) [...] in der Ferne eine Hütte
[...]. Zur Vergleichung Cook's voyage round the world. (Abb. 6-8) ${ }^{44}$

Blumenbach hätte in der Göttinger Sammlung auf eine beachtliche Anzahl von Originalen aus den beschriebenen Regionen zurückgreifen können - Objekte, die oft

42 Gundolf Krüger, Mummified heads (mokomokai / upoko tui) from New Zealand in the Ethnographic Collection of Goettingen University, in: Dominik Collet / Marian Füssel / Roy McLeod (Hg.), The University of Things. History, practice, epistemology, Yearbook for European culture of science 9, (in Vorbereitung).

43 Nutz, 2009 (wie Anm. 41), S. 260f. und Céline Trautmann, Die Werkstatt Johann Friedrich Blumenbachs (1752-1840), in: Hans Erich Bödecker u.a. (Hg.), Die Wissenschaft vom Menschen in Göttingen um 1800. Wissenschaftliche Praktiken, institutionelle Geographie, europäische Netzwerke, Göttingen 2008, S. 213-254, hier S. $237 f$.

44 Blumenbach betonte, dass die Vignetten nicht etwa bloßzur Zierde des Buchs, sondern wesentlich nothwendig 
dem mit der Personalunion entstandenen Netzwerk entstammten. Aufgrund ihrer schlechten Dokumentation verließ er sich aber lieber auf die Autorität etablierter Bücher.

Es lassen sich also erstaunliche Parallelen zwischen den beiden Fallbeispielen beobachten: Die nahezu wortgleiche Propaganda für Sammlungen und Objektwissen als gelehrtes Reformprojekt, der jeweils vergebliche Versuch neue, dezidiert akademische Sammlungsformen zu etablieren, der Rückgriff auf die Technik des Fragebogens und des eigenen Experiments und schließlich die pragmatische Rückkehr zu traditionellen papiergebundenen Praktiken.

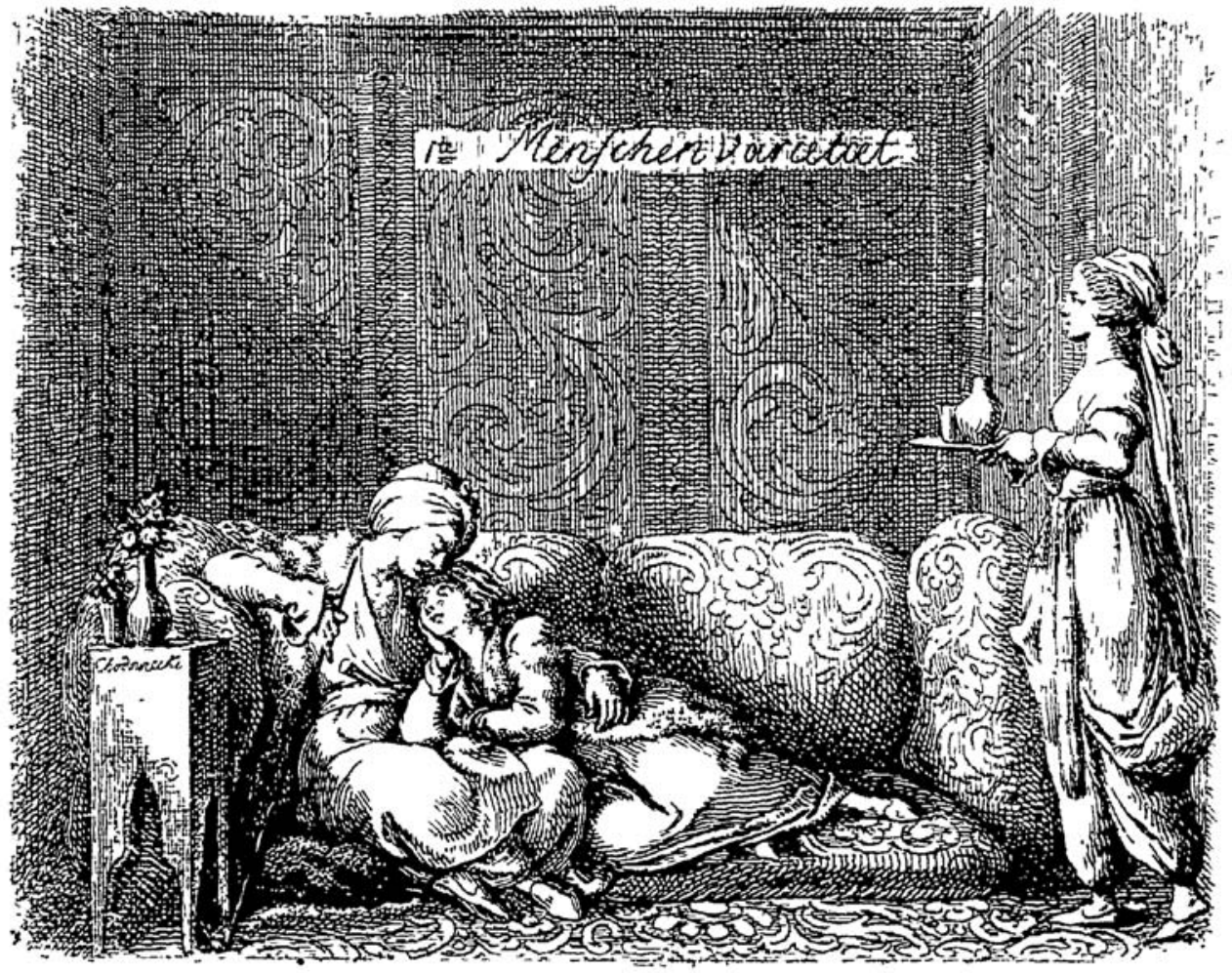

Abb. 6-8: Daniel Chodowiecki, Menschen-Varietäten, aus: Johann Friedrich Blumenbach, Beyträge zur Naturgeschichte. Göttingen 1790, SUB Göttingen

seien. Dougherty, 2006-2012 (wie Anm. 38), Bd. 1, S. 289-293. Die Illustrationen erschienen nach mehreren Korrekturen erstmals in: Johann Friedrich Blumenbach, Beyträge zur Naturgeschichte, Göttingen 1790. 

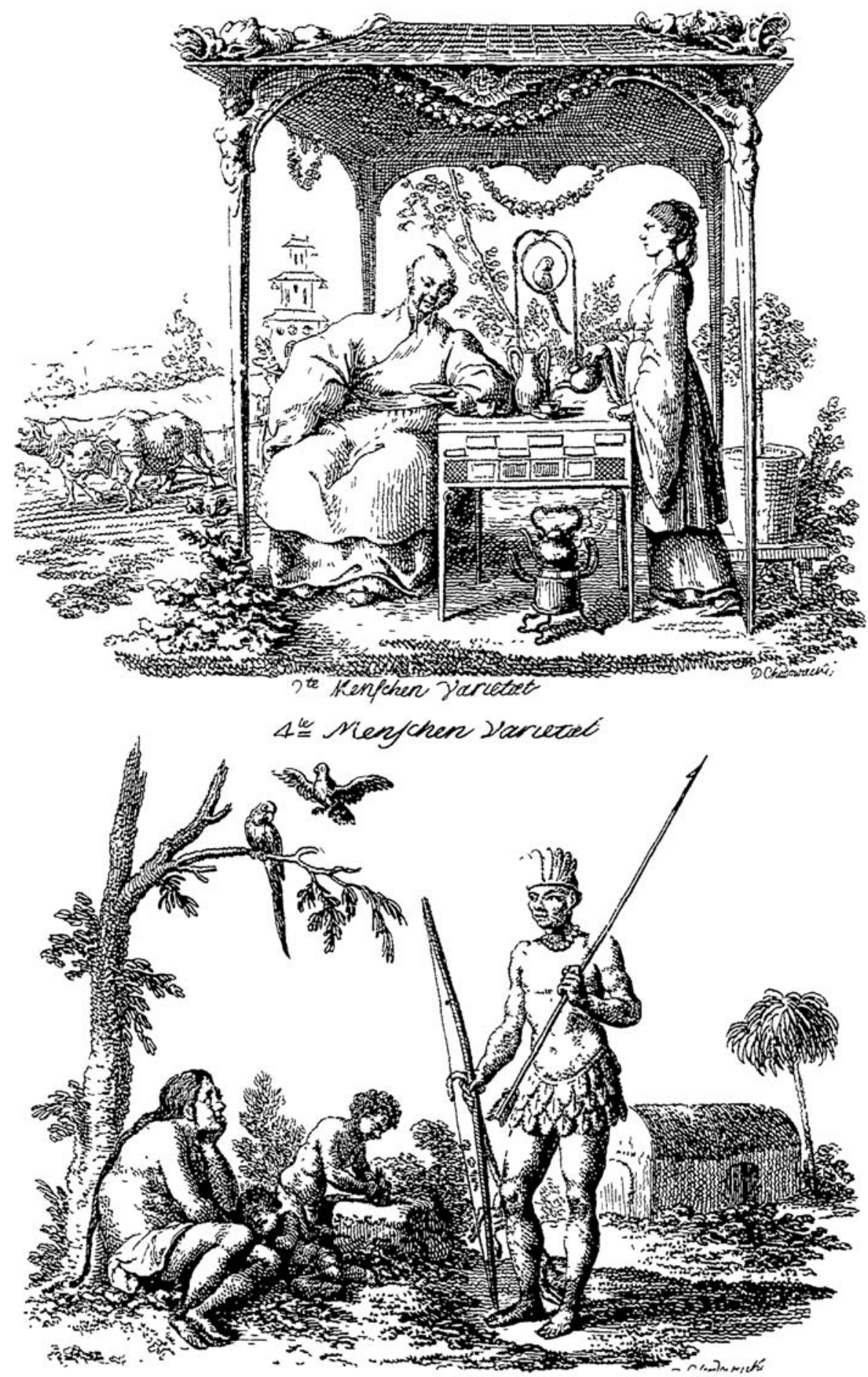


\section{Kreative Missverständnisse}

Es läge daher nah, das self-fashioning der Göttinger nach britischen Vorbildern als einen Fehlschlag oder zumindest als bedauernswertes Missverständnis zu deuten eine Interpretation, die sich nahtlos in das dominante Verständnis anglo-hannoveranischer Kontakte als historisch unbedeutend einfügen ließe und die Kurhannover als weitgehend passiven Empfänger britischer Ideen beschreibt. Man übersähe allerdings einen ganz zentralen Punkt: Die Göttinger Objekte begannen bald ein wirkmächtiges Eigenleben zu führen. Zwar hatten sie ihre ursprüngliche Aufgabe nicht erfüllt - ein Fehlschlag, der weniger in der räumlichen Distanz zwischen Hannover, Großbritannien und den Kolonien begründet lag, als in der sozialen Distanz zwischen Professoren und Sammlern. Sie übernahmen aber rasch ganz andere, gewichtige Aufgaben. Das Göttinger Academische Museum materialisierte die internationalen Netzwerke der jungen Universität - beispielsweise in der (wissenschaftlich zunächst enttäuschenden) James-Cook-Sammlung. ${ }^{45}$ Sie fungierte auch als Schauraum und als Erinnerungsort der Professoren und ihrer Erfolge. Ihr Direktor, Johann Friedrich Blumenbach, begriff aber, dass die Sammlung noch weiteres Potential hatte. Die Sammlung diente ihm dazu, die Institution Universität für zahlreiche neue Gruppen von Experten, Förderern und Naturliebhabern zu öffnen - eine Öffnung, die vielleicht ebenso viel zu Göttingens neuartigem Fokus in der Naturkunde beigetragen hat, wie die eigentlichen Forschungen ihrer Professoren. ${ }^{46}$

Anders als die Fellows der Royal Society vermochte es Blumenbach, die visuelle Evidenz der Exponate über seine Autorität als Professor mit akademischen Textpraktiken zu kombinieren. Während anderswo heftige Debatten darüber geführt wurden, ob Objekten oder Theorien im wissenschaftlichen Prozess der Vorrang gebühre - etwa zwischen dem Weltreisenden Georg Forster und dem Professor Immanuel Kant wusste Blumenbach beide Wissenskulturen geschmeidig miteinander zu verknüpfen. Seine geschickte Nutzung neuer materieller Ressourcen erlaubte es ihm eine Haltung einzunehmen, die man als „lächelndes Akzeptieren der Tradition“ bezeichnet hat. Im wissenschaftlichen Disput - etwa zur Natur der Fossilien oder zur Möglichkeit biologischer „Evolution“ - vermochte er dank seiner Objekte auch unorthodoxe Ergebnisse zu vertreten, ohne Widerspruch zu provozieren. ${ }^{47}$ Auf diese Weise erschloss Blu-

45 Das ethnographische Material der Cook-Forster-Sammlung war natürlich nur in den Augen der Zeitgenossen zunächst enttäuschend. Vgl. Dougherty, 2006-2012 (wie Anm. 38), Bd. 1, S. 327. Heute bildet ihre einzigartige materielle Überlieferung des Pazifiks und Nordamerikas eine unschätzbare Ressource ethnographischer Forschungen - ein Hinweis auf die häufigen Umdeutungen akademischer cinderella collections. Vgl. Krüger (wie Anm. 42) sowie Brigitta Hauser-Schäublin / Gundolf Krüger (Hg.), James Cook. Gaben und Schätze aus der Südsee. Die Göttinger Sammlung Cook / Forster, München / New York 1998.

46 Collet, 2012 (wie Anm. 24) und Trautmann, 2008 (wie Anm. 43).

47 Dougherty, 2006-2012 (wie Anm. 38), Bd. 3, S. 446 sowie Trautmann, 2008 (wie Anm. 43), S. 246. 
menbach der Universität neue, ehemals curieuse Wissensfelder. Exotika und Schädel, die sich in frühen Sammlungen großer Beliebtheit erfreuten, nutzte Blumenbach nun um die Völkerkunde und die physische Anthropologie als eigenständige universitäre Disziplinen zu fördern. ${ }^{48}$

Diese neue Verflechtung von Forschen und Zeigen positionierte die universitären Sammlungen bald im Zentrum des Prozesses akademischer Ausdifferenzierung. Sie half entstehende akademische Felder zu etablieren und naturalisierte zugleich deren Existenz. Viele akademische Fächer entstanden in Göttingen in enger Verbindung mit oder aufgrund der universitären Sammlungen: Neben der Völkerkunde und der Anthropologie zählten dazu auch die eng mit der Skulpturensammlung verbundene Kunstgeschichte, die in Göttingen ihren ersten deutschen Lehrstuhl bekam. Ganz ähnlich stützte der von Joseph Banks mit Pflanzen unterstützte „öconomische Garten“ später die Gründung der Forstwissenschaft, die wiederum die Loslösung der Biologie von der medizinischen Fakultät beförderte. ${ }^{49}$ Was als Fehlinterpretation früherer englischer Erfolge begonnen hatte, entwickelte sich rasch zu einem Katalysator neuer wissenschaftlicher Disziplinen und Praktiken, die schon bald weit über Göttingen hinaus kopiert wurden, bezeichnenderweise auch in Großbritannien. Als man in England zu Beginn des 19. Jahrhunderts daran ging die mittlerweile ins British Museum verlegte Sammlung der Royal Society neu zu ordnen, bediente man sich mit Carl (Charles) König eines Blumenbachschülers, der das Museum nach dem in der Göttinger Sammlung erprobten System neu strukturierte. Zwei weitere Blumenbachschüler, George Bellas Greenough und Carl Ludwig Giesecke, trugen später dazu bei, die objektgestützten Natur- und Geowissenschaften auch als Einzeldisziplinen in der britischen Wissenslandschaft zu etablieren. ${ }^{50}$

Diese Ergebnisse fügen sich in die Forschungen zu interkulturellen Kontakten in den letzten Jahren ein: Sie zeigen, dass Transferprozesse gerade nicht durch starre, vollständige Übernahmen gelingen, sondern dass der Austausch gerade da besonders rege ist, wo Ambivalenzen Transfers besonders attraktiv machen. ${ }^{51}$ Objekte sind aus dieser

48 Nutz, 2009 (wie Anm. 41), S. 275f.

49 Vgl. Collet, 2012 (wie Anm. 24), S. 48; sowie Schwibbe, 2002 (wie Anm. 38), S. 182. Zur engen Verbindung der Sammlungen mit der Genese der Fächer in Göttingen vgl.: Georg-August-Universität Göttingen (Hg.), Dinge des Wissens. Die Sammlungen, Museen und Gärten der Universität Göttingen, Göttingen 2012.

50 Thomas Biskup, The university of Göttingen and the Personal Union, 1737-1837, in: Simms und Riotte (Hg.), 2007 (wie Anm. 3) S. 150; Neil Chambers, Joseph Banks and the British Museum. The World of Collecting 1770-1830, London 2007, S. 34-43, 61-73 sowie Dougherty, 2006-2012 (wie Anm. 38), Bd. 3, S. 329. Vor der Neuordnung der Naturgeschichte im British Museum durch König beschwerten sich Besucher vom Kontinent: nothing is in order, every thing is out of its place; and this assemblage is rather an immense magazin [...] than a scientific collection. Hugh S. Torrens, Natural History in eighteenth-Century Museums in Britain, in: R.G.W. Anderson u.a. (Hg.), Englightening the British. Knowledge, discovery and the museum in the eighteenth century, London 2004, S. 81-91, hier S. 84.

51 Johannes Paulmann, Internationaler Vergleich und interkultureller Transfer. Zwei Forschungsansätze zur 
Perspektive deshalb außergewöhnlich effizient, weil sie besonders offen sind - wie sich etwa an der Göttinger Cook-Sammlung beobachten lässt, deren Objekte von den Zeitgenossen zugleich als Symbole für das Britische Empire, als Forschungsobjekte und als unterhaltende Kuriositäten verstanden wurden.

\section{Im Netz der Dinge}

Zusammenfassend lässt sich feststellen: Die Wissenspraxis des Sammelns konstituiert ein Netz der Dinge, ein Handlungsgeflecht, das eine sehr heterogene Gruppe von Akteuren miteinander in Beziehung bringt. Für viele Gelehrte des 17. und 18. Jahrhunderts lag die Herausforderung dieser Form des Kontakts nicht in der Überwindung der geographischen Distanz zwischen Hannover, England und der kolonialen Welt, sondern in der sozialen Distanz zwischen den Beteiligten - dies galt insbesondere in der fragilen, ganz besonders auf Stand und Stellung bedachten Welt der Gelehrten. Als Göttinger Professoren nach Reformmodellen Ausschau hielten, blickten sie zunächst auf den neuen Kommunikations- und Wissensraum, der mit der Personalunion entstanden war - Haller, Michaelis und Blumenbach reisten selbst nach London. Für Blumenbach war sein Englandbesuch im Jahr 1793 die einzige Auslandsreise überhaupt. Ihre gutwillige Übernahme der vermeintlichen Erfolge der Royal Society lässt sich als Missverständnis interpretieren, das auch auf den Wunsch zurückging, innerhalb der neuen Allianz von Hannover und Großbritannien tätig zu werden. Allerdings initiierte dieses Missverständnis unerwartete Innovationen. Die Übersetzung eines britischen Sammlungsmodells in den Rahmen einer deutschen Universität kreierte eine Wissenskultur, die neue Disziplinen, neue Expertengruppen und neue Formen von Soziabilität, Evidenz und Beweis etablierte - Bereiche, die in der Wissenschaftsgeschichte mittlerweile als zentrale Felder des wissenschaftlichen Prozesses verstanden werden..$^{52}$ Als Kontaktraum für gelehrte Geselligkeit trugen die Sammlungen wesentlich dazu bei, neuen Erkenntnissen zum Durchbruch zu verhelfen, wissenschaftliche Codes zu verbreiten und entstehende Wissensfelder institutionell zu konsolidieren. Über die Visualisierung von Evidenz am materiellen Zeugen konnte akademisches Wissen leichter zwischen Lehrern und Schülern, Sammlern und Besuchern, Kuratoren und Amateuren zirkulieren.

europäischen Geschichte des 18. bis 20 Jahrhunderts, in: Historische Zeitschrift 267 (1998), S. 649-685; Michael Werner / Bénédicte Zimmermann, Vergleich, Transfer, Verflechtung. Der Ansatz der Histoire croisée und die Herausforderung des Transnationalen, in: Geschichte und Gesellschaft 28 (2002), S. 607-636.

52 Vgl. etwa: Steven Shapin, Never Pure. Historical Studies of Science as if It Was Produced by People with Bodies, Situated in Time, Space, Culture and Society, and Struggling for Credibility and Authority, Baltimore 2010. 
Es ist daher keineswegs zufällig, dass viele dieser unintendierten Neuschöpfungen im Laufe des 19. Jahrhunderts mit Blumenbachs Schülern wieder zurück auf die britischen Inseln gelangten und sich die Göttinger Taxonomien und Wissensfelder im British Museum, den britischen wissenschaftlichen Gesellschaften und dem modernen Universitätscurriculum in beiden Territorien etablierten. Die Dynamik solcher kreativen Missverständnisse ist im Feld der Wissenschaft besonders sichtbar und anhand von Objekten auch materiell direkt nachvollziehbar. Sie markiert aber eine Form des unintendierten Austauschs, die auch in anderen Bereichen häufig und wirkmächtig gewesen sein könnte - Bereiche, in denen Kulturtransfers bisher allzu rasch ausgeschlossen worden sind. ${ }^{33}$

53 Zur möglichen Neubewertung von Austauschprozessen in den Feldern der Kunst, der Wissenschaft, der Diplomatie, des Militärs sowie der Ökonomie vgl. Hölscher/Schlitte 2014; Horst Carl / Uwe Ziegler (Hg.), ,In unserer Liebe nicht glücklich'. Kultureller Austausch zwischen Großbritannien und Deutschland 1770-1840, Göttingen 2014; Katja Lembke (Hg.), Hannovers Herrscher auf Englands Thron 1714-1837, Dresden 2014. 



\section{Anschriften der Autoren}

Prof. Dr. Arnd Reitemeier

Georg-August-Universität Göttingen

Institut für Historische Landesforschung

Heinrich-Düker-Weg 14

D-37073 Göttingen

Prof. Dr. Barbara Schaff

Georg-August-Universität Göttingen

Seminar für Englische Philologie

Käte-Hamburger-Weg 3

D-37073 Göttingen

Prof. Dr. Volker Depkat

Universität Regensburg

Institut für Anglistik und Amerikanistik

Universitätsstraße 31

D-93053 Regensburg

Prof. Dr. Marian Füssel

Georg-August-Universität Göttingen

Seminar für Mittlere und Neuere Geschichte

Heinrich-Düker-Weg 14

D-37073 Göttingen

Prof. Dr. Jürgen Elvert

Universität zu Köln

Historisches Institut

Gronewaldstraße 2

D-50931 Köln

Professor Stephen Conway

University College London

Department of History

24 Gordon Square

London WC1H 0AG

Great Britain 
Prof. Dr. Manfred Jakubowski-Tiessen

Georg-August-Universität Göttingen

Seminar für Mittlere und Neuere Geschichte

Heinrich-Düker-Weg 14

D-37073 Göttingen

PD Dr. Christian Scholl

Georg-August-Universität Göttingen

Kunstgeschichtliches Seminar und Kunstsammlung

Nikolausberger Weg 15

D-37073 Göttingen

Prof. Dr. Andreas Waczkat

Georg-August-Universität Göttingen

Musikwissenschaftliches Seminar

Kurze Geismarstraße 1

D-37073 Göttingen

Prof. Dr. Peter Aufgebauer

Georg-August-Universität Göttingen

Institut für Historische Landesforschung

Heinrich-Düker-Weg 14

D-37073 Göttingen

Dr. Wilfried Enderle

Georg-August-Universität Göttingen

Niedersächsische Staats- und Universitätsbibliothek Göttingen

Platz der Göttinger Sieben 1

D-37073 Göttingen

Dr. Dominik Collet

Universität Heidelberg

Historisches Seminar

Grabengasse 3-5

D-69117 Heidelberg

Dr. Michaela Kipp

Georg-August-Universität Göttingen

Institut für Historische Landesforschung

Promotionskolleg „Die Personalunion“

Heinrich-Düker-Weg 10

D-37073 Göttingen 
it der Krönung von Georg Ludwig, Kurfürst von Braunschweig-Lüneburg (Hannover), zum englischen König Georg I. am 31. Oktober 1714 verschoben sich die politischen Kräfteverhältnisse in Europa. Die Personalunion hatte weitreichende Folgen für den Kontinent und den transatlantischen Raum, doch wichtiger noch waren die nun intensiv gegebenen Möglichkeiten eines Kulturtransfers zwischen Großbritannien und dem Kurfürstentum Hannover. Diese vielfältigen kulturellen, sozialen, wissenschaftlichen und ökonomischen Verflechtungen stehen im Zentrum der Beiträge, die immer wieder auf die besondere Bedeutung der Universität Göttingen hinweisen, von der wichtige Impulse für die Personalunion und ihre Kommunikationsnetzwerke ausgingen. Zugleich verdeutlichen die Aufsätze, dass sowohl Großbritannien als auch das Kurfürstentum Hannover aus heterogenen Landesteilen bestanden und dass stets der Kontext des sich wandelnden Europas des 18. Jahrhunderts gesehen werden muss.

Der Sammelband beruht auf den Vorträgen, die im Rahmen der Ringvorlesung des Wintersemesters 2013-2014 an der Universität Göttingen gehalten wurden. 